MARISA PADOVANI

APOIO À DECISÃO NA SELEÇÃO DO PORTFÓLIO DE PROJETOS:

UMA ABORDAGEM HÍBRIDA USANDO OS MÉTODOS AHP E PROGRAMAÇÃO INTEIRA 
MARISA PADOVANI

\section{APOIO À DECISÃO NA SELEÇÃO DO PORTFÓLIO DE PROJETOS: UMA ABORDAGEM HÍBRIDA USANDO OS MÉTODOS AHP E PROGRAMAÇÃO INTEIRA}

Dissertação apresentada à Escola Politécnica da Universidade de São Paulo para obtenção do título de Mestre em Engenharia

Área de Concentração:

Engenharia de Produção

Orientador: Prof. Dr. Antonio Rafael Namur Muscat 
Padovani, Marisa

Apoio à decisão na seleção do portfólio de projetos / uma abordagem híbrida usando os métodos AHP e programação inteira/ M. Padovani. - São Paulo, 2007.

p. 267

Dissertação (Mestrado) - Escola Politécnica da Universidade de São Paulo. Departamento de Engenharia de Produção.

1. Sistemas de apoio à decisão 2. AHP 3. Gestão de Portfólio.

I Universidade de São Paulo. Escola Politécnica. Departamento de Engenharia de Produção II.t. 


\section{AGRADECIMENTOS}

Ao professor Antonio Rafael Namur Muscat, pela orientação e pelo constante estímulo transmitido durante todo o trabalho.

À professora Marly Monteiro de Carvalho pelas sugestões de referências bibliográficas e pela indicação de especialistas no uso do método AHP, para a elaboração da parte prática deste trabalho.

Ao professor Jorge L. Biazzi pela revisão deste trabalho, proposições de melhorias e questionamentos feitos durante a preparação do autor para sua qualificação.

Ao professor Roberto Camanho pelo fornecimento do software Decision Lens, utilizado neste trabalho, pela orientação quanto ao uso dessa ferramenta, através do fornecimento de referências bibliográficas e da apresentação de sua aplicação em casos reais.

Aos colegas de trabalho Celestino Hissao, Décio Daltin, Flávio B. C. Cavalcanti, Ivan Lavez, José Ricardo Tavares, Marcelo Faro, Maria Victória Miron, Rafael Makoto, Sérgio Ruivo Jr., Sidney Puosso da Cunha, Simone Ap.Batistela, Paulo Takakura e Victor Guidobono da Silva, sem os quais não teria sido possível a realização da parte prática deste projeto de pesquisa, e a todos que colaboraram direta ou indiretamente, na execução deste trabalho. 


\section{RESUMO}

Escolher dentre dezenas ou centenas de alternativas, àquelas que deverão compor a carteira de projetos de uma organização e com qual prioridade, é um problema de decisão multicritério complexo. Este trabalho teve como objetivo principal propor um modelo de gestão de portfólio de projetos utilizando-se os métodos AHP (Analytic Hierarchy Process) e programação inteira, integrados. Pretendeu-se ainda, validar e avaliar a importância e utilidade desse modelo no auxílio à tomada de decisões relacionadas à seleção e priorização de projetos. Assim, tal modelo foi aplicado para selecionar e priorizar os projetos de uma empresa do setor químico, escolhida como unidade de análise e, os diferentes cenários obtidos com o modelo de decisão proposto foram comparados com o cenário real da organização. Para a realização deste estudo utilizou-se o método de pesquisa-ação, visto que o autor não foi apenas um observador, mas interagiu no processo decisório da empresa. Pôde-se observar que o uso do modelo contribui para o alinhamento estratégico, permitindo a troca de conhecimento entre os representantes da empresa; possibilita a simulação de cenários estratégicos em tempo real e a verificação do impacto na carteira de projetos em execução; prioriza os projetos de forma justificável e estruturada através de um modelo matemático consagrado; permite a alocação de recursos baseada em prioridades e possibilita a introdução de um ciclo de melhoria contínua no processo decisório da empresa, dado que todos os passos da implantação do modelo, definições e critérios de decisão são documentados. O uso do modelo demonstrou ser mais eficaz que o resultado real da empresa na alocação dos recursos financeiros.

Este trabalho apresenta ainda sugestões para estudos futuros complementares.

Palavras-chave: Sistemas de apoio à decisão. AHP. Gestão de Portfólio de Projetos 


\begin{abstract}
Choosing among dozens or hundreds of alternatives for those which shall compound the portfolio of projects of an organization and with such a priority, it is a complex multicriteria decision matter. This work has aimed mainly at proposing a management model of portfolio of projects, utilizing the method AHP (Analytic Hierarchy Process) and integer program being both integrated. It has also. It has also had as a purpose to validate and evaluate the importance and utility of that model on helping the decisionmaking related to the selection and prioritization of projects. Thus, such a model has been applied to select and prioritize the projects of an enterprise in the chemical sector, chosen as the unit of analysis. The different scenarios obtained from the decision-making model proposed were compared to the real scenario of the company. Since the author interacted in the enterprise decision-making not just as an observer, to carry out the study it was chosen the research-action method, for being the most adequate to the case. It could be noticed that the use of the model contributed first, to the strategic alignment of the projects permitting the exchange of knowledge between the enterprise representatives; secondly, it allows the simulation of strategic scenarios in real time and as well as the verification of the impact of the portfolio of projects being carried out; thirdly, it prioritizes the projects in a justifiable and structural like way through an established mathematical model; finally, it enables o allocate the resources based on priorities and it allows the introduction of a continuous improvement cycle in the enterprise decision-making process, once every step of the implementation of the model, definitions and decision-making criteria are validated. The use of the model has proven to be more efficacious than the enterprise real result in allocating the financial resources. The work also suggests further complementary studies.
\end{abstract}

Keywords: Decision-Making systems. AHP. Portfolio's Management. 


\section{LISTA DE ILUSTRAÇÕES}

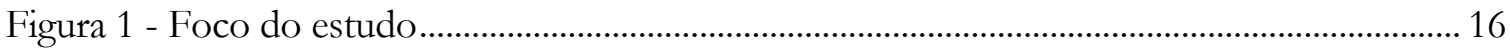

Figura 2 - Diagrama do Processo de Decisão (Fonte: Clemen, 1991)............................................. 22

Figura 3 - Matriz de classificação de projetos segundo inovação da tecnologia de processo .... 35

Figura 4 - Estrutura para Seleção de Projetos de um Portfólio (Fonte: Archer et al., 1999)........ 38

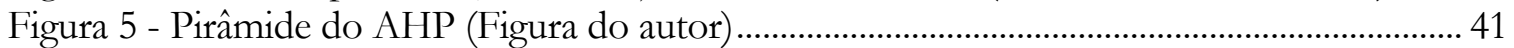

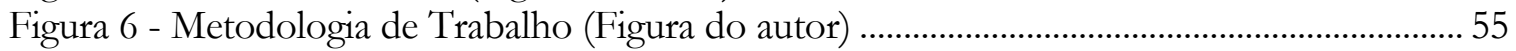

Figura 7 - Ciclo da pesquisa-ação (Adaptado de Coughlan \& Coghlan; 2002) ............................... 55

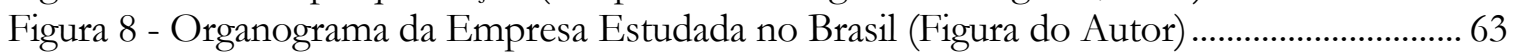

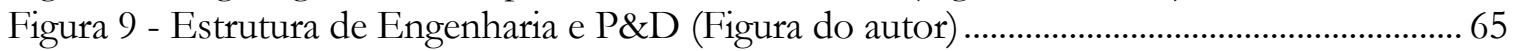

Figura 10 - Estrutura de Manutenção das Unidades Industriais (Figura do Autor) ……………... 66

Figura 11 - Estrutura de Informática da Organização Estudada (Figura do Autor)......................67

Figura 12 - Origem dos Projetos que compõem o Portfólio da Empresa (Figura do autor)..... 68

Figura 13 - Fluxo de Desenvolvimento de Produtos e Processos da Organização ........................ 69

Figura 14 - Fluxo de aprovação dos projetos da Organização (Figura do Autor) ......................... 74

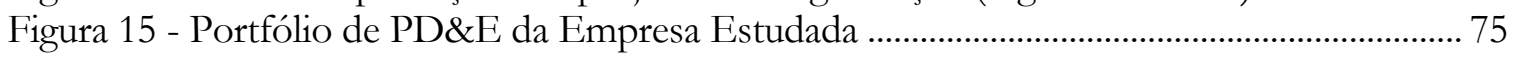

Figura 16 - Número de Projetos de PD\&E x Tipo ............................................................................... 76

Figura 17 - Margem Bruta dos Projetos de PD\&E x Tipo................................................................. 77

Figura 18 - Matriz de Atratividade por área de Negócio da Empresa ............................................... 88

Figura 19 - Matriz de Atratividade x Posicionamento para o Negócio IS ........................................ 89

Figura 20 - Matriz de Atratividade x Posicionamento para o Negócio T........................................ 90

Figura 21 - Matriz de Atratividade x Posicionamento para o Negócio S ....................................... 91

Figura 22 - Matriz de Atratividade x Posicionamento para o Negócio OPP................................... 91

Figure 23 - Probabilidade de Sucesso x Fase do Ciclo de Vida ......................................................... 93

Figure 24 - Matriz de Processo para Classificação do Grau de Inovação na Indústria................ 93

Figure 25 - Análise do Perfil de Investimentos Correntes da Empresa ......................................... 94

Figura 26 - Proposta de Modelo de Seleção do Portfólio de Projetos da Empresa ................... 105

Figura 27 - Probabilidade de Sucesso x Fase do Ciclo de Vida ...................................................... 124

Figura 28 - Classificação do Estágio de Desenvolvimento Tecnológico da Organização......... 125

Figura 29 - Perfil de Investimentos dos "Projetos de Engenharia".............................................127

Figura 30 - Fases do Modelo de Decisão - Parametrização do Software ........................................129

Figura 31 - Estrutura Hierárquica de Decisões para Projetos de P\&D da Empresa.................. 131

Figura 32 - Pesos de Critérios e Subcritérios dos Projetos de P\&D................................................. 133

Figura 33 - Estrutura Hierárquica de Decisões para Projetos com Investimento......................... 137

Figura 34 - Comparação dos Critérios aos Pares usando AHP - Estrutura Principal ............... 138

Figura 35 - Pesos dos Critérios da Estrutura Principal ...........................................................139

Figura 36 - Pesos dos Projetos da Estrutura Principal ................................................................. 140

Figura 37 - Estrutura de Projetos de Infra-estrutura de P\&D - Proposta do Autor ................... 142

Figura 38 - Estrutura de Projetos de Infra-estrutura de P\&D - Versão Final.............................. 142

Figura 39 - Pesos dos critérios para Projetos de Infra-estrutura de P\&D ..................................... 143

Figura 40 - Matriz de Inconsistências dos critérios para Projetos de Infra-estrutura de P\&D 144

Figura 41 - Análise de Sensibilidade para Projetos de Infra-estrutura de P\&D.......................... 147

Figura 42 - Estrutura de Projetos de Informática - Versão Final ................................................... 149

Figura 43 - Prioridades dos Critérios dos Projetos de TI ...........................................................150

Figura 44 - Pesos dos Critérios e subcritérios dos Projetos de TI. .................................................. 151

Figura 45 - Estrutura de Projetos de Engenharia - Versão Final (Fonte: Figura do Autor).... 156

Figura 46 - Pesos dos Critérios dos Projetos de Engenharia .......................................................... 158

Figura 47 - Pesos dos Subcritérios relacionados com "Impacto no Negócio".............................. 159

Figura 48 - Pesos dos Subcritérios relacionados com "riscos" ..................................................... 160

Figura 49 - Pesos dos Subritérios relacionados com a "complexidade" ....................................... 160

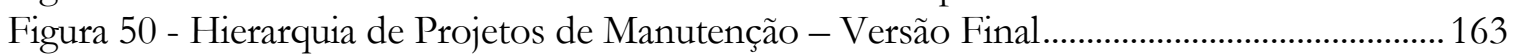


Figura 51 - Pesos dos Critérios dos Projetos de Manutenção - Versão Inicial

Figura 52 - Comparação por pares dos Critérios de maior inconsistência - Proj. Manutenção166

Figura 53 - Pesos dos Critérios dos Projetos de Manutenção - Versão Final. 166

Figura 54 - Pesos dos Subcritérios de "Riscos da Não-Execução"- Projetos de Manutenção 167

Figura 55 - Pesos dos Subcritérios de "Ganhos Esperados"-Projetos Manutenção ................... 168

Figura 56 - Pesos dos Subcritérios de "Complexidade"- Projetos de Manutenção ..................... 169

Figura 57 - Pesos dos critérios e subcritérios dos Projetos de Manutenção - Versão Final.... 169

Figura 58 - Tela Principal do Software Decision Lens v.1.6.16 ..........................................................205

Figura 59 - Módulo de criação da Árvore de Decisões- Software Decision Lens v.1.6.16............... 206

Figura 60- Módulo de Comparação dos Critérios - Software Decision Lens v.1.6.16 ....................... 207

Figura 61 - Módulo de Avaliação de Alternativas do Software Decision Lens v.1.6.16 ................... 208

Figura 62 - Módulo de Alocação de Recursos do Software Decision Lens v.1.6.16 .......................... 209 


\section{LISTA DE QUADROS}

Quadro 1 - Critérios de atratividade e competitividade tecnológica (Fonte: Jolly, 2003) ........... 36

Quadro 2 - Valores de Preferência (Fonte: Saaty, 1970) .................................................................. 42

Quadro 3 - Checklist para um projeto hipotético (Fonte: Elmaghraby \& Moder, 1978) ............. 47

Quadro 4 - Exemplo de Scoring Model (Fonte: Elmaghraby \& Moder, 1978) ................................ 48

Quadro 5: Classificação dos Projetos segundo sua Característica (Fonte: Dados da Empresa) 72

Quadro 6 - Matriz de Stakeholders/Objetivos/Tipos de Projetos ............................................... 99

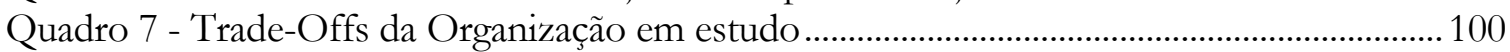

Quadro 8 - Relacionamento entre classificação de projetos da empresa e proposta pelo autor109

Quadro 9 - Definição dos critérios de seleção e priorização dos Projetos de P\&D................... 132

Quadro 10 - Definição dos critérios de seleção e priorização Proj. Infra-Estrutura de P\&D 143

Quadro 11 - Definição dos ratings para os critérios dos Projetos. Infra-estrutura de P\&D .... 145

Quadro 12 - Resultado da priorização - Projetos de Infra-estrutura de P\&D com o AHP.....146

Quadro 13 - Definição dos critérios e subcritérios de seleção e priorização- Projetos de TI.. 149

Quadro 14 - Escala de valores para os subcritérios de seleção e priorização - Projetos de TI 151

Quadro 15 - Resultado da seleção e priorização para os Projetos de TI com o AHP ............... 152

Quadro 16 - Definição dos critérios e subcritérios dos Projetos de Engenharia ......................... 157

Quadro 17 - Resultado das Prioridades dos Projetos de Engenharia com o AHP..................... 162

Quadro 18 - Definição dos critérios e subcritérios de Projetos de Manutenção ......................... 164

Quadro 19 - Definição da escala de valores para os subcritérios - Projetos de Manutenção .. 170

Quadro 20 - Resultado da seleção e priorização - Projetos de Manutenção - Fábrica 1...........172

Quadro 21 - Resultado da seleção e priorização - Projetos de Manutenção - Fábrica 2.......... 172

Quadro 22 - Resultado da seleção e priorização Projetos de Manutenção - Fábrica 3.......... 173

Quadro 23 - Resultado da seleção e priorização - Projetos de Manutenção - Fábrica 4........... 173

Quadro 24 - Resultado das simulações dos cenários de Projetos de Infra-estrutura de P\&D 176

Quadro 25 - Resultado das simulações dos cenários de Projetos de TI ......................................178

Quadro 26 - Resultado dos Cenários de Otimização do Portfólio - Projetos de Engenharia.180

Quadro 27 - Resultado da Simulação de Cenários dos Projetos de Manutenção - Fábrica 1.184

Quadro 28 - Resultado a Simulação dos Cenários dos Projetos de Manutenção - Fábrica 2.185

Quadro 29 - Resultado da Simulação dos Cenários dos Projetos de Manutenção - Fábrica 3186

Quadro 30 - Resultado da Simulação dos Cenários dos Projetos de Manutenção - Fábrica 4187

Quadro 31 - Perfil dos Participantes da Validação do Modelo.....................................................211

Quadro 32 - Escala de Valores dos Subcritérios de Projetos de P\&D......................................... 214

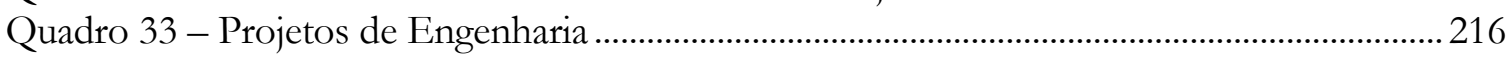

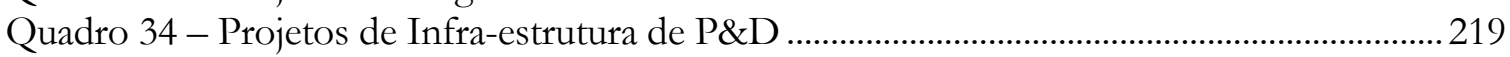

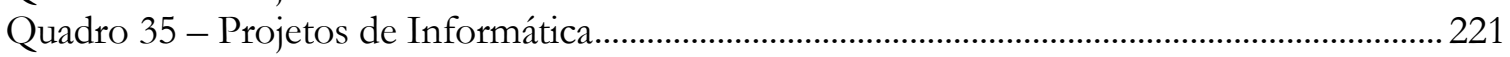

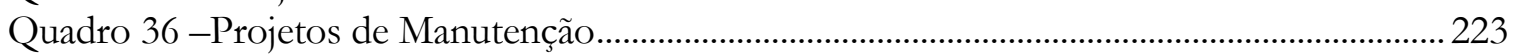

Quadro 37 -Escala de Valores de Subcritérios de Projetos de Engenharia ..................................232

Quadro 38 -Planilha de Votação dos Projetos de Manutenção- Fábrica 1................................... 234

Quadro 39 -Planilha de Votação dos Projetos de Manutenção - Fábrica 2 ................................. 235

Quadro 40 -Planilha de Votação dos Projetos de Manutenção - Fábrica 3................................. 236

Quadro 41 -Planilha de Votação dos Projetos de Manutenção - Fábrica 4................................ 237

Quadro 42 -Planilha de Votação dos Projetos de Informática ........................................................238

Quadro 43 -Planilha de Votação dos Projetos de Engenharia..........................................................239

Quadro 44 - Planilha de Votação dos Projetos de Infra-estrutura de P\&D ................................ 241

Quadro 45 -Exemplo de Portfolio de Projetos de P\&D da Organização ....................................267 


\section{LISTA DE TABELAS}

Tabela 1 - Histórico dos Investimentos Estratégicos Orçados x Realizados................................... 78

Tabela 2 - Histórico Anual de Projetos de Natureza Corrente por site e total................................ 78

Tabela 3 - 6 Maiores Investimentos Correntes - Atendimento a prazos e Orçamento .............. 86

Tabela 4 - Prioridades reais adotadas pela empresa para os 4 Tipos de Projetos em 2005 ...... 140

Tabela 5 - Alocação do Orçamento de Investimentos para 4 Tipos de Projetos ........................ 175

Tabela 6 - Rateio do Orçamento de Engenharia por Subtipo de Projeto ....................................... 182

Tabela 7 - Rateio do Orçamento de Manutenção para 4 as fábricas ................................................183

Tabela 8 - Rateio do Orçamento de Manutenção para 4 as fábricas por subtipo........................ 183

Tabela 9 - Relação de Projetos da Organização com investimento aprovado de 2001 ............. 243

Tabela 10 - Relação de Projetos da Organização com investimento aprovado de 2002 .......... 248

Tabela 11 - Relação de Projetos da Organização com investimento aprovado de 2003 .......... 252

Tabela 12 - Relação de Projetos da Organização com investimento aprovado de 2004 .......... 257

Tabela 13 - Relação de Projetos da Organização com investimento aprovado de 2005 .......... 261 


\section{LISTA DE GRÁFICOS}

Gráfico 1 - Histórico de Número de Projetos/Característica/Ano ………………………….......... 79

Gráfico 2 - Histórico do n ${ }^{\circ}$. de Projetos/Característica/Ano - Matriz ............................................ 80

Gráfico 3 - Histórico do nº de Projetos/Característica/Ano - Fábrica 1 ....................................... 80

Gráfico 4 - Histórico do nº de Projetos/Característica/Ano - Fábrica 2 ........................................ 81

Gráfico 5 - Histórico do n ${ }^{\circ}$. de Projetos x Característica x Ano - Fábrica 3.................................. 81

Gráfico 6 - Histórico do nº de Projetos x Característica x Ano - Fábrica 4................................. 82

Gráfico 7 - Histórico do total de Investimentos em Projetos Orçados x Realizados ................... 82

Gráfico 8 - Histórico de Investimentos em Projetos. Orçados x Realizados - Matriz................. 83

Gráfico 9 - Histórico de Investimentos em Projetos Orçados x Realizados-Fábrica 1 1............ 84

Gráfico 10 - Histórico de Investimentos em Projetos Orçados x Realizados-Fábrica 2......... 84

Gráfico 11 - Histórico de Investimentos em Projetos Orçados x Realizados-Fábrica 3......... 85

Gráfico 12 - Histórico de Investimentos em Projetos Orçados x Realizados - Fábrica 4........... 86

Gráfico 13 - Histórico de Número de Projetos/Característica/Ano - Total ................................. 110

Gráfico 14 - Histórico de Número de Projetos/Característica/Ano - Matriz ................................ 111

Gráfico 15 - Histórico de Número de Projetos/Característica/Ano - Fábrica 1 1........................ 111

Gráfico 16 - Histórico de Número de Projetos/Característica/Ano - Fábrica 2 2........................ 112

Gráfico 17 - Histórico de Número de Projetos/Característica/Ano - Fábrica 3 ......................... 113

Gráfico 18 - Histórico de Número de Projetos/Característica/Ano - Fábrica 4......................... 114

Gráfico 19 - Histórico de Número de Projetos de Infra-Estrutura de P\&D................................ 115

Gráfico 20 - Histórico de Número de Projetos de Engenharia................................................... 115

Gráfico 21 - Histórico de Número de Projetos de Infra-Estrutura de Manutenção................... 116

Gráfico 22 - Histórico de Número de Projetos de TI.................................................................. 117

Gráfico 23 - Valores Acumulados Orçados x Reais - Proj. Infra-estrutura de P\&D ............... 118

Gráfico 24 - Valores Acumulados Orçados x Reais - Projetos de Engenharia ............................ 119

Gráfico 25 - Valores Acumulados Orçados x Reais - Projetos de Manutenção........................... 119

Gráfico 26 - Valores Acumulados Orçados x Reais - Projetos de TI ...........................................120

Gráfico 27 - Desvio entre Valores Orçados e Reais ...................................................................... 121

Gráfico 28 - Duração dos Projetos de Engenharia ............................................................................. 121

Gráfico 29 - Duração dos Projetos de Engenharia por Subtipo em meses .................................. 122

Gráfico 30 - Desvio entre término dos projetos real e previsto, em meses. .................................. 123 


\section{SUMÁRIO}

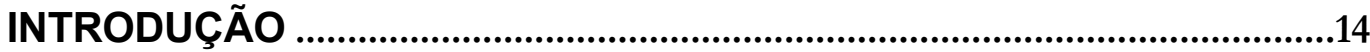

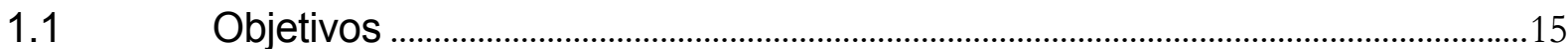

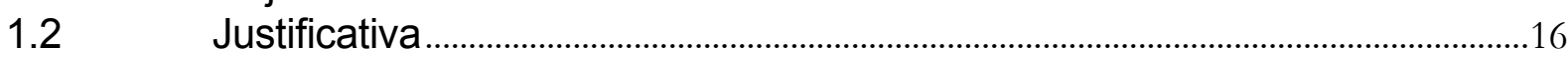

$1.3 \quad$ Etapas da Pesquisa ...............................................................................................18

$2 \quad$ REFERENCIAL TEÓRICO ..............................................................19

2.1 Princípios de Análise de Decisão...…………………………………………………1. 19

2.2 Estratégia e a Tomada de Decisões..........................................................................23

$2.3 \quad$ Teoria dos Stakeholders ............................................................................................26

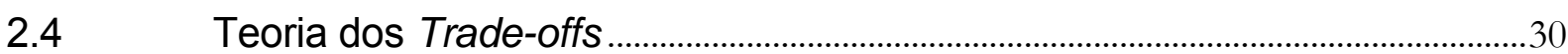

2.5 Gestão de Portfólio de Projetos ....................................................................................32

2.6 Os Modelos de Seleção e Priorização.....................................................................39

2.6.1 O Método AHP ....................................................................................................................

2.6.2 Checklists e Scoring Models .......................................................................................4

2.6.3 Modelos de Portfólio ...........................................................................................................48

2.7 Resumo e Análise da Bibliografia Consultada ........................................................50

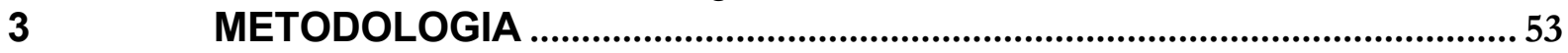

$4 \quad$ APRESENTAÇÃO DO CASO ESTUDADO ……...........................................61

4.1 Caracterização da Empresa ....................................................................................61

4.2 Origens dos Projetos do Portfólio da Organização ..............................................67

4.3 Classificação dos Projetos da Empresa....................................................................68

4.4 Critérios para Aprovação, Priorização e Revisão de Projetos do Portfólio .72

4.5 Caracterização dos Projetos de P\&D.........................................................................75

4.6 Caracterização dos Projetos com Investimento Aprovado..................................77

$4.7 \quad$ Análise do Portfólio........................................................................................................87

4.8 Resultados das Entrevistas com os Tomadores de Decisão .............................95

4.9 Análise dos Objetivos dos Stakeholders e Trade-offs da Organização........97

4.10 Conclusões sobre o Portfólio da Organização......................................................100

$5 \quad$ MODELO DE SELEÇÃO DE PORTFÓLIO PROPOSTO .............................104

5.1 Planejamento da Aplicação/Validação do Modelo Proposto ............................106

5.2 Reclassificação dos Projetos da Organização.......................................................107

5.3 Desenvolvimento do Modelo de Priorização e Seleção de Projetos.............128

5.3.1 Projetos de P\&D (Pré-Filtro) ....................................................................................130

5.3.2 Projetos com Investimento (Filtro) .........................................................................135

5.4 Simulações dos Cenários .....................................................................................173

5.4.1 Resultados da Simulação para os Projetos de Infra-estrutura de P\&D ......175

5.4.2 Resultados da Simulação para os Projetos de TI.................................................177

5.4.3 Resultados da Simulação para os Projetos de Engenharia..............................179

5.4.4 Resultados da Simulação para os Projetos de Manutenção.............................182

5.5 Análise dos Resultados Apresentados ................................................................187

6 CONCLUSÕES E SUGESTÕES PARA TRABALHOS FUTUROS...........194

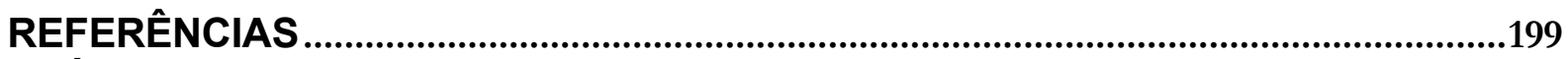

APÊNDICE A - O Software Decision Lens Versão 1.6.16 ............................................ 205

APÊNDICE B - Perfil dos Participantes da Validação do Modelo ..............................210

APÊNDICE C - Escala de Valores dos Subcritérios dos Projetos de P\&D ............212

APÊNDICE D - Nova Classificação dos Projetos com Investimento Aprovado..215 
APÊNDICE E- Escala de Valores dos Subcritérios de Projetos de Engenharia. 232 APÊNDICE F - Planilhas de Votação dos Projetos................................................... 234

ANEXO A - Histórico de Projetos de 2001 a 2005 por site ....................................... 242

ANEXO B - Relação dos Projetos de P\&D........................................................... 267 


\section{INTRODUÇÃO}

Com a globalização dos mercados ocorrida na última década, a concorrência se intensificou no cenário mundial e mais fortemente no âmbito nacional. Para sobreviver, as organizações passaram a estudar alternativas para reduzir seus custos e aumentar a competitividade. Nesse contexto, em que a velocidade de mudanças do mercado é crescente e a exigência dos clientes quanto ao desempenho de produtos e qualidade de serviços prestados aumenta a cada momento, constata-se que as empresas estão gastando mais tempo em projetos e menos em atividades de rotina (Elton e Roe, 1998).

Mas será que as organizações estão preparadas para gerenciar adequadamente seu portfólio? Aparentemente, não. Muitas publicações falam sobre problemas na gestão de escopo, cumprimento de prazos e orçamentos em projetos individuais, como se observa nos trabalhos de Goldratt (1998) e Mcfarlan (1981); outras citam como fator de dificuldade para gerir projetos, o grau de incerteza envolvido, como se verifica nos estudos de Hammond, Keeney e Raiffa (1998), Shimizu (2001), Simon (1997), Clemen (1991), entre outros. Elton e Roe (1998) comentam que, segundo sua experiência, gerir portfólio de projetos é muito mais complicado que gerir projetos individuais sendo que em muitos casos, atrasos em projetos individuais são decorrentes não só de erros da gerência do projeto, mas também de problemas de seleção e priorização do portfólio; atividades que não estão sob sua responsabilidade direta. Segundo os mesmos autores há o problema da falta de liderança e perfil dos gerentes de projeto. Na mesma linha de raciocínio, Saaty (1994) argumenta que muitos excelentes decisores não utilizam uma teoria para ajudá-los a decidir, deixando no ar a seguinte questão: "as boas decisões são acidentais, ou existem princípios lógicos que guiam o raciocínio na tomada de decisão? Estes princípios são completos e consistentes?".

Para tratar o problema da gestão de portfólio de projetos e projetos individuais, uma vasta literatura propõe técnicas de classificação, seleção e priorização, de modo lógico e que facilite a decisão sobre quais projetos comporão a carteira das organizações e como acompanhar sua evolução no tempo de forma a trazer maior retorno. São exemplos dessa bibliografia os trabalhos de Archer \& Ghasemzadeh 
(1999), Cooper et al. (1997, 1998,1999 e 2001), Goldratt (1998), Greiner \& Fowler (2003), Jolly (2003), Roussel et al. (1991) e Saaty (1991 e 1999). Entretanto, existe uma lacuna na literatura no que se refere à aplicação dessas técnicas na gestão de projetos das organizações, especialmente no Brasil.

\subsection{Objetivos}

O objetivo deste trabalho é propor um método que permita a gestão da carteira de projetos de uma empresa nacional, de capital intensivo do setor químico e petroquímico, de maneira que aspectos quantitativos (tais como, retorno sobre o investimento, produtividade, cumprimento de prazos e orçamentos) e qualitativos, (riscos ambientais, satisfação do cliente, aspectos de segurança, interesses da comunidade ou questões políticas, entre outros) estejam presentes.

Para a elaboração do trabalho, inicialmente será realizado um estudo sobre como é selecionado e gerido o portfólio da organização objeto de análise, de modo a se obter uma fotografia da situação atual. Na seqüência, pretende-se analisar o referido processo confrontando-o com a teoria existente sobre o assunto identificandose os gaps entre a teoria e prática. Como último passo da pesquisa, será proposto um modelo para a seleção e priorização dos projetos da organização aplicando ao portfólio da empresa uma abordagem mista através dos métodos Analytic Hierarchy Process (AHP) e programação inteira.

Serão considerados os seguintes objetivos específicos:

- Aplicar e verificar a utilidade e a importância do método proposto nas tomadas de decisões da área de projetos;

- Analisar os efeitos da qualidade do processo decisório sem o suporte de ferramentas de apoio a decisão e o grau de alinhamento estratégico dos projetos com o negócio;

- Despertar o espírito crítico relacionado ao processo decisório e a gestão de portfólio de projetos.

A Figura 1, a seguir, mostra o foco deste estudo que se concentra no nível de planejamento estratégico da organização. Neste nível, são tomadas decisões para gestão da capacidade de produção, com o objetivo de garantir o crescimento da 
companhia no longo prazo e manter a continuidade e excelência de suas operações no curto prazo. Esses objetivos são satisfeitos mediante o processo dinâmico de proposição, seleção, priorização, reavaliação e execução de projetos de ampliação e manutenção da capacidade instalada.

O modelo proposto no presente trabalho constitui-se numa ferramenta para facilitar as decisões envolvidas nesse processo.

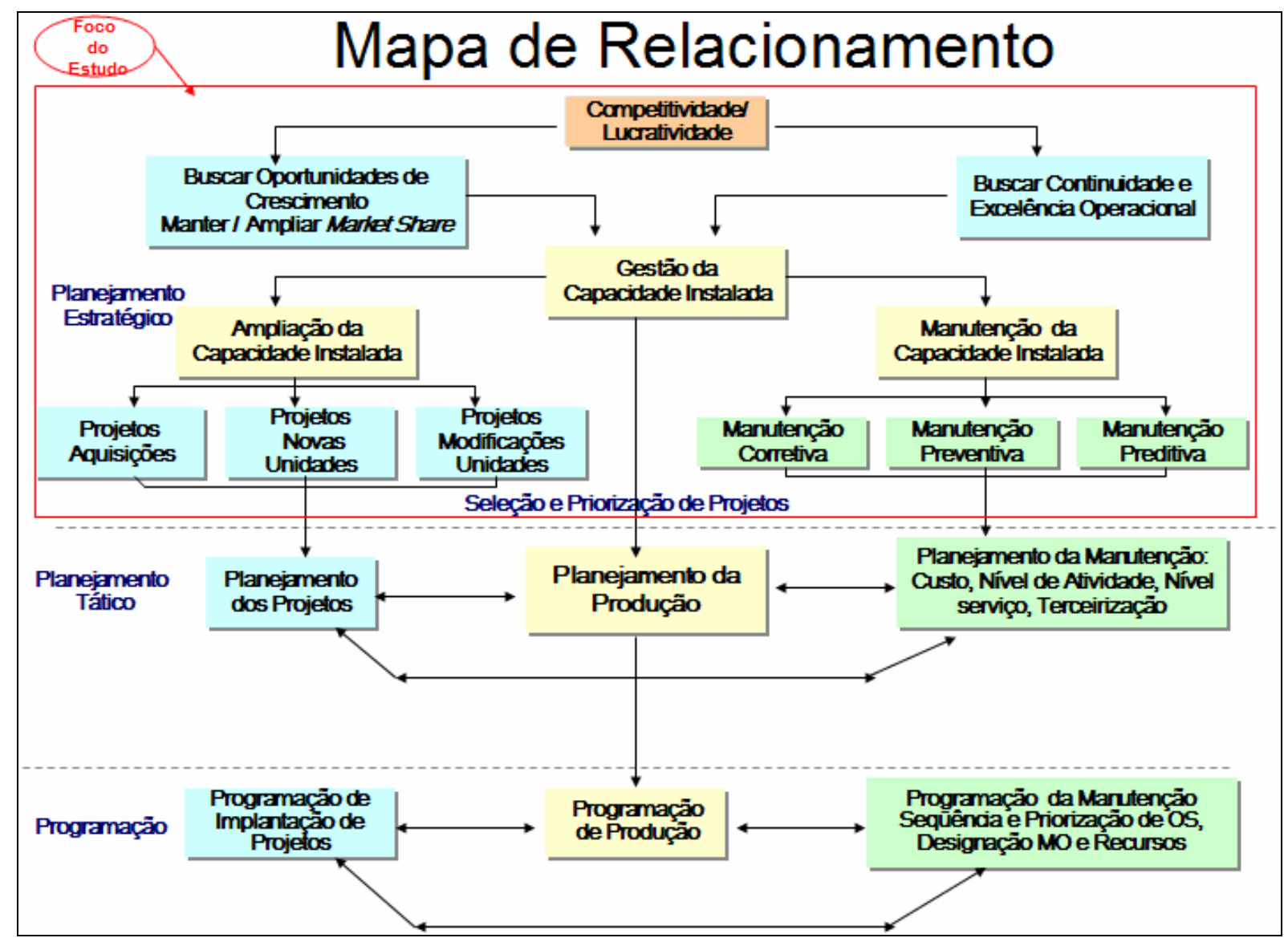

Figura 1 - Foco do estudo

\subsection{Justificativa}

No ambiente de turbulência atual, com a redução das barreiras comerciais, a competitividade e o valor das grandes empresas estão fortemente atrelados à criação de vantagens competitivas em termos globais, seja pela inovação, qualidade ou liderança em custos através de ganhos de economia de escala. Com os efeitos do aumento da concorrência, da saturação da oferta e maturação das indústrias, da 
rápida difusão de novas tecnologias e da regulação anti-truste, o enfoque passa a ser o balanceamento e crescimento dos negócios atrativos vigentes e o desenvolvimento de novos negócios, principalmente visando a diversificação de riscos e, também, contrapondo à obsolescência tecnológica e à regulação (Garcez, 2005). Assim, as organizações têm sido levadas a dedicar uma parcela maior de seu tempo com a implantação de projetos, seja para adequação de capacidade instalada, construção de novas unidades para atender a demanda por novos mercados e novos negócios, ou para incorporar as inovações tecnológicas, que permitem a flexibilização de processos, a redução de custos operacionais, a garantia da qualidade de produtos e a segurança das instalações.

Para atender a essa demanda, especialmente em empresas de capital intensivo, a função de gerenciamento de projetos passou a ter destacada importância para o negócio. É durante o projeto que as especificações de equipamentos, sobressalentes e materiais são definidas. Decisões tomadas nesta fase influenciarão diretamente na vida útil desses ativos após o início da operação da nova planta. Definições do projeto também interferem no estoque de peças e sobressalentes da empresa. Deve-se ainda destacar que o objetivo do projeto é atender as necessidades do cliente em termos de produtos e serviços ao menor custo e prazo possíveis. Grande parte dos projetos existentes nas organizações envolve trade-offs, tais como: aumento da capacidade instalada e aumento de custos fixos, paradas para manutenção visando a continuidade operacional e atendimento à demanda, custos de desenvolvimento e probabilidade de sucesso, disponibilidade de recursos e prazo dos projetos.

A importância do estudo está no fato de permitir selecionar os projetos mais relevantes para a organização, segundo critérios previamente definidos por um grupo de especialistas, de modo a manter o foco nos objetivos estratégicos, bem como identificar qual é o impacto de cada projeto quando considerados aspectos estratégicos e econômicos.

A pesquisa bibliográfica empreendida mostrou que não faltam metodologias e ferramentas para auxiliar os tomadores de decisões nas organizações. Entretanto, observa-se que os responsáveis pela gestão de projetos das organizações não têm buscado modelos racionais baseados em metodologias e ferramentas de apoio à decisão. 
Esse estudo foi motivado por contribuir para o conhecimento geral disponível, através da apresentação de um caso prático de gestão de portfólio, numa indústria nacional do setor químico e petroquímico, cuja análise compreende o período de 5 anos, tempo no qual é possível a verificação dos resultados decorrentes das decisões tomadas, bem como avaliar a aplicabilidade do modelo proposto.

\subsection{Etapas da Pesquisa}

A pesquisa é apresentada em 6 capítulos. O capítulo 1 apresenta na introdução o contexto nacional e o problema da gestão de portfólio no Brasil, na seqüência são apresentados os objetivos da pesquisa, justificativa e motivação para seu desenvolvimento. Por último é apresentado um roteiro com as etapas da pesquisa.

No capítulo 2 será apresentada uma revisão bibliográfica sobre os temas gestão de portfólio de projetos e processo e metodologias de tomadas de decisão, teoria dos stakeholders e teoria dos trade-offs e será feita uma análise da literatura existente, limitando o contexto deste trabalho.

O capítulo 3 trata da metodologia e método de pesquisa adotado.

O estudo do caso, com a descrição da empresa estudada e suas características, a apresentação do portfólio de projetos e a apresentação da pesquisa, são mostrados no capítulo 4.

O capítulo 5 apresenta o modelo de seleção de projetos proposto para atendimento dos stakeholders da organização, o planejamento das atividades para a implantação desse modelo na empresa estudada e os resultados obtidos com a simulação de diferentes cenários com a utilização do método AHP integrado a programação inteira. Nesse capítulo é proposto, ainda, um novo modelo de classificação dos projetos da organização.

O capítulo 6 traz as conclusões do estudo, suas limitações e sugestões de estudos futuros.

O trabalho é finalizado com as referências bibliográficas, apêndices e anexos. 


\section{REFERENCIAL TEÓRICO}

\subsection{Princípios de Análise de Decisão}

Tomada de decisão é um processo de escolha entre alternativas para atender a metas e objetivos (Forman \& Selly, 2001). Segundo o prêmio Nobel Herbert Simon (1960), o processo de tomada de decisão é sinônimo de prática de gestão e envolve questões básicas de decisão sobre o que deve ser feito, quando, como, onde e por quem. Outras funções gerenciais como organizar, implementar e controlar, estão correlacionadas fortemente com a tomada de decisão.

O processo de tomada de decisão nas organizações está se transformando rapidamente nos últimos anos, sobretudo pela velocidade do avanço da tecnologia da informação, de comunicações e de automação. As fronteiras das empresas e países estão se ampliando, os meios de comunicação facilitam cada vez mais o intercâmbio rápido de informações, o que torna as sociedades mais exigentes na aquisição de produtos, acabando por intensificar a concorrência.

Esse novo cenário pressiona as organizações a tomarem decisões cada vez mais rápidas e acuradas.

Com o objetivo de melhorar a qualidade da tomada de decisões, diversos estudos têm sido desenvolvidos na área de processo decisório.

Saaty (1991) afirma que o tomador de decisões, quer esteja motivado pela necessidade de prever ou de controlar, geralmente enfrenta um complexo sistema de componentes correlacionados, sendo de seu interesse analisar esse sistema. É claro que quanto mais o tomador de decisões compreender essa complexidade, melhor será a sua decisão.

Decisões ruins podem prejudicar o negócio. Em muitos casos, elas são conseqüências de não se ter definido claramente as alternativas, não se ter coletado a informação certa ou não ter sido feita uma análise de custo/ benefício com a precisão devida (Hammond, Keeney \& Raiffa, 1998). Os autores comentam ainda que muitos erros na tomada de decisões não são devidos ao processo de tomada de decisão, mas estão relacionados com a mente do decisor e a forma como seu cérebro trabalha. 
Nesse sentido os autores alertam para a existência de armadilhas tais como a armadilha da âncora, a armadilha do status quo, do custo-afundado (sunk-cost), da confirmação da evidência, da forma de apresentação e a armadilha das estimativas e previsões. No caso da âncora, ao receber informações para a tomada de decisões, a mente dá pesos desproporcionais às informações recebidas. Impressões iniciais, estimativas ou dados são fixados de modo a induzir raciocínios e julgamentos futuros, causando distorções nas decisões. Por outro lado, no caso da armadilha do statusquo os autores argumentam que muitos estudos realizados comprovaram que no momento de tomar decisões, os decisores, ao se defrontarem com diferentes alternativas, quase sempre optam pela de menor risco aparente ou pela manutenção da situação atual, assumindo uma postura de adotar sempre a solução mais confortável. A armadilha do sunk-cost é relativa a fazer escolhas para justificar escolhas passadas, ainda que num passado próximo elas fossem válidas. Ocorrem com mais freqüência, segundo os autores, em ambientes onde existem punições para decisões erradas. A armadilha da confirmação da evidência ocorre quando a decisão já foi tomada, porém o decisor usa do artifício de pedir a opinião de outras pessoas com o mesmo conhecimento com o objetivo de obter apoio e confirmar sua posição. A armadilha da forma trata de como as questões são apresentadas, dependendo de como a formulação do problema é feita, as decisões podem ser afetadas profundamente. Por último, relativamente à armadilha de previsões e estimativas, Hammond, Keeney e Raiffa (1998) argumentam que constantemente os decisores fazem previsões sobre prazos, distâncias, pesos e volumes, fazendo julgamentos sobre essas variáveis e pegando feedback sobre seu julgamento. Entretanto, tais decisores raramente buscam feedback sobre os desvios entre as previsões e a realidade, devido a excesso de confiança, prudência ou lembranças de eventos passados e isso causa desvios cada vez maiores.

Para Forman \& Selly (2001) a tomada de decisões é indubitavelmente a mais difícil e primordial das funções de um gestor, sendo esta habilidade a mais importante dos negócios.

De acordo com Nutt (2002), o pior modo para se chegar a uma decisão é através da imposição de idéias na organização. Em seu estudo, o autor conclui através de um survey elaborado com um universo de 356 empresas, que 1 entre 5 executivos entrevistados envolveu o Staff no processo de tomada de decisões, $41 \%$ deles tomou decisões por persuasão e $40 \%$ por determinação. Dentre os casos de 
persuasão $53 \%$ das decisões resultaram em falha no projeto e dentre os de determinação $65 \%$ foram mal sucedidos.

Para Shimizu (2001), com exceção das tomadas de decisões rotineiras e bem conhecidas, o processo de formular alternativas de decisão e escolher a melhor delas é complexo e caótico.

Kaufmann (1975) questiona se as decisões devem continuar sendo tomadas baseadas em intuições, considerando-se que a evolução da tecnologia cresce numa curva exponencial, o que torna o mundo cada vez mais complexo.

Simon (1997) recorre à metáfora de um grande rio que traz de seus afluentes as premissas incontáveis que constituem e dão forma a um processo de decisão, para explicar a complexidade do processo de tomada de decisões. O autor lembra que, em qualquer decisão, a dinâmica e a cultura da organização estarão presentes, afetando com maior ou menor intensidade seus processos.

Decisão não é um evento, é um processo que se desdobra durante semanas, meses, ou até mesmo anos, e que carrega consigo jogos de poder e políticas, estando repleto de tons pessoais e história institucional (Garvin \& Roberto, 2001; Kaufmann, 1975).

Samson (1980) e Shimizu, Laurindo e Morita (2001) afirmam que a Teoria da Decisão pode ser considerada uma filosofia e, ao mesmo tempo, um processo formal de análise, propondo que tal processo seja constituído pelos seguintes passos:

o Identificação do problema, escolha e estruturação do modelo de decisão;

- Avaliação das probabilidades e das magnitudes envolvidas;

o Uso de um critério de decisão para modelar o processo de seleção de alternativas;

- Análise de Sensibilidade, para determinar a consistência das soluções;

o Implementação da estratégia preferida ou escolhida hierarquicamente.

Idéia semelhante é apresentada por Clemen (1991) os processos de tomada de decisão, indicando ferramentas de apoio os tomadores de decisão e sistematizando seu pensamento sobre os grandes problemas, de modo a melhorar a qualidade das decisões tomadas. O autor menciona quatro dificuldades para a tomada de decisão: a complexidade do problema, as informações imprecisas ou incertas, vários objetivos para um único problema e conclusões diferentes, aplicando-se a 
mesma sistemática, devido à mudança dos dados. A figura 2 mostra sinteticamente 0 processo de tomada de decisão sugerido por Clemen (1991) na forma de um diagrama.

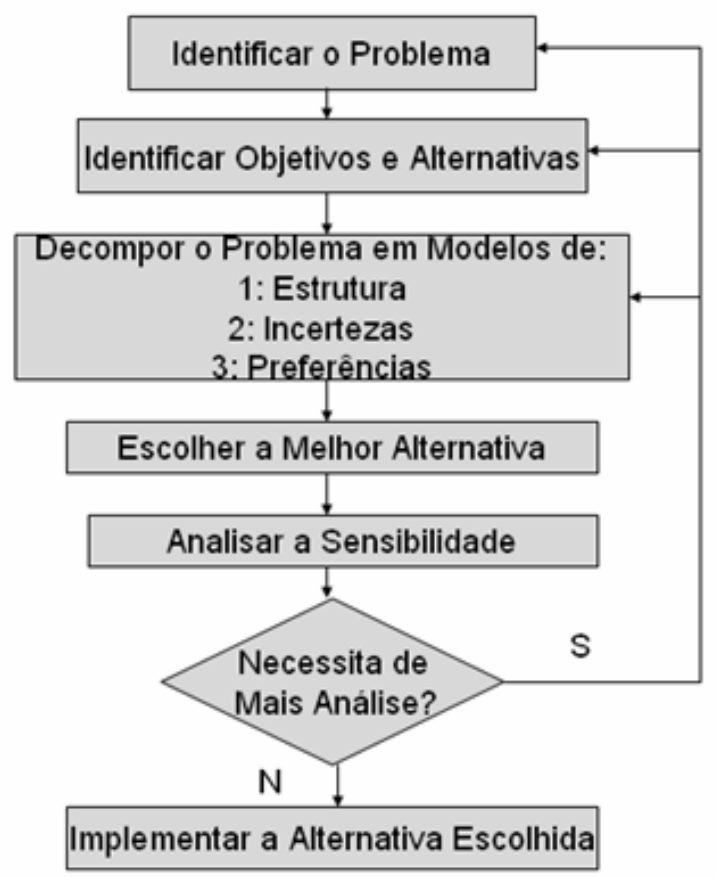

Figura 2 - Diagrama do Processo de Decisão (Fonte: Clemen, 1991)

Para Garber, (2002), a etapa de identificação do objetivo não é difícil, mas caso não se consiga executá-la com precisão, corre-se o risco de tratar o problema de forma equivocada. Segundo este autor, a fase de identificação dos objetivos e alternativas é um processo de criação.

A modelagem do problema na maior parte da literatura é tratada com a técnica de decomposição do problema em modelos, sendo definidas nesta fase as alternativas candidatas a solução. O modelo de estrutura representa o resultado da análise detalhada do problema utilizando-se ferramentas para decompor em elementos, tais como diagramas de relacionamento, matrizes de decisão, diagramas de árvores e intercâmbio de informações, quando o problema envolver um grupo de pessoas.

O modelo de incertezas indica, através do uso da estatística e da simulação, as bases para a obtenção das informações que complementam os modelos. 
O modelo de preferências constitui-se na representação matemática do problema, para que o tomador de decisão possa escolher a melhor alternativa, considerando os objetivos e o equilíbrio entre os elementos de conflito, através do fator subjetividade.

$\mathrm{Na}$ etapa seguinte, seleciona-se a melhor alternativa. O próximo passo é fazer a análise de sensibilidade, que é o processo de observar a variação que o modelo matemático indicaria se as condições do problema mudassem. Essa avaliação ajuda a definir se uma solução necessita ou não de uma análise mais profunda, até a implementação da solução. A análise de sensibilidade verifica relações de efeito da incerteza na estimativa de variáveis externas, efeitos de diferentes interações entre variáveis, robustez de decisões sob condições de mudanças, impacto de mudanças em variáveis externas (incontroláveis) e parâmetros na (s) variável (eis) de saída e impacto de mudanças em decisões na(s) variável (eis) de saída. A análise de sensibilidade pode levar o tomador de decisão a reconsiderar o melhor possivel a natureza de um problema (Shimizu et al., 2001). A questão que pode ser formulada na realização de uma análise de sensibilidade neste nível é: "Estamos resolvendo o problema correto?" Caso uma análise mais detalhada seja necessária, se retorna aos passos anteriores do processo até que a solução mais adequada seja encontrada e então parte-se para a fase de implementação.

A análise de decisão ajuda a dar suporte aos processos decisórios e às habilidades intuitivas e cognitivas do decisor. Os modelos aplicados são baseados em abstrações da realidade, que focalizam cada estágio de solução do problema, desde a identificação e a formulação, até a solução do mesmo.

\subsection{Estratégia e a Tomada de Decisões}

A tomada de decisões nas organizações deve estar alinhada com sua estratégia.

Por isso a primeira coisa que se deve fazer ao tomar decisões numa organização é conhecer sua estratégia, quais as formas que ela utiliza para competir, quem são seus stakeholders e quais são suas competências essenciais. Para tanto, a organização deve dispor de uma estratégia definida. 
Luehrman (1998) afirma que a estratégia pode ser desenhada em termos de um mix de insights financeiros e estratégicos. Segundo o autor, quando executivos criam a estratégia eles projetam a si próprios e suas organizações para o futuro, criando padrões de onde estão hoje e onde desejam estar após alguns anos. Para Luehrman (1998), uma abordagem interessante para ajudar os executivos a pensarem estrategicamente seria incorporar as incertezas inerentes ao negócio na atividade de tomada de decisão requerida para que a estratégia seja bem sucedida.

Para Carvalho \& Laurindo (2003) a escolha de uma estratégia repercute nas dimensões estratégicas, que exigem trade-offs. Segundo os autores, podem-se identificar as seguintes dimensões estratégicas: especialização - grau em que a empresa se esforça para ampliar sua linha de produtos, segmentos de clientes e mercados; identificação de marcas - grau com que a empresa busca a identificação da marca, através do marketing; política de canal - grau em que a empresa busca desenvolver identificação de marca diretamente com o consumidor final e o apoio aos canais de distribuição na venda de seus produtos; seleção do canal - escolha dos canais de distribuição; qualidade do produto - nível de qualidade do produto em termos de matérias-primas, especificações, tolerâncias e características; liderança tecnológica - grau com que a empresa procura liderança tecnológica, em vez de comportamento imitativo; integração vertical - o montante do valor agregado refletido no nível de integração para frente e para trás, envolvendo aspectos como canais de distribuição cativos, lojas de varejo exclusivas, etc.; posição de custo - grau com que a empresa busca posição de mais baixo custo na fabricação e distribuição; atendimento - grau com que proporciona serviços auxiliares com sua linha de produtos, como assistência técnica, crédito, etc.; política de preços - posição relativa de preço no mercado, relacionado a custo e qualidade; alavancagem - grau de alavancagem financeira e operacional; relacionamento com a matriz - exigências em relação à matriz.

Carvalho \& Laurindo (2003) comentam que é possível identificar grupos estratégicos em determinada indústria que estão seguindo uma estratégia idêntica ou semelhante ao longo das dimensões estratégicas, mas esses grupos divergem em sua maioria nas abordagens de produtos e de marketing. Para os autores, nem sempre a empresa com maior parcela de mercado tem maior rentabilidade. Segundo eles, empresas maiores serão mais rentáveis se competirem em grupos estratégicos mais protegidos por barreiras de mobilidade e com posição mais forte em relação à 
cadeia; já as pequenas serão mais rentáveis se não houver grandes economias de escala e se adotarem estratégias de diferenciação, de atendimento e de inovação tecnológica.

Carvalho \& Laurindo (2003) falam ainda que a análise e a escolha dos grupos estratégicos onde se deseja competir afetam a formulação da estratégia, devendo decisões desse tipo levar em consideração pontos fortes e fracos da empresa, sejam eles estruturais ou em relação à implementação da estratégia. Os autores sugerem a análise de SWOT (Strengths, Weaknesses, Opportunities, Threats) ou (Forças, Fraquezas, Oportunidades e Ameaças) como ferramenta para a visualização estruturada do impacto dos grupos estratégicos na estratégia.

Boldwijn \& Kumpe (1990) comentam que a estratégia industrial de produtores multinacionais sofreu profundas mudanças nos últimos anos. Os autores fizeram uma análise de várias organizações européias por eles visitadas, onde foi possível discutir com os produtores sua estratégia, fazer observações pontuais em unidades produtivas e conhecer as melhores práticas de manufatura. Como resultado dessa pesquisa os autores chegaram a conclusão que o conhecimento é evolutivo, não sendo possível pular etapas. No início da era industrial as empresas davam ênfase ao crescimento de escala, com a competição internacional passaram a sofrer pressões por preços baixos, depois por produtos de qualidade e na seqüência por flexibilidade de Mix, entrega ou volume. Por último a inovação passou a ser o diferencial.

Prahalad e Hamel (1990) afirmam que os caminhos mais poderosos para competir globalmente ainda são invisíveis para algumas organizações. Os autores argumentam que com a grande velocidade com que produtos são criados, novos mercados estão emergindo e novos padrões estão sendo estabelecidos, criar uma organização capaz de inventar novos produtos com funcionalidades irresistíveis, ou ainda, criar produtos necessários que ainda nem foram imaginados é um desafio. Os autores dão o exemplo da NEC e da GTE para ilustrar como mudanças na liderança de mercados ocorrem e tiram o seguinte aprendizado: o segredo do sucesso da NEC foi devido a sua estratégia bem concebida e a posterior criação de um comitê de gerentes de alto escalão para identificar, cultivar e monitorar o desenvolvimento de produtos e competências entendidos como essenciais à organização (Core Products e Core Competences). Segundo os autores a NEC deu lugar aos grupos e comitês que eliminaram negócios cujos interesses fossem pessoais. A NEC passou a ter um portfólio de competências e não um portfólio de negócios; essa estratégia diferenciou- 
a das demais organizações, pois investiram em consolidar tecnologias, habilidades de produção e competências individuais difíceis de copiar e que a tornaram uma empresa com rápido poder de adaptação a mudanças.

Banerjee (2003) concluiu em seu estudo sobre core competence realizado em empresas de software indianas que as competências essenciais proporcionam agilidade às organizações. $\mathrm{O}$ autor avalia que o conhecimento que leva a capacidade de decisão pode ser recombinado entre os recursos, produtos e projetos influenciando diretamente a geração de competências essenciais.

Slack et al. (1997) classificam os critérios competitivos (critérios com que consumidores julgam a relevância de características de um produto em relação a outro) em três tipos: ganhadores de pedido, qualificadores e critérios menos importantes. Segundo os autores, os critérios ganhadores de pedido são os que contribuem de maneira significativa para a realização de um negócio, sendo os aspectos mais importantes e que definem a posição competitiva da empresa. Já os critérios qualificadores são aspectos da competitividade em que o desempenho da organização deve estar acima de um nível mínimo para ser considerado pelo cliente. Por último, os critérios menos importantes são os que têm pouco impacto sobre os consumidores.

Slack (1993) propôs um modelo de lacunas (gaps) para viabilizar a identificação dos critérios competitivos mais importantes e sua avaliação perante os concorrentes. Esse modelo é consolidado em duas dimensões: o grau de importância do critério competitivo e o desempenho obtido nesse critério face aos concorrentes. $O$ modelo proposto por Slack (1993) é uma importante ferramenta para as organizações direcionarem suas decisões alinhados com a estratégia.

\subsection{Teoria dos Stakeholders}

Ackoff (1974) apud Muscat (2004) define os stakeholders como os interessados do sistema de produção. Para este autor os stakeholders podem ser os clientes, os acionistas, recursos humanos, os fornecedores, a comunidade a sociedade e o governo, entre outros. Tais stakeholders têm objetivos específicos, que podem ser conflitantes com os objetivos dos demais interessados pelo sistema produtivo. Por 
exemplo, para os clientes qualidade, preço, disponibilidade, flexibilidade e inovação costumam ser seus objetivos. Já para o acionista, o objetivo é o retorno de capital e para o governo a arrecadação.

Os stakeholders em geral oferecem contrapartida aos objetivos atendidos; por exemplo, o cliente proporciona a receita da empresa, por isso eles devem ser conhecidos e seus objetivos levados em consideração na tomada de decisões, pois tais objetivos estão diretamente relacionados com o atendimento de necessidades e estratégias das organizações.

Seguindo a mesma linha de pensamento, Clarkson (1995) afirma que existem diferentes grupos de stakeholders, os primários, que contemplam investidores, empregados, clientes e fornecedores e os stakeholders públicos, que são o governo e a comunidade, que provêem infra-estrutura e mercado e cujas leis e regulações devem ser obedecidas. Outros autores como Cohen (1995) e Donaldson e Preston (1995) incluem ainda na lista de stakeholders associações de negócios, acionistas e grupos de meio ambiente.

A literatura existente sobre stakeholders sugere que diferentes abordagens para lidar com o grupo de stakeholders primários e os demais poderiam ser adotadas. As abordagens propostas são: proatividade, acomodação, defesa e reação (Carrol, 1978; Clarkson, 1988,1991, 1995; Gatewood \& Carroll, 1981; Wartick \& Coachran, 1985). Segundo esses autores, proatividade inclui fazer o melhor que puder para atender aos stakeholders, incluindo antecipar e solucionar questões. Já a estratégia de acomodação recomenda que seja feito o mínimo necessário para atender aos stakeholders. A estratégia de defesa envolve atender minimamente aos aspectos legais requeridos pelos stakeholders e, por último a estratégia de reação pressupõe litígios com stakeholders ou a opção de ignorá-los.

Mitchell et al. (1997) propõe uma classificação dos stakeholders segundo os atributos de poder, legitimidade e urgência. De acordo com essa tipologia, se um stakeholder possui só um atributo dos três possíveis, ele é chamado latente e tem pouca evidência. Se esse único atributo é poder, o stakeholder é chamado de dormente; se o único atributo do stakeholder é legitimidade ele é chamado de arbitrário e se o único atributo do stakeholder é a urgência, ele é chamado de exigente. O destaque do stakeholder é moderado, quando dois atributos estiverem presentes em cada um dos stakeholders, que são chamados de espectadores. Stakeholders espectadores que têm poder e legitimidade são chamados dominantes; 
àqueles que têm legitimidade e urgência são denominados dependentes e os que têm poder e urgência são chamados de perigosos. A importância do stakeholder é alta quando ele tem os três atributos: poder, legitimidade e urgência, chamando-se stakeholder definitivo. Considerando-se o conceito de dinâmica dos stakeholders, pode-se perceber que um stakeholder pode migrar de um tipo para outro, ao longo do ciclo de vida da organização.

Jawahar \& McLaughlin (2001) propuseram uma teoria descritiva para stakeholders que engloba outras duas teorias: a da dependência de recursos e os modelos de ciclo de vida da organização. A teoria apresentada pelos autores identifica uma estratégia particular que a empresa deve usar para lidar com os stakeholders em cada estágio do seu ciclo de vida, considerando-se que a importância dos stakeholders muda ao longo do ciclo de vida da organização. Eles prescrevem, ainda, quais stakeholders são importantes em cada estágio de vida da organização.

A teoria de Jawahar \& McLaughlin (2001) é constituída de 4 proposições básicas; uma para cada estágio do ciclo de vida da organização, ou seja, estágio de partida (start up), crescimento, maturidade e declínio/transição (reestruturação). Na partida os autores ressaltam que são importantes para a sobrevivência da organização a existência de fundos, fluxo de caixa e aceitação dos clientes. Empregados e fornecedores também são importantes, mas não tanto quanto os stakeholders anteriormente citados. Assim, a primeira proposição dos autores é que durante a partida decisões de alocação de recursos são tomadas num contexto de perdas e a estratégia é de busca de riscos, devendo-se usar a estratégia de defesa ou reação com stakeholders não críticos para a sobrevivência da organização. A corporação assumirá a estratégia de reação com problemas com associações de negócios e grupos de meio ambiente. Por outro lado a estratégia de defesa será utilizada quando se tiver que negociar com governo ou comunidade. Na partida a corporação usará, ainda, a estratégia de proatividade com bancos e órgãos de financiamento/crédito e clientes e a estratégia de acomodação no tratamento de funcionários e fornecedores, desde que eles não sejam críticos para a sobrevivência da organização. A segunda proposição da teoria de Jawahar \& McLaughlin (2001), relativa à fase de crescimento da organização, prevê que nesta etapa do ciclo de vida, a decisão sobre alocação dos recursos ocorre num contexto de ganhos e a estratégia é de negociação com os stakeholders, com aversão ao risco. Neste caso, questões com entidades de crédito, empregados, fornecedores e associações de negócios 
poderão ser resolvidas com a estratégia de proatividade. Por outro lado, questões com clientes, governo, comunidade e grupos de meio ambiente poderão ser tratadas com a estratégia de acomodação. Segundo os autores, no estágio de maturidade, a velocidade de crescimento diminui e o clima da organização é de excesso de confiança e incertezas sobre os novos rumos a seguir. Nessa fase é freqüente que as organizações tenham um fluxo de caixa significativo, mas sem oportunidades atrativas para investimento. Para esta fase a terceira proposição dos autores quanto à estratégia de negociação com stakeholders é que decisões sobre alocação de recursos ocorrem num contexto de ganhos e aversão ao risco, devendo-se adotar a estratégia de proatividade com todos os stakeholders, exceto entidades de crédito, que devem ser tratadas com acomodação. Na última fase do ciclo de vida da organização, declínio/transição, a demanda por produtos e serviços diminui, passam a ser consideradas estratégias de fusões organizacionais e redução de pessoal (downsizing), para a sobrevivência da empresa. Nessa etapa, a eficiência técnica é importante, para se obter melhorias de produtividade e políticas de estímulo ao lançamento de novos produtos são úteis para estimular o crescimento. Nesse contexto a quarta proposição dos autores é de que na fase de declínio/transição, a alocação de recursos ocorre num contexto de perdas e busca do risco, devendo-se adotar a estratégia de defesa ou reação para stakeholders não críticos. Assim, especialmente para no caso de associações de negócios, e grupos de meio ambiente deve-se usar a estratégia de reação. No caso de governo e comunidade deve-se adotar a defesa. A estratégia de proatividade pode ser usada com entidades de crédito e clientes e a acomodação pode ser usada para negociar com empregados e fornecedores, desde que não sejam críticos para a sobrevivência da organização.

Elias et al. (2002), em seu trabalho, fazem uma análise dos stakeholders envolvidos no processo de gestão um projeto de pesquisa e desenvolvimento (P\&D) da Nova Zelândia. E concluem que a metodologia utilizada pode ser muito útil na compreensão dos interesses dos Stakeholders dos projetos e na sua identificação, tornando mais fácil a gestão dos projetos. No artigo, os autores aplicam 8 passos a seguir, baseados em Freeman (1984) e Mitchell et al. (1997):

o Desenvolver o mapa de stakeholders do projeto;

o Preparar a carta dos stakeholders específicos;

o Identificar os interesses do stakeholders;

o Elaborar uma grade de poder versus interesse; 
- Elaborar a análise dos stakeholders no nível de processos;

o Elaborar a análise dos stakeholders no nível transacional

- Determinar a capacidade de gestão dos stakeholders no projeto de P\&D e analisar a dinâmica dos stakeholders.

É importante conhecer os stakeholders envolvidos no processo de gestão de projetos, a estratégia da empresa e a fase do ciclo de vida em que ela se encontra para que se incorpore no modelo de decisão, estratégias de abordagem dos stakeholders mais convenientes para a organização, dependendo do cenário que se apresente.

\subsection{Teoria dos Trade-offs}

Segundo Boldwijn \& Kumpe (1990), caso uma empresa não esteja em dado patamar evolutivo, mas queira atuar como se nele estivesse, terá de pagar um preço por essa decisão. Essa relação de troca que envolve perdas de curto prazo e ganhos de longo prazo é denominada trade-offs. Tais trade-offs podem ser exercidos por curtos períodos de tempo, até que a empresa aprenda e não tenha mais que perder para se manter no mercado. Segundo os autores, para compatibilizar os ganhos de longo prazo com os trade-offs de curto prazo a empresa deve monitorar as necessidades do mercado e a concorrência e elaborar um plano estratégico, com planos de ação de médio e longo prazo, que contemplem o atendimento dessas demandas de clientes. Assim, a empresa poderá arcar pontualmente com custos para atender dado cliente em áreas onde não tenha competência momentânea, mas sabendo que em pouco tempo terá através do cumprimento de seu planejamento.

Para Slack (1998) a análise dos trade-offs é importante não somente como forma de conceitualização do processo de melhoria no desempenho operacional, mas também para explicar porque certos trade-offs são escolhidos pelas organizações.

Em seu trabalho Slack (1998) primeiramente faz um levantamento das teorias existentes sobre trade-offs, descrevendo 3 escolas de pensamento: a tradicionalista, a das técnicas World Class, de melhoria contínua, e a escola baseada nos trabalhos de Hayes, Pisano e Upton. Na seqüência o autor propõe a existência de 3 tipos genéricos de trade-offs que os gestores das organizações devem conhecer para direcionar suas 
ações no sentido de superá-los ao longo do tempo. O estudo de Slack (1998) coloca a flexibilidade como um aspecto chave para a superação dos trade-offs.

Segundo a escola tradicionalista de Skinner, existem restrições tecnológicas que nos impedem de sermos bons em tudo. Assim, ao tratar de gestão de operações, esta escola afirma que não é possível ter perfeição na qualidade, cumprimento às datas de entrega, flexibilidade e baixo custo. Esta escola de pensamento prega, também, que os trade-offs são vivos e dinâmicos.

Já para os seguidores da escola das técnicas World Class de melhoria, tradeoffs não existem, o que ocorre é que constantemente se faz escolhas sobre diferentes aspectos de desempenho até se chegar à perfeição. Segundo esta escola, com a tecnologia, novas formas de organização, layouts celulares, simplificação de fluxos de trabalho e automação permitem que os trade-offs sejam superados. A terceira escola de pensamento, de Hayes, Pisano e Upton, prega que posicionamento e trade-offs são estratégias distintas que as organizações adotam em diferentes momentos de seu ciclo de vida. Para esta escola, a chave para a superação das restrições está na construção de capacidades de operação adequadas, depende da estratégia adotada e envolve reposicionamento da empresa.

Um estudo realizado por Slack (1998) em duas organizações, uma confecção e um restaurante tipo fast food, mostrou que os gestores dessas empresas tendiam a misturar trade-offs de desempenho operacionais e financeiros. $\mathrm{O}$ autor concluiu que os trade-offs identificados podem ser agrupados em 3 tipos: working capital, representados pelos inventários; custo de manufatura e riscos de perda de faturamento, relacionado com a incerteza de como o mercado receberá mudanças de especificação de produto, prazo de validade, variedade (mix) e entrega. Para o autor, a flexibilidade é o pivô entre a magnitude da mudança e custos, tempo ou dificuldade de promover a mudança. Slack (1998) identificou em seu trabalho a existência não só de trade-offs operacionais, mas também em diferentes partes das empresas. Aspectos importantes do estudo são relacionados com os conceitos de sensibilidade e rigidez do trade-off. O primeiro mede o potencial de melhoria de desempenho enquanto a mudança acontece, o outro mede o grau de dificuldade em se promover a mudança. 


\subsection{Gestão de Portfólio de Projetos}

Atualmente, a relevância do alinhamento entre a estratégia de negócio das organizações e seu portfólio de projetos tem sido objeto crescente de estudos. Assim, o gerenciamento do portfólio vem assumindo um papel de importância estratégica, como sugerido por diversos autores (Carvalho e Laurindo, 2003; Roussel et al, 1991; Cooper et al, 1999 e 2001).

Além disso, Carvalho et al (2003) argumentam que as saídas do processo de gestão de portfólio deveriam ser capazes de atender aos requisitos estratégicos da companhia e também alcançar suas metas, de forma que se obtenha uma vantagem competitiva. Em poucas palavras, eficácia deve ser compreendida como a habilidade de "fazer a coisa certa" (Drucker, 1963) e no contexto deste trabalho, de escolher os projetos mais adequados.

Entretanto, a implementação da gestão de portfólio com sucesso não é uma tarefa trivial; ela engloba incertezas de mercado e tecnológicas; a negociação por recursos quase sempre escassos (mão-de-obra, orçamento, tempo) entre diferentes áreas da companhia e constantes mudanças devido à turbulência do mercado (Brown e Eisenhardt, 1998; Eisenhardt e Brown, 2000). Além disso, é importante enfatizar as dificuldades decorrentes da natureza dinâmica da gestão de portfólio, devendo se constituir num processo contínuo com o engajamento dos principais atores do processo de tomada de decisão e com um fluxo de processo bem definido e pontos de verificação pré-estabelecidos.

Neste trabalho, é utilizado o conceito de gestão de portfólio proposto por Cooper et al (1999) isto é, "um processo de decisão dinâmico, por meio do qual uma lista com os projetos é constantemente atualizada e revisada. Neste processo, novos projetos são avaliados, selecionados e priorizados; projetos existentes podem ser acelerados, eliminados ou ter sua prioridade reduzida, sendo os recursos alocados e realocados para os projetos ativos. O processo de decisão do portfólio é caracterizado pela incerteza e mudanças das informações, oportunidades dinâmicas, múltiplas metas e considerações estratégicas, interdependência entre projetos e múltiplas tomadas de decisões e locais". 
Para estes autores, gestão de portfólio é a manifestação da estratégia do negócio, que estabelece onde e como o investimento será feito no futuro. Os autores também citam que maximizar o valor do portfólio significa obter retorno sobre os investimentos feitos em pesquisa e desenvolvimento (P\&D), balanceando o portfólio dos projetos e alinhando a estratégia de investimentos com a estratégia da companhia.

Dentro da mesma linha de pensamento, Roberts e Berry (1985) propuseram um modelo matricial para a seleção de modalidades ótimas de projetos ou estratégias para crescimento que se baseia na familiaridade da organização com a tecnologia empregada e o mercado de atuação, aumentando a probabilidade de sucesso desses empreendimentos. Segundo os autores, tais projetos podem ser dos seguintes tipos:

o Desenvolvimento Interno, que consiste em explorar os recursos internos como base para o estabelecimento do novo negócio para a empresa em vez de buscá-los externamente;

o Aquisições, ou seja, compra do controle acionário de outras empresas;

o Licenciamentos ou direito de uso de tecnologia não proprietária;

o Internal Ventures, que é o desmembramento em novas empresas ou unidades de negócio a partir de uma empresa-mãe;

o Joint-Ventures que consiste na associação de empresas na qual a participação e a gestão são compartilhadas pelos parceiros e;

o Participações Minoritárias que, em geral, visam a redução de riscos em negócios de baixo domínio de conhecimento podendo ser divididas em: Private Equity, quando ocorre a aquisição de participação acionária em empresa de médio/grande porte, em geral com bom potencial de retorno financeiro no médio prazo; Venture Capital que é a participação acionária minoritária em empresa menor, em geral com grande potencial de retorno financeiro de longo prazo, sem apoio à gestão ou com apoio à gestão no caso de Venture Nurturing e; por último; Aquisições Educativas (Educational Acquisitions) que são aquisições de controle acionário em empresas menores de alta tecnologia com o propósito específico de apropriação de conhecimento.

Garcez (2005) testou e validou o modelo de seleção das estratégias de crescimento e entrada em novos negócios proposto por Roberts e Berry (1985) para o caso de uma grande empresa petroquímica de brasileira, BRASKEM, analisando 26 
episódios de crescimento dessa organização obtendo uma aderência do modelo de $88,46 \%$.

Archer et al (1999) analisaram vários métodos de gestão de portfólio e concluíram que os mais apropriados pressupõem atividade de seleção periódica das propostas de projetos disponíveis e reavaliação dos projetos existentes e em fase de execução, possibilitando o atendimento aos objetivos estratégicos da empresa, sem exceder recursos disponíveis ou violar outras restrições do negócio, atendendo aos requisitos mínimos da organização de acordo com diferentes critérios. São exemplos desses requisitos: lucratividade potencial, aceitabilidade potencial, montante de investimentos e outros.

Cooper et al (1999) estudaram o processo de gestão do portfólio de projetos e sua implementação em diferentes empresas e encontraram uma gama dos mais diversos métodos, como listado a seguir:

o Métodos financeiros $(77,3 \%)$;

o Métodos de estratégia do negócio (64,8\%);

o Diagramas de bolhas (40,6\%);

o Scoring Models (37,9\%);

o Checklists $(20,9 \%)$.

Como este levantamento sugere, as empresas utilizam múltiplos métodos de gestão de portfólio, sendo os métodos financeiros os mais utilizados. Entretanto, este não é o melhor método, quando utilizado isoladamente, pois é negativamente afetado pela má qualidade dos dados, ocasionando distorções e decisões equivocadas (Cooper, R.; Edgett, S.; Kleinschmidt, E., 2001).

Assim, é possível concluir que existe a possibilidade do uso de mais de um método de modo sinérgico e complementar. Outra conclusão plausível é que a empresa deve ser capaz de escolher o melhor conjunto de métodos disponíveis, de modo a atender suas necessidades básicas na gestão de portfólio.

McFarlan (1981) ratifica este ponto de vista e afirma que diferentes projetos requerem diferentes abordagens de gerenciamento. Entretanto, este autor adverte que as companhias estudam exaustivamente os benefícios financeiros, qualidade dos projetos, custos de implementação, prazos e competências necessárias, mas elas raramente armazenam dados sobre riscos dos projetos. Estes riscos são descritos como sendo atrasos no cronograma de implantação, estouro no valor orçado, falhas 
técnicas e problemas com desempenho após a implantação por ignorar a possibilidade de tais problemas.

Assim, é necessário classificar os projetos de modo que seja possível diferenciá-los e compará-los com projetos similares. De acordo com McFarlan (1981), um projeto pode ser classificado em 3 dimensões: tamanho do projeto, experiência com a tecnologia utilizada e estrutura do projeto.

Por outro lado, Lager (2002) sugere um modelo de classificação de projetos de processo segundo uma escala. Ele propõe 3 graus de inovação para a tecnologia de processo existente: baixo, quando a tecnologia de processo é conhecida e comprovada; médio, quando a tecnologia do processo é uma melhoria de uma tecnologia conhecida anteriormente; e alto, quando a tecnologia de processo é completamente nova. Lager (2002) também sugere 3 graus de inovação quanto à tecnologia de processos utilizada no sistema produtivo da organização. De acordo com este autor, estes graus de inovação são: baixo, quando a nova tecnologia de processos pode ser utilizada numa planta existente; médio, quando a nova tecnologia de processos requer modificações na planta ou equipamentos adicionais e; alto, quando a nova tecnologia de processos requer novo processo e nova unidade produtiva. A correlação entre inovação na tecnologia de processos e alterações necessárias nas plantas é mostrada na figura 3.

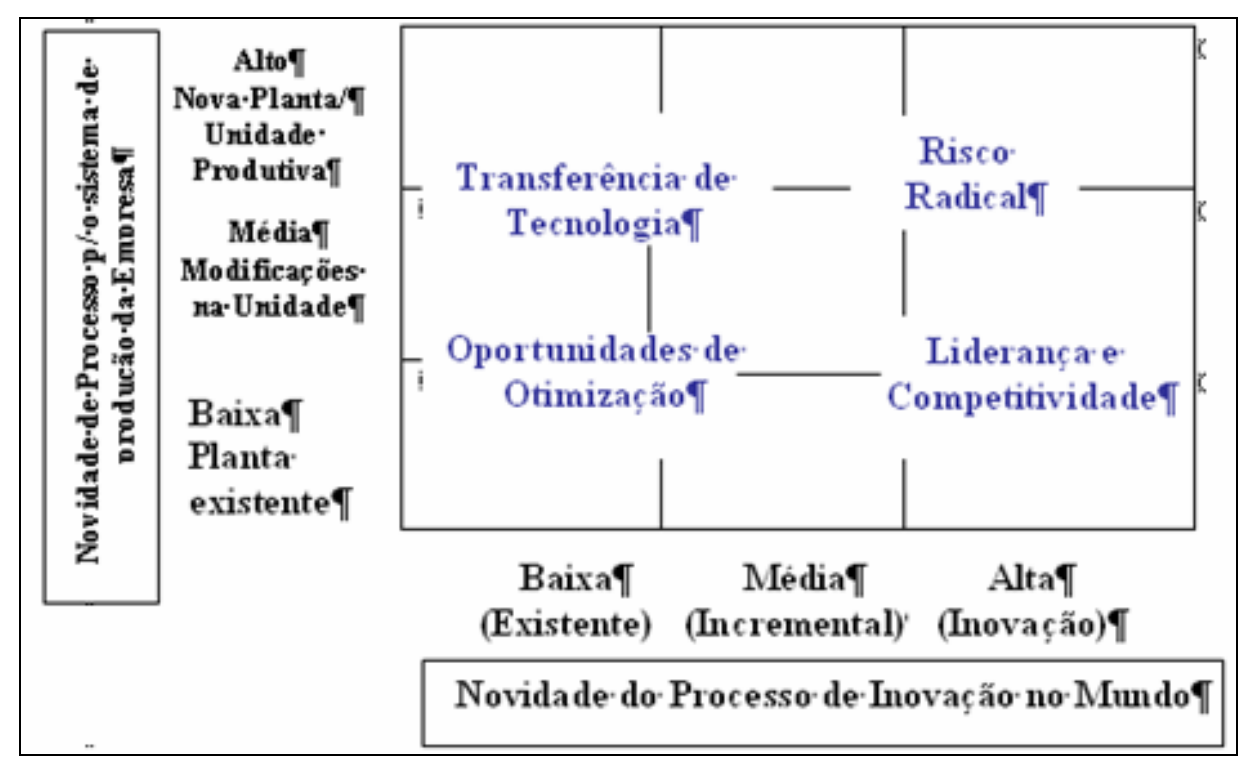

Figura 3 - Matriz de classificação de projetos segundo inovação da tecnologia de processo

(Lager, 2002) 
oportunidades emergentes entre as diversas fontes, tais como tecnologia de suprimento, produtos e desenvolvimento de processos, incorporando e capitalizando os ganhos das novas tecnologias, é também um processo crítico na gestão de portfólio (Adler and Ferdows, 1990). Além disso, o gerenciamento do processo de inovação na gestão de portfólio depende da sua natureza. Chesbrough \& Teece (1996), classificam a inovação como autônoma ou sistêmica. A primeira, autônoma, pode ser desenvolvida independentemente das outras inovações, e a segunda, sistêmica, gera valor somente quando atua em complementaridade com outras inovações. Idéia similar foi concebida por Christensen \& Overdorf (2000) e Christensen et al (2001), a qual considera que a natureza da mudança pode ser explicada por duas categorias básicas de inovação: sustentação e ruptura.

Inovações do tipo sustentação têm o objetivo de melhorar o desempenho de tecnologias existentes e com produtos e mercados conhecidos, enquanto que inovações de ruptura criam mercados completamente novos. Finalmente, uma terceira classificação da inovação pode ser encontrada em Utterback (1994), onde inovações incrementais são aquelas que introduzem mudanças relativamente menores em produtos existentes ao passo que inovações radicais estabelecem novos parâmetros para o projeto.

A literatura acadêmica também destaca a importância de se conseguir um equilíbrio entre os projetos do portfólio em vários aspectos tais como balanceamento entre projetos revolucionários e incrementais, balanceamento entre inovação de produto e inovação de processo, balanceamento entre risco e oportunidade e, balanceamento entre curto prazo e longo prazo (Adner and Levinthal, 2001; Roussel et al, 1991; Cooper et al, 1997, 1998, 1999 and 2001; Tritle et al, 2000; Wheelwright and Clark, 1992; Archer et al., 1999).

Para auxiliar as empresas a visualizar o equilíbrio entre as diferentes variáveis, o diagrama de bolhas pode ser usado para mostrar, em um gráfico bidimensional, vários parâmetros. Por exemplo, o diagrama de bolhas pode representar risco em um dos eixos e oportunidade no outro e a área das bolhas pode representar o valor do investimento orçado para cada projeto. Além disso, também é usual neste tipo de modelo se definirem quatro quadrantes, onde cada um representa um possível papel para os projetos do portfólio da organização como um todo, tais como as categorias propostas por Cooper et al (2001):"Elefantes Brancos" (projetos que não valem a pena), "Pérolas" (projetos em que vale a pena investir), "Ostras" (projetos em que 
existe potencial de ganho) e "Pão com Manteiga" (projetos de baixo ganho e baixo risco). Uma outra configuração do diagrama de bolhas foi proposta por Roussel et al (1991), na qual probabilidade de sucesso é alocada no eixo vertical e as fases do ciclo de vida no eixo horizontal.

Archer et al. (1999) observam que a gestão do portfólio é muito importante nas atividades das organizações. Entretanto, há muitas técnicas, algumas das quais divergentes e outras não aplicáveis devido à sua complexidade. Para contribuir com a simplificação dos processos de gestão de portfólio, os autores consideram o uso de um modelo integrado para a seleção do portfólio de projetos, em que há uma fase de seleção dos projetos, uma fase de ajuste e uma fase de otimização, sendo esta última fase assistida por um modelo de programação linear. No estágio de seleção do portfólio são recomendadas as técnicas AHP, Q-Sort ou comparação por pares (pairwise comparison). O modelo esquemático considerado por Archer (1999) é apresentado na Figura 4.

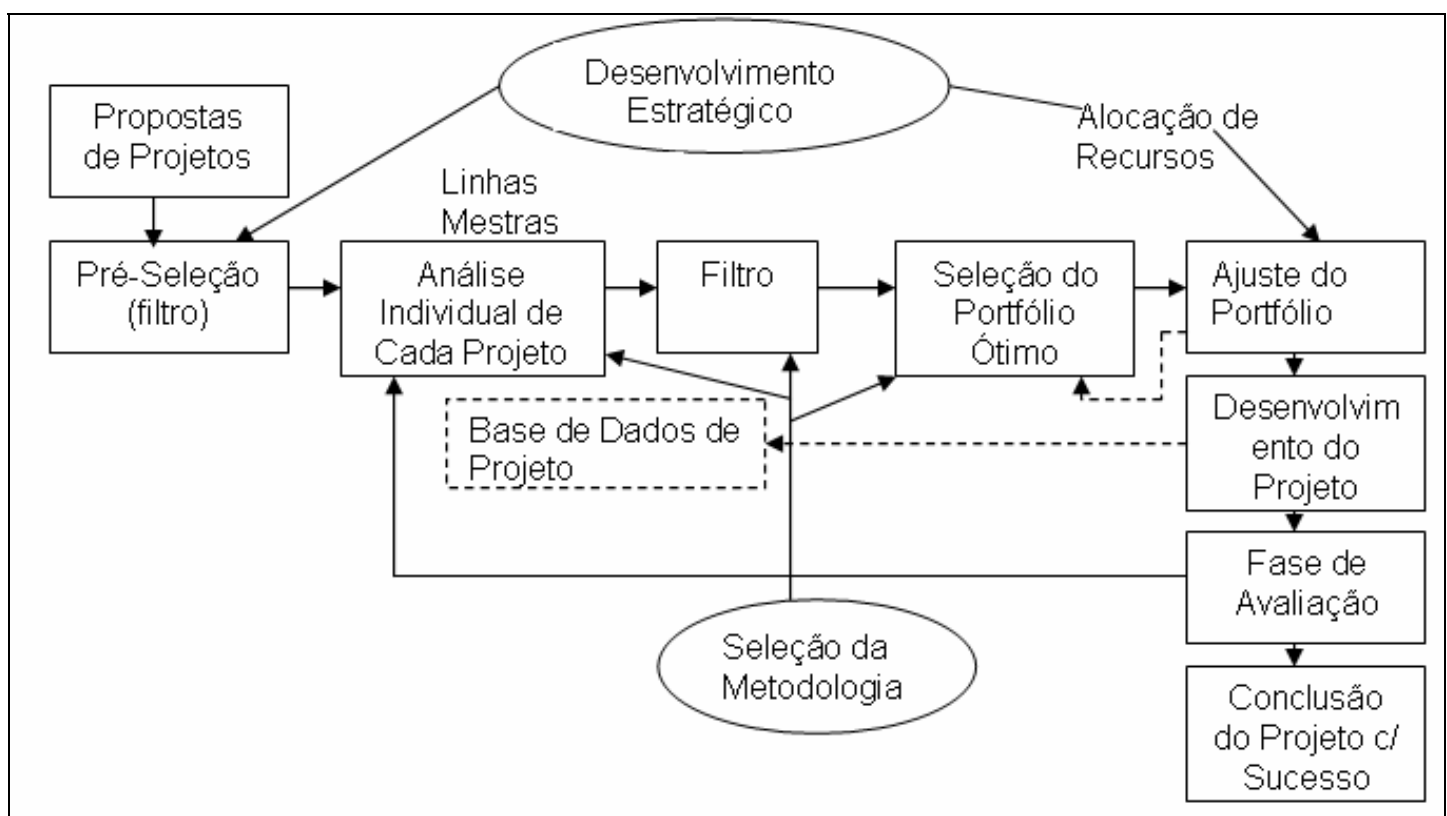

Figura 4 - Estrutura para Seleção de Projetos de um Portfólio (Fonte: Archer et al., 1999)

Finalmente, Greiner et al. (2003) apresentam uma aplicação de um modelo semelhante ao proposto por Archer (1999) para o monitoramento e seleção de projetos para o Departamento de Defesa Norte-Americano, pertencente à força área daquele país. Na fase de otimização Greiner et al. (2003) utilizaram a programação 
inteira e diferentes heurísticas. Os autores concluíram que houve melhoria substancial no valor do portfólio, que a definição da hierarquia e comparação entre critérios no método AHP é rápida e que a técnica é útil em ambientes que exijam avaliações de aspectos qualitativos e quantitativos.

\subsection{Os Modelos de Seleção e Priorização}

Para a solução do problema de seleção e priorização de projetos, vários métodos de auxílio à decisão podem ser aplicados, conforme já mencionado anteriormente: AHP, Q-Sort, comparação por pares, checklists, modelos de índices econômicos, árvores de decisões, Multi-attribute Utility Theory (MAUT), Multiple Criteria Decision Aiding (MCDA), Promethée, Macbeth, etc. Alguns desses métodos serão descritos a seguir, destacando-se os métodos AHP e Programação Inteira por se constituírem no foco desta pesquisa.

\subsubsection{O Método AHP}

O processo de análise hierárquica é uma técnica de análise de decisão desenvolvida por Thomas L. Saaty, em 1970, para resolver problemas de decisão multicritério, nos quais o tomador de decisão deve fazer uma escolha entre várias alternativas. O método tem como objetivo simular a maneira como as pessoas pensam. O AHP é uma ferramenta poderosa e flexível no auxílio à priorização e decisão no caso em que há presença de fatores qualitativos e quantitativos.

Para Saaty (1980), o processo de tomada de decisão depende da avaliação específica das alternativas propostas, resultando na seleção daquela que melhor atenda a um conjunto de critérios. Segundo Garber (2002), o mais importante na análise de decisão são a seleção e escolha de fatores relevantes. No AHP estes fatores são organizados em uma hierarquia, começando com o objetivo, seguido pelos critérios e subcritérios e finalizando no nível das alternativas ou soluções. 
O método de Análise Hierárquica é um sistema para análise e síntese de problemas complexos que permite justificar as decisões e avaliações complicadas, tornando possível examinar os elementos ou partes de um problema de forma isolada (Forman \& Selly, 2001). Cada elemento é comparado com outro, sempre segundo um dos critérios. $O$ processo de decisão em análise é simplificado, pois as comparações são feitas aos pares.

Segundo Saaty (1980), "esta teoria tem suas origens no outono de 1971, quando ele estava trabalhando no planejamento para o Departamento de Defesa Americano. Sua adolescência ocorreu em 1972, num estudo para o racionamento de energia para indústrias. A origem da escala que relaciona opiniões a números (quadro 3), remonta aos graves acontecimentos de junho/julho de 1972, no Cairo, enquanto ele analisava a situação econômica, política e militar do Egito. A maturidade da teoria surgiu com o Estudo dos Transportes do Sudão, em 1973, que ele dirigia. Seu enriquecimento teórico veio ocorrendo durante um longo caminho, intensificando-se entre 1974 e 1978. Suas aplicações até agora foram variadas e bem sucedidas".

Atualmente a metodologia está estruturada em um software (Decision Lens $®$ ) e é aplicada em: TQM (Total Quality Management), alocação de recursos, avaliação de funcionários, estratégia de marketing, decisões em grupo, gestão de conflitos, análise custo/benefício, formulação e avaliação de políticas, seleção de fornecedores, análise de crédito, entre outras. São usuários desta metodologia órgãos empresariais e governamentais no Brasil e no exterior.

O AHP consiste nos seguintes passos:

o Definição do problema, objetivo, alternativas de solução e critérios (e/ou subcritérios), pelos quais as alternativas de solução serão avaliadas.

o Organização das definições anteriores em uma hierarquia, onde o primeiro nível é composto pelo objetivo, o segundo pelos critérios, o terceiro e outros por subcritérios, sendo o último nível o das alternativas de solução.

- O terceiro passo é comparar cada elemento do mesmo nível entre si, tendo em vista o nível superior. Por exemplo, os critérios que compõem o segundo nível deverão ser comparados entre si, estabelecendo importâncias relativas com relação ao alcance do nível imediatamente superior. 
o O quarto passo consiste na determinação dos vetores de priorização de cada nível.

o O último passo refere-se à obtenção do vetor de priorização das alternativas de solução. Este vetor informará qual a alternativa é preferível.

o A conclusão indica a decisão a tomar dada pela classificação das alternativas de forma hierárquica.

A estruturação do problema pode ser esquematizada como apresentado na Figura 5.

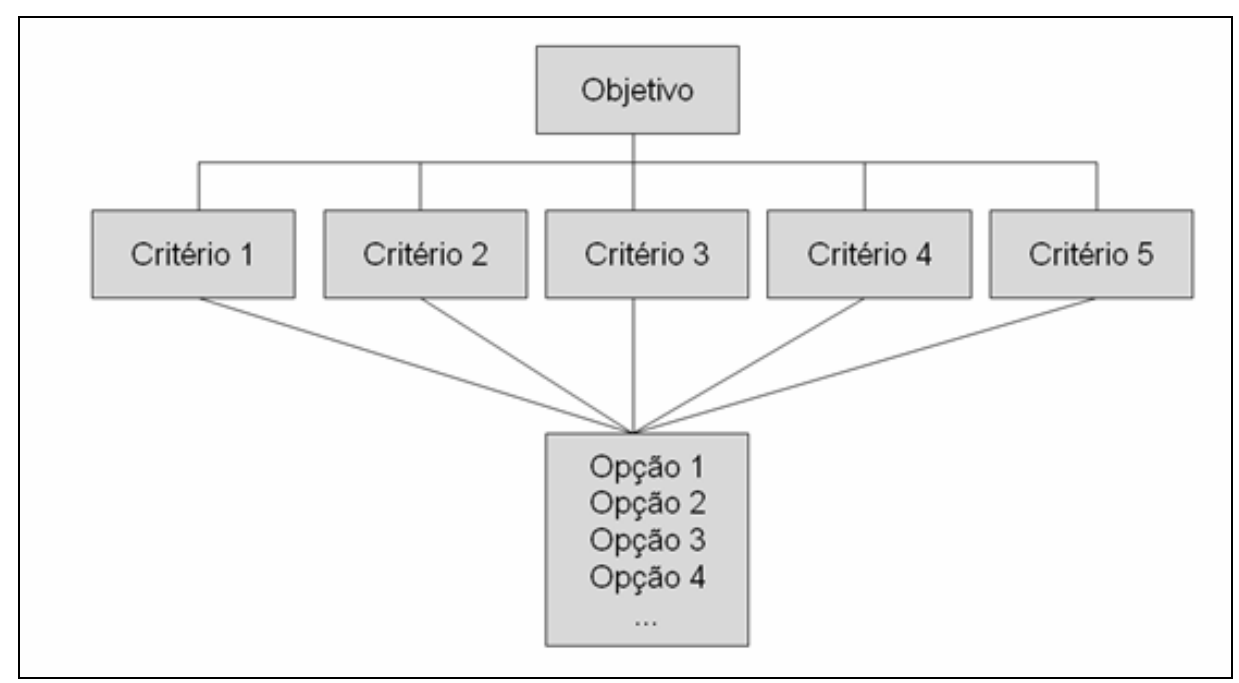

Figura 5 - Pirâmide do AHP (Figura do autor)

Verifica-se na Figura 5 que para atingir o objetivo, alguns critérios serão avaliados. Estes, por sua vez, podem ser formados por subcritérios. Por exemplo, tendo como objetivo a compra de um apartamento, teremos que avaliar diferentes alternativas. A escolha poderá ser feita comparando-as com base em critérios que consideramos importantes, como, por exemplo, localização, preço, opções de lazer e número de vagas na garagem. Um subcritério derivado da localização pode ser a proximidade com linhas de metrô ou vista para área arborizada.

No contexto deste tipo de problema a questão central, em termos da hierarquia ou, estrutura de decisão, é determinar com que peso os fatores ou critérios individuais do nível mais baixo da hierarquia influenciam o objetivo geral. No nosso exemplo, qual 
o peso que cada critério como preço, localização, opções de lazer e número de vagas na garagem influenciam na escolha do apartamento.

Como esta influência não é necessariamente uniforme em relação aos fatores, o método permite explicitarem-se suas intensidades ou prioridades. Assim o processo de tomada de decisão refletirá as preferências do tomador de decisão ou do grupo envolvido na decisão, pois ressalta suas preferências particulares em relação ao contexto da decisão.

A determinação das prioridades dos fatores mais baixos, com relação ao objetivo, pode reduzir-se a uma seqüência de problemas de prioridade, um para cada nível, sendo que cada um desses problemas de prioridade podem ser resolvidos através de uma seqüência de comparações por pares. Essas comparações representam o ingrediente central da metodologia AHP.

Para a aplicação do método AHP utiliza-se a escala proposta por Saaty (1970) na etapa de comparação aos pares dos critérios e subcritérios, conforme Quadro 2. Como a escala numérica pode trazer dificuldade para o decisor, Saaty (1970) propôs o uso da escala de preferências que posteriormente é traduzida para números. Assim, no caso da compra do apartamento compara-se, por exemplo, o preço com a localização perguntando-se ao decisor quanto o critério preço é mais importante que a localização. Se o decisor responder, por exemplo, que o preço está entre moderadamente e fortemente mais importante que a localização, esta resposta será entendida com o valor igual a 4.

\begin{tabular}{|l|r|}
\hline Pareceres de Preferências & Valores lluméricos \\
\hline Absoluta & 9 \\
\hline Muito Forte & 7 \\
\hline Forte & 5 \\
\hline Moderadta ( pouco mehor) & 3 \\
\hline Lgual (equivalente) & 1 \\
\hline
\end{tabular}

Quadro 2 - Valores de Preferência (Fonte: Saaty, 1970) 
A prioridade relativa que é calculada para cada elemento chave (critérios e subcritérios), segundo Saaty (1994), deve ter um valor entre 0 e 1. Para cada grupo de fatores, a soma total dos pesos deve resultar em um valor unitário, isto é, a soma dos pesos de todos os critérios da hierarquia e a soma dos pesos de todos os subcritérios que compõe um critério devem ser iguais a 1.

O método AHP pode ser expresso matematicamente através da definição de uma matriz de comparação de pares de critérios e subcritérios e de vetores de prioridade. O AHP utiliza o método do autovetor para determinar as prioridades relativas.

Assim, dada a matriz quadrada $A$, onde $a_{i j}$ representa o valor da comparação entre o critério de decisão da linha $i$ com o critério da coluna $j$., sendo que, se aij $=$ $1 / \alpha, \alpha$ é diferente de zero e, se aij=1 e aji $=1$ e, em particular, aii= 1 , então as alternativas $C_{j}$ terão igual importância.

$$
A=\left[\begin{array}{cccc}
1 & a_{12} & \ldots . . & a_{1 n} \\
1 / a_{12} & 1 & \ldots . . & a_{2 n} \\
\ldots \ldots & . & \ldots . . & . \\
1 / a_{1 n} & & \ldots . . & 1
\end{array}\right]
$$

A matriz A tem a particularidade cada elemento $a_{i j}$ ser o inverso do elemento $a_{j i}$ da mesma matriz.

$O$ vetor de prioridades relativas $P$ é definido pela equação (2), onde $A$ é a matriz quadrada de $n$ linhas e $n$ colunas, sendo $\lambda_{\text {máx. }}$ o maior autovalor de A, e P é o autovetor associado.

$$
\text { A.P }=\lambda_{\text {máx }} \cdot P
$$

Como ilustração da aplicação da matriz de comparação, é apresentada na seqüência, a matriz para a compra do apartamento anteriormente citado. 


\begin{tabular}{|c|c|c|c|c|}
\hline & Preço & Localização & $\begin{array}{c}\text { Área de } \\
\text { Lazer }\end{array}$ & $\begin{array}{c}N^{0} \text {. de } \\
\text { Vagas } \\
\text { Garagem }\end{array}$ \\
\hline Preço & 1 & 4 & 3 & 2 \\
\hline Localização & $1 / 4$ & 1 & $1 / 2$ & $1 / 3$ \\
\hline $\begin{array}{c}\text { Área de } \\
\text { Lazer }\end{array}$ & $1 / 3$ & 2 & 1 & $1 / 2$ \\
\hline $\begin{array}{c}\text { No.de } \\
\text { Vagas } \\
\text { Garagem }\end{array}$ & $1 / 2$ & 3 & 2 & 1 \\
\hline
\end{tabular}

A determinação do vetor de prioridade é feita somando-se os pesos de cada elemento de uma dada linha $i$ da matriz. Os valores obtidos devem ser normalizados.

A normalização consiste na divisão do peso de cada critério da matriz pelo somatório dos pesos de todos os critérios. Desta forma, se obterá um valor adimensional expresso por um número decimal para cada elemento da coluna, sendo que o somatório deles resulta na unidade. A seguir se calcula a média dos valores de cada linha, dispondo-as num vetor coluna. Esse procedimento é de fundamental importância na aplicação do método, pois permite a análise de elementos quantitativos dimensionais junto com os pareceres subjetivos do avaliador.

A seguir é apresentado o exemplo de determinação do vetor de prioridade para o caso da compra do apartamento, anteriormente descrito.

Vetor de Prioridade

\begin{tabular}{lrc|}
\hline Preço: & $1+4+3+2=$ & $\mathbf{1 0 , 0 0}$ \\
Localização: & $1 / 4+1+1 / 2+1 / 3=$ & $\mathbf{2 , 0 8}$ \\
Área de Lazer: & $1 / 3+2+1+1 / 2=$ & $\mathbf{3 , 8 3}$ \\
№ de Vagas na Garagem: $1 / 2+3+2+1=$ & $\frac{\mathbf{6 , 5 0}}{\mathbf{2 2 , 4 1}}$ \\
Total: &
\end{tabular}


Como se pode verificar pela equação (5), a soma dos elementos do vetor de prioridade normalizado é igual a 1.

Repetindo-se o mesmo procedimento para comparar as alternativas de acordo com um critério, obtemos a matriz hierárquica das alternativas para esse critério. $O$ exemplo de matriz de comparação de alternativas é dado a seguir.

\section{Comparação de Alternativas}

\begin{tabular}{|c|c|c|}
\hline Preço & Apartamento A & Apartamento B \\
\hline Apartamento A & 1 & 2 \\
\hline Apartamento B & $1 / 2$ & 1 \\
\hline
\end{tabular}

\begin{tabular}{|c|c|c|}
\hline Localização & Apartamento A & Apartamento B \\
\hline Apartamento A & 1 & 1 \\
\hline Apartamento B & 1 & 1 \\
\hline
\end{tabular}

(6)

\begin{tabular}{|c|c|c|}
\hline Área de Lazer & Apartamento A & Apartamento B \\
\hline Apartamento A & 1 & $1 / 3$ \\
\hline Apartamento B & 3 & 1 \\
\hline
\end{tabular}

\begin{tabular}{|c|c|c|}
\hline $\begin{array}{c}\text { N. }{ }^{\circ} \text { Vagas na } \\
\text { Garagem }\end{array}$ & Apartamento A & Apartamento B \\
\hline Apartamento A & 1 & 4 \\
\hline Apartamento B & $1 / 4$ & 1 \\
\hline
\end{tabular}

Na seqüência, determina-se o vetor de prioridade para cada alternativa como apresentado pelas equações conforme descrito anteriormente para a definição do vetor de prioridade de critérios e exemplificado a seguir.

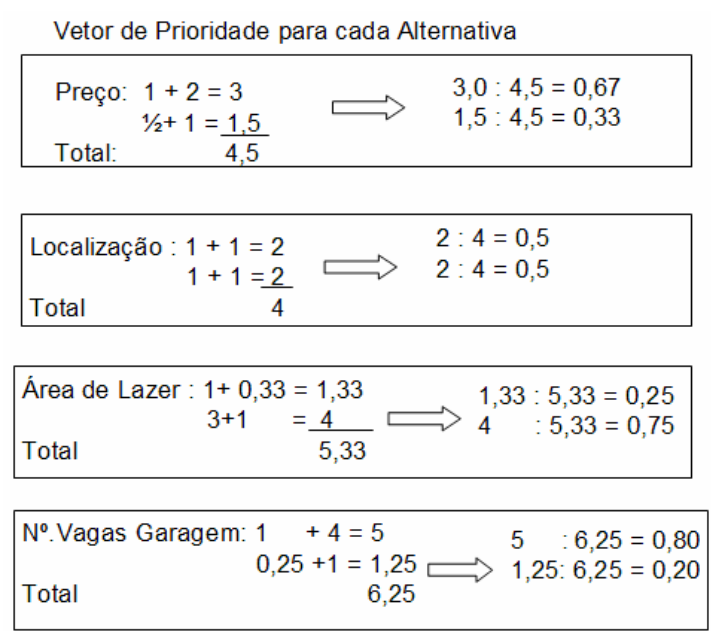


Por último, constrói-se uma matriz consolidada, pela justaposição das matrizes das alternativas para cada critério, na ordem em que os critérios estarão alinhados na matriz hierárquica dos critérios, correspondendo cada coluna da primeira a cada linha desta última. Finalmente, multiplicamos as duas matrizes obtendo, como resultado, uma matriz de uma coluna e tantas linhas quantas opções foram analisadas e cada valor representa a hierarquia de cada uma delas. A equação (11) serve de ilustração para a determinação das prioridades de cada alternativa.

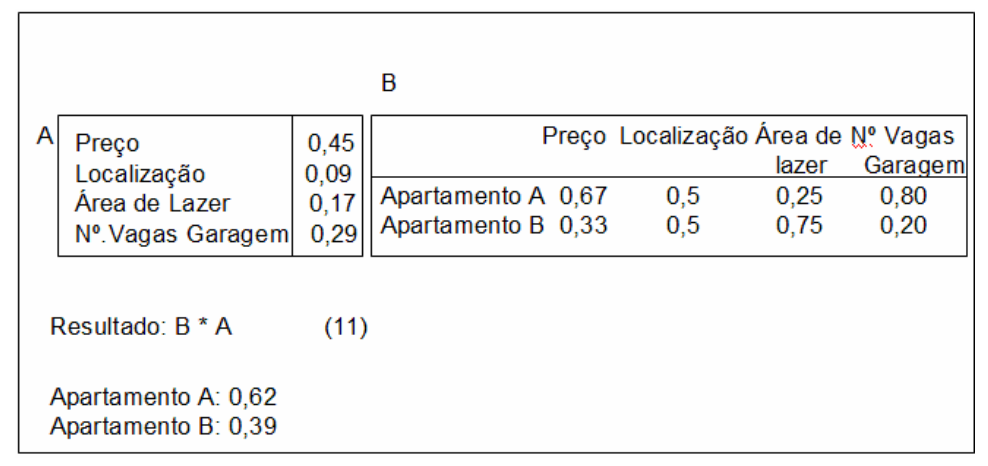

Há uma atividade muito importante a ser executada entre cada etapa, que é a verificação da coerência dos dados que foram utilizados no julgamento. Esta coerência é basicamente a indicação do desvio que apresenta o cálculo dos resultados a um valor ideal para a mesma quantidade de critérios adotados na avaliação e denomina-se índice de inconsistência.

O indicador ou coeficiente de inconsistência (C.I.) é definido por Saaty (1980) pela equação (12)

$$
\text { C.I. }=\frac{\lambda_{\text {máx }}-n}{n-1}
$$

Segundo Forman \& Selly (2001) e Saaty (1970), o índice de inconsistência menor ou igual a $10 \%$ é considerado aceitável, sendo que em circunstancias particulares ele pode ser maior, pois é possível ser perfeitamente consistente, mas 
consistentemente errado. Para os autores é mais importante ter precisão que consistência.

\subsubsection{Checklists e Scoring Models}

Onde os projetos são altamente exploratórios, tais como os de P\&D, somente informações qualitativas devem existir e as variáveis de decisão provavelmente contém muita incerteza. Nestes casos, um critério de checklists ou requisitos de desempenho pode ser útil para a tomada de decisão sobre aceitar ou rejeitar os projetos. Uma lista dos critérios mais utilizados é proposta por Elmaghraby \& Moder (1978); essa lista é apresentada no quadro 3, a seguir:

\begin{tabular}{|c|c|c|c|}
\hline & \multicolumn{3}{|c|}{ Avaliação } \\
\hline Critérios & Alto & Médio & Baixo \\
\hline É patenteável? & $\mathbf{x}$ & & $\mathbf{x}$ \\
\hline $\begin{array}{c}\text { Potencial de } \\
\text { Mercado }\end{array}$ & & & \\
\hline $\begin{array}{c}\text { Probabilidade de } \\
\text { Sucesso }\end{array}$ & & $\mathbf{x}$ & \\
\hline $\begin{array}{c}\text { Custos de } \\
\text { Produção }\end{array}$ & $\mathbf{x}$ & & \\
\hline Custos de P\&D & & $\mathbf{x}$ & \\
Quadro 3 - Checklist para um projeto hipotético (Fonte: Elmaghraby \& Moder, 1978)
\end{tabular}

Quando mais informações estão disponíveis no que diz respeito a importância relativa dos critérios e onde os projetos podem ser medidos ao longo de uma escala de números, então teremos o primeiro passo para os modelos de score, ou scoring models. Num modelo de score, cada um dos $j=1, \ldots, n$ candidatos a projetos são pontuados ao longo de uma escala para cada $i=1, \ldots, m$ critérios. Estes critérios de pontuação para cada projeto são então combinados e seu respectivo critério de importância, $\omega i$ (peso), para se chegar a pontuação total, T], para cada projeto. Projetos são então ordenados de acordo com os valores de $T$,. Um exemplo de scoring model e sua forma de utilização é dado pelo quadro 4. 


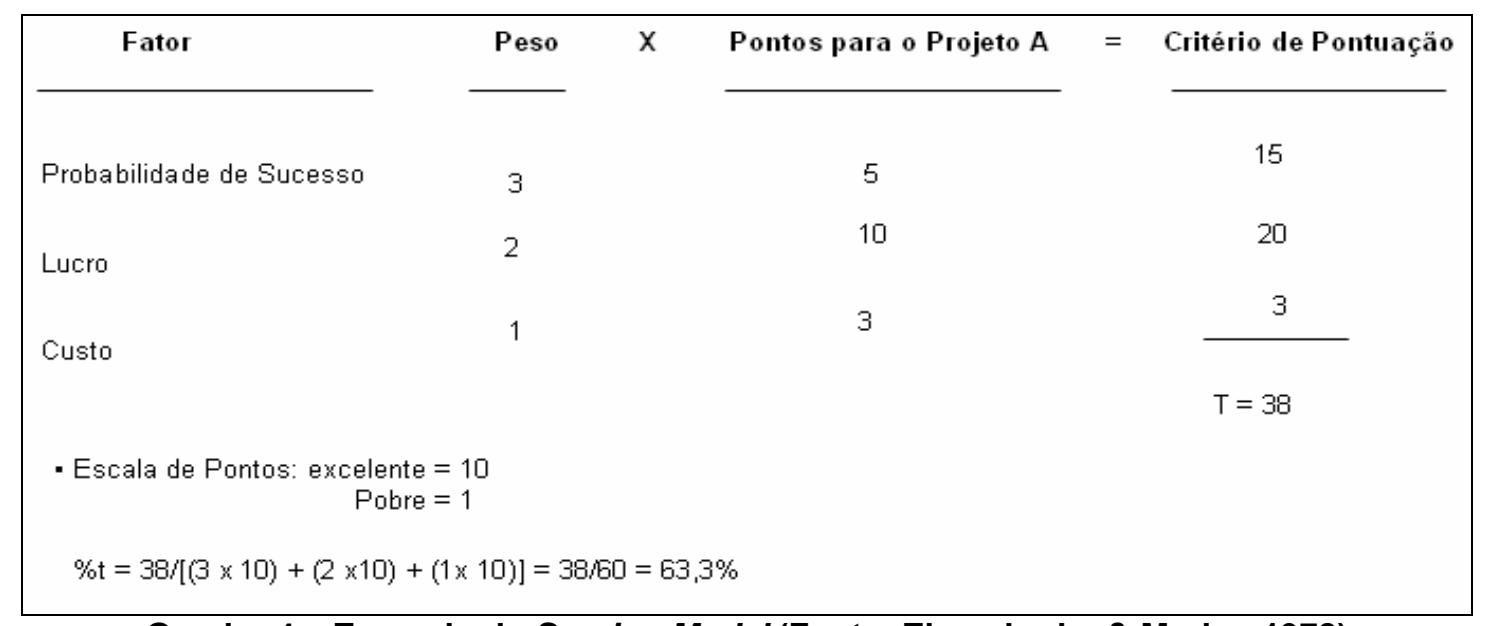

Quadro 4 - Exemplo de Scoring Model (Fonte: Elmaghraby \& Moder, 1978)

No exemplo, o critério de pontuação é representado por:

$$
\mathrm{T}_{j}=\Sigma \mathrm{s}_{i j} \omega_{i}
$$

Onde Sij é a pontuação no critério i-ésimo para o projeto j.

\subsubsection{Modelos de Portfólio}

Num modelo de portfólio, projetos propostos são implicitamente priorizados segundo a quantidade de recursos para eles alocados. Segundo Elmaghraby e Moder (1978) a forma geral desses modelos é dada pelas equações:

$$
\operatorname{máx} \Sigma v_{j}\left(\mathrm{X}_{j}\right)
$$

Sendo que,

$$
\Sigma v_{j}\left(\mathrm{X}_{j}\right)<\mathrm{B}
$$


Onde $\mathrm{X}_{\mathrm{j}}$ representa o valor do investimento para o projeto $\mathrm{j}$ e $\mathrm{B}$ o valor total do orçamento de investimentos para $\mathrm{j}=1$ até $\mathrm{n}$ projetos propostos. Segundo o autor, o valor da função $v_{j}\left(X_{j}\right)$ pode ser não linear, linear ou um valor-simples. No caso de ser um valor-simples, (um valor para $v_{j}$ e um valor para o investimento $X_{j}$ para cada projeto j), o modelo de portfólio será um modelo de índice com $v_{\mathrm{j}}$ sendo o índice de priorização.

Uma variedade de valores pode ser usada na equação (14), acima.

Elmaghraby e Moder (1978) afirmam que muitos modelos de portfólio usam valores esperados de modo que a equação (14) deve sofrer uma alteração incluindo a probabilidade de $v j$, denominada $\pi j$. Neste caso a equação (14) se torna:

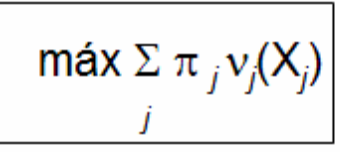

No caso da equação (15) uma restrição típica aplicada é dada pela equação (17):

$$
\beta j(-)<X j<\beta j(+)
$$

Onde, $\beta \mathrm{j}(-)$ e $\beta \mathrm{j}(+)$ são os limites superior e inferior de desembolsos de cada projeto.

Elmaghraby \& Moder (1978) ainda mencionam que os modelos de portfólio podem ser desenvolvidos para múltiplos períodos de tempo.

O modelo de Dean e Nishry's é citado por Elmaghraby e Moder (1978) como sendo uma abordagem de programação matemática usando o modelo de score. Este modelo encontra para os valores de $v_{j}$ iguais a 0 e 1 o portfólio de projetos da equação (14) e atendendo as restrições de orçamento propostos pela equação (15). Neste caso, se o projeto $j$ não for selecionado $v_{j}=0$, se o projeto $\mathrm{j}$ for selecionado $v_{\mathrm{j}}$ $=1$. 
O autor cita ainda os modelos de Bel et al. (1967), que utiliza programação linear, o modelo de Watters (1967) que utiliza a abordagem de programação binária, do tipo 0-1, para maximizar o valor da utilidade para o portfólio e o modelo de RosenSouder (1965) que usa programação dinâmica para maximizar o retorno líquido de P\&D.

Segundo Elmaghraby \& Moder (1978), os modelos de portfólio parecem ser ferramentas apropriadas para um administrador que deva decidir como alocar recursos escassos para uma quantidade muito diferente de projetos disponíveis, permitindo maximizar o total de recursos utilizados com eficácia. A escolha do modelo de seleção de projetos a ser adotado depende do objetivo dos tomadores de decisão. Onde o objetivo é maximizar lucro através do desejo de controlar gastos, estudos feitos por Souder (1973) apud Elmaghraby \& Moder (1978), obtiveram melhores resultados com os modelos do tipo 0-1 e índice de probabilidade.

\subsection{Resumo e Análise da Bibliografia Consultada}

A análise da literatura consultada indica que o tema alinhamento entre estratégia do negócio e seu portfólio de projetos é muito relevante e envolve uma grande e complexa gama de decisões.

Para promover esse alinhamento, a literatura prescreve que se deva conhecer a estratégia da organização, saber como projetá-la e revisá-la, conhecer as relações e implicações nas dimensões estratégicas, conhecer e saber classificar a organização estudada nos grupos estratégicos existentes, além de saber quem são os stakeholders da organização e quais são seus principais objetivos e critérios competitivos que utilizam (Carvalho \& Laurindo 2003, Luehrman, 1998, Muscat, 2004, Slack et al. 1997, Slack 1993).

Para atuar em diferentes mercados, muitas vezes a empresa se defronta com trade-offs, devendo estabelecer planos de ação para que possa superá-los e se manter em posição competitiva sustentável (Boldwijn \& kumpe, 1990). Estes trade-offs estão relacionados com a gestão da capacidade dos recursos, em geral se traduzem na necessidade de se ter flexibilidade e podem ser encontrados em diversas áreas das organizações e não somente na gestão de produção (Slack, 1998). 
Como as organizações que pertencem ao mesmo grupo estratégico têm formas de atuar muito parecidas, investir nas competências e produtos essenciais cria uma vantagem competitiva para a organização (Prahalad e Hamel, 1990; Banerjee, 2003).

A literatura apresenta ainda ferramentas e modelos para auxiliar na concepção da estratégia e análise do posicionamento estratégico da empresa frente à concorrência.

Quanto à tomada de decisão, a literatura consultada questiona a forma como os executivos tomam decisões, fala sobre as conseqüências das decisões ruins, do processo de tomada de decisão, das armadilhas, concluindo que esse processo é complexo e caótico, repleto de incertezas, tendo múltiplas variáveis, objetivos e alternativas (Saaty, 1991, Nutt, 2002, Hammond, Keeney \& Raiffa, 1998, Shimizu, 2001, Kaufmann, 1975, Simon, 1997).

Para facilitar o processo de tomada de decisão são propostos modelos e ferramentas como: Q-Sort, AHP, árvore de decisões, modelos de verificação e pontuação (checklists e scoring models) e modelos de portfólio (Saaty, 1980, Elmaghraby e Moder, 1978, Winston, 2004).

No que tange ao tema gestão de portfólio, foram consultados os autores Roussel et al (1991), Cooper et al (1999), Lager (2002), Jolly (2003), Archer et al. (1999) e Greiner et al (2003), que apresentam métodos para a classificação e seleção do portfólio de projetos. Outros autores consultados tratam da necessidade de existir um balanceamento do portfólio de projetos quanto ao tipo (incrementais ou revolucionários), quanto ao horizonte de execução (curto ou longo prazo), quanto a inovação (autônoma ou sistêmica) e quanto ao ciclo de vida de produtos e tecnologias.

Observa-se que a maior parte dos textos consultados é teórica. Apenas Greiner et al, (2003) aplica o modelo proposto para a indústria de armas do governo americano. Observam-se ainda poucas publicações nacionais a respeito de gestão de portfólio e alinhamento estratégico.

No que se refere à bibliografia sobre stakeholders, os textos consultados tratam do conceito de stakeholder, identificação, forma de classificação, dinâmica e quais estratégias devem ser adotadas para negociar com os stakeholders em diferentes estágios do ciclo de vida da organização.

Este trabalho pretende aplicar os conceitos de alinhamento estratégico, tomada de decisão e gestão de portfólio a uma organização nacional do setor químico e 
petroquímico. Na primeira etapa de caracterização do portfólio da empresa, baseando-nos principalmente nos conceitos apresentados por Roussel et al (1991), Cooper et al. (1999), Lager (2002), Jolly (2003), Archer et al. (1999), serão identificados os stakeholders da organização e seus objetivos conforme Ackoff (1974) apud Muscat (2004). Também será aplicada a escala de pontos para a elaboração dos diagramas de bolhas relativos a posicionamento e atratividade da empresa, conforme Carvalho \& Laurindo (2003), Elmaghraby e Moder (1978) e Jolly (2003). Uma vez identificada a situação atual da organização, na segunda etapa deste trabalho de pesquisa, será proposto um modelo de gestão de portfólio que utiliza as técnicas AHP e Programação Inteira (uma das técnicas de gestão de portfólio) para selecionar o portfólio de projetos, considerando-se as restrições existentes. Nesta etapa nos basearemos nos trabalhos de Saaty (1970), Greiner et al. (2003) e Elmaghraby e Moder (1978).

Os conceitos trazidos pelas teorias dos trade-offs e stakeholders serão úteis na etapa de concepção e validação do método AHP, onde será necessária a definição dos critérios de seleção e priorização de projetos, os quais envolvem trade-offs, e na escolha dos funcionários da empresa que participarão da construção e validação das estruturas de decisões e votação dos projetos. Esses participantes deverão se constituir numa amostra representativa dos stakeholders internos da organização.

Espera-se validar o modelo proposto para a organização estudada, ampliar o conhecimento existente sobre o assunto e buscar possíveis generalizações. A contribuição deste trabalho está no fato de aplicar o modelo proposto a um caso real, nacional do setor químico e petroquímico. O trabalho contribui para o conhecimento existente por ter como escopo todos os projetos da organização, sendo que em estudos similares os autores definem como escopo apenas partes da empresa e um pequeno grupo de projetos. 


\section{METODOLOGIA}

O principal objetivo deste trabalho é identificar questões críticas na gestão de portfólio em indústrias brasileiras, propor e testar um modelo aplicado a um caso real. A abordagem metodológica selecionada foi a pesquisa-ação, como sugerido por Thiollent (2004). O autor define a pesquisa-ação como "um tipo de pesquisa social com base empírica que é concebida e realizada em estreita associação com uma ação ou com a resolução de um problema coletivo e no qual, pesquisadores e participantes, representativos da situação ou do problema, estão envolvidos de modo cooperativo ou participativo".

Na mesma linha de raciocínio, Bryman (1989) define a pesquisa-ação como sendo uma abordagem aplicada na pesquisa social, em que o pesquisador e um cliente colaboram no desenvolvimento de um diagnóstico e solução científica de um problema, garantindo que isso contribuirá para o estoque de conhecimento num domínio empírico particular. Esse tipo de enfoque está mais voltado para a solução de problemas, porém também contribui para o entendimento das práticas das organizações. Para realizar esse tipo de pesquisa, o investigador precisa envolver-se diretamente com a organização estudada, passando a ser virtualmente um membro dela. Entretanto, ele deve manter um papel de alimentar com informações os membros da equipe, composta por pessoas da organização e estruturar as relações entre os membros da equipe e da organização.

Segundo Bryman (1989), o que diferencia a pesquisa-ação do método de estudo de caso é o relacionamento desenvolvido entre o pesquisador e as pessoas da organização, que participam do projeto de pesquisa.

Segundo Voss, Tsikritsis e Frolich, (2002) o estudo de caso pode ser definido como a "história de um fenômeno passado ou presente, extraída a partir de múltiplas fontes de evidências".

A configuração da pesquisa-ação depende dos seus objetivos e do contexto no qual é aplicada. Existem três casos possíveis de pesquisa-ação, o primeiro onde ela é organizada para realizar objetivos práticos de um ator social homogêneo, dispondo de suficiente autonomia para encomendar e controlar a pesquisa. $O$ ator é frequentemente representado por um agrupamento ativo ou associação. No segundo 
caso, a pesquisa-ação é realizada numa organização (empresa ou escola, por exemplo), na qual existe uma hierarquia ou grupos. No terceiro caso, a pesquisa ação é organizada em meio aberto, por exemplo, bairro popular, comunidade rural, etc. (Thiollent, 2004).

Uma das características da pesquisa-ação consiste no relacionamento entre os objetivos de pesquisa e os objetivos de ação. Assim, o objetivo prático é contribuir para o melhor equacionamento possível do problema central na pesquisa, com levantamento de soluções e propostas de ações correspondentes às "soluções" para auxiliar o pesquisador na sua atividade de transformador da situação. O objetivo de conhecimento, por outro lado, visa obter informações que seriam de difícil acesso por meio de outros procedimentos e aumentar nosso conhecimento de determinadas situações, avaliando a possibilidade de generalizações.

Yin (1994) argumenta que para se realizar um estudo de caso deve-se ter especial atenção com a confiabilidade e a validade durante a coleta e análise dos dados. No caso da pesquisa-ação Thiollent (2004) prescreve que a coleta dos dados deve ser efetuada em grupos de observação sob orientação de pesquisadores. As principais técnicas utilizadas são entrevistas coletivas, nos locais de moradia ou trabalho, e a entrevista individual aplicada de modo aprofundado. Os locais de investigação e os indivíduos ou grupos são escolhidos em função do plano de amostragem com controle estatístico ou com critérios intencionais. Também se pode utilizar da observação participante, diários de campo, consulta a bancos de dados da organização, etc. No final do trabalho deve haver um feedback entre os participantes para promover a visão de conjunto e o aprendizado.

Por apresentar tais características, a pesquisa-ação foi selecionada como o melhor método de condução do presente trabalho de pesquisa. A pesquisa empírica desenvolvida se enquadra no segundo caso de pesquisa-ação, e está sendo realizada em uma empresa do setor químico e petroquímico nacional. A figura 6 apresenta uma síntese da metodologia aplicada na presente pesquisa.

Inicialmente, foi realizada uma pesquisa bibliográfica preliminar, sobre os temas: gestão de portfólio de projetos, princípios da análise de decisão, estratégia e tomada de decisões, com o objetivo de conhecer os principais problemas de decisão na área de gestão de portfólio, quais as tratativas que têm sido dadas a tais problemas e qual a relação entre estratégia nas organizações e a gestão de portfólio de projetos. 
A avaliação dessa bibliografia tornou possível a delimitação do problema a ser estudado.

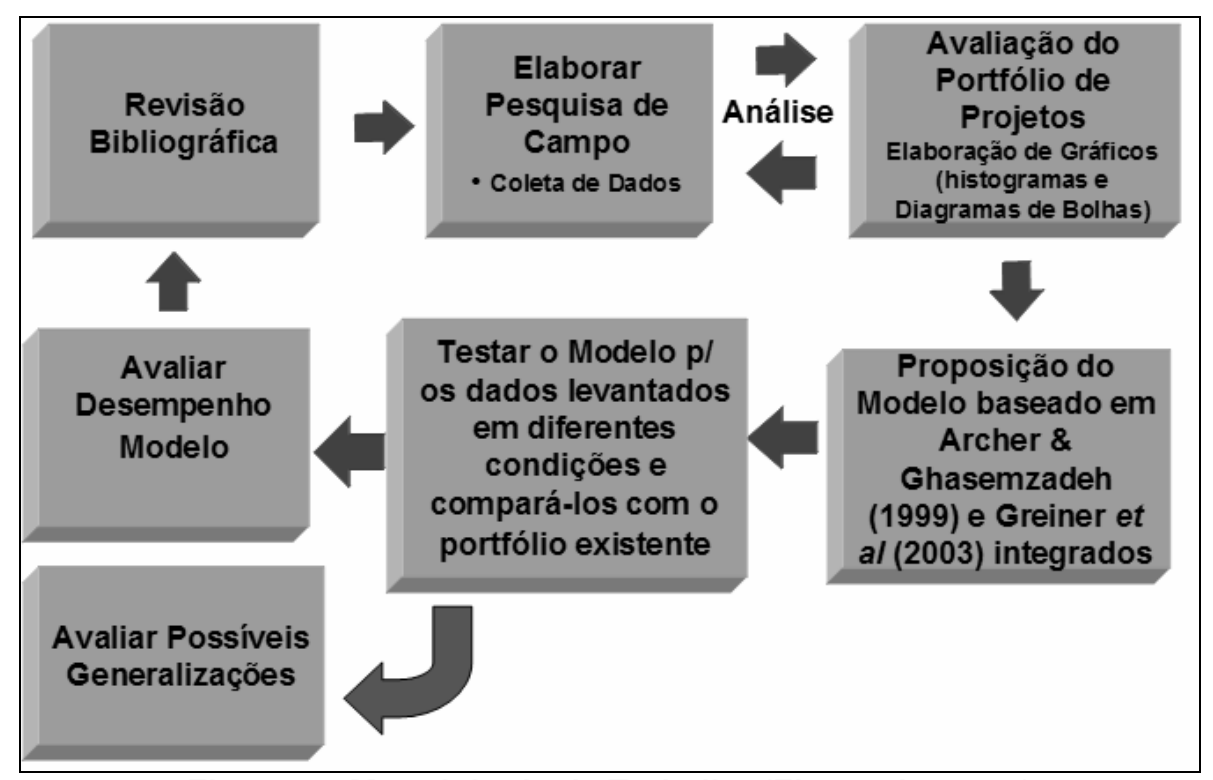

Figura 6 - Metodologia de Trabalho (Figura do autor)

Com o avanço do trabalho, a revisão bibliográfica foi complementada com textos sobre teoria dos stakeholders e dos trade-offs, pois se percebeu que o processo de tomada de decisão é influenciado pelos stakeholders que fazem parte do processo decisório em cada etapa do ciclo de vida da organização e, que tais decisões envolvem trade-offs que precisam ser conhecidos e avaliados para que a decisão tomada seja a mais adequada.

Este trabalho foi iniciado em 2005, seguindo as etapas propostas por Coughlan \& Coghlan (2002), para o ciclo de vida da pesquisa-ação, conforme apresentado pela Figura 7 , a seguir:

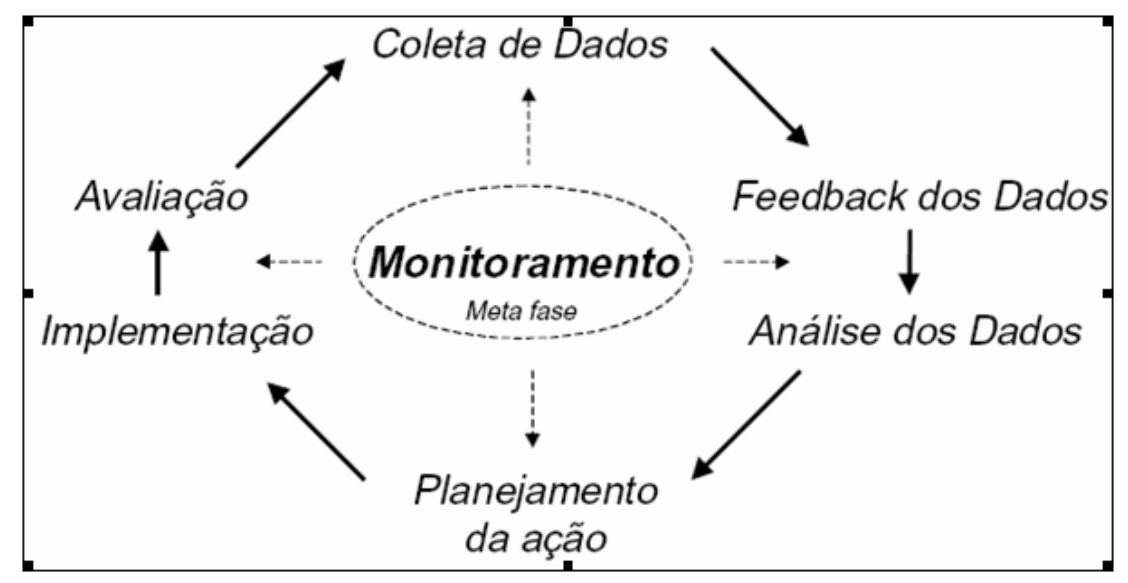

Figura 7 - Ciclo da pesquisa-ação (Adaptado de Coughlan \& Coghlan; 2002) 
Duas fontes de pesquisas principais foram utilizadas para a coleta de dados: consulta aos bancos de dados de sistemas de gestão de projetos e investimentos da organização e consulta a documentos da empresa. Cerca de 1000 projetos realizados no período de 2001 a 2005 foram analisados.

Os dados coletados foram utilizados para elaborar diferentes histogramas de modo a se caracterizar o portfólio de projetos da empresa, com investimento aprovado, em termos de número histórico de projetos total e por fábrica, tipo e característica e fazer uma análise comparativa entre valores orçados e valores gastos por característica dos investimentos e por ano.

Na seqüência, foram elaborados 3 diagramas de bolhas com objetivo de se avaliar o portfólio de projetos com investimentos aprovados, em termos de estágio de maturidade das tecnologias empregadas e de sua posição competitiva, grau de inovação dos projetos e perfil do investimento.

Também se buscou caracterizar o portfólio dos projetos de P\&D, sem investimento aprovado, em termos de número de projetos de P\&D versus margem por segmento/ano e área de negócio. Para a elaboração dessa caracterização foram desenhados 5 diagramas de bolhas visando avaliar o portfólio de projetos de P\&D em relação à atratividade e posicionamento, segundo os critérios propostos por Jolly (2003).

Como complemento a análise gráfica dos dados coletados, também foram realizadas entrevistas com os gestores de projetos de pesquisa e desenvolvimento (P\&D) e de projetos de engenharia, pessoas-chave no processo de gestão do portfólio da organização. Nestas entrevistas foram utilizadas como ferramentas de apoio entrevistas não estruturadas e reuniões de brainstorming.

$\mathrm{Na}$ etapa seguinte do ciclo de vida da pesquisa-ação, apresentado pela figura 7, fez-se a análise do portfólio da organização estudada, conforme proposto por Archer \& Ghasemzadeh (1999) tendo sido possível delimitar a situação inicial e os gaps existentes em relação aos objetivos dos stakeholders.

Após a discussão dos resultados encontrados com os gestores de projetos de engenharia e P\&D da empresa, foi proposto um modelo de gestão de portfólio de projetos para toda a empresa, incluindo projetos de P\&D, projetos de engenharia, tecnologia da informação e manutenção. Este modelo prevê a utilização dos métodos AHP, para a seleção e priorização dos projetos do portfólio e a programação inteira, 
para a otimização do modelo, permitindo a introdução de restrições e a simulação de diferentes cenários.

Ao iniciar a atividade de desenhar a árvore de critérios para os "projetos com investimento aprovado", utilizando-se o método AHP, foi observado que existiam diferentes tipos de projetos dentro dessa categoria, não sendo possível estabelecer critérios únicos para todos os tipos de projetos existentes. Por isso foi necessário retornar a fase de avaliação do portfólio e propor uma reclassificação dos projetos segundo a similaridade dos critérios de decisão utilizados. A reclassificação dos projetos também permitiu a identificação de distorções existentes na primeira análise, por excluir do portfólio de projetos de engenharia, os projetos denominados pela empresa de estratégicos e, também por excluir projetos de infra-estrutura de P\&D e de Tecnologia da Informação ( $\mathrm{TI})$, que são projetos de suporte às operações da empresa estudada.

A reclassificação dos projetos agrupou estudos de novos produtos e aplicações como "Projetos de P\&D"; projetos de aquisição e substituição de equipamentos de P\&D e reforma das instalações de P\&D como "Projetos de Infra-Estrutura de P\&D"; projetos de substituição de equipamentos industriais em final de vida útil, de segurança, de controle ambiental e de redução de custos como "Projetos de Manutenção"; projetos de aumento de capacidade, desenvolvimento de novos produtos, processos e aplicações, otimizações das instalações, melhoria da qualidade, compra de tecnologia, venda de tecnologia, joint-ventures/parcerias e participações minoritárias em outras empresas como "Projetos de Engenharia" e; projetos de aquisição/ implantação de software, desenvolvimento de software e aquisição/instalação de hardware como "Projetos de Tl".

Após a reclassificação dos projetos, os histogramas de número de projetos com investimento aprovado por ano e valor do investimento orçado versus real por ano, foram refeitos para cada grupo de projetos definido (Projetos de Infra-Estrutura de P\&D, Projetos de TI, Projetos de Engenharia e Projetos de Manutenção), utilizando-se os mesmos dados, do período de 2001 a 2005. Também foram redesenhados os diagramas de bolhas para os Projetos de Engenharia, desta vez utilizando-se os dados de 2005, por serem mais recentes e existirem em maior número, melhorando a qualidade da análise. Tais diagramas não foram desenhados para os projetos de Infra-Estrutura de P\&D, TI e Manutenção, por não serem projetos relacionados a tecnologia, inovação e crescimento da organização. 
Os gráficos gerados considerando a nova classificação foram analisados e as conclusões deles tiradas foram confrontadas com as conclusões obtidas no levantamento preliminar. O resultado dessa análise foi apresentado para os gerentes de engenharia e P\&D que participaram da primeira rodada de análise do portfólio da empresa como feedback.

A partir dessa última análise iniciou-se o trabalho de modelagem e validação do modelo, com a definição dos critérios de seleção de projetos e elaboração das hierarquias de decisão utilizando-se o método AHP. Para essa fase foi utilizado o software Decision Lens versão 1.6.16, desenvolvido pelo Dr. Thomas Saaty da Wharton School of Business, que utiliza os métodos AHP e a programação inteira.

Para validação do modelo foram utilizados os projetos relativos ao exercício de 2005, por estarem mais presentes na memória dos gestores, tornando mais fácil as discussões de priorização dos projetos. Para esses projetos, são dados conhecidos: o número de projetos, tipo, duração, escopo, os valores de orçamentos e valores reais desembolsados, EVA (Economic Value Added) e margem.

Para as cinco classificações de projetos anteriormente definidas (Projetos de P\&D, Infra-Estrutura de P\&D, TI, Engenharia e Manutenção), foi aplicado o método AHP para selecionar e priorizar o portfólio de projetos, segundo critérios estabelecidos pelo autor, tomando como base as referências bibliográficas e apoio de especialista no método AHP no Brasil. Tais critérios foram criticados, modificados e validados pelos gestores das áreas de projetos e P\&D da empresa, durante reuniões de discussão do método AHP. Esse procedimento permitiu que os participantes se sentissem parte do processo de modelagem e, desta forma, o modelo refletisse o "pensamento da organização".

Durante as reuniões de validação de cada estrutura hierárquica de projeto com os participantes, foi realizada uma análise de sensibilidade dos critérios, onde se variava o peso de um dado critério, para mais e para menos, e se verificava o impacto causado na seqüência dos projetos. Também foi avaliado o índice de inconsistência obtido nas votações de critérios, sendo que para valores desse índice superior a 0,10; a etapa de votação dos pesos dos critérios era revisada. Essas técnicas, recomendadas por Saaty (1970), ajudavam os participantes a avaliarem se as votações dos critérios e ratings eram consistentes.

Para a votação dos projetos de cada estrutura hierárquica de decisões, não foram realizadas reuniões, exceto no caso dos projetos de manutenção. O autor 
exportou os dados dos projetos, equipe, critérios e ratings das estruturas de decisão de cada tipo de projeto para o Excel e encaminhou para os membros das diferentes equipes para que a votação fosse feita segundo o tempo disponível de cada um. A explicação de como fazer a votação foi dada durante as reuniões com as equipes. Após receber as planilhas Excel com os resultados da votação de cada árvore, o autor importou essas informações para o sistema Decision Lens e determinou os resultados da priorização dos projetos, inicialmente sem restrições. No caso dos projetos de manutenção, o representante de cada unidade fabril votou apenas os projetos de sua unidade, pois eles afirmaram não ter condições de julgar se um projeto de outra fábrica era mais ou menos importante que um projeto da unidade onde eles trabalhavam. Esse fato tornou necessário que estabelecêssemos um critério de rateio do valor do investimento disponível para manutenção para cada site. O critério de rateio definido foi que cada site receberia um valor proporcional ao valor se seus ativos.

Numa fase seguinte, a restrição de orçamento foi simulada para diferentes cenários e comparada com o cenário real utilizando o valor do investimento aprovado para o ano de 2005. Tais cenários de simulação utilizaram programação inteira e binária do tipo 0 ou 1 . Em alguns dos cenários simulados para os projetos de engenharia foram estabelecidas relações de dependência entre os projetos, de tal forma que projetos que requeriam a execução de outros projetos ou que precisassem ser realizados juntos ou numa dada relação de precedência, fossem assim priorizados. Também foram simulados cenários utilizando-se de rateios dos valores dos investimentos por subtipo de projeto para os projetos de engenharia e manutenção.

Após a aplicação da programação inteira e das restrições foram obtidos os resultados de quais projetos teriam sido selecionados em cada cenário, com o uso do AHP, da programação inteira e com o modelo híbrido, AHP com programação inteira. Tais resultados foram comparados com os resultados que ocorreram na prática, já que os dados são de eventos passados. Os resultados obtidos foram apresentados aos participantes da etapa de validação do modelo.

No total foram realizadas 8 reuniões com os diferentes participantes para a etapa de validação dos critérios de decisão de cada estrutura de decisões, votação dos critérios e definição dos ratings e seus valores. Dessas reuniões, 3 foram com a 
equipe de manutenção, 2 com a equipe de P\&D, 1 com a equipe de Engenharia, 1 com o analista de negócio de TI e 1 com a equipe da Diretoria.

Para a definição dos funcionários da empresa que participariam da validação da estrutura hierárquica de decisão de cada tipo de projeto levaram-se em consideração os critérios de conhecimento que tinham sobre o assunto analisado, experiência, tempo de empresa e função que ocupavam na organização. Os perfis dos funcionários da empresa que participaram desta pesquisa podem ser consultados no APÊNDICE B.

A metodologia utilizada foi considerada a mais adequada devido à dificuldade de agendar reuniões com os gestores e também pelo fato de parte deles trabalharem em diferentes unidades da organização, o que exigiria viagens para a realização das reuniões. Como o autor conhece bem a empresa por ser funcionário dela, optou por fazer esboços das árvores de decisão e seus critérios, sendo necessárias reuniões com os gestores apenas para validação do modelo e votação dos pesos dos critérios, ratings e projetos utilizando-se a técnica de comparação por pares (pairwise comparison).

A utilização de fontes diferentes de informações, via bancos de dados, reuniões de grupo e entrevistas individuais tornam as informações confiáveis e garantem sua validade, através de sua comparação, conforme proposto por Thiollent (2004). 


\section{APRESENTAÇÃO DO CASO ESTUDADO}

Este capítulo tem como objetivo a apresentação da empresa objeto de estudo e seu sistema de seleção, priorização e acompanhamento de projetos, inserindo-a no contexto deste trabalho. Assim, o presente tópico descreve o laboratório utilizado para a realização da pesquisa e coleta de dados.

\subsection{Caracterização da Empresa}

A empresa alvo deste estudo é nacional, privada e de capital intensivo, pertencente aos segmentos químico e petroquímico, com sede em São Paulo. Tratase de uma empresa de grande porte, com atuação no mercado interno e externo, dispondo de 4 unidades industriais no Brasil e 2 no exterior.

Seu faturamento total supera 1,5 bilhões de reais/ ano, sendo alocados em pesquisa e desenvolvimento cerca de $2 \%$ de sua receita anual. Verifica-se sua presença no mercado externo em mais de 40 países, do Extremo Oriente, América Latina, Europa, Estados Unidos, Canadá e África do Sul, tendo cerca de 30\% sua produção exportada através de uma rede de distribuidores.

Do total de aproximadamente 900 funcionários no Brasil, $12 \%$ pertencem às áreas de pesquisa e desenvolvimento (P\&D) e engenharia (Projetos).

Além das unidades industriais, a empresa dispõe de um moderno centro de pesquisas. Das 4 plantas produtivas, a maior fica na Bahia e a segunda maior na grande São Paulo. Essas fábricas têm processos iguais com capacidades diferentes e alguns processos complementares, sendo que uma produz intermediários para a outra. As demais plantas têm processos e linhas de produtos diferentes, sendo uma localizada no interior de São Paulo, produtora de especialidades químicas e a outra localizada no Rio Grande do Sul, produtora de um único produto para o segmento de solventes através de um processo petroquímico.

As linhas de produtos da organização abrangem intermediários orgânicos, solventes, tenso-ativos e especialidades químicas, produzidos nas diferentes 
unidades produtivas de cada planta, através de processos produtivos contínuos e descontínuos.

Para chegar a configuração de instalações atual a empresa passou por uma fusão há cerca de 15 anos, quando ocorreu um processo de verticalização. Desde então, com o objetivo de buscar maior produtividade e competitividade, a empresa estudada tem implantado diferentes programas, tais como: certificações da qualidade (ISO 9001, QS 9000, ISO 14000 e SA 8000), reengenharia dos processos organizacionais, implantação de programas de modernização e automação das unidades, com a aquisição e implantação de modernos sistemas de controle de produção integrados com um ERP (Enterprise Resource Planning) e um EAM (Enterprise Asset Management). Em 2003, foi iniciado um processo de expansão, através da aquisição de unidades no exterior. No final de 2006, nova aquisição ocorreu no Brasil, com a incorporação de uma produtora de tenso-ativos sulfatados.

O impacto de tais mudanças na gestão de operações foi significativo, tanto em termos de custos dos produtos, como em termos de prazos. A necessidade da rápida adaptação à nova realidade, associada às mudanças de conceitos administrativos provocou diversas alterações nas unidades, tais como extinção de áreas, mudança de responsabilidades, substituição da diretoria e mudanças no chão de fábrica. Essas mudanças afetaram todos os setores da empresa entre elas a área de engenharia, que devido a um processo de downsizing, sofreu terceirização de parte de suas atividades. As fábricas foram impactadas na medida em que recursos de manutenção passaram a ter também a responsabilidade de participar da concepção e implantação dos projetos junto com a engenharia, tendo que dividir seu tempo entre atividades de manutenção e de projetos. A área de pesquisa e desenvolvimento, além de ter o pessoal reduzido, passou a atender uma demanda crescente por novos produtos e aplicações.

A estrutura resultante para a empresa no Brasil pode ser representada pelo organograma apresentado pela Figura 8. 


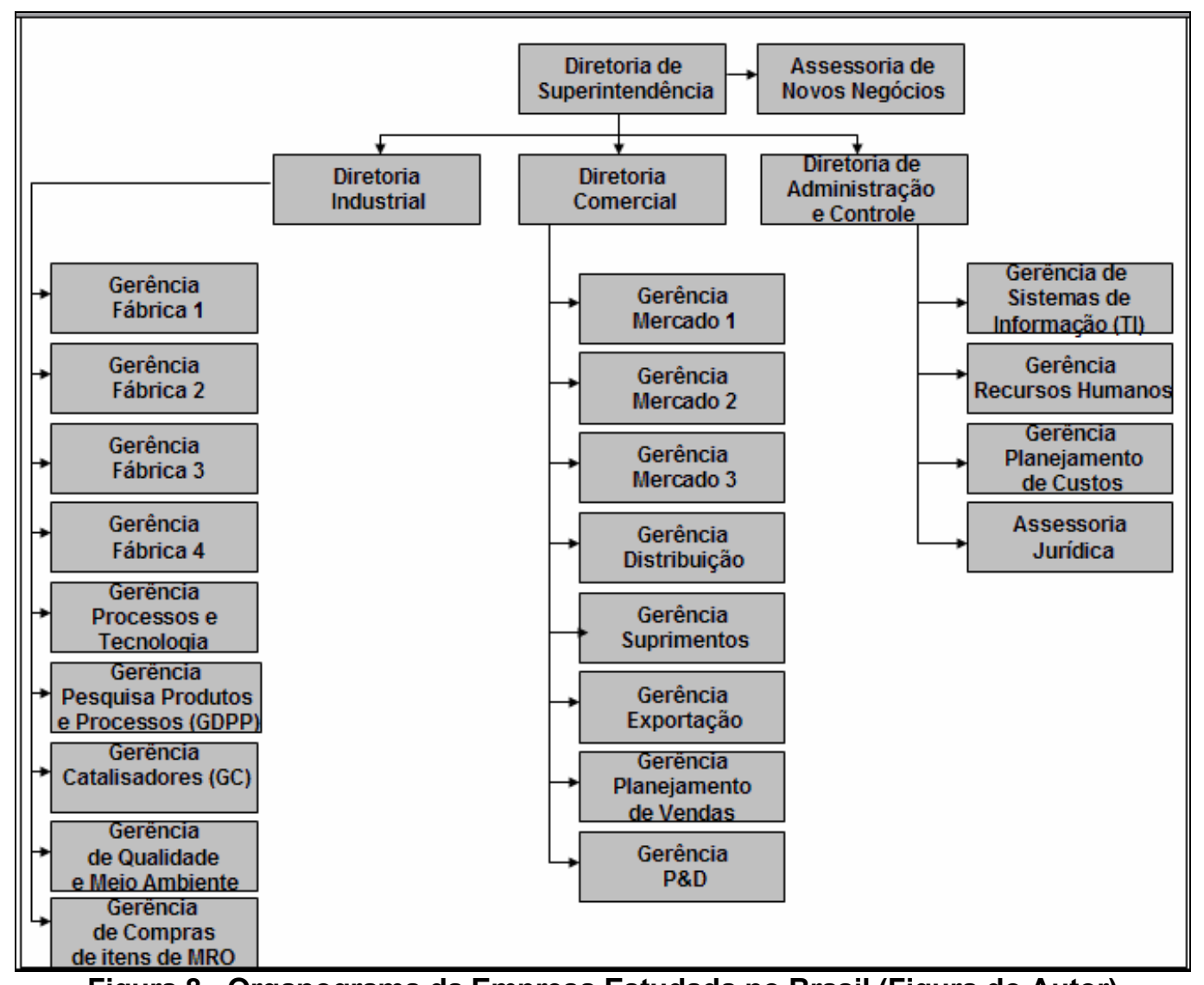

Figura 8 - Organograma da Empresa Estudada no Brasil (Figura do Autor)

As áreas de pesquisa e desenvolvimento (P\&D), engenharia e assessoria de novos negócios, apesar de responderem hierarquicamente a diretorias diferentes, (comercial, industrial e superintendência), têm uma sinergia muito grande e, na prática, se constituem numa grande atividade Core da empresa, que é o projeto de novos produtos, processos e aplicações.

A área de P\&D é subdividida em gerência de aplicações de produtos (GA) e gerência de pesquisa analítica (GPA); já a engenharia se subdivide em gerência de processos (GP), gerência de implantação de projetos (GIP), gerência de desenvolvimento de processos e produtos (GDPP) e gerência de catalisadores (GC).

A área de aplicações de produtos é responsável pela assistência técnica aos clientes da empresa, bem como pelo desenvolvimento e testes de novas aplicações e/ou produtos em seus laboratórios. Essa área se subdivide em três gerências para atender a linhas de produtos de diferentes segmentos de mercado. A área de pesquisa analítica tem como finalidade suportar os processos de desenvolvimento e aplicações de novos produtos e o processo produtivo, através do desenvolvimento e 
aperfeiçoamento de métodos analíticos para as diferentes linhas de produtos e matérias-primas.

A gerência de desenvolvimento de processos e produtos tem como objetivo trabalhar no desenvolvimento de novos produtos em escala piloto e gerar amostras comerciais, além de fazer otimizações de produtos e processos de linha, auxiliando a eliminar não-conformidades e reduzir ciclos produtivos, melhorando a produtividade das fábricas e reduzindo os custos de fabricação.

A gerência de catalisadores é uma área exclusiva para desenvolvimento de produtos da linha de catálise da empresa. Trata-se de um negócio estratégico e por isso tem uma estrutura separada das demais linhas de produtos.

A gerência de processos (GP), pertencente à equipe de engenharia, basicamente desenvolve a etapa de projeto de processos, para projetos com investimento aprovado e realiza estudos e simulações em computador para apoio a etapa de desenvolvimento de novos produtos, solução de problemas das unidades produtivas ou otimizações. A etapa de projeto de processos é onde são feitos os balanços de massa e energia, estudos das reações químicas e elaboração dos documentos de engenharia de processos, característicos de plantas químicas (fluxogramas de processos, fluxogramas de engenharia, etc.). Nesta área basicamente o corpo técnico é composto por engenheiros químicos.

A gerência de implantação de projetos (GIP) trabalha na implantação de investimentos aprovados para a construção de novas unidades e modificações em unidades existentes. Em conjunto com os engenheiros da gerência de processos, esta área desenvolve o que é conhecido na empresa por projeto básico, em que, tendo as informações de processos, se dimensionam equipamentos, especificam linhas, instrumentos, etc., gerando diversos documentos tais como folhas de dados de equipamentos e instrumentos, índices de linhas, entre outros. Esta área tem especialistas de diferentes áreas, fazendo parte de seu corpo técnico: engenheiros mecânicos, de instrumentação, civis, de tubulação e elétricos. Esta área também é responsável pelo acompanhamento físico e financeiro dos projetos, por isso dispõe de especialistas em elaboração de estimativas de investimentos, e administração.

A fase de engenharia de detalhamento em que as informações contidas no projeto básico são especificadas no nível de quantidade de itens para cada especificação, com elaboração de requisições de material e outros documentos 
necessários à montagem industrial é terceirizada, sendo contratada equipe específica para cada projeto.

A montagem industrial também é terceirizada, feita por empreiteiras contratadas para cada projeto; entretanto, esta fase é coordenada e fiscalizada por coordenadores de implantação, pertencentes à gerência de implantação de projetos (GIP). A figura 9 apresenta as estruturas de engenharia e P\&D.

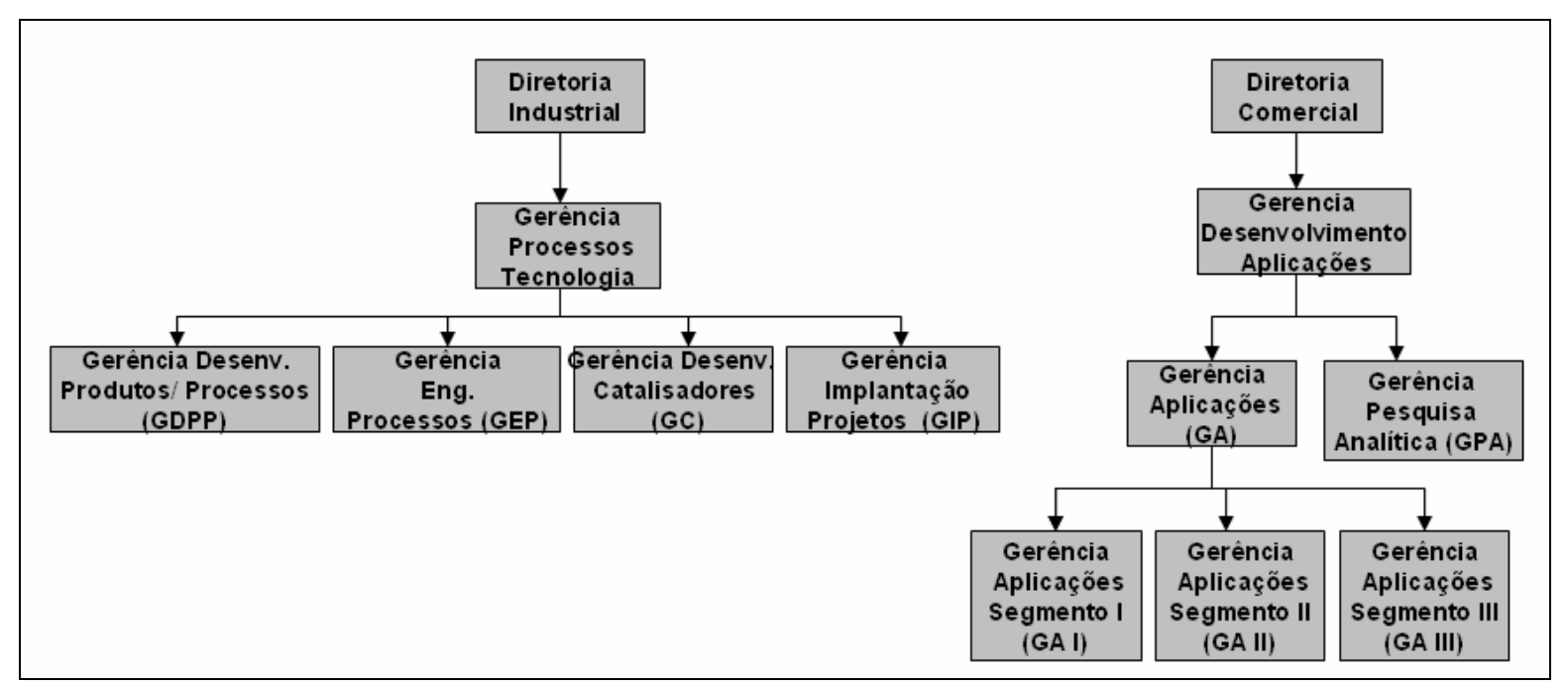

Figura 9 - Estrutura de Engenharia e P\&D (Figura do autor)

A Assessoria de Novos Negócios é constituída em sua totalidade por engenheiros químicos que tem a função de prospectar através do estudo de patentes, leitura de literatura científica relacionada com as áreas de interesse da empresa, leitura de jornais de negócios, acompanhamento de bolsas de valores, entre outras fontes, oportunidades de introdução de novos produtos e crescimento da empresa, seja através de desenvolvimentos internos ou aquisições de empresas, participações minoritárias ou associações com outras organizações. Os profissionais dessa área são $100 \%$ próprios, pois a área é considerada estratégica, não se justificando terceirizações. Eles se reportam ao Assessor da Diretoria de Superintendência.

Para cada fábrica existe uma área de manutenção cuja estrutura é dada pela figura 10. Existe uma hierarquia em que todas as especialidades de manutenção se reportam a uma chefia única, que é responsável pelo planejamento e designação dos recursos. 


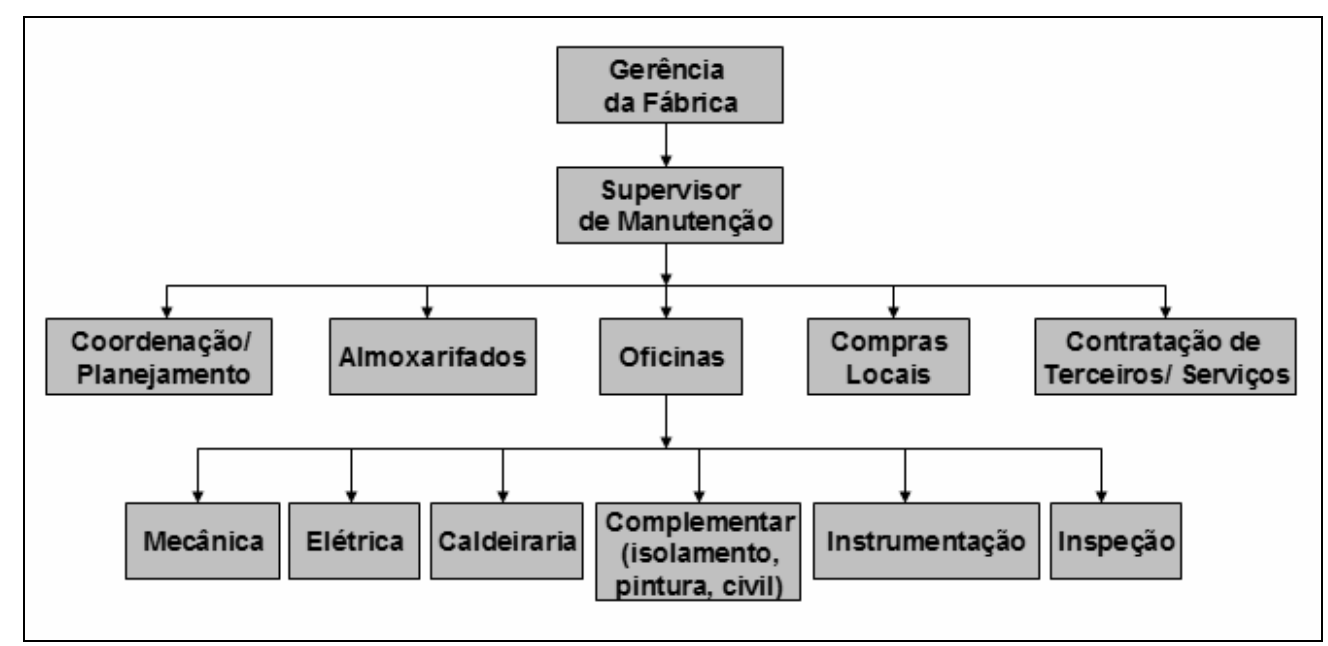

Figura 10 - Estrutura de Manutenção das Unidades Industriais (Figura do Autor)

A área de manutenção é responsável por realizar a rotina de manutenções corretivas, preventivas e preditivas das diferentes áreas produtivas e implantar projetos com investimento aprovado que envolva substituição de equipamentos em final de vida útil, controle ambiental, segurança e redução de custos. Entretanto, seus profissionais mais qualificados, normalmente os coordenadores, são frequentemente requisitados pela engenharia para dar apoio na implantação de projetos para aumento de capacidade e introdução de novos produtos o que acarreta sobrecarga de trabalho. Entre 30 e $40 \%$ do pessoal que trabalha nas oficinas de manutenção, nas diferentes especialidades, é terceirizado.

A área de Tecnologia de Informação (TI) da organização é responsável pela implantação de projetos com investimento aprovado dos tipos desenvolvimento, aquisição e implantação de software e também projetos relacionados com a infraestrutura de TI. Tal área é considerada de apoio às operações, tendo em sua estrutura analistas de negócios subordinados à gerência de TI, que são responsáveis por coordenar as atividades dos profissionais de desenvolvimento, consultores e técnicos, todos terceirizados. A figura 11, a seguir, mostra a estrutura simplificada da área de TI da organização. 


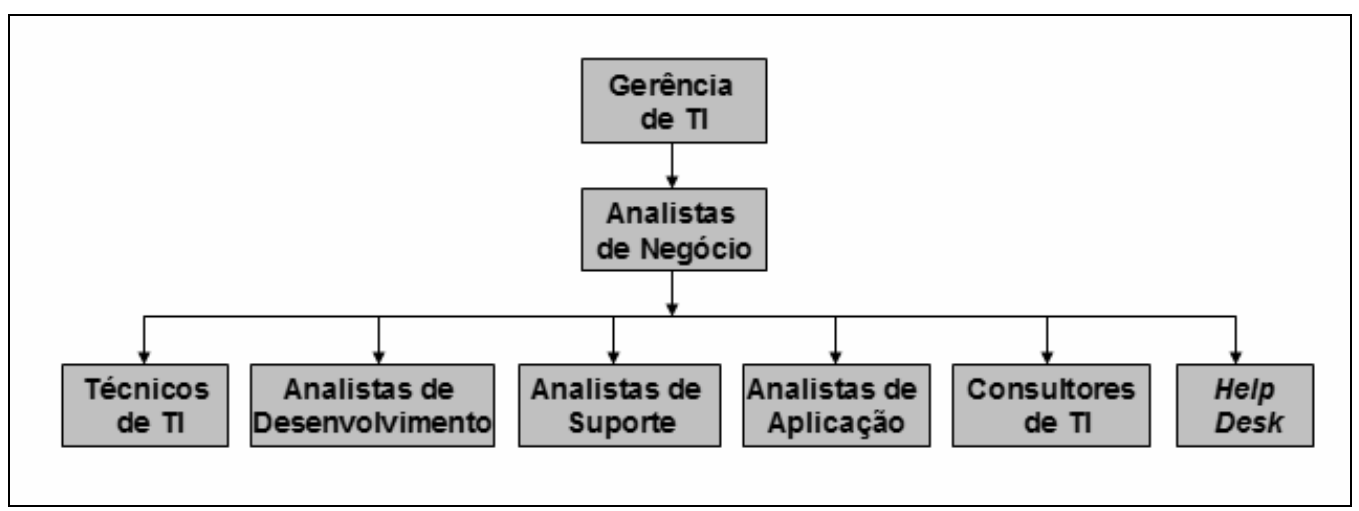

Figura 11 - Estrutura de Informática da Organização Estudada (Figura do Autor)

\subsection{Origens dos Projetos do Portfólio da Organização}

A empresa ora analisada tem a prática de realizar reuniões entre todos seus executivos no segundo semestre de cada ano para elaborar o documento denominado "Plano Estratégico", que apresenta a visão do mercado, linhas de produtos, processos e projetos que serão necessários no horizonte dos 3 anos seguintes. Essas reuniões acontecem pouco antes do período orçamentário, onde são elaborados os orçamentos de investimentos, despesas e produção do próximo ano. Encerrada a fase de planejamento estratégico, cada área, baseada no documento "Plano Estratégico", elabora seus planos de ação e respectivos orçamentos para o próximo ano. As propostas de investimento e despesas são encaminhadas para a diretoria que as analisa e aprova ou rejeita segundo critérios pré-estabelecidos pela direção da organização.

Conforme mostrado na figura 12, são várias as entradas de novos projetos candidatos a compor o portfólio da organização em estudo:

- Força de vendas, que durante as visitas periódicas aos clientes identifica seus anseios e necessidades;

o Clientes-chave, que semanas antes do início do período de planejamento estratégico são convidados a visitar a organização e fazer apresentações sobre seus novos negócios, perspectivas do mercado onde atuam e projeções de vendas ligadas às linhas de produtos fornecidas pela empresa estudada. 
o Marketing, através de pesquisas de mercado realizadas a cada 2 anos.

o Área de Novos Negócios, através do estudo de patentes e tecnologias ou possíveis aquisições.

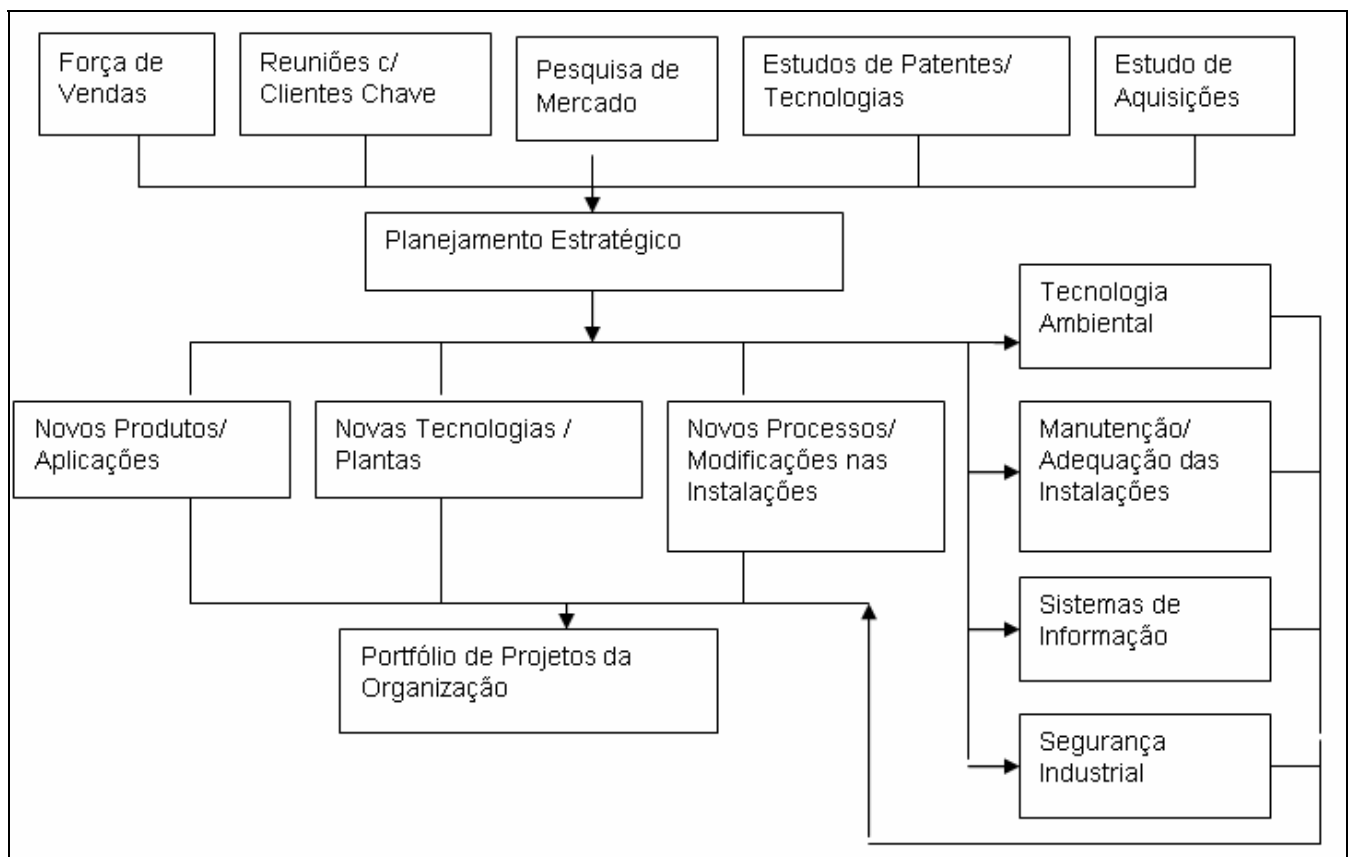

Figura 12 - Origem dos Projetos que compõem o Portfólio da Empresa (Figura do autor)

Essas demandas acabam gerando necessidades de adequação das instalações se desdobrando em solicitações de atendimento a requisitos de segurança, questões ambientais, infra-estrutura de TI e manutenção industrial.

\subsection{Classificação dos Projetos da Empresa}

A empresa em análise tem dois portfólios de projetos distintos dependendo da fase em que se encontrem e de suas características: existem os projetos que fazem parte do fluxo de P\&D e aqueles relacionados a informática, manutenção e segurança industrial e modernização das instalações.

Os que fazem parte do fluxo de P\&D, enquanto estão na fase de estudos, não tem investimento aprovado. Normalmente estão relacionados com a qualidade de 
produtos existentes, desenvolvimento de novos produtos, processos, ampliação de capacidade das instalações e implantação de novas unidades com processos existentes ou não. Tais projetos podem evoluir para projetos de engenharia, sendo que para isso precisam ter os investimentos estimados aprovados pela diretoria.

As idéias provenientes das áreas de vendas, marketing e desenvolvimento de novos negócios são inseridas no sistema de gestão de projetos e serviços da organização (GPS). Neste momento recebem um número de controle de solicitações de serviços e passam a fazer parte do fluxo de desenvolvimento de novos produtos e processos da organização. Nesse sistema, a área solicitante designa um coordenador e os membros da equipe de trabalho que serão responsáveis pela condução de cada projeto e são feitos os apontamentos do estágio de avanço de cada um deles.

A figura 13 mostra o fluxo de desenvolvimento de produtos e processos da organização. Esse fluxo é composto por 5 fases, desde a entrada da idéia no sistema até sua conclusão, podendo tais fases serem executadas ou não, dependendo do grau de complexidade do projeto em questão e da análise de sua viabilidade. As atividades desse fluxo são executadas pelas áreas de P\&D e engenharia.

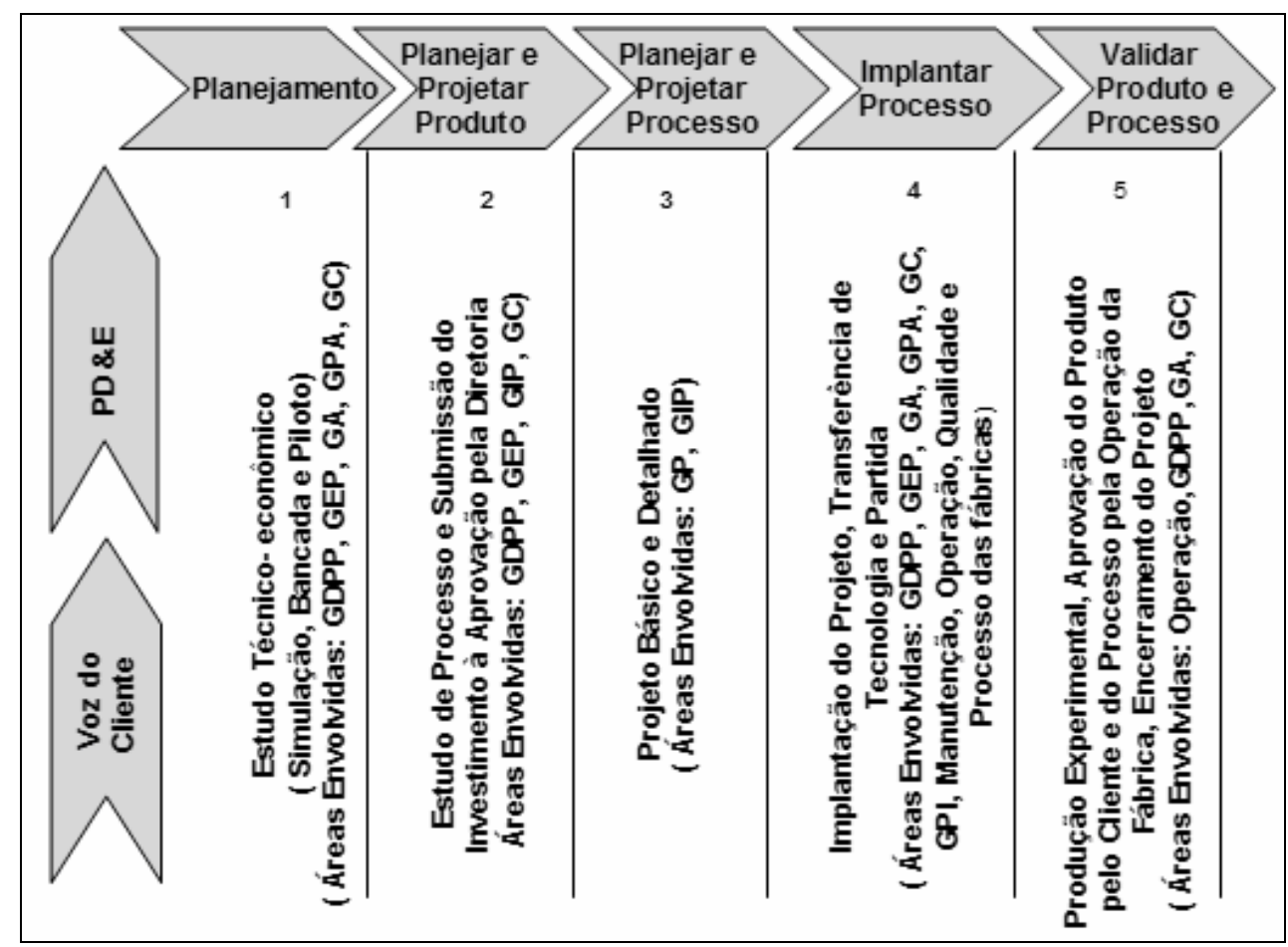

Figura 13 - Fluxo de Desenvolvimento de Produtos e Processos da Organização (Fonte: PD\&E, 2004, adaptado pelo autor) 
Os projetos de P\&D são divididos em duas categorias:

o Serviços técnicos;

o Projetos de Produtos: desenvolvimento de novos produtos, processos e aplicações; ou otimizações de produtos de linha.

Os serviços técnicos normalmente se constituem na elaboração de testes e pequenos estudos para assistência a clientes e em geral não passam da Fase 2 do fluxo de desenvolvimento apresentado na figura 13 , não necessitando de investimentos futuros.

Já os projetos de produtos, tratam do desenvolvimento e estudos de otimizações e em geral abragem as Fases de 1 a 4 . Tais projetos são relacionados a construção de novas unidades e/ou edificações, modificações de unidades existentes e/ ou substituição ou reposição de instalações, equipamentos, sistemas e/ou instrumentos existentes em final de vida. Esses projetos são subdivididos nas etapas de estudos iniciais de viabilidade técnico-econômica (Fase1), desenvolvimento do produto (Fase 2), projeto básico (Fase 3) e implantação (Fase 4).

Os projetos de P\&D dos tipos serviços técnicos e projetos de produtos são subdivididos por área de negócio e por segmento de mercado. São 5 áreas de negócio, IS (Intermediários de síntese), T (tenso-ativos), S (solventes) e OPP (outros produtos de desempenho) e catalisadores.

O negócio IS é constituído por 10 segmentos de mercado, o negócio T responde por 11 segmentos de mercado, o negócio $S$ atende a 9 segmentos de mercado e o negócio OPP atende a 11 segmentos. O negócio "catalisadores" atende a um único segmento.

Os projetos de produtos são classificados ainda pelo grau de complexidade, podendo pertencer aos tipos:

o Tipo I - Planta e tecnologias existentes - podem ser de otimização de produtos ou processos;

o Tipo II - Planta e tecnologias existentes - trata do desenvolvimento de novos produtos e/ou aplicações;

o Tipo III - Planta modificada e tecnologia existente ou produção em terceiros;

o Tipo IV - Planta e/ou tecnologia nova 
o Tipo Especial - Projetos de impacto significativo nos resultados/crescimento da empresa que, devido ao escopo e complexidade, teriam dificuldade de ser viabilizados pelas áreas operacionais da empresa, necessitando para tanto de grupo multifuncional.

o Catalisadores - desenvolvimento de novos catalisadores ou serviços remunerados relacionados (regeneração, etc.) Os projetos desse tipo não estarão sendo analisados no presente trabalho de pesquisa por terem um tratamento diferenciado.

Os projetos de informática, manutenção, segurança industrial e modernização são executados por diferentes áreas da empresa, devendo, para serem iniciados, ter o investimento aprovado pela diretoria.

Projetos relacionados à segurança industrial (SG) e modificações de instalações existentes para substituição de sistemas, equipamentos ou peças devido a desgaste, ou seja, fim de vida útil (VU) são propostos pelas áreas de operação e manutenção das unidades e normalmente são implantados pelas áreas de manutenção das unidades, com apoio da engenharia.

Projetos de informática (IF) são de infra-estrutura e são propostos por todas as áreas da organização, sendo implantados ou pela engenharia ou pela área de informática da empresa, dependendo do escopo.

Os projetos relacionados com a segurança industrial (SG), final de vida útil (VU), informática (IF) e administrativos (AD) não pertencem ao fluxo de desenvolvimento de produtos e processos descritos na figura 13 e não são inseridos no sistema de gestão de projetos e serviços da organização.

No caso de projetos com investimento aprovado dos tipos engenharia nas Fases 3 e 4, informática, manutenção, modernização e segurança industrial, a empresa divide seu portfólio segundo sua natureza, tipo e característica. Essa classificação é utilizada na proposição do orçamento de investimentos.

Segundo sua natureza, esses projetos podem ser correntes ou estratégicos. No que se refere ao tipo, os projetos se dividem em:

o Aquisição simples de bens ou serviços, ex: veículos, maquinário de catálogo, etc. (Tipo A)

o Substituição de equipamentos existentes ou reparos em sistemas existentes (Tipo B) 
o Implementação de equipamentos, instalações, sistemas, unidades e fábricas, segundo projetos de engenharia específicos e serviços de construção e montagem industrial (Tipo C).

E quanto à Característica (finalidade principal do investimento), os projetos são classificados conforme o quadro 5.

\begin{tabular}{|l|l|}
\hline Característica do Investimento & \multicolumn{1}{|c|}{ Descrição } \\
\hline CP - Aumento de Capacidade & $\begin{array}{l}\text { Projetos de ampliações de capacidade da linha de produtos } \\
\text { atual }\end{array}$ \\
\hline NP - Novos Produtos & Investimentos que visam o lançamento de novos produtos \\
\hline RC - Redução de Custos & $\begin{array}{l}\text { Investimentos cuja implantação resulta em redução de custos } \\
\text { de produção, pela alteração de ciclos de produção, utilização } \\
\text { de itens menos onerosos, etc. }\end{array}$ \\
\hline AD - Administrativo & $\begin{array}{l}\text { Investimentos em ativos, não relacionados à informática, } \\
\text { fabricação e/ou logística. }\end{array}$ \\
\hline CA - Controle Ambiental & $\begin{array}{l}\text { Investimentos cuja implantação visa atendimento de } \\
\text { requisitos de proteção ambiental }\end{array}$ \\
\hline IF - Informática & $\begin{array}{l}\text { Investimentos em Software, Hardware e outros ativos de } \\
\text { informática. }\end{array}$ \\
\hline SG - Segurança Industrial & $\begin{array}{l}\text { Investimentos que visam garantir a segurança operacional e } \\
\text { resguardar o patrimônio instalado e humano }\end{array}$ \\
\hline QS - Qualidade & Investimentos em melhoria na qualidade de Produtos \\
\hline VU - Fim de Vida Util & $\begin{array}{l}\text { Investimentos que visam a substituição de um bem devido a } \\
\text { exaustão ou obsolescência }\end{array}$ \\
\hline EE - Estudos Preliminares de & $\begin{array}{l}\text { Investimentos Destinados à execução de Estudos de } \\
\text { Viabilidade de novos negócios e que serão contabilizados no } \\
\text { ativo diferido }\end{array}$ \\
\hline Viabilidade & segundo sua Caracteristica (Fonte: Dados da Empresa \\
\hline
\end{tabular}

Quadro 5: Classificação dos Projetos segundo sua Característica (Fonte: Dados da Empresa)

\subsection{Critérios para Aprovação, Priorização e Revisão de Projetos do Portfólio}

No caso dos projetos de P\&D (Fases 1 e 2), todas as idéias que entram no sistema de gestão de projetos e serviços (GPS) automaticamente passam a fazer parte do seu portfólio, não existindo um filtro para eliminar projetos de pouco interesse para a empresa, nem regras de priorização dos mesmos.

Quanto aos projetos que pertencem às Fases 3 e 4, àqueles de natureza estratégica, são propostos pela diretoria da empresa aos acionistas, após estudos detalhados feitos pela área de assessoria de desenvolvimento. Normalmente tais projetos se referem a aquisições ou inovações de rotas de produção e tecnologias vindas de estudos de patentes e outras fontes. Para serem aprovados, eles são avaliados quanto aos riscos envolvidos, tamanho do mercado, concorrência, tecnologia, espectro de aplicações, relação com o Core Business, valor do investimento e outros critérios financeiros como ROI (Return on Investments), EVA 
(Economic Value Added). Tais projetos, quando aprovados, são acompanhados separadamente dos demais projetos que compõem o portfólio. São monitorados quanto ao desempenho em termos de cumprimento do escopo e cronogramas de execução físico e financeiro. Normalmente contam com equipe de implantação dedicada.

No caso dos investimentos de natureza corrente, a diretoria recebe após a conclusão do período orçamentário, a relação de todos os investimentos propostos, estratificados em investimentos por site, por característica e tipo, contendo a descrição individual de cada investimento, objetivo, cronogramas físico e financeiro propostos com respectiva previsão de desembolso mensal e total. Para cada projeto proposto deve vir uma justificativa anexada, contendo análise de retorno do investimento, o cálculo do ROI e EVA. A Diretoria analisa o valor total dos investimentos propostos, estabelecendo um valor máximo para investimentos correntes. Na seqüência, verifica a diferença entre o valor total de investimentos propostos e o teto e define o valor que deve ser cortado por site. Uma análise individual dos projetos propostos por fábrica e característica define quais projetos serão cortados para se chegar à meta. Os gerentes das áreas são informados sobre quais projetos foram aprovados e quais foram cortados e têm um prazo para renegociar os cortes, podendo substituir projetos não aprovados na primeira rodada de avaliação pela diretoria, por outros que foram mantidos, segundo justificativa encaminhada aos diretores. Após a revisão dos cortes, são aprovados oficialmente os projetos do portfólio que serão iniciados no ano de exercício seguinte. Durante o ano, muitas vezes são propostos investimentos extraorçamentários, interferindo nas prioridades e cronogramas já estabelecidos.

A figura 14 apresenta um resumo do fluxo de aprovação dos projetos da organização.

Uma vez aprovados, os projetos correntes de maior valor e os estratégicos (Fases 3 e/ou 4), são analisados individualmente pelas gerências responsáveis e pela diretoria, através de relatórios mensais de acompanhamento de investimentos, onde os avanços físico e financeiro são acompanhados, segundo a análise da curva $S$. Os projetos menores são consolidados em grandes blocos onde apenas se verifica o total do desembolso já realizado no período. Existe uma regra pela qual, se um investimento tiver uma previsão de gasto $10 \%$ superior ao valor orçado, ele deve ser reapresentado à diretoria para que seja avaliada a viabilidade de concluí-lo ou não. Entretanto, esta regra raramente é seguida. 


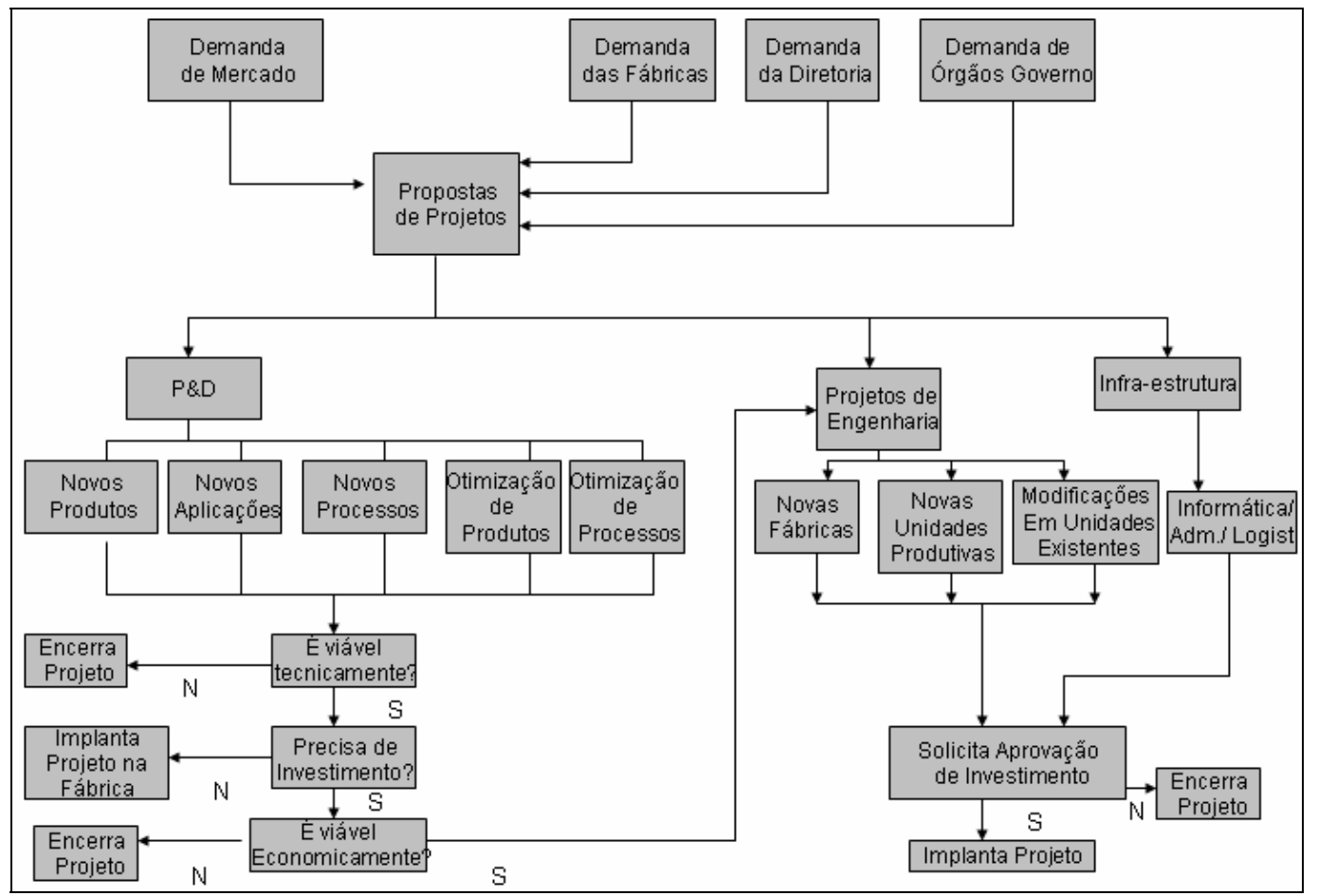

Figura 14 - Fluxo de aprovação dos projetos da Organização (Figura do Autor)

Os projetos extra-orçamentários, aprovados durante o ano, apenas entram no portfólio, mas não ocorre nova reunião com executivos para revisar as prioridades e analisar possíveis alterações de escopo em projetos aprovados em orçamento. No final do ano, durante as reuniões de apresentação dos planos de ação das áreas à diretoria, ocorre uma prestação de contas de projetos executados, projetos que entraram durante o ano em exercício e projetos que foram deixados de lado. Nesta mesma ocasião são apresentados os planos de cada área para o ano seguinte.

No que se refere aos projetos nas fases 1 e 2 também não existe revisão de prioridade ao longo do ano. Faz-se apenas o balanço do que foi realizado e o que não foi no final do ano, durante a reunião de apresentação dos planos de ação para o próximo ano, para a diretoria da empresa. O acompanhamento do avanço das atividades é feito através de relatório mensal elaborado pelas diversas gerências responsáveis pelos projetos.

Não existe uma regra clara que defina a prioridade de um projeto em relação a outro. Todos os projetos aprovados estão de acordo com critérios de importância já analisados durante as reuniões de planejamento estratégico e tem-se a expectativa de que todos sejam executados segundo o cronograma proposto. Não se considera restrição de recursos. Teoricamente os projetos mais prioritários são os de natureza 
estratégica, seguidos pelos correntes de maior retorno, os que envolvam segurança industrial ou qualidade de produto, mas na prática todos os projetos aprovados são cobrados pelas respectivas áreas que os propuseram.

\subsection{Caracterização dos Projetos de P\&D}

Para os projetos de P\&D a caracterização foi feita considerando-se o número de projetos por tipo e margem bruta para o ano de 2004.

Observando-se a Figura 15, verifica-se que em 2004 o portfólio de P\&D da empresa tinha 372 projetos, sendo 109 projetos de produto e 263 serviços técnicos. Dos projetos de produtos, 92 se encontravam nas fases 1 ou 2 de desenvolvimento, sem investimento aprovado, e 17 eram projetos de engenharia (Fases 3 e 4) com investimento aprovado. Dos 263 serviços em execução, 251 tratavam de serviços técnicos e 12 eram estudos junto às universidades. Aproximadamente $50 \%$ do esforço de P\&D era gasto com assistência técnica aos clientes.

Um novo levantamento dos dados de Projetos de P\&D mostrou que, até maio de 2006, o total de projetos do portfólio era de 490. O perfil de distribuição entre assistência técnica, projetos de produtos e serviços continuava o mesmo.

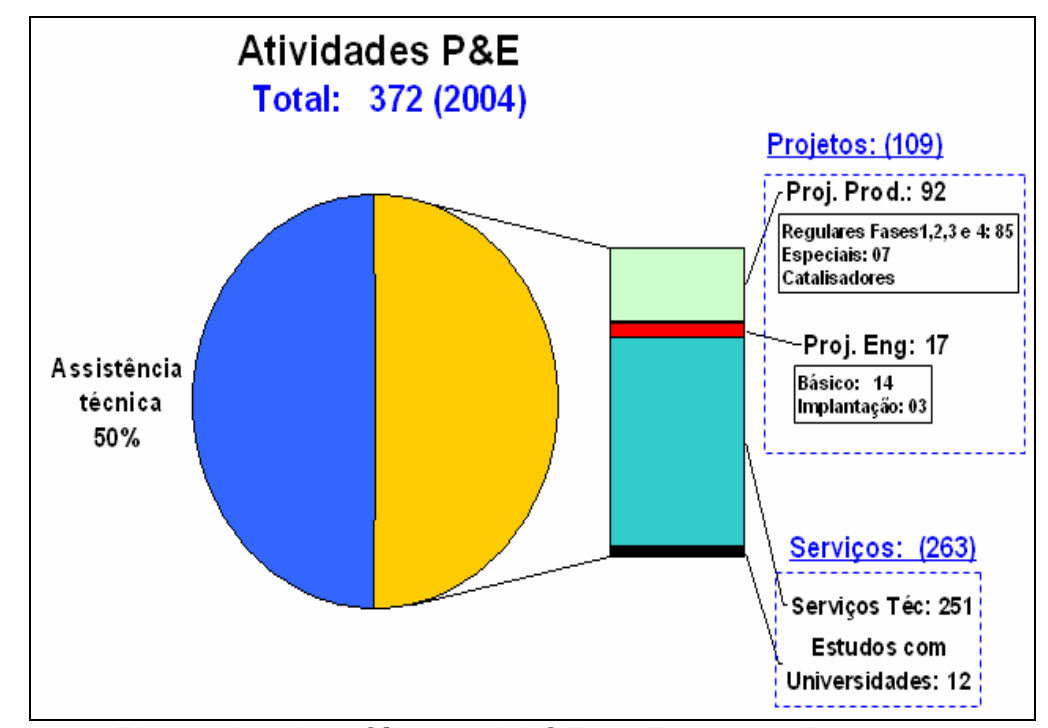

Figura 15 - Portfólio de PD\&E da Empresa Estudada

(Fonte: Dados da Empresa, Sistema de Solicitações de Serviços Técnicos, 2004) 
A Figura 16 apresenta uma visão explodida do número de projetos de produto por tipo, segundo o seu grau de complexidade. Verifica-se que a maior parte dos projetos pertence ao tipo II, ou seja, projetos que tratam do desenvolvimento de novos produtos e/ou aplicações com planta e tecnologia existentes, sendo projetos de baixa complexidade. Os projetos do tipo básico e de implantação têm o mesmo grau de complexidade dos tipos I e II, porém encontram-se num estágio do fluxo de desenvolvimento de produtos mais adiantado. Não se observa no portfólio de PD\&E de 2004 projetos do Tipo IV (Planta e Tecnologias novas).

Constata-se, ao avaliar a figura 16 que a empresa investe pouco esforço em projetos de maior complexidade, optando por projetos de risco menor, em que a tecnologia é dominada e as instalações já existem, sendo necessário baixo investimento para implantá-los.

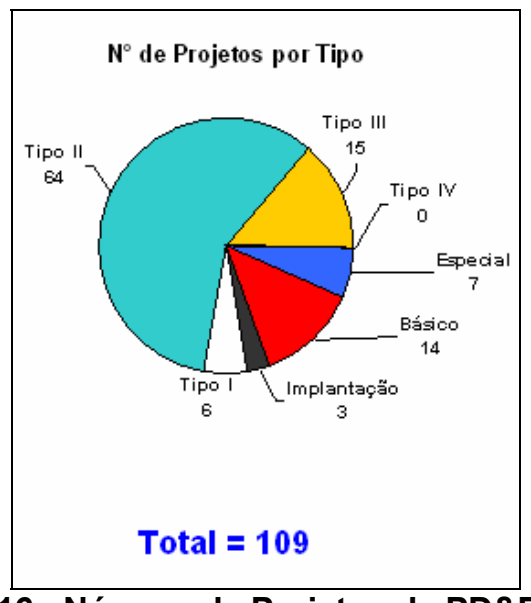

Figura 16 - Número de Projetos de PD\&E x Tipo

(Fonte: Dados da Empresa, Sistema de Solicitações de Serviços Técnicos, 2004)

A Figura 17 mostra uma outra visão dos projetos de produto, apresentando, para cada tipo de projeto, qual a margem bruta média estimada. Pelo que se pode observar, os projetos cujo potencial de ganho é maior são os dos tipos especial e Tipo III, sendo justamente aqueles em que a empresa investe menos. Estes projetos também são os que envolvem os maiores riscos e maiores valores de investimentos e os que não se têm o domínio da tecnologia. 


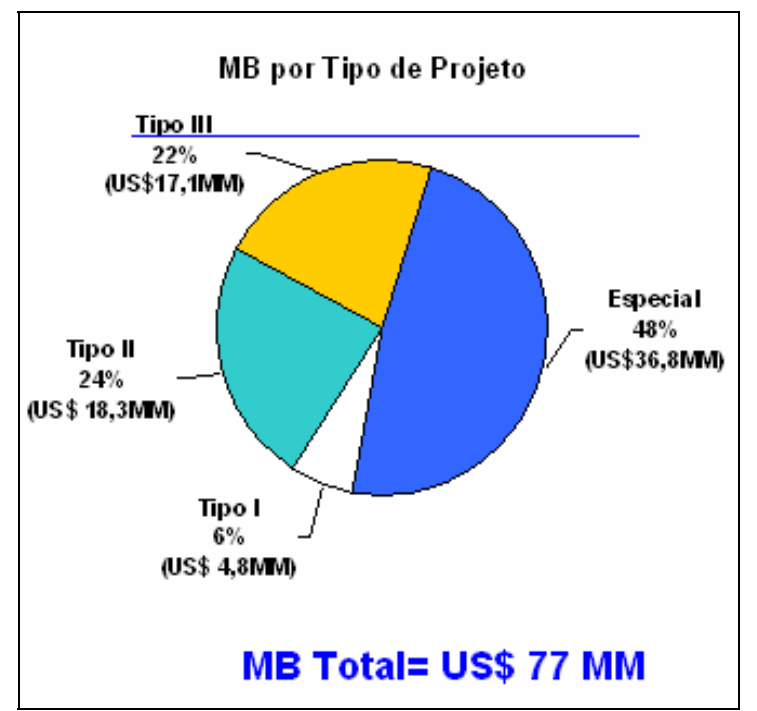

Figura 17 - Margem Bruta dos Projetos de PD\&E x Tipo

(Fonte: Dados da Empresa, Sistema de Solicitações de Serviços Técnicos, 2004)

\subsection{Caracterização dos Projetos com Investimento Aprovado}

Para os projetos de engenharia, a caracterização foi feita de acordo com sua natureza, valor do investimento e risco tecnológico. A classificação é apresentada por unidade produtiva e total da empresa utilizando-se dados relativos aos anos de 2001 a 2005 (vide Anexo A).

Analisando-se o portfólio da companhia estudada em termos de número de projetos de natureza estratégica, por característica e por ano, observa-se um total de 7 projetos, sendo 2 deles relativos a fechamento de capital no mercado acionário e aquisições de ações, 2 deles relativos à expansão de unidades existentes, 1 sobre estudos de novas unidades com nova tecnologia e linha de produtos existentes, 1 sobre relativo a projetos de nova unidade, tecnologia e linha de produtos e 1 sobre compra de nova planta. Os projetos relacionados com mercado acionário e aquisições são exclusivos da diretoria, não sendo analisados neste momento. Os demais projetos serão analisados comparando-se os valores orçados com realizados e a duração real com a estimada.

Pode-se observar através da análise das tabelas 1 e 2 que, geralmente, o número de projetos estratégicos é menor que os correntes, variando de 1 a 2 por ano. Embora os investimentos estratégicos tenham um acompanhamento do cronograma mais rigoroso e detalhado, este geralmente não é cumprido. No que tange aos 
valores, verifica-se gastos inferiores ao orçado. Em entrevista com os coordenadores dos dois projetos concluídos, nos foi informado que os desvios foram causados por alterações de escopo quando o projeto já se encontrava em fase de montagem, tendo havido redução do número de equipamentos a serem comprados e instalados.

Tabela 1 - Histórico dos Investimentos Estratégicos Orçados x Realizados

\begin{tabular}{|l|c|c|c|c|c|}
\hline \multicolumn{1}{|c|}{ Caracteristica } & Projeto & $\begin{array}{c}\text { Valor } \\
\text { Orçado } \\
\text { (USDx1000) }\end{array}$ & $\begin{array}{c}\text { Valor } \\
\text { Realizado } \\
\text { (USDx1000) }\end{array}$ & $\begin{array}{c}\text { Duração } \\
\text { Estimada } \\
\text { (meses) }\end{array}$ & $\begin{array}{c}\text { Duração } \\
\text { Real } \\
\text { (meses) }\end{array}$ \\
\hline $\begin{array}{l}\text { CP-Aumento de } \\
\text { Capacidade }\end{array}$ & $\mathrm{A}$ & 8.800 & 6.252 & 48 & 56 \\
\hline $\begin{array}{l}\text { CP-Aumento de } \\
\text { Capacidade }\end{array}$ & $\mathrm{B}$ & 6.204 & 4.067 & 25 & 47 \\
\hline $\begin{array}{l}\text { EE - Estudos de novas } \\
\text { Tecnologias e linha de } \\
\text { produtos existente }\end{array}$ & $\mathrm{C}$ & 3.000 & 1.500 & 6 & $\begin{array}{c}\text { Em } \\
\text { execução }\end{array}$ \\
\hline $\begin{array}{l}\text { NP-New Unit with New } \\
\text { Technology, Process and } \\
\text { Product line }\end{array}$ & $\mathrm{D}$ & 94.000 & $\begin{array}{c}\text { Até } \\
\text { setembro/05 } \\
=18.458\end{array}$ & 24 & $\begin{array}{c}\text { Em } \\
\text { execução }\end{array}$ \\
\hline
\end{tabular}

(Fonte: Dados da Empresa, Sistema de Acompanhamento de Investimentos, 2001 a 2005)

A Tabela 2 apresenta uma fotografia da quantidade dos projetos de natureza corrente da companhia estudada, por ano e por característica. Como se pode verificar, o portfólio de projetos da empresa por ano era superior a 200 , tendo sido reduzido para o patamar de 140 em 2005. Observa-se que o número de projetos aparentemente está relacionado com o tamanho das plantas.

Tabela 2 - Histórico Anual de Projetos de Natureza Corrente por site e total

\begin{tabular}{|c|c|c|c|c|c|c|}
\hline & Matriz & Fábrica 1 & Fábrica 2 & Fábrica 3 & Fábrica 4 & $\begin{array}{c}\text { Total } \\
\text { Empresa }\end{array}$ \\
\hline 2001 & 13 & 64 & 72 & 33 & 20 & 202 \\
\hline 2002 & 13 & 68 & 77 & 38 & 15 & 211 \\
\hline 2003 & 14 & 73 & 72 & 28 & 16 & 203 \\
\hline 2004 & 16 & 75 & 75 & 30 & 10 & 198 \\
\hline 2005 & 11 & 38 & 50 & 30 & 11 & 140 \\
\hline
\end{tabular}

O gráfico 1 apresenta o total de projetos com investimento aprovado da empresa, por característica e por ano. Através dele é possível verificar que há uma maior quantidade de projetos com característica de final de vida útil (VU), seguida de projetos relacionados com segurança industrial (SG) e qualidade (QS). Projetos de modernização (MD) apresentam tendência decrescente, chegando a zero em 2005. 
Isso ocorre devido a alteração do critério de classificação de projetos ocorrida em 2003, com eliminação da característica modernização. Essa característica foi unificada com a de final de vida útil (VU). Nota-se que o número de projetos com características VU, SG, RC, CA, QS e AD apresentam tendência a redução, enquanto que os projetos de aumento de capacidade (CP), novos produtos (NP) e estudos (EE) apresentam tendência de crescimento.

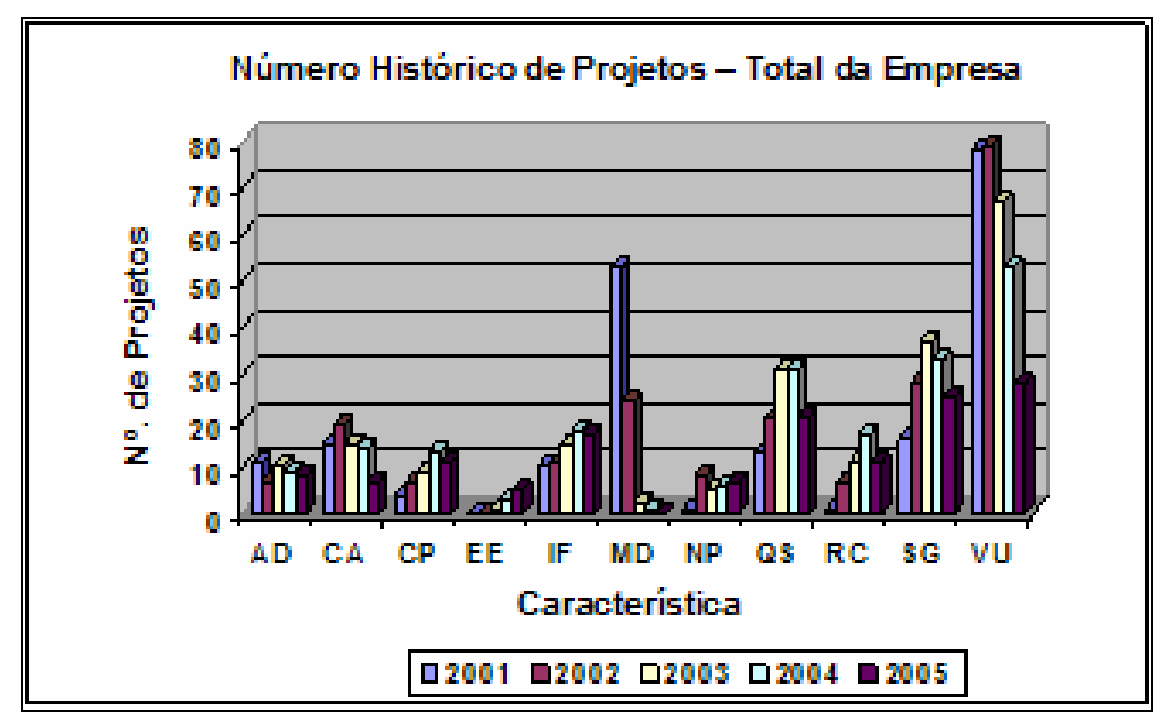

Gráfico 1 - Histórico de Número de Projetos/Característica/Ano

Uma análise detalhada de cada site nos permite identificar diferenças no portfólio de projetos da Matriz, quando confrontado com as demais unidades. $\mathrm{O}$ Gráfico 2 mostra o perfil de investimentos da administração central (matriz), onde se evidencia uma diferença em relação ao perfil da empresa (Gráfico 1). Isso ocorre pelo fato das áreas de novos negócios e informática ficarem sediadas na matriz e também pelo fato dos maiores projetos de informática serem corporativos, tendo sua execução e instalações de hardware centralizados. 


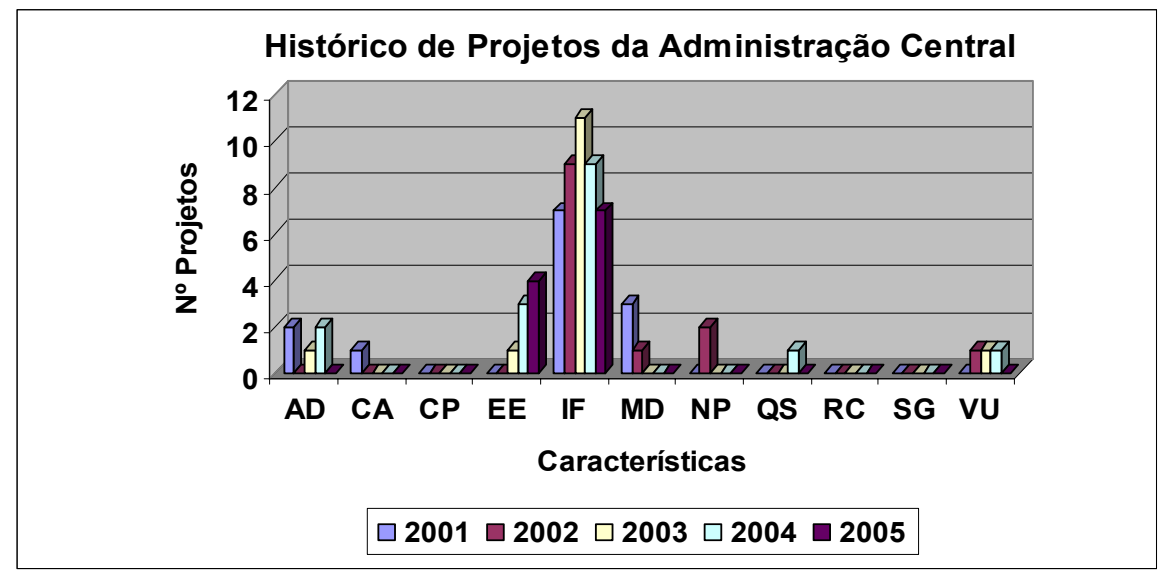

Gráfico 2 - Histórico do $n^{\circ}$. de Projetos/Característica/Ano - Matriz

Quando analisados os gráficos 3, 4, 5 e 6, relativos ao portfólio das unidades industriais, verifica-se a existência de diferenças sutis no perfil de cada planta. O perfil de projetos da maior planta, (Fabrica1) em termos de quantidade, prioriza as características fim de vida útil (VU) e modernização (MD). Segurança (SG), redução de custos (RC) e qualidade (QS) são as outras prioridades desta fábrica. Entretanto, observa-se no período analisado uma tendência de redução dos investimentos com característica VU, MD e QS, enquanto que os projetos com característica RC e SG tiveram um período de crescimento e em 2005 foram reduzidos para número inferior ao de 2002.

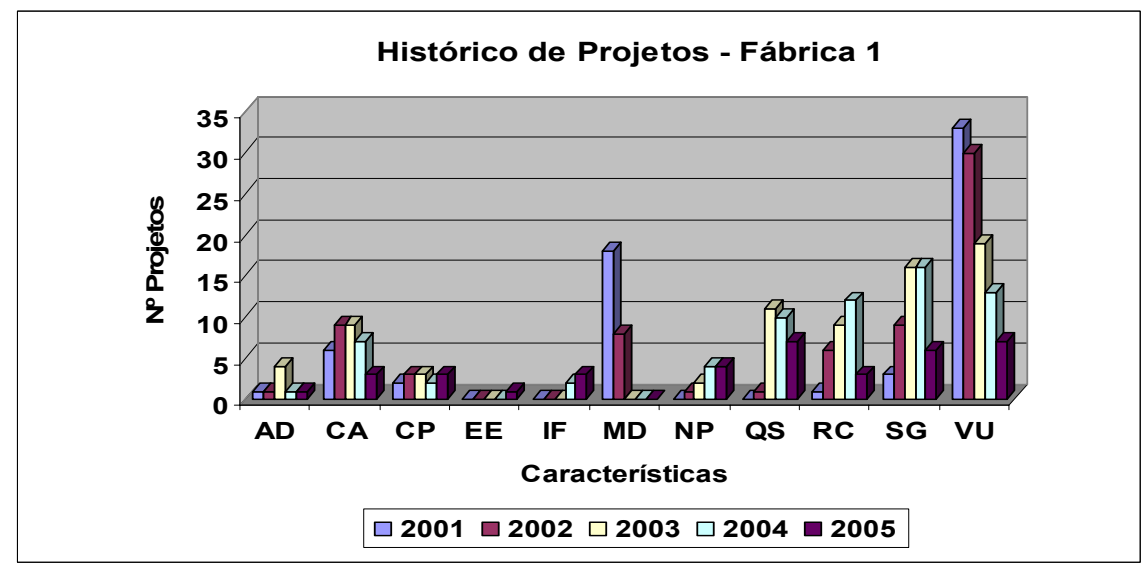

Gráfico 3 - Histórico do nº de Projetos/Característica/Ano - Fábrica 1 
O gráfico 4 apresenta o perfil de investimentos da segunda maior fábrica da empresa em estudo. Observa-se um comportamento muito semelhante ao da fábrica 1 , exceto para a característica RC, que apresenta tendência de crescimento.

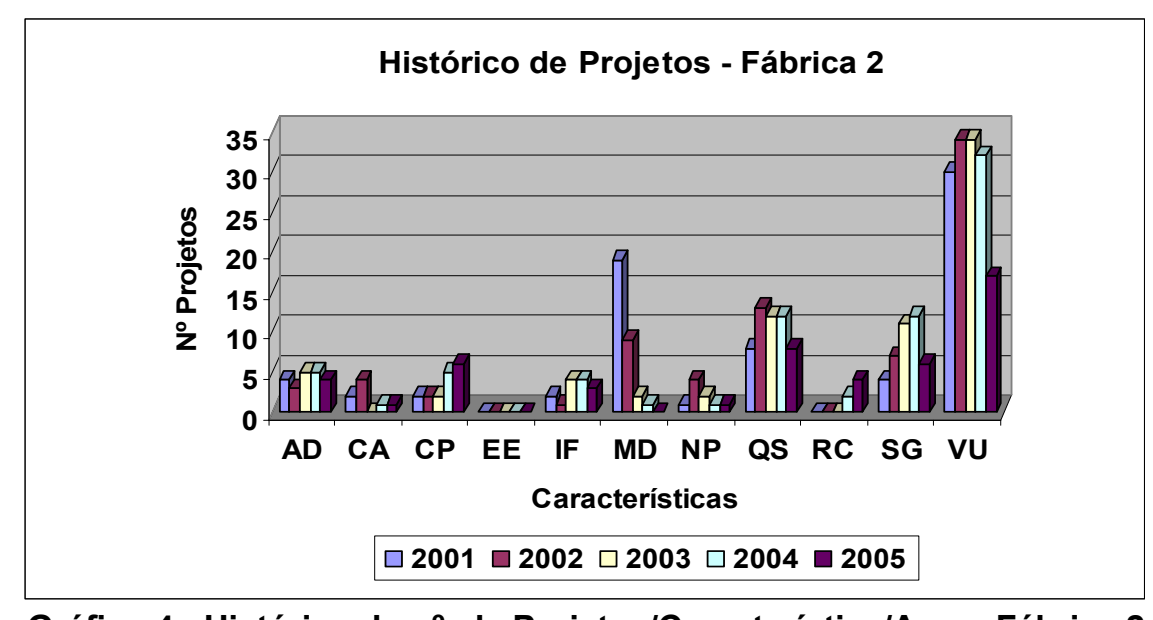

Gráfico 4 - Histórico do nº de Projetos/Característica/Ano - Fábrica 2

A Fábrica 3, conforme se pode ver no gráfico 5 tem como maior parte de seus projetos àqueles ligados a fim de vida útil (VU) e segurança (SG), em igual proporção, seguidos dos projetos relacionados à qualidade (QS) e modernização (MD). Destacase a preocupação com segurança (SG) e qualidade (QS) nesta unidade.

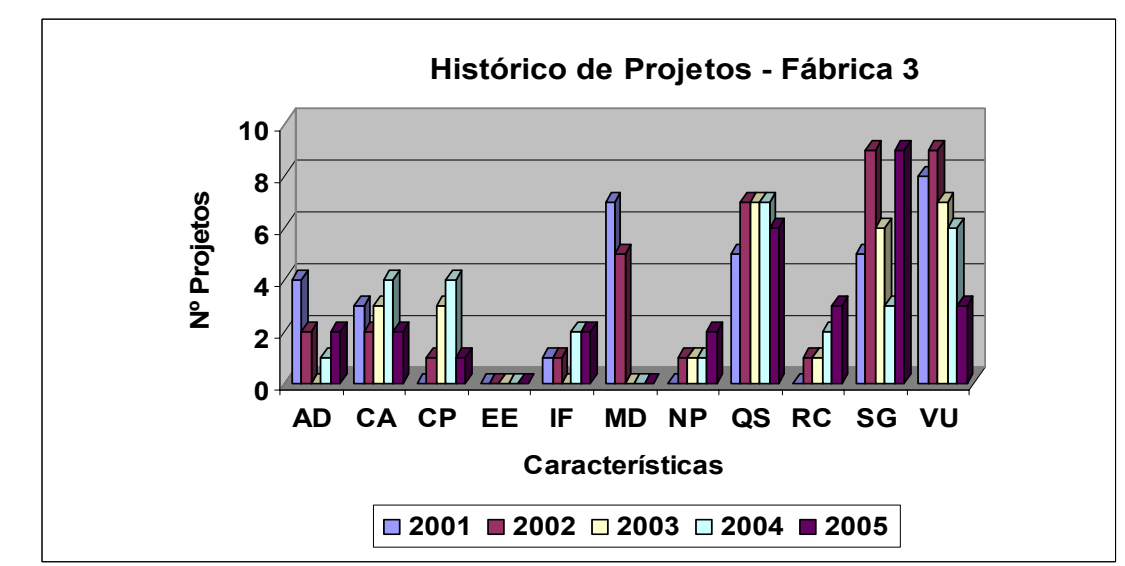

Gráfico 5 - Histórico do $n^{\circ}$. de Projetos x Característica x Ano - Fábrica 3

O perfil de investimentos da menor unidade, fábrica 4 , pode ser analisado através do gráfico 6. Neste caso, fim de vida útil (VU), segurança (SG) e controle 
ambiental (CA) são mais freqüentes, mas todos com número decrescente ao longo do período estudado. Por outro lado, observa-se certa preocupação com aumento de capacidade (CP).

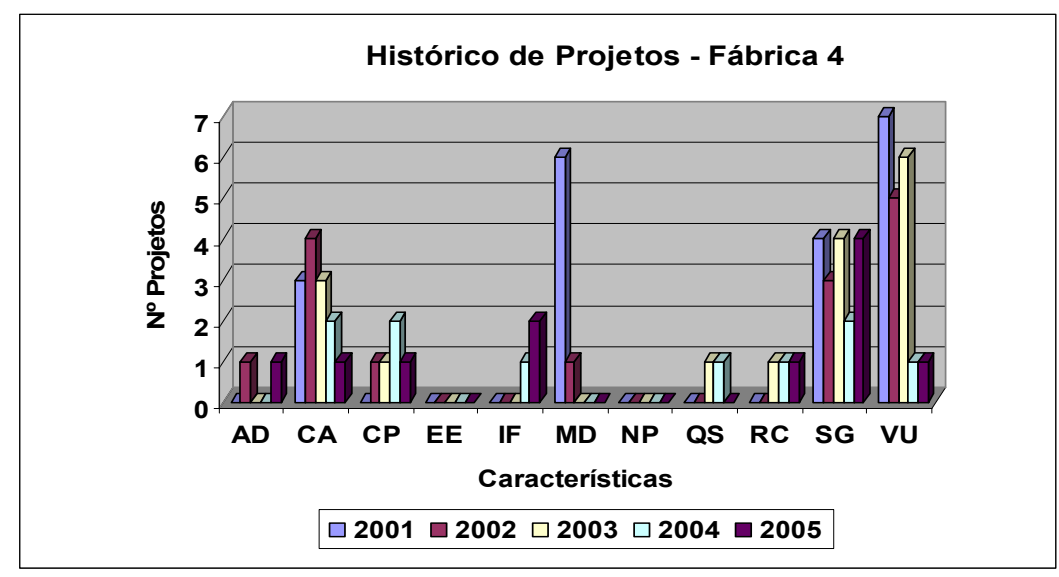

Gráfico 6 - Histórico do $n^{\circ}$. de Projetos x Característica x Ano - Fábrica 4

O gráfico 7, a seguir, nos apresenta uma outra visão do perfil de projetos da organização estudada. Observa-se que o total de desembolsos com investimentos com aumento de capacidade (CP), estudos de novas unidades e tecnologias (EE) foi maior que os investimentos com característica final de vida útil (VU) em 2004 e 2005. Investimentos em segurança (SG), qualidade (QS), novos produtos (NP) e informática (IF) estão situados na mesma faixa de valores. Esse gráfico também mostra que os valores orçados normalmente são maiores que os realizados, o que caracteriza baixa capacidade de execução dos projetos propostos ou grandes desvios nas estimativas de investimento.

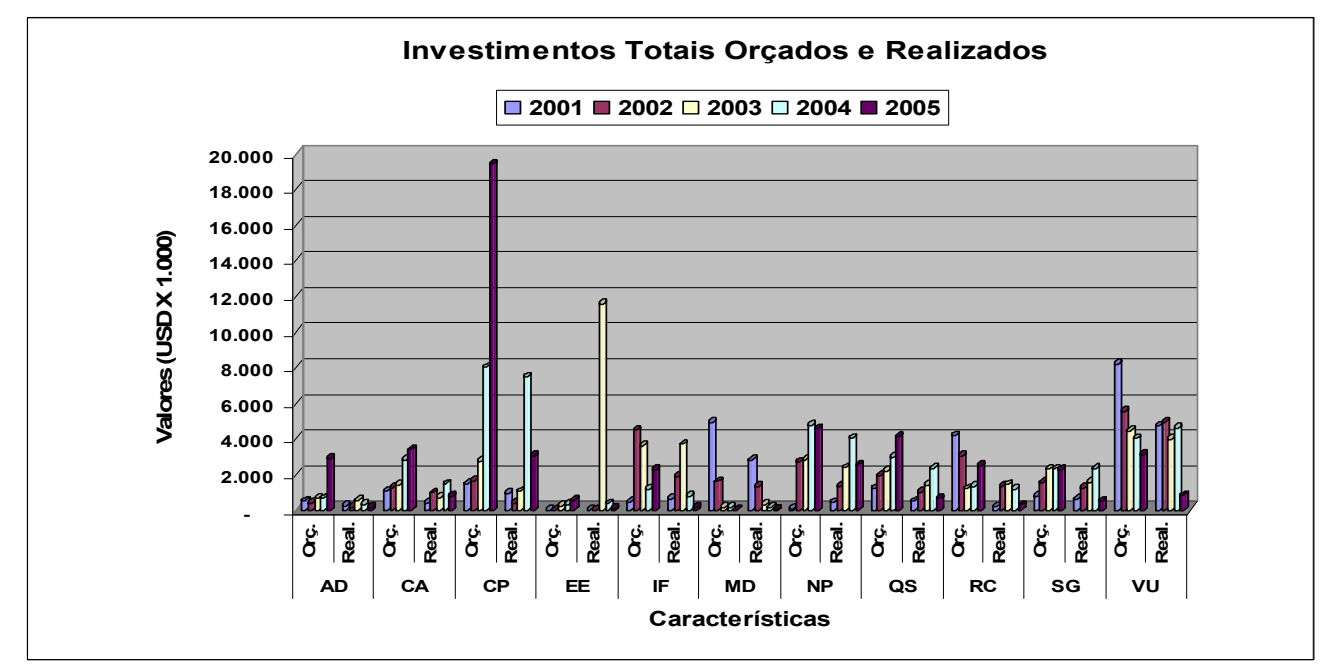

Gráfico 7 - Histórico do total de Investimentos em Projetos Orçados x Realizados 
O gráfico 8 apresenta os valores orçados e realizados nos projetos da matriz; nesse caso, os projetos são basicamente de informática e estudos, como observado no gráfico de quantidades de projetos por/ano. Comparando-se os valores orçados e realizados ano a ano, verifica-se sempre um valor orçado acima do realizado, seguindo o perfil da empresa. Aparentemente a organização se propõe a executar mais projetos do que tem capacidade. Outra hipótese para o perfil observado, seria a de que os orçamentos são superestimados. Entretanto, em entrevistas com coordenadores de projetos de informática e de engenharia, a explicação encontrada foi que os projetos são submetidos à aprovação da Diretoria prematuramente. Assim, seu escopo sofre muitas alterações, e isso atrasa a implantação e, por conseqüência, os desembolsos.

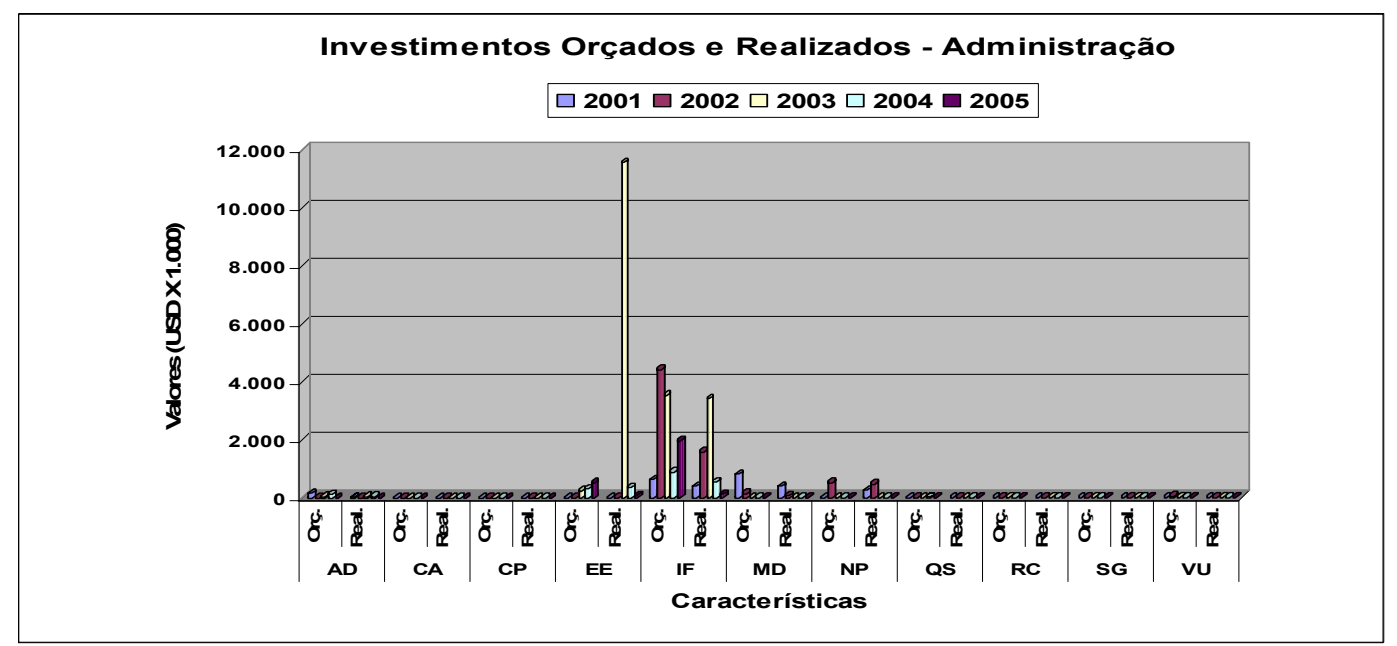

Gráfico 8 - Histórico de Investimentos em Projetos. Orçados x Realizados - Matriz

A análise do gráfico 9 nos mostra que, embora o maior número de projetos da unidade 1 seja fim de vida útil (VU), em termos de valores orçados os poucos projetos de aumento de capacidade (CP) e novos produtos (NP) são mais significativos. Aparentemente, desde 2004 a empresa está investindo grandes valores em projetos com essas características e vem reduzindo o valor dos investimentos com final de vida útil (VU). Pode-se inferir que a unidade já tenha se modernizado nos anos anteriores e agora esteja em expansão. Quanto ao comparativo entre valores orçados e realizados, valem os mesmos comentários feitos anteriormente, ou seja, os valores reais são sempre menores que os orçados. 


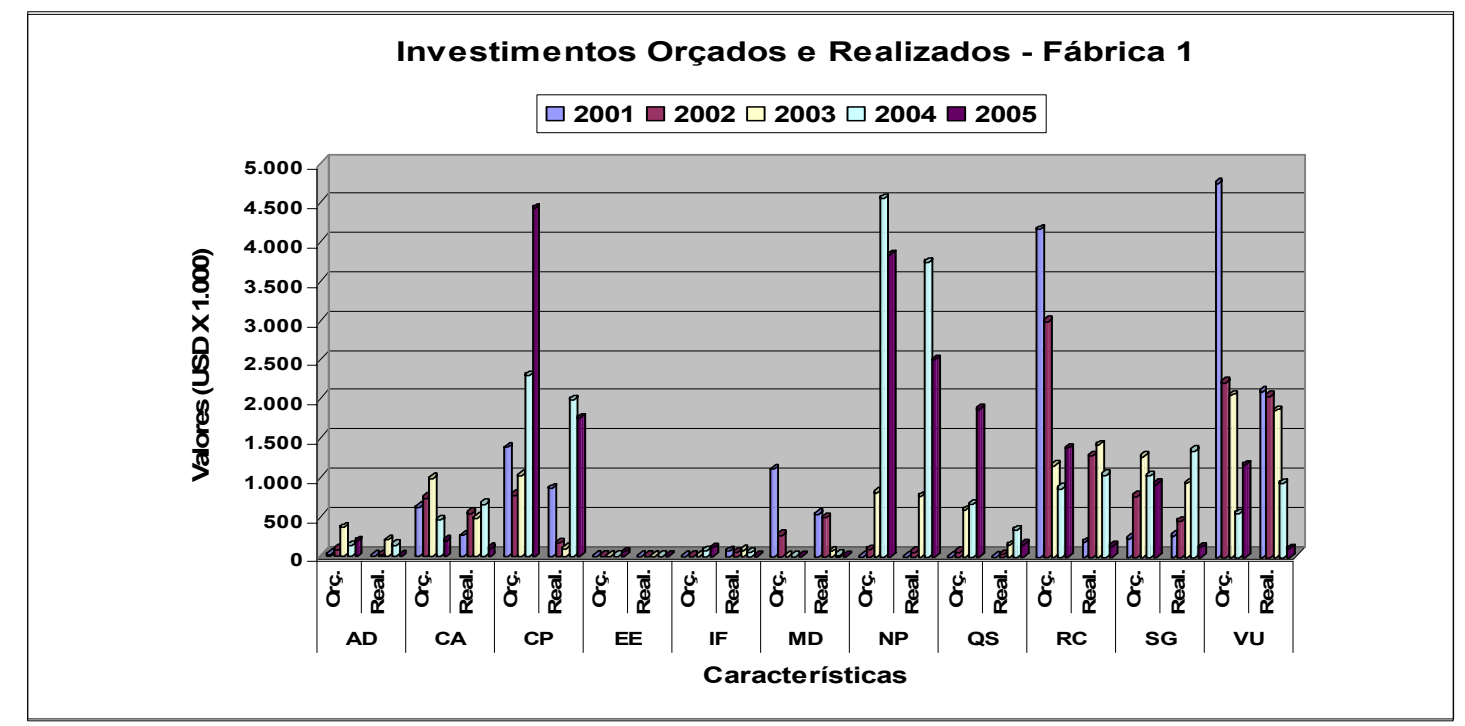

Gráfico 9 - Histórico de Investimentos em Projetos Orçados x Realizados—Fábrica 1

A fábrica 2, como se pode observar no gráfico 10 , também está investindo grandes valores desde 2004 em aumento de capacidade (CP) e controle ambiental (CA). Fim de vida útil (VU), apesar de ser importante em termos de quantidade, em valores aparece em $3^{\circ}$ lugar. A unidade está executando um grande projeto de construção de uma estação de tratamento de efluentes e uma nova fábrica de uma das principais linhas de produtos. Esses poucos projetos justificam a proporção dos investimentos. Ainda assim, ao longo dos 5 anos observa-se um valor de investimentos constante com final de vida útil (VU), fato que denota preocupação em manter as instalações.

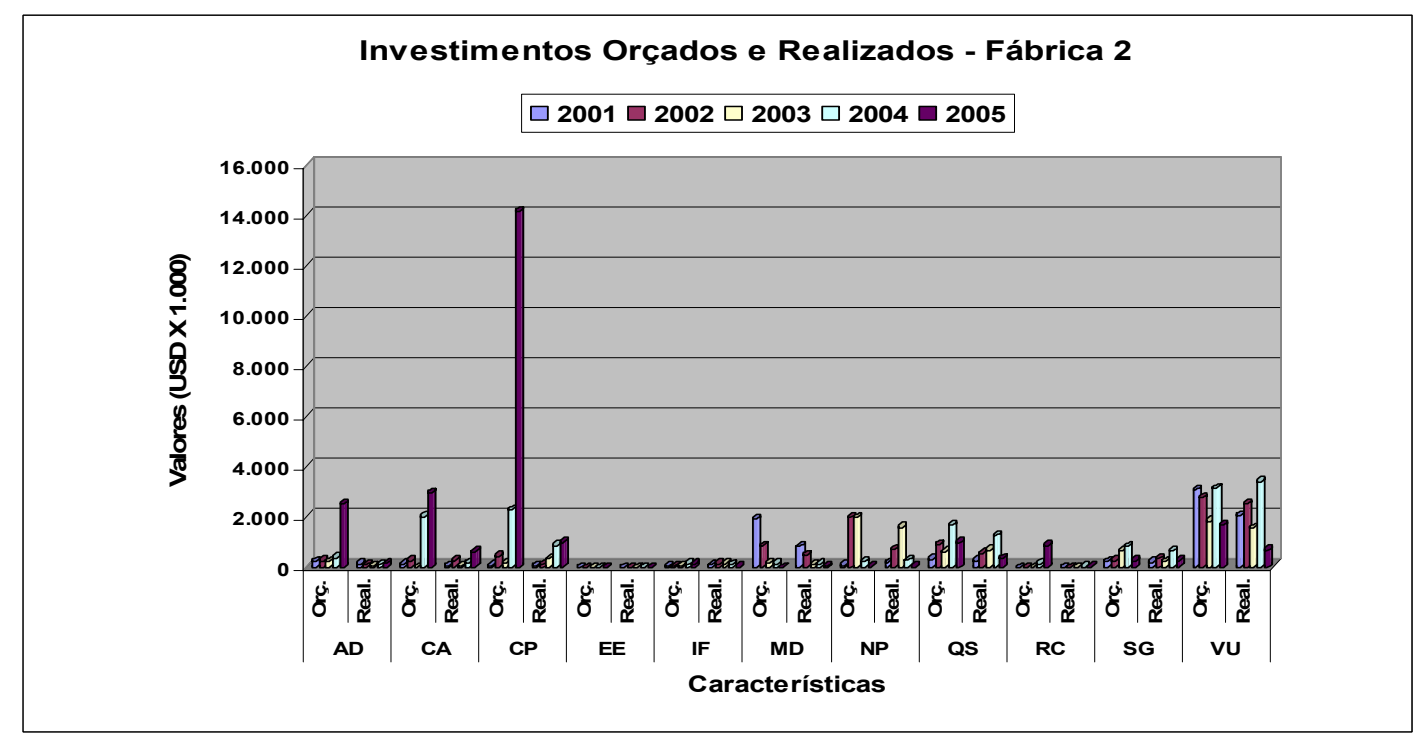

Gráfico 10 - Histórico de Investimentos em Projetos Orçados x Realizados-Fábrica 2 
O gráfico 11 mostra o perfil de investimentos da fábrica 3. Pode-se verificar que grandes projetos foram iniciados em 2004 para aumento de capacidade (CP). Nota-se também que nesta unidade são priorizados projetos de ampliações e projetos relacionados com a qualidade (QS). Isso se deve ao fato da unidade trabalhar com produtos do segmento cosmético, que são passíveis de contaminação e exigirem atenção especial. Quando comparamos os valores orçados e realizados por ano e por característica, verificamos grandes estouros no orçamento em 2003 e 2004 principalmente nos tipos administrativo (AD), controle ambiental (CA) e aumento de capacidade (CP). Neste caso, presume-se que ocorreram problemas de gerenciamento nos projetos.

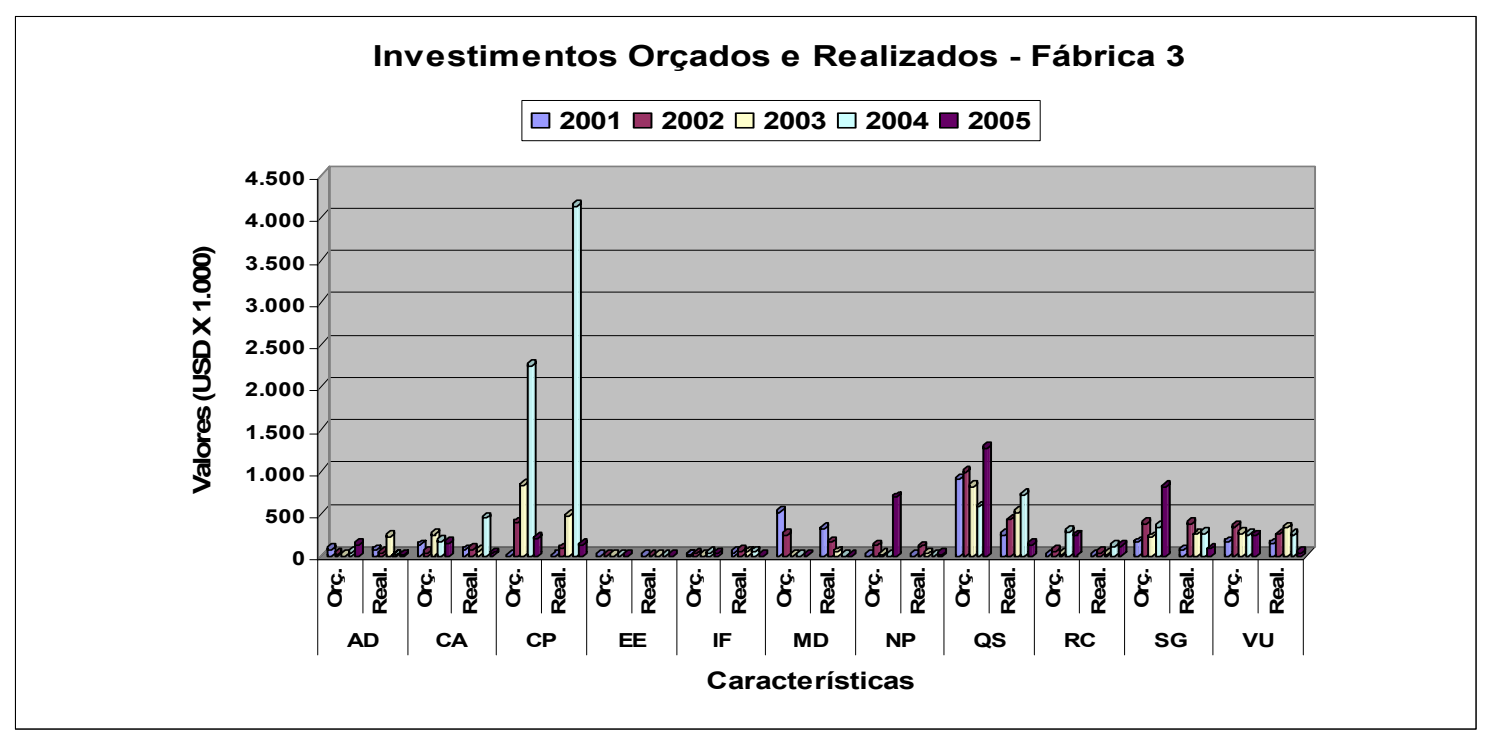

Gráfico 11 - Histórico de Investimentos em Projetos Orçados x Realizados_Fábrica 3

O gráfico 12 mostra os investimentos da menor unidade da organização. Essa fábrica é monoprodutora e tem investido em ampliações. Verifica-se o cumprimento do orçamento desde 2002. 


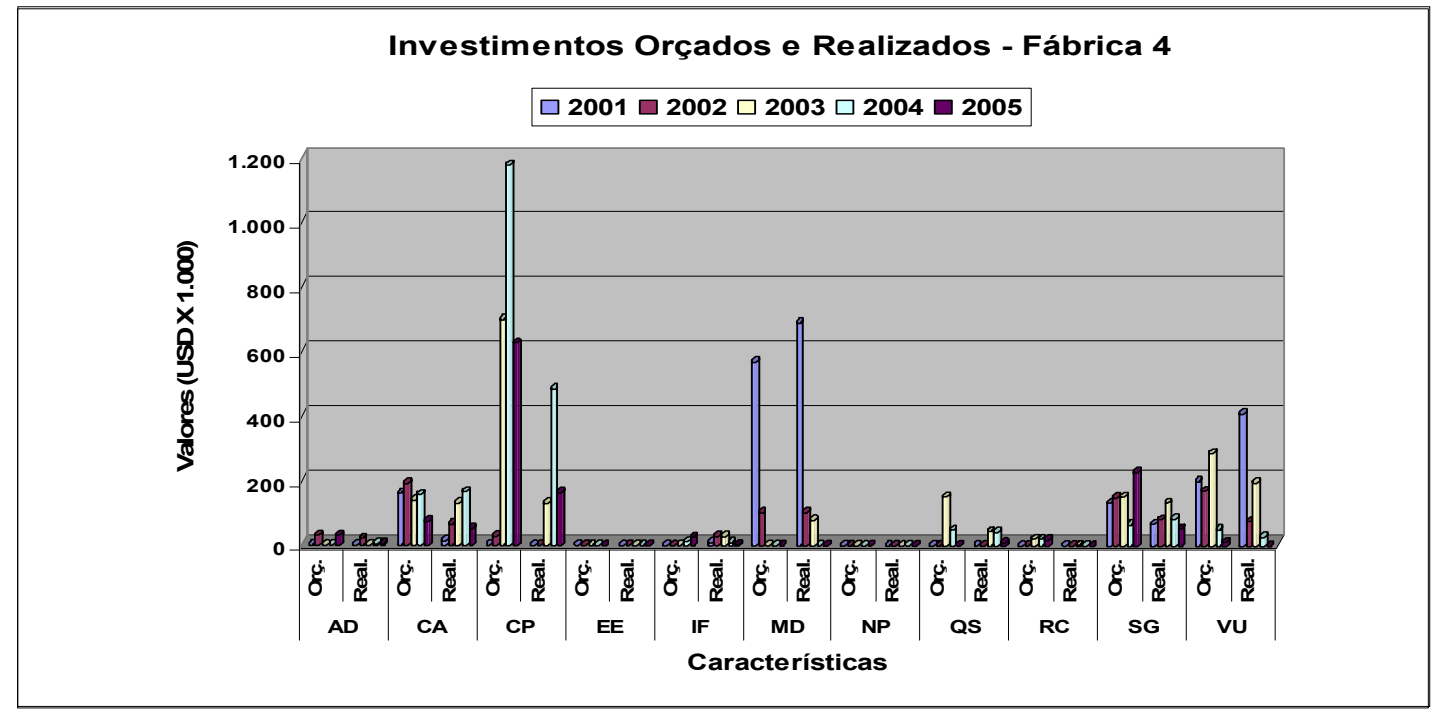

Gráfico 12 - Histórico de Investimentos em Projetos Orçados x Realizados - Fábrica 4

Considerando-se o grande número de projetos do tipo investimentos correntes, optou-se por selecionar para análise individual somente os projetos de maior valor.

A tabela 3 nos dá uma visão de como foi o desempenho dos 6 maiores projetos da organização objeto deste estudo nos últimos 5 anos.

Tabela 3 - 6 Maiores Investimentos Correntes - Atendimento a prazos e Orçamento

\begin{tabular}{|c|l|c|r|r|}
\hline Característica & \multicolumn{1}{|c|}{ Escopo } & Início & Término & $\begin{array}{r}\text { Valor Orçado } \\
\text { (U S\$ x1000) }\end{array}$ \\
\hline RC & Sistema Elétrico - Fábrica 1 & jan/00 & ago/04 & 4740,4 \\
\hline IF & ERP & abr/02 & $\mathrm{mai} / 03$ & 5080,0 \\
\hline NP & Adequação Estocagem - Fábrica 1 & set/03 & abr/05 & 4404,7 \\
\hline CP & $\begin{array}{l}\text { Desengargalamento de Unidade - } \\
\text { Fábrica 1 }\end{array}$ & set $/ 03$ & ago/05 & 3506,2 \\
\hline NP & $\begin{array}{l}\text { 1. Nova Unidade com Nova Tecnologia e } \\
\text { linha de produtos - Fábrica 2 }\end{array}$ & jan/99 & jun/04 & 2749,5 \\
\hline NP & $\begin{array}{l}\text { 2. Nova unidade com nova linha de } \\
\text { produtos - Fábrica 2 }\end{array}$ & ago/02 & mar/03 & 2427,3 \\
\hline
\end{tabular}

Nos casos selecionados, prazos e orçamentos foram cumpridos, tendo-se observado os seguintes problemas: o escopo do projeto do sistema elétrico foi alterado, tendo sido reduzido; o projeto do ERP teve problemas de qualidade na implantação e reclamações de usuários originaram outro projeto de melhorias; o projeto1 relativo a nova unidade produtiva, com nova tecnologia e nova linha de produtos sucedâneos teve a nova planta desativada por falta de mercado logo após a 
sua conclusão; no projeto 2 referente a nova unidade, com nova linha de produtos, o, foi constatado que o mercado potencial era muito maior que o previsto logo após sua conclusão, tendo sido necessário novo projeto para ampliação. A situação identificada aumenta os custos totais do projeto, subutiliza o pessoal envolvido e traz problemas de lay out na planta, que não tem espaço para ampliações.

\subsection{Análise do Portfólio}

Com o objetivo de analisar o balanceamento do portfólio de projetos da organização, nas perspectivas de $P \& D$, no que se refere a posição competitiva da empresa por negócio e segmento de mercado e nas perspectivas tecnológica, de inovação e financeira, foram desenvolvidos 8 diagramas de bolhas.

Relativamente à posição de P\&D, foram desenhados os diagramas das figuras 18 a 22. Tais diagramas mostram a matriz de atratividade por área de negócio e por segmento da organização.

Para montar as matrizes de atratividade, foram utilizados os dados de atratividade e posicionamento de um banco de dados da empresa que gerencia projetos por segmento, margem e área de negócio. Esse sistema foi desenvolvido pela empresa estudada após a realização de um projeto de reengenharia na área de P\&D em que 7 critérios para medir a atratividade e 7 para medir o posicionamento foram definidos. Para cada critério foi estabelecido um peso, definido segundo a experiência ou feeling dos 12 gerentes presentes nas reuniões. Foi utilizada uma escala de pontos de 1 a 5 para que se definisse o intervalo de variação de cada critério: baixo, médio ou alto. A multiplicação do peso de cada critério pela nota de cada projeto, utilizando-se a escala de valores proposta, define o valor da atratividade e do posicionamento por projeto. Esse método adotado pela organização, permite que os projetos do portfólio de P\&D sejam classificados e priorizados.

O diagrama da figura 18 foi desenhado com o objetivo de avaliar a situação da empresa em termos de atratividade por negócio. Este diagrama foi montado alocandose o posicionamento no eixo $X$ (horizontal) e a atratividade no eixo y (vertical). $O$ tamanho das bolhas representa a margem bruta do negócio e a cor representa cada uma das 4 áreas de negócio da empresa. Ao observar este diagrama, verifica-se que os negócios IS e T se situam entre as regiões de alto e médio posicionamento e 
média atratividade. $O$ negócio $S$ encontra-se na região de médio posicionamento e média atratividade e por último, observa-se que o segmento OPP situa-se entre as regiões de médio e baixo posicionamento e média atratividade. Segundo a definição da empresa para atratividade e posicionamento, vale a pena investir esforços no negócio intermediários de síntese (IS), sendo recomendado manter a estratégia atual e avaliar a disponibilidade de recursos para promover o crescimento. No caso dos segmentos de tensoativos ( $\mathrm{T}$ ) e solventes $(\mathrm{S})$, vale a pena investir esforços, porém com cautela, devendo-se avaliar se a aplicação de esforços é sustentável. É possível verificar que o negócio tensoativos está mais bem posicionado que o de solventes, sendo menores os riscos de investir esforços. Por último, ao analisar o negócio outros produtos de performance (OPP), identifica-se que a empresa se situa numa posição delicada, pois o negócio é medianamente atrativo, mas a empresa encontra-se entre as regiões de posicionamento médio e baixo, o que denota fraqueza em alguns segmentos que pertencem ao negócio.

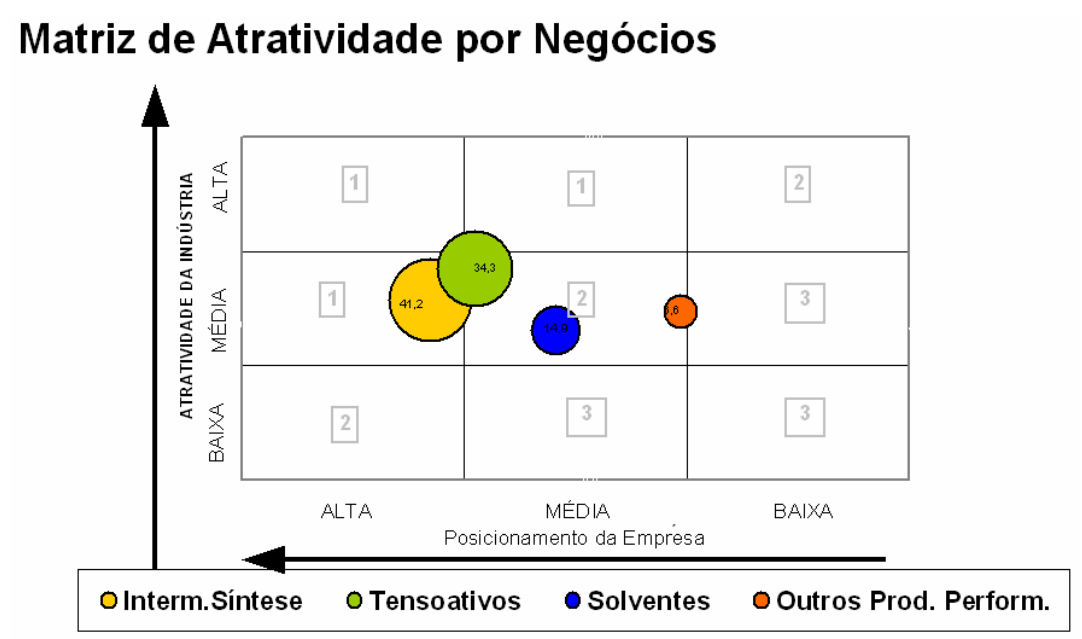

Figura 18 - Matriz de Atratividade por área de Negócio da Empresa

Com o objetivo de obter uma visão estratificada de cada negócio por segmento de mercado, foram montados os diagramas de bolhas apresentados nas figuras de 19 a 22, que apresentam o posicionamento por segmento de mercado em relação a atratividade da indústria. 


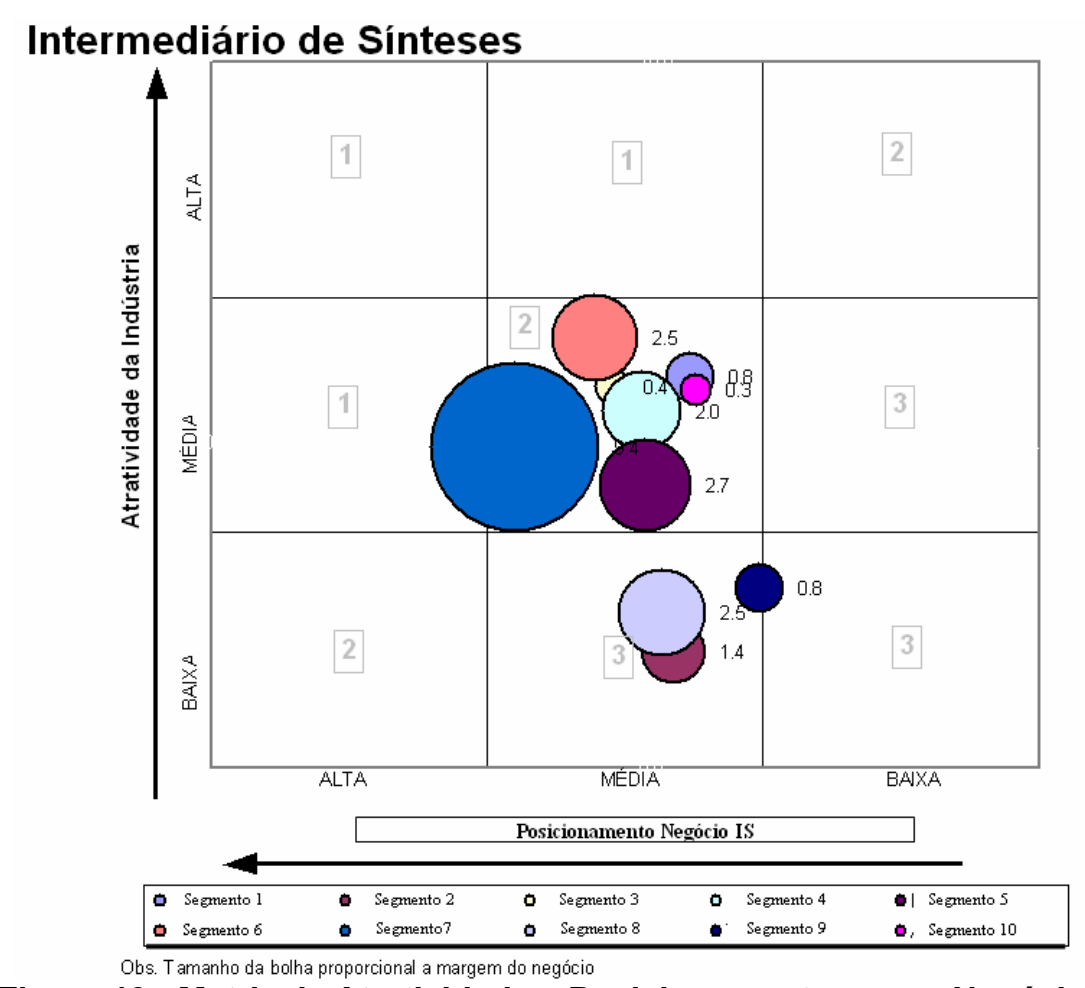

Figura 19 - Matriz de Atratividade x Posicionamento para o Negócio IS

Esses gráficos foram montados colocando-se no eixo horizontal o posicionamento da organização por segmento de mercado e no eixo vertical a atratividade da indústria. O diâmetro das bolhas representa a margem bruta dos segmentos e a cor das bolhas representa cada segmento do negócio selecionado.

A Figura 19 mostra que 7 dos 10 segmentos que pertencem ao negócio"Intermediários de Síntese" se situam região de médio posicionamento e média atratividade. Também se pode verificar que 3 segmentos se encontram na região de baixa atratividade e médio posicionamento. A figura 19 mostra que o negócio"Intermediários de Síntese" tem segmentos com expressiva margem de contribuição.

A atratividade e o posicionamento dos segmentos que pertencem ao negócio "Tensoativos" são apresentados na Figura 20. Dos 11 segmentos que compõem o negócio tensoativos, apenas o segmento 9 tem baixa atratividade, apesar de ter uma margem de contribuição significativa. Os demais segmentos se situam na região de média atratividade e médio posicionamento, sendo suas margens de contribuição em sua maior parte, significativas. 


\section{Tensoativos}

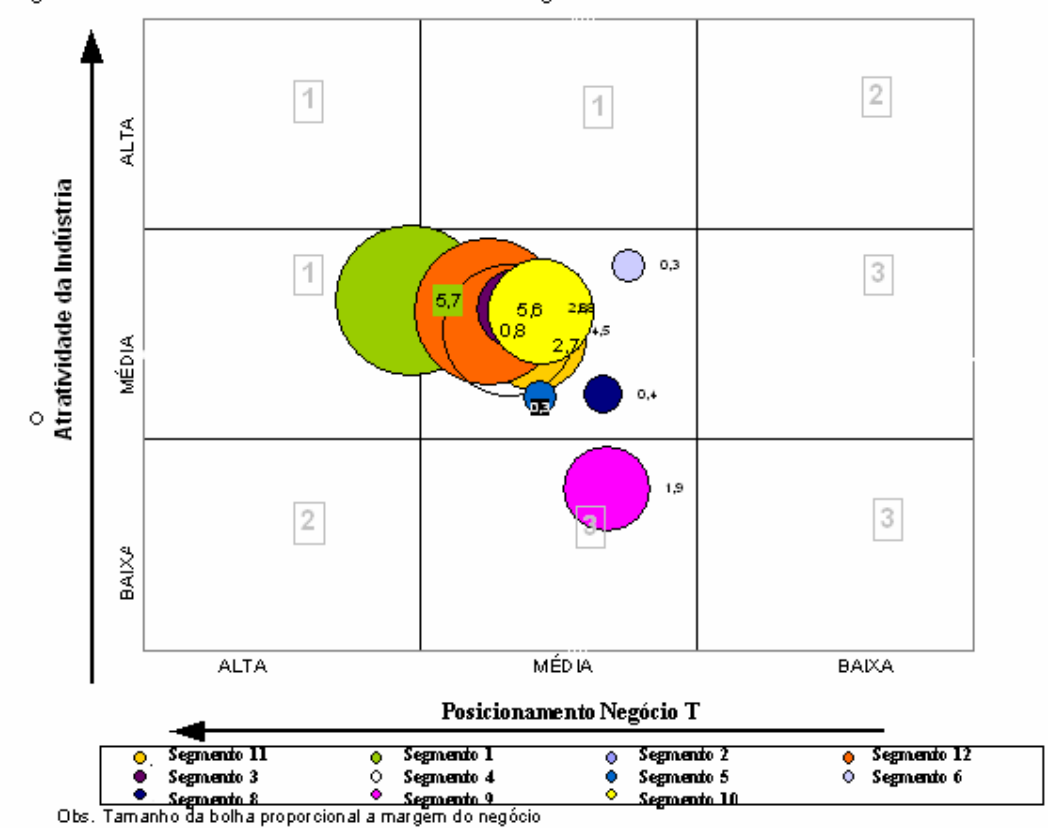

Figura 20 - Matriz de Atratividade x Posicionamento para o Negócio T

A Figura 21 apresenta a matriz de atratividade do negócio "Solventes". Também nesse negócio se verifica que a maior parte dos segmentos se situa na região de médio posicionamento e média atratividade, estando nessa situação 4 dos 9 segmentos que compõem o negócio. $O$ segmento 3 tem média atratividade, porém margem representativa e posicionamento entre médio e alto. Já o segmento 5 apesar da margem muito expressiva, tem posicionamento médio e atratividade entre média e baixa. Dois segmentos, 2 e 10, estão na região de média atratividade, porém baixo posicionamento, ou seja, apesar de serem segmentos interessantes, a empresa não está preparada para atendê-los e para enfrentar os concorrentes. Observa-se que nos segmentos 2 e 10 a margem de contribuição é pequena, talvez não valendo a pena investir esforços para melhorar o posicionamento. Entretanto são segmentos alternativos para escoar a produção de solventes, cujos produtos são commodities no estágio de maturidade do ciclo de vida. 


\section{Solventes e Líquidos para Freios}

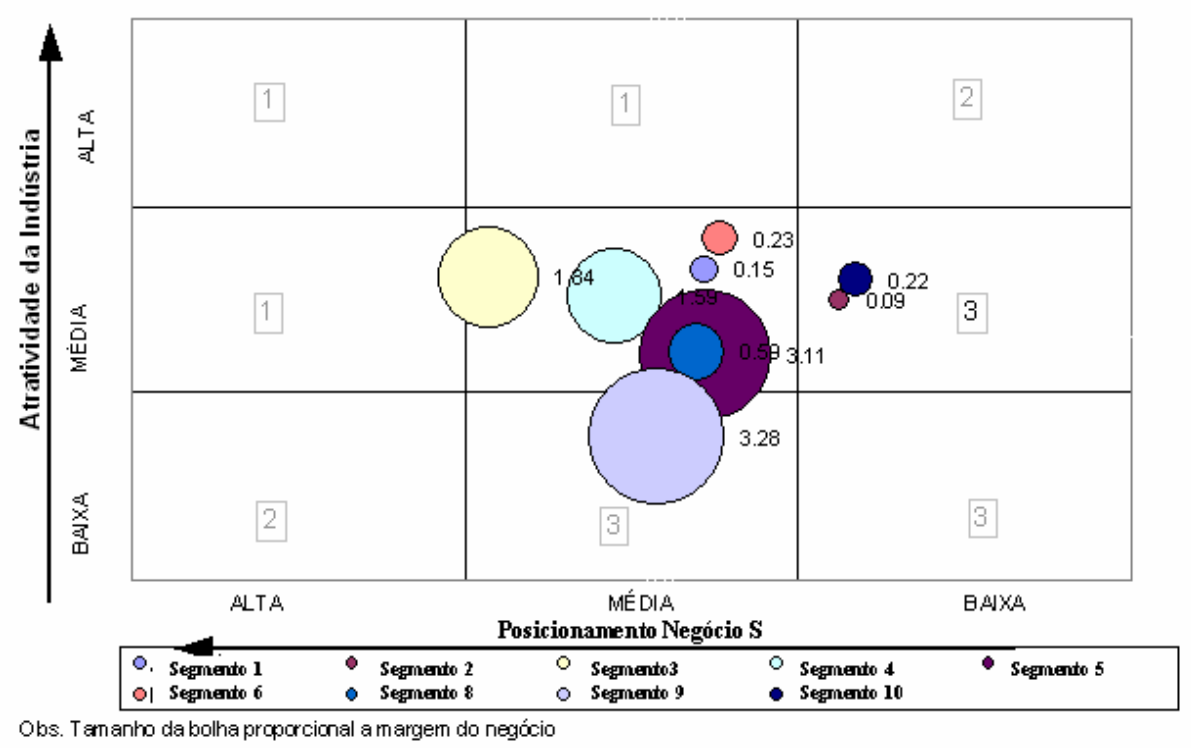

Figura 21 - Matriz de Atratividade x Posicionamento para o Negócio S

A figura 22 mostra que para o mercado outros produtos de performance existem muitos segmentos nas regiões de média atratividade e baixo posicionamento da empresa e um na região de baixa atratividade e posicionamento, sendo 7 dos 11 segmentos do negócio. Verifica-se que o segmento 9 se situa numa situação em que não vale a pena investir esforços, pois tanto a atratividade como o posicionamento são baixos. Apenas três segmentos, segmento 1, 3 e 6 têm médio posicionamento e média atratividade e margens de contribuição grandes.

Outros Produtos de Performance

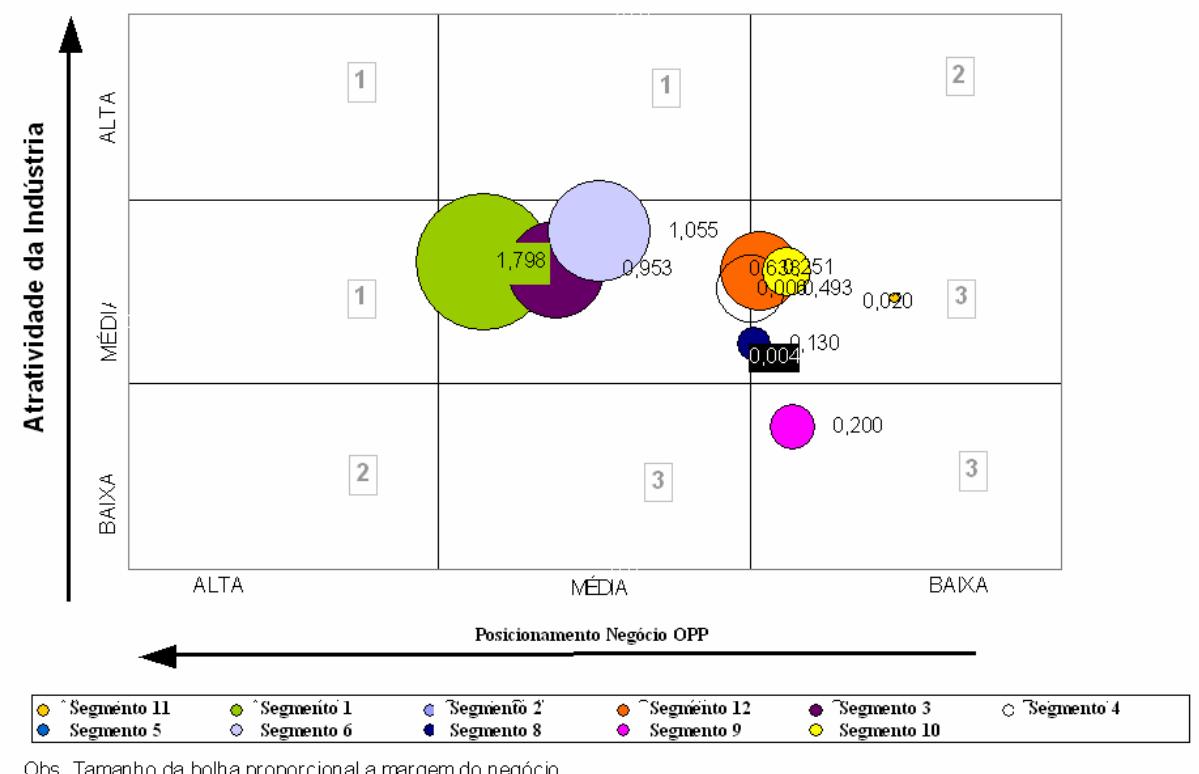

Figura 22 - Matriz de Atratividade x Posicionamento para o Negócio OPP 
A análise dos gráficos de 19 a 22 confirma o que já tinha sido identificado através do diagrama da Figura 18, ou seja, a existência de segmentos pouco atrativos para a empresa, especialmente para o negócio OPP. Contata-se que a empresa investe esforços em segmentos que não agregam valor e acaba por pulverizar demais seu portfólio de $P \& D$, levando a um grande número de projetos e a falta de foco nos projetos que são de real interesse para a organização.

Relativamente à maturidade das tecnologias empregadas, posição competitiva e grau de inovação foram desenvolvidos os diagramas 23 e 24 . A perspectiva financeira do portfólio é analisada levando-se em consideração a área de concentração dos investimentos, quando observados os riscos envolvidos e alavancagem do negócio, tal como se pode ver na Figura 25.

Os dados utilizados para desenhar os diagramas 23, 24 e 25 são referentes aos projetos da organização com investimento aprovado, do tipo correntes (Fases 3 e 4), executados em 2004. Este período foi escolhido para a coleta de dados devido ao fato da empresa ter iniciado a utilizar a EVA (Economic Value Added) como critério para seleção de projetos do portfólio a partir dessa data, não existindo essas informações em períodos anteriores. As cores das bolhas representam os diferentes projetos escolhidos para a análise. Já o tamanho das bolhas representa o valor do investimento aprovado.

Na figura 23 pode-se observar no diagrama de bolhas o perfil dos projetos, com investimento aprovado, da companhia em análise, como proposto por Roussel et al (1991). Neste diagrama, a probabilidade de sucesso foi alocada no eixo vertical e as fases do ciclo de vida (embrionária, crescimento, maturidade e declínio) no eixo horizontal. Pode-se ver através deste gráfico que grande parte dos projetos se situa na região compreendida entre crescimento e maturidade, e também que tais projetos estão entre as faixas de posição competitiva de favorável a predominante, estando a empresa numa posição confortável no curto prazo. Pode-se inferir que os dirigentes da organização analisada preferem trabalhar com projetos em que exista uma elevada probabilidade de sucesso.

Entretanto, em termos de balanceamento, observa-se que a ausência de projetos na fase embrionária pode representar uma perda de continuidade no longo prazo. 


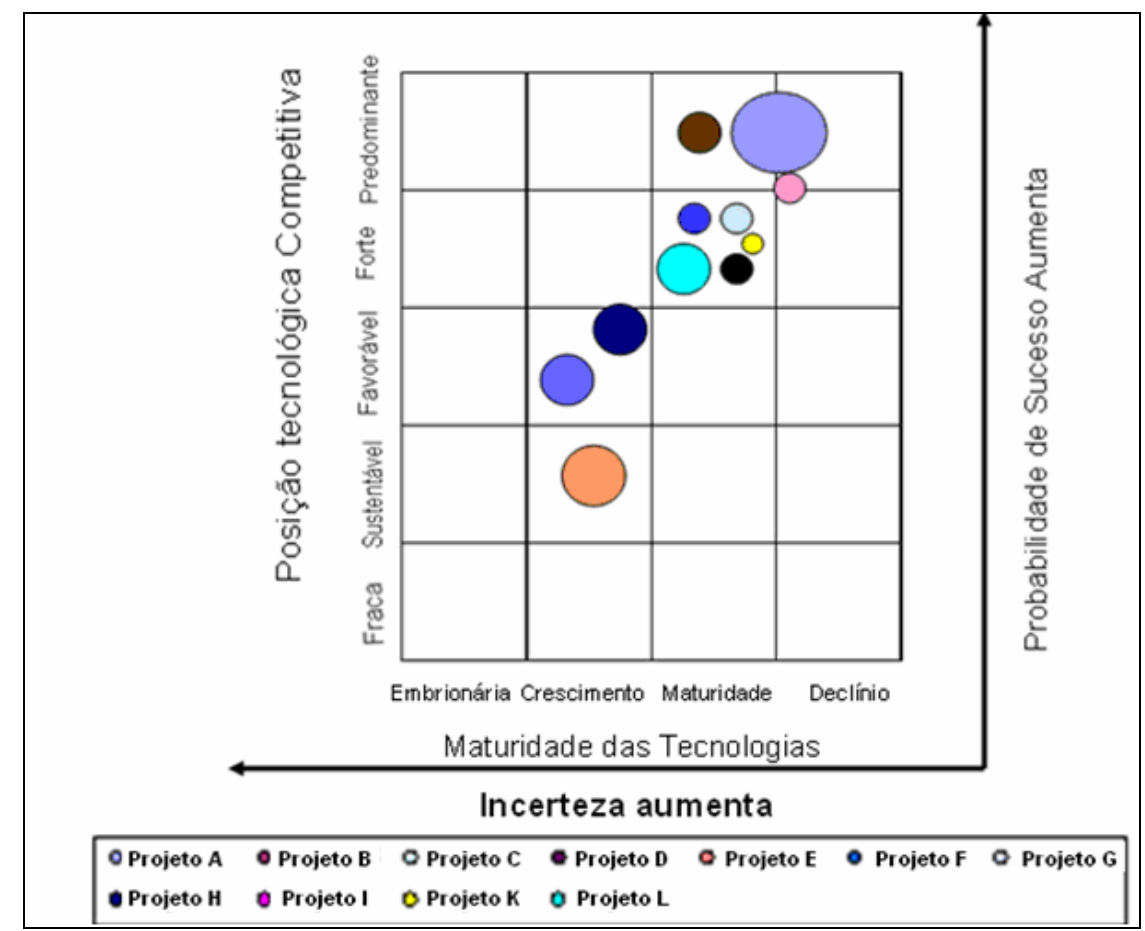

Figure 23 - Probabilidade de Sucesso x Fase do Ciclo de Vida (Fonte: Roussel et al, 1991; Dados da Empresa, 2004)

A figura 24, como proposto por Lager (2002), apresenta o grau de inovação para cada projeto com investimento aprovado da organização do ponto de vista dos processos existentes no mundo e no sistema produtivo da empresa. Como se pode ver, quase todos os projetos são relativos à otimização ou transferência de tecnologia.

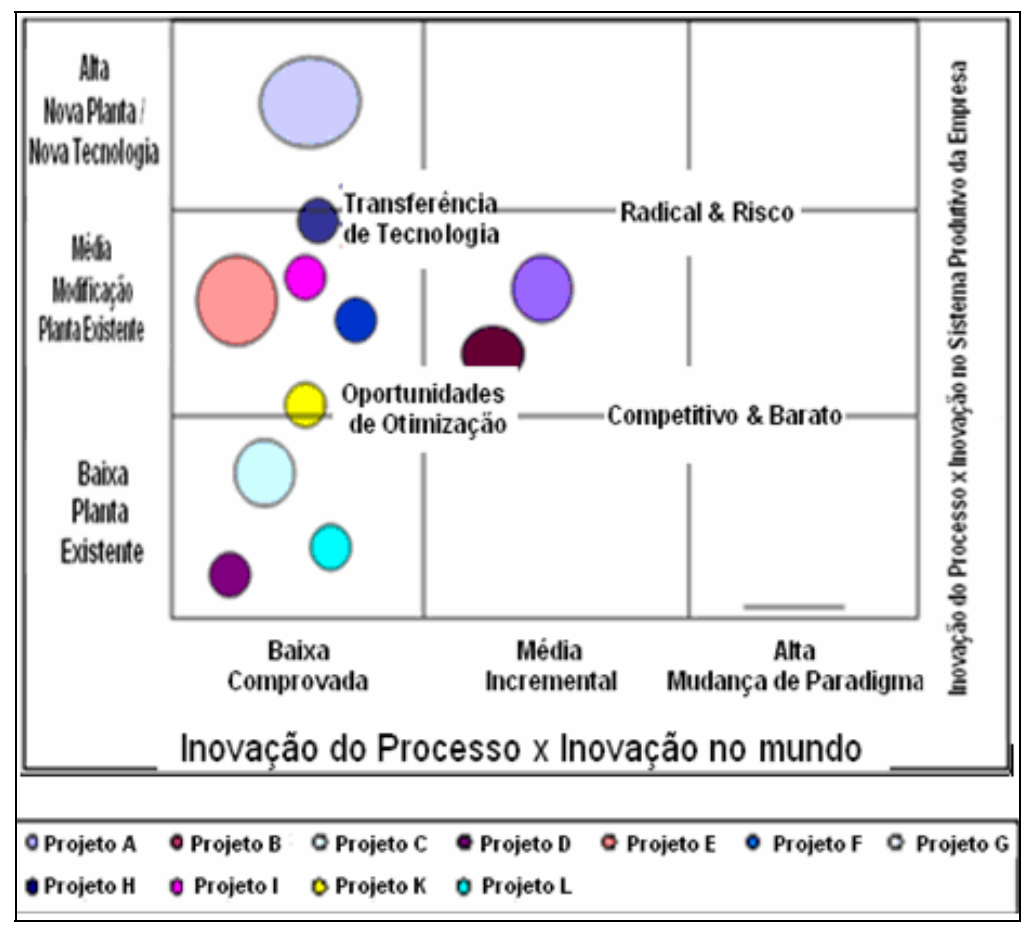

Figure 24 - Matriz de Processo para Classificação do Grau de Inovação na Indústria (Fonte: Lager, 2002; Dados de Empresa, 2004) 
A Figura 25 mostra um diagrama de bolhas que foi desenhado para o mesmo grupo de projetos usado nas figuras 23 e 24, alocando-se valores dos investimentos no eixo $X$ (horizontal) e EVA no eixo $Y$ (vertical). A duração dos projetos é representada pela área do circulo ou bolha e as cores são representações dos diferentes tipos de projetos, de acordo com a classificação interna da empresa estudada. Este diagrama foi classificado em quatro regiões, as quais representam o papel dos projetos no balanceamento do portfólio. Tais regiões foram designadas como: "Investimentos Marginais", "Investimentos Estratégicos", "Investimentos Tipo Plataforma" e "Suporte". O quadrante de "Investimentos Estratégicos" representa projetos de alto valor de investimento e EVA, e, em conseqüência, alta lucratividade. O quadrante de "Investimentos Tipo Plataforma" são os que alto valor, porém, baixo EVA, representando projetos que darão sustentação ao negócio para empreendimentos futuros, mas que sozinhos não trazem retorno. Os projetos do tipo "Investimentos Marginais" são aqueles de baixo valor de investimento, porém, alto EVA. Por último, o quadrante dos projetos de suporte concentra iniciativas que têm baixo investimento e baixo EVA, estando relacionadas com atividades de otimização e manutenção das operações. Observando-se a figura 25, pode-se perceber que grande parte dos projetos da empresa está posicionada na região de "investimentos marginais" e "suporte". Somente um projeto é estratégico e não há projetos do tipo plataforma. A distribuição apresentada nos leva a concluir que a companhia privilegia projetos de curta duração com baixo valor de investimento e elevado retorno sobre o valor investido. Não há equilíbrio no portfólio de projetos da organização.

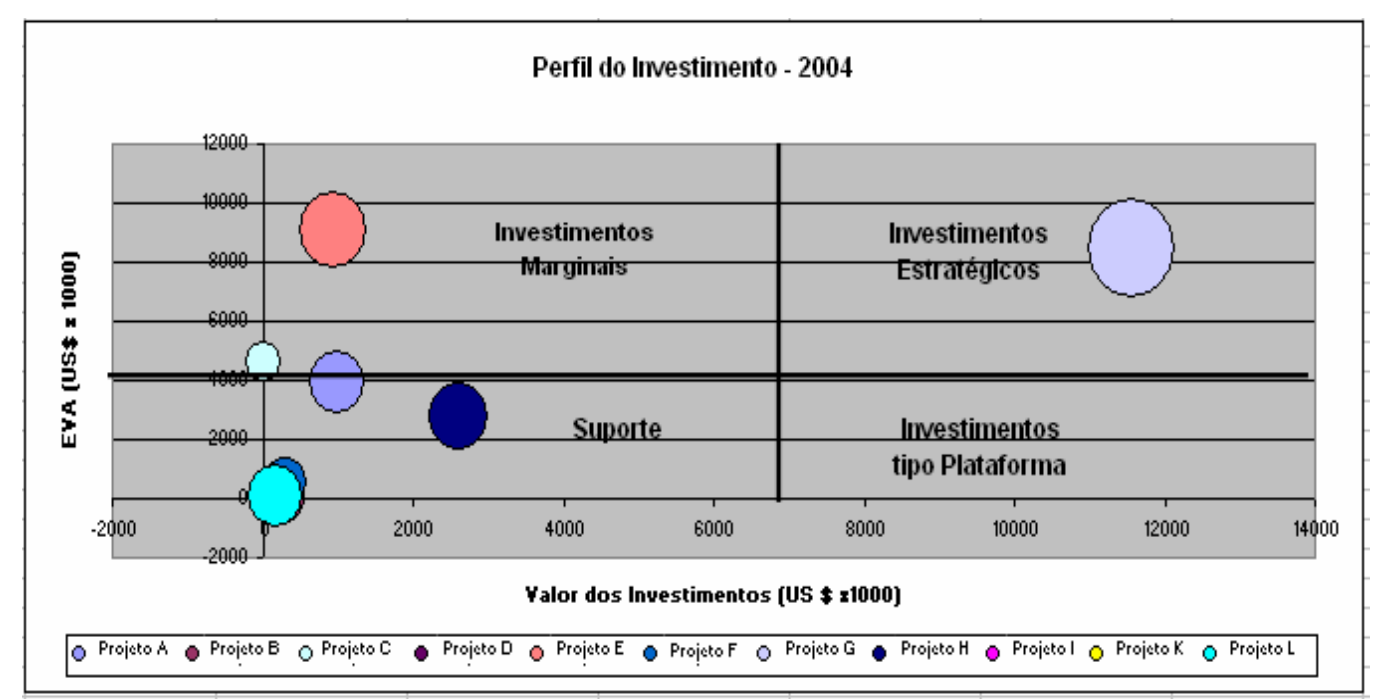

Figure 25 - Análise do Perfil de Investimentos Correntes da Empresa (Fonte: Lager, 2002; Dados da empresa, 2004) 
A análise da matriz de Lager (2002) dada pela Figura 25 confirma o que já foi observado através das figuras 23 e 24, ou seja, a companhia estudada utiliza como estratégia trabalhar com projetos em que a tecnologia é dominada, onde o risco é baixo, dando preferência aos projetos de otimização para aumento de sua lucratividade, o que confirma o perfil conservador da organização. Também é possível verificar que o portfólio da empresa, para o período estudado e corte adotado, é caracterizado como "sistêmico", de "suporte" e "incremental" quando analisado o nível de inovação dos projetos conforme Chesbrough \& Teece (1996), Christensen et al. (2001), Christensen \& Overdorf (2000), Cordero(1991) e Utterback (1994).

\subsection{Resultados das Entrevistas com os Tomadores de Decisão}

Para obter mais informações sobre a gestão de portfólio da empresa visando complementar a análise do portfólio obtida com a coleta de dados, adotou-se a técnica de realização de entrevistas com tomadores de decisão das áreas de P\&D, de acompanhamento de investimentos e coordenação de projetos de engenharia.

As entrevistas com os gerentes de P\&D mostraram que o enfoque estratégico para P\&D é insuficiente, faltando diretrizes claras de qual rumo seguir, gerando uma grande demanda por projetos e serviços sem foco e com controle inadequado.

Foi informado pelos especialistas dos segmentos das três gerências de aplicação (GAs) que os clientes e os vendedores fazem solicitações diretamente a eles. Eles inserem esses chamados no sistema de gestão de projetos e serviços da organização e eles mesmos definem os prazos e prioridades para a conclusão de tais serviços. Quando um serviço demanda recursos de outras áreas, especialmente engenharia, o pesquisador responsável pelo serviço indica a equipe que deve fazer parte das reuniões para estudos e desenvolvimento de projetos, se for o caso. Essa indicação dos participantes da equipe de um projeto sem uma análise do portfólio existente e definição de prioridades, gera gargalos nas áreas de engenharia.

Existe uma dificuldade das áreas de desenvolvimento de novos produtos e processos (GDPP) e engenharia de processos (GP) atenderem aos prazos estabelecidos pelas GAs, devido a concorrência técnicos dos diferentes segmentos pelos mesmos recursos de desenvolvimento de processos e produtos, e pela, planta 
piloto (unidade igual a industrial, em escala menor, onde são feitos os testes de novos produtos e processos).

O fato dos pesquisadores e gerências de P\&D serem divididos por segmentos de mercado e as áreas de engenharia serem organizadas por processo produtivo, por unidade industrial e por investimento causa dificuldades de integração e entendimento entre áreas, que são complementares. A área de pesquisa tem como objetivo principal atendimento ao cliente em prazos muito curtos, para garantir sua satisfação. Por outro lado, as áreas de engenharia têm foco em continuidade operacional e elaboração de projetos que garantam a qualidade dos produtos, a capacidade projetada e a segurança das instalações. Para executar suas tarefas a engenharia precisa de prazos longos.

Os pesquisadores e gerentes são unânimes no que se refere ao excesso de serviços de assistência técnica, fato que reduz muito o tempo disponível para o desenvolvimento de novas aplicações e novos produtos que venham a melhorar o posicionamento da empresa em mercados de grande interesse, abrir novos mercados e trabalhar com inovações.

Segundo os gestores das áreas de P\&D e engenharia, para atender aos diferentes negócios da organização, são necessárias diferentes competências tecnológicas, tais como capacidade de inovação, habilidades técnicas específicas, instalações adequadas, intimidade com os clientes e conhecimento dos fenômenos químicos e físico-químicos aplicados aos diferentes produtos, processos, aplicações. Também são necessários conhecimentos sobre tendências tecnológicas, legislação e sobre as plantas existentes e como operá-las. Para os gestores a empresa tem muitos pontos fortes, porém, apresenta gaps quanto a capacidade de inovação, desenvolvimento de processos e aplicações e conhecimento dos fenômenos químicos e físico-químicos para diversos segmentos e aplicações.

Em entrevista com os tomadores de decisão das áreas responsáveis pela monitoração dos investimentos e coordenação dos projetos de engenharia, foi possível verificar que com freqüência ocorre mudança na seqüência de execução dos projetos, devido a pressões da área comercial, que negocia prazos unilateralmente, sem levar em conta a existência de gargalos de recursos humanos para a execução dos projetos.

De acordo com os entrevistados, também é comum a variação de escopo dos projetos, já que são iniciados prematuramente. Outro ponto destacado é que a equipe 
responsável pela implantação dos projetos de engenharia é pequena, sendo 3 coordenadores de implantação na matriz e mais 12 engenheiros de diferentes especialidades que trabalham nas fábricas. Estes, entretanto, dividem seu tempo com a tarefa de administrar projetos e executar tarefas que compõem a rotina de manutenção.

Os dados coletados apontam para um grande número de projetos tanto de produto como de engenharia com natureza de investimentos do tipo "correntes", o que resulta em perda de foco. Já os investimentos estratégicos são em pequeno número, com planejamento, execução e acompanhamento detalhados. Mesmo assim, sofrem variações de escopo, o que prejudica o cumprimento de prazos e orçamentos.

Como os projetos de novos produtos e aplicações, otimizações de produtos existentes e projetos de aumento de capacidade têm seu início nas áreas de P\&D, é fácil supor que o fato da área de P\&D não ter filtros para seleção e priorização de projetos interfira na engenharia, quando da execução dos projetos com investimento aprovado, sendo um fator de perturbação a mais.

O fato de não existir uma metodologia para priorização dos projetos de produto e de engenharia de natureza "correntes", nem uma sistemática de revisar a lista de projetos ativos e dar feedback, indica um problema que pode levar a atrasos no cronograma, execução dos projetos errados, perda de competitividade e rentabilidade e estouro no orçamento, todos problemas encontrados na organização estudada.

As informações levantadas e apresentadas nesta análise denotam a falta de um processo de gestão de portfólio nesta organização. Muitos aspectos-chave sobre gestão de portfólio não foram constatados no processo de tomada de decisão de ações de curto prazo.

\subsection{Análise dos Objetivos dos Stakeholders e Trade-offs da Organização}

Para a organização em estudo, os seguintes stakeholders foram identificados: Acionistas, Clientes, Fornecedores, Empregados/Fábricas, Fontes de Financiamento, Mídia, Comunidade Externa, Órgãos de Tratam de Aspectos Legais e Políticos e Governo. 
Esses stakeholders têm diferentes objetivos, em muitos casos convergentes e outras vezes divergentes.

O quadro 6, a seguir, apresenta os principais objetivos de cada stakeholder da organização em análise e quais as maneiras de atender à sua demanda através da execução de projetos, conforme a classificação adotada pela empresa.

As diferentes possibilidades de atendimento aos objetivos dos stakeholders são traduzidas pela empresa como idéias que são propostas e que podem ou não se transformar em projetos da organização.

Para atendimento aos diversos negócios da empresa é preciso conhecer quais os fatores são qualificadores e quais são ganhadores de pedidos. Os objetivos dos clientes apresentados na Quadro 6 se traduzem nos fatores "ganhadores de pedidos" para cada negócio. Verifica-se que esses negócios estão em estágios diferentes quando se observa os objetivos de desempenho: custo, qualidade, prazos, flexibilidade, confiabilidade e inovação. Duas áreas de negócio valorizam a inovação e a flexibilidade, mas a empresa ainda está no estágio intermediário entre qualidade e flexibilidade, não tendo projetos de inovação, como observado no item 4.5 e 4.6.

\begin{tabular}{|c|c|c|c|c|}
\hline \multicolumn{2}{|c|}{ Stakeholder } & Objetivos & Projetos para atender aos objetivos & $\begin{array}{l}\text { Tipo } \\
\text { Projeto }\end{array}$ \\
\hline & Acionistas & $\begin{array}{l}\text { Melhor remuneração do Capital } \\
\text { empregado (EBDTA, EVA, Lucro) } \\
\text { Manutenção das Instalações }\end{array}$ & $\begin{array}{l}\text { Aumento de vendas (volume); } \\
\text { Aumento da margem; } \\
\text { Redução de custos operacionais através de otimizações de produtos e processos } \\
\text { e manutenção das instalações; } \\
\text { Aumento da Produtividade ( redução de perdas/ desperdícios) }\end{array}$ & $\begin{array}{l}\text { CP, RC, P\&DE, } \\
\text { VU, MD,SG }\end{array}$ \\
\hline \multirow{4}{*}{ 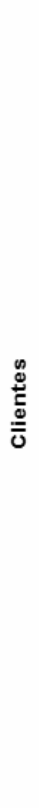 } & $\begin{array}{c}\text { Negócio } \\
\text { Intermediários } \\
\text { de Síntese }\end{array}$ & $\begin{array}{l}\text { Preço baixo dos Produtos } \\
\text { Receber Serviços de Alta Qualidade } \\
\text { Agregados aos Produtos }\end{array}$ & $\begin{array}{l}\text { Otimização de Processos e Produtos } \\
\text { Capacitação do Pessoal técnico nos principais mercados de atuação } \\
\text { Oferecer serviços de Assitência Técnic a de Qualidade } \\
\text { Modificação/ adequação de instalações Existentes } \\
\text { Modemização das Unidades/Automação }\end{array}$ & $\begin{array}{l}\text { MD, VU, } \\
\text { QS, RC }\end{array}$ \\
\hline & Tensoativos & $\begin{array}{l}\text { Diversificação de Produtos/Flexibilidade de } \\
\text { MIX; Produtos Inovadores (Aplicação, } \\
\text { formulação e serviços); } \\
\text { Flexibilidade de Entrega }\end{array}$ & $\begin{array}{l}\text { Desenvolvimento de Aplicações; } \\
\text { Otimização e Desenvolvimento de produtos e processos; } \\
\text { Modificação/ adequação de instalações existentes } \\
\text { Assistência técnica capacitada p/atenção especial a cada cliente chave } \\
\text { Projetos de Novas Fábricas/ Unidades } \\
\text { Aqusição de Novas Plantas }\end{array}$ & $\begin{array}{l}C P, N P \\
P D \& E, M D \\
A D, Q S\end{array}$ \\
\hline & Solventes & $\begin{array}{l}\text { Soluções Customizadas (es pecialidades); } \\
\text { Desenvolvimento de Produtos Ecológicos; } \\
\text { Preço Baixo }\end{array}$ & $\begin{array}{l}\text { Capacitação de Pessoal no Desenvolvimento de Formulações } \\
\text { Treinamento em Normas reguladoras do Setor; } \\
\text { Capacitação e acompnhamento de Avanços Tecnológicos desses mercados; } \\
\text { Otimização e Desenvolvimento de Produtos e Porc essos } \\
\text { Projetos de Novas Fábricas/ Unidades } \\
\text { Projetos de Desenvolvimento de Novas Aplicações } \\
\text { Aquisição de tecnologia } \\
\text { Adequação/ modernização das unidades existentes } \\
\text { Manutenção das instalações }\end{array}$ & $\begin{array}{l}\mathrm{VU}, \mathrm{CP} \\
\mathrm{MD}, \mathrm{AD}, \mathrm{PD} \& \mathrm{E}, \\
\mathrm{QS}, \mathrm{CA}\end{array}$ \\
\hline & $\begin{array}{l}\text { Outros Produtos } \\
\text { de Performance }\end{array}$ & $\begin{array}{l}\text { Inovação } \\
\text { Flexibilidade de MIX }\end{array}$ & $\begin{array}{l}\text { Projetos de Desenvolvimento de Novas Aplicaç̃̃es; } \\
\text { Capacitação de Pessoal no desenvolvimento de novas formulações, produtos e } \\
\text { processos; } \\
\text { Modificaçõ̃es/ Adequaç̃̃es de Unidades Existentes } \\
\text { Construção de Novas Fábrica/ Unidades } \\
\text { Aquisição de Novas Plantas com novos produtos e processos } \\
\text { Aquisição de Tecnologia }\end{array}$ & $\begin{array}{l}\mathrm{CP}, \mathrm{AD}, \\
\mathrm{NP}, \mathrm{QS}\end{array}$ \\
\hline
\end{tabular}




\begin{tabular}{|c|c|c|c|}
\hline Fomecedores & $\begin{array}{l}\text { Contratos de Longo Prazo; } \\
\text { Parcerias. }\end{array}$ & $\begin{array}{l}\text { Projetos de Novas Fábricas/ Unidades } \\
\text { Aumento no Volume de Vnedas } \\
\text { Desenvolvimento de Fornec edores }\end{array}$ & $\begin{array}{l}\text { AD (logística/ } \\
\text { Informática), CP }\end{array}$ \\
\hline Empregados & $\begin{array}{l}\text { Aumento Salário ( fixo ou varável (PLR) } \\
\text { Segurança no Trabalho } \\
\text { Respeito aos Meio Ambiente; } \\
\text { Atendimento aos Aspéctos Legais; } \\
\text { Capacitação; } \\
\text { Empregabilidade }\end{array}$ & $\begin{array}{l}\text { Aumento de Vendas em volume e margem; } \\
\text { Aumento da produtividade com redução de custos } \\
\text { Modemização e automação das Unidades } \\
\text { Capacitação dos funcionários nas novas tecnologias } \\
\text { Investimentos em Manutenção das Instalações }\end{array}$ & $\begin{array}{l}\text { MD, VU, QS, } \\
R C, S G, C A\end{array}$ \\
\hline $\begin{array}{l}\text { Comunidade } \\
\text { Externa }\end{array}$ & $\begin{array}{l}\text { Segurança; } \\
\text { Respeito ao Meio Ambiente; } \\
\text { Aumento do } n^{\circ} \text { de Empregos }\end{array}$ & $\begin{array}{l}\text { Para atender segurança, são necessários investimentos em manutenção/ } \\
\text { substituição de equipamentos críticos (segundo critérios de risco de explosão, } \\
\text { incêndio, perda de produção, contaminação de produto e meio ambiente, etc); } \\
\text { Respeito ao meio ambiente exige projetos relacionados c/ tecnologia ambiental, } \\
\text { educaçãa ambiental e ISO 14000) }\end{array}$ & $\begin{array}{l}\text { SG, VU, MD, CA, } \\
\text { RC }\end{array}$ \\
\hline $\begin{array}{c}\text { Órgãos } \\
\text { Governamentais }\end{array}$ & $\begin{array}{l}\text { Aumento do } n^{0} \text { de Empregos; } \\
\text { Maior Arrecadação de Impostos; } \\
\text { Respeito aos Meio Ambiente; } \\
\text { Atendimento aos Aspéctos Legais. }\end{array}$ & $\begin{array}{l}\text { Emprego depende de projetos de crescimento da empresa através da construção } \\
\text { de novas fábricas, ampliações de fábricas existentes e aquisições. } \\
\text { A arrecadação de impostos é alavancada pelo aumento no lucro da empresa, que } \\
\text { depende do aumento do faturamento através de aumento de margem bruta ou do } \\
\text { volume de vendas. O aumento de margem implica em aumento de preços ao } \\
\text { consumidor ou redução de custos de fabricação. } \\
\text { Atendimento a legislação depende de manutenções preventivas relacionadas com } \\
\text { Nomas (Ex: NR 13), BPF, obtenção de livenças de instalação, operação, registros } \\
\text { de marcas, etc. } \\
\text { Respeito ao meio ambiente já foi mencionado no item anterior. }\end{array}$ & $\begin{array}{l}\text { CP, } \\
\text { aumento de } \\
\text { vendas, } \\
\text { CA, SG, QS }\end{array}$ \\
\hline
\end{tabular}

Quadro 6 - Matriz de Stakeholders/Objetivos/Tipos de Projetos (Fonte: Elaborado pelo autor)

Conforme Boldwijn e Kumpe (1990), pelo fato de uma empresa ainda não dispor de algumas competências, que Ihe proporcionarão ganhos de longo prazo, existem trade-offs de curto prazo que ela precisa exercitar para atuar nos mercados/negócios que exigem essas competências. Segundo os autores, na linha evolutiva, primeiro as empresas competem por preço, depois qualidade, a seguir flexibilidade e por último como empresa inovadora, não sendo obrigatório que se chegue até o último estágio. Essa decisão vai depender da estratégia competitiva da empresa e do mercado onde ela atua.

No caso da empresa estudada, identificaram-se os trade-offs apresentados no quadro 7, podendo estes serem trade-offs para um mercado e não para outro.

A análise do quadro 7 nos leva a mesma conclusão de Slack (1998) em que os gestores das organizações tendem a misturar trade-offs de desempenho operacionais e econômicos. Pelo quadro 7 pode-se observar trade-offs relacionados com inventários, custos de manufatura, trade-offs relacionados com atendimento a especificação, conformidade de produto, variedade e entrega. Verifica-se a existência não só de trade-offs de produção, mas também de diferentes partes da empresa. A flexibilidade também parece ser o fator chave de superação dos trade-offs, pois permite o ajuste de capacidade às necessidades da organização, conforme proposto por Slack (1998). 


\begin{tabular}{|l|c|l|c|}
\hline Flexibilidade de Mix & $\uparrow$ & Capacidade Produtiva & $\downarrow$ \\
\hline Flexibilidade de Mix & $\uparrow$ & Custos de Produção & $\uparrow$ \\
\hline Capacidade de Produção & $\uparrow$ & Estoques & $\downarrow$ \\
\hline Estoques & $\uparrow$ & Custos com Armazenagem & $\uparrow$ \\
\hline Custos de Manutenção & $\uparrow$ & Custos de Perdas de Produção & $\downarrow$ \\
\hline $\begin{array}{l}\text { Investimentos em Ampliação } \\
\text { das Instalações }\end{array}$ & $\uparrow$ & Custos com Manutenção & $\uparrow$ \\
\hline Custos com Manutenção & $\uparrow$ & Segurança Industrial & $\uparrow$ \\
\hline Segurança Industrial & $\uparrow$ & Risco de Acidentes & $\downarrow$ \\
\hline Qualidade & $\uparrow$ & $\begin{array}{l}\text { Custos de Rejeitos, Não } \\
\text { Conformidades, reprocessos. }\end{array}$ & $\downarrow$ \\
\hline No. Empregados & $\downarrow$ & Automação & $\uparrow$ \\
\hline Automação & $\uparrow$ & Qualidade & $\uparrow$ \\
\hline Capadidade de Inovação & $\uparrow$ & $\begin{array}{l}\text { Investimentos em Capacitação } \\
\text { de Pessoal }\end{array}$ & $\uparrow$ \\
\hline $\begin{array}{l}\text { Desenvolvimento Produtos/ } \\
\text { Processos }\end{array}$ & $\uparrow$ & $\begin{array}{l}\text { Investimentos em. Novas. } \\
\text { Instalações / Modificação } \\
\text { instalaçes existentes. }\end{array}$ & $\uparrow$ \\
\hline Margem & $\downarrow$ & Impostos & $\uparrow$ \\
\hline Preço Matéria-Prima & $\uparrow$ & Custo Produtos & $\uparrow$ \\
\hline $\begin{array}{l}\text { Tempo p/ livre Manutenções } \\
\text { Preventivas }\end{array}$ & $\uparrow$ & Tempo livre p/ Produção & $\downarrow$ \\
\hline Restrições Ambientais & $\uparrow$ & $\begin{array}{l}\text { Investimentos Controle } \\
\text { Ambiental }\end{array}$ & $\uparrow$ \\
\hline
\end{tabular}

Quadro 7 - Trade-Offs da Organização em estudo

(Fonte: Empresa, adaptado pelo autor)

\subsection{Conclusões sobre o Portfólio da Organização}

Comparando-se os resultados do caso estudado com a teoria, verifica-se que a empresa utiliza critérios de seleção de projetos conforme proposto por McFarlan (1981) quanto ao tamanho e conhecimento da tecnologia. Utilizando-se a matriz proposta por Lager (2002) para analisar o portfólio da organização em questão, observa-se que grande parte dos projetos da empresa se encontra nas regiões de baixo e médio risco, sendo do tipo oportunidades de otimização e transferência de tecnologia. Esta estratégia caracteriza a incerteza no cenário econômico do país e poderá afetar a companhia no longo prazo. Os fatores abordados por Jolly (2003) para seleção de projetos, apresentados no quadro 1 deste trabalho, também foram identificados na empresa estudada. 
Os diagramas de bolhas analisados por negócio e por segmento, conforme Cooper et al. (2001), mostram que grande parte do portfólio de PD\&E encontra-se nas regiões de médio posicionamento e média atratividade, tendo sido encontrados segmentos nas regiões de médio e baixo posicionamento. Essa observação exige uma reflexão dos dirigentes no sentido de avaliar se a empresa tem investido em segmentos e produtos pouco interessantes do ponto de vista da estratégia da organização e desafia os gestores a proporem ações que melhorem o posicionamento de seus produtos. Neste ponto, é preciso que os gestores avaliem os trade-offs existentes na questão de posicionamento versus atratividade. Se for de interesse para a organização entrar em um mercado muito atrativo, mas onde seu posicionamento é baixo, um esforço deverá ser feito para que em um período curto de tempo a empresa invista em capacitação de pessoal, logística, infra-estrutura, melhorando seu posicionamento de baixo para médio ou alto, caso contrário poderão ocorrer mais perdas que ganhos no longo prazo, conforme observado em estudos realizados por Boldwijn \& Kumpe (1990) e Slack (1998).

Percebe-se, ainda, que para o período de coleta de dados, a gestão e seleção dos projetos de PD\&E apresentavam enfoque estratégico insuficiente, faltavam diretrizes claras para pesquisa, desenvolvimento e engenharia (PD\&E) e a demanda por serviços técnicos e projetos não tinha foco nem controle adequados. Essa situação, nos projetos nas fases 1 e 2, acabava ocasionando perturbações nas fases 3 e 4, sendo provavelmente uma das causas do grande número de projetos de engenharia e das constantes mudanças de escopo. Essa observação confirma proposição de Carvalho e Laurindo (2003) de que a escolha de uma estratégia repercute nas dimensões estratégicas, exigindo trade-offs. $\mathrm{O}$ fato da empresa não ter uma estratégia clara de desenvolvimento acaba por influenciar suas decisões quanto ao grau de especialização necessário, política de canal, qualidade de produto, liderança tecnológica e integração vertical. A literatura sugere ações para as organizações manterem o foco nas atividades que agregam mais valor. Carvalho e Laurindo (2003) propõem o uso da análise SWOT para que a empresa leve em consideração seus pontos fortes e fracos para a definição da estratégia e a escolha dos grupos estratégicos onde se deseja competir. Prahalad e Hamel (1990) sugerem que as organizações criem um comitê de gerentes de alto escalão para identificar, cultivar e monitorar o desenvolvimento de produtos e competências essenciais à 
organização. As ações propostas pela literatura não foram observadas durante a etapa de coleta de dados para a execução deste trabalho.

A gestão dos projetos selecionados com investimento aprovado, nas Fases 3 e 4, tem sua gestão feita por dois critérios básicos: o financeiro e o estratégico, confirmando as observações de Cooper, Edgett e Kleinschmidt (2001) de as as empresas utilizam múltiplos métodos de gestão de portfólio, sendo o financeiro o mais empregado. Neste caso, observa-se, para os dados coletados, a ausência de regras de priorização para os projetos do portfólio; tendo como conseqüência, freqüentes alterações de escopo, atrasos no cronograma, estouros de orçamentos e problemas de qualidade pós-implantação. Todos esses problemas são citados pela literatura por McFarlan (1991), Elton e Roe (1998), Goldratt (1998), entre outros e foram constatados.

O fato de existirem muitos projetos tira o foco da organização. As áreas de PD\&E da organização têm um "viés" de atuar como área de apoio, ao invés de focar suas atividades em ações que geram vantagens competitivas. Não foi observado na organização o uso de um método estruturado para a identificação dos critérios competitivos mais importantes e sua avaliação perante a concorrência, como proposto no modelo de lacunas de Slack (1993). Apenas em 2005, após o desenvolvimento do sistema de gerenciamento de projetos e serviços (GPS) a empresa passou a controlar, através de uma ferramenta corporativa, seu portfólio de projetos de P\&DE, não tendo sido possível observar os benefícios trazidos por sua implementação neste trabalho.

Ao analisar o aspecto inovação, segundo a natureza definida por Chesbrough \& Teece (1996), é possível concluir pelos dados analisados que a empresa adota a técnica de inovação sistêmica, sempre em complementaridade com outras inovações. Quando adotamos a idéia de inovação concebida por Christensen \& Overdorf (2000), percebe-se que a empresa estudada se utiliza de técnicas de inovação de sustentação, tendo o objetivo de melhorar o desempenho de tecnologias existentes com produtos e mercados conhecidos. Esse fato é comprovado pelos diversos projetos de otimização encontrados no portfólio analisado. Por último, ao analisarmos os critérios de inovação de Utterback (1994), verifica-se que o portfólio da empresa prima por inovações incrementais, não existindo inovações radicais. Essa constatação vai ao encontro com o que os entrevistados definiram como sendo "o posicionamento 
estratégico da organização em termos de P\&D", sendo uma empresa do tipo "Primeira Seguidora" e não inovadora. 


\section{MODELO DE SELEÇÃO DE PORTFÓLIO PROPOSTO}

Considerando-se as conclusões resultantes da análise do portfólio estudado, propôs-se o desenvolvimento, aplicação e validação de um modelo de gestão de portfólio de projetos para a organização estudada com o intuito de verificar sua utilidade e eficácia na redução do número de projetos de P\&D e de projetos com investimentos aprovados, reduzindo o grau de complexidade da gestão do portfólio e permitindo que a tomada de decisão ocorra de maneira estruturada, segundo critérios lógicos, pré-estabelecidos, e permita, ainda, o atendimento dos stakeholders da organização nas diferentes fases do seu ciclo de vida. Em outras palavras, o modelo proposto deve mudar o "viés" dos projetos de PD\&E de "apoio à estrutura existente" para "área cuja finalidade principal seja identificar e implantar projetos que tragam vantagens competitivas a organização". O modelo deve, também, permitir a obtenção de um portfólio de projetos alinhado com a estratégia da empresa e balanceado quanto aos aspectos de maturidade da tecnologia, grau de inovação e perfil de investimentos.

Além disso, sugeriu-se criação de equipes distintas para atendimento à rotina de manutenção e atividades de implantação de projetos.

Como ferramenta para auxiliar a organização a selecionar seus projetos de acordo com sua estratégia, propôs-se neste trabalho adaptar os modelos sugeridos por Archer \& Ghasemzadeh (1999) e Greiner et al (2003), que utilizam o método AHP para selecionar e priorizar o portfólio de produtos e projetos, integrado a programação inteira, para otimizar o portfólio, considerando-se as restrições e dependências dos projetos.

A Figura 26 apresenta o modelo estrutural para a seleção e priorização de projetos proposto nesse trabalho. Existem dois marcos para análise do portfólio: um pré-filtro inicial, para selecionar as idéias tecnicamente viáveis, de acordo com critérios previamente definidos pela equipe de gestores que participou das reuniões de elaboração deste trabalho e; um segundo filtro, na etapa de aprovação de investimentos, para avaliar, segundo os critérios financeiros e objetivos estratégicos da organização, se tais projetos são viáveis e se é recomendado investir. Após o segundo filtro, o modelo proposto na Figura 26 utiliza um otimizador onde são 
aplicadas restrições aos projetos para permitir que a empresa escolha o melhor portfólio de projetos, do ponto de vista da utilização do orçamento aprovado.

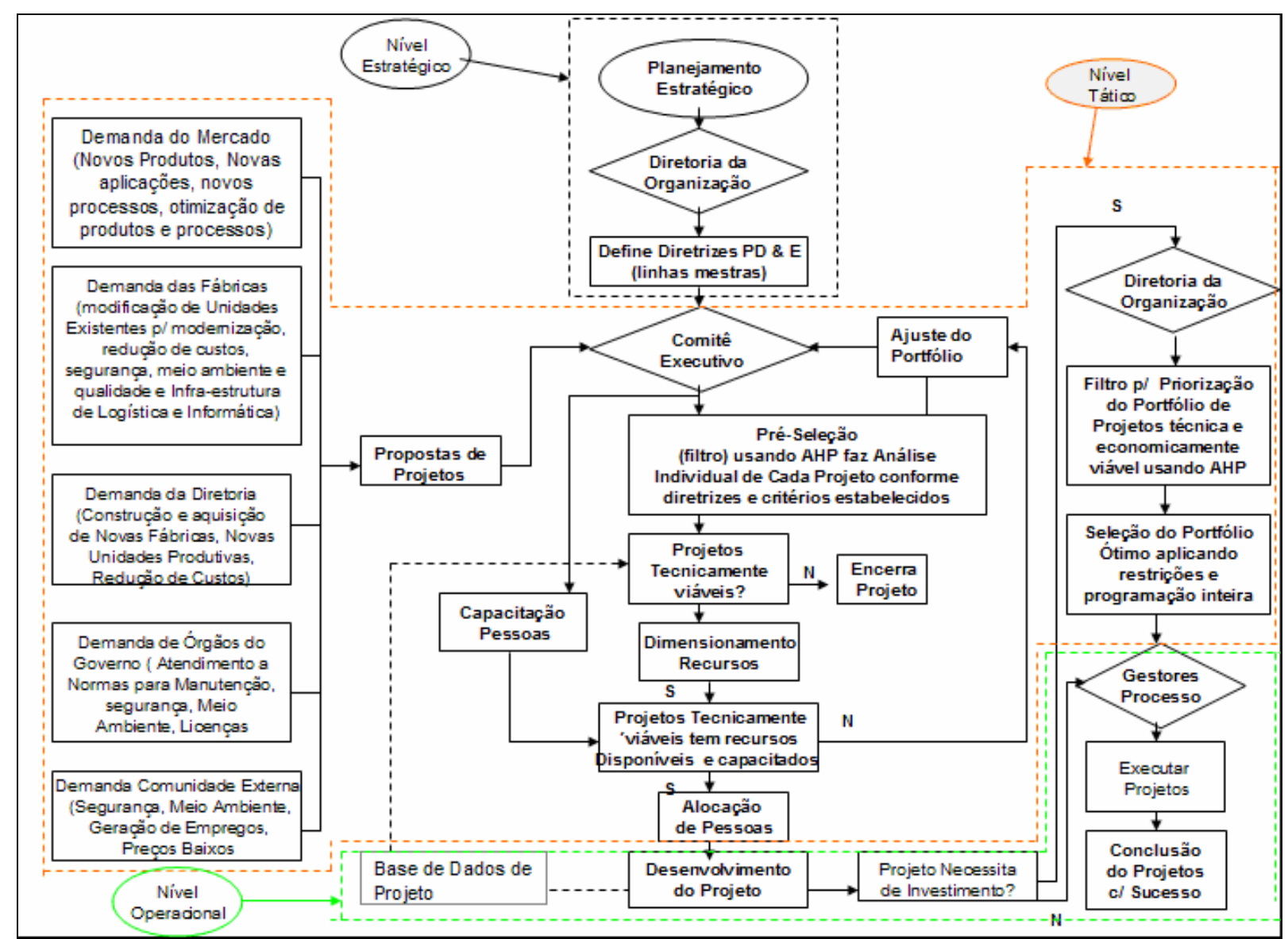

Figura 26 - Proposta de Modelo de Seleção do Portfólio de Projetos da Empresa (Fonte: Figura do Autor)

O modelo prevê a criação de um comitê executivo, formado por gerentes de P\&D, engenharia, fábricas, marketing, área de novos negócios e vendas para analisar os projetos, selecioná-los e priorizá-los, conforme recomendado por Prahalad \& Hamel (1990), de forma que, com o modelo, seja possível o desenvolvimento de produtos e competências fundamentais para a organização.

Esse modelo tenta promover o alinhamento dos objetivos dos Stakeholders com os objetivos estratégicos da organização, adotando-se uma estratégia de negociação diferenciada segundo seus atributos de poder e classe de stakeholders a que pertencem (Mitchell et al., 1997). 
A tomada de decisão deve se basear em múltiplos critérios, dependendo de qual stakeholder e objetivo está sendo avaliado, qual a área de negócio da empresa, quais os fatores ganhadores de pedido nestas áreas de negócio, tipo de projeto, localidade onde o projeto será implantado e restrições existentes em cada uma das fases.

A análise dos trade-offs deve ser um direcionador para a atribuição dos pesos de cada critério definido para a avaliação das soluções.

\subsection{Planejamento da Aplicação/Validação do Modelo Proposto}

A aplicação do método AHP para a organização estudada necessitou de um período de planejamento, onde as seguintes etapas foram realizadas:

o Definição de qual software seria utilizado;

o Obtenção e instalação do software escolhido;

o Aprendizado dos recursos do software e da metodologia AHP;

o Parametrização do software através da elaboração da estrutura de decisões para os projetos da organização, inserção dos critérios de decisão, nomes dos participantes e relação dos projetos a serem votados.

o Definição das restrições e dependências entre os projetos e aplicação do modelo otimizador.

o Análise dos resultados obtidos.

A definição do software ocorreu em agosto de 2006. Para a utilização do método AHP, tinham-se como opções o desenvolvimento do modelo em Excel ou outra ferramenta, ou a utilização um software disponível no mercado. Optou-se pela utilização do software Decision Lens versão 1.6.16, desenvolvido pelo Prof. Thomas Saaty, por ser uma ferramenta que utiliza em sua concepção os métodos AHP e programação inteira, integrados. Essa decisão também se baseou em critérios práticos, considerando-se que o objetivo deste trabalho não era o desenvolvimento de um software e sim a aplicação dos métodos AHP e programação inteira para selecionar e priorizar projetos do portfólio da organização tida como unidade de análise. 
Detalhes sobre o software Decison Lens podem ser consultados no Apêndice A deste trabalho.

Uma vez definida a ferramenta, fez-se um contato com o representante do software Decision Lens no Brasil, para a obtenção de uma licença de uso durante o período da pesquisa. A licença do Decision Lens foi fornecida ao autor em setembro de 2006, mediante o envio de um resumo deste trabalho para a avaliação do Prof. Saaty.

Entre os meses de setembro e outubro de 2006, foram realizadas 3 reuniões de cerca de 4 h de duração entre o autor e o fornecedor do software para treinamento do autor nos recursos do software e da metodologia AHP.

Após a fase de capacitação do autor na utilização do decision lens e do método AHP, verificou-se que, para a aplicação do método AHP, para o escopo proposto neste trabalho, seria necessário criar mais de uma estrutura de decisões para os projetos, agrupando-os por similaridade de tal forma que fosse possível definir critérios de decisão válidos para todos os projetos agrupados na mesma categoria. Como o método AHP prevê a comparação dos critérios aos pares, para a definição dos pesos relativos, era necessário ter dentro da mesma hierarquia de decisões critérios que fossem comparáveis. Esta constatação levou a necessidade de retornar-se a etapa anterior, de caracterização dos projetos da organização, para que se fizesse uma reclassificação desses projetos, segundo suas características, de tal forma que se pudessem definir critérios de decisão comuns para os projetos pertencentes às novas classificações criadas. A necessidade de reclassificação dos projetos confirma as observações de McFarlan (1981) de que é necessário classificar os projetos de modo que seja possível diferenciá-los e compará-los com projetos similares.

\subsection{Reclassificação dos Projetos da Organização}

A reclassificação dos projetos da organização afetou principalmente os projetos com necessidade de investimentos aprovados e envolve todos os projetos da empresa, inclusive os de natureza estratégica, anteriormente segregados da análise.

O item 4.6 deste documento mostrou que a empresa classifica seus projetos com investimento aprovado por natureza, tipo e característica. 
Para a nova classificação proposta, projetos com característica final de vida útil (VU), controle ambiental (CA), segurança industrial (SG) e modernização (MD) foram agrupados e denominados "Projetos de Manutenção". Essa designação foi usada devido ao fato de projetos dos tipos VU, CA, SG e MD serem normalmente implantados pelas áreas de manutenção das unidades industriais, terem duração inferior a um ano e complexidade entre média e baixa. Os projetos caracterizados pela empresa como redução de custos (RC), foram incorporados a uma das classificações existentes (SG, MD, VU ou CA) de acordo com o descritivo de seu escopo, dado que havia uma sobreposição entre a classificação RC e VU e MD que, em geral, levam a redução de custos.

Projetos anteriormente classificados como qualidade (QA) ou final de vida útil (VU), cujo escopo abrangia equipamentos/instalações de laboratório, foram reclassificados como "Projetos de Infra-estrutura de P\&D”. Nesta nova classificação, estão incluídos projetos de compra e instalação de novos equipamentos para novas aplicações, produtos e processos, substituição de equipamentos existentes obsoletos e reforma e modernização das instalações de P\&D.

"Projetos de Informática (IF) ou Projetos de TI" constituem-se em outra classe de projetos da empresa. Nela estão previstas aquisições e implantações de softwares de mercado, desenvolvimento e implantação de softwares especialistas, aquisição de sobressalentes e peças de reposição e adequação de infra-estrutura de hardware com compra e substituição de microcomputadores, impressoras, scanners, ampliação de links de comunicação entre unidades e adequação de capacidade das redes dos diferentes sites.

Por último, foram agrupados os projetos de aumento de capacidade (CP), estudos estratégicos (EE) e projetos de novos produtos (NP) formando na nova classificação os "Projetos de Engenharia". Dentro desse tipo se inserem aquisições de novas fábricas, joint-ventures/parcerias, licenciamentos, ampliações de unidades (REVAMPs), modificações de plantas existentes para melhoria na qualidade do produto ou desengargalamento. Tais projetos são os que contribuem para o crescimento da empresa e também para o aumento do mix de produtos. Também fazem parte dos "Projetos de Engenharia" venda de tecnologia e participações minoritárias em outras empresas, sendo tais projetos estratégicos, pois contribuem para a imagem da empresa no mercado nacional e internacional, facilitando negócios futuros, podendo também resultar em novos produtos. Os desenvolvimentos internos 
de tecnologia que colaboram com o crescimento e a inovação e também se enquadram em "Projetos de Engenharia". A denominação "Projetos de Engenharia" vem do fato deste tipo de projetos ser implantado pela área de engenharia da empresa, sendo projetos de complexidade média e alta e duração superior a 1 ano.

O quadro 8, a seguir, apresenta o relacionamento entre a classificação de projetos com investimento aprovado adotada pela organização e a nova classificação proposta.

\begin{tabular}{|c|c|c|c|}
\hline Classificação Proposta & Classificação da Empresa & Descrição & Local de Aplicação \\
\hline \multirow{5}{*}{ Projetos de Manutenção } & VU- Fim de vida útil & $\begin{array}{l}\text { Investimentos que visam a substituição de um bem devido a } \\
\text { exaustão ou obsolescência }\end{array}$ & Instalação Industrial \\
\hline & CA- Controle Ambiental & $\begin{array}{l}\text { Investimentos cuja implantação visa atendimento de requisitos de } \\
\text { proteção ambiental }\end{array}$ & Instalação Industrial \\
\hline & SG-Segurança Industrial & $\begin{array}{l}\text { Investimentos que visam garantir a segurança operacional e } \\
\text { resguardar o patrimônio instalado }\end{array}$ & Instalação Industrial \\
\hline & MD- Modernização & $\begin{array}{l}\text { Investimentos que visam automatizar e incorporar as instalações } \\
\text { novas tecnologias para aumento de produtividade, segurança, } \\
\text { qualidade ou redução de custos }\end{array}$ & Instalação Industrial \\
\hline & RC- Redução de Custos & $\begin{array}{l}\text { Investimentos cujo objetivo principal seja reduzir os custos de } \\
\text { produção }\end{array}$ & Instalação Industrial \\
\hline \multirow{2}{*}{$\begin{array}{l}\text { Projetos de Infra-estrutura } \\
\text { de P\&D }\end{array}$} & QS- Qualidade & Investimentos em melhoria da qualidade de produtos & Laboratórios de P\&D \\
\hline & VU- Fim de vida útil & $\begin{array}{l}\text { Investimentos que visam a substituição de um bem devido a } \\
\text { exaustão ou obsolescência, inclui reforma das instalações }\end{array}$ & Laboratórios de P\&D \\
\hline Projetos de Informática & IF-Informática & $\begin{array}{l}\text { Investimentos em software, hardware e outros ativos } \\
\text { de informática }\end{array}$ & \begin{tabular}{|l|} 
Instalação Industrial \\
Instalações de P\&D \\
Instalações Administrativas
\end{tabular} \\
\hline \multirow[b]{3}{*}{ Projetos de Engenharia } & CP-Aumento de Capacidade & Projetos de amliações de capacidade da linha de produtos atual & Instalação Industrial \\
\hline & NP-Novos Produtos & Investimentos que visam o lançamento de novos produtos & Instalação Industrial \\
\hline & EE-Estudos Estratégicos & $\begin{array}{l}\text { Investimentos destinados à execução de estudos de viabilidade de } \\
\text { novos negócios e que serão contabilizados como ativo diferido (inc lui } \\
\text { aquisição de novas empresas, participações minoritárias, joint } \\
\text { ventures/parcerias, venda de tecnologia). }\end{array}$ & Instalação Industrial \\
\hline
\end{tabular}

Quadro 8 - Relacionamento entre classificação de projetos da empresa e proposta pelo autor

Ao se fazer a reclassificação dos projetos para os mesmos dados coletados de 2001 a 2005, foi necessária a elaboração de novos histogramas e diagramas de bolhas, para que fosse verificado se as conclusões anteriormente obtidas permaneciam válidas. Os dados dos projetos com a nova classificação podem ser consultados no Apêndice $D$ deste trabalho.

Assim, primeiramente foram desenvolvidos os gráficos 13 a 18 relativos ao número de projetos por site, por ano e para os novos tipos de projetos definidos. Observa-se no gráfico 13 uma tendência a redução dos projetos de manutenção, tendo seu número reduzido de 158 em 2001 para 69 em 2005. Os projetos de engenharia, mudaram de patamar ao longo dos 5 anos analisados, sendo que em 2001 e 2002 o número de projetos girava em torno de 20 a 30, passando para um número superior a 40 nos anos de 2003 a 2005. Os projetos de TI tiveram uma 
pequena elevação em 2002, mas desde 2003 tem apresentado tendência decrescente. Por último, pode-se verificar que desde 2002 o número de projetos de infra-estrutura de P\&D se mantém em torno de 20 projetos.

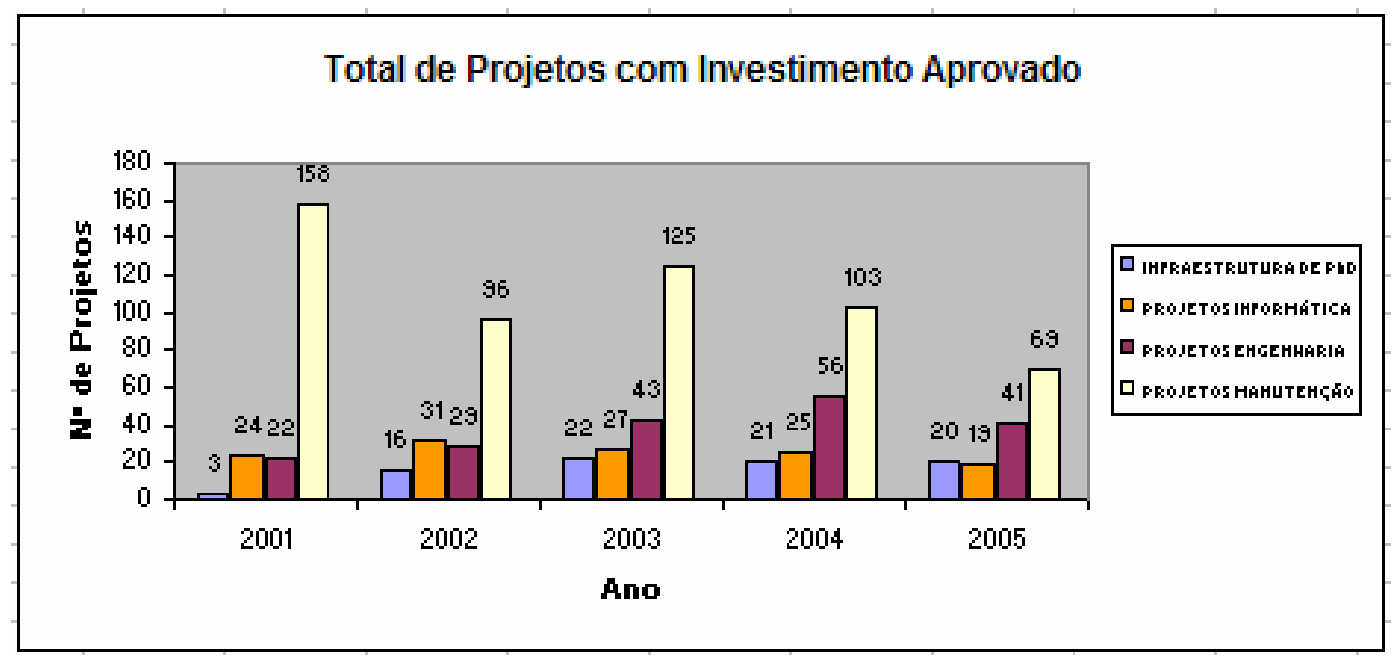

Gráfico 13 - Histórico de Número de Projetos/Característica/Ano - Total

Fazendo-se a mesma análise para os projetos estratificados por unidade, podese verificar consultando-se o gráfico 14 que existe uma grande concentração de projetos de informática na matriz da empresa. Tal fato também foi observado no gráfico 2, quando foi feita a caracterização dos projetos com investimento aprovado. Entretanto, com a nova classificação dos projetos, é possível perceber-se uma tendência decrescente do número de projetos de TI desde 2003, quando ocorreu a implantação do ERP (Enterprise Resource Planning) da empresa. Também é possível verificar-se uma tendência crescente dos projetos de engenharia na matriz, fato que no gráfico 2 não podia ser visto porque os projetos de estudos estratégicos, aumento de capacidade e novos produtos estavam pulverizados e as aquisições de novas empresas e participações minoritárias tinham sido excluídas da análise. 


\section{Projetos com Investimento Aprovado - Matriz}

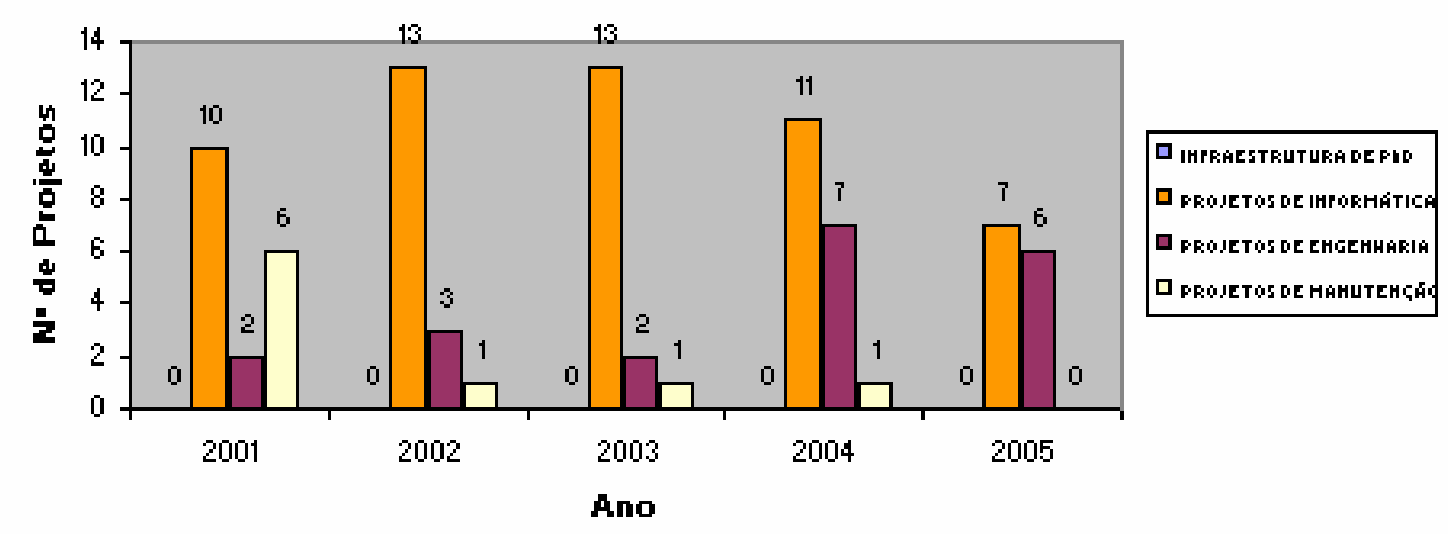

Gráfico 14 - Histórico de Número de Projetos/Característica/Ano - Matriz

O gráfico 15 apresenta o perfil de projetos da fábrica 1, a maior da empresa em termos de capacidade de produção. A análise deste gráfico mostra uma forte tendência a redução do número de projetos de manutenção desde 2003, ao mesmo tempo em que apresenta uma curva de crescimento do número de projetos de engenharia, chegando a um patamar em torno de 20 projeto ano em 2003. Esta fábrica não tem projetos de infra-estrutura de P\&D porque o centro de pesquisas de empresa fica situado na fábrica $2 \mathrm{e}$ atende a demanda de todas as unidades fabris. $\mathrm{O}$ gráfico 15 mostra, ainda, que a fábrica 1 tem um número constante de projetos de TI.

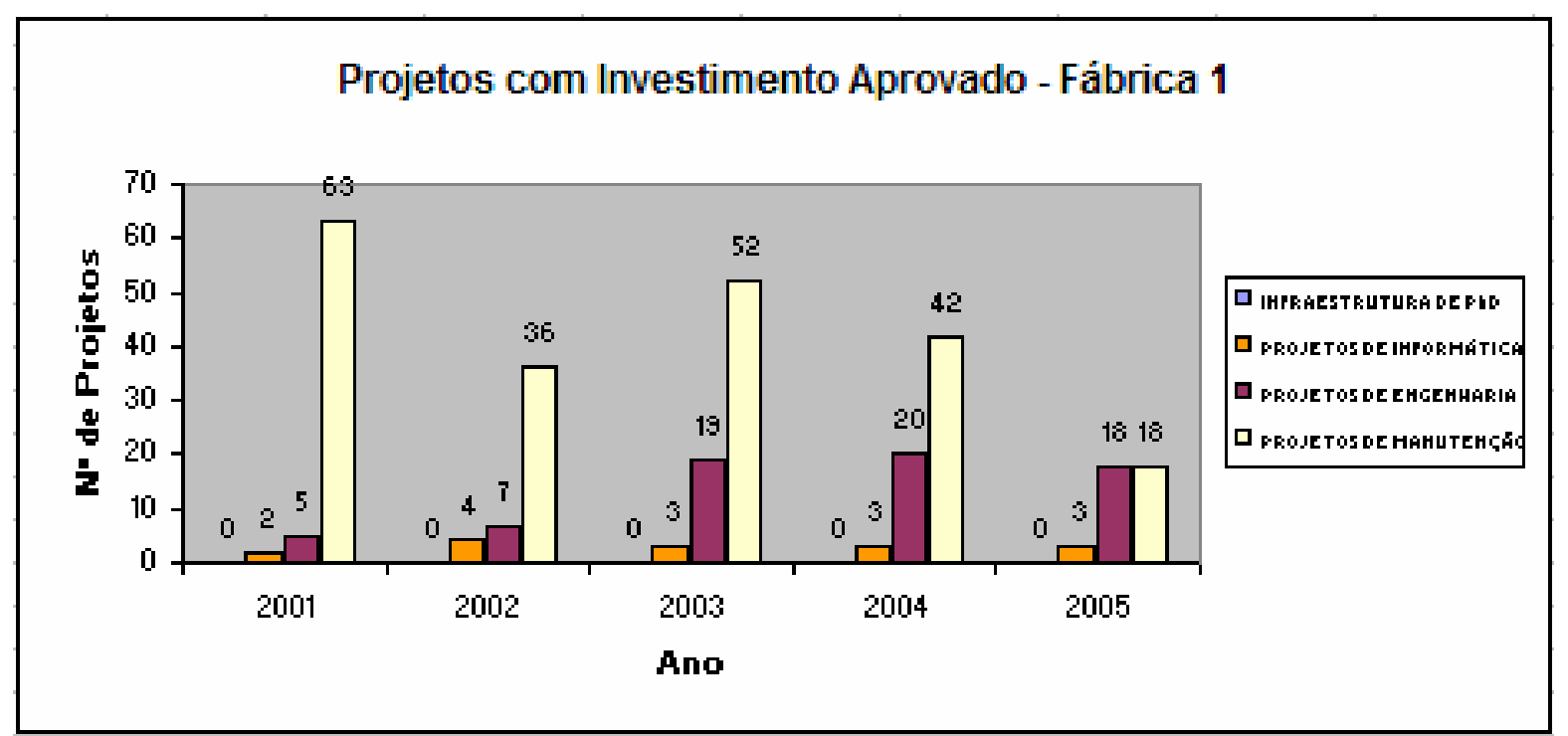

Gráfico 15 - Histórico de Número de Projetos/Característica/Ano - Fábrica 1 
O gráfico 16 apresenta o perfil de projetos com investimento aprovado da segunda maior planta da empresa, denominada neste trabalho de fábrica ou unidade 2. Nesta unidade, o número de projetos de manutenção só começou a decrescer em 2004 sendo, em quantidade, muito maior que da fábrica 1. O número de projetos de engenharia nesta planta oscila em torno da média de 10 projetos por ano. Como esta fábrica é a única que dispõe de um centro de pesquisas, é nela que se concentram todos os projetos de infra-estrutura de P\&D. Tais projetos têm apresentado forte tendência de crescimento entre os anos de 2001 a 2005. A tendência de crescimento dos projetos de infra-estrutura de P\&D se deve a política da empresa de investir 0 valor de $2 \%$ do seu faturamento ao ano em P\&D. Como nesse período o faturamento foi crescente, os investimentos cresceram proporcionalmente ao valor faturado por ano. Os projetos de informática se mantém em torno de 6 por ano, só apresentando uma redução em 2005, fato que não pode ser considerado uma tendência. As observações feitas através do gráfico 16 não puderam ser verificadas na análise do gráfico 4 feita anteriormente, também devido a pulverização das informações em muitos tipos de projetos e ao fato de estudos estratégicos, aquisições e participações minoritárias terem sido excluídas da análise anterior. Os investimentos em P\&D não eram visíveis com a classificação adotada pela empresa. A nova classificação permitiu que a estratégia da empresa com relação a P\&D fosse destacada.

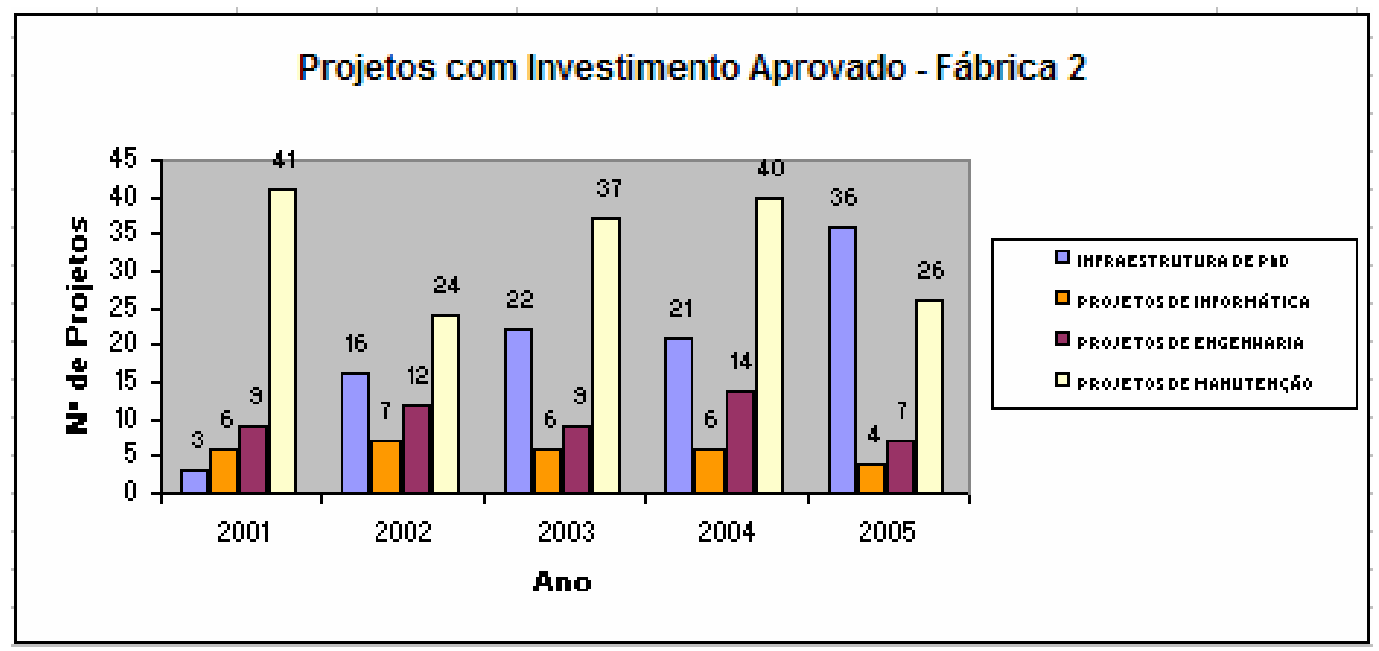

Gráfico 16 - Histórico de Número de Projetos/Característica/Ano - Fábrica 2 
O histórico de projetos da fábrica 3, a terceira em tamanho e a mais complexa em termos de quantidade de produtos ativos e número de processos, é apresentado no gráfico 17. Nesta unidade, verifica-se que no período de 2001 a 2004 houve uma tendência de aumento do número de projetos de engenharia e redução do número de projetos de manutenção, entretanto, essa tendência se inverteu em 2005. A fábrica 3 é a menos automatizada da empresa, talvez por esse motivo, mesmo com investimentos em modernização e substituição de equipamentos ainda existam muitos projetos de manutenção. Esta unidade não tem projetos de infra-estrutura de P\&D por não dispor de centro de pesquisas. Assim como nas demais fábricas, os projetos de TI têm um número constante. Aparentemente a política da empresa é investir pouco em tecnologia da informação.

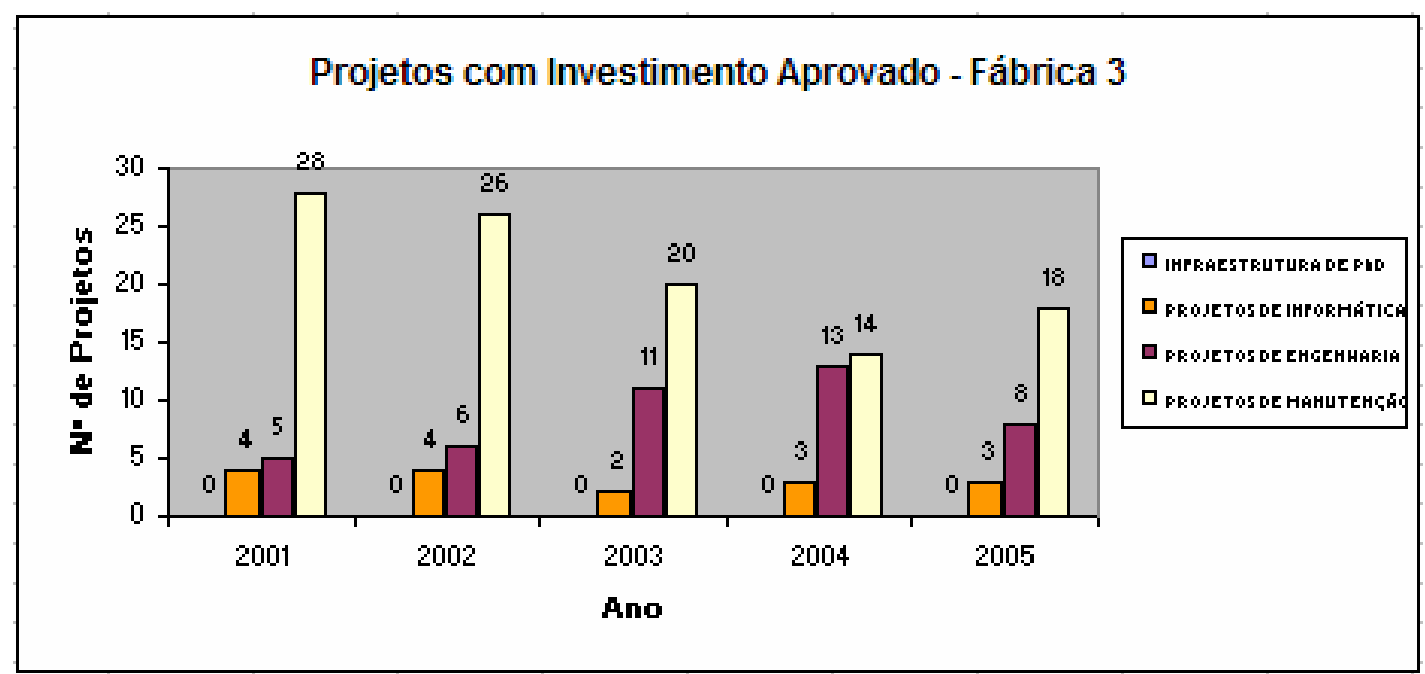

Gráfico 17 - Histórico de Número de Projetos/Característica/Ano - Fábrica 3

A menor planta, fábrica 4, tal como a maior, apresenta uma tendência de queda no número de projetos de manutenção. O gráfico 18 mostra que o número de projetos de TI é estável e não existem projetos de infra-estrutura de P\&D devido a inexistência de centro de pesquisa neste local. O número de projetos de engenharia é estável pelo fato da unidade ser monoprodutora, o que aumenta os riscos de investir nesta planta e ao mesmo tempo limita as opções de desenvolvimento de novos produtos e aplicações. Em geral os projetos são de aumento de capacidade do tipo REVAMP (desengargalamento). 


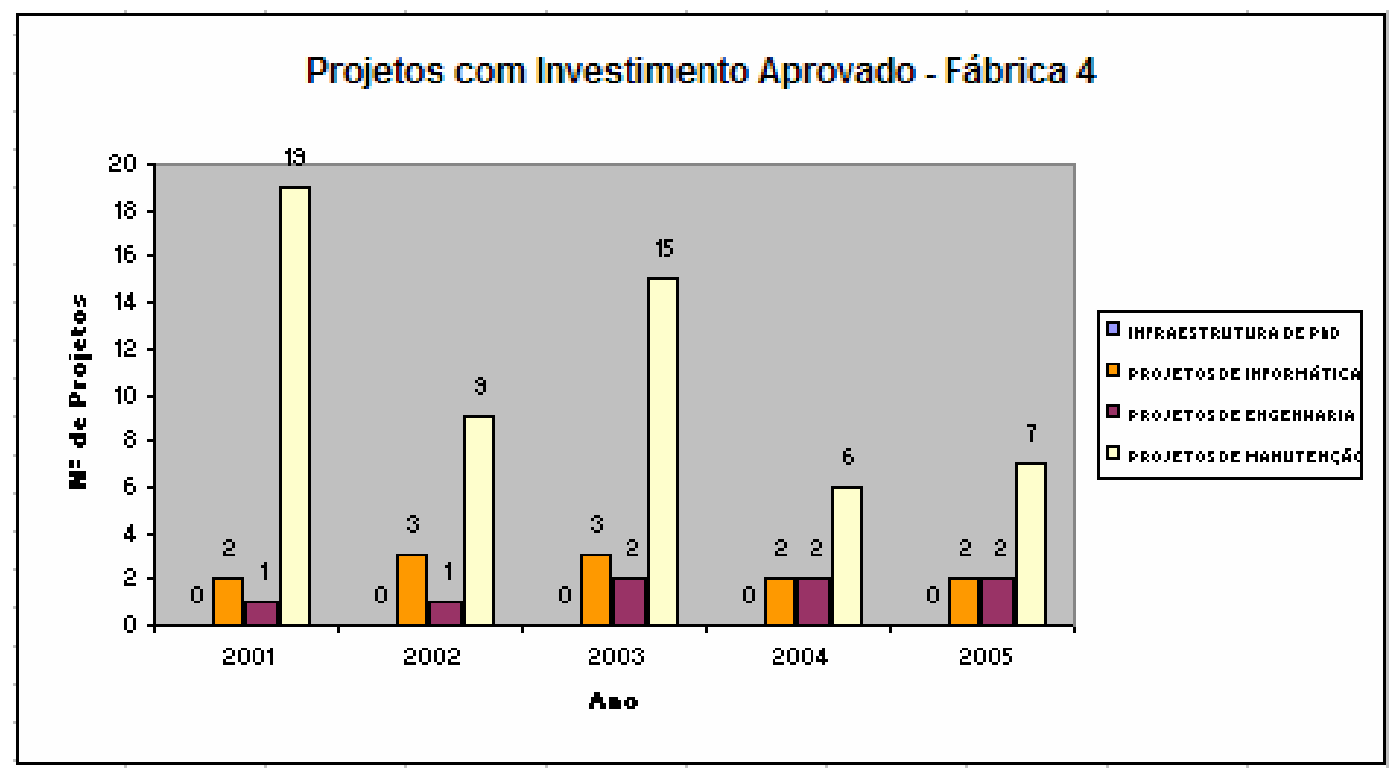

Gráfico 18 - Histórico de Número de Projetos/Característica/Ano - Fábrica 4

Uma outra forma de analisar os dados do número histórico de projetos da empresa é apresentada pelos gráficos de 19 a 22. Nestes gráficos, foi feita a explosão dos dados apresentados no gráfico 13, estratificados para cada tipo de projeto em subtipos principais. Assim, o gráfico 19 mostra do total de projetos de infra-estrutura de P\&D executados entre 2001 e 2005, quantos são relativos a reforma das instalações, quantos se referem a aquisição de equipamentos e quantos são relacionados com a melhoria das instalações. Verifica-se nesse gráfico que a maior parte dos projetos são de aquisição e instalação de equipamentos, seguido pelos projetos de melhoria das instalações. O gráfico reflete uma preocupação da empresa em manter suas instalações de P\&D atualizadas e adequadas para atender as demandas por novos produtos e aplicações, em como dar suporte aos seus clientes internos e externos. 


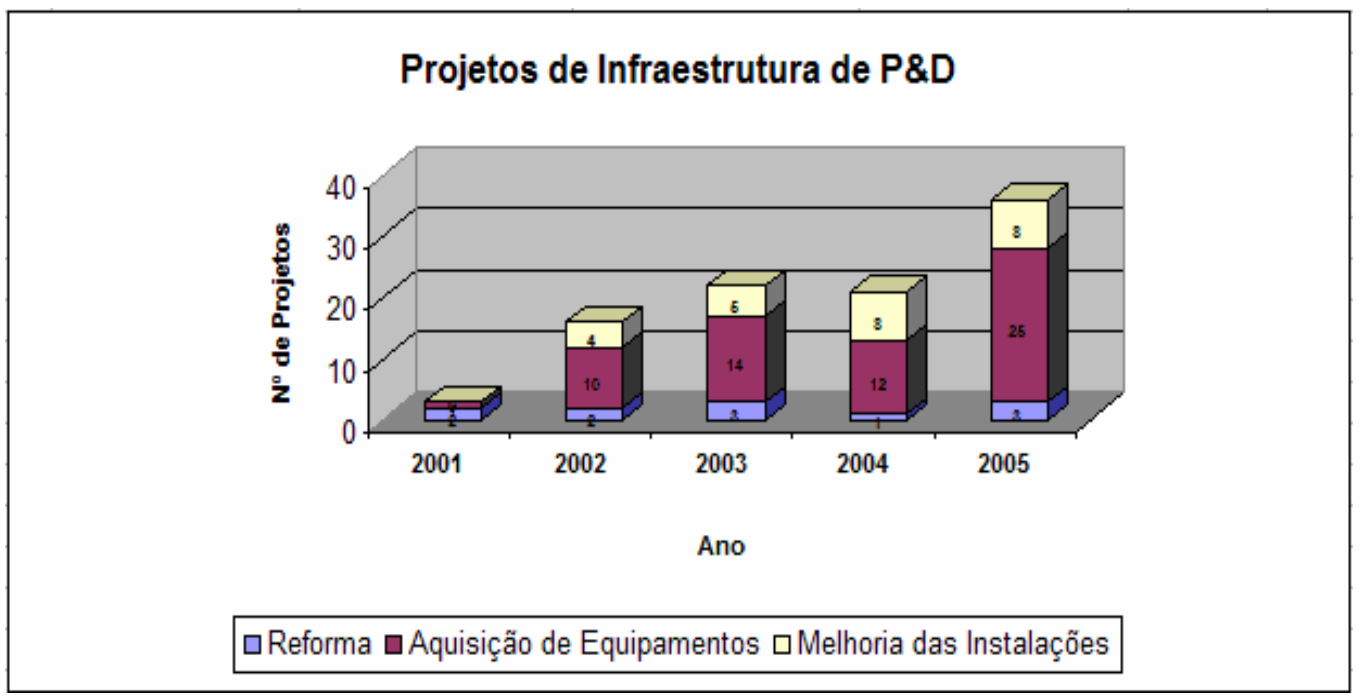

Gráfico 19 - Histórico de Número de Projetos de Infra-Estrutura de P\&D

O gráfico 20 apresenta o portfólio de projetos de engenharia da empresa por subtipo e por ano. Verifica-se que a maior parte dos projetos da organização está relacionada com melhoria das instalações e desengargalamentos de unidades produtivas (REVAMPs). Essa observação já tinha sido feita ao analisarmos a figura 21, que trata do grau de inovação dos processos da empresa. Pelo que se observa, claramente, ao longo dos 5 anos analisados, a empresa direcionou seus esforços na realização de projetos com tecnologia conhecida e planta existente, sendo baixo o grau de inovação. Entretanto, especialmente a partir de 2004, nota-se um aumento no número de outros tipos de projetos tais como, joint-ventures/parceria, nova tecnologia, aquisições e licenciamentos, o que indica um movimento no sentido de aumentar o grau de inovação.

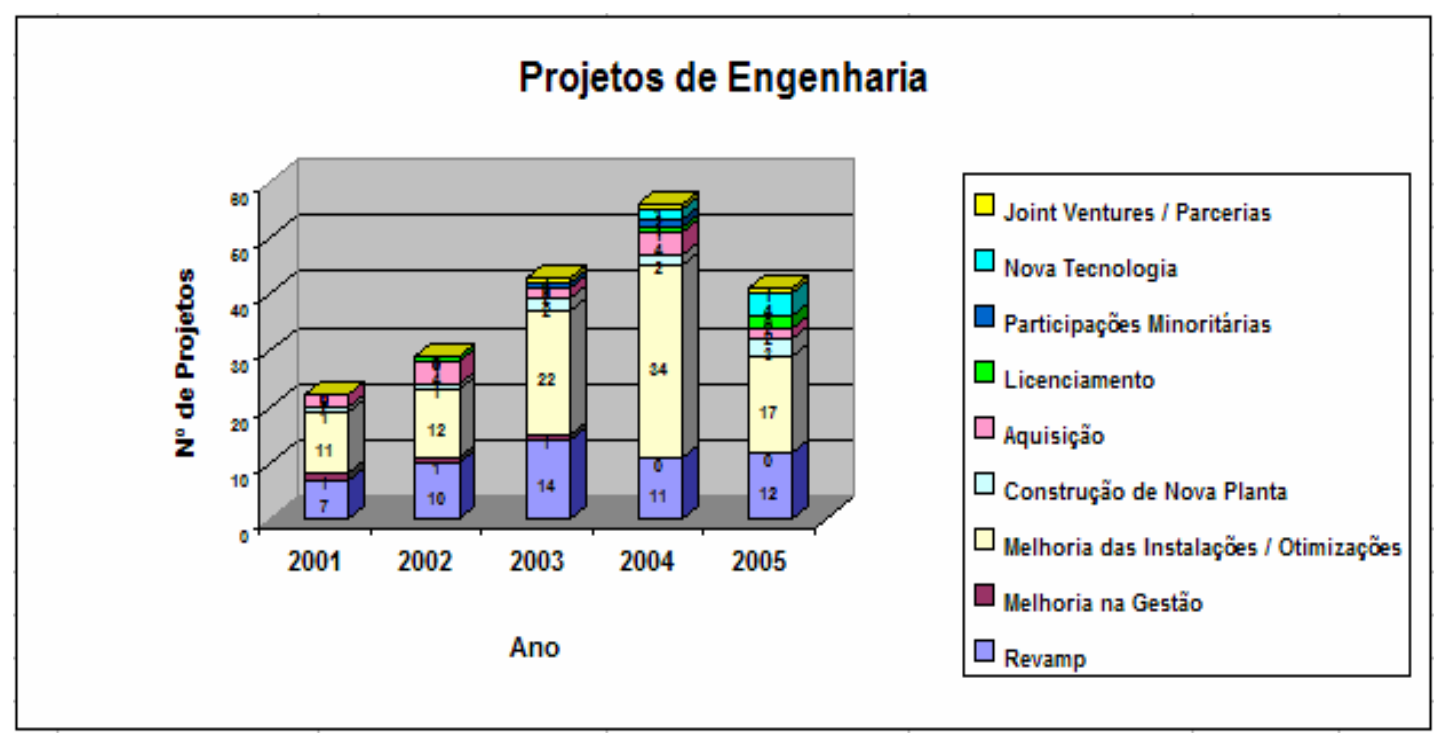

Gráfico 20 - Histórico de Número de Projetos de Engenharia 
O gráfico 21 apresenta os projetos de manutenção estratificados por subtipo por ano. Este gráfico complementa as informações obtidas no gráfico 13, mostrando onde houve a redução de projetos de manutenção. Pode-se verificar que no ano de 2001 investiu-se muito em modernização/automação e em substituição de equipamentos em final de vida útil. A partir deste ano, houve uma tendência a redução dos investimentos em manutenção, supostamente porque grande parte dos itens importantes das unidades eram novos, não precisando de investimentos nos anos seguintes. A estratégia de modernização dá a empresa fôlego para investir em projetos de engenharia, dado que ela compartilha seus recursos humanos de manutenção com projetos de engenharia. O gráfico 21 também mostra preocupação crescente com itens de segurança industrial entre os anos de 2001 a 2003.

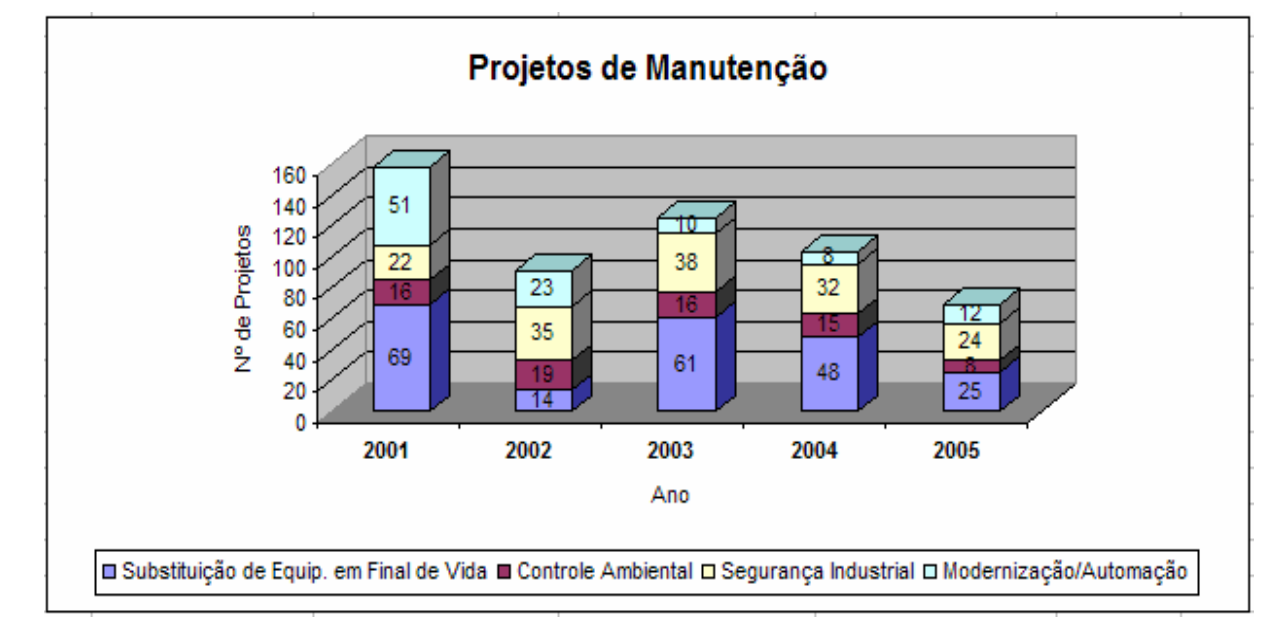

Gráfico 21 - Histórico de Número de Projetos de Infra-Estrutura de Manutenção

Por último, o gráfico 22 destaca qual a composição do portfólio de projetos de TI da empresa. Pelo que se pode verificar a maior parte dos investimentos de TI são de infra-estrutura, existindo uma tendência a redução do número total de projetos. Esse gráfico confirma a política da empresa de não priorizar os projetos de informática de seu portfólio, buscando manter o funcionamento das instalações existentes, mas não incentivando projetos nesta área. 


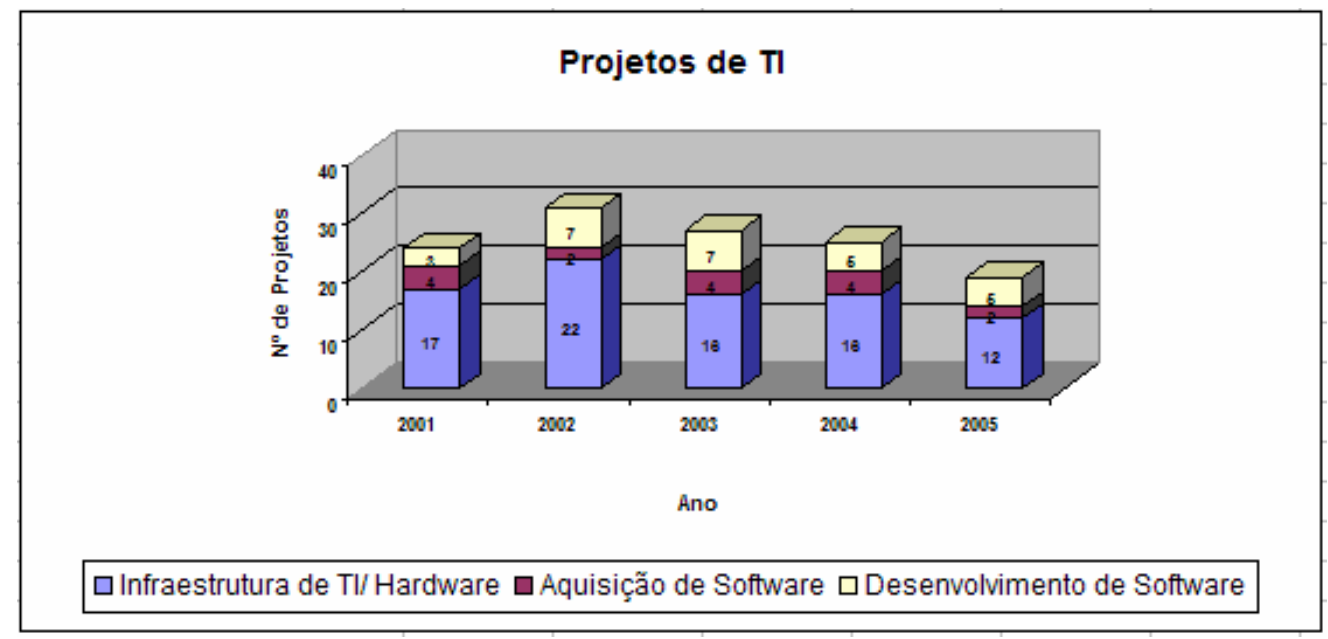

Gráfico 22 - Histórico de Número de Projetos de TI

Outra forma de analisar o portfólio de projetos ao longo do período de 2001 a 2005 é fazendo a comparação entre os valores orçados e reais neste intervalo de tempo. Os gráficos de 23 a 26 apresentam os valores orçados e efetivamente desembolsados no intervalo de 5 anos considerando-se a nova classificação adotada para os projetos: Infra-estrutura de P\&D, Engenharia, Manutenção e Projetos de Informática (TI) .

Pelo que se pode observar através do gráfico 23, no caso dos projetos de P\&D, o maior volume de dinheiro é destinado para subtipo de projeto que ocorre em maior número, ou seja, aquisição de equipamentos. Também é possível observar que nos 3 subtipos de projetos, reforma, aquisição e melhoria o valor orçado é muito maior que o real. Esse fato nos induz a acreditar que exista falta de capacidade de execução dos projetos por falta de recursos humanos para conduzi-los, erro no orçamento, atraso no desembolso resultante de atraso na execução ou atraso na execução devido a alteração de escopo. Todos esses problemas foram previstos por McFarlan (1981), Elton e Roe (1998), e Goldratt (1998) e tendo sido mencionados anteriormente e, segundo os gestores, realmente ocorrem na organização. O problema de não cumprir o planejamento de desembolsos é que o valor previsto para os pagamentos deixa de ser aplicado. Atrasos em projetos financiados têm que ser justificados para os órgãos de financiamento. Além disso, o dinheiro não aplicado poderia ser direcionado para outros projetos cujo retorno para a empresa fosse maior. Assim, os acionistas e os órgãos de financiamento acabam sendo negativamente afetados pelas decisões tomadas, sendo que segundo a literatura estes stakeholders deveriam ser sempre 
atendidos, sendo segundo Clarkson (1995) stakeholders primários e segundo Mitchell et al. (1997) stakeholders definitivos, ou seja, aqueles que têm poder, legitimidade e urgência.

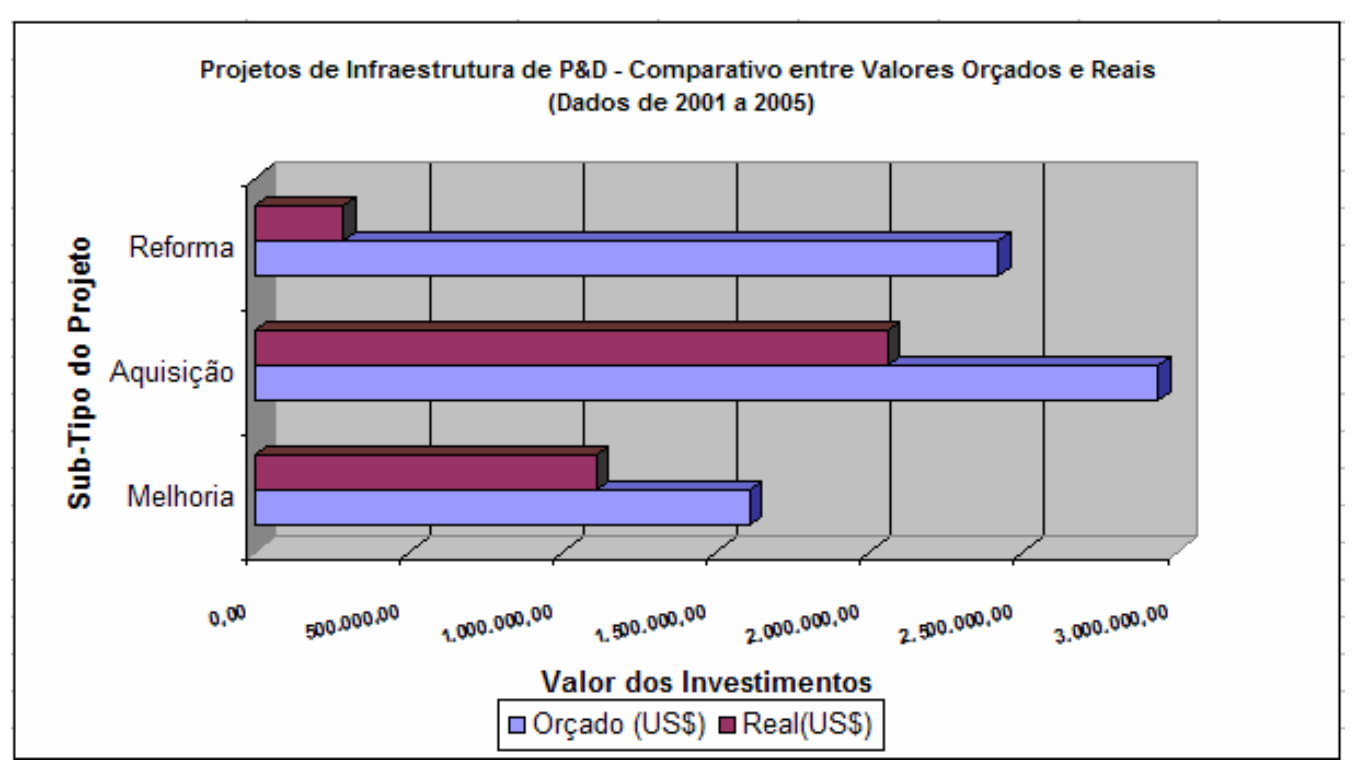

Gráfico 23 - Valores Acumulados Orçados x Reais - Proj. Infra-estrutura de P\&D

O gráfico 24 apresenta o comparativo entre valores orçados e reais para cada subprojeto de engenharia. Da mesma forma que os Projetos de Infra-Estrutura de P\&D, os valores orçados são maiores que os reais desembolsados. Neste caso notase um grande desvio nos projetos do subtipo licenciamento. Isso ocorre porque os projetos deste tipo encontram-se em fase inicial de implantação, tendo sido pagas apenas parcelas relativas a compra da tecnologia, não tendo ocorrido até a data em que os dados foram coletados os pagamentos relacionados com a compra de equipamentos. 


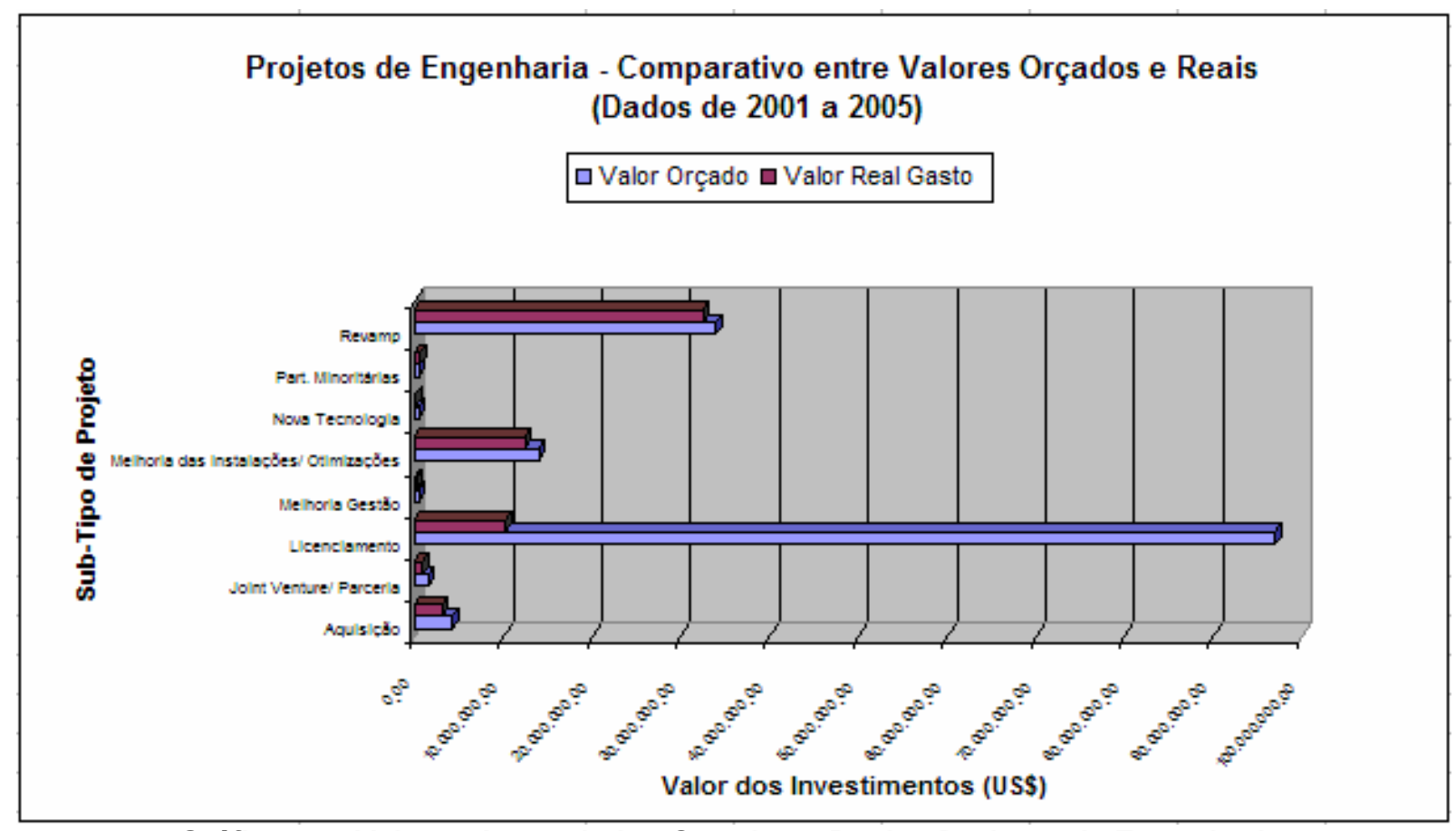

Gráfico 24 - Valores Acumulados Orçados x Reais - Projetos de Engenharia

No caso dos projetos de manutenção apresentados no gráfico 25, pode-se observar que os gastos reais são quase sempre superiores aos orçamentos. Esse tipo de desvio não pôde ser observado com a classificação de projetos adotada pela empresa. O que se pode perceber é que ao invés de se controlar cada projeto individualmente, o controle é realizado apenas pelos totais. Assim, se somarmos o total orçado e desembolsado nos 5 anos analisados, chegamos a valores aproximadamente iguais. Essa conclusão confirma o processo de gestão dos projetos de natureza corrente e de baixo valor apresentada anteriormente.

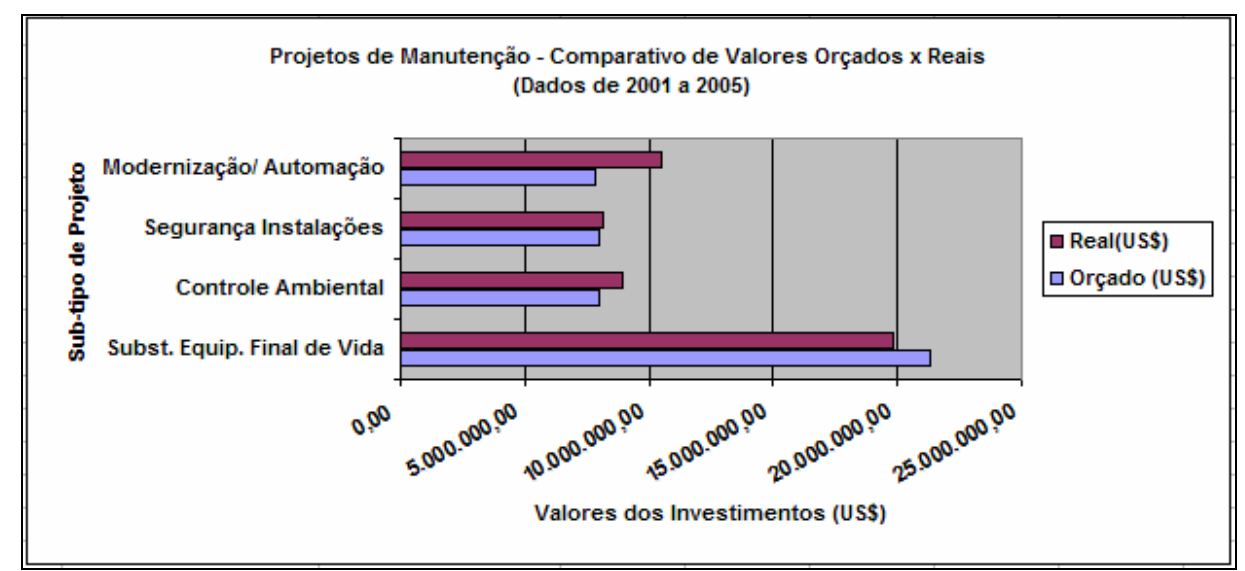

Gráfico 25 - Valores Acumulados Orçados x Reais - Projetos de Manutenção 
Por último, pode-se ver o comparativo dos valores orçados e reais de projetos de TI de 2001 a 2005 no gráfico 26. Verifica-se que as aquisições de softwares do tipo pacote são os projetos de TI que envolvem maior valor. Percebe-se que neste caso, assim como ocorre nos projetos de infra-estrutura de P\&D e de engenharia, que os valores orçados em geral são maiores que os efetivamente gastos. A causa provável da diferença não necessariamente é a falta de capacidade de execução dos projetos e sim falta de priorização dos mesmos. Em entrevista com pessoas da área de $\mathrm{TI}$ e analisando-se os projetos propostos nos 5 anos em estudo, percebe-se que qualquer oscilação de mercado em que a diretoria da empresa visualize tendência de redução nas vendas, os primeiros projetos a serem paralisados são os de TI.

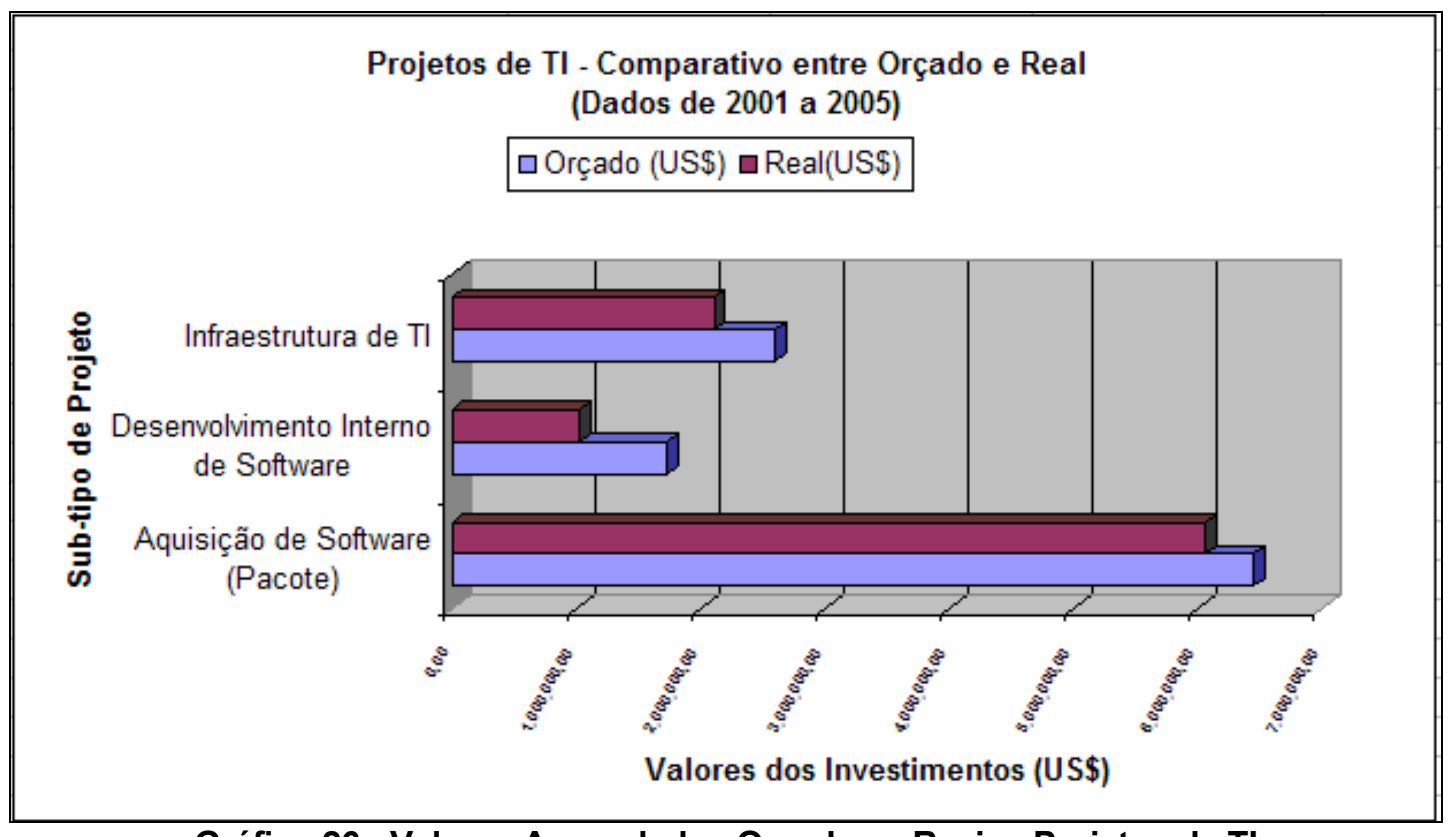

Gráfico 26 - Valores Acumulados Orçados x Reais - Projetos de TI

Para refazer a análise do cumprimento de prazos e orçamentos feita anteriormente apenas para os 5 maiores projetos de 2004, conforme apresentado na tabela 3, optou-se por utilizar a ferramenta MiniTAB para a geração dos gráficos e cálculos estatísticos, a seguir. Os dados analisados correspondem a todos os "Projetos de Engenharia" de 2005. A mesma análise não foi feita para os projetos de manutenção, Infra-estrutura de P\&D e Informática por serem menos complexos, de menor valor e com período de execução em geral inferior a 1 ano. 
O gráfico 27, a seguir, apresenta para o conjunto de dados selecionados 0 perfil do desvio entre os valores orçados e reais. Verifica-se que a distribuição é Normal, estando o desvio médio em torno do valor "zero". Entretanto, existe uma grande dispersão dos valores, podendo tanto superar o orçamento, como ficar muito abaixo do valor previsto. Esse grande desvio pressupõe alterações de escopo e problemas na gestão individual dos projetos, bem como necessidade de ajustes nas estimativas de investimento. Ao analisar os dados da tabela 3 , não foi possível chegar-se a mesma conclusão devido ao pequeno número de projetos selecionados.

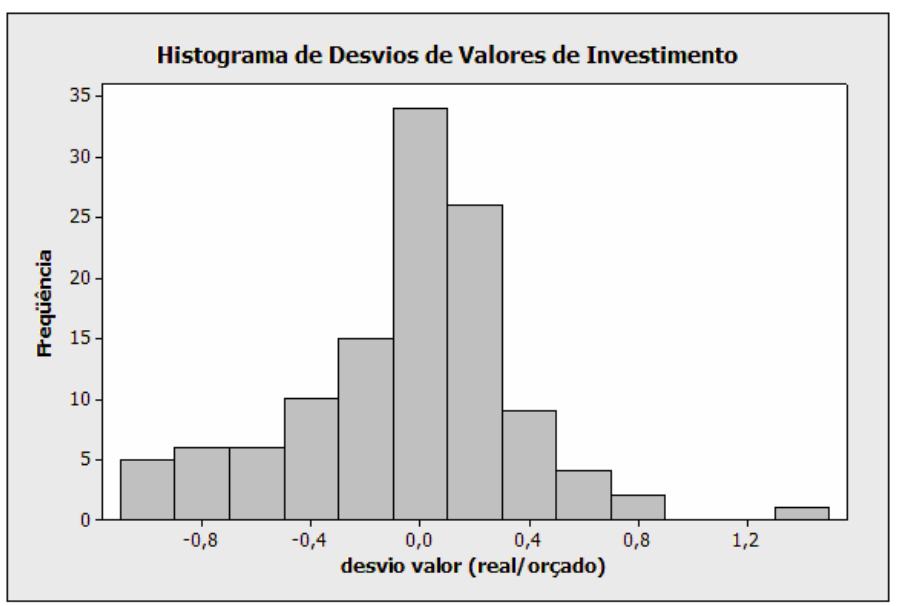

Gráfico 27 - Desvio entre Valores Orçados e Reais

(Fonte: Dados da Empresa - Projetos de Engenharia de 2005)

O gráfico 28 foi montado utilizando-se os mesmos dados coletados para o gráfico 27 e se refere ao perfil de duração dos "Projetos de Engenharia". Os projetos

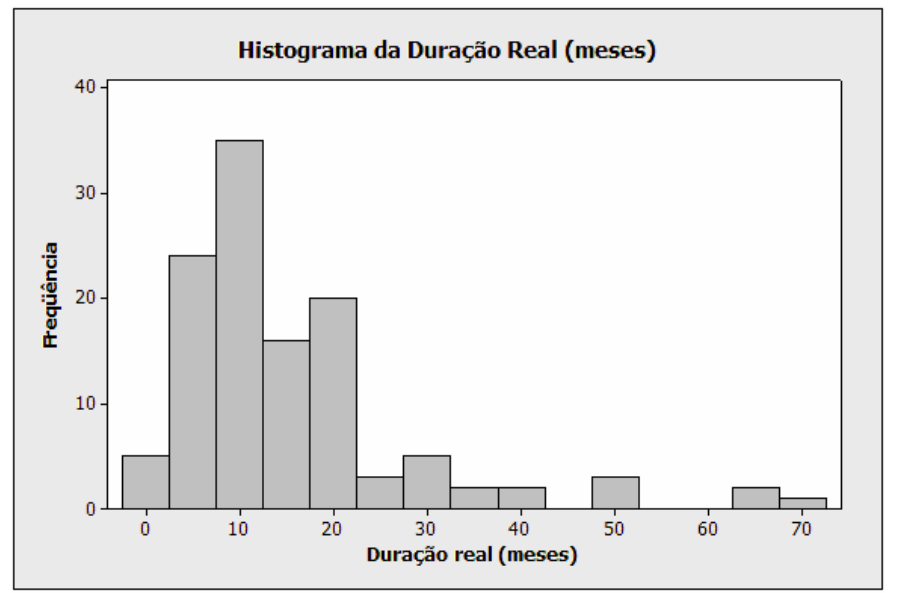

Gráfico 28 - Duração dos Projetos de Engenharia

(Fonte: Dados da Empresa - 2005) 
com duração igual a zero são relativas àqueles que ainda não tinham sido iniciados na época da coleta dos dados, mas já tinham investimento aprovado. Pode-se verificar que os "Projetos de Engenharia" tem duração entre 5 e 20 meses, existindo algumas exceções com duração maior.

No gráfico 29 , pode ser observada a duração dos mesmos projetos apresentado no gráfico 28 , estratificado por subtipo de projeto. Percebe-se grande dispersão na duração dos projetos do subtipo REVAMP. Esta análise fica um pouco prejudicada pelo fato do tamanho da amostra para projetos dos diversos subtipos ser muito pequena, exceto para o caso de Revamps e Melhoria das Instalações.

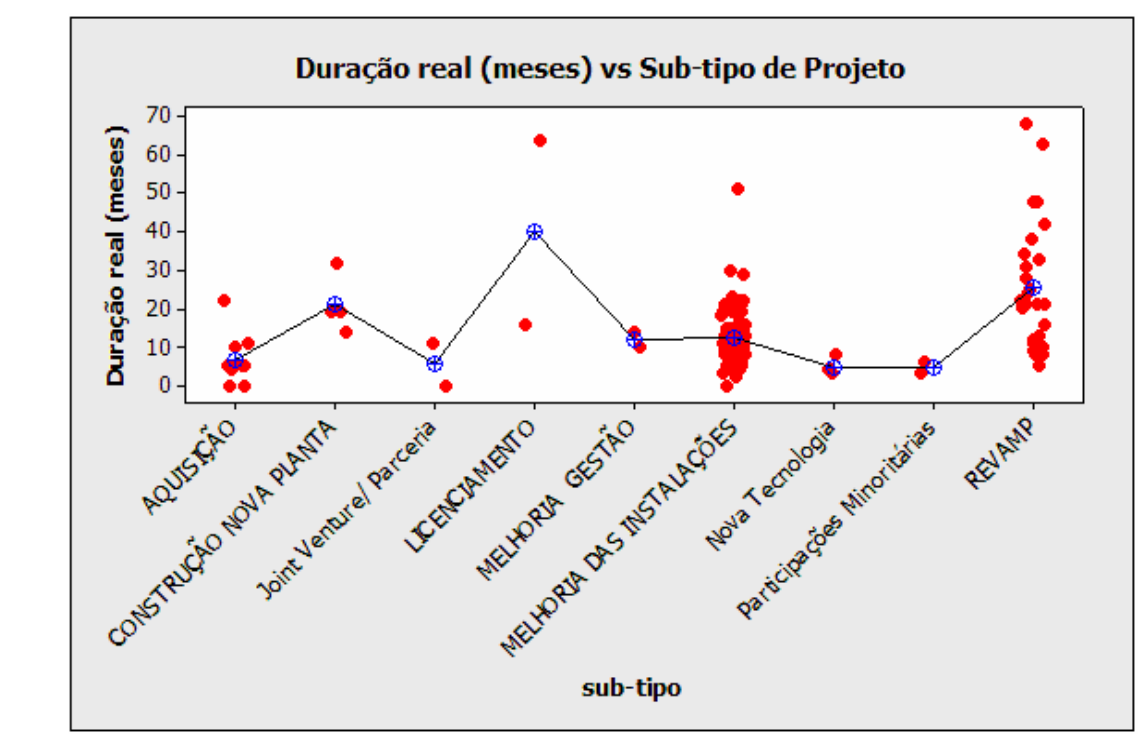

Gráfico 29 - Duração dos Projetos de Engenharia por Subtipo em meses (Fonte: Dados da Empresa - 2005)

O gráfico 30 apresenta o desvio dos projetos em termos de data de término prevista, ou seja, dá um indicativo dos atrasos dos projetos de engenharia. Como se pode verificar, a tendência é de haver um atraso médio em torno de 6 meses, estando a maior parte dos projetos na faixa que compreende atraso zero até um atraso de 12 meses. 


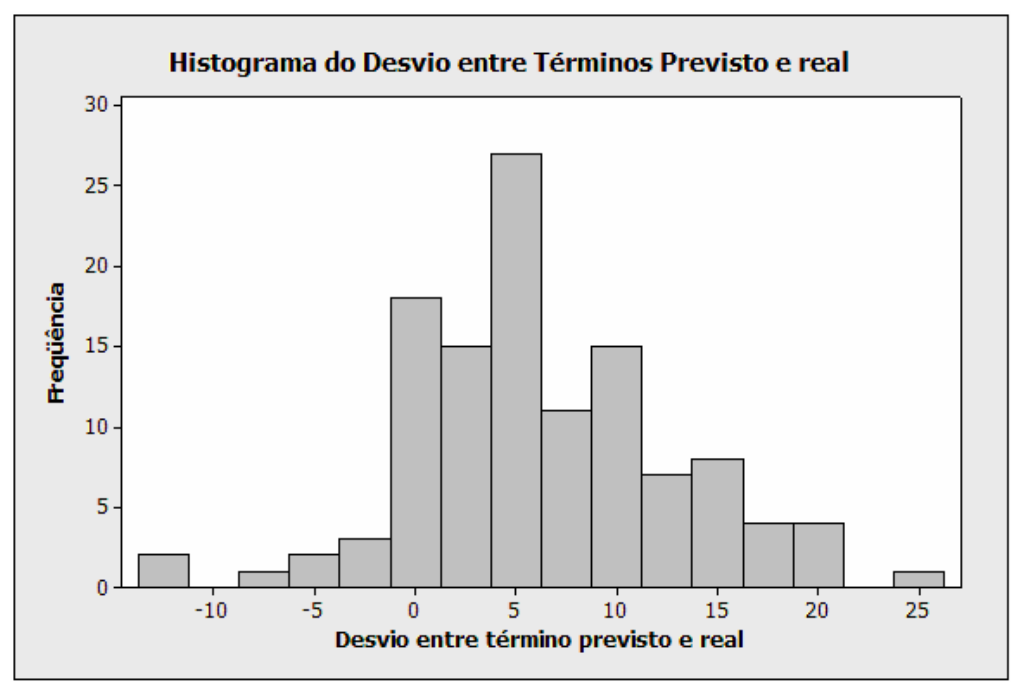

Gráfico 30 - Desvio entre término dos projetos real e previsto, em meses.

(Fonte: Dados da Empresa - Projetos de Engenharia 2005)

Os resultados apresentados pelos gráficos de 26 a 30 , confirmam os pressupostos de Cooper, Edgett e Kleinschmidt (2001) de que os métodos financeiros não são os melhores para gerir projetos de um portfólio, se utilizados isoladamente, podendo ocorrer distorções. Também foi possível comprovar através da análise dos mesmos gráficos a hipótese de McFarlan (1981) sobre a existência de riscos de projetos dos tipos atraso no cronograma de implantação e estouro no orçamento, sendo que tais riscos não costumam ser quantificados pelas organizações. A organização estudada também não armazena dados deste tipo.

A análise do portfólio feita anteriormente para os projetos denominados investimentos correntes e apresentada pelas figuras de 23 a 25, foi refeita para os projetos denominados "Projetos de Engenharia" segundo a nova classificação de projetos. A nova análise só foi realizada para os projetos de engenharia porque somente para eles tem sentido a avaliação de maturidade das tecnologias, posição competitiva da empresa, perfil de inovação e perfil dos investimentos. Somente os projetos de engenharia têm EVA (Economic Value Added) calculado e apresentado junto com a justificativa de investimentos.

Assim, a figura 27, a seguir, apresenta o perfil dos projetos de engenharia da companhia, aprovados para o ano de 2005. No total são 41 projetos representados pela cor das bolhas. Como observado anteriormente, através da figura 23, grande parte dos projetos se situa nas regiões de crescimento e maturidade. Entretanto, ao contrário do que foi mostrado pela figura 23, o diagrama da figura 27 mostra a existência de projetos na fase embrionária. Tais projetos não puderam ser observados 
na figura 23 devido ao corte feito pelo autor, expurgando os projetos estratégicos da análise, e isso causou uma distorção nas conclusões. Quanto ao posicionamento competitivo da empresa, a mesmas conclusões obtidas anteriormente são válidas, isto é, os projetos da empresa se situam na faixa que compreende uma posição competitiva entre favorável e predominante, em sua maioria. Esse posicionamento dá a empresa conforto no curto prazo. Quanto a probabilidade de sucesso, percebe-se uma mudança de cenário, em que a empresa passou a assumir mais riscos, existindo um projeto com alto valor, onde o valor é representado pelo tamanho das bolhas, numa faixa de probabilidade de sucesso intermediária.

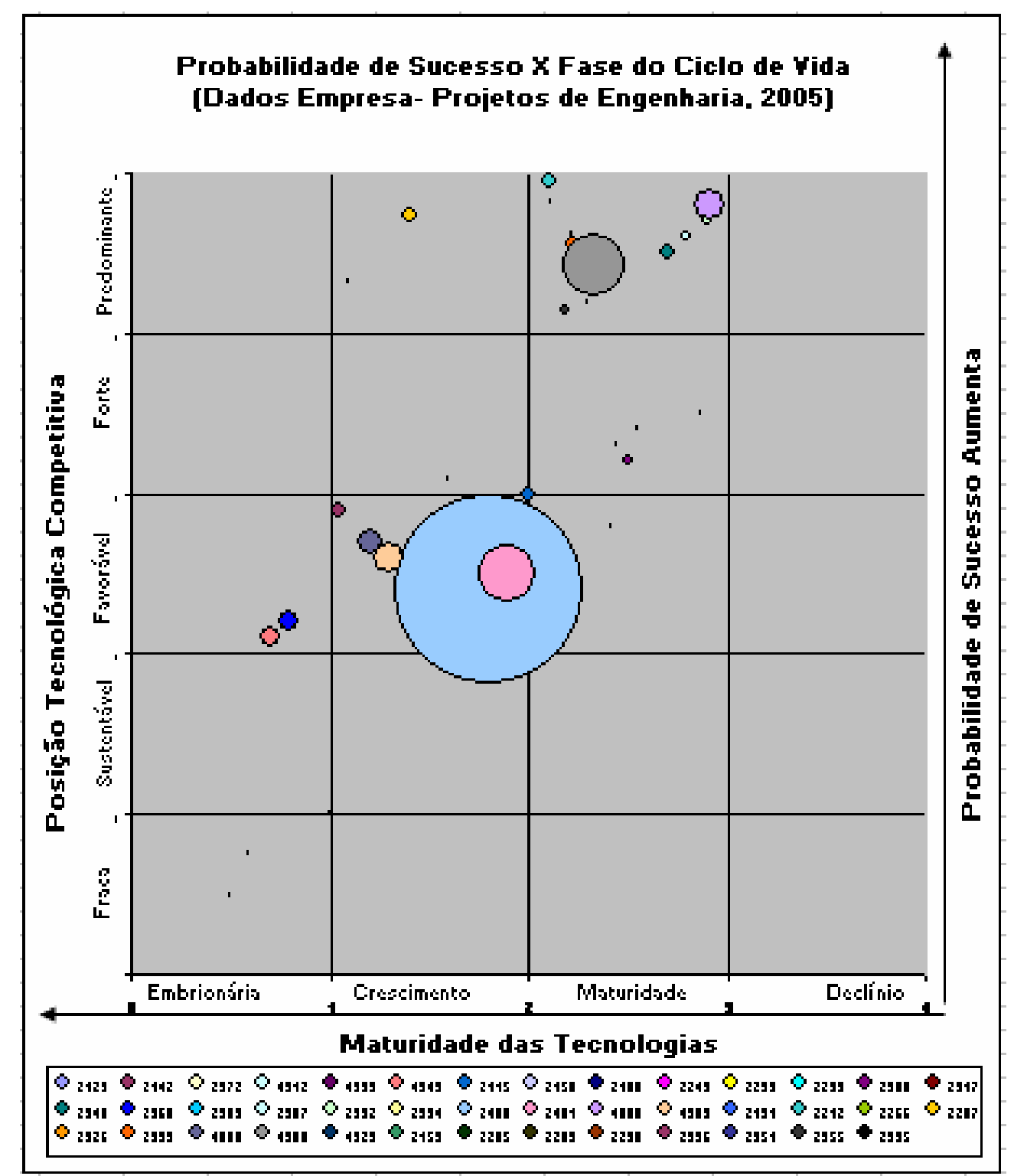

Figura 27 - Probabilidade de Sucesso x Fase do Ciclo de Vida

(Fonte: Roussel et al., 1991, Dados da Empresa, Projetos de Engenharia, 2005) 
Através da figura 28 faz-se análise idêntica a realizada com a figura 24, porém para os projetos do subtipo "Projetos de Engenharia" aprovados em 2005. Neste diagrama, conforme proposto por Lager (2002), os projetos do portfólio da empresa são representados pela cor das bolhas, o diâmetro das bolhas é dado pelo valor do investimento. Como se pode verificar, a maior parte dos projetos se situa na faixa de baixa inovação tecnológica e média inovação do processo, sendo grande parte dos projetos relacionados com a modificação de plantas existentes. Essa constatação coincide com o que já foi apresentado no gráfico 20 , em que a maior parte dos projetos de engenharia é referente a melhorias das instalações e REVAMPs.

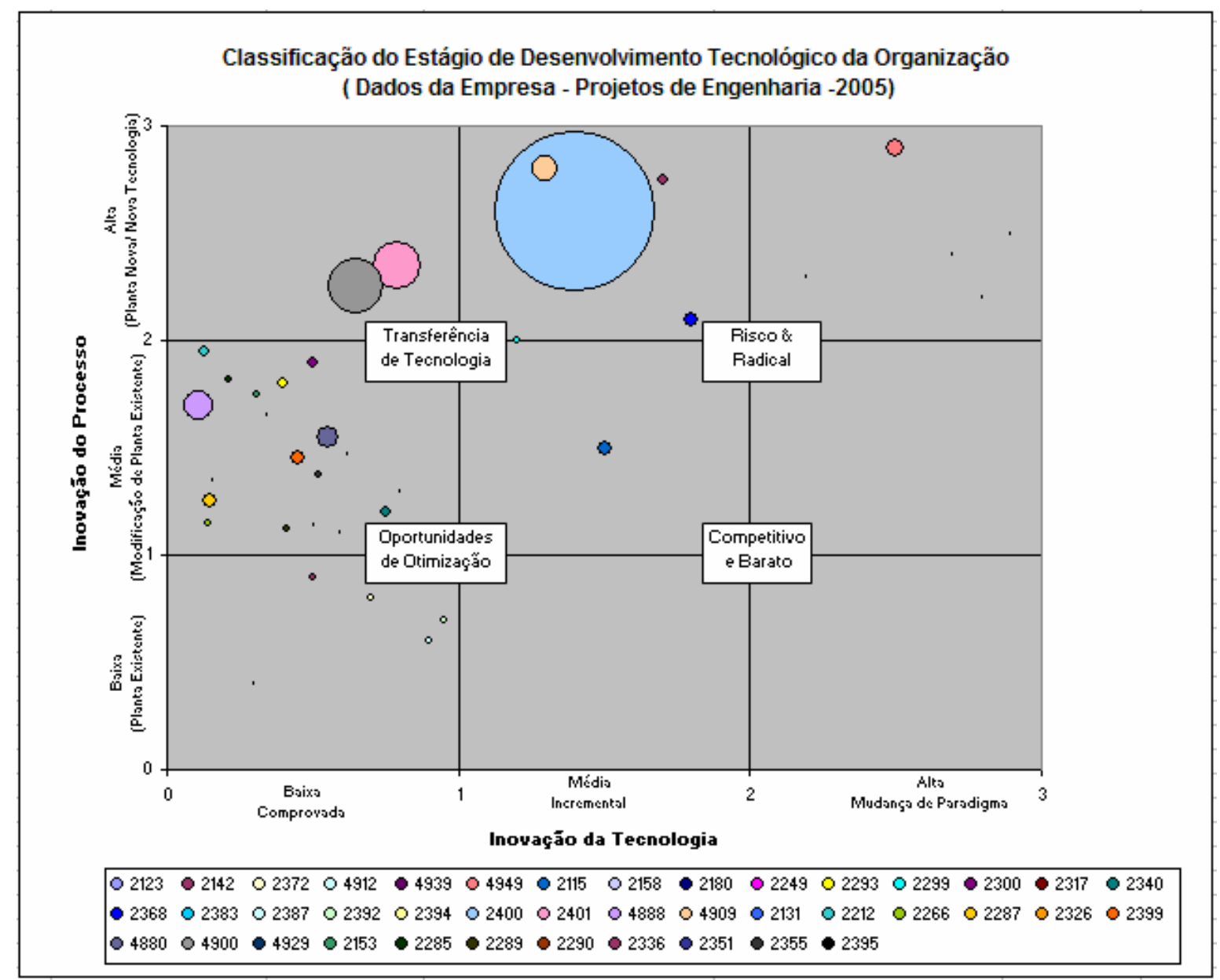

Figura 28 - Classificação do Estágio de Desenvolvimento Tecnológico da Organização

(Fonte: Lager, 2002, Dados da Empresa, Projetos de Engenharia, 2005)

Entretanto, a nova classificação nos permitiu identificar no portfólio da empresa projetos onde a inovação do processo é alta, com inovação da tecnologia em todos os 
graus, ou seja, baixa e comprovada, média e incremental e mudança de paradigma. Estes são os casos dos projetos de construção de novas plantas com nova tecnologia, dos tipos parcerias e licenciamentos, aquisições de novas plantas e novos negócios. Projetos de baixa inovação de processo com inovação tecnológica incremental ou mudança de paradigma, não foram observados nesse conjunto de dados por não precisarem de investimento. Para a empresa estudada esses projetos englobam projetos para a prospecção de novos mercados para produtos, processos e plantas existentes ou desenvolvimento de novas aplicações para produtos, processos e plantas existentes. Tais projetos são aqueles caracterizados como Projetos de P\&D do tipo "Projetos de Produto" tipos I e II, conforme descrito no item 4.3 deste trabalho.

Como última análise da nova classificação de projetos proposta, temos a figura 29, a seguir, que apresenta o perfil dos projetos com investimento aprovado do subtipo "Projetos de Engenharia".

A figura 29 mostra um diagrama de bolhas onde o diâmetro das bolhas representa a duração prevista para os projetos, enquanto que as cores das bolhas identificam cada um dos 41 projetos analisados, referentes ao ano de 2005. No eixo horizontal (eixo $\mathrm{X}$ ) foram alocados os valores dos investimentos em dólares americanos e no eixo vertical (eixo Y) foram alocados o EVA dos projetos, também em dólares.

A análise da matriz de Lager (2002) apresentada pela figura 29 chega ao mesmo resultado da figura 25, anteriormente analisada para os projetos de 2004, com investimento aprovado, isto é, não existem projetos com investimento do tipo Plataforma e a maior parte dos projetos se concentra no quadrante de projetos do tipo suporte.

A análise das figuras 27, 28 e 29 em conjunto, mostra que apesar da empresa ter como característica básica trabalhar em um ambiente onde a tecnologia é dominada, dando preferência a projetos de otimização, existe um movimento em relação aos dados de 2004, anteriormente analisados, através das figuras 23, 24 e 25, no sentido de inovar mais e assumir mais riscos. Quanto aos critérios de inovação de Chesbrough \& Teece (1996), Christensen \& Overdorf (2000), Christensen et al (2001) e Utterback (1994), o portfólio da empresa apresentou uma pequena mudança em relação aos dados anteriormente analisados, sendo os projetos caracterizados por terem inovação sistêmica, mas apresentando em seu portfólio projetos de inovação dos tipos sustentação e de ruptura e também projetos com inovação dos tipos 
incremental e radical. A maior parte dos projetos permanece com inovação de sistêmica, de sustentação e incremental.

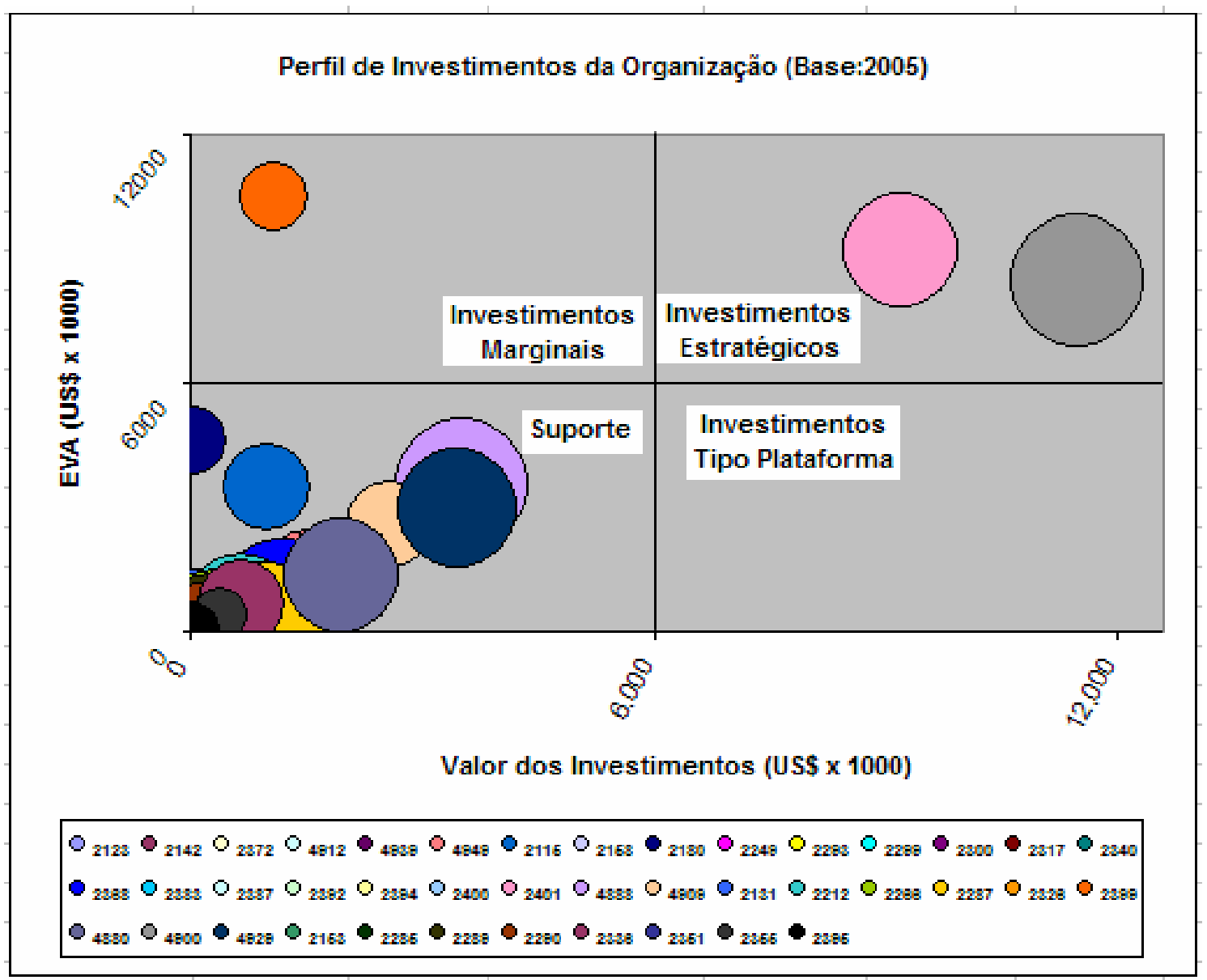

Figura 29 - Perfil de Investimentos dos "Projetos de Engenharia"

(Fonte: Dados da Empresa, 2005)

Assim, não se pode mais concluir que existe um desbalanceamento do portfólio da organização em relação ao grau de inovação. Também não é válido afirmar que não existem projetos embrionários. Foi possível notar uma mudança na estratégia da empresa com relação ao seu portfólio de projetos de 2004 para 2005, comprovando o caráter dinâmico da gestão de portfólio e a dificuldade de implantá-la com sucesso devido a constante negociação por recursos escassos entre diferentes áreas da companhia, e constantes mudanças devido à turbulência do mercado, conforme descrito por Brown e Eisenhardt (1998) e Eisenhardt e Brown (2000). Observa-se, entretanto, que a ausência de projetos do tipo plataforma permanece. A nova 
classificação proposta para a análise do portfólio, aparentemente é mais consistente com a realidade da empresa, sendo esta nova classificação utilizada para a aplicação do método AHP para o desenvolvimento do modelo de seleção e priorização de projetos proposto anteriormente. O recorte dos dados adotado para a caracterização dos projetos com investimento afetou as conclusões obtidas da análise do item 4.6 conforme previsto por Hammond, Keeney \& Raiffa (1998) ao falar das armadilhas do processo de tomada de decisão.

\subsection{Desenvolvimento do Modelo de Priorização e Seleção de Projetos}

Uma vez concluída a fase de reclassificação e análise dos projetos da organização em estudo, foi realizada uma atividade de feedback, com apresentação da nova classificação e novas conclusões dela decorrentes aos gestores da empresa conforme previsto no ciclo de pesquisa-ação proposto por Coughlan e Coghlan (2002). A partir deste ponto, o trabalho retornou a etapa de aplicação/validação do modelo, denominada no item 5.1 de parametrização do software. Nesta etapa, a parametrização é feita através da definição dos objetivos, identificação de critérios e subcritérios, seleção das alternativas de projetos, definição dos participantes, construção da estrutura de decisões e votação de pesos dos critérios e escala de variação dos critérios (ratings), além do cadastro dessas informações no software adotado como ferramenta de trabalho. Na seqüência foram definidas as restrições e relações de dependências entre os projetos. Por último foi feita a votação dos projetos para a definição das prioridades com o AHP e, a seguir, essa priorização foi refinada através do uso das restrições e dependências previamente definidas. Uma ilustração da seqüência de atividades executadas nesta etapa é apresentada pela figura 30 , abaixo. 


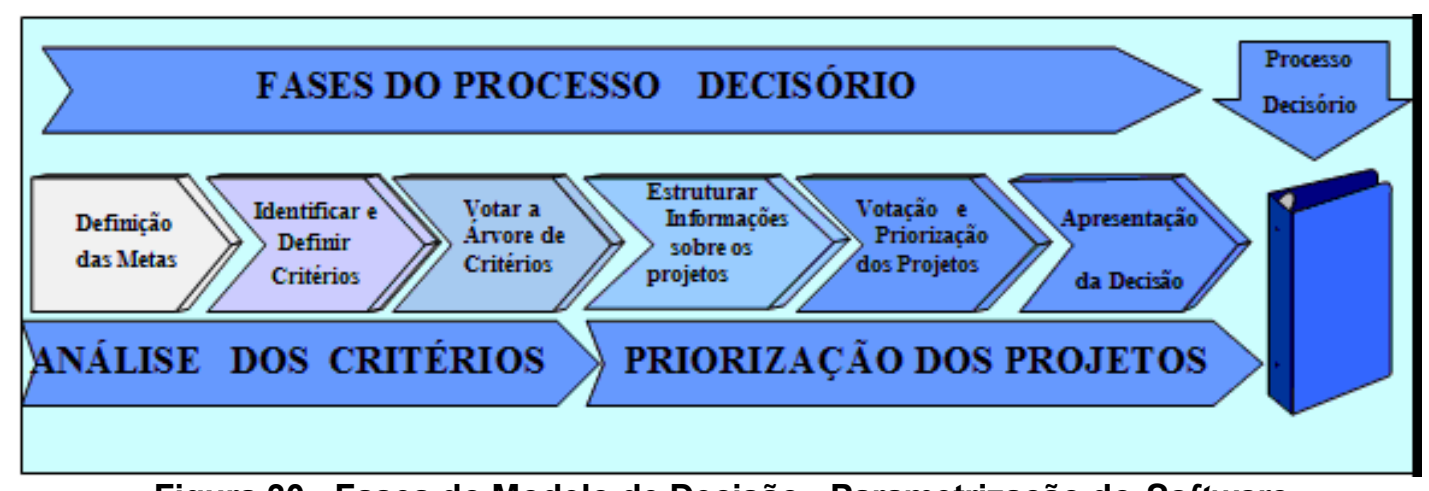

Figura 30 - Fases do Modelo de Decisão - Parametrização do Software

(Fonte: Figura do Autor)

As fases do modelo foram executadas 6 vezes, com diferentes grupos de participantes, pois a reclassificação dos projetos nos levou a necessidade de criar 6 estruturas de decisão, para os diferentes tipos de projetos identificados. A técnica de decomposição do problema em modelos de estrutura, bem como todos os passos do processo de decisão descritos por Clemen (1991) e apresentados na figura 2, foram empregados nesta etapa do trabalho.

Assim, foi criada uma estrutura de decisões para os projetos de P\&D, que é independente das demais e tem a função do pré-filtro proposto no modelo de decisão ilustrado pela figura 26. Esse pré-filtro será utilizado pelo comitê executivo da empresa para avaliar se novas propostas de projetos de P\&D devem ou não passar a compor o portfólio da organização e se projetos existentes devem ser mantidos ou paralisados.

Outras 4 estruturas de decisões foram criadas para os projetos de InfraEstrutura de P\&D, Informática (ou Tecnologia da Informação), Engenharia e de Manutenção. Essas 4 estruturas tratam da priorização de projetos com investimento aprovado, se constituindo no filtro para seleção e priorização de projetos técnica e economicamente viáveis a serem avaliados pela diretoria da organização. Para que a avaliação da diretoria esteja alinhada com a estratégia da organização, foi concebida uma estrutura principal, à qual as 4 estruturas anteriores são subordinadas. $\mathrm{Na}$ estrutura principal, o grau de contribuição das 4 estruturas a ela subordinadas com os 2 objetivos estratégicos da empresa, excelência e crescimento, constituem-se nos critérios de decisão.

Para a construção de todas as estruturas de decisão, o autor optou pela elaboração de um esboço, para posterior validação com os participantes definidos para os diferentes processos decisórios. Essa estratégia teve o objetivo de minimizar o número de reuniões com os funcionários da empresa, selecionados para atuarem 
como participantes na construção das diferentes estruturas de decisão, dado que havia grande dificuldade na conciliação de datas em que todos pudessem estar presentes. Como o autor é funcionário da organização em estudo, a estratégia se tornou viável, pois ele dispõe de conhecimento sobre a empresa e facilidade na coleta dos dados necessários.

A construção de cada uma das estruturas é detalhada a seguir.

\subsubsection{Projetos de P\&D (Pré-Filtro)}

A concepção do modelo de seleção e priorização dos projetos de P\&D, que se constitui no pré-filtro apresentado na figura 26, utiliza somente o método AHP para a priorização das propostas de projetos. Optou-se pela não inserção de restrições para evitar que idéias, potencialmente interessantes para a empresa, fossem eliminadas devido a falta de informações precisas nesta fase, que é essencialmente de elaboração de estudos.

A construção da estrutura de decisões foi baseada no modelo de seleção proposto por Lager (2002) e nos 32 critérios de atratividade e competitividade propostos por Jolly (2003). O critério de complexidade foi sugerido tentando-se inserir no modelo as 3 dimensões de projetos propostas por McFarlan (1981), tamanho do projeto, experiência com a tecnologia e estrutura do projeto. Além disso, foram introduzidos critérios já utilizados no modelo da empresa estudada e não identificados na literatura consultada.

A definição dos participantes foi fundamentada no critério de conhecimento das atividades da área de P\&D e disponibilidade. Somente uma pessoa pôde colaborar com esta fase do projeto de pesquisa, sendo o gerente de desenvolvimento de produtos e processos (GDPP). O perfil detalhado do participante dessa etapa do projeto de pesquisa é apresentado no APÊNDICE B.

Em 29/11/2006, foi realizada uma reunião na sede da empresa, com a participação do gerente de desenvolvimento de produtos e processos (GDPP) e o autor durante a qual foram validadas a estrutura de decisões dos projetos de P\&D esboçada pelo autor, os critérios de decisão, a escalas de valores (ratings) e suas 
definições. Na mesma ocasião foram votadas as prioridades dos projetos. Todos os passos da aplicação do método AHP propostos por Saaty (1991) e descritos no item 2.6.1 foram seguidos.

A figura 31 apresenta a estrutura de decisões resultante da discussão com o gerente da área GDPP.

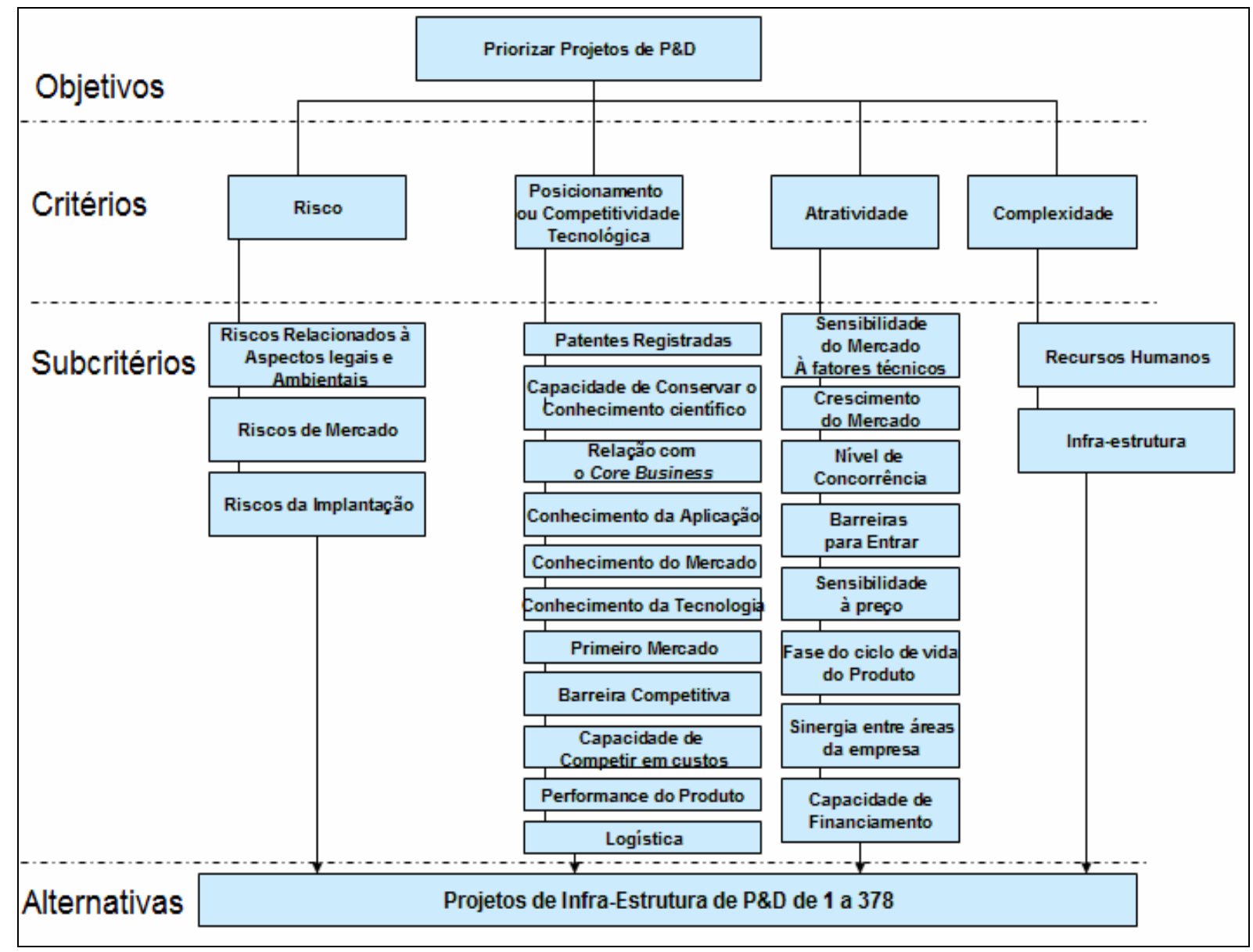

Figura 31 - Estrutura Hierárquica de Decisões para Projetos de P\&D da Empresa. Projetos sem Investimento (Fonte: Figura do Autor)

A definição de cada critério é apresentada no quadro 9, a seguir. 


\begin{tabular}{|c|c|}
\hline Critérios / subcritérios & Definicões \\
\hline Riscos & $\begin{array}{l}\text { Todo processo de decisão envolve riscos. Para projetos de P\&D estes riscos estão relacionados com cumprimento de legislação, desvios na } \\
\text { expectativa de mercado e riscos decorrentes da implantação do projeto. }\end{array}$ \\
\hline Riscos Relacionados aos Aspectos Legais e Ambientis & $\begin{array}{l}\text { Estä̃o relacionados a atendimento de requisitos das legisapuées governamentais a ambientais podendo ser alto, médio ou baixo dependendo da linha de } \\
\text { produtos. }\end{array}$ \\
\hline Risco de mercado & Eo risco de ociosidade por näo ter o mercado confirmado. \\
\hline Riscos da Implantação & $\begin{array}{l}\text { Atraso na montagem, partida com produto nâo especcificado, custos acima do orcado, atraso no projeto básico, atraso na compra } \\
\text { de equipamentos criticos, erros de espeecificação de equipamentios e materias, acidentes de trabalho }\end{array}$ \\
\hline Posicionamento ou Competitividade Tecnológica & A competitividade é medida em termos de número de patentes registradas, conhecimento da aplicação, mercado e tecnologia. \\
\hline \begin{tabular}{|l|l|} 
Patentes Registradas \\
\end{tabular} & Número de patentes registradas e submetidas a sprovaçăo. \\
\hline Conhecimento da Aplicaģão & 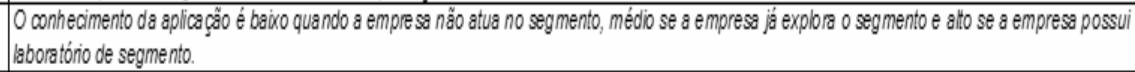 \\
\hline Conhecimento do Mercado & 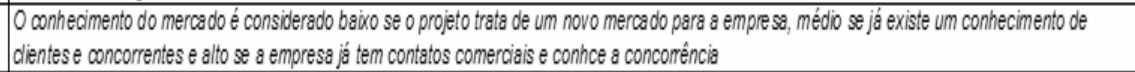 \\
\hline Conhecimento da Tecrologis & 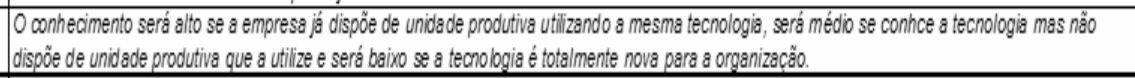 \\
\hline Primeiro Mercodo & Existem as opcōes da empresa ser a primeira no mercado, ou nöo ser prime ra porque existem muitos players. \\
\hline Bareira compettiva & 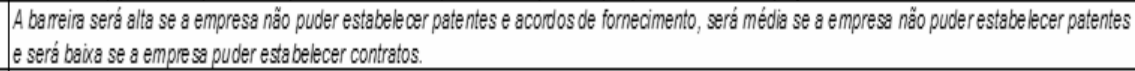 \\
\hline Capacidade de competir em custos de produção & $\begin{array}{l}\text { Pode variar entre atto, se a empress possui atla capa cidade de superar a concorrênnia, médio, se possui capocidade de competirno mercado e baixo, } \\
\text { se tem pouca capacidade de competir no mercado. }\end{array}$ \\
\hline Periomanae do Produto & Pode ser alta se o produto da empresa for superior a concorrência, média se for similar a conourrência e bàixa se for pior que a concomência \\
\hline Logistice & A empress pode ter logística inferior so mercado, similar so mercado ou superior so mercado \\
\hline Complexidade & A complexidade é medida em funcão da disponibilidade de recursos humanos e infraestrutura. \\
\hline Rec. humanos & 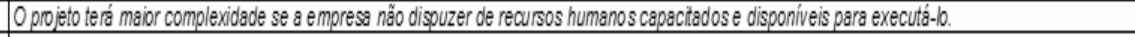 \\
\hline Infraestrutura & 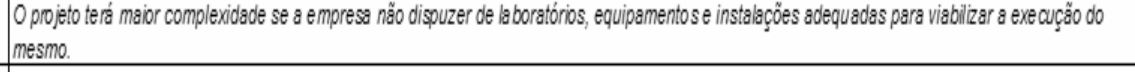 \\
\hline Atratividade & $\begin{array}{l}\text { A Atratividade é medida em função de fatores técnicos, nivel de crescimento do mercado e concorrência, existência de barreiras de entrada, } \\
\text { sensibilidade do produto à preço, ciclo de vida do produto, capacidade de obtenção de financiamento e sinergia com áreas da empresa. }\end{array}$ \\
\hline Sensibilidade do Mercado a Fatores Técnicos & Quanto o atendimento à especcica ção técmica, a performance na aplicação e a qualidade geral do produto interferem na decisão do cliente. \\
\hline Crescimento de Mercado & Éo\% de crescimento do mercado por ano \\
\hline Nivel de Concorrêncis & Refere-se so número de concorrentes stuantes para o mesmo mercado, segmentio ou produto. \\
\hline Bareiras para Entrar & $\begin{array}{l}\text { Barreiras para cópias ou imitapoes devido a existência de contratose patentes;devido a necessidade de alto investimento; pelo fato das matérias primas } \\
\text { serem importadascom baxa disponibilidade ou devido a existêncla de dientes integrados. }\end{array}$ \\
\hline Sensibilidade à Preço & O mercado é sensivel a variaģeses de prẹp, podendo uma pequena reduçăo de preçs proporcionar aumento significativo de vendase via-verse. \\
\hline Fase do Cido de Vida do Produto & O tempo de vida do produto seré considerado curto até 2 anos, médio até 5 anos e longo até 10 anos. \\
\hline Sinergia entre áress da Emoress & O projeto pode ser especifico de uma área ou ter sinergia entre diversas áreas. \\
\hline Capacidade de Financiamento & 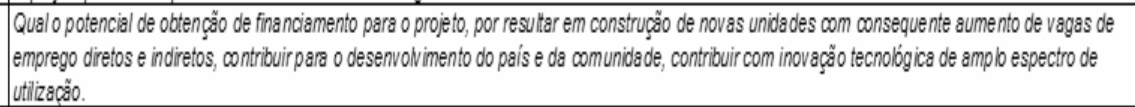 \\
\hline
\end{tabular}

Quadro 9 - Definição dos critérios de seleção e priorização dos Projetos de P\&D

Na seqüência foram dados dos pesos para cada critério. Para a execução desta etapa, o representante da empresa (GDPP), instruído pelo autor desta dissertação, fez a comparação de pares de critérios, respondendo a questão "quanto um critério é mais importante que o outro na seleção e priorização dos projetos de P\&D?".

O resultado da comparação dos critérios aos pares é apresentado pela figura 32.

Pelo que se pôde verificar, o critério mais importante para seleção de projetos de P\&D é o posicionamento/competitividade tecnológica, com peso igual a 0,213. $O$ segundo critério mais importante é a atratividade do negócio com peso de 0,192. A 
complexidade aparece em terceiro lugar, com peso igual a 0,053 e, por último, aparece o risco, com peso de 0,042. Esse resultado ratifica o pressuposto de McFarlan (1981) de que as empresas não levam em consideração riscos dos projetos.

\begin{tabular}{|l|l|}
\hline Decision Goal: Selecionar e Priorizar Proj. de P\&D \\
\hline 0,042 & Risco \\
\hline 0,005 & Riscos Relacionados aos Aspectos Legais e \\
\hline 0,028 & Risco de mercado \\
\hline 0,010 & Riscos da Implantação \\
\hline 0,213 & Posicionamento ou Competitividade Tecnológica \\
\hline 0,004 & Patentes Registradas \\
\hline 0,013 & Capacidade de Conservar o Conhecimento Cientifico \\
\hline 0,044 & Relação com o Core Business \\
\hline 0,012 & Conhecimento da Aplicaçăo \\
\hline 0,018 & Conhecimento do Mercado \\
\hline 0,019 & Conhecimento da Tecnologia \\
\hline 0,016 & Primeiro Mercado \\
\hline 0,038 & Barreira competitiva \\
\hline 0,024 & Capacidade de competir em custos de produçăo \\
\hline 0,012 & Performance do Produto \\
\hline 0,012 & Logistica \\
\hline 0,053 & Complexidade \\
\hline 0,040 & Rec. humanos \\
\hline 0,013 & Infraestrutura \\
\hline 0,192 & Atratividade \\
\hline 0,010 & Sensibilidade do Mercado a Fatores Técnicos \\
\hline 0,029 & Crescimento de Mercado \\
\hline 0,037 & Nivel de Concorrència \\
\hline 0,052 & Barreiras para Entrar \\
\hline 0,017 & Sensibilidade à Preço \\
\hline 0,015 & Fase do Ciclo de Vida do Produto / Tempo de vida do \\
\hline 0,028 & Sinergia entre áreas da Empresa \\
\hline 0,006 & Capacidade de Financiamento \\
\hline
\end{tabular}

Figura 32 - Pesos de Critérios e Subcritérios dos Projetos de P\&D

A análise do coeficiente de inconsistência dado pela equação 12, que mede a coerência das respostas dadas na etapa de comparação dos pares de critérios, foi realizada, conforme descrito no item 2.6.1. O valor para o coeficiente de inconsistência resultante da comparação dos critérios foi de 0,05 ; não sendo necessário rever a comparação, pois seu valor é menor que 0,10 . Os valores para as inconsistências resultantes da comparação dos subcritérios risco, posicionamento, complexidade e atratividade foi de 0,$13 ; 0,073 ; 0,0$ e 0,$10 ;$ respectivamente. Como somente o coeficiente de inconsistência da comparação dos subcritérios relacionados aos riscos foi maior que 0,10; esta foi a única votação reavaliada. Neste caso, os riscos da implantação foram considerados moderadamente mais importantes que os riscos 
legais e ambientais. A análise da matriz hierárquica de critérios frente a teoria recomendava que tais subcritérios tivessem pesos iguais, entretanto, o participante da empresa preferiu manter seu voto, baseando-se no histórico de projetos da organização. Essa decisão confirma a afirmação de Forman \& Selly (2001) e Saaty (1991), em que o índice de inconsistência menor ou igual a $10 \%$ é considerado aceitável, sendo que em circunstancias particulares ele pode ser maior, pois é possível ser perfeitamente consistente, mas consistentemente errado.

A fase seguinte foi a da concepção da escala de valores e suas definições. Para a definição do intervalo de variação de cada subcritério, utilizou-se novamente o recurso da comparação de pares. O escala de valores obtida é apresentada no APÊNDICE C, ela mede a intensidade com que cada subcritério de decisão para a estrutura de projetos de P\&D pode variar.

O último passo da aplicação do método AHP foi a votação dos projetos em relação a cada subcritério. Neste ponto, o autor desta dissertação se deparou com duas dificuldades: o representante da empresa (GDPP) não tinha conhecimento suficiente para votar todos os projetos de P\&D do portfólio e o número de projetos deste tipo era muito grande, num total de 378 . Como cada projeto teria que ser votado para os 24 subcritérios da estrutura de decisões, o número de combinações seria excessivo, levando-se muito tempo, o que se mostrou inviável.

Por isso o autor sugeriu que os 378 projetos fossem subdivididos por área de negócio, de tal forma que se conseguisse reduzir o número de projetos a serem votados pelo mesmo grupo de participantes. Na seqüência o autor propôs que cada gerente de mercado juntamente com representantes da área de marketing de cada área de negócios, auxiliasse o gerente de desenvolvimento de produtos e processos (GDPP) a votar a parte dos projetos em que são especialistas. Assim, para a mesma árvore, seriam feitas votações de cinco áreas de negócios: Intermediários de Síntese, Tensoativos, Solventes, outros produtos de performance e catalisadores. A sugestão de fragmentar o problema dos projetos de P\&D por área de negócio é suportada por Clemen (1991) que sugere que a técnica de decomposição do problema em modelos de estrutura seja usada para simplificar problemas complexos que envolvam um grupo de pessoas e por McFarlan (1981) que afirma que é necessário classificar os projetos de modo que seja possível diferenciá-los e compará-los com projetos similares. Esse trabalho não foi concluído devido a dificuldade de conciliar a disponibilidade dos representantes da empresa com prazo para a conclusão desse trabalho de mestrado. 
Fica, portanto, a recomendação para que seja feita a validação completa desta parte do modelo em trabalho futuro. Um exemplo dos projetos de P\&D, utilizados neste trabalho, encontra-se no ANEXO B, não tendo sido apresentados em sua totalidade devido ao grande número (da ordem de 500) e por não terem sido utilizados.

Um procedimento similar ao proposto aqui para a validação da estrutura de decisão de projetos de P\&D foi seguido para os projetos de manutenção descrito no item 5.3.2.5, onde a votação dos projetos foi feita por site, devido a dificuldade dos chefes de manutenção de cada fábrica compararem os projetos de sua unidade com os das demais unidades produtivas. Acredita-se que os resultados obtidos através da análise da estrutura de manutenção sejam semelhantes ao que se obteria no caso dos projetos de $\mathrm{P} \& \mathrm{D}$, não se tendo perdido qualidade de informações para este estudo.

\subsubsection{Projetos com Investimento (Filtro)}

Conforme descrito anteriormente, a concepção da parte do modelo de seleção e priorização de projetos com investimento aprovado (filtro da figura 26) utiliza os métodos AHP e programação inteira. A construção desse modelo se deu através da elaboração de 5 estruturas de projetos, sendo uma principal e 4 à ela subordinadas, correspondentes aos 4 tipos de projetos resultantes da nova classificação proposta que são os projetos de Infra-Estrutura de P\&D; Projetos de Tecnologia da Informação; Projetos de Engenharia e Projetos de Manutenção.

Inicialmente, os esboços dessas 5 estruturas foram desenhados pelo autor. Nesta fase foram propostos os objetivos, critérios de decisão e ratings para cada estrutura, correspondentes às duas primeiras etapas das fases de decisão apresentadas na figura 30 .

Foram utilizados os dados dos projetos relativos ao ano de 2005, reclassificados, conforme Apêndice $D$, como alternativas a serem priorizadas em cada estrutura de decisões. A escolha dos dados obedeceu aos seguintes critérios:

o Por se tratar de projetos recentes os participantes ainda tinham em mente os porquês das decisões tomadas, o escopo de cada projeto, 
problemas ocorridos durante a implantação, tais como alterações de escopo, atrasos ou estouro no orçamento. A lembrança dos projetos e estratégia adotada nas decisões facilitava a discussão;

o Para o conjunto de projetos selecionado existiam dados disponíveis sobre EVA, valores orçados e reais, duração estimada e real, e seqüência de execução ocorrida. Assim, era possível a utilização de informações reais dos projetos para avaliar os resultados do modelo de decisão proposto.

Para a realização das fases seguintes representadas na figura 30 (validação da árvore de decisões, votação dos pesos dos critérios, estruturação e votação dos projetos e apresentação dos resultados), foi escolhido um grupo de funcionários fortemente envolvido no processo de seleção e priorização de projetos da empresa. Para cada tipo de projetos foi selecionado um grupo de participantes diferente, segundo os critérios intencionais descritos a seguir, que estão de acordo com as técnicas de coleta de dados prescritas por Thiollent (2004) para a pesquisa-ação:

o Disponibilidade dos tomadores de decisão para participar do estudo;

o Conhecimento dos participantes sobre cada projeto;

o Experiência dos participantes na função de gestão dos projetos;

o Área de negócio a que os participantes pertencem;

o Tempo que os participantes trabalham na empresa estudada.

O perfil dos participantes da concepção e validação de cada estrutura de decisão pode ser consultado no APÊNDICE B.

\subsubsection{A Estrutura Principal de Projetos com Necessidade de Investimento}

Para a votação dos pesos dos critérios da estrutura principal, foram escolhidos como participantes, o diretor industrial da organização e um assessor de diretoria.

A estrutura principal, apresentada na figura 33 foi validada pelos participantes e tem o objetivo de promover o alinhamento estratégico dos projetos selecionados. 


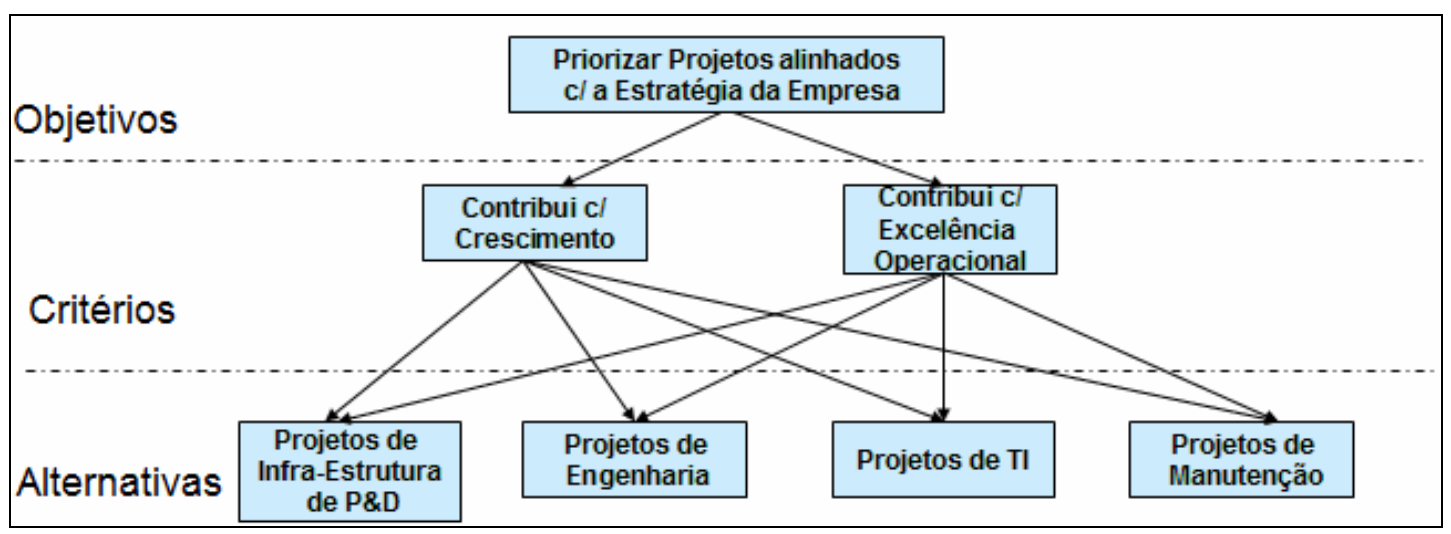

Figura 33 - Estrutura Hierárquica de Decisões para Projetos com Investimento Árvore Principal (Fonte: Figura do Autor)

Considerando-se que existe um valor limite de investimentos a ser aprovado por ano, propôs-se aos participantes, durante uma reunião de apresentação da metodologia, que dessem pesos aos 2 objetivos estratégicos da organização, tendo como foco a priorização dos 4 tipos de projetos alinhados com a estratégia da empresa.

Esses objetivos, definidos pelo plano estratégico da empresa, são "crescimento" e "excelência operacional". O critério de "crescimento" é definido pela organização como sendo "ações de aumento de capacidade" tais como: REVAMPs, construção de novas plantas, otimizações de plantas existentes, aquisições de novas plantas, ampliação da linha de produtos e vendas, associações ou aquisições de participações em outras empresas. Os projetos de "excelência operacional" são aqueles de manutenção das instalações através da substituição de equipamentos/sistemas em final de vida, modernização, automação industrial, projetos para garantir a segurança das instalações e funcionários e ações de controle ambiental, garantindo o cumprimento rigoroso da legislação e normas existentes.

As alternativas de projetos onde a empresa pode investir, conforme anteriormente descrito são: Projetos de Infra-estrutura de P\&D, Projetos de TI, Projetos de Engenharia e Projetos de Manutenção.

A idéia da utilização do método AHP na estrutura principal é obter um critério de alocação claro para o valor a ser investido para cada tipo de projeto, considerandose que exista um valor máximo de investimento total anual aprovado pelos acionistas da empresa. Outro objetivo é tomar decisões alinhadas com a estratégia da organização. Nesse sentido, a idéia proposta é suportada por Saaty $(1991,1999)$, que 
afirma que o método AHP tem sido aplicado com sucesso na solução de problemas de alocação de recursos, formulação e avaliação de políticas e alinhamento estratégico.

Essa alocação é resultado do processo de comparação por pares dos 2 critérios conduzido junto com os representantes da empresa e da votação de cada projeto em relação a cada um dos critérios.

Neste processo, foi solicitado aos tomadores de decisão, ou participantes, que votassem a importância relativa dos critérios em relação ao objetivo, usando a escala de valores de Saaty (1991) apresentada no quadro 2, com variação de 1 a 9, onde o valor 1 significa que os critérios têm a mesma importância relativa e 9 significa que um dos critérios é extremamente mais importante que o outro. Os valores 3,5 e 7 são intermediários na escala, significando que um critério é moderadamente, fortemente e muito fortemente mais importante que o outro, respectivamente.

A figura 34 ilustra a comparação por pares dos critérios de decisão acima descrita.

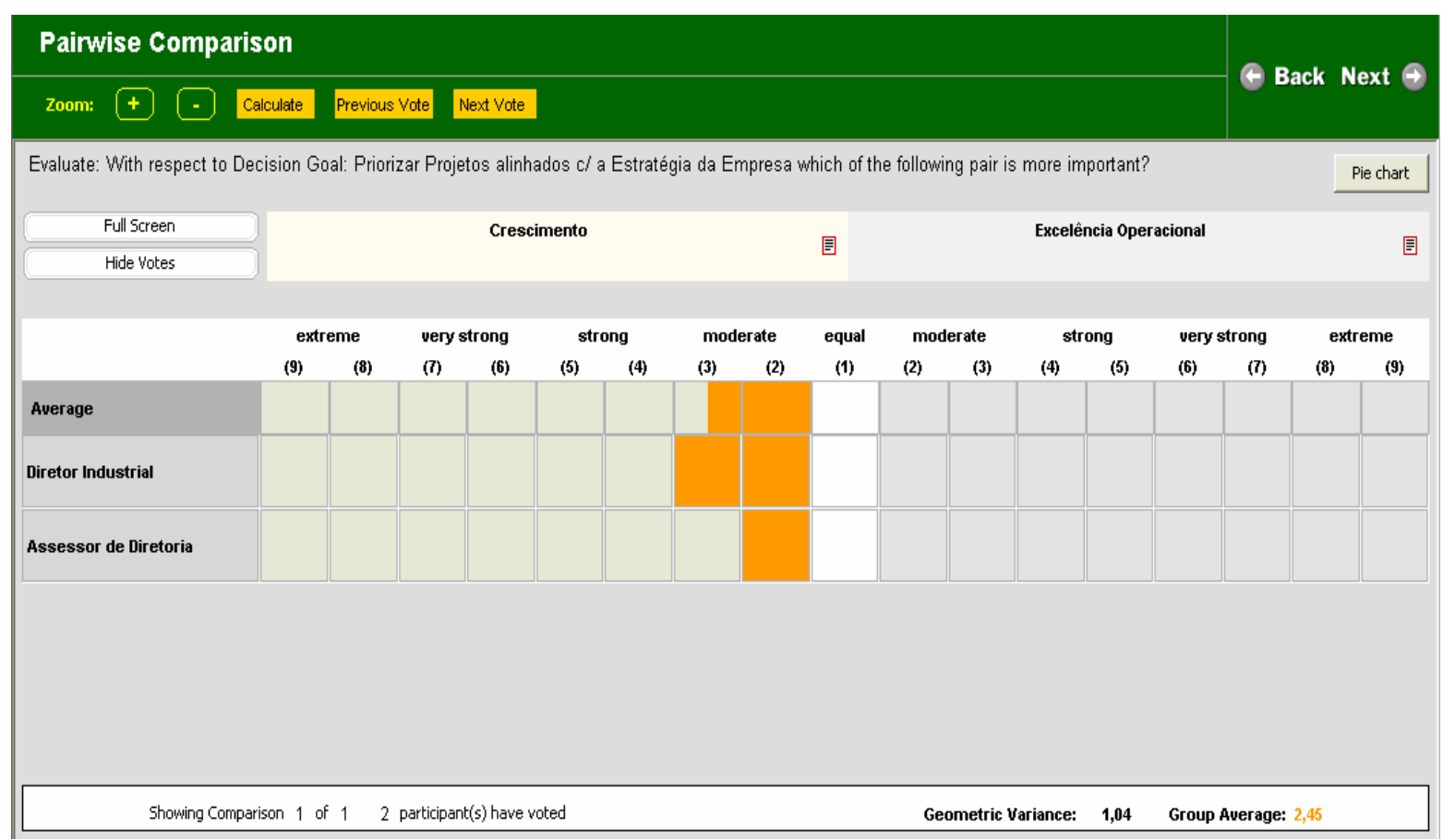

Figura 34 - Comparação dos Critérios aos Pares usando AHP - Estrutura Principal

A votação dos participantes teve coeficiente de inconsistência, calculado segundo a equação (12), igual a zero, mostrando que eles estão alinhados entre si. A 
média da votação resultou num valor de 2,45; sendo considerado o critério crescimento moderadamente mais importante que a excelência operacional. A variância obtida foi de 1,04. O gráfico de prioridades resultante é apresentado pela figura 35. Nesta figura é possível verificar o resultado da comparação por pares, em que o critério de crescimento ficou com peso 0,71 enquanto que excelência tem peso 0,29 .

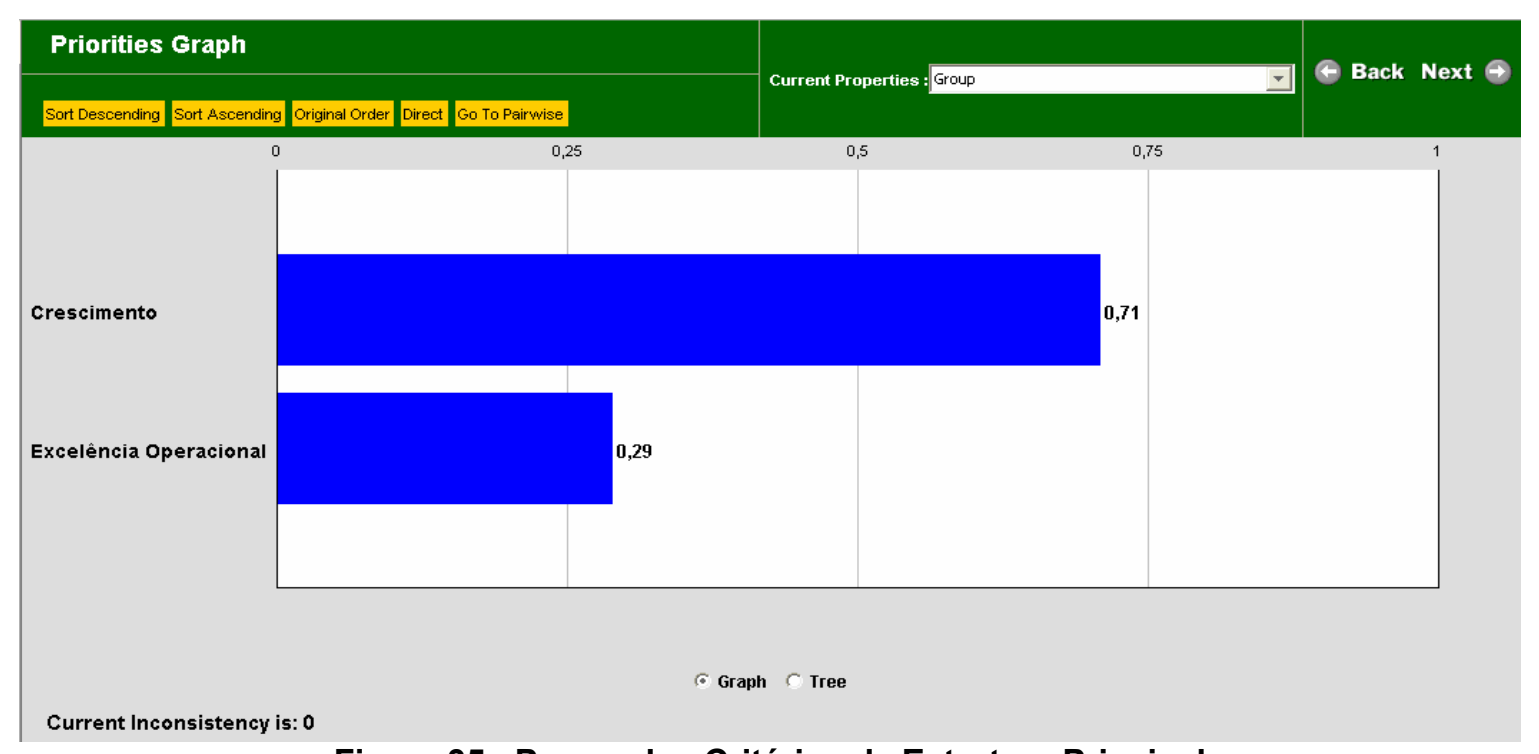

Figura 35 - Pesos dos Critérios da Estrutura Principal

Uma vez concluídas as comparações por pares dos critérios, foi solicitado aos participantes que passassem para a etapa final do AHP, que é a avaliação dos 4 tipos de projetos frente aos 2 critérios. Nesta fase foram votadas as importâncias relativas de cada alternativa de projeto em relação a cada critério, também com o uso da escala de 9 pontos de Saaty (1980), proposta anteriormente. Para a execução dessa atividade, foi perguntado aos participantes qual a contribuição de cada tipo de projeto para aumentar o crescimento da empresa e depois, qual o potencial dos mesmos tipos de projetos melhorarem a excelência operacional da empresa.

Como resultado da aplicação do método AHP para determinação de quais as prioridades ou pesos para cada tipo de projeto para a organização, obteve-se que os "Projetos de Engenharia" são os mais importantes, seguidos dos "Projetos de Manutenção", depois pelos "Projetos de Infra-Estrutura de P\&D" e, por último; pelos 
"Projetos de $\mathrm{Tl}$ ". Os pesos relativos de cada tipo de projeto são apresentados pela figura 36.

\begin{tabular}{|c|c|c|c|c|}
\hline Order & Alternatives & 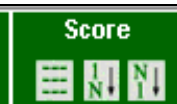 & $\begin{array}{l}\text { Crescimento } \\
0,71\end{array}$ & $\begin{array}{l}\text { Excelência Operacional } \\
0,29\end{array}$ \\
\hline 1 & Projetos de Engenharia & 0,51 & 0,70 & 0,05 \\
\hline 2 & Projetos de Manutençẫo & 0,22 & 0,05 & 0,64 \\
\hline 3 & Projetos de Infraestrutura de P\&D & 0,18 & 0,18 & 0,20 \\
\hline 4 & Projetos de TI & 0,09 & 0,08 & 0,11 \\
\hline
\end{tabular}

Figura 36 - Pesos dos Projetos da Estrutura Principal

Os resultados obtidos se aproximam dos valores reais orçados para os 4 tipos de projetos para o ano de 2005, conforme se pode observar pela tabela 4 . Verifica-se que, na prática, a empresa investiu $8 \%$ a mais com projetos do tipo manutenção, $6 \%$ a menos com projetos de infra-estrutura de P\&D e 3\% a menos com projetos de TI que o resultado proposto pelo modelo.

Tabela 4 - Prioridades reais adotadas pela empresa para os 4 Tipos de Projetos em 2005

\begin{tabular}{||l|r|r||}
\hline Tipo de Projeto & Valor do Orçamento Aprovado (US\$) & \multicolumn{1}{|c|}{$\%$} \\
\hline Infraestrutura de P\&D & 4.477 .700 & 0,12 \\
\hline Tecnologia da Informação (TI) & 2.375 .100 & 0,06 \\
\hline Engenharia & 19.767 .949 & 0,52 \\
\hline Manutenção & 11.722 .060 & 0,30 \\
\hline Total & 38.342 .809 & 1,00 \\
\hline Base (Ano 2005) & & \\
\hline
\end{tabular}

A realização da análise de sensibilidade, conforme proposto por Clemen (1991) e Shimizu e Laurindo (2001), através da variação dos pesos dos critérios de decisão mostrou que a prioridade dos tipos de projetos não muda mesmo se os pesos dos critérios "Excelência" e "Crescimento" ficarem iguais, isto é, com valor igual 0,50. Quando variamos o peso do critério "Excelência" para Zero, o tipo de projeto de maior prioridade ainda permaneceu o de "Engenharia". Por outro lado, ao variarmos o peso do critério "Crescimento" para zero, os projetos do tipo "Manutenção" assumiram maior prioridade. Essa análise mostra que o resultado obtido foi consistente com a realidade, não sendo afetado por pequenas variações nas votações. 


\subsubsection{A Estrutura dos Projetos de Infra-Estrutura de P\&D}

Para montar a estrutura hierárquica dos projetos de infra-estrutura de P\&D, como já comentado, o autor trabalhou num primeiro momento sozinho, na criação do esboço da estrutura de decisões.

Na seqüência foi realizada uma reunião em 29/11/06 para a aplicação do método AHP, em que foi feita a validação da hierarquia, dos critérios e escalas de valores (ratings) e de suas definições junto com os participantes, funcionários da empresa. Na mesma reunião foram votadas as prioridades dos projetos.

Os dados dos projetos a serem priorizados para esta árvore de decisões se referem aos projetos de infra-estrutura de P\&D aprovados para o ano de 2005. Tais projetos somam o total de 36 alternativas. Os dados sobre os 36 projetos do tipo infraestrutura de P\&D podem ser consultados no Apêndice D.

Foram definidos como participantes para a aplicação do método AHP para os projetos de infra-estrutura de P\&D o gerente da área de desenvolvimento de produtos e processos (GDPP) e um especialista da área de aplicações, indicado pela gerência de aplicações (GA).

No início da reunião, o autor apresentou o método AHP, o software Decison Lens e os objetivos da pesquisa aos participantes.

$\mathrm{Na}$ seqüência, deu-se continuidade a reunião, discutindo-se a validade da estrutura de decisões esboçada pelo autor. Esta estrutura é apresentada na figura 37.

Os participantes não reconheceram o esboço proposto como válido para a tomada de decisões relacionadas com os projetos de Infra-Estrutura de P\&D. Assim, após uma discussão, com uso da técnica de brainstorming, foi possível a construção de uma estrutura mais simples e mais próxima da realidade dos participantes. 


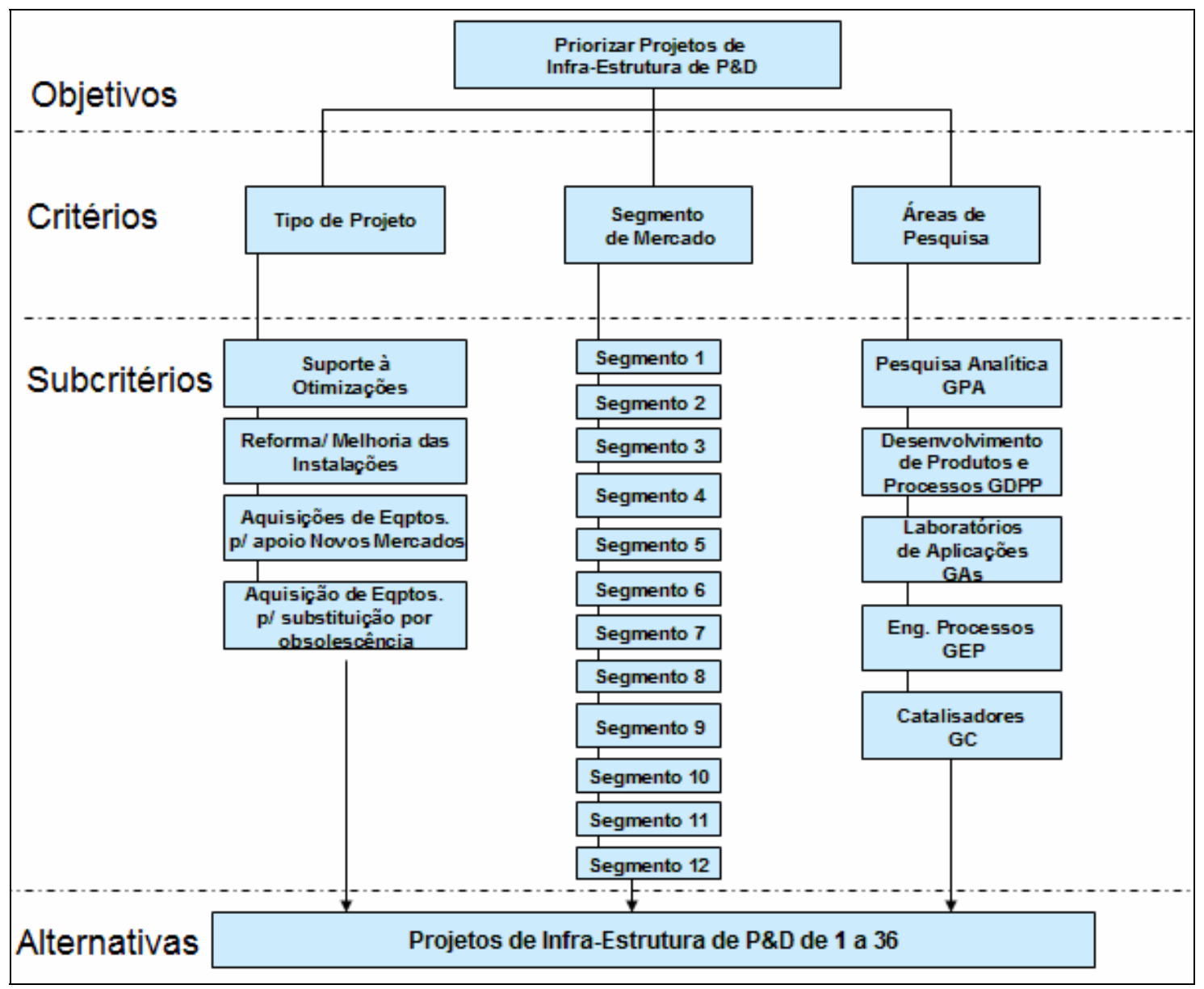

Figura 37 - Estrutura de Projetos de Infra-estrutura de P\&D - Proposta do Autor

A nova estrutura, proposta pelos participantes, é apresentada pela figura 38 .

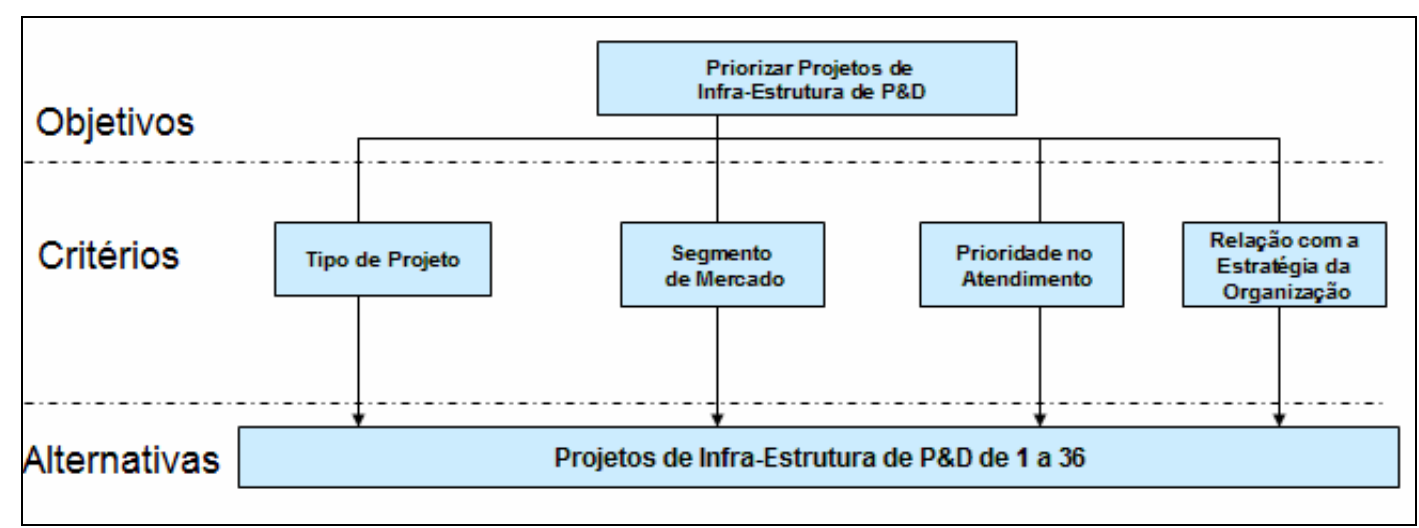

Figura 38 - Estrutura de Projetos de Infra-estrutura de P\&D - Versão Final

A definição dos critérios de decisão utilizados na estrutura de projetos de Infraestrutura de P\&D é apresentada no quadro 10. A prioridade no atendimento e a relação com a estratégia da organização são critérios relacionados com a atratividade e competitividade tecnológica propostos por Jolly (2003). Tipo de projeto e segmento 
de mercado são critérios relacionados com a complexidade dos projetos, mas não encontrados na literatura exatamente como encontrados na organização estudada.

\begin{tabular}{|c|c|}
\hline Critério & Definição \\
\hline Tipo de Projeto & Substituição de Equipamentos, Compra de Equipamentos Novos, Atendimento à Normas SSMA (Saúde, Segurança e Meio Ambiente) \\
\hline Segmento de Mercado & 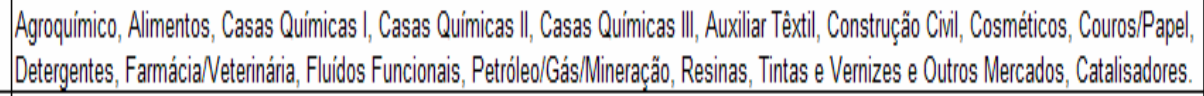 \\
\hline Prioridade no Atendimento & Os atendimentos podem ser para atender RNC ( Registros de Näa.Conformidades), atendimento ao cliente, desenvolimentio ou capacitaçâa \\
\hline Relação com a Estratégia da Organização & Se o projett tem ligaçäo com projeltos estratégicos ou se é estratégico para o escoamento de co-produtos. \\
\hline
\end{tabular}

Quadro 10 - Definição dos critérios de seleção e priorização dos Projetos Infra-Estrutura de P\&D

A etapa seguinte da aplicação do método AHP se constituiu na obtenção dos pesos para cada critério. Para a execução desta etapa, os participantes foram conduzidos pelo autor a fazer a comparação de cada critério aos pares, respondendo a questão "quanto um critério é mais importante que o outro na seleção e priorização dos projetos de infra-estrutura de P\&D?".

O resultado da comparação dos critérios é apresentado pela figura 39. Pelo que se pode verificar, o critério mais importante para seleção de projetos de infraestrutura de P\&D é a relação com a estratégia da organização, com peso igual a 0,55. O segundo critério mais importante é a prioridade no atendimento com peso de 0,33 ; o segmento de mercado aparece com peso igual a 0,08 e, por último, aparece o tipo de projeto, com peso de 0,04 .

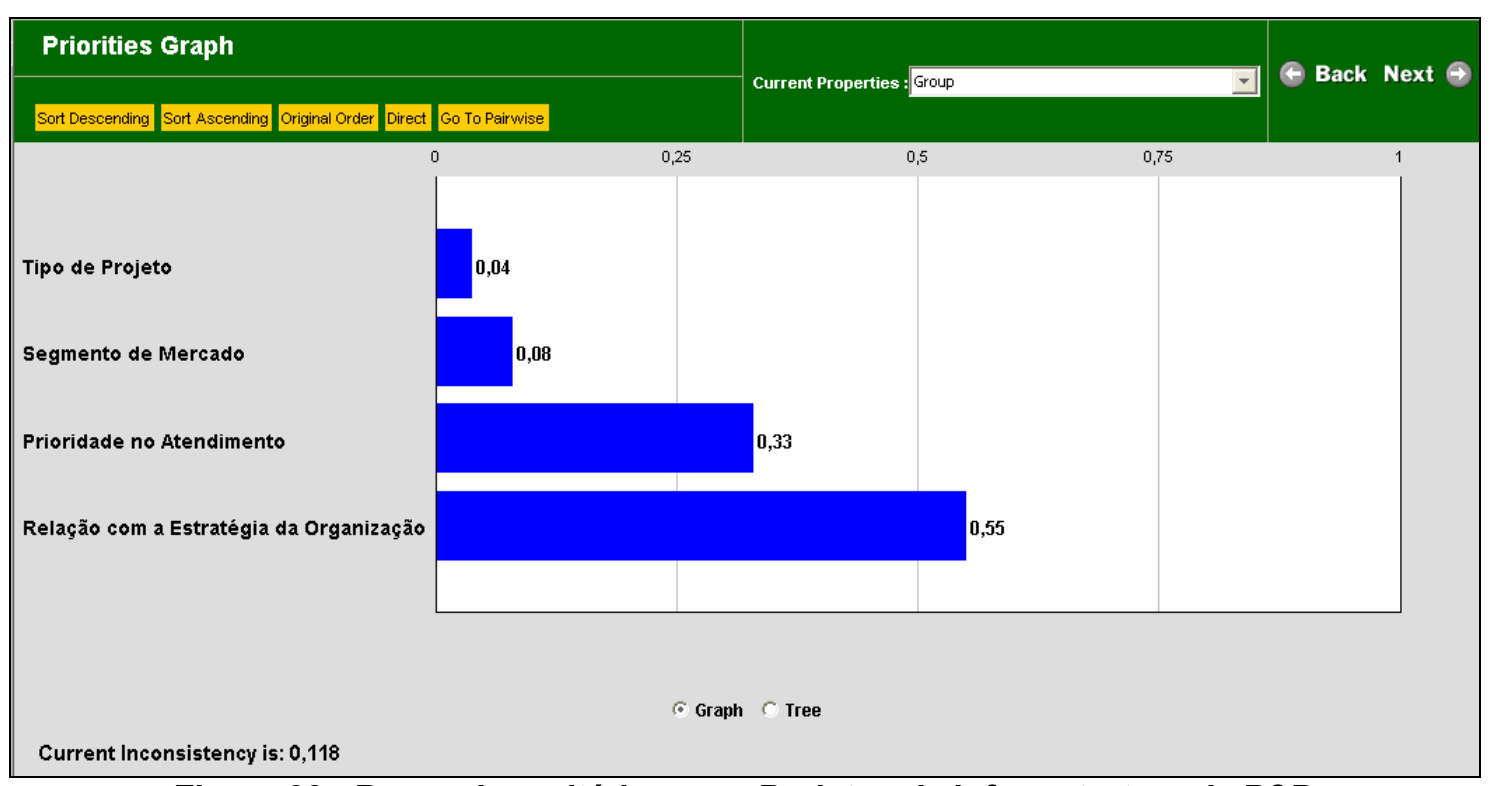

Figura 39 - Pesos dos critérios para Projetos de Infra-estrutura de P\&D 
O processo de comparação dos critérios aos pares gerou um coeficiente de inconsistência nas respostas igual a 0,118; pouco superior ao limite de 0,10; recomendado por Saaty (1991). A inconsistência foi devida a 3 comparações realizadas pelos participantes: prioridade no atendimento $\mathrm{x}$ relação com a estratégia da organização, tipo de projeto $x$ relação com a estratégia da organização e segmento de mercado $x$ prioridade no atendimento. $O$ valor do coeficiente de inconsistência poderia ser reduzido para um valor inferior a 0,1 se os votos dos participantes fossem alterados, reduzindo-se o peso do critério "relação com a estratégia da organização" em relação a "prioridade no atendimento" de 3 para 2, ou seja, colocando-se um peso entre igual e moderado, por exemplo. Nesse caso o valor da inconsistência mudaria para 0,079.

A matriz de inconsistências é apresentada pela figura 40 a seguir.

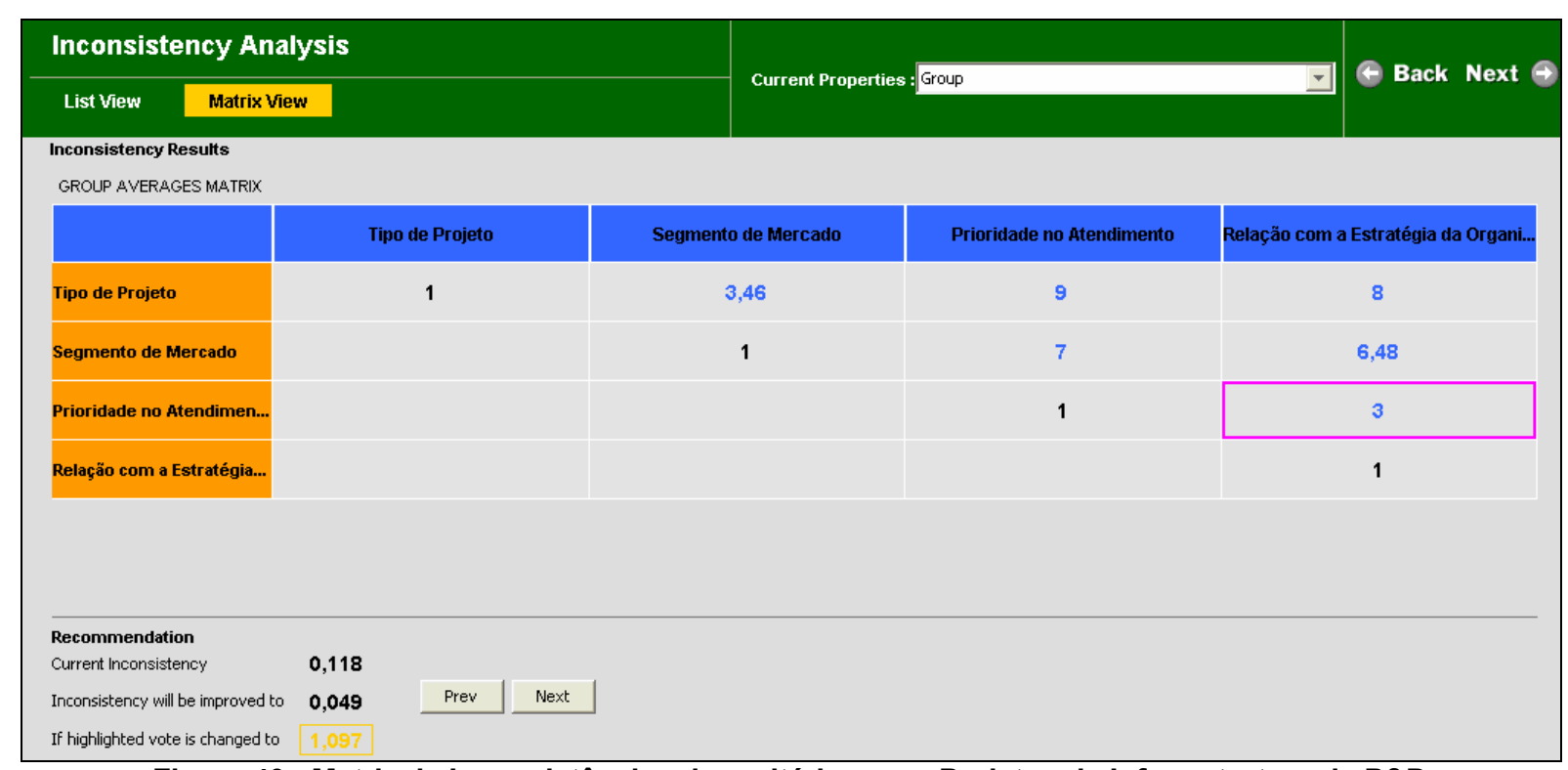

Figura 40 - Matriz de Inconsistências dos critérios para Projetos de Infra-estrutura de P\&D

No caso da votação realizada, os participantes não quiseram alterar seus votos, estando satisfeitos com os pesos dos critérios obtidos e apresentados pela figura 39. Esse resultado indica que a empresa pode ter inconsistências em sua estratégia ou diferença de entendimento dos seus funcionários sobre sua estratégia, conforme previsto por Saaty (1991) e Forman e Selly (2001).

Assim, optou-se por dar continuidade à aplicação do método AHP com a elaboração das escalas de valores (ou ratings) para cada critério. 
Através de uma discussão com os participantes chegou-se a escala de valores apresentada no quadro 11. Para definição dos pesos de cada item da escala aplicouse novamente a técnica de comparação por pares.

\begin{tabular}{|c|c|c|c|}
\hline Critérios & Escala de Valores (Ratings) & Definiçāo da Escala (ratings) & Peso dos ratings \\
\hline \multirow[b]{2}{*}{ Tipo de Projeto } & Alta Importâncis & Aquisicäo de equipamentos novos pars atender clientes internos e externos. & 1,00 \\
\hline & Médialmportâñis & $\begin{array}{l}\text { Aquisiç̧o de equipamentos para substituiçäo de outros en final de vida } \\
\text { e gtendimento a SSMA (Saide, Seguranca e Meio Ambiente). }\end{array}$ & 0,41 \\
\hline \multirow{3}{*}{ Segmento de Mercado } & Magem Alta & 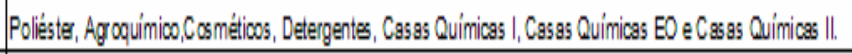 & 1,00 \\
\hline & Magoem Médig & 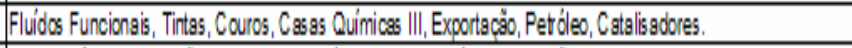 & 0,35 \\
\hline & Mrgam Bgixa & 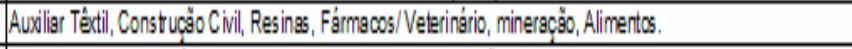 & 0,11 \\
\hline \multirow{3}{*}{ Prioridade no Atendimento } & RNC/ Clientes & O projeto visa stender à clientes ou tratar RNCs (Registros de nö0-conformidgoges). & 1,0 \\
\hline & Desenvolvimento & O projeto é pars o desenvolvimento de novos produtos e ou splicacoes. & 0,37 \\
\hline & Cspactitgcä & 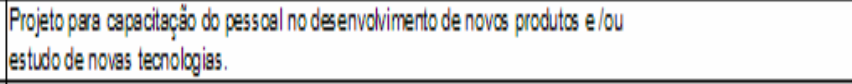 & 0,14 \\
\hline \multirow{3}{*}{$\begin{array}{l}\text { Relaģäo com a Estratégia } \\
\text { da Organizaçäo }\end{array}$} & Alta & $\begin{array}{l}\text { Ligasos à projetos de impacto ou dientes stratégicos elov es cosmento de produtos. } \\
\text { Segmentos onde a empess stá investindo ou de atto ces cimento. }\end{array}$ & 1,0 \\
\hline & Média & Atendimento à carteira de dientes e de produtos. Segmentos de investimentos estáveis. & 0,27 \\
\hline & Bave & Segmentos onde s empess está desinvestindo ou de baixo cescimento. & 0,13 \\
\hline
\end{tabular}

Quadro 11 - Definição dos ratings para os critérios de seleção e priorização dos Proj. Infra-estrutura de P\&D

Na seqüência, promoveu-se junto aos participantes a votação de cada projeto em relação a cada um dos 4 critérios anteriormente definidos.

Os resultados da votação dos 36 projetos de infra-estrutura de P\&D, aplicandose o método AHP, são apresentados no quadro 12. Nesse quadro pode-se verificar a prioridade obtida para cada projeto. Como se pode observar muitos projetos têm prioridade igual a 0,32 e 0,24. Ao analisarmos os conteúdos dos projetos, percebeu-se que esse resultado é devido à forma como os projetos são abertos e como são justificados. Como a justificativa é quase sempre vaga, foi difícil para os representantes das áreas de P\&D fazerem a votação dos projetos.

Foi um consenso dos participantes que a elaboração da justificativa dos projetos deva ser melhorada, respondendo minimamente às questões relacionadas com os critérios de decisão sugeridos, caso contrário o ato de aprovar ou não um projeto será meramente baseado no valor e não em critérios lógicos que melhorem o posicionamento da empresa. Este resultado confirma as observações de Kaufmann (1975) e Garvin \& Roberto (2001) em que o processo de decisão não é um evento, mas um processo que se desdobra durante semanas, meses ou anos e carrega consigo jogos de poder e políticas, estando repleto de tons pessoais e história 
institucional. Os resultados também estão de acordo com Garber (2002), que fala do risco de se tratar o problema de forma equivocada se o problema não for corretamente estruturado.

\begin{tabular}{|c|c|c|c|c|c|}
\hline Projetos de Infra-estrutura de $P t D$ & $\begin{array}{c}\text { Prioridades } \\
\text { dos Projetos } \\
\end{array}$ & Tipo de Projeto & Segmento de Mercado & $\begin{array}{c}\text { Prioridade } \\
\text { no Atendimento }\end{array}$ & $\begin{array}{c}\text { Relação com a Estratégia } \\
\text { da Organização }\end{array}$ \\
\hline 2365 & 1 & 1 & 1 & 1 & 1 \\
\hline 4706 & \begin{tabular}{|l|l|}
0.98 \\
\end{tabular} & 0,409 & 1 & 1 & 1 \\
\hline 2233 & 0.92 & 0,409 & 0,351 & 1 & 1 \\
\hline 2312 & 0.79 & 1 & 1 & 0,375 & 1 \\
\hline 2380 & 0.77 & 0,409 & 1 & 0,375 & 1 \\
\hline 2204 & 0.74 & 1 & 0,351 & 0,375 & 1 \\
\hline 2223 & 0,74 & 1 & 0,351 & 0,375 & 1 \\
\hline 2376 & 0,72 & 0,409 & 0,351 & 0,375 & 1 \\
\hline 2398 & 0.53 & 1 & 0,11 & 1 & 0,272 \\
\hline 2364 & 0.52 & 0,409 & 0,351 & 1 & 0,272 \\
\hline 2388 & 0.52 & 0,409 & 0,351 & 1 & 0,272 \\
\hline 4604 & 0.5 & 0,409 & 0,11 & 1 & 0,272 \\
\hline 2308 & 0.5 & 0,409 & 0,11 & 1 & 0,272 \\
\hline 2224 & 0,34 & 1 & 0,351 & 0,375 & 0,272 \\
\hline 2319 & 0,34 & 1 & 0,351 & 0,375 & 0,272 \\
\hline 2306 & 0,33 & 0,705 & 0,351 & 0,375 & 0,272 \\
\hline 2231 & 0,32 & 0,409 & 0,351 & 0,375 & 0,272 \\
\hline 2369 & 0.32 & 1 & 0,11 & 0,375 & 0,272 \\
\hline 2338 & 0.32 & 0,409 & 0,351 & 0,375 & 0,272 \\
\hline 2342 & 0,32 & 0,409 & 0,351 & 0,375 & 0,272 \\
\hline 2347 & 0,32 & 0,409 & 0,351 & 0,375 & 0,272 \\
\hline 2359 & 0,32 & 0,409 & 0,351 & 0,375 & 0,272 \\
\hline 2375 & 0.32 & 0,409 & 0,351 & 0,375 & 0,272 \\
\hline 2234 & 0.32 & 0,409 & 0,351 & 0,375 & 0,272 \\
\hline 4889 & 0,32 & 0,409 & 0,351 & 0,375 & 0,272 \\
\hline 4999 & 0,32 & 0,409 & 0,351 & 0,375 & 0,272 \\
\hline 2381 & 0,3 & 0,409 & 0,11 & 0,375 & 0,272 \\
\hline 2229 & 0.26 & 1 & 0,351 & 0,141 & 0,272 \\
\hline 2230 & 0,26 & 1 & 0,351 & 0,141 & 0,272 \\
\hline 2237 & 0,24 & 0,409 & 0,351 & 0,375 & 0,129 \\
\hline 2325 & 0.24 & 0,409 & 0,351 & 0,375 & 0,129 \\
\hline 2344 & 0.24 & 0,409 & 0,351 & 0,375 & 0,129 \\
\hline 2360 & 0.24 & 0,409 & 0,351 & 0,141 & 0,272 \\
\hline 2228 & 0.22 & 0,409 & 0,11 & 0,375 & 0,129 \\
\hline 2333 & 0.22 & 0,409 & 0,11 & 0,375 & 0,129 \\
\hline 2353 & 0.17 & 1 & 0,11 & 0,141 & 0,129 \\
\hline
\end{tabular}

Quadro 12 - Resultado da priorização - Projetos de Infra-estrutura de P\&D com o AHP

Durante a reunião com os funcionários da empresa da área de P\&D, GDPP e GA, foi feita a análise de sensibilidade dos projetos, variando-se o peso dos critérios e verificando-se os efeitos desta variação nas prioridades dos projetos, conforme proposto por Clemen (1991), Samson (1980) e Laurindo, Shimizu e Morita (2001).

A figura 41 mostra que uma variação dos pesos do critério "tipo de projeto" para 0,07; "segmento de mercado" para 0,14; "prioridade no atendimento" para 0,59 e "relação com a estratégia da empresa" para 0,20; a colocação dos 3 projetos de maior prioridade não muda. Observa-se, ainda, que a maior parte dos projetos que ocupam as 15 primeiras posições mudou de prioridade, mas continuam entre os 15 mais importantes. Isso mostra que a prioridade dos projetos é pouco sensível a variação do peso dos critérios. Esta análise nos dá mais segurança para afirmar que se algum 
projeto precisasse ser cortado, o corte se daria nos projetos de menor importância para a organização.

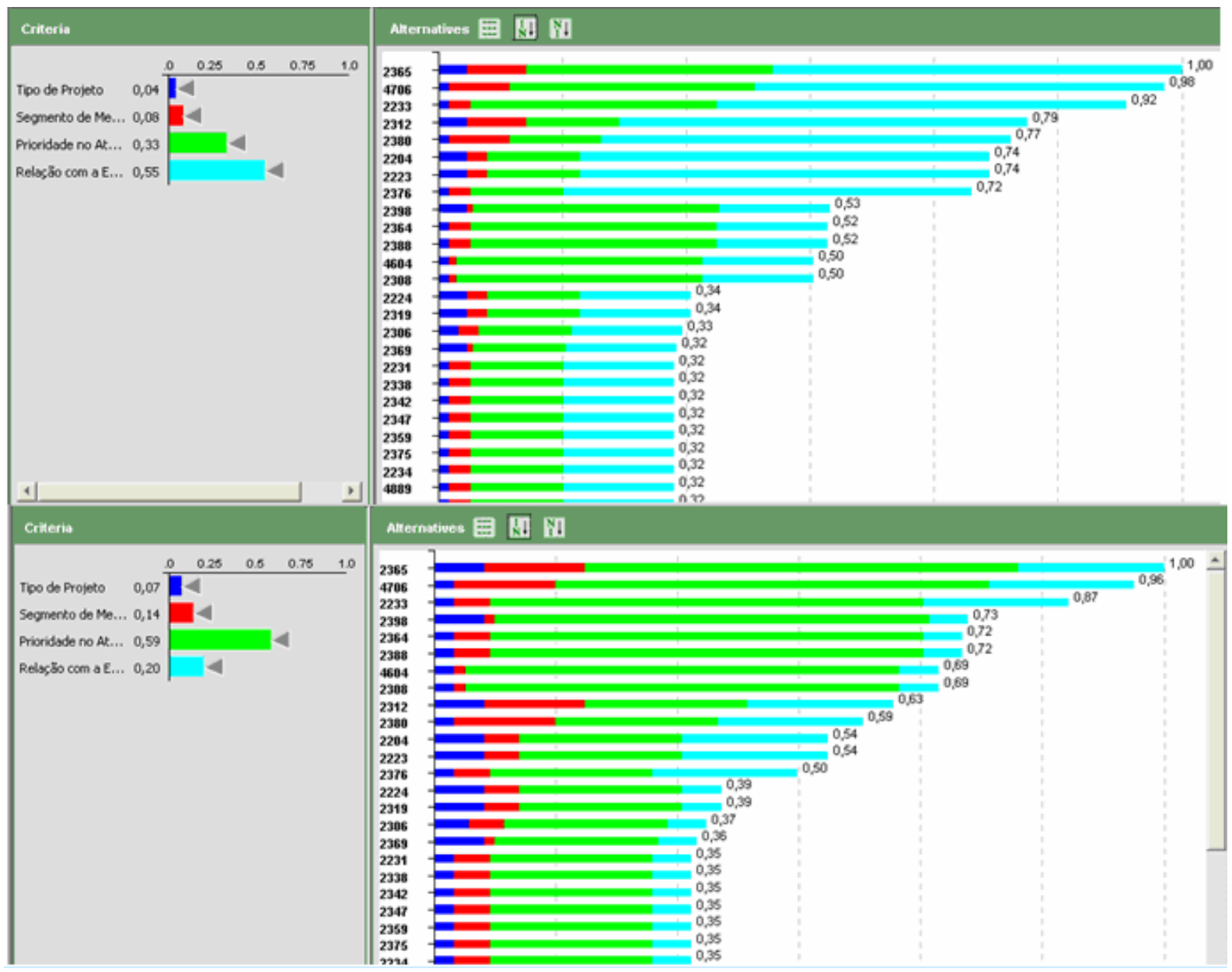

Figura 41 - Análise de Sensibilidade para Projetos de Infra-estrutura de P\&D

Ao final da reunião, os participantes da área de P\&D da empresa disseram acreditar que o método AHP é aplicável à organização, tendo um grande potencial de ganho por permitir que as decisões sejam tomadas com base em critérios objetivos, de conhecimento de todos e também por ser possível avaliar diferentes cenários. Esta observação no caso estudado vai ao encontro dos questionamentos de Kaufmann (1975) se as decisões deveriam continuar a serem tomadas com base em intuições num ambiente onde a tecnologia cresce numa curva exponencial e Saaty (1991) e Hammond, Keeney e Raiffa (1998) sobre a qualidade das decisões e os riscos de se cair em armadilhas. 


\subsubsection{A Estrutura dos Projetos de TI}

Para a concepção e validação da estrutura de decisões de projetos do tipo "Tecnologia da Informação", foi convidado um analista de negócios, funcionário da gerência de sistemas da organização. Este funcionário desenvolve trabalhos de apoio à diretoria industrial da empresa e tem o conhecimento da organização necessário para desenvolver esta etapa do presente trabalho. Seu perfil pode ser consultado no Apêndice B.

Da mesma forma que descrito nos itens anteriores, antes de agendar a reunião com o representante da área de informática da empresa, foi elaborado um esboço da estrutura como proposta, em cima do qual se faria a validação ou alteração de critérios, subcritérios, definições e escalas de valores.

Os projetos escolhidos como alternativas a serem selecionadas e priorizadas são projetos de $\mathrm{TI}$, num total de 19, aprovados para o ano de 2005 . Os dados desses projetos estão disponíveis para consulta no Apêndice D.

A reunião de validação ocorreu dia 21/11/06, nas dependências da empresa, e teve a duração de $4 \mathrm{~h}$ aproximadamente.

Durante a reunião, o autor primeiramente explicou os conceitos do método AHP, o escopo do trabalho e a ferramenta que seria utilizada para desenvolvê-lo.

Na seqüência foi apresentado o esboço da estrutura proposta, para validação ou alterações, onde necessário.

A figura 42 apresenta a estrutura de decisões validada pelo representante da empresa.

O participante da empresa não fez alterações na estrutura de decisões proposta. Segundo ele melhorias podem ser feitas caso a empresa opte pela implantação do método AHP em seu processo de decisões, mas, considerando-se que hoje não existe nenhuma ferramenta similar que apóie as decisões, principalmente no que se refere a seleção e priorização de projetos de TI, a proposta foi considerada adequada.

Dando-se continuidade aos trabalhos, foi discutido o conceito de cada critério e subcritério apresentado na figura 42, para que não existissem dúvidas na fase seguinte, de comparação dos critérios aos pares com o objetivo de determinar seus pesos relativos. 


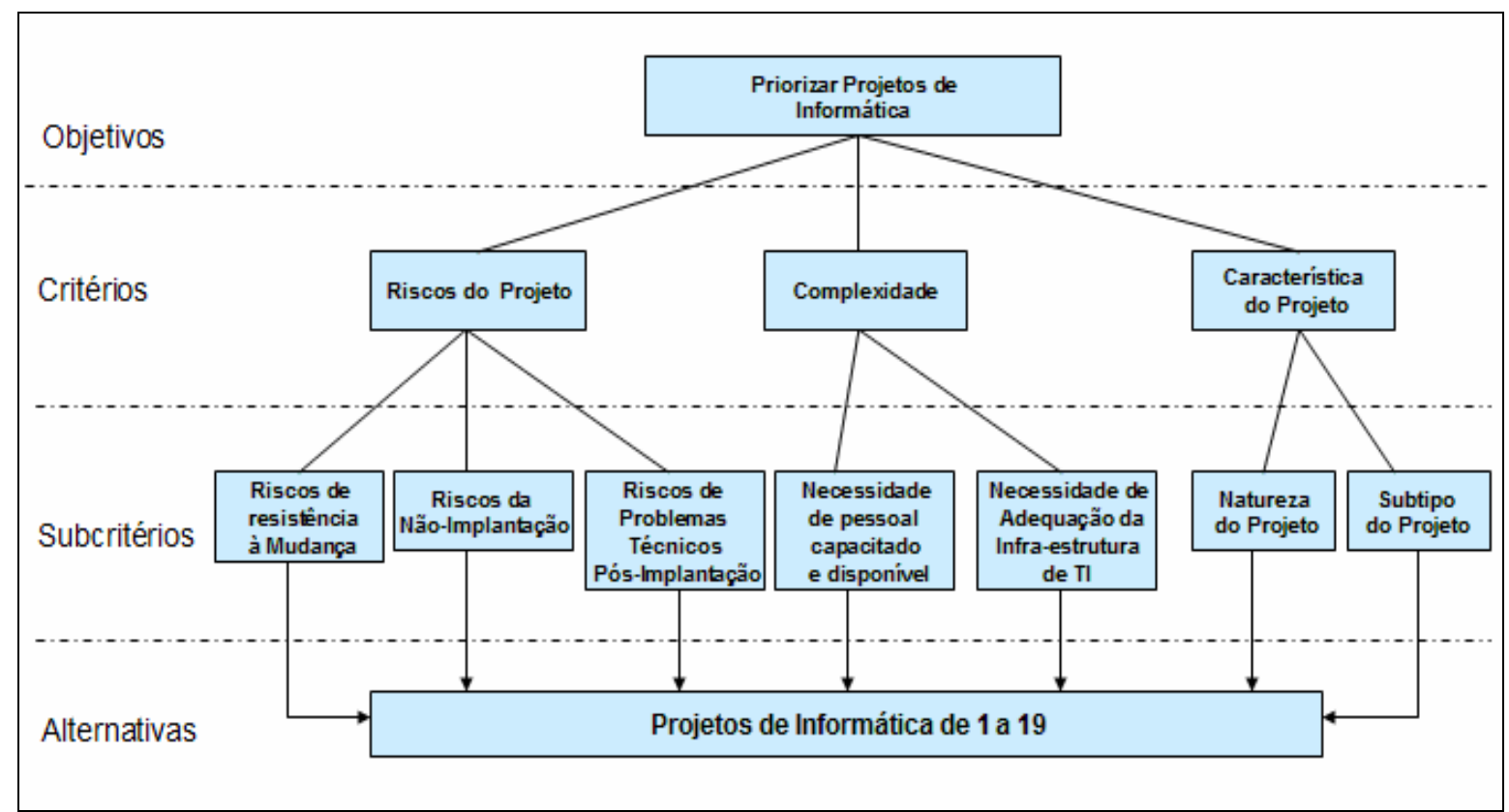

Figura 42 - Estrutura de Projetos de Informática - Versão Final

As definições dos critérios e subcritérios são apresentadas no quadro 13.

\begin{tabular}{|c|c|}
\hline Critérios/Subcritérios & Definição \\
\hline Riscos do Projeto & $\begin{array}{l}\text { São riscos de problemas de implantação devida a resistência a mudança, riscos de ocorrerem problemas } \\
\text { técnicos após a implantação ou riscos decorrentes da decisão de não implantar os projetos e ter a perdas } \\
\text { na produtividade da empresa ou perdas de clientes. }\end{array}$ \\
\hline $\begin{array}{l}\text { Risco de resistência a } \\
\text { Mudança }\end{array}$ & $\begin{array}{l}\text { A resistência a mudança tende a ser maior, quanto maior o } n^{\circ} \text { de pessoas afetadas pelo projeto. Assim, o } \\
\text { Risco é alto se projeto impacta em várias áreas da empresa, médio se o projeto envolve uma área da } \\
\text { empresa e baixo se a mudança não afeta ninguém diretamente, caso projetos de infraestrutura de TI. }\end{array}$ \\
\hline $\begin{array}{l}\text { Riscos da Não } \\
\text { Implantação }\end{array}$ & $\begin{array}{l}\text { Trata-se dos efeitos causados pela decisão de não executar um projeto. O risco é alto quando Cliente } \\
\text { externo não é atendido; Médio se ocorre não atendimento a cliente interno e baixo quano o efeito percebido } \\
\text { é baixa qualidade no atendimento a clientes externos e internos sem que se deixe de atendê-los. }\end{array}$ \\
\hline $\begin{array}{l}\text { Riscos de Problemas } \\
\text { Técnicos Pós-implantação }\end{array}$ & $\begin{array}{l}\text { Refere-se a probabilidade de ocorrerem problemas técnicos após o término do projeto tais como: } \\
\text { Performancedo sistema abaixo do esperado, identificação de bugs, problemas com interfaces, etc. }\end{array}$ \\
\hline Complexidade & $\begin{array}{l}\text { A complexidade nos projetos de TI pode ser medida pela necessidade de recursos adicionais para se } \\
\text { conseguir implantar um projeto. } \\
\text { Esses recursos adicionais podem se referir a necessidade de adequação da infraestrutura existente e a } \\
\text { necessidade de contratação e capacitação de pessoal. }\end{array}$ \\
\hline $\begin{array}{l}\text { Necessidade de } \\
\text { Adequação da } \\
\text { Infraestrutura de TI }\end{array}$ & $\begin{array}{l}\text { A complexidade do projeto aumenta com a necessidade de recursos de infraestrutura para viabilizá-lo. } \\
\text { Assim, para infraestrutura disponivel a complexidade é baixa, se infraestrutura é parcialmente disponivel a } \\
\text { complexidade é média e se a infraestrutura não está disponivel a complexidade é alta, pois precisa de } \\
\text { negociação para aprovação de investimentos adicionais. }\end{array}$ \\
\hline $\begin{array}{l}\text { Necessidade de Pessoal } \\
\text { Capacitado e Disponivel }\end{array}$ & $\begin{array}{l}\text { A complexidade também varia se existe pessoal capacitado e disponivel ou não para a execução de um } \\
\text { projeto. Se existe pessoal capacitado e disponivel a complexidade é baixa, se existe pessoal parcialmente } \\
\text { capacitado e disponivel a complexidade é média e se não existe pessoal capacitado e disponivel a } \\
\text { complexidade é alta, pois exige negociação de recursos com outras áras, re-priorização de tarefas e/ou } \\
\text { contratação e treinamento de pessoal. }\end{array}$ \\
\hline Característica do Projeto & $\begin{array}{l}\text { Relativamente a suas características, um projeto de TI pode ser para a aquisição e implantação de um } \\
\text { software de mercado, para o desenvolvimento interno de um software especialista ou para a aquisição e } \\
\text { instalação de hardware (micros, impressoras, links de comunicação, redes, etc). Esses projetos podem } \\
\text { ainda ser classificados quanto a natureza em estratégicos e operacionais. }\end{array}$ \\
\hline Natureza do Projeto & Se o projeto é estratégico ou operacional. \\
\hline Sub-Tipo de Projeto & $\begin{array}{l}\text { Se é um projeto de aquisição de software do tipo pacote, desenvolvimento de software ou infraestrutura de } \\
\text { TI (adequação de links, rede, micros, impressoras, etc). }\end{array}$ \\
\hline
\end{tabular}

Quadro 13 - Definição dos critérios e subcritérios de seleção e priorização dos Projetos de TI 
Uma vez definidos os critérios e subcritérios, foi iniciado o processo de comparação por pares dos critérios e, depois, dos subcritérios, para se chegar aos pesos dos mesmos.

O resultado obtido pode ser observado através da figura 43 que apresenta na forma gráfica os pesos dos critérios. O coeficiente de inconsistência resultante foi de 0,052; considerado um valor aceitável por Saaty (1991), não sendo necessária nova votação. Pelo que se pode verificar, a área de informática considera mais crítico o critério de riscos do projeto, sendo o peso obtido de 0,53 . A complexidade, cujo peso resultante foi 0,33 ; é importante porque se os recursos necessários para a implantação em termos de disponibilidade de mão-de-obra capacitada e infraestrutura não existirem, não adiantará ter o investimento aprovado, pois fatalmente o projeto sofrerá atrasos ou não será executado.

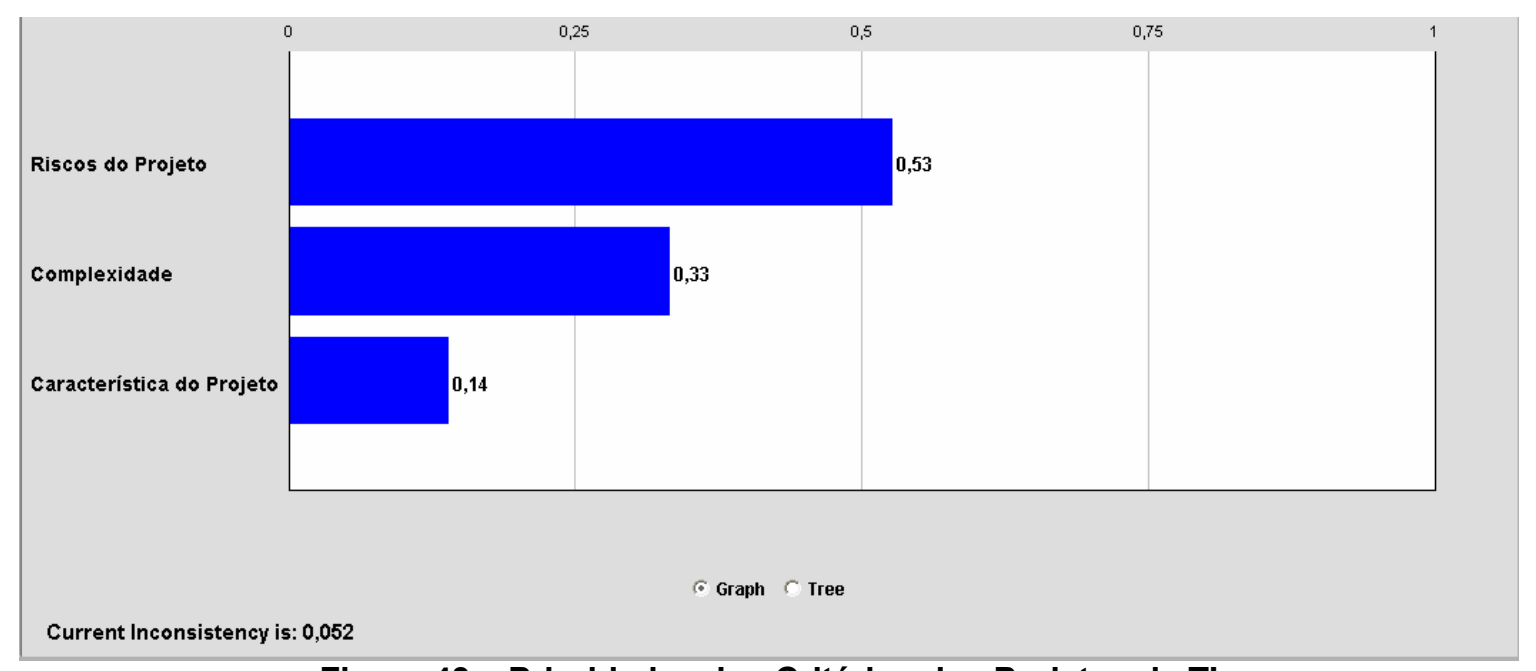

Figura 43 - Prioridades dos Critérios dos Projetos de TI

Os resultados das prioridades ou pesos obtidos para a votação dos subcritérios são apresentados pela figura 44 .

Como se pode observar dentre todos os riscos de projetos de $\mathrm{TI}$, os considerados mais importantes são os relacionados com a probabilidade de ocorrer resistência à mudança, com peso de 0,49 do total de riscos. Em termos de complexidade, o participante afirmou que é muito crítico não ter pessoal capacitado e disponível, pois atualmente existe dificuldade de se encontrar pessoas capacitadas no 
mercado, no caso de novas contratações. Existe, também, dificuldade de retenção das pessoas contratadas devido ao "aquecimento do mercado" na área de $\mathrm{TI}$ no momento atual. Por isso o peso para a necessidade de pessoal capacitado e disponível foi 0,75 contra os 0,25 relativos a infra-estrutura. No que se refere ao critério característica do projeto, o participante pontuou a natureza do projeto com valor maior, pois segundo ele se o projeto é estratégico ele passará na frente dos demais.

\begin{tabular}{|c|}
\hline 1,00 Decision Goal: Selecionar e Priorizar Projetos de Informática \\
0,53 Riscos do Projeto \\
0,49 Risco de resistência a Mudança \\
0,31 Riscos da Não Implantação \\
0,20 Riscos de Problemas Técnicos pós Implantação \\
$-0,33$ Complexidade \\
0,25 Necessidade de Adequação da Infraestrutura de TI \\
0,75 Necessidade de Pessoal Capacitado e Disponivel \\
$-0,14$ Característica do Projeto \\
0,67 Natureza do Projeto \\
0,33 Sub-Tipo de Projeto \\
\hline
\end{tabular}

Figura 44 - Pesos dos Critérios e subcritérios dos Projetos de TI.

A etapa seguinte da reunião foi a criação da escala de valores (ratings) para os subcritérios, essa escala é apresentada no quadro 14, a seguir.

\begin{tabular}{|c|c|c|c|}
\hline Subcritérios & $\begin{array}{l}\text { Escala de Valores } \\
\qquad \text { (ratings) }\end{array}$ & Definição da escala de valores ou ratings & $\begin{array}{c}\text { Pesos } \\
\text { dos } \\
\text { ratings }\end{array}$ \\
\hline \multirow{3}{*}{$\begin{array}{l}\text { Risco de } \\
\text { resistência a } \\
\text { Mudança }\end{array}$} & Alto & Projeto impacta várias áreas da empresa (caso do ERP) & 1,00 \\
\hline & Médio & Projeto para uma única área da empresa & 0,23 \\
\hline & Baixo & $\begin{array}{l}\text { Projetos de baixo impacto na rotina dos usuários (caso de aumento de capacidade de link, } \\
\text { modificações em redes, aquisição de micros e impressoras, etc.) }\end{array}$ & 0,06 \\
\hline \multirow{3}{*}{$\begin{array}{l}\text { Riscos da Não } \\
\text { Implantação }\end{array}$} & Alto & Não atendimento à cliente externo & 1,00 \\
\hline & Médio & Não atendimento à cliente interno & 0,24 \\
\hline & Baixo & Baixo nivel de atendimento à cliente externo ou interno & 0,05 \\
\hline Riscos de & Muito Crítico & Problemas de Performance do sistema (lentidão) ou Bugs que inviabilizem o trabalho dos funcionário & 1,00 \\
\hline Problemas & Crítico & Problemas com funcionamento de interfaces entre sistemas, reduzindo a confiabilidade das informaç & 0,23 \\
\hline Técnicos Pós- & Não Crítico & Necessidade de funcionalidades adicionais e melhorias (relatórios, novos campos, etc.) & 0,06 \\
\hline Necessidade de & Muito Crítico & Infraestrutura não disponível, é necessário investimento em sua totalidade & 0,07 \\
\hline Adequação da & Crítico & Infraestrutura parcialmente disponivel, é necessário algum investimento & 0,20 \\
\hline Infraestrutura de & Não Crítico & Infraestrutura existente, não é necessário nenhum investimento & 1,00 \\
\hline \multirow{3}{*}{$\begin{array}{l}\text { Necessidade de } \\
\text { Pessoal } \\
\text { Capacitadoe }\end{array}$} & Muito Crítico & Necessária contratação de pessoal especializado. Pessoal próprio não disponivel & 0,06 \\
\hline & Crítico & Pessoal próprio e capacitado parcialmente disponivel & 0,20 \\
\hline & Não Crítico & Pessoal próprio e capacitado disponível & 1,00 \\
\hline \multirow{2}{*}{$\begin{array}{l}\text { Natureza do } \\
\text { Projeto }\end{array}$} & Estratégico & Projetos definidos pela empresa como sendo estratégicos & 1,00 \\
\hline & Operacional & Projetos denominados pela empresa de correntes & 0,20 \\
\hline \multirow{2}{*}{$\begin{array}{l}\text { Sub-Tipo de } \\
\text { Projeto }\end{array}$} & Aquisição de Software & Aquisição e implantação de softwares do tipo pacote com interfaces com vários softwares e áreas da & 1,00 \\
\hline & \begin{tabular}{|l|} 
Desenvolvimento de Softw \\
Adequacão Infraestrutura T|
\end{tabular} & $\begin{array}{l}\text { Desenvolvimento de software especialista para uma área específica da empresa } \\
\text { Adequacão de redes, intranet, internet. link de comunicacão, aquisicão e instalação de hardware }\end{array}$ & 0,27 \\
\hline
\end{tabular}

Quadro 14 - Escala de valores para os subcritérios de seleção e priorização - Projetos de TI

O risco de ocorrerem problemas técnicos pós-implantação é citado na literatura por McFarlan (1981). A complexidade, de certa forma é mencionada por Brown \& Eisenhardt (1998) e Eisenhardt e Brown (2000) quando afirmam que a gestão de 
portfólio com sucesso engloba incertezas e pressupõe a negociação por recursos quase sempre escassos tais como mão-de-obra, tempo e orçamento. O critério característica do projeto busca o alinhamento estratégico da decisão, conforme proposto por Carvalho et al. (2003) em que argumentam que as saídas do processo de gestão de portfólio deveriam ser capazes de atender aos requisitos estratégicos da companhia para que se obtenha uma vantagem competitiva.

Uma vez concluída a etapa de concepção da escala de valores, foi realizada, junto com o participante de $\mathrm{TI}$, a votação dos projetos em relação a cada subcritério. $\mathrm{O}$ resultado da votação para os 19 projetos de TI é apresentado no quadro 15, a seguir.

\begin{tabular}{|c|c|c|c|c|c|c|c|c|}
\hline \multicolumn{2}{|c|}{ Pesos dos subcritérios } & \multirow{2}{*}{$\begin{array}{c}.2604 \\
\text { Risco de } \\
\text { resistência } \\
\text { a Mudança } \\
\end{array}$} & \multirow{2}{*}{\begin{tabular}{|c|}
.1641 \\
$\begin{array}{c}\text { Riscos da Năo } \\
\text { Implantacão }\end{array}$ \\
\end{tabular}} & \multirow{2}{*}{\begin{tabular}{|c|}
.1034 \\
Riscos de Problemas \\
Técnicos pós \\
Implantação \\
\end{tabular}} & \multirow{2}{*}{\begin{tabular}{c|}
.0831 \\
Necessidade de \\
Adequação \\
da Infraestrutura de TI \\
\end{tabular}} & \multirow{2}{*}{$\begin{array}{c}.2494 \\
\text { Necessidade de Pessoal } \\
\text { Capacitado e Disponível }\end{array}$} & \multirow{2}{*}{$\begin{array}{c}.0931 \\
\\
\text { Natureza } \\
\text { do Projeto }\end{array}$} & \multirow{2}{*}{$\begin{array}{c}.0465 \\
\text { Sub-Tipo } \\
\text { de Projeto }\end{array}$} \\
\hline Projetos de TI & \begin{tabular}{|l|} 
Prioridades \\
dos \\
Projetos \\
\end{tabular} & & & & & & & \\
\hline 2151 & 0,69 & 1 & 1 & 1 & 0,075 & 0,063 & 1 & 1 \\
\hline 4840 & 0,65 & 1 & 1 & 0.231 & 1 & 0,203 & 0.205 & 1 \\
\hline 2391 & 0,42 & 1 & 0.237 & 0,231 & 0,201 & 0,063 & 0,205 & 1 \\
\hline 4959 & 0,39 & 0,063 & 0,054 & 0,056 & 1 & 1 & 0,205 & 0,174 \\
\hline 2216 & 0,32 & 0,063 & 0,054 & 0,056 & 0,201 & 1 & 0.205 & 0,174 \\
\hline 2303 & 0,32 & 0,063 & 0,054 & 0,056 & 0,201 & 1 & 0,205 & 0,174 \\
\hline 2217 & 0,32 & 0,063 & 0,054 & 0,056 & 0.201 & 1 & 0,205 & 0,174 \\
\hline 2318 & 0,32 & 0,063 & 0,054 & 0,056 & 0,201 & 1 & 0,205 & 0,174 \\
\hline 2341 & 0,32 & 0,063 & 0,054 & 0,056 & 0,201 & 1 & 0,205 & 0,174 \\
\hline 2322 & 0,32 & 0,063 & 0,054 & 0,056 & 0,201 & 1 & 0,205 & 0,174 \\
\hline 2335 & 0,32 & 0,063 & 0,054 & 0,056 & 0,201 & 1 & 0,205 & 0,174 \\
\hline 2218 & 0,32 & 0,063 & 0,054 & 0,056 & 0,201 & 1 & 0,205 & 0,174 \\
\hline 2313 & 0,32 & 0,063 & 0,054 & 0,056 & 0,201 & 1 & 0,205 & 0,174 \\
\hline 2328 & 0,32 & 0,063 & 0,054 & 0,056 & 0,201 & 1 & 0,205 & 0,174 \\
\hline 2349 & 0,32 & 0,063 & 0,054 & 0,056 & 0,201 & 1 & 0.205 & 0,174 \\
\hline 2310 & 0,29 & 0,235 & 0.237 & 0,231 & 1 & 0,203 & 0,205 & 0,273 \\
\hline 4655 & 0,24 & 0,235 & 0,054 & 0,056 & 1 & 0,203 & 0,205 & 0.273 \\
\hline 2220 & 0,22 & 0,235 & 0,237 & 0,231 & $\mathbf{0 , 2 0 1}$ & 0,203 & 0,205 & 0,273 \\
\hline 2331 & 0,22 & 0,235 & 0,237 & 0,231 & 0,201 & 0,203 & 0,205 & 0,273 \\
\hline
\end{tabular}

Quadro 15 - Resultado da seleção e priorização para os Projetos de TI com o AHP

Pelo que se pode observar pelo quadro 15, muitos projetos acabaram tendo a mesma prioridade resultante. Este é o caso dos projetos com prioridade igual a 0,32. Todos são projetos de infra-estrutura. A organização tem como prática criar um projeto de aquisição e instalação de micros e impressoras e um projeto para adequação de links de comunicação, redes, intranet e hardware para cada site. Como nosso modelo não previu um critério de priorização do site, os pesos de todos os projetos ficaram iguais. Ao questionar o participante se não deveríamos retornar a etapa de definição dos critérios e subcritérios de decisão e incluir a opção site, obteve- 
se como resposta que não seria necessário. Segundo o participante, a empresa deveria fazer uma melhor gestão de seus ativos de TI estabelecendo um valor "teto" para investimento em infra-estrutura e fazendo a gestão dos ativos de forma corporativa e não por site. Entretanto, para que essa mudança seja feita é preciso que a empresa mantenha atualizado o cadastro de ativos de $\mathrm{Tl}$ com configuração e localização do hardware e software existentes, de maneira que se possa fazer a substituição ou adequação de capacidade planejada de acordo com a necessidade de cada site. Hoje cada fábrica solicita o hardware e software desejado na época do orçamento e estes itens são comprados e instalados se aprovados pela diretoria, não existe otimização do uso desses recursos.

O participante de $\mathrm{TI}$ destacou ainda, que alguns projetos da empresa relacionados a desenvolvimento de software são na verdade uma "cesta" prevendo vários desenvolvimentos. Esse é o caso dos 2 projetos cuja prioridade resultante da votação é igual a 0,22 . Para poder fazer a votação dos projetos corretamente foi necessário que o participante fizesse o levantamento do escopo de cada um desses projetos e atribuísse a cada um deles notas mais próximas da realidade. Pelo que o próprio participante concluiu, para uma melhor análise do portfólio de $\mathrm{Tl}$ e tomada de decisão com base em critérios claros, é necessário para o orçamento de investimentos dos próximos anos que se identifique separadamente cada projeto de desenvolvimento, estudando-se para cada um deles os benefícios, riscos e complexidade.

Os resultados encontrados estão de acordo com Clemen (1991) e Garber (2002) ao mencionarem as dificuldades do processo de modelagem da tomada de decisão, sendo citadas o uso de informações imprecisas ou incertas e o risco de tratar o problema de forma equivocada.

Segundo o participante de TI a metodologia proposta neste projeto de pesquisa parece ser de muita utilidade para a organização e o estudo permitiu que se enxergassem oportunidades de melhoria na gestão atual do portfólio de TI. Os três projetos de maior prioridade resultante da aplicação do método AHP, são considerados pela organização os mais importantes. Esse resultado valida o uso do método de pesquisa-ação para este trabalho de pesquisa, indicado que o objetivo de aprendizado coletivo foi atingido. 


\subsubsection{A Estrutura dos Projetos de Engenharia}

Os projetos de engenharia são os mais importantes para a organização, tendo peso 0,51 em relação aos demais projetos com necessidade de investimento aprovado, conforme resultado obtido com a aplicação do método AHP para a estrutura principal (vide item 5.3.2.1). Tais projetos são realizados para atender aos objetivos estratégicos de crescimento da organização via aumento de capacidade ou lançamento de novos produtos. Dentro dessa categoria se encontram os projetos de construção de fábricas novas de produtos e processos existentes, ampliações de unidades existentes (REVAMPs), melhorias nas instalações através de modificações de projetos, construção de fábricas novas com aquisição de nova tecnologia (licenciamentos), parcerias com outras empresas para a construção ou aquisição de novas plantas, compras de novas empresas, participações minoritárias, venda da tecnologia e desenvolvimento internos de tecnologia, produtos e processos.

Por sua importância para a organização, a concepção da estrutura dos projetos de engenharia foi bastante criteriosa. Foram seguidos os passos do método AHP descritos na no item 2.6.1 para a validação do modelo proposto. Num primeiro momento o autor desenhou um esboço da estrutura baseado nos subtipos de projetos apresentados nos itens 4 e 5.2 deste trabalho. Esse esboço foi elaborado com base nos trabalhos de Roberts e Berry (1985) e Garcez (2005) sobre estratégias de crescimento, de McFarlan (1981) sobre riscos e classificação dos projetos, de Cooper et al (1999) sobre os diferentes métodos de gestão de portfólio e de Archer e Ghasemzadeh (1999) sobre a estrutura de seleção de projetos. Após modificações julgadas pertinentes, agendou-se uma reunião de validação com os representantes da empresa escolhidos para participar desta etapa do projeto de pesquisa.

Foram convidados a participar desta fase os cinco gerentes da engenharia da empresa: gerente de processos e tecnologia, gerente de desenvolvimento de produtos e processos (GDPP), gerente de engenharia de processos (GP), gerente de catalisadores (GC) e gerente de implantação de projetos (GIP). Dentre os convidados, apenas o gerente de catalisadores não pode participar da reunião de validação. $O$ perfil dos participantes detalhado pode ser consultado no Apêndice B. 
Foram selecionados para esta etapa os "Projetos de engenharia" que incluem os projetos dos tipos CP, NP, QA e EE da empresa aprovados para o ano de 2005 num total de 41 projetos cujos detalhes podem ser consultados no Apêndice D.

A reunião de validação da hierarquia ocorreu no dia 04/12/06, nas dependências da organização estudada, com a presença dos quatro gerentes da engenharia anteriormente citados. O autor conduziu a reunião que teve a participação de um especialista em AHP para apresentação do método e suas aplicações, fazendo a introdução no início dos trabalhos de construção e validação da estrutura de decisões de projetos de engenharia, critérios, subcritérios, escala de valores (ratings) e determinação das prioridades para execução dos projetos.

Após a apresentação do escopo do trabalho o autor mostrou aos participantes a estrutura de decisões proposta, para validação.

Os participantes propuseram algumas modificações no esboço apresentado, eliminando a duração e a natureza do projeto da lista de subcritérios relacionados ao critério complexidade. Apesar de, aparentemente, projetos mais complexos terem duração maior, os participantes não julgaram este um critério de priorização válido para os projetos da empresa, na literatura a duração também não foi identificada como critério de decisão. No caso da natureza dos projetos, apesar de ser um critério utilizado na priorização dos projetos pela organização, os participantes argumentaram que este subcritério se sobrepunha ao subtipo do projeto, por isso optaram por excluílo. Essa decisão dos participantes diverge da teoria, onde a natureza dos projetos, embora com outra denominação, está relacionada com o alinhamento estratégico do projeto, sendo este um critério citado por diversos autores (Carvalho et al, 2003; Carvalho e Laurindo, 2003, Roussel et al, 1991; Cooper et al, 1999 e 2001).

A versão final da estrutura de projetos validada pelos participantes é apresentada pela figura 45.

Ao observar a figura 45, o autor argumentou que o subcritério "Avanço do Projeto" não era recomendado pela literatura por induzir os participantes a cair nas armadilhas de decisão relatadas por Hammond, Keeney \& Raiffa (1998). A introdução de uma restrição em que projetos já iniciados têm peso maior que os projetos novos poderia levar a empresa a finalizar projetos que não valessem a pena, caindo na armadilha do custo afundado (sunk-cost). Os participantes contra-argumentaram que a empresa raramente investe em "elefantes brancos" e a priorização de projetos pelo avanço físico era uma prática da empresa. Assim, o subcritério "Avanço do Projeto" foi 
mantido na estrutura de decisões. Essa decisão nos leva a supor que os participantes tenham caído na armadilha da âncora.

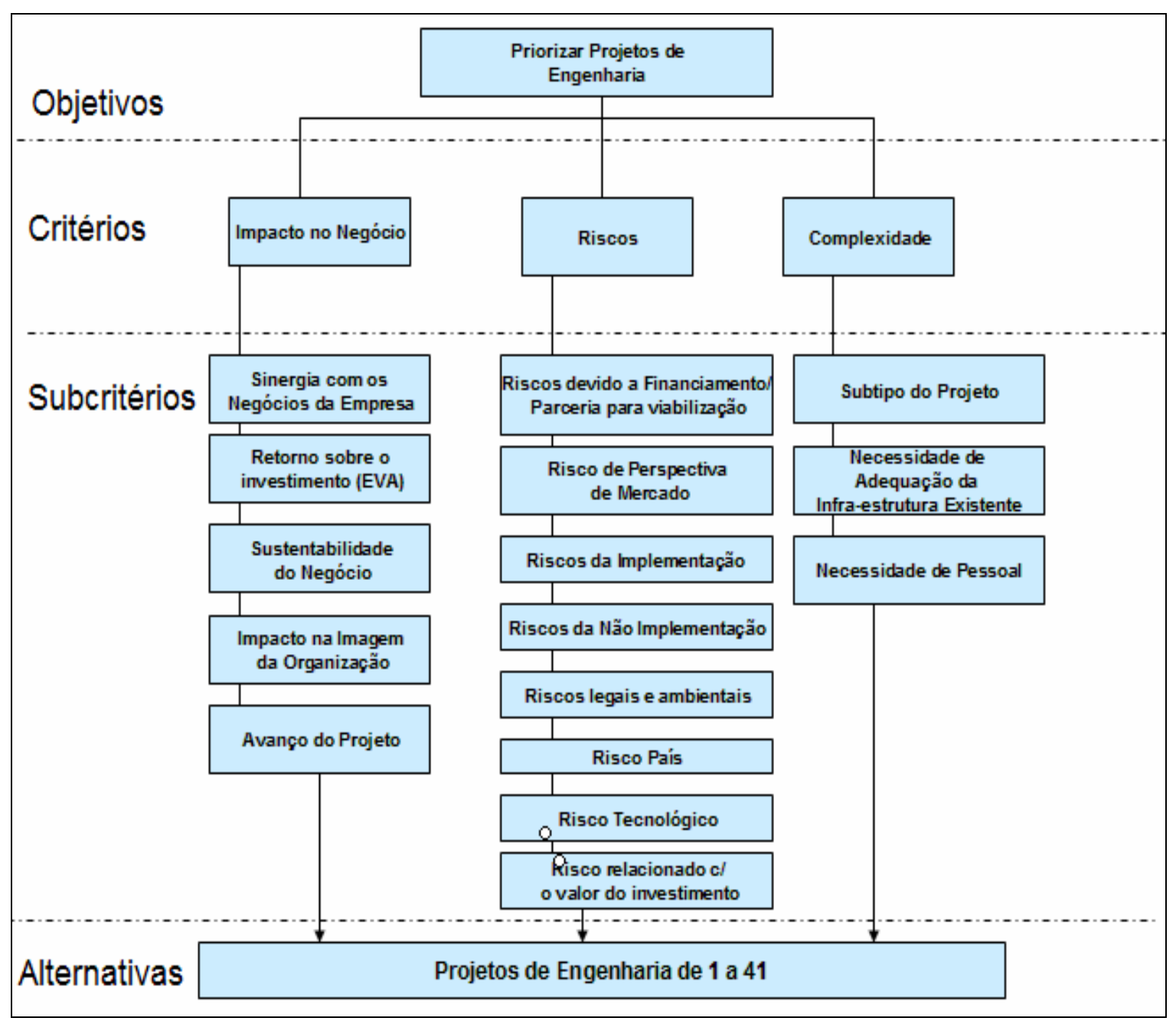

Figura 45 - Estrutura de Projetos de Engenharia - Versão Final (Fonte: Figura do Autor)

As definições dos critérios e subcritérios resultante da discussão para construção e validação da estrutura são dadas pelo quadro 16, a seguir. 


\begin{tabular}{|c|c|}
\hline Critteriol suberiterio & Dascrica do do Critorilo/s uc briterio \\
\hline Impacto no Nagoclo & 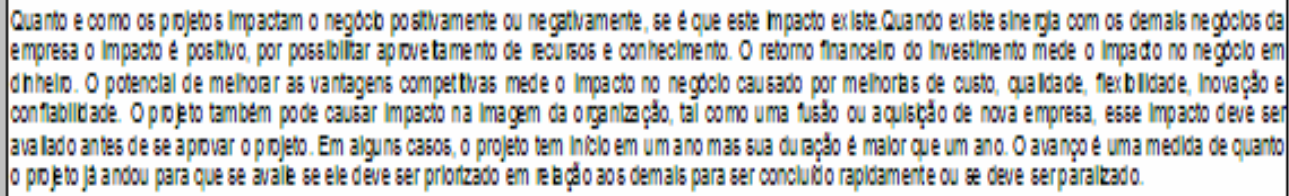 \\
\hline $\begin{array}{l}\text { Insorola com os } \\
\text { Novoolos da Emprese }\end{array}$ & 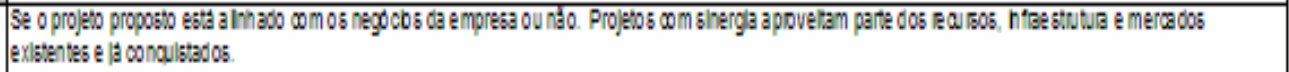 \\
\hline Rotorno sob no o investimentio EVA & 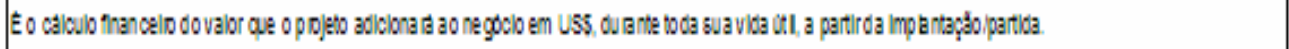 \\
\hline 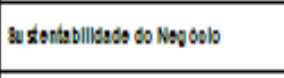 & 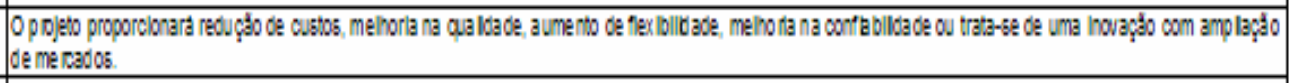 \\
\hline mpecto in imsam da Orgenizasto & 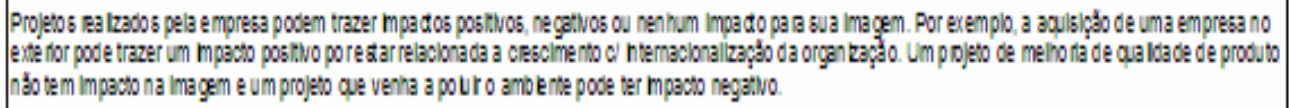 \\
\hline Avanpo do Projesto & 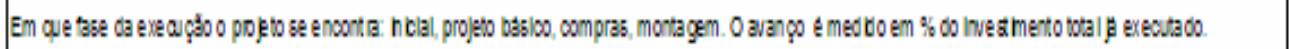 \\
\hline Risco6 & 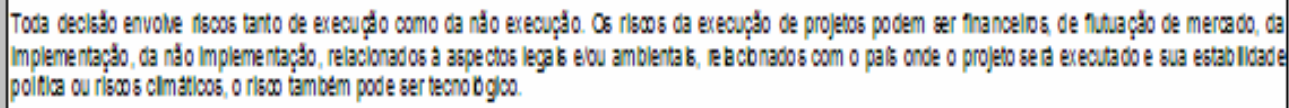 \\
\hline 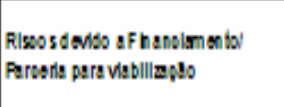 & 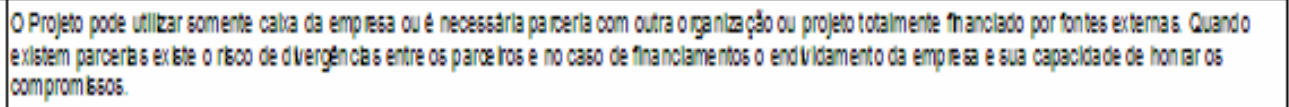 \\
\hline Rlesos de Perspedilie de Menado & 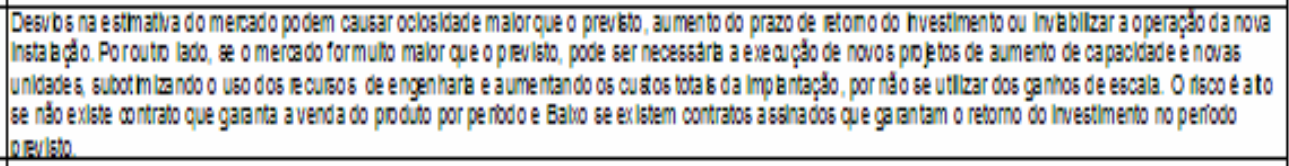 \\
\hline Flesos da implamentsado & 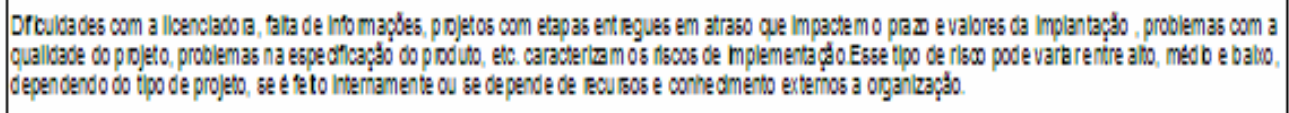 \\
\hline Rlewos da Nalo imp imentaglo & 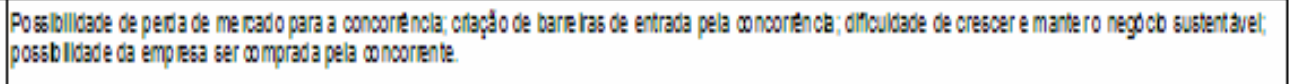 \\
\hline Rlesos lovals o mbinbials & 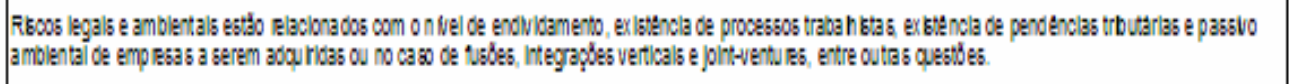 \\
\hline Fliso Pals & 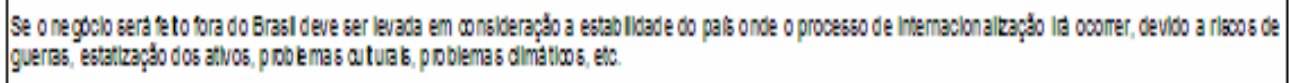 \\
\hline Fleso Toun olbolso & 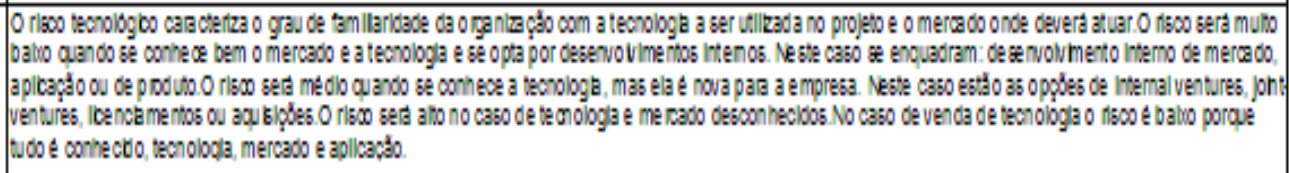 \\
\hline $\begin{array}{l}\text { Riseo rolaso naso com } \\
\text { o valordo In vestimento }\end{array}$ & 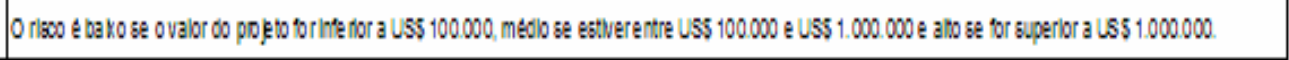 \\
\hline Complaxidads & 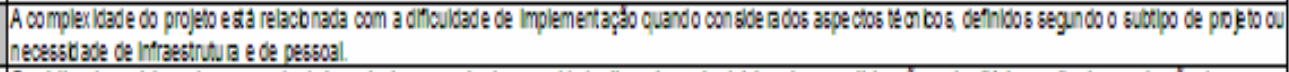 \\
\hline 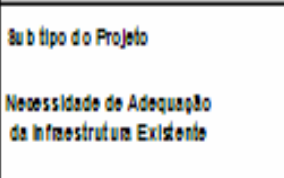 & 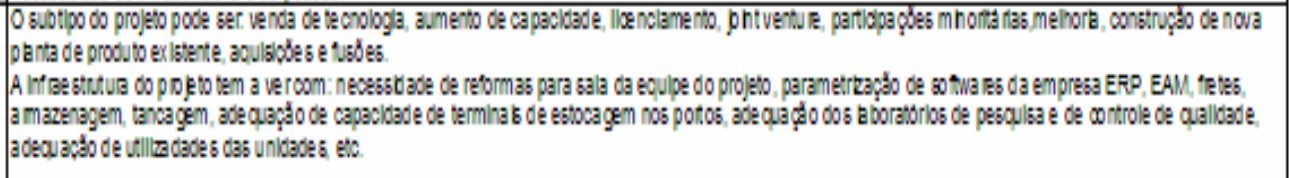 \\
\hline Novessilaso do Possos & 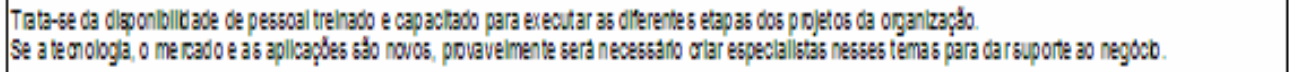 \\
\hline
\end{tabular}

Quadro 16 - Definição dos critérios e subcritérios de seleção e priorização - Projetos de Engenharia

Na seqüência, o autor conduziu, junto aos participantes, a comparação por pares de critérios e subcritérios.
A figura 46 apresenta os resultados da votação dos critérios feita pelos 4

participantes da engenharia da empresa. Pelo que se pode observar, o maior peso foi 
atribuído ao critério "impacto no negócio", cujo valor é de 0,59; o segundo critério mais importante foi "riscos", com peso de 0,28 e; por último, ficou a "complexidade", com peso de 0,13. A figura 46 também mostra o valor da inconsistência resultante da votação de 0,061; inferior ao máximo recomendado por Saaty (1991) de 0,10; por isso não foi necessário fazer nova comparação dos critérios.

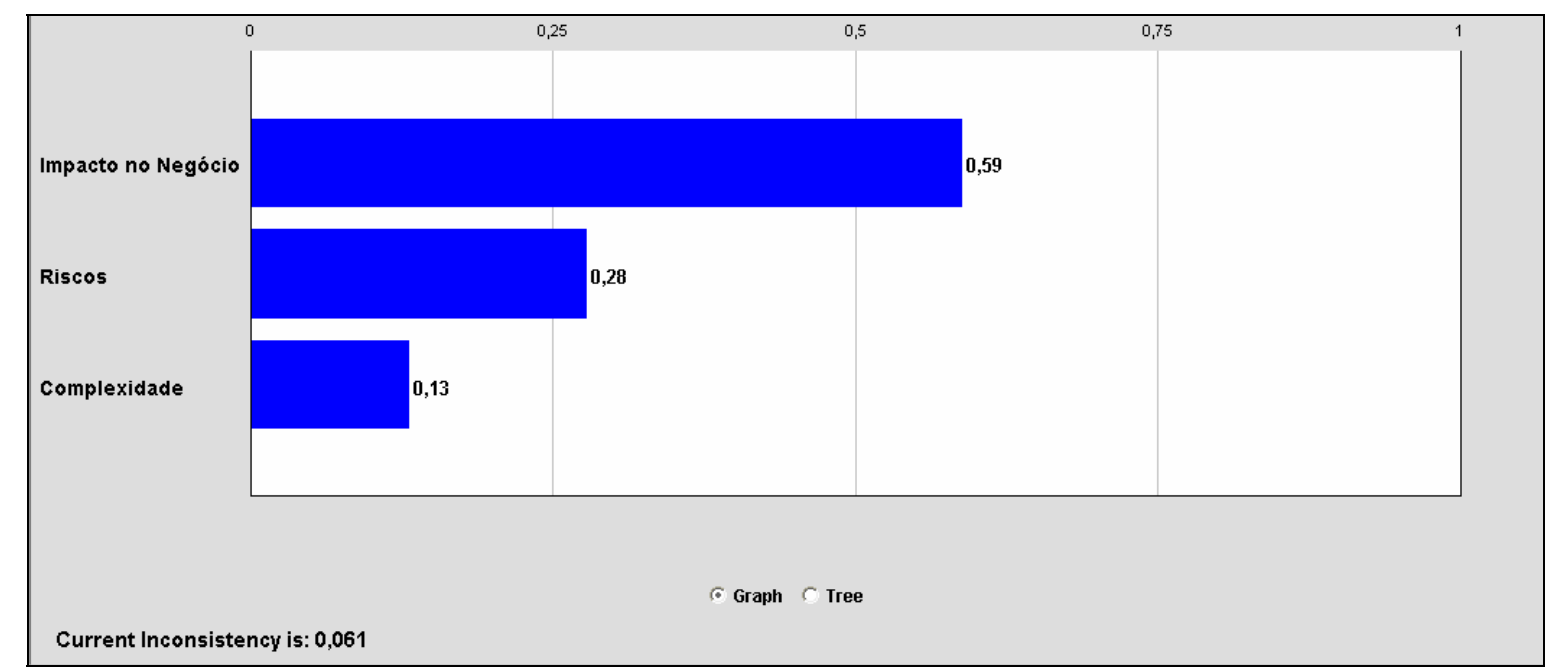

Figura 46 - Pesos dos Critérios dos Projetos de Engenharia

O próximo passo foi a realização da comparação por pares dos subcritérios feita junto aos 4 participantes da empresa, obtendo-se os resultados apresentados pelas figuras 47, 48 e 49, a seguir.

Pelo que se pode observar na figura 47, o "avanço do projeto" foi considerado o subcritério de maior impacto no projeto, com peso igual a 0,41. Justamente este subcritério tinha sido objeto de discussão para a construção da estrutura de decisões, para que fosse eliminado. O subcritério "sustentabilidade do negócio" foi o segundo mais importante tendo peso igual a 0,26. Em terceiro lugar aparece "sinergia com os negócios da empresa", com peso igual a 0,15. Para o autor esse resultado pareceu estranho, pois a análise do histórico de projetos da empresa mostrou o retorno do investimento ser um dos itens mais importantes de decisão adotados pela organização, não tendo essa importância refletida na votação, onde o subcritério só apareceu na $4^{a}$ posição. Ao discutir os resultados com os participantes foi consenso entre eles que o resultado obtido para o peso dos subcritérios representava adequadamente o processo de decisão da empresa, desta forma o autor optou por 
não propor revisão das comparações. Essa opção estava suportada pelo cálculo da inconsistência da votação desses subcritérios que foi de 0,07 .

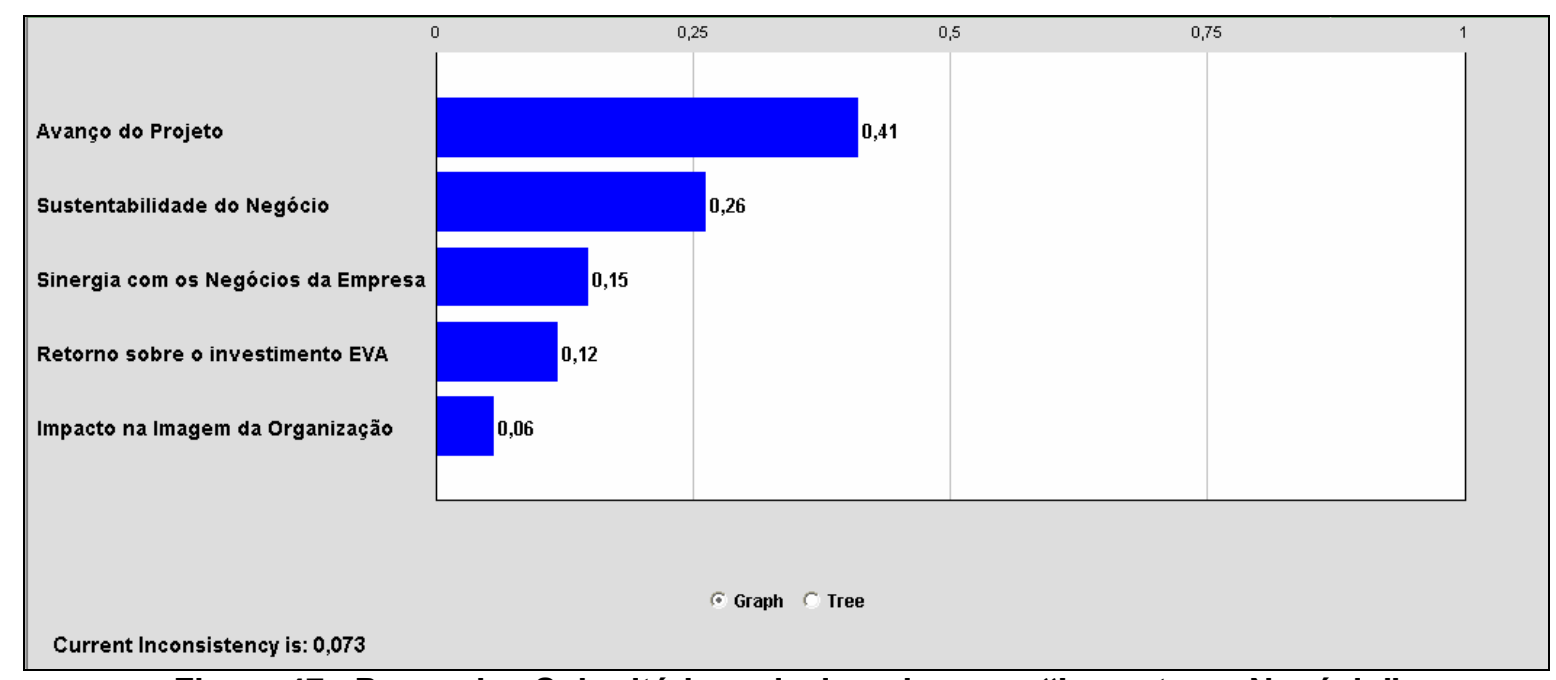

Figura 47 - Pesos dos Subcritérios relacionados com "Impacto no Negócio"

Ao analisarmos a figura 48, que apresenta os resultados da votação dos pesos dos subcritérios relacionados aos riscos dos projetos, verifica-se que de todos os riscos, àqueles decorrentes da implementação e da perspectiva de mercado são os de maiores pesos relativos, sendo seu valor de 0,29 e 0,19; respectivamente. Neste caso, o coeficiente de inconsistência resultante foi de 0,123 ; que, sendo um valor elevado, tornou necessário reavaliarmos a comparação dos subcritérios. Ao analisarmos a comparação "riscos legais e ambientais" versus "riscos da nãoimplementação", verificou-se que os primeiros foram considerados fortemente mais importantes que os últimos. Alterando-se as notas deixando os riscos legais e ambientais moderadamente mais importantes que os riscos da não-implementação o coeficiente de inconsistência ficaria abaixo de 0,10. Entretanto, os participantes não quiseram alterar seus votos, por acreditarem que o resultado da votação refletia a realidade da empresa. Assim, o resultado da figura 47 foi mantido. 


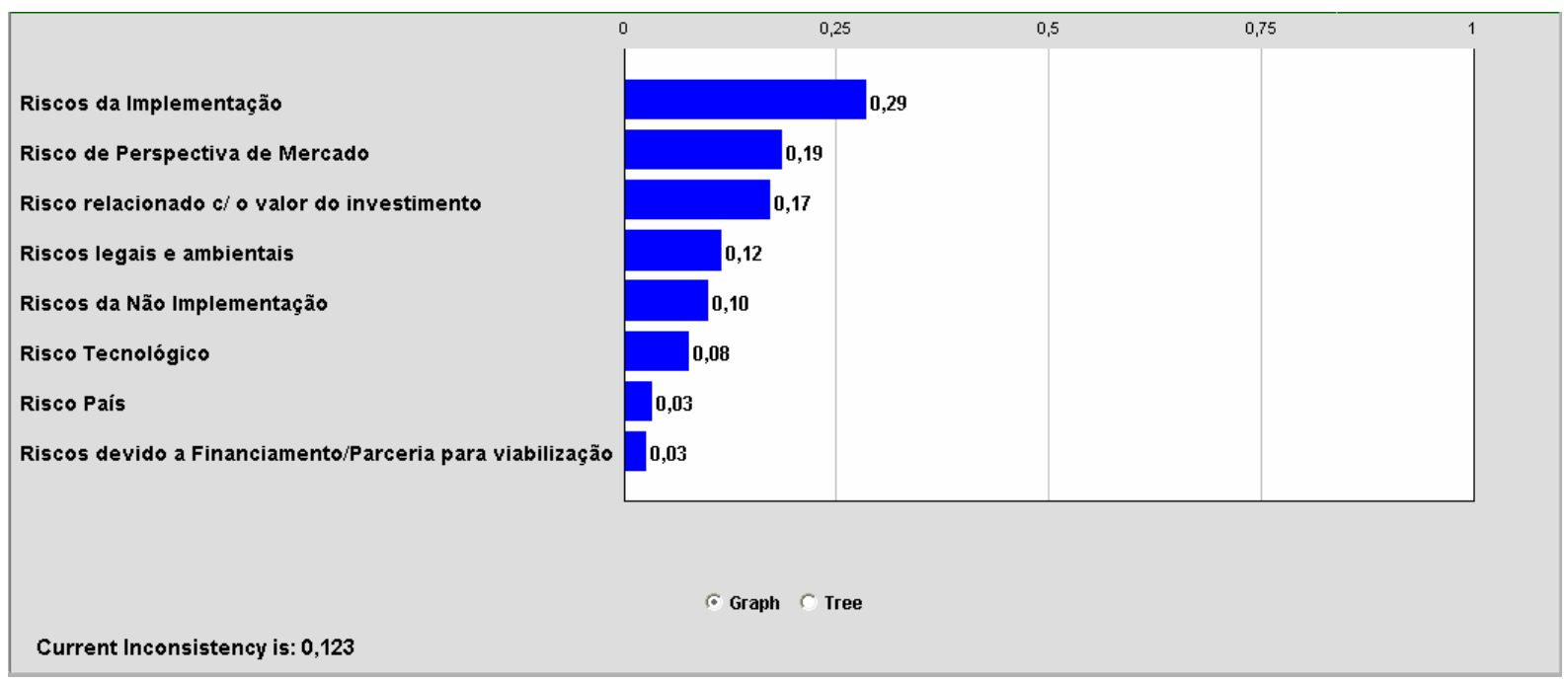

Figura 48 - Pesos dos Subcritérios relacionados com "riscos"

A figura 49 mostra o resultado da comparação dos subcritérios relacionados com a complexidade. Pelo que se pode verificar a necessidade de pessoal capacitado é o item mais importante com peso igual a 0,52. A necessidade de infra-estrutura aparece em seguida com peso de 0,37 . Os participantes justificaram suas respostas dizendo que, nos últimos 2 anos, o mercado na área de projetos está aquecido sendo muito difícil contratar pessoal capacitado. Sem recursos humanos não é possível executar os projetos cumprindo prazos pré-estabelecidos.

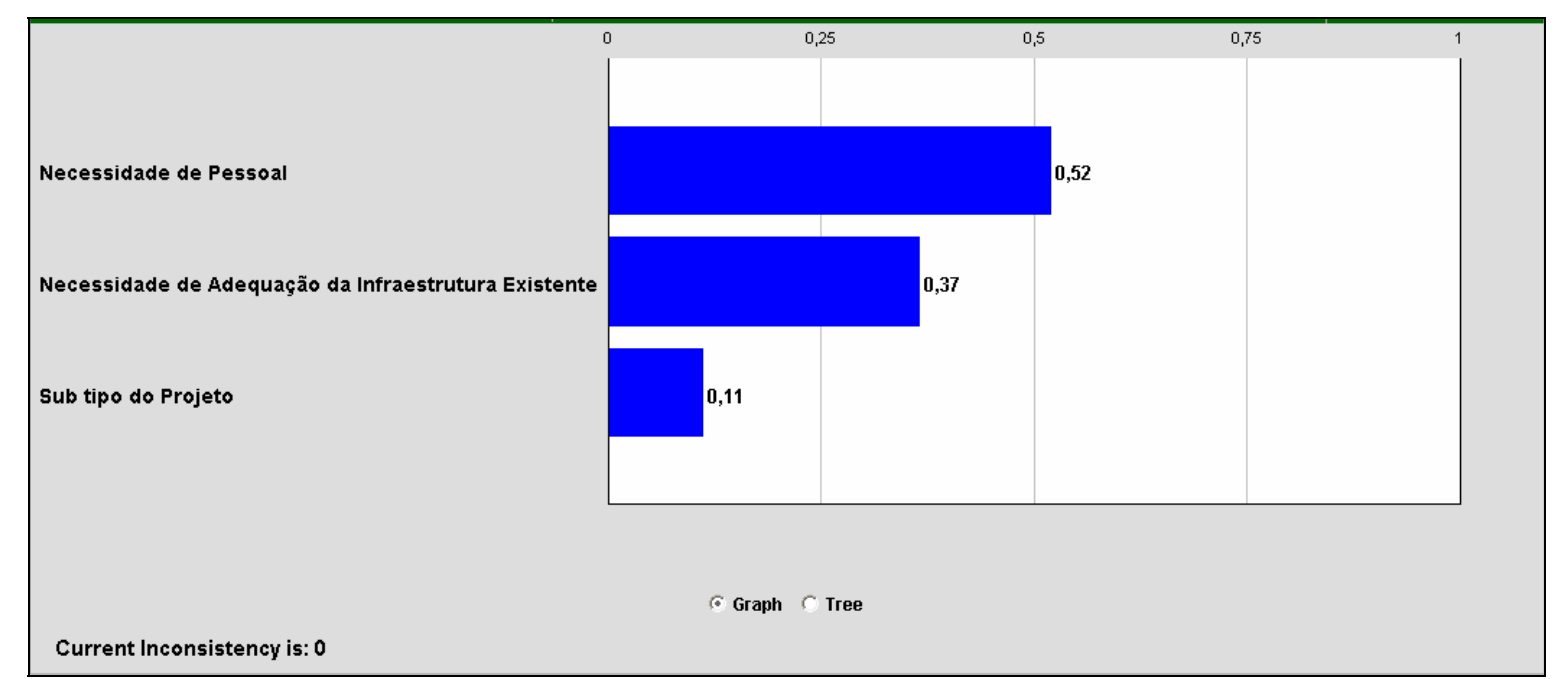

Figura 49 - Pesos dos Subritérios relacionados com a "complexidade" 
Na seqüência foi discutida a escala de valores (ratings) para os subcritérios. A descrição dos ratings e seus pesos relativos são apresentados no Apêndice E.

Depois da construção da escala de valores, foi dada uma explicação aos participantes de como seria o processo de votação de cada projeto em relação a todos os subcritérios definidos na etapa anterior, para que fossem encontradas as prioridades dos projetos.

Durante a reunião de 04/12/06, não houve tempo de executar a votação dos projetos. Optou-se pela elaboração e distribuição de uma planilha de votação para que os participantes preenchessem e entregassem ao autor, no prazo de uma semana. A um exemplo da planilha de votação para projetos de engenharia é apresentado no Apêndice F. Os dados das votações de cada participante foram inseridos no sistema Decision Lens pelo autor para que as prioridades para os projetos fossem calculadas.

O resultado da votação, com as prioridades de cada projeto, é apresentado no quadro 17.

Segundo os participantes da empresa, a reunião para aplicação do método AHP ao processo de seleção e priorização de projetos de engenharia serviu como um aprendizado sobre o método e suas etapas de implantação e para verificação do entendimento dos participantes sobre a estratégia da organização. Foi observado que a escala de valores proposta precisa ser revisada, pois ao fazer a votação dos projetos, se percebeu que em alguns casos faltavam opções que se ajustassem adequadamente a um dado projeto. Os participantes votaram todos os projetos fazendo aproximações. Essa constatação é prevista na literatura por Clemen (1991), Garber (2002), Shimizu et al. (2001) ao abordarem as dificuldades de modelagem do problema, propondo que no processo de decisão exista uma etapa cíclica de análise até que se consiga chegar a uma versão final do modelo de decisão que represente a realidade da melhor forma. O aprendizado coletivo, novamente citado, é resultado da aplicação da pesquisa-ação, conforme previsto por Thiollent (2004). 


\begin{tabular}{|c|c|c|c|c|c|c|c|c|c|c|c|c|c|c|c|c|c|}
\hline \multicolumn{2}{|c|}{$\begin{array}{l}\text { Pes05 d05 } \\
\text { Subcriterlo5 }\end{array}$} & \multirow[b]{2}{*}{ 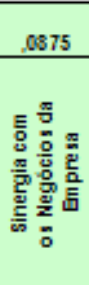 } & \multirow[b]{2}{*}{ 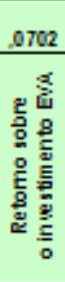 } & \multirow[b]{2}{*}{ 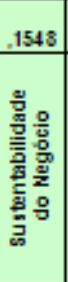 } & \multirow[b]{2}{*}{ 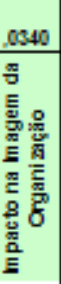 } & \multirow[b]{2}{*}{$\begin{array}{c}2421 \\
8 \\
\frac{8}{8} \\
\frac{8}{8} \\
\frac{0}{0} \\
\frac{0}{5} \\
\frac{9}{\alpha}\end{array}$} & \multirow[b]{2}{*}{$\frac{.0075}{}$} & \multirow[b]{2}{*}{ 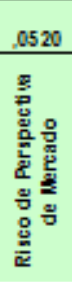 } & \multirow[b]{2}{*}{ 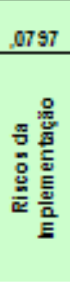 } & \multirow[b]{2}{*}{ 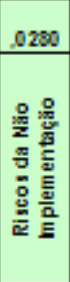 } & \multirow[b]{2}{*}{ 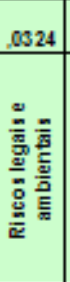 } & \multirow[b]{2}{*}{ 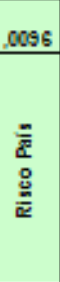 } & \multirow[b]{2}{*}{ 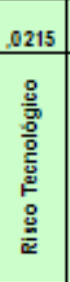 } & \multirow[b]{2}{*}{ 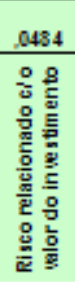 } & \multirow[b]{2}{*}{$\begin{array}{c}.0149 \\
8 \\
\frac{8}{8} \\
\frac{\pi}{8} \\
\circ \\
\circ \\
\circ \\
0 \\
0 \\
\end{array}$} & \multirow[b]{2}{*}{ 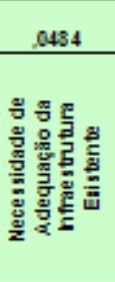 } & \multirow[b]{2}{*}{ 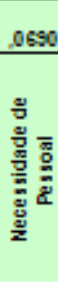 } \\
\hline$\frac{8}{\frac{m}{2}}$ & 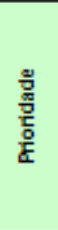 & & & & & & & & & & & & & & & & \\
\hline 2287 & 0,88 & 1 & 1 & 1 & 1 & 1 & 1 & 1 & 0.309 & 1 & 1 & 1 & 1 & 0.283 & 1 & 1 & 0.631 \\
\hline 4888 & 0,77 & 1 & 0.25 & 1 & 0.274 & 1 & 1 & 1 & 0.392 & 0.292 & 1 & 1 & 1 & 1 & 1 & 0.364 & 0.262 \\
\hline 4850 & 0,77 & 1 & 1 & 1 & 1 & 0.331 & 1 & 1 & 0.392 & 0.292 & 1 & 1 & 1 & 1 & 1 & 1 & 1 \\
\hline 4500 & 0,69 & 1 & 1 & 1 & 1 & 0,331 & 1 & 0.326 & 0.392 & 1 & 1 & 1 & 0.578 & 1 & 1 & 0.632 & 0,447 \\
\hline 4929 & 0,68 & 1 & 1 & 1 & 1 & 0,195 & 1 & 1 & 0,392 & 0,292 & 1 & 1 & 1 & 1 & 1 & 0,682 & 0,447 \\
\hline 2372 & 0,67 & 1 & 1 & 1 & 1 & 0,563 & 1 & 0.326 & 0.226 & 1 & 0.128 & 0.095 & 1 & 1 & 0.41 & 0.364 & 0,262 \\
\hline 2239 & 0,65 & 1 & 0.059 & 0.792 & 0.274 & 0,563 & 1 & 1 & 0.392 & 0,043 & 1 & 1 & 1 & 0.283 & 0,123 & 1 & 1 \\
\hline 2180 & 0,64 & 1 & 1 & 0.239 & 0.274 & 0,563 & 1 & 1 & 0.392 & 1 & 1 & 1 & 1 & 0.283 & 1 & 0.364 & 1 \\
\hline 2285 & 0,63 & 1 & 0,059 & 1 & 1 & 0,331 & 1 & 0,326 & 0,351 & 0,242 & 1 & 1 & 1 & 0.283 & 1 & 1 & 1 \\
\hline 2131 & 0,62 & 1 & 0.059 & 0.663 & 0.274 & 0,563 & 1 & 1 & 0.392 & 0,043 & 1 & 1 & 1 & 0.08 & 0,123 & 1 & 1 \\
\hline 2401 & 0,51 & 1 & 1 & 0.239 & 0.274 & 0.331 & 1 & 1 & 0.392 & 1 & 1 & 0.254 & 1 & 1 & 1 & 0.364 & 1 \\
\hline 4509 & 0,61 & 1 & 0.25 & 1 & 1 & 0.331 & 1 & 0.124 & 0.392 & 1 & 1 & 1 & 1 & 1 & 1 & 0,364 & 0.262 \\
\hline 2212 & 0,61 & 1 & 0,059 & 1 & 1 & 0,331 & 1 & 1 & 0,309 & 0,091 & 1 & 1 & 1 & 0.283 & 1 & 1 & 0,262 \\
\hline 2299 & 0.5 & 1 & 0.25 & 1 & 1 & 0,331 & 1 & 0.326 & 0.392 & 1 & 1 & 1 & 0,578 & 1 & 1 & 0,128 & 0.262 \\
\hline 2400 & 0.5 & 1 & 0.25 & 1 & 1 & 0,331 & 1 & 0.326 & 0.392 & 1 & 1 & 1 & 0.578 & 1 & 1 & 0,128 & 0.262 \\
\hline 2395 & 0,59 & 1 & 0,059 & 1 & 1 & 0,195 & 1 & 1 & 0,392 & 0,043 & 1 & 1 & 1 & 0,08 & 1 & 0,364 & 1 \\
\hline 2256 & 0,58 & 1 & 0,059 & 0.506 & 1 & 0,563 & 1 & 1 & 0.392 & 0,192 & 1 & 1 & 1 & 0.283 & 0,123 & 1 & 0.262 \\
\hline 2290 & 0,57 & 1 & 0.059 & 1 & 1 & 0.331 & 1 & 1 & 0.392 & 0,043 & 1 & 1 & 1 & 0.283 & 0,123 & 0.364 & 0.262 \\
\hline 2115 & 0,56 & 1 & 0,059 & 0.663 & 0.274 & 0,331 & 1 & 1 & 0.392 & 0,043 & 1 & 1 & 0.578 & 0.283 & 0,123 & 1 & 1 \\
\hline 2293 & 0,54 & 1 & 0.25 & 1 & 0.274 & 0,195 & 1 & 1 & 0.392 & 0,141 & 1 & 1 & 1 & 0.283 & 1 & 0.364 & 0.262 \\
\hline 2300 & 0,54 & 1 & 0,059 & 0.663 & 0.274 & 0,195 & 1 & 1 & 0,392 & 0,043 & 1 & 1 & 1 & 0.283 & 0,123 & 1 & 1 \\
\hline 2326 & 0,54 & 1 & 0.059 & 0.663 & 0.274 & 0,195 & 1 & 1 & 0.392 & 0,043 & 1 & 1 & 1 & 0.283 & 0,123 & 1 & 1 \\
\hline 2158 & 0,53 & 0.231 & 0.059 & 0.506 & 0.274 & 0.563 & 1 & 1 & 0.392 & 0,043 & 1 & 1 & 1 & 0.08 & 0,123 & 1 & 1 \\
\hline 2368 & 0,53 & 1 & 0.25 & 1 & 0.274 & 0.195 & 1 & 0.325 & 0.392 & 0.292 & 1 & 1 & 0.578 & 1 & 1 & 0.364 & 0.262 \\
\hline 2386 & 0,53 & 1 & 0.25 & 1 & 1 & 0,195 & 1 & 0.326 & 0.392 & 0,292 & 1 & 1 & 1 & 0.283 & 1 & 0,364 & 0.262 \\
\hline 2355 & 0,52 & 1 & 0,059 & 1 & 1 & 0,195 & 1 & 0.326 & 0.268 & 0,091 & 1 & 1 & 1 & 0.283 & 1 & 0,682 & 0.262 \\
\hline 2153 & 0,51 & 1 & 0.059 & 0.506 & 1 & 0.195 & 1 & 0.326 & 0.392 & 0.292 & 1 & 1 & 1 & 0.283 & 0,123 & 1 & 1 \\
\hline 2142 & 0,49 & 1 & 0.25 & 1 & 1 & 0,331 & 1 & 0.124 & 0.226 & 0,043 & 0.128 & 0.254 & 1 & 0.283 & 0.41 & 0.364 & 0.262 \\
\hline 2399 & 0,49 & 1 & 1 & 0.239 & 0.274 & 0,195 & 0.438 & 0.325 & 0.309 & 1 & 1 & 1 & 0.578 & 0.283 & 1 & 1 & 0,447 \\
\hline 2249 & 0,43 & 0.231 & 0,059 & 0,506 & 0.274 & 0,331 & 1 & 1 & 0,392 & 0,043 & 1 & 1 & 1 & 0.283 & 0,123 & 1 & 1 \\
\hline 4912 & 0,47 & 0,142 & 1 & 1 & 1 & 0.331 & 0,438 & 0.124 & 0.268 & 0,091 & 0.128 & 0.254 & 0,152 & 1 & 1 & 0,128 & 0.083 \\
\hline 2353 & 0,47 & 0,231 & 0.059 & 0.506 & 1 & 0.195 & 1 & 1 & 0.732 & 0.292 & 1 & 1 & 1 & 0,08 & 0,123 & 0,364 & 1 \\
\hline 2351 & 0,47 & 1 & 0.059 & 0.239 & 0.274 & 0.195 & 1 & 1 & 0.392 & 0,091 & 1 & 1 & 1 & 0.08 & 0,123 & 1 & 1 \\
\hline 4989 & 0,45 & 0,053 & 1 & 1 & 1 & 0,331 & 0,438 & 0,124 & 0.226 & 0,091 & 0,128 & 0.254 & 0,152 & 1 & 1 & 0,128 & 0,088 \\
\hline 2317 & 0,44 & 0.231 & 0,059 & 0,506 & 0.274 & 0,195 & 1 & 1 & 0.392 & 0,043 & 1 & 1 & 1 & 0.08 & 0,123 & 1 & 1 \\
\hline 2392 & 0,44 & 0.231 & 0.059 & 0.506 & 1 & 0.195 & 1 & 1 & 0.392 & 0,091 & 1 & 1 & 1 & 0.283 & 0,123 & 0,364 & 1 \\
\hline 2387 & 0,4 & 0.231 & 0,059 & 0.506 & 1 & 0,195 & 1 & 1 & 0.392 & 0,292 & 1 & 1 & 1 & 0.283 & 0,123 & 0,364 & 0.262 \\
\hline 2394 & 0,4 & 0.231 & 0.25 & 1 & 1 & 0,229 & 0,179 & 0,124 & 0,309 & 0,091 & 1 & 0,095 & 0,578 & 0.283 & 1 & 0,128 & 0,083 \\
\hline 2340 & 0,39 & 0.231 & 0.059 & 0.506 & 1 & 0.195 & 1 & 1 & 0.392 & 0,043 & 1 & 1 & 1 & 0.283 & 0,123 & 0,364 & 0.262 \\
\hline 2123 & 0,34 & 0,053 & 0.059 & 0,327 & 1 & 0,331 & 0,438 & 0.124 & 0.732 & 0,043 & 1 & 1 & 0,152 & 0.283 & 1 & 0,364 & 0,083 \\
\hline 4949 & 0,3 & 0.231 & 0.059 & 0.239 & 1 & 0.331 & 0,179 & 0.124 & 0,309 & 0,091 & 0.128 & 0.774 & 0,152 & 1 & 1 & 0.128 & 0.083 \\
\hline
\end{tabular}

Quadro 17 - Resultado das Prioridades dos Projetos de Engenharia com o AHP

\subsubsection{A Estrutura dos Projetos de Manutenção}

Sendo os projetos de manutenção classificados pela estrutura principal em segundo lugar em importância, o autor optou por fazer, também para esse caso, um trabalho mais minucioso na elaboração da estrutura.

Foram escolhidos para participar desta etapa do projeto de pesquisa 4 funcionários da empresa, todos chefes das áreas de manutenção, representantes de cada uma das 4 fábricas, cujos perfis encontram-se no Apêndice $B$.

Inicialmente o autor montou um esboço da estrutura de projetos de manutenção. Esse esboço analisado frente a teoria em reunião ocorrida em 20/10/06 com acadêmicos especialistas método AHP. 
Uma vez feitas as alterações julgadas pertinentes, foram agendadas reuniões nos dias 26/10/06, 08/11/06 e 23/11/06 para a validação da estrutura de decisões proposta, definição de critérios, subcritérios e ratings.

As duas primeiras reuniões foram realizadas com a presença do representante da fábrica 4, que na época estava realizando um trabalho na sede da empresa, fato que permitiu sua participação. Utilizou-se estas reuniões para apresentar o escopo do projeto de pesquisa, o método AHP, a ferramenta utilizada e discussão da estrutura de decisões esboçada pelo autor, para uma validação prévia com o participante 4, com o objetivo de evitar um excesso de reuniões, dado que dos 4 representantes de fábricas, ele é o mais experiente.

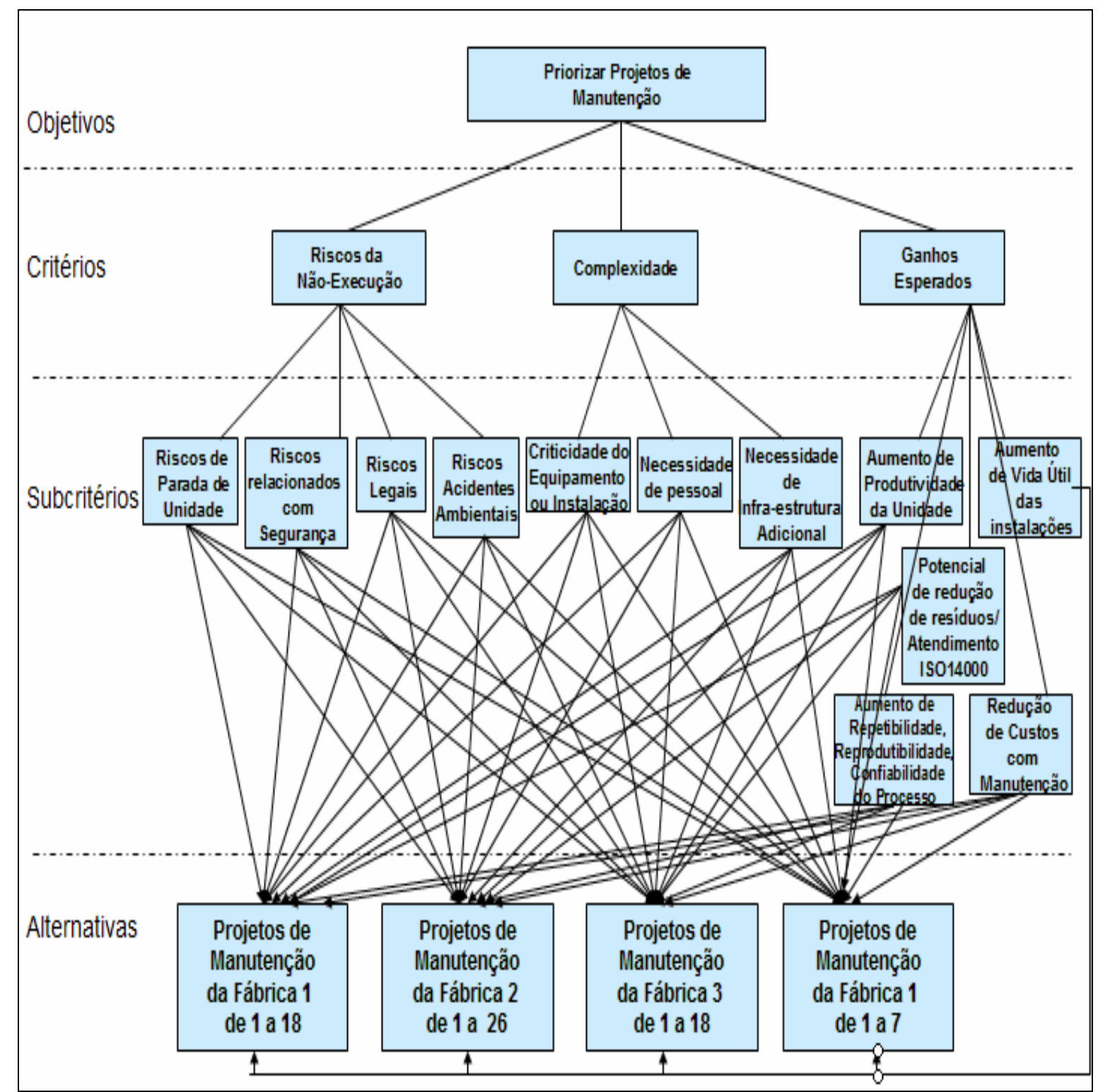

Figura 50 - Hierarquia de Projetos de Manutenção - Versão Final 
A estrutura de decisões resultante das discussões foi validada com os participantes das demais unidades na reunião do dia 23/11/06. Esta estrutura, definida para os projetos de manutenção, é apresentada pela figura 50.

O conceito de cada critério e subcritério foi discutido primeiramente com o participante da fábrica 4 . Na reunião de 23/11/06 houve a validação dos critérios e subcritérios com os participantes das 4 fábricas, chegando-se a versão final apresentada pelo quadro 18 , a seguir.

\begin{tabular}{|c|c|}
\hline Critérios/Subcritérios & Definição \\
\hline Riscos da Não Execuçāo & $\begin{array}{l}\text { Impacto na imagem da empresa devido a ocorrência de dano ambiental, acidentes com mortes, paradade unidade com } \\
\text { perda de produção (lucros cessantes). } \\
0 \text { risco da não execução será tanto maior quanto mais critico for o equipamento ou unidade produtiva para o funcionamento } \\
\text { da empresa. A existência de equipamentos reserva minimizam a criticidade do equipamento e portanto o risco da não }\end{array}$ \\
\hline Risco de Parada de Unidade & Se pode ocorrer parada com perda de produção, parada sem perda de produção ou nenhum risco. \\
\hline $\begin{array}{l}\text { Riscos relacionados c/ Segurança } \\
\text { Industrial }\end{array}$ & Riscos de acidentes com danos a propriedade ou funcionários ou nenhum. \\
\hline Riscos Legais & Riscos de autuaçâo, fechamento de unidade ou ambos ou nenhum risco legal. \\
\hline Riscos de Acidentes Ambientais & Vazamentos de produto para o meio ambiente, com ou sem contaminação do solo. \\
\hline Ganhos Esperados & Ganhos de produtividade e confiabilidade/qualidade do produto. \\
\hline $\begin{array}{l}\text { Aumento da Produtividade da } \\
\text { Unidade }\end{array}$ & Aumento de produtividade pode ser medido por redução nas perdas de produção por quebra de equipamentos. \\
\hline $\begin{array}{l}\text { Aumento da Vida Útil das } \\
\text { Instalaçóes }\end{array}$ & $\begin{array}{l}\text { Pode ser medido considerando aumento de vida útil alto } 25 \% \text { maior que a vida do equip. anterior; } 10 \% \text { médio e } 5 \% \text { baixo ou } \\
\text { nenhum aumento de vida útil. }\end{array}$ \\
\hline \begin{tabular}{|l|} 
Potencial de redução de resíduos / \\
Contribuição para atender ISO 14000
\end{tabular} & Projeto elimina geração ou não elimina geração de resíduos \\
\hline $\begin{array}{l}\text { Aumento da Repetibilidade } \\
\text { /Reprodutibilidade/Confiabilidade } \\
\text { do Processo }\end{array}$ & $\begin{array}{l}\text { Os recursos propostos podem permitir um melhor controle do processo produtivo, melhorando a qualidade do produto e a } \\
\text { confiabilidade das instalaçôes. Projetos de automaçấo tem confiabilidade } 100 \% \text {. }\end{array}$ \\
\hline Redução de Custos com Manutenção & $\begin{array}{l}\text { Redução de custos com manutenção corretiva ou preventiva devido a modernização da instalação elou inclusão de recursos } \\
\text { que aumentem a disponibilidade da planta. Redução de custos alta = 4\%, média } 2 \% \text { e baixa } 1 \% \text {. }\end{array}$ \\
\hline Complexidade & $\begin{array}{l}\text { Quanto o projeto é crítico no que se refere a necessidade de pessoal, infraestrutura e a criticidade de equipamentos ou } \\
\text { instalacoes. }\end{array}$ \\
\hline $\begin{array}{l}\text { Criticidade do Equipamento ou } \\
\text { Instalação }\end{array}$ & $\begin{array}{l}\text { O projeto proposto pode ser para um equipamento ou instalaçâo de alta, média ou baixa criticidade dependendo se a } \\
\text { instalaçâo tem equipamentos reservas, se é de risco ou nâo, do grau de ocupaçâo da unidade com produção, do prazo de } \\
\text { entrega de peças sobressalentes e equipamentos similar.(Alto equipamento é único para a unidade, médio tenho } \\
\text { equipamento reserva mas o equipamento pára a unidade, baixo equipamento não pára a unidade). }\end{array}$ \\
\hline Necessidade de Pessoal & $\begin{array}{l}\text { Pessoal para o projeto pode ser: próprio existente e capacitado; próprio parcialmente existente e capacitado; próprio } \\
\text { inexistente -com necessidade de contratacảo. }\end{array}$ \\
\hline $\begin{array}{l}\text { Necessidade de Infraestrutura } \\
\text { Adicional }\end{array}$ & $\begin{array}{l}\text { Se a infraestrutura para execução do serviço está disponivel, parcialmente disponivel ou não disponivel, exigindo } \\
\text { investimento adicional e planejamento previo. }\end{array}$ \\
\hline
\end{tabular}

Quadro 18 - Definição dos critérios e subcritérios de seleção e priorização - Projetos de Manutenção 
No mesmo dia, após a validação dos critérios e subcritérios iniciou-se o processo de comparação por pares para que se definissem os pesos de cada critério e subcritério.

O resultado obtido pode ser observado através da figura 51 que apresenta na forma gráfica os pesos dos critérios. A inconsistência resultante foi de 0,145 ; acima do valor máximo recomendado por Saaty (1991), o que nos levou a reavaliar os votos.

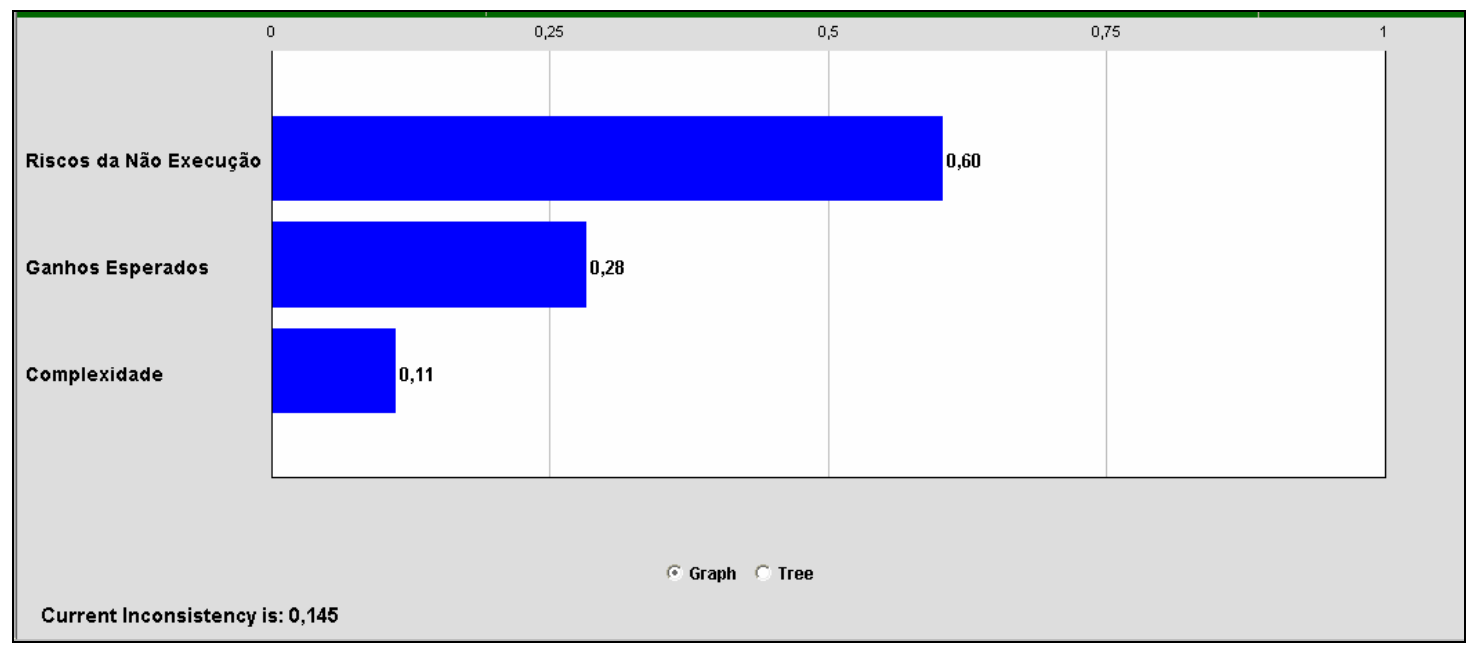

Figura 51 - Pesos dos Critérios dos Projetos de Manutenção - Versão Inicial

A análise do coeficiente de inconsistência mostrou que na votação dos critérios "Riscos da não-execução" versus "ganhos esperados", foi dado um peso excessivo para os riscos da não-execução, sendo a média do grupo 3,13. Retornando-se a comparação por pares na votação destes subcritérios, foi possível verificar que os participantes das fábricas 2 e 3 deram os maiores pesos para os riscos da nãoexecução, puxando a média para um valor mais alto. Esses dois participantes são os menos experientes na função de chefia da manutenção e talvez por isso tenham tido essa tendência. Uma observação dos próprios participantes durante a discussão do motivo do peso elevado atribuído ao critério "riscos da não-execução" foi que as notas dadas não representavam a estratégia da empresa e sim o que os participantes acreditavam ser eticamente correto, por isso ao final da discussão as notas acabaram sendo alteradas resultando num peso pouco menor para o subcritério "riscos da não execução" quando comparado com os "ganhos esperados". A figura 52 apresenta os resultados da comparação por pares dos critérios de maior inconsistência, acima descritos. 


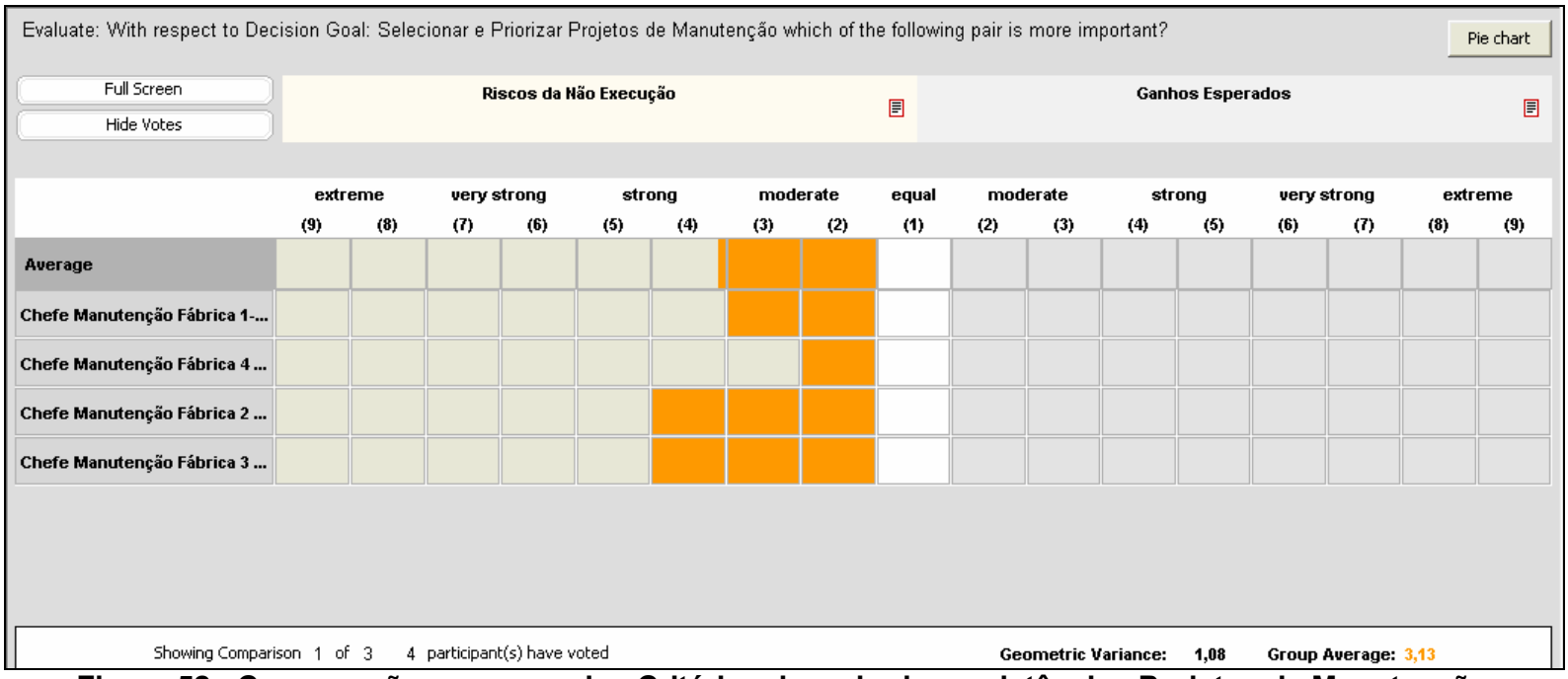

Figura 52 - Comparação por pares dos Critérios de maior inconsistência - Projetos de Manutenção

Após nova discussão entre os 4 participantes, o voto do participante da fabrica 2 foi alterado para moderado (3) e o da fábrica 1 foi alterado para (2), isto é, "riscos da não-execução" estão entre moderadamente mais importante e igual aos "ganhos esperados".

A nova votação resultou numa inconsistência de 0,09 ; aceitável para a continuidade do nosso trabalho de pesquisa, conforme Saaty (1991) e Forman e Selly (2001). Os pesos obtidos com a nova votação são apresentados pela figura 53, a seguir.

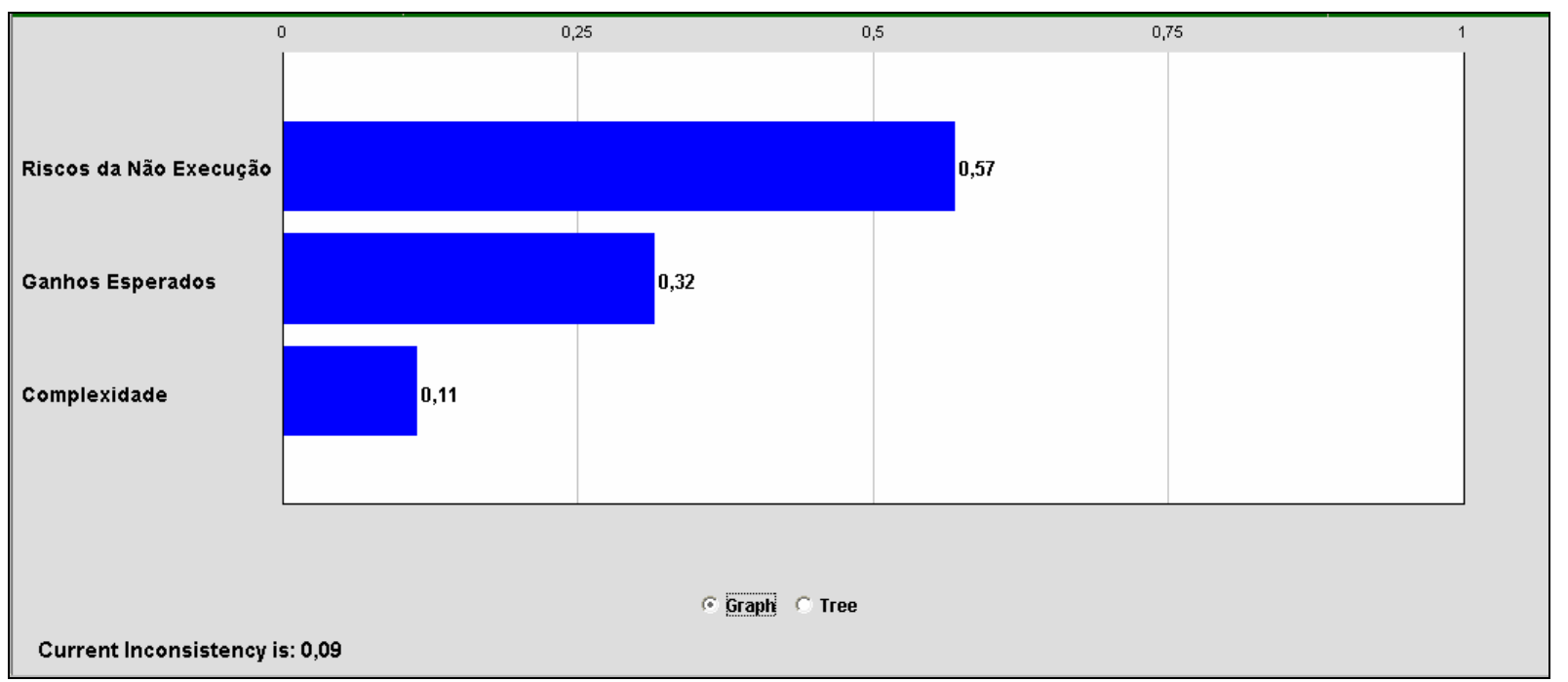

Figura 53 - Pesos dos Critérios dos Projetos de Manutenção - Versão Final 
Pelo que se pôde verificar, a área de manutenção considera mais crítico o critério de "riscos da não-execução" do projeto, pois ele está relacionado com atendimento à legislação, problemas ambientais e segurança, sendo o peso obtido de 0,57 . Os "ganhos esperados", cujo peso resultante foi 0,32 ; é o segundo critério mais importante. Eles estão relacionados com a possibilidade de aumento da competitividade da empresa através de aumento de produtividade, redução de custos, melhoria na confiabilidade, repetibilidade e reprodutibilidade dos processos, melhoria na qualidade de produtos, redução de ciclos produtivos e aumento da vida útil dos equipamentos. A complexidade teve o menor peso porque, apesar de importante, os participantes disseram ser uma característica inerente ao negócio. Observa-se uma preocupação no atendimento aos stakeholders públicos e primários, conforme as definições de Clarkson (1995) e Donaldson e Preston (1995).

O próximo passo do trabalho de validação da estrutura de projetos de manutenção foi a votação dos pesos dos subcritérios, também usando a comparação por pares.

Ao final da votação dos subcritérios novamente houve grandes inconsistências nas votações, pelo que se observa pelas figuras 54,55 e 56, com os pesos dos subcritérios e inconsistências resultantes.

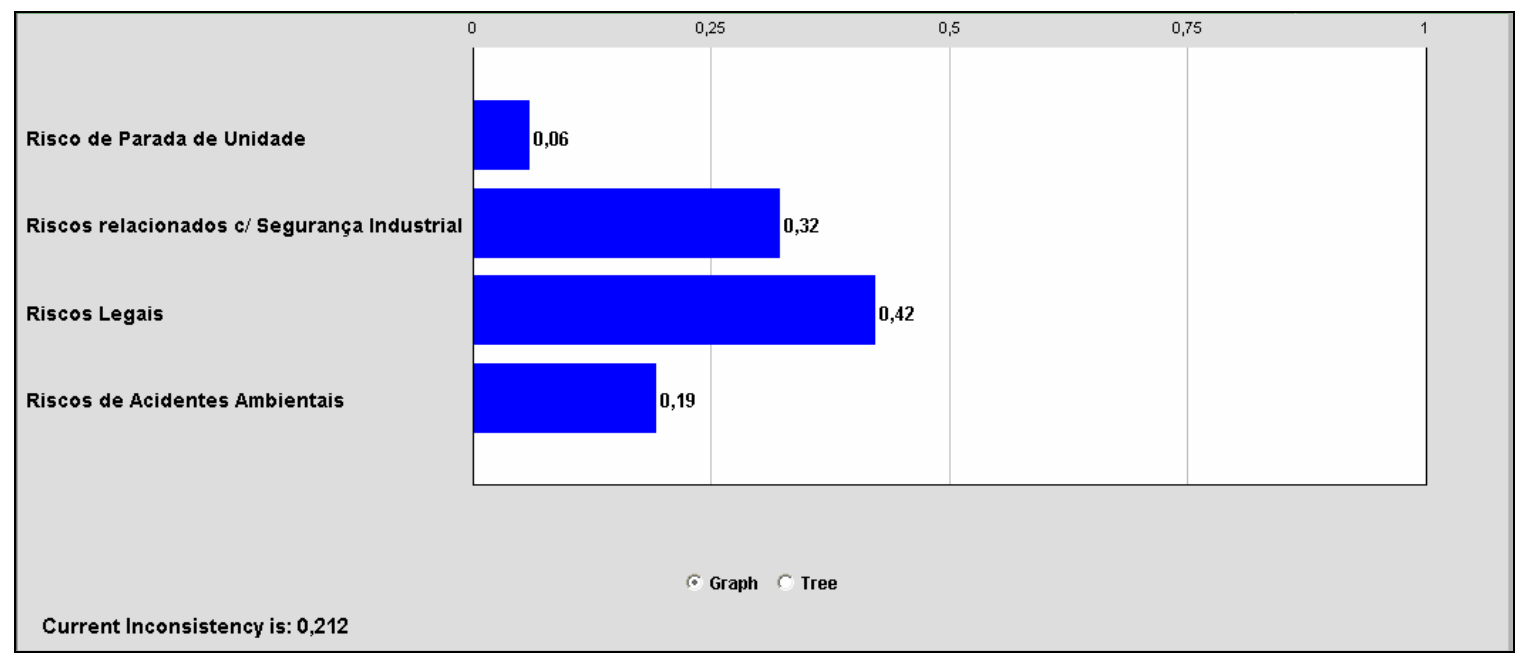

Figura 54 - Pesos dos Subcritérios Relacionados com “Riscos da Não-Execução”-Projetos de Manutenção

A análise da figura 54 mostra um coeficiente de inconsistência de 0,212; resultado da comparação por pares dos subcritérios relacionados aos riscos da não- 
execução dos projetos. A causa principal dessa inconsistência foi a comparação entre os subcritérios: "riscos relacionados com segurança" e "riscos de acidentes ambientais". O primeiro foi considerado fortemente mais crítico que o último. Após nova discussão entre os participantes, houve consenso em mudar os votos deixando o critério "riscos relacionados a segurança" moderadamente mais importante que os "riscos ambientais", pois acidentes e não cumprimento a legislação podem trazer penalidades altas para a empresa, tais como mortes, perda de produção e fechamento da fábrica; mas problemas ambientais também podem levar a fechamento de unidades industriais.

Uma outra discrepância observada foi na comparação entre os subcritérios: "riscos legais" e "riscos de acidentes ambientais", os participantes ficaram divididos, parte deles opinando que os riscos legais eram moderadamente mais importantes que os riscos ambientais e parte deles achando exatamente o contrário. O desvio se deve a diferentes graus de exigência ambiental e diferenças na legislação dos estados onde as fábricas estão localizadas. Neste caso optou-se por não refazer a votação dos subcritérios, sendo a inconsistência resultante de 0,133.

A figura 55 mostra os pesos resultantes da comparação por pares dos subcritérios relativos aos "ganhos esperados". Neste caso a inconsistência resultante foi igual a 0,042; dentro dos limites aceitáveis não sendo necessária nova votação.

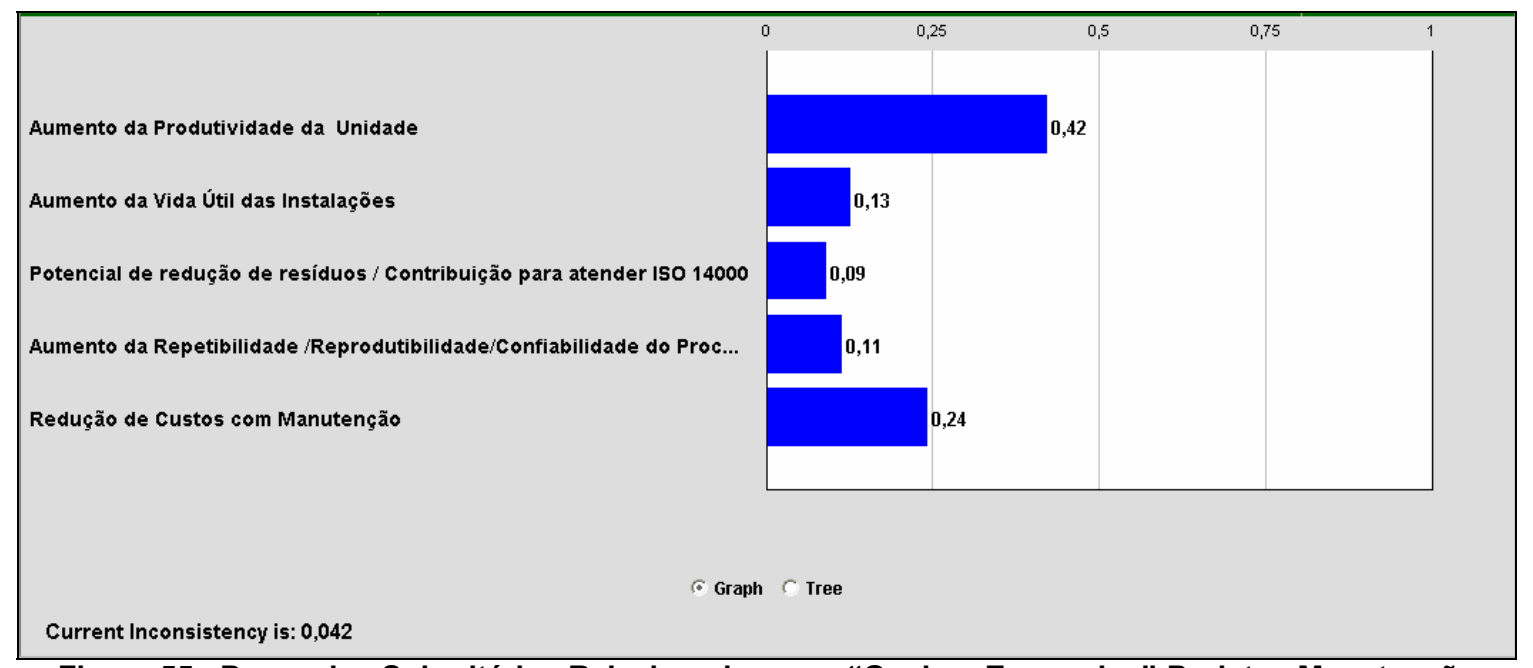

Figura 55 - Pesos dos Subcritérios Relacionados com “Ganhos Esperados”-Projetos Manutenção

A figura 56 apresenta os resultados da comparação por pares dos subcritérios relacionados com o critério "complexidade". Nesta votação, novamente foi observada 
uma inconsistência grande, igual a 0,204; tornando necessária a análise das causas dessa distorção. Observa-se que todas as comparações foram discrepantes segundo o cálculo das inconsistências realizado pelo sistema. Na comparação necessidade de pessoal versus necessidade de infra-estrutura da primeira votação, os participantes deram uma importância muito mais forte para a infra-estrutura que para o pessoal, e após a nova discussão chegaram a conclusão que infra-estrutura e pessoal têm importância relativa muito próxima.

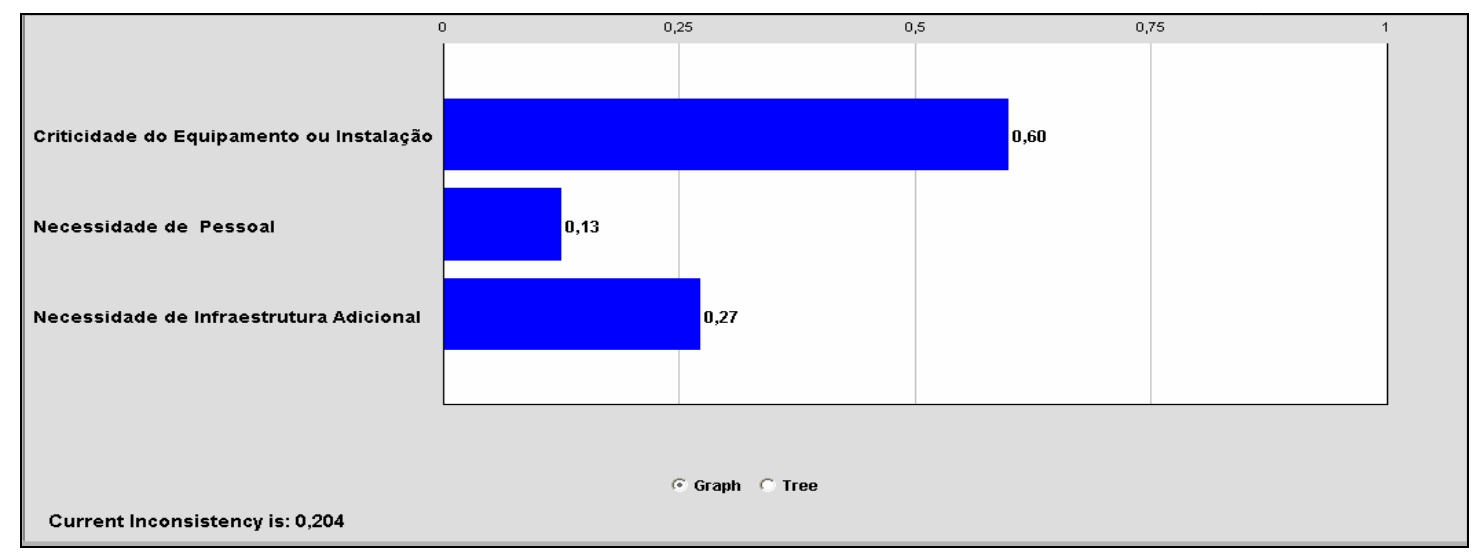

Figura 56 - Pesos dos Subcritérios dos Relacionados com "Complexidade"-Projetos de Manutenção

Após a nova votação o coeficiente de inconsistência caiu para 0,095 . Os resultados finais dos pesos dos critérios e subcritérios são apresentados na figura 57.

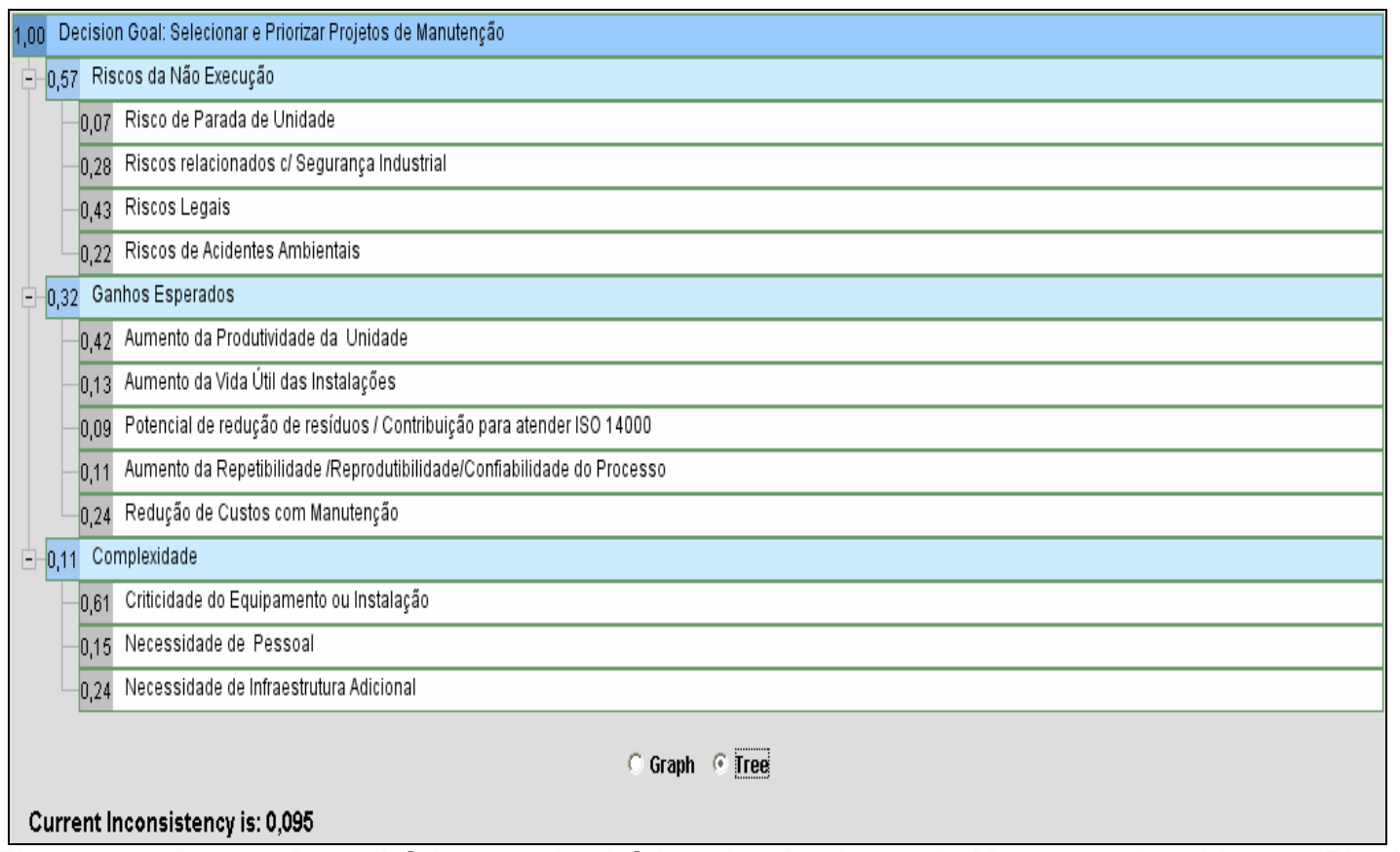

Figura 57 - Pesos dos critérios e subcritérios dos Projetos de Manutenção - Versão Final 
$\mathrm{Na}$ seqüência, o autor conduziu a discussão para a validação da escala de valores (ratings) dos subcritérios. Os resultados obtidos são apresentados no quadro 19.

\begin{tabular}{|c|c|c|c|}
\hline Subcritérios & Escala de Valores (ratings) & Definiçäo da escala de valores ou ratings & Pesos dos ratings \\
\hline Risco de Parada de Unidade & $\begin{array}{l}\text { Mutito Critico } \\
\text { Critico } \\
\text { Näso Critico }\end{array}$ & 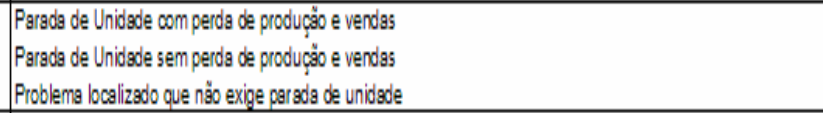 & $\begin{array}{l}1,00 \\
0,22 \\
0,08\end{array}$ \\
\hline Riscos relacionacos c/Segurança Industrial & $\begin{array}{l}\text { Mutito Critico } \\
\text { Critico } \\
\text { Näo Critice }\end{array}$ & $\begin{array}{l}\text { Acidentes com daros a savide dos funcionários } \\
\text { Acidentes com danos ao patimónio } \\
\text { Nenhum risco as segurances }\end{array}$ & $\begin{array}{l}1,00 \\
0,51 \\
0,08\end{array}$ \\
\hline Riscos Legais & \begin{tabular}{|l|} 
Alto \\
Médio \\
Bgixo \\
Nenhum \\
\end{tabular} & $\begin{array}{l}\text { Autugç̧o e fechamento de Unidgole } \\
\text { Autusço } \\
\text { Advetêncis } \\
\text { Nenhum risco } \\
\end{array}$ & $\begin{array}{l}1,00 \\
0,28 \\
0,09 \\
0,05\end{array}$ \\
\hline Riscos de Acidentes Am bientiais & $\begin{array}{l}\text { Muto Critico } \\
\text { Critico } \\
\text { Näso Critico } \\
\end{array}$ & 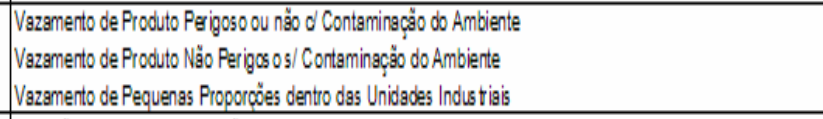 & $\begin{array}{l}1,00 \\
0,22 \\
0,08 \\
\end{array}$ \\
\hline Aum ento da Frodutividade da Unidade & $\begin{array}{l}\text { Alto } \\
\text { Méolio } \\
\text { Bgixo } \\
\end{array}$ & 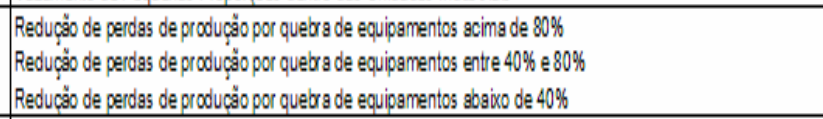 & $\begin{array}{l}1,00 \\
0,27 \\
0,07\end{array}$ \\
\hline Aumentio da Vida Útili das Insetalaģôes & $\begin{array}{l}\text { Alto } \\
\text { Méolio } \\
\text { Bgixo } \\
\end{array}$ & 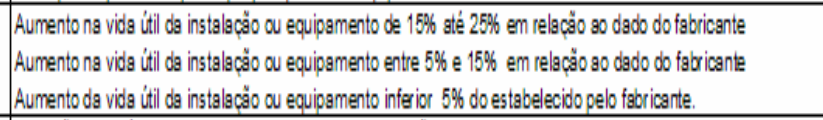 & $\begin{array}{l}1,00 \\
0,24 \\
0,07 \\
\end{array}$ \\
\hline 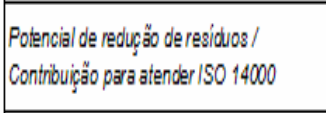 & $\begin{array}{l}\text { Alto } \\
\text { Méolio } \\
\text { Bgixo }\end{array}$ & 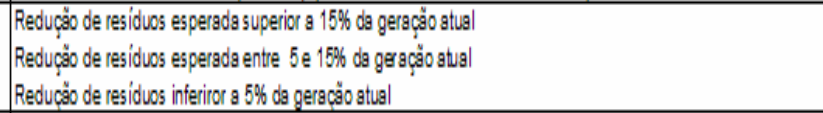 & $\begin{array}{l}1,00 \\
0,42 \\
0,13\end{array}$ \\
\hline 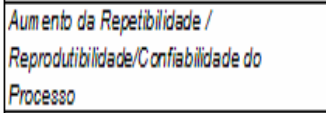 & Impscts & 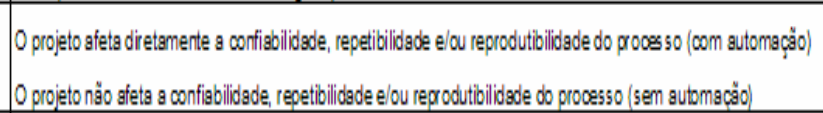 & $\begin{array}{l}1,00 \\
0,11\end{array}$ \\
\hline Reduç̧ö de Custos com Manuterç̧̄o & Alito & 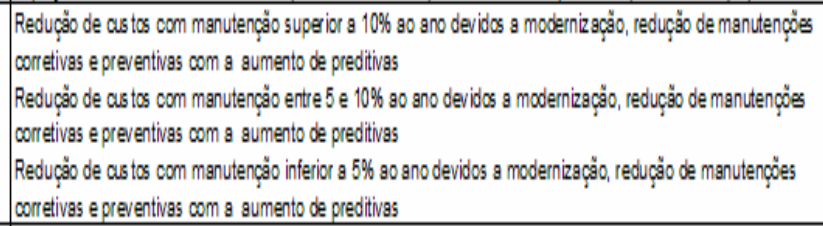 & $\begin{array}{l}1,00 \\
0,41 \\
0,18\end{array}$ \\
\hline Criticidade do Equipam ento ou Insialabăso & $\begin{array}{l}\text { Mutio Critico } \\
\text { Criticos } \\
\text { Näo Critico }\end{array}$ & 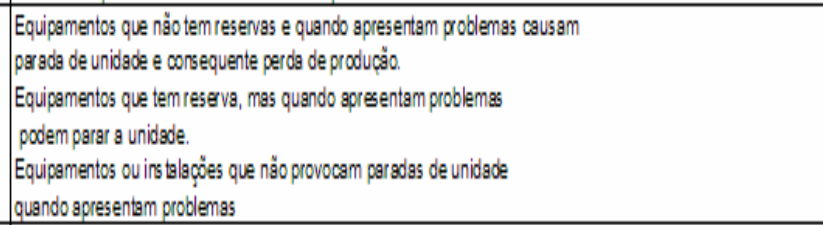 & $\begin{array}{l}1,00 \\
0,30 \\
0,08\end{array}$ \\
\hline Necessidade de Peesoal & \begin{tabular}{|l} 
Nenhuma \\
Parcial \\
Total \\
\end{tabular} & 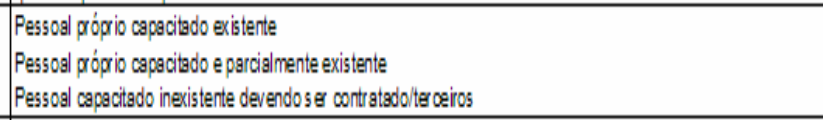 & $\begin{array}{l}1,00 \\
0,28 \\
0,10 \\
\end{array}$ \\
\hline Necessidgde de Infrges truturg Adicional & $\begin{array}{l}\text { Infrresstuturg Exis tente } \\
\text { Infrgestruturg } \\
\text { Parciamente Existente } \\
\text { Infrrestrutura Inexistente }\end{array}$ & 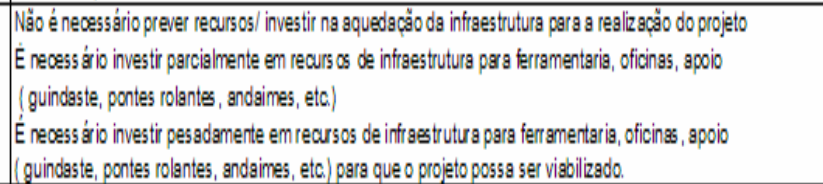 & $\begin{array}{l}1,00 \\
0,28 \\
0,10\end{array}$ \\
\hline
\end{tabular}

Quadro 19 - Definição da escala de valores para os subcritérios dos Projetos de Manutenção

A última fase do trabalho de modelagem e validação da estrutura de decisões para os projetos de manutenção foi a votação dos projetos. 
No total, 69 projetos de manutenção foram selecionados, todos relativos ao ano de 2005. O portfólio é constituído por 18 projetos da fábrica (1), 26 projetos da fábrica (2), 18 projetos da fábrica (3) e 7 projetos da fábrica (4). A relação completa dos projetos utilizados neste estudo é apresentada no Apêndice D.

Ao propor a votação de todos os projetos utilizando-se uma única estrutura de decisões, o autor se deparou com o problema dos participantes não se julgarem aptos a votar as prioridades de projetos de outras fábricas, alegando não ter conhecimento para isso. Assim, foi proposto pelos participantes utilizar a mesma estrutura de decisões de projetos de manutenção, porém, cada participante votaria separadamente os projetos de sua unidade produtiva.

Devido à solicitação dos representantes das unidades, foi necessária a adoção de um critério de rateio para distribuir, por site, o montante de investimentos definido pela estrutura principal, para os projetos de manutenção. O critério de rateio definido de comum acordo com os participantes foi o de cada unidade receber um valor proporcional ao valor dos seus ativos instalados. Esse rateio era necessário para o uso do otimizador do modelo com a programação inteira.

Durante a reunião do dia 23/11/06 não houve tempo para que a votação dos projetos de cada site fosse feita. Por isso, foi elaborada uma planilha de votação para cada participante, com os projetos de sua fábrica, para que a votação fosse realizada e entregue ao autor para cálculo e análise dos resultados. Os resultados foram apresentados em uma reunião de encerramento do estudo. Os representantes das fábricas (1) e (4), por terem disponibilidade agendaram um outro dia para fazer a votação diretamente no sistema, enquanto que os representantes das fabricas (2) e (3) optaram pelo preenchimento da planilha de votação. As planilhas de votação podem ser consultadas no Apêndice $F$

Os resultados da votação, com as prioridades para cada projeto obtido para as quatro fábricas são apresentados pelos quadros de 20 a 23. Pela avaliação dos representantes da empresa, as prioridades resultantes do modelo refletem 0 pensamento deles, podendo o modelo ser considerado válido. 


\begin{tabular}{|c|c|c|c|c|c|c|c|c|c|c|c|c|c|}
\hline \multicolumn{2}{|c|}{$\begin{array}{l}\text { Pesos dos } \\
\text { Subcritérios }\end{array}$} & \multirow[b]{2}{*}{$\begin{array}{l}\text {,0379 } \\
\text { Risco de } \\
\text { Parada } \\
\text { de Unidade }\end{array}$} & \multirow[b]{2}{*}{\begin{tabular}{|c|}
, 1601 \\
Riscos \\
relacionados \\
com \\
Segurança \\
Industrial \\
\end{tabular}} & \multirow[b]{2}{*}{\begin{tabular}{|l}
2453 \\
Riscos \\
Legais
\end{tabular}} & \multirow[b]{2}{*}{\begin{tabular}{|l|}
, 1266 \\
Riscos de \\
Acidentes \\
Ambientais
\end{tabular}} & \multirow[b]{2}{*}{\begin{tabular}{|c|}
, 1335 \\
Aumento da \\
Produtividade \\
da Unidade
\end{tabular}} & \multirow[b]{2}{*}{\begin{tabular}{|c|}
, 0405 \\
Aumento \\
da Vida \\
Útil das \\
Instalaçōes \\
\end{tabular}} & \multirow[b]{2}{*}{$\begin{array}{c}\text { 0288 } \\
\text { Potencial de } \\
\text { reduçáa } \\
\text { de resíduos/ } \\
\text { Contribuiçáo para } \\
\text { atender ISO }\end{array}$} & \multirow[b]{2}{*}{$\begin{array}{c}\text {,0360 } \\
\text { Aumento da } \\
\text { Repetibilidade/ } \\
\text { Reprodutibilidade/ } \\
\text { Confiabilidade do } \\
\text { Processo }\end{array}$} & \multirow[b]{2}{*}{\begin{tabular}{|c|}
, 0765 \\
\\
Reduçajo de \\
Custos com \\
Manutençáo \\
\end{tabular}} & \multirow[b]{2}{*}{\begin{tabular}{|c|}
, 0701 \\
\\
Criticidade do \\
Equipamento \\
ou Instalaçacio
\end{tabular}} & \multirow[b]{2}{*}{$\begin{array}{l}\text { Necessidade } \\
\text { de Pessoal }\end{array}$} & \multirow[b]{2}{*}{\begin{tabular}{|c|}
, 0277 \\
Necessidade \\
de \\
Infraestrutura \\
Adicional
\end{tabular}} \\
\hline Projetos & \begin{tabular}{|c|} 
Prioridades \\
dos \\
Projetos
\end{tabular} & & & & & & & & & & & & \\
\hline 2126 & 0,5 & 1 & 0.508 & 0,285 & 1 & 0,067 & 1 & 0,132 & 0,111 & 0,405 & 1 & 1 & 0.265 \\
\hline 2352 & 0,46 & 0.218 & 1 & 0,046 & 0,217 & 0,067 & 1 & 0,132 & 0,111 & 1 & 1 & 1 & 1 \\
\hline 2273 & 0,4 & 0.061 & 1 & 0,046 & 0,057 & 0.067 & 0.235 & 0,132 & 1 & 1 & 1 & 0.284 & 0.265 \\
\hline 2363 & 0,39 & 1 & 0.508 & 0,046 & 0,057 & 0.067 & 1 & 0,132 & 1 & 1 & 1 & 0.284 & 0.265 \\
\hline 2274 & 0,31 & 1 & 0.084 & 0,046 & 0,217 & 0,067 & 0,235 & 0,132 & 0,111 & 1 & 1 & 1 & 1 \\
\hline 2193 & 0,28 & 0,061 & 0.084 & 0,285 & 0.217 & 0.067 & 0.235 & 0,42 & 1 & 1 & 0,061 & 1 & 0.265 \\
\hline 2346 & 0,28 & 1 & 0,084 & 0,046 & 0.217 & 0,067 & 1 & 0,132 & 1 & 0,405 & 0,303 & 1 & 1 \\
\hline 2374 & 0,26 & 0,061 & 0,084 & 0,046 & 0,217 & 1 & 0,069 & 0,132 & 1 & 0,164 & 0,061 & 0,284 & 0,265 \\
\hline 2324 & 0,24 & 0,061 & 0.508 & 0,088 & 0,057 & 0.067 & 0,069 & 0,132 & 1 & 0,405 & 0,303 & 1 & 0.265 \\
\hline 2332 & 0,24 & 0,061 & 0,508 & 0,285 & 0,057 & 0,067 & 0,069 & 0,132 & 0,111 & 0,164 & 0,061 & 1 & 1 \\
\hline 2337 & 0,24 & 1 & 0,084 & 0,046 & 0,057 & 0,067 & 0,069 & 0,132 & 0,111 & 0,405 & 1 & 1 & 1 \\
\hline 2396 & 0,24 & 0,061 & 0,508 & 0,046 & 0,057 & 0,067 & 0.235 & 0,132 & 0,111 & 1 & 0,303 & 0,284 & 0.265 \\
\hline 2239 & 0,17 & 0.061 & 0,508 & 0,088 & 0,057 & 0,067 & 0,069 & 0,132 & 0,111 & 0,164 & 0,061 & 1 & 0.265 \\
\hline 2311 & 0,17 & 0,061 & 0,050 & 0,088 & 0,057 & 0,067 & 0,069 & 0,132 & 0,111 & 0,164 & 0,061 & 1 & 0.265 \\
\hline 2370 & 0,17 & 0,061 & 0,084 & 0,285 & 0,057 & 0,067 & 0,069 & 0,132 & 0,111 & 0,164 & 0,061 & 1 & 1 \\
\hline 2358 & 0,16 & 0.061 & 0,084 & 0,046 & 0,217 & 0.265 & 0,069 & 0,132 & 1 & 0,164 & 0,061 & 0,284 & 0.265 \\
\hline 2379 & 0,11 & 0,061 & 0,084 & 0,046 & 0,057 & 0,067 & 0,069 & 0,132 & 1 & 0,164 & 0,061 & 0,284 & 0.265 \\
\hline 2305 & 0,1 & 0,061 & 0,084 & 0,046 & 0,057 & 0,067 & 0,069 & 0,132 & 0,111 & 0,164 & 0,061 & 1 & 0.265 \\
\hline
\end{tabular}

Quadro 20 - Resultado da seleção e priorização para os Projetos de Manutenção com o AHP - Fábrica 1

\begin{tabular}{|c|c|c|c|c|c|c|c|c|c|c|c|c|c|}
\hline \multicolumn{2}{|c|}{$\begin{array}{c}\text { Pesos dos } \\
\text { subcritérios }\end{array}$} & \multirow[b]{2}{*}{\begin{tabular}{|c|}
, 0371 \\
Risco de \\
Parada \\
de \\
Unidade
\end{tabular}} & \multirow[b]{2}{*}{\begin{tabular}{|c}
,1618 \\
Riscos \\
relacionados \\
c/ Segurança \\
Industrial
\end{tabular}} & \multirow[b]{2}{*}{\begin{tabular}{|l}
2451 \\
Riscos \\
Legais
\end{tabular}} & \multirow[b]{2}{*}{\begin{tabular}{|c|}
, 1259 \\
\\
Riscos de \\
Acidentes \\
Ambientais
\end{tabular}} & \multirow[b]{2}{*}{\begin{tabular}{|c|}
, 1330 \\
Aumento da \\
Produtividade \\
da Unidade
\end{tabular}} & \multirow[b]{2}{*}{\begin{tabular}{|c|}
, 0397 \\
Aumento da \\
Vida Útil \\
das \\
Instalaçōes
\end{tabular}} & \multirow[b]{2}{*}{\begin{tabular}{|c|}
0,0286 \\
Potencial de \\
redução \\
deresíduos/ \\
Contribuiçäo \\
p/atender ISO \\
14000 \\
\end{tabular}} & \multirow[b]{2}{*}{$\begin{array}{c}\text {,0333 } \\
\text { Aumento da } \\
\text { Repetibilidade } \\
\text { eprodutibilidade } \\
\text { onfiabilidade do } \\
\text { Processo }\end{array}$} & \multirow[b]{2}{*}{\begin{tabular}{|c|}
, 0807 \\
\\
Reduçāo de \\
Custos com \\
Manutençäo
\end{tabular}} & \multirow[b]{2}{*}{\begin{tabular}{|c|}
,0701 \\
\\
Criticidade do \\
Equipamento \\
ou Instalaçào \\
\end{tabular}} & \multirow[b]{2}{*}{\begin{tabular}{|c|}
, 0171 \\
Necessidade \\
de Pessoal
\end{tabular}} & \multirow[b]{2}{*}{\begin{tabular}{|c|}
, 0277 \\
Necessidade de \\
Infraestrutura \\
Adicional
\end{tabular}} \\
\hline Projetos & $\begin{array}{c}\text { Prioridade } \\
\text { dos } \\
\text { Projetos }\end{array}$ & & & & & & & & & & & & \\
\hline 4600 & 0,45 & 1 & 0,508 & 0,285 & 1 & 0,067 & 0,069 & 1 & 0,111 & 0,164 & 1 & 0,101 & 0,265 \\
\hline 4977 & 0,4 & 0,061 & 1 & 0,046 & 1 & 0,067 & 0,069 & 0,132 & 1 & 0,164 & 0,061 & 0,284 & 1 \\
\hline 2350 & 0,4 & 1 & 0,508 & 0,046 & 0,057 & 0,067 & 0,235 & 0,42 & 1 & 1 & 1 & 1 & 1 \\
\hline 2323 & 0,38 & 1 & 0,508 & 0,046 & 0,057 & 0,067 & 0,235 & 0,42 & 1 & 1 & 1 & 0,284 & 1 \\
\hline 4881 & 0,38 & 1 & 1 & 0,046 & 0,057 & 0,067 & 0,235 & 0,132 & 0,111 & 0,405 & 1 & 0,284 & 1 \\
\hline 2334 & 0,35 & 0,218 & 1 & 0,046 & 0,057 & 0,067 & 0,069 & 0,132 & 0,111 & 0,405 & 1 & 1 & 1 \\
\hline 2160 & 0,31 & 1 & 0,508 & 0,046 & 0,057 & 0,067 & 0,235 & 0,132 & 0,111 & 1 & 0,303 & 1 & 1 \\
\hline 2259 & 0,31 & 1 & 0,508 & 0,046 & 0,057 & 0,067 & 0,235 & 0,132 & 0,111 & 0,405 & 1 & 1 & 1 \\
\hline 2354 & 0,3 & 1 & 1 & 0,046 & 0,057 & 0,067 & 0,069 & 0,132 & 0,111 & 0,405 & 0,061 & 0,101 & 1 \\
\hline 2308 & 0,29 & 0,061 & 1 & 0,088 & 0,057 & 0,067 & 0,069 & 0,132 & 1 & 0,164 & 0,061 & 0,101 & 1 \\
\hline 2130 & 0,27 & 0,061 & 0,084 & 0,046 & 0,057 & 0,265 & 1 & 0,42 & 1 & 1 & 0,061 & 0,284 & 1 \\
\hline 2101 & 0,27 & 0,218 & 1 & 0,088 & 0,057 & 0,067 & 0,069 & 0,132 & 0,111 & 0,164 & 0,061 & 0,284 & 1 \\
\hline 4941 & 0,27 & 1 & 0,084 & 0,046 & 0,057 & 0,067 & 0,069 & 0,132 & 1 & 0,405 & 1 & 1 & 1 \\
\hline 2343 & 0,25 & 0,218 & 1 & 0,046 & 0,057 & 0,067 & 0,069 & 0,132 & 0,111 & 0,164 & 0,061 & 0,101 & 1 \\
\hline 2314 & 0,23 & 0,218 & 0,508 & 0,046 & 0,057 & 0,067 & 0,069 & 0,132 & 0,111 & 0,405 & 0,303 & 1 & 1 \\
\hline 2339 & 0,21 & 0,218 & 0,508 & 0,046 & 0,057 & 0,067 & 0,069 & 0,132 & 0,111 & 0,405 & 0,061 & 1 & 1 \\
\hline 2390 & 0,2 & 0,061 & 0,508 & 0,046 & 0,057 & 0,067 & 0,069 & 0,132 & 0,111 & 0,405 & 0,061 & 1 & 1 \\
\hline 2261 & 0,19 & 1 & 0,084 & 0,046 & 0,057 & 0,067 & 0,235 & 0,132 & 0,111 & 0,405 & 0,303 & 1 & 1 \\
\hline 2320 & 0,19 & 0,061 & 0,084 & 0,285 & 0,057 & 0,067 & 0,235 & 0,132 & 0,111 & 0,405 & 0,061 & 0,284 & 1 \\
\hline 2364 & 0,19 & 0,061 & 0,508 & 0,088 & 0,057 & 0,067 & 0,069 & 0,132 & 0,111 & 0,164 & 0,061 & 1 & 1 \\
\hline 2348 & 0,17 & 0,218 & 0,508 & 0,046 & 0,057 & 0,067 & 0,069 & 0,132 & 0,111 & 0,164 & 0,061 & 0,101 & 1 \\
\hline 2371 & 0,17 & 0,218 & 0,508 & 0,046 & 0,057 & 0,067 & 0,069 & 0,132 & 0,111 & 0,164 & 0,061 & 0,101 & 1 \\
\hline 4907 & 0,16 & 0,061 & 0,084 & 0,046 & 0,057 & 0,067 & 0,069 & 0,132 & 1 & 0,405 & 0,061 & 1 & 1 \\
\hline 2251 & 0,13 & 0,061 & 0,084 & 0,046 & 0,057 & 0,067 & 0,235 & 0,132 & 0,111 & 0,405 & 0,061 & 0,101 & 1 \\
\hline 2385 & 0,13 & 0,061 & 0,084 & 0,046 & 0,057 & 0,067 & 0,235 & 0,132 & 0,111 & 0,405 & 0,061 & 0,101 & 1 \\
\hline 2360 & 0,1 & 0,061 & 0,084 & 0,046 & 0,057 & 0,067 & 0,069 & 0,132 & 0,111 & 0,164 & 0,061 & 0,101 & 1 \\
\hline
\end{tabular}

Quadro 21 - Resultado da seleção e priorização para os Projetos de Manutenção com o AHP - Fábrica 2 


\begin{tabular}{|c|c|c|c|c|c|c|c|c|c|c|c|c|c|}
\hline \multicolumn{2}{|c|}{ Pesos dos Subcritérios } & \multirow[b]{2}{*}{\begin{tabular}{|c|}
.0371 \\
Risco de \\
Parada de \\
Unidade
\end{tabular}} & \multirow[b]{2}{*}{\begin{tabular}{|c|}
.1618 \\
Riscos \\
relacionados \\
c/ \\
Segurança \\
Industrial \\
\end{tabular}} & \multirow{2}{*}{\begin{tabular}{|l|}
.2451 \\
\\
Riscos \\
Legais
\end{tabular}} & \multirow[b]{2}{*}{\begin{tabular}{|c|}
1259 \\
Riscos de \\
Acidentes \\
Ambientais
\end{tabular}} & \multirow[b]{2}{*}{\begin{tabular}{|c|}
.1335 \\
Aumento da \\
Produtividade \\
da Unidade \\
\end{tabular}} & \multirow[b]{2}{*}{\begin{tabular}{|c|}
.0405 \\
Aumento da \\
Vida Útil das \\
Instalaç̧oes \\
\end{tabular}} & \multirow[b]{2}{*}{\begin{tabular}{|c|}
.0288 \\
Potencial de reduçäo \\
de resíduos \\
Contribuiçáa \\
p/atender ISO 14000 \\
\end{tabular}} & \multirow[b]{2}{*}{\begin{tabular}{|c|}
.0360 \\
Aumento da \\
Repetibilidade \\
/Reprodutibilidad \\
e/Confiabilidade \\
do Processo
\end{tabular}} & \multirow[b]{2}{*}{\begin{tabular}{|c|}
.0765 \\
Reduçaio de \\
Custos com \\
Manutençäo \\
\end{tabular}} & \multirow[b]{2}{*}{\begin{tabular}{|c|}
.0701 \\
Criticidade \\
do \\
Equipament \\
o ou \\
Instalaçáa \\
\end{tabular}} & \multirow{2}{*}{\begin{tabular}{|c|}
.0171 \\
Necessidade \\
de Pessoal
\end{tabular}} & \multirow[b]{2}{*}{\begin{tabular}{|c|}
.0277 \\
Necessidade \\
de \\
Infraestrutura \\
Adicional \\
\end{tabular}} \\
\hline Projetos & $\begin{array}{c}\text { Prioridade } \\
\text { dos } \\
\text { Projetos }\end{array}$ & & & & & & & & & & & & \\
\hline 2280 & 0,73 & 0,218 & 1 & 1 & 0,057 & 0,265 & 1 & 0,132 & 1 & 1 & 1 & 1 & 1 \\
\hline 2327 & 0,73 & 0,218 & 1 & 1 & 0,057 & 0,265 & 1 & 0,132 & 1 & 1 & 1 & 1 & 1 \\
\hline 2393 & 0,68 & 0,218 & 1 & 1 & 0,217 & 0,067 & 1 & 0,132 & 1 & 0,405 & 1 & 1 & 1 \\
\hline 2397 & 0,63 & 0,218 & 1 & 0,088 & 0,217 & 1 & 1 & 0,42 & 1 & 1 & 1 & 1 & 1 \\
\hline 2389 & 0,47 & 0,061 & 0,508 & 0,285 & 0,217 & 0,067 & 1 & 0,42 & 1 & 1 & 1 & 1 & 1 \\
\hline 2362 & 0,45 & 0,218 & 0,508 & 0,285 & 0,217 & 0,265 & 1 & 0,42 & 1 & 1 & 0,303 & 1 & 1 \\
\hline 2386 & 0,44 & 0,061 & 0,084 & 0,046 & 0,057 & 1 & 1 & 0,132 & 1 & 1 & 1 & 1 & 1 \\
\hline 2367 & 0,38 & 0,218 & 0,508 & 0,088 & 0,057 & 0,265 & 1 & 0,132 & 1 & 1 & 0,303 & 1 & 1 \\
\hline 2382 & 0,38 & 0,218 & 0,508 & $0,0,088$ & 0,057 & 0,265 & 1 & 0,132 & 1 & 1 & 0,303 & 1 & 1 \\
\hline 2373 & 0,33 & 0,061 & 0,084 & 0,046 & 0,057 & 1 & 1 & 0,132 & 1 & 0,164 & 0,303 & 1 & 1 \\
\hline 2345 & 0,31 & 0,218 & 0,084 & 0,088 & 0,057 & 0,265 & 1 & 0,132 & 1 & 1 & 0,303 & 1 & 1 \\
\hline 2377 & 0,26 & 0,061 & 0,508 & 0,088 & 0,057 & 0,265 & 1 & 0,132 & 0,111 & 0,164 & 0,061 & 1 & 1 \\
\hline 2301 & 0,24 & 0,061 & 0,508 & $0,0,088$ & 0,057 & 0,265 & 0,235 & 0,132 & 0,111 & 0,164 & 0,303 & 1 & 1 \\
\hline 2315 & 0,23 & 0,061 & 0,084 & 0,046 & 0,057 & 0,067 & 1 & 0,132 & 0,111 & 1 & 0,303 & 1 & 1 \\
\hline 2357 & 0,23 & 0,061 & 0,508 & 0,088 & 0,217 & 0,067 & 0,235 & 0,42 & 0,111 & 0,164 & 0,061 & 1 & 1 \\
\hline 2281 & 0,13 & 0,061 & 0,084 & \begin{tabular}{|l|}
0,088 \\
\end{tabular} & 0,057 & 0,067 & 0,235 & 0,132 & 0,111 & 0,164 & 0,061 & 1 & 1 \\
\hline 2304 & 0,13 & 0,061 & 0,084 & 0,088 & 0,057 & 0,067 & 0,069 & 0,132 & 0,111 & 0,164 & 0,061 & 1 & 1 \\
\hline 2309 & 0,13 & 0,061 & 0,084 & 0,088 & 0,057 & 0,067 & 0,235 & 0,132 & 0,111 & 0,164 & 0,061 & 1 & 1 \\
\hline
\end{tabular}

Quadro 22 - Resultado da seleção e priorização para os Projetos de Manutenção com o AHP - Fábrica 3

\begin{tabular}{|c|c|c|c|c|c|c|c|c|c|c|c|c|c|}
\hline \multicolumn{2}{|c|}{$\begin{array}{c}\text { Pesos } \\
\text { dos Subcritérios }\end{array}$} & \multirow[b]{2}{*}{\begin{tabular}{|c|}
.0393 \\
Risco de \\
Parada de \\
Unidade
\end{tabular}} & \multirow[b]{2}{*}{\begin{tabular}{c|}
.1715 \\
Riscos \\
relacionados \\
c/ Segurança \\
Industrial \\
\end{tabular}} & \multirow[b]{2}{*}{\begin{tabular}{|l|}
.2598 \\
\\
\\
Riscos \\
Legais
\end{tabular}} & \multirow[b]{2}{*}{$\begin{array}{c}.1335 \\
\\
\text { Riscos de } \\
\text { Acidentes } \\
\text { Ambientais }\end{array}$} & \multirow[b]{2}{*}{\begin{tabular}{c|}
.1202 \\
Aumento da \\
rodutividade \\
da Unidade
\end{tabular}} & \multirow[b]{2}{*}{\begin{tabular}{|c|}
.0364 \\
Aumento \\
da Vida Útil \\
das \\
Instalaçòes
\end{tabular}} & \multirow[b]{2}{*}{\begin{tabular}{|c|}
.0259 \\
Potencial de reduçäo \\
de resíduos / \\
Contribuição \\
p/atender ISO 14000
\end{tabular}} & \multirow[b]{2}{*}{\begin{tabular}{|c|}
0324 \\
Aumento da \\
Repetibilidade/ \\
Reprodutibilidade \\
/Confiabilidade \\
do Processo \\
\end{tabular}} & \multirow[b]{2}{*}{\begin{tabular}{c|}
.0689 \\
Reduçäo de \\
Custos com \\
Manutençäo
\end{tabular}} & \multirow[b]{2}{*}{$\begin{array}{c}.0684 \\
\text { Criticidade } \\
\text { do } \\
\text { Equipamento } \\
\text { ou } \\
\text { Instalaçäo }\end{array}$} & \multirow[b]{2}{*}{\begin{tabular}{|c|}
.0167 \\
\\
\\
Necessidade \\
de Pessoal \\
\end{tabular}} & \multirow[b]{2}{*}{\begin{tabular}{|c|}
.0270 \\
Necessidade \\
de \\
Infraestrutura \\
Adicional \\
\end{tabular}} \\
\hline Projetos & $\begin{array}{c}\text { Prioridade } \\
\text { dos } \\
\text { Projetos }\end{array}$ & & & & & & & & & & & & \\
\hline 2361 & 0,44 & 0,218 & 1 & 0,046 & 1 & 0,067 & 0,069 & 0,42 & 1 & 0,405 & 0,061 & 1 & 0,265 \\
\hline 2356 & 0,34 & 0,218 & 1 & 0,046 & 0,057 & 0,067 & 0,235 & 0,132 & 0,111 & 1 & 0,303 & 1 & 0,265 \\
\hline 2366 & 0,32 & 0,061 & 1 & 0,285 & 0,057 & 0,067 & 0,069 & 0,132 & 0,111 & 0,164 & 0,061 & 0,284 & 1 \\
\hline 2378 & 0,28 & 0,061 & 1 & 0,088 & 0,057 & 0,067 & 0,069 & 0,132 & 0,111 & 0,164 & 0,061 & 1 & 1 \\
\hline 2316 & 0,26 & 0,061 & 0,508 & 0,285 & 0,217 & 0,067 & 0,235 & 0,132 & 0,111 & 0,164 & 0,061 & 1 & 0,265 \\
\hline 2384 & 0,16 & 0,061 & 0,084 & 0,285 & 0,057 & 0,067 & 0,069 & 0,132 & 0,111 & 0,164 & 0,061 & 0,101 & 1 \\
\hline 2329 & 0,09 & 0,061 & 0,084 & 0,046 & 0,057 & 0,067 & 0,069 & 0,132 & 0,111 & 0,164 & 0,061 & 1 & 0,265 \\
\hline
\end{tabular}

Quadro 23 - Resultado da seleção e priorização para os Projetos de Manutenção com o AHP - Fábrica 4

\subsection{Simulações dos Cenários}

O passo final da metodologia híbrida proposta é considerar os efeitos das restrições de recursos na seleção do portfólio de projetos da organização.

$\mathrm{Na}$ otimização do portfólio, foi considerada a restrição de orçamento, conforme descrito no item 2.6.3, que descreve os modelos de portfólio.

A formulação geral para o componente de otimização é dada a seguir: 


\section{Parâmetros e variáveis}

$0 \quad \mathrm{i}=$ alternativa de projeto a ser avaliada;

o $n=$ número de alternativas de projetos;

o $\mathrm{pi}=$ prioridades para cada projeto determinada na etapa de aplicação do método AHP;

O c i = custo de cada projeto $\mathrm{i}$;

o $\mathrm{B}=$ valor de orçamento máximo disponível para investir nos projetos;

o $\quad \mathrm{X} i=$ variável de decisão que deve ter o valor entre 0 e 1 , onde o valor 0 indica que o projeto não foi selecionado para fazer parte do portfólio e o valor 1 indica que o projeto foi selecionado. Valores intermediários entre 0 e 1 indicam que o projeto teve apenas parte do valor alocado;

o Também foram simulados cenários considerando-se um rateio do valor máximo orçado por subtipo de projeto no caso dos projetos de manutenção e engenharia.

É importante ressaltar que a utilização da regra de seleção de projetos em que $0<x i<1$ pressupõe que os projetos sejam divisíveis, fato que nem sempre é verdadeiro. No caso desta pesquisa esta regra é totalmente válida para os projetos de TI e P\&D que basicamente envolvem compra de equipamentos e materiais. No caso dos projetos de manutenção e engenharia a regra foi admitida como possível devido ao fato dos desembolsos para esses tipos de projetos ocorrerem num horizonte de tempo maior que um ano, sendo possível realizar o projeto com valores menores que o proposto, ajustando-se o cronograma de execução e desembolsos ao orçamento disponível.

Valor do Portfólio a ser Maximizado

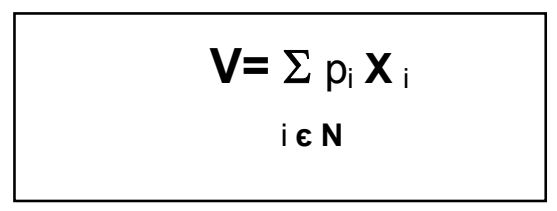

\section{Restrições do modelo:}

$$
\sum_{i \in N} C_{i} X_{i \leq B}
$$


A otimização do portfólio usando a programação matemática foi aplicada aos quatro tipos de projetos definidos anteriormente: Infra-estrutura de P\&D, Projetos de TI, Projetos de Engenharia e Projetos de Manutenção.

O valor máximo do orçamento estabelecido para cada estrutura de projetos é definido segundo alocação apresentada na figura 36. Adotando-se valor de US\$ 38.342.809, valor real aprovado para os projetos de 2005, pode-se calcular o valores de investimentos para cada um dos 4 tipos de projetos. O resultado desse cálculo é apresentado na tabela 5 . Os valores de investimento apresentados definem 0 parâmetro orçamento $(\mathrm{B})$, utilizado para cada tipo de projeto.

Tabela 5 - Alocação do Orçamento de Investimentos para 4 Tipos de Projetos

\begin{tabular}{|l|c|r|}
\hline \multicolumn{1}{|c|}{ Tipo de Projeto } & $\begin{array}{c}\text { Peso do } \\
\text { Projeto }\end{array}$ & $\begin{array}{c}\text { Orçam ento por } \\
\text { Tipo de Projeto (US\$) }\end{array}$ \\
\hline Engenharia & 0,51 & 19.554 .833 \\
Manutenção & 0,22 & 8.435 .418 \\
Infraestrutura de P\&D & 0,18 & 6.901 .706 \\
Tecnologia da Informação (TI) & 0,09 & 3.450 .853 \\
\hline Valor Total Orçado (US\$) & & 38.342 .809 \\
\hline
\end{tabular}

Os resultados das simulações para cada um dos tipos de projetos são apresentados na seqüência.

\subsubsection{Resultados da Simulação para os Projetos de Infra-estrutura de P\&D}

Como a área de P\&D é considerada estratégica para a empresa, todos os projetos da área solicitados são aprovados pela diretoria. A única restrição existente é que o investimento em P\&D seja limitado a $2 \%$ do faturamento anual da empresa. Assim, se a empresa passar a faturar menos, o montante de recursos destinados ao P\&D caem proporcionalmente, e se faturar mais, os recursos aumentam na mesma proporção. Por isso, no caso dos projetos de infra-estrutura de P\&D o valor máximo disponível no orçamento é maior que o montante de investimentos solicitado para o ano de 2005 , sendo o valor total de investimentos propostos de US $\$ 3.799 .700$, contra 
os US\$6.901.706 definido pelo rateio resultante da estrutura principal e apresentado na tabela 5.

Como neste cenário não há restrição de recursos, $100 \%$ dos projetos propostos serão contemplados.

Assim, optou-se por fazer uma variação do valor máximo do investimento disponível para $50 \%$ a menos, ou seja, US\$ 3.450 .853 (cenário 1). Como resultado verifica-se que quase todos os projetos têm $100 \%$ da alocação, exceto o projeto 2398 que trata da reforma do prédio de P\&D, tendo alocação de $84 \%$ do valor solicitado.

\begin{tabular}{|c|c|c|c|c|c|c|c|}
\hline \multicolumn{4}{|c|}{ Prof. de Infra $\theta 5$ trutura de P\&D } & \multicolumn{2}{|c|}{ Cenario [1] } & \multicolumn{2}{|c|}{ Cenarlo Real } \\
\hline Seq. & Projeto & Prioridsde & $\begin{array}{c}\text { Valor } \\
\text { solicitado } \\
\text { [Uss) }\end{array}$ & $\begin{array}{c}\text { Valor } \\
\text { Atribuldo } \\
\text { (Us\$) }\end{array}$ & $\begin{array}{c}\% \\
\text { Atribuido }\end{array}$ & $\begin{array}{c}\text { Valor } \\
\text { Atribuido } \\
\text { [Uss] }\end{array}$ & $\%$ A tribu ido \\
\hline 1 & 2204 & 0,741 & 186.100 & 186.100 & 100 & 98.210 & $52, \pi$ \\
\hline 2 & 2223 & 0,741 & 500 & 500 & 100 & 13.661 & 2732,14 \\
\hline 3 & 2224 & 0,34 & 1.000 & 999 & 100 & 31.338 & 3133,84 \\
\hline 4 & 2228 & 0,22 & 400 & 399 & 100 & 2.833 & 708,32 \\
\hline 5 & 2229 & 0,263 & 5.000 & 5.000 & 100 & 21.216 & 424,32 \\
\hline 6 & 2230 & 0,263 & 5.000 & 5.000 & 100 & 43.090 & 861,80 \\
\hline 7 & 2231 & 0,317 & 100 & 100 & 100 & 360 & 360,48 \\
\hline 8 & 2233 & 0,925 & 3.300 & 3.300 & 100 & 7.764 & 235,28 \\
\hline 9 & 2237 & 0,239 & 44.000 & 44.000 & 100 & 23.469 & 53,34 \\
\hline 10 & 2319 & 0,34 & 5.000 & 5.000 & 100 & 3.500 & 70,00 \\
\hline 11 & 2325 & 0,239 & 4.500 & 4.500 & 100 & 3.400 & 75,56 \\
\hline 12 & 2344 & 0,239 & 139.300 & 139.300 & 100 & 29.110 & 20,90 \\
\hline 13 & 2353 & 0,165 & 75.000 & 75.000 & 100 & $\underline{0}$ & 0,00 \\
\hline 14 & 2365 & 1 & 84.500 & 84.500 & 100 & 16.090 & 19,04 \\
\hline 15 & 2369 & 0,321 & 25.000 & 25.000 & 100 & $\overline{0}$ & 0,00 \\
\hline 16 & 2381 & 0,298 & 169.000 & 168.999 & 100 & 168.780 & 99,87 \\
\hline 17 & 2398 & 0.528 & 2.227 .700 & 1.878 .853 & 84,3 & 273.220 & 12,26 \\
\hline 18 & 4604 & 0,505 & 34.000 & 34.000 & 100 & 76.285 & 224,37 \\
\hline 19 & 4706 & 0,977 & 82.700 & 82.700 & 100 & 33.000 & 39,90 \\
\hline 20 & 2306 & 0,329 & 40.900 & 40.900 & 100 & 26.870 & 65,70 \\
\hline 21 & 2308 & 0,505 & 18.100 & 18.100 & 100 & $\underline{0}$ & 0,00 \\
\hline 22 & 2312 & 0,793 & 12.500 & 12.500 & 100 & 10.900 & 87,20 \\
\hline 23 & 2333 & 0,22 & 47.100 & 47.100 & 100 & 0 & 0,00 \\
\hline 24 & 2338 & 0,317 & 500 & 500 & 100 & 580 & 116,00 \\
\hline 25 & 2342 & 0,317 & 13.700 & 13.700 & 100 & 9.570 & 69,85 \\
\hline 26 & 2347 & 0,317 & 180.000 & 179.999 & 100 & $\overline{0}$ & 0,00 \\
\hline 27 & 2359 & 0,317 & 11.500 & 11.500 & 100 & 9.260 & 80,52 \\
\hline 28 & 2360 & 0,24 & 40.200 & 40.200 & 100 & 45.820 & 113,98 \\
\hline 29 & 2364 & 0,524 & 30.000 & 30.000 & 100 & $\overline{0}$ & 0,00 \\
\hline 30 & 2375 & 0,317 & 45.000 & 44.999 & 100 & 19.950 & 44,33 \\
\hline 31 & 2376 & 0,718 & 121.500 & 121.500 & 100 & 136.000 & 111,93 \\
\hline 32 & 2380 & $0, \pi 7$ & 17.200 & 17.200 & 100 & 2.890 & 16.80 \\
\hline 33 & 2388 & 0,524 & 18.400 & 18.400 & 100 & 5.390 & 29,29 \\
\hline 34 & 2234 & 0,317 & 95.000 & 94.999 & 100 & $\overline{0}$ & 0,00 \\
\hline 35 & 4889 & 0,317 & 1.000 & 1.000 & 100 & 4.050 & 405,00 \\
\hline 36 & 4999 & 0,317 & 15.000 & 14.999 & 100 & 16.760 & 111,73 \\
\hline \multicolumn{2}{|c|}{ Totels } & & 3.799 .700 & 3.450 .845 & & 1.133 .367 & \\
\hline \multicolumn{2}{|c|}{ \% P ortfollo } & & 110,11 & 100,00 & & 32,84 & \\
\hline
\end{tabular}

Quadro 24 - Resultado das simulações dos cenários de Projetos de Infra-estrutura de P\&D

O quadro 24 apresenta os resultados da simulação descrita e do cenário real. Pelo que se pode constatar o uso do método AHP integrado a programação inteira permite uma melhor alocação dos recursos disponíveis. Esse resultado também foi encontrado por Greiner et al (2003). O caso real mostra que $32,84 \%$ dos recursos solicitados foram utilizados, isso mostra uma baixa capacidade de execução da área de P\&D. Verifica-se, também, que os valores gastos são muito diferentes dos 
solicitados, podendo existir ou uma baixa qualidade na elaboração das estimativas dos investimentos ou gastos dos valores concedidos em contas diferentes das propostas. Archer et al (1999) propõe que uma das causas desses problemas seja a utilização de modelos de gestão que não contemplam a reavaliação periódica dos projetos. Outra possível causa dos grandes desvios entre os valores reais gastos por projeto é que o gestor responsável por eles tenha caído na armadilha do custo afundado relatada por Hammond, Keeney e Raiffa (1998). Segundo Saaty (1991) uso do método AHP permite ao decisor entender melhor a complexidade do processo de decisão, tendo o potencial de melhorar a qualidade da decisão.

\subsubsection{Resultados da Simulação para os Projetos de TI}

Para os projetos de TI, observa-se que o investimento proposto para o ano de US\$ 2.375.100 é menor que o investimento disponível de US\$ 3.450.843, definido pelo rateio do total de investimentos correntes da empresa dado pela tabela 5 . Nesse caso, não existem restrições, sendo todos os projetos contemplados.

Entretanto, quando ocorre uma mudança no mercado com previsões de vendas piores que o previsto, os primeiros projetos a sofrerem cortes são os de TI. Assim, foi realizada a simulação de um cenário pessimista, com um valor de investimentos limitado a $50 \%$ do disponível, ou seja, US\$1.725.421, permitindo-se inicialmente somente projetos com todo o valor previsto fossem contemplados (cenário 1) e numa segunda simulação, permitindo-se que projetos tivessem parte do valor solicitado aprovado (cenário 2). Para ambos os cenários foram consideradas as relações de dependência entre os projetos. Assim, o projeto 2151 que trata da aquisição e implantação de um software de "tipo pacote", precisa dos projetos de infra-estrutura 2141, 2335, 2218 e 2349 para ser viável. Os projetos 2331, 2391 e 4655, com escopo de implantação de software "tipo pacote" ou "desenvolvimento interno", dependem do projeto 2216 de infra-estrutura para serem implantados.

O resultado desses cenários é apresentado no quadro 25. 


\begin{tabular}{|c|c|c|c|c|c|c|c|c|c|}
\hline \multicolumn{4}{|c|}{ Projetos de Informática } & \multicolumn{2}{|c|}{ Cenário 1} & \multicolumn{2}{|c|}{ Cenário 2} & \multicolumn{2}{|c|}{ Cenário Real } \\
\hline Seq. & Projeto & Prioridade & $\begin{array}{c}\text { Valor } \\
\text { Solicitado } \\
\text { (US\$) }\end{array}$ & $\begin{array}{l}\text { Valor } \\
\text { Atribuído } \\
\text { (US\$) }\end{array}$ & $\begin{array}{c}\% \\
\text { Atribuido }\end{array}$ & $\begin{array}{l}\text { Valor } \\
\text { Atribuído } \\
\text { (U S\$) }\end{array}$ & $\begin{array}{c}\% \\
\text { Atribuído }\end{array}$ & $\begin{array}{l}\text { Valor Atribuído } \\
\text { (US\$) }\end{array}$ & $\begin{array}{c}\% \\
\text { Atribuido }\end{array}$ \\
\hline 1 & 2151 & 0,689 & 1.133 .000 & 1.133 .000 & 100 & 973.720 & 85,9 & 1.005 .860 & 88,78 \\
\hline 2 & 2216 & 0,324 & 21.000 & 21.000 & 100 & 20.999 & 100 & 43.780 & 208,48 \\
\hline 3 & 2220 & 0,223 & 47.000 & 47.000 & 100 & 46.999 & 100 & 55.836 & 118,80 \\
\hline 4 & 2303 & 0,324 & 181.200 & 0 & 0 & 181.199 & 100 & 152.600 & 84,22 \\
\hline 5 & 2331 & 0,223 & 490.400 & 0 & 0 & 0 & 0 & 64.400 & 13,13 \\
\hline 6 & 2391 & 0,421 & 52.000 & 52.000 & 100 & 52.000 & 100 & 22.900 & 44,04 \\
\hline 7 & 4840 & 0,648 & 77.000 & 77.000 & 100 & 77.000 & 100 & 44.935 & 58,36 \\
\hline 8 & 2217 & 0,324 & 18.000 & 18.000 & 100 & 18.000 & 100 & 11.264 & 62,58 \\
\hline 9 & 2318 & 0,324 & 84.400 & 84.400 & 100 & 84.400 & 100 & 48.600 & 57,58 \\
\hline 10 & 2341 & 0,324 & 14.800 & 14.800 & 100 & 14.799 & 100 & 10.650 & 71,96 \\
\hline 11 & 2322 & 0,324 & 22.200 & 22.200 & 100 & 22.200 & 100 & 11.300 & 50,90 \\
\hline 12 & 2335 & 0,324 & 4.000 & 4.000 & 100 & 4.000 & 100 & 0 & 0,00 \\
\hline 13 & 2218 & 0,324 & 27.000 & 27.000 & 100 & 27.000 & 100 & 19.840 & 73,48 \\
\hline 14 & 2313 & 0,324 & 96.900 & 96.900 & 100 & 96.900 & 100 & 88.080 & 90,90 \\
\hline 15 & 4655 & 0,241 & 20.000 & 20.000 & 100 & 20.000 & 100 & 16.406 & 82,03 \\
\hline 16 & 4959 & 0,391 & 6.400 & 6.400 & 100 & 6.400 & 100 & 4.935 & 77,11 \\
\hline 17 & 2310 & 0,289 & 23.000 & 23.000 & 100 & 22.999 & 100 & 9.690 & 42,13 \\
\hline 18 & 2328 & 0,324 & 43.900 & 43.900 & 100 & 43.899 & 100 & 24.300 & 55,35 \\
\hline 19 & 2349 & 0,324 & 12.900 & 12.899 & 100 & 12.899 & 100 & 9.400 & 72,87 \\
\hline & Totais & & 2.375 .100 & 1.703 .499 & & 1.725 .413 & & 1.644 .775 & \\
\hline$\% \mathrm{~F}$ & Portfólio & & 137,65 & 98,73 & & 100,00 & & 95,33 & \\
\hline
\end{tabular}

Quadro 25 - Resultado das simulações dos cenários de Projetos de TI

A análise do quadro 25 mostra que no cenário (1), onde apenas projetos com alocação integral dos valores propostos são aceitas, não foram alocados valores para os projetos 2303 e 2331. Quando é permitida a alocação parcial de recursos, o projeto 2151 , com a maior prioridade passou a ter alocação parcial, com 85,9\% do valor total orçado e o projeto 2303 que no cenário (1) não tinha sido contemplado passou a ter alocação integral dos recursos solicitados. O projeto 2331 não teve recursos alocados em nenhum dos dois cenários de simulação, porém no cenário real recebeu $84,22 \%$ do valor solicitado.

Verifica-se que o cenário (2) permite uma melhor utilização dos recursos disponíveis, tendo $100 \%$ dos projetos contemplados, esse resultado foi o mesmo encontrado por Greiner et al (2003). Ao analisar o cenário real, pode-se observar que a utilização dos recursos teve desempenho pior que os cenários (1) e (2) e que os projetos 2216 e 2220 gastaram muito mais do que o valor aprovado e esse "estouro" foi compensado não se concluindo os demais projetos, para garantir que o orçamento global da área de informática não fosse superior ao teto aprovado. O uso do AHP conforme proposto por Saaty (1991), Forman \& Selly (2002), Archer e Ghasemzadeh (1999) e Greiner et al (2003) ajudam o decisor a compreender melhor o processo de decisão e as variáveis envolvidas, melhorando a qualidade da decisão e contribuindo para o melhor desempenho dos gestores nas funções de organizar, implementar e controlar, funções estreitamente relacionadas com a tomada de decisão. 


\subsubsection{Resultados da Simulação para os Projetos de Engenharia}

Como os projetos de engenharia são os mais importantes para a empresa e são os mais complexos, o autor optou por elaborar vários cenários para simulação.

Existem alguns projetos de engenharia que precisam da execução de outros para que eles sejam implantados com sucesso. Essa relação de dependência entre os projetos foi prevista em três cenários analisados e são descritas a seguir:

o Projetos 2400 e 2401, em que o primeiro tem como escopo a construção de uma nova fábrica e o segundo a instalação de uma nova caldeira para geração de vapor para a unidade do projeto 2400 , respectivamente.

o Projetos 2299 e 2400, em que o projeto 2400 só deveria ser feito após a conclusão do projeto 2299. O projeto 2299 trata do estudo de viabilidade que resultou o projeto da construção da fábrica nova (escopo do projeto 2400) e toda a fase de projeto básico, feito pela área de engenharia da empresa.

o Projetos 2399 e 4900, em que o projeto 2399 trata do aumento de capacidade de uma unidade produtiva (Revamp) que garantirá a matéria-prima para o 4900, cujo escopo é a construção de uma nova planta para linha de produtos existente.

o Projetos 2287 e 4929. Ambos os projetos têm o mesmo escopo de aumento de capacidade de produção da mesma planta (Revamp). Nesse caso o projeto 2287 já estava em fase final quando se percebeu que a capacidade resultante não seria suficiente para atender ao mercado e novo projeto de ampliação seria necessário. A relação de dependência é que o projeto 4929 só poderia ser iniciado quando o 2287 estivesse concluído.

Assim, foram simulados 5 cenários para os projetos de engenharia. $O$ cenário (1) utilizou a programação inteira do tipo 0 ou 1, também chamada de programação binária, para otimizar a utilização do uso do orçamento de investimentos destinado aos projetos de engenharia. Para este cenário não foram consideradas as relações de dependência entre os projetos. No cenário (2), para o mesmo conjunto de projetos, foi utilizada a programação matemática permitindo alocação parcial de recursos sem considerar a existência de relações de dependências entre os projetos. O cenário (3) 
foi simulado com as mesmas condições do cenário (1), porém acrescentando as relações de dependências existentes entre os projetos. A simulação do cenário (4) é similar ao cenário (2), considerando-se as dependências entre os projetos. Por último, o cenário (5), além de utilizar a programação binária e a relação de dependências entre os projetos, também foi incluído um rateio do total orçado para projetos de engenharia no valor de US\$ 19.554 .833 por subtipo de projeto.

\begin{tabular}{|c|c|c|c|c|c|c|c|c|c|c|c|c|c|c|}
\hline \multicolumn{3}{|c|}{ Proj. de Engenharia } & \multicolumn{2}{|c|}{$\begin{array}{c}\text { Cenário (1) } \\
\text { s/ dependências (0-1) }\end{array}$} & \multicolumn{2}{|c|}{$\begin{array}{c}\text { Cenário (2) } \\
\text { s/ de pendéncias parcial }\end{array}$} & \multicolumn{2}{|c|}{$\begin{array}{c}\text { Cenário (3) } \\
\text { c/ dependências (0-1) }\end{array}$} & \multicolumn{2}{|c|}{$\begin{array}{c}\text { Cenário (4) } \\
\text { c/ dependências parcial }\end{array}$} & \multicolumn{2}{|c|}{$\begin{array}{c}\text { Cenário (5) } \\
\text { s/ dependências (0-1) } \\
\text { e rateio subtipo proj }\end{array}$} & \multicolumn{2}{|c|}{ Cenário Real } \\
\hline Projeto & Prioridade & $\begin{array}{c}\text { Valor } \\
\text { Solicitado } \\
\text { (USS) }\end{array}$ & $\begin{array}{c}\text { Valor } \\
\text { Atribuido } \\
\text { (US5) }\end{array}$ & $\begin{array}{c}\% \\
\text { Atribuido }\end{array}$ & $\begin{array}{c}\text { Valor } \\
\text { Atribuido } \\
\text { (US\$) }\end{array}$ & $\begin{array}{c}\% \\
\text { Atribuido }\end{array}$ & $\begin{array}{c}\text { Valor } \\
\text { Atribuido } \\
\text { (USS) }\end{array}$ & $\begin{array}{c}\% \\
\text { Atribuido }\end{array}$ & $\begin{array}{l}\text { Valor } \\
\text { Atribuído } \\
\text { (USS) }\end{array}$ & $\begin{array}{c}\% \\
\text { Atribuido }\end{array}$ & $\begin{array}{c}\text { Valor } \\
\text { A tribuido } \\
\text { (US5) }\end{array}$ & $\begin{array}{c}\% / \\
\text { A tribuido }\end{array}$ & $\begin{array}{l}\text { Valor } \\
\text { Atribuído } \\
\text { (USS) }\end{array}$ & $\begin{array}{c}\% / \\
\text { Atribuido }\end{array}$ \\
\hline 2115 & 0,56 & 999.500 & 999.500 & 100 & 999.500 & 100 & 999.500 & 100 & 999.500 & 100 & 999.500 & 100 & 1.142 .908 & 114 \\
\hline 2123 & 0,34 & 52200 & 52200 & 100 & 52.200 & 100 & 52.200 & 100 & 52.200 & 100 & 0 & 0 & 58.559 & 112 \\
\hline 2131 & 0,62 & 21.800 & 21.600 & 100 & 21.800 & 100 & 21.800 & 100 & 21.800 & 100 & 21.800 & 100 & 6.422 & 30 \\
\hline 2142 & 0,49 & 280.000 & 280.000 & 100 & 280.000 & 100 & 280.000 & 100 & 280.000 & 100 & 280.000 & 100 & 130.482 & 47 \\
\hline 2153 & 0,51 & 240.000 & 240.000 & 100 & 240.000 & 100 & 240.000 & 100 & 240.000 & 100 & 240.000 & 100 & 41.740 & 17 \\
\hline 2158 & 0,53 & 27.900 & 27.900 & 100 & 27.900 & 100 & 27.900 & 100 & 27.900 & 100 & 27.900 & 100 & 33.256 & 119 \\
\hline 2180 & 0,64 & 25.300 & 25,300 & 100 & 25.300 & 100 & 25.300 & 100 & 25.300 & 100 & 25,300 & 100 & 19.402 & 77 \\
\hline 2212 & 0,81 & 675.000 & 675.000 & 100 & 675.000 & 100 & 675.000 & 100 & 675.000 & 100 & 675.000 & 100 & 514.630 & 78 \\
\hline 2249 & 0,48 & 151.700 & 151.700 & 100 & 151.700 & 100 & 151.700 & 100 & 151.700 & 100 & 151.700 & 100 & 147.459 & 97 \\
\hline 2288 & 0,58 & 286.400 & 288.400 & 100 & 286.400 & 100 & 288.400 & 100 & 288.400 & 100 & 286.400 & 100 & 278.225 & 97 \\
\hline 2285 & 0,83 & 234200 & 234200 & 100 & 234.200 & 100 & 234200 & 100 & 234.200 & 100 & 234200 & 100 & 288.519 & 123 \\
\hline 2287 & 0,88 & 950.000 & 950.000 & 100 & 950.000 & 100 & 950.000 & 100 & 950.000 & 100 & 950.000 & 100 & 1.443 .764 & 152 \\
\hline 2289 & 0,85 & 240.000 & 240,000 & 100 & 240.000 & 100 & 240.000 & 100 & 240.000 & 100 & 240.000 & 100 & 174.827 & 73 \\
\hline 2290 & 0,57 & 124.000 & 124.000 & 100 & 124.000 & 100 & 124.000 & 100 & 124.000 & 100 & 124.000 & 100 & 129.625 & 105 \\
\hline 2293 & 0,54 & 309.000 & 309.000 & 100 & 309.000 & 100 & 309.000 & 100 & 309.000 & 100 & 309.000 & 100 & 580.397 & 188 \\
\hline 2299 & 0,8 & 250.000 & 250.000 & 100 & 250.000 & 100 & 250.000 & 100 & 250.000 & 100 & 250.000 & 100 & 274.402 & 110 \\
\hline 2300 & 0,54 & 507.900 & 507.900 & 100 & 507.900 & 100 & 507.900 & 100 & 507.900 & 100 & 507.900 & 100 & 509.830 & 100 \\
\hline 2317 & 0,44 & 71.700 & 71.700 & 100 & 71.700 & 100 & 71.700 & 100 & 71.700 & 100 & 71.700 & 100 & 850 & 1 \\
\hline 2328 & 0,54 & 187.300 & 187,300 & 100 & 187.300 & 100 & 187.300 & 100 & 187.300 & 100 & 187.300 & 100 & 124.640 & 87 \\
\hline 2336 & 0,53 & 680.000 & 680.000 & 100 & 680.000 & 100 & 680.000 & 100 & 680.000 & 100 & 680.000 & 100 & 351.110 & 53 \\
\hline 2340 & 0,39 & 799.100 & 799.100 & 100 & 799.100 & 100 & 799.100 & 100 & 799.100 & 100 & 0 & 0 & 214.940 & 27 \\
\hline 2351 & 0,47 & 20.000 & 20.000 & 100 & 20.000 & 100 & 20.000 & 100 & 20.000 & 100 & 20.000 & 100 & 27.410 & 137 \\
\hline 2355 & 0,52 & 376.000 & 376.000 & 100 & 378.000 & 100 & 378.000 & 100 & 376.000 & 100 & 376.000 & 100 & 433.050 & 115 \\
\hline 2388 & 0,53 & 1.217 .200 & 0 & 0 & d & 0 & 0 & 0 & d & 0 & 1.217 .200 & 100 & 948.030 & 78 \\
\hline 2372 & 0,67 & 310.000 & 310.000 & 100 & 310.000 & 100 & 310.000 & 100 & 310.000 & 100 & 310.000 & 100 & 202.840 & 65 \\
\hline 2383 & 0,47 & 50.500 & 50.500 & 100 & 50.500 & 100 & 50.500 & 100 & 50.500 & 100 & 50.500 & 100 & 51.400 & 102 \\
\hline 2387 & 0,4 & 429.500 & 429,500 & 100 & 429.500 & 100 & 429.500 & 100 & 429.500 & 100 & 0 & 0 & 120.860 & 28 \\
\hline 2392 & 0,44 & 381.600 & 381.800 & 100 & 381.800 & 100 & 381.800 & 100 & 361.800 & 100 & 381.600 & 100 & 170.550 & 47 \\
\hline 2394 & 0,4 & 63.000 & 63.000 & 100 & 83.000 & 100 & 83.000 & 100 & 83.000 & 100 & 0 & 0 & 19.880 & 32 \\
\hline 2395 & 0,59 & 57.800 & 57.600 & 100 & 57.800 & 100 & 57.800 & 100 & 57.600 & 100 & 57.600 & 100 & 42.480 & 74 \\
\hline 2399 & 0,49 & 1.069 .000 & 1.089 .000 & 100 & 1.089 .000 & 100 & 1.069 .000 & 100 & 1.069 .000 & 100 & 1.069 .000 & 100 & 120.950 & 11 \\
\hline 2400 & 0,6 & 94.000 .000 & & 0 & o & 0 & & 0 & 0 & 0 & 0 & 0 & 7373.810 & 8 \\
\hline 2401 & 0,81 & 9.208 .100 & 0 & 0 & d & 0 & & 0 & d & 0 & 0 & 0 & 5.810 & 0 \\
\hline 4880 & 0,77 & 1.942 .300 & 1.942 .300 & 100 & 1.942 .300 & 100 & 1.942 .300 & 100 & 1.942 .300 & 100 & 1.942 .300 & 100 & 2.435 .552 & 125 \\
\hline 4888 & 0,77 & 3.508 .200 & 3.506200 & 100 & 3.506 .200 & 100 & 3.506 .200 & 100 & 3.508 .200 & 100 & 3.500 .200 & 100 & 3.489 .210 & 100 \\
\hline 4900 & 0,89 & 11.500 .000 & 0 & 0 & 0 & 0 & 0 & 0 & d & 0 & 0 & 0 & 2307.022 & 20 \\
\hline 4909 & 0,81 & 2.598 .600 & 2.598 .600 & 100 & 2.598 .800 & 100 & 2.598 .600 & 100 & 2.598 .600 & 100 & 0 & 0 & 2.708 .981 & 104 \\
\hline 4912 & 0,47 & 150.000 & 150.000 & 100 & 150.000 & 100 & 150.000 & 100 & 150.000 & 100 & 0 & 0 & 2.680 & 2 \\
\hline 4929 & 0,68 & 125.000 & 125.000 & 100 & 125.000 & 100 & 125.000 & 100 & 125.000 & 100 & 125.000 & 100 & 630 & 1 \\
\hline 4939 & 0,46 & 192.000 & 192.000 & 100 & 192.000 & 100 & 192.000 & 100 & 192.000 & 100 & 0 & 0 & 5.920 & 3 \\
\hline 4949 & 0,3 & 1.500 .000 & 0 & 0 & 1.210 .732 & 81 & 0 & 0 & 1.210 .733 & 81 & 0 & 0 & 791.150 & 53 \\
\hline Total & & 135.769 .400 & 18.344 .100 & & 19.554 .832 & & 18.344 .100 & & 19.554 .832 & & 15.276 .900 & & 27.721 .950 & \\
\hline $\begin{array}{l}\text { Orçamento } \\
\text { (US\$) }\end{array}$ & & .833 & & & & & & & & & & & & \\
\hline \% Portfólio & & 694,30 & 93,81 & & 100,00 & & 93,81 & & 100,00 & & 78,12 & & 141,77 & \\
\hline
\end{tabular}

Quadro 26 - Resultado dos Cenários de Otimização do Portfólio dos Projetos de Engenharia

Os resultados dos diferentes cenários são apresentados no quadro 26 . Pelo que se pode observar através da análise do quadro 26 , dos 41 projetos propostos, 5 
não teriam nenhum valor alocado no cenário (1). Este é o caso dos projetos 4900, 2401, 2400, 2368 e 4949.

Verifica-se que no cenário (1) foram contemplados projetos com prioridades maiores e produto da prioridade pelo valor solicitado menor. Assim projetos com valores estimados muito elevados não foram alocados, mesmo quando sua prioridade era alta.

Analisando-se o cenário (2), onde valores parciais poderiam ser atribuídos aos projetos, verifica-se que o projeto 4949 passou a ser contemplado com valor de $81 \%$ do total solicitado. O cenário (2) permitiu que $100 \%$ do orçamento de investimento fossem alocados, ao passo que o cenário (1) sendo mais restritivo, permitiu que apenas $93,81 \%$ do orçamento fossem alocados. Esse resultado também foi encontrado por Greiner et al (2003) e na simulação dos projetos de infra-estrutura de P\&D e informática, parecendo ser independente do tipo de projeto analisado.

No cenário (3) observa-se que o fato de se acrescentar relações de dependências entre os projetos no modelo não teve reflexo na seleção dos projetos, obtendo-se o mesmo resultado encontrado no cenário (1). Ao se analisar o cenário (4), novamente se observa que o acréscimo da relação de dependências entre os projetos não alterou a seleção dos projetos, nem o montante alocado, quando comparado como cenário (2). Na literatura consultada não foi encontrada nenhuma referência sobre a influência da relação de dependências entre projetos na resultado da otimização obtido com o AHP e a programação inteira, integrados.

Os projetos que não puderam ser alocados nos cenários de simulação são estratégicos para a empresa, e na prática foram aprovados pela organização com recursos adicionais em período extra-orçamentários. O fato dos projetos estratégicos não terem sido contemplados é devido a decisão de se excluir a natureza do projeto, se estratégico ou operacional, da relação dos subcritérios da estrutura de decisões mencionado no item 5.3.2.4. Assim, para a estrutura de decisões sobre projetos de engenharia, os projetos só são priorizados pelo tipo, e não pelo fato de contribuírem ou não com a estratégia da empresa.

Para a elaboração do cenário (5), foi estabelecido um critério de rateio do valor total disponível por subtipo de projeto. Este cenário teve como objetivo obter um portfólio balanceado em relação ao tipo de subprojeto Os percentuais de cada subtipo de projeto utilizados são a média dos valores gastos com cada subtipo de projeto nos anos de 2001 a 2005, apresentados na tabela 6. 


\section{Tabela 6 - Rateio do Orçamento de Engenharia por Subtipo de Projeto}

\begin{tabular}{|l|r|r|r|}
\hline \multicolumn{1}{|c|}{ Subtipo de Projeto } & $\begin{array}{c}\text { Valor } \\
\text { Real gasto } \\
\text { de } \mathbf{2 0 0 1 - 2 0 0 5} \\
\text { (US\$) }\end{array}$ & $\begin{array}{c}\% \\
\text { Valor } \\
\text { Real }\end{array}$ & $\begin{array}{r}\text { Valor do Rateio } \\
\text { Orçamento por } \\
\text { Subprojeto (US\$) }\end{array}$ \\
\hline Aquisição & 3.145 .271 & 5,23 & 1.022 .061 \\
\hline Joint Venture/ Parceria & 851.110 & 1,41 & 276.570 \\
\hline Licenciamento & 10.319 .662 & 17,15 & 3.353 .392 \\
\hline Melhoria Gestão & 200.947 & 0,33 & 65.298 \\
\hline Melhoria das Instalações/ Otimizações & 12.457 .516 & 20,70 & 4.048 .091 \\
\hline Nova Tecnologia & 139.406 & 0,23 & 45.300 \\
\hline Part. Minoritárias & 557.592 & 0,93 & 181.190 \\
\hline Revamp & 32.506 .153 & 54,02 & 10.562 .930 \\
\hline Total Projetos de Engenharia & $\mathbf{6 0 . 1 7 7 . 6 5 7}$ & $\mathbf{1 0 0 , 0 0}$ & $\mathbf{1 9 . 5 5 4 . 8 3 3}$ \\
\hline
\end{tabular}

(Fonte: Dados de investimentos e ativos da empresa, 2001-2005)

Com cenário (5) chega-se a um resultado mais restritivo, onde apenas $78,12 \%$ do orçamento foi alocado para o projetos.

O quadro 26 apresenta, ainda, o cenário real da empresa. Nele verifica-se que quase todos os projetos tiveram gastos, sendo que o valor total investido foi muito superior ao valor teto estabelecido na simulação de US $\$ 19.554833$, devido a alocação de todos os projetos que a empresa considera estratégicos. Observa-se também, que parte dos projetos concluídos tiveram estouro nos valores estimados e a maior parte foi iniciada, porém não foi concluída. É possível concluir que o uso do modelo proposto houve substancial melhoria no valor de portfólio, se considerados apenas os projetos operacionais. A inclusão dos projetos estratégicos na relação de projetos a serem priorizados pressupõe que se todos os projetos fossem submetidos a nova priorização, passando novamente pelo filtro definido na figura 26. O resultado encontrado foi diferente porque essa reavaliação dos projetos do portfólio não foi feita pela organização.

\subsubsection{Resultados da Simulação para os Projetos de Manutenção}

Para os projetos de manutenção foram elaborados 4 cenários. No primeiro, cenário (1) usando-se a programação binária do tipo 0 ou 1, é permitida somente a alocação total dos valores solicitados por projeto. O segundo, cenário (2), admite a seleção de projetos com atribuição de valores parciais. O cenário (3) se constitui na combinação do cenário (1) com a inclusão de um rateio do valor do investimento com manutenção pelo subtipo de projeto. O último, cenário (4), é a combinação do cenário (2) com a inclusão do rateio do investimento por subtipo de projeto de manutenção. 
No caso de projetos de manutenção não existem relações de dependências entre as alternativas.

Como as votações para os projetos ocorreram separadamente para cada fábrica da empresa estudada, para a simulação dos cenários foi necessário executar o mesmo procedimento 4 vezes, uma vez para cada fábrica.

Para a simulação dos cenários de cada fábrica, assumiu-se que o valor limite de investimentos em manutenção é proporcional ao valor dos ativos de cada planta. Assim, o valor de US\$8.435.418, definido pela hierarquia principal de projetos, foi rateado proporcionalmente ao valor dos ativos de cada planta, conforme dados apresentados na tabela 7 .

Tabela 7 - Rateio do Orçamento de Manutenção para 4 as fáb
\begin{tabular}{||r|r|r|r||}
\hline \hline & $\begin{array}{c}\text { Valor dos Ativos 2005 } \\
\text { (US\$) }\end{array}$ & $\begin{array}{c}\text { \% } \\
\text { Ativo }\end{array}$ & $\begin{array}{c}\text { Valor do Investimento } \\
\text { em Manutenção (US\$) }\end{array}$ \\
\hline Fábrica & 317.696 .060 & 47,76 & 4.028 .927 \\
\hline Fábrica 1 & 177.492 .354 & 26,68 & 2.250 .905 \\
\hline Fábrica 2 & 84.787 .904 & 12,75 & 1.075 .255 \\
\hline Fabrica 3 & 85.188 .116 & 12,81 & 1.080 .330 \\
\hline Fábrica 4 & $\mathbf{6 6 5 . 1 6 4 . 4 3 5}$ & $\mathbf{1 0 0 , 0 0}$ & $\mathbf{8 . 4 3 5 . 4 1 8}$ \\
\hline Total & Total &
\end{tabular}

(Fonte: Dados de investimentos e ativos da empresa, 2005)

Os valores dos investimentos assumidos para os cenários (3) e (4) foram definidos, utilizando-se como base para o rateio, a proporção real dos investimentos de 2001 a 2005 por subtipo de projeto de manutenção. Tais valores são apresentados pela tabela 8 .

Tabela 8 - Rateio do Orçamento de Manutenção para 4 as fábricas por subtipo

\begin{tabular}{||l|r|r|r|r|r|r||}
\hline \multicolumn{1}{|c|}{ Subtipo projeto } & \multicolumn{1}{|c|}{$\begin{array}{c}\text { Investimento } \\
\text { Real com Projetos } \\
\text { de Manutenção } \\
\text { de 2001 a 2005 (U S\$) }\end{array}$} & $\begin{array}{r}\text { \%Gasto } \\
\text { Projetos } \\
\text { Manutenção }\end{array}$ & Fábrica 1 & Fábrica 2 & Fábrica 3 & Fábrica 4 \\
\hline Subst. Equip. Final de Vida & 19.792 .262 & 41,73 & 1.681 .328 & 939.334 & 448.719 & 450.837 \\
\hline Controle Ambiental & 8.971 .999 & 18,92 & 762.160 & 425.808 & 203.408 & 204.368 \\
\hline Segurança Instalações & 8.189 .230 & 17,27 & 695.665 & 388.658 & 185.662 & 186.538 \\
\hline Modernização/ Automação & 10.474 .240 & 22,08 & 889.774 & 497.104 & 237.466 & 238.587 \\
\hline Total Projetos de Manutenção & $\mathbf{4 7 . 4 2 7 . 7 3 1}$ & $\mathbf{1 0 0 , 0 0}$ & $\mathbf{4 . 0 2 8 . 9 2 7}$ & $\mathbf{2 . 2 5 0 . 9 0 5}$ & $\mathbf{1 . 0 7 5 . 2 5 5}$ & $\mathbf{1 . 0 8 0 . 3 3 0}$ \\
\hline
\end{tabular}

(Fonte: Dados de investimentos e ativos da empresa, 2005) 
Os resultados das simulações dos cenários de investimentos em projetos de manutenção são apresentados pelos quadros de 27 a 30. Estes quadros apresentam, também, os valores reais gastos com cada um dos projetos das 4 unidades industriais.

Pelo que se pode verificar através de uma análise do quadro 27, no caso do portfólio de projetos de manutenção da fábrica 1, os cenários que permitem a melhor alocação de recursos são os cenários (1) e (2), onde $100 \%$ dos projetos são contemplados. Esse resultado foi possível porque o valor total de investimentos disponível para essa unidade era maior do que o montante solicitado. Ainda analisando o quadro 27, podemos verificar que todos os cenários de simulação permitiram uma alocação de recursos melhor do que o cenário real, onde apenas $40,42 \%$ dos recursos disponíveis foram utilizados. No cenário real a empresa iniciou todos os projetos, tendo concluído uma parte deles. Verifica-se que foram concluídos projetos de baixa prioridade, tal como o 2379, ao passo que projetos de prioridade elevada foram iniciados, porém não foram concluídos, como ocorreu com os projetos 2126 e 2352. A fábrica 1 mostrou ter baixa capacidade de execução dos projetos, não conseguindo aproveitar os recursos disponibilizados.

\begin{tabular}{|c|c|c|c|c|c|c|c|c|c|c|c|c|}
\hline \multicolumn{3}{|c|}{ Proj. de Manutenção-Fábrica 1} & \multicolumn{2}{|c|}{ Cenário (1) } & \multicolumn{2}{|c|}{ Cenário (2) } & \multicolumn{2}{|c|}{ Cenário (3) } & \multicolumn{2}{|c|}{ Cenário (4) } & \multicolumn{2}{|c|}{ Cenário Real } \\
\hline Projeto & Prioridade & $\begin{array}{c}\text { Valor } \\
\text { Solicitado } \\
\text { (US\$) }\end{array}$ & $\begin{array}{c}\text { Valor } \\
\text { Atribuído } \\
\text { (USS) }\end{array}$ & $\%$ Atribuído & $\begin{array}{c}\text { Valor } \\
\text { Atribuído } \\
\text { (USS) }\end{array}$ & $\%$ Atribuido & \begin{tabular}{c|} 
Valor \\
Atribuído \\
(USS)
\end{tabular} & \% Atribuído & $\begin{array}{c}\text { Valor } \\
\text { Atribuído } \\
\text { (USS) }\end{array}$ & $\%$ Atribuído & $\begin{array}{l}\text { Valor } \\
\text { Atribuído } \\
\text { (US\$) }\end{array}$ & $\%$ Atribuído \\
\hline 2126 & 0,5 & 260.000 & 260.000 & 100 & 260.000 & 100 & 260.000 & 100 & 260.000 & 100 & 12.860 & 5 \\
\hline 2352 & 0,46 & 281.600 & 281.600 & 100 & 281.600 & 100 & 281.600 & 100 & 281.600 & 100 & 73.180 & 26 \\
\hline 2273 & 0,4 & 36.000 & 36.000 & 100 & 36.000 & 100 & 36.000 & 100 & 36.000 & 100 & 37.090 & 103 \\
\hline 2363 & 0,39 & 380.800 & 380.800 & 100 & 380.800 & 100 & 380.800 & 100 & 380.800 & 100 & 170.680 & 45 \\
\hline 2274 & 0,31 & 46.400 & 46.400 & 100 & 46.400 & 100 & 46.400 & 100 & 46.400 & 100 & 44.140 & 95 \\
\hline 2193 & 0,28 & 7.900 & 7.900 & 100 & 7.900 & 100 & 7.900 & 100 & 7.900 & 100 & 6.780 & 86 \\
\hline 2346 & 0,28 & 93.500 & 93.500 & 100 & 93.500 & 100 & 93.500 & 100 & 93.500 & 100 & 94.470 & 101 \\
\hline 2374 & 0,26 & 395.800 & 395.800 & 100 & 395.800 & 100 & 0 & 0 & 319.374 & 80,7 & 239.630 & 61 \\
\hline 2332 & 0,24 & 174.400 & 174.400 & 100 & 174.400 & 100 & 174.400 & 100 & 174.400 & 100 & 183.150 & 105 \\
\hline 2324 & 0,24 & 80.000 & 80.000 & 100 & 80.000 & 100 & 80.000 & 100 & 80.000 & 100 & 49.850 & 62 \\
\hline 2396 & 0,24 & 439.600 & 439.600 & 100 & 439.600 & 100 & 0 & 0 & 50.004 & 0 & 146.050 & 33 \\
\hline 2337 & 0,24 & 153.100 & 153.100 & 100 & 153.100 & 100 & 153.100 & 100 & 153.100 & 100 & 145.030 & 95 \\
\hline 2370 & 0,17 & 4.200 & 4200 & 100 & 4.200 & 100 & 4.200 & 100 & 4.200 & 100 & 4.560 & 109 \\
\hline 2239 & 0,17 & 17.200 & 17.200 & 100 & 17.200 & 100 & 17.200 & 100 & 17.200 & 100 & 8.860 & 52 \\
\hline 2311 & 0,17 & 116.300 & 116.300 & 100 & 116.300 & 100 & 116.300 & 100 & 116.300 & 100 & 98.820 & 85 \\
\hline 2358 & 0,16 & 109.600 & 109.600 & 100 & 109.600 & 100 & 109.600 & 100 & 109.600 & 100 & 98.640 & 90 \\
\hline 2379 & 0,11 & 180.900 & 180.900 & 100 & 180.900 & 100 & 180.900 & 100 & 135.675 & 75 & 188.090 & 104 \\
\hline 2305 & 0,1 & 188.700 & 188.700 & 100 & 188.700 & 100 & 188.700 & 100 & 45.225 & 25 & 26.790 & 14 \\
\hline Total & & 2.966 .000 & 2.966 .000 & & 2.966 .000 & & 2.130 .600 & & 2.216 .049 & & 1.628 .670 & \\
\hline \% Portfólio & & 73,62 & 73,62 & & 73,62 & & 52,88 & & 55,00 & & 40,42 & \\
\hline
\end{tabular}

Quadro 27 - Resultado da Simulação de Cenários dos Projetos de Manutenção - Fábrica 1

Observa-se que mesmo os cenários (3) e (4), onde se balanceou o portfólio segundo o subtipo de projeto o valor do portfólio foi melhor que o cenário real, apesar de ser mais restritivo que os cenários (1) e (2). 
O quadro 28 apresenta os resultados da simulação dos mesmos cenários discutidos para a fábrica (1), só que para a fábrica (2). Esta unidade tem um valor máximo de investimento disponível menor que o solicitado. Para a fábrica 2 , o cenário (2) foi o que permitiu a melhor alocação dos recursos disponíveis, permitindo a alocação parcial de recursos para projetos, sem que seja utilizado o rateio por subprojeto, pois esse rateio atua como uma restrição a mais. Ao fazermos a comparação dos resultados obtidos com o cenário real, observa-se que todos os projetos tiveram alocação, mesmo os 2251 e 2380 ambos com prioridade baixa. É possível verificar que muitos projetos tiveram gastos maiores que o previsto (\% atribuído maior que 100\%). A fábrica 2 demonstrou boa capacidade de execução dos projetos, pois investiu cerca de US\$2.500.000, excluindo-se o projeto 4600, que é obrigatório por se tratar da construção de uma estação de tratamento de efluentes para adequação dos efluentes da unidade à legislação ambiental. Pode-se observar, ainda, que o projeto 4600 , sendo muito crítico, teve um tratamento diferenciado, tendo recebido uma parcela elevada do total solicitado em regime extra-orçamentário.

\begin{tabular}{|c|c|c|c|c|c|c|c|c|c|c|c|c|}
\hline \multicolumn{3}{|c|}{ Proj. de Manutenção-Fábrica 2} & \multicolumn{2}{|c|}{ Cenário (1) } & \multicolumn{2}{|c|}{ Cenário (2) } & \multicolumn{2}{|c|}{ Cenário (3) } & \multicolumn{2}{|c|}{ Cenário (4) } & \multicolumn{2}{|c|}{ Cenário Real } \\
\hline Projeto & Prioridade & $\begin{array}{c}\text { Valor } \\
\text { Solicitado } \\
\text { (US\$) }\end{array}$ & $\begin{array}{c}\text { Valor } \\
\text { Atribuido } \\
\text { (US\$) }\end{array}$ & \begin{tabular}{|c|}
$\%$ \\
Atribuído
\end{tabular} & $\begin{array}{l}\text { Valor } \\
\text { Atribuido } \\
\text { (USS) }\end{array}$ & $\begin{array}{c}\% \% \\
\text { Atribuido }\end{array}$ & $\begin{array}{l}\text { Valor } \\
\text { Atribuído } \\
\text { (USS) }\end{array}$ & $\begin{array}{c}\% \\
\text { Atribuido }\end{array}$ & $\begin{array}{l}\text { Valor } \\
\text { Atribuído } \\
\text { (USS) }\end{array}$ & $\begin{array}{c}\% \% \\
\text { Atribuído }\end{array}$ & $\begin{array}{c}\text { Valor } \\
\text { Atribuido } \\
\text { (USS) }\end{array}$ & $\begin{array}{c}\% \\
\text { Atribuido }\end{array}$ \\
\hline 4600 & 0,45 & 3.459 .100 & 0 & 0 & 0 & 0 & 0 & 0 & 425.808 & 12,3 & 2.500 .650 & 72,3 \\
\hline 4977 & 0,4 & 37.000 & 37.000 & 100 & 37.000 & 100 & 37.000 & 100 & 37.000 & 100 & 35.200 & 95,1 \\
\hline 2350 & 0,4 & 114.200 & 114.200 & 100 & 114.200 & 100 & 114.200 & 100 & 114.200 & 100 & 4.150 & 3,6 \\
\hline 2323 & 0,38 & 550.000 & 550.000 & 100 & 545.605 & 99,2 & 0 & 0 & 287.205 & 52,2 & 13.300 & 2,4 \\
\hline 4881 & 0,38 & 286.000 & 286.000 & 100 & 286.000 & 100 & 0 & 0 & 0 & 0 & 851.718 & 297.8 \\
\hline 2334 & 0,35 & 37.200 & 37.200 & 100 & 37.200 & 100 & 37.200 & 100 & 37.200 & 100 & 42.260 & 113,6 \\
\hline 2259 & 0,31 & 17.000 & 17.000 & 100 & 17.000 & 100 & 17.000 & 100 & 17.000 & 100 & 97.322 & 572.5 \\
\hline 2160 & 0,31 & 140.000 & 140.000 & 100 & 140.000 & 100 & 140.000 & 100 & 140.000 & 100 & 159.498 & 113,9 \\
\hline 2354 & 0,3 & 150.400 & 150.400 & 100 & 150.400 & 100 & 150.400 & 100 & 150.400 & 100 & 13.620 & 9,1 \\
\hline 2308 & 0,29 & 18.100 & 18.100 & 100 & 18.100 & 100 & 18.100 & 100 & 18.100 & 100 & 930 & $\frac{1}{5,1}$ \\
\hline 2130 & 0,27 & 113.000 & 113.000 & 100 & 113.000 & 100 & 113.000 & 100 & 113.000 & 100 & 90.502 & 80,1 \\
\hline 2101 & 0,27 & 99.000 & 99.000 & 100 & 99.000 & 100 & 99.000 & 100 & 99.000 & 100 & 111.674 & 112,8 \\
\hline 4941 & 0,27 & 92.800 & 92.800 & 100 & 92.800 & 100 & 92.800 & 100 & 92.800 & 100 & 96.030 & 103,5 \\
\hline 2343 & 0,25 & 148.400 & 148.400 & 100 & 148.400 & 100 & 148.400 & 100 & 126.734 & 85,4 & 157.860 & 106,4 \\
\hline 2314 & 0,23 & 55.500 & 55.500 & 100 & 55.500 & 100 & 55.500 & 100 & 55.500 & 100 & 12.000 & 21,6 \\
\hline 2339 & 0,21 & 30.000 & 30.000 & 100 & 30.000 & 100 & 30.000 & 100 & 30.000 & 100 & 27.170 & 90,6 \\
\hline 2390 & 0.2 & 64.300 & 64.300 & 100 & 64.300 & 100 & 64.300 & 100 & 64.300 & 100 & 64.550 & 100,4 \\
\hline 2364 & 0,19 & 30.000 & 30.000 & 100 & 30.000 & 100 & 30.000 & 100 & 30.000 & 100 & 14.210 & 47,4 \\
\hline 2261 & 0,19 & 53.000 & 53.000 & 100 & 53.000 & 100 & 53.000 & 100 & 53.000 & 100 & 56.084 & 105,8 \\
\hline 2320 & 0,19 & 30.000 & 30.000 & 100 & 30.000 & 100 & 30.000 & 100 & 30.000 & 100 & 51.700 & 172,3 \\
\hline 2348 & 0,17 & 50.400 & 50.400 & 100 & 50.400 & 100 & 0 & 0 & 50.400 & 100 & 49.660 & 98,5 \\
\hline 2371 & 0,17 & 54.900 & 54.900 & 100 & 54.900 & 100 & 54.900 & 100 & 54.900 & 100 & 76.760 & 139.8 \\
\hline 4907 & 0,16 & 43.900 & 43.900 & 100 & 43.900 & 100 & 43.900 & 100 & 43.900 & 100 & 20.270 & 46,2 \\
\hline 2251 & 0,13 & 210.800 & 0 & 0 & 0 & 0 & 210.800 & 100 & 0 & 0 & 398.411 & 189.0 \\
\hline 2385 & 0,13 & 352.400 & 0 & 0 & 0 & 0 & 0 & 0 & 0 & 0 & 125.510 & 35,6 \\
\hline 2360 & 0,1 & 40.200 & of & 0 & 40.200 & 100 & 40.200 & 100 & 40.200 & 100 & 45.820 & 114,0 \\
\hline Totais & & 6.277 .600 & 2.215 .100 & & 2.250 .905 & & 1.579 .700 & & 2.110 .647 & & 5.116 .859 & \\
\hline \% Portfólio & & 278,89 & 98,41 & & 100,00 & & 70,18 & & $93, \pi 7$ & & 227,32 & \\
\hline
\end{tabular}

Quadro 28 - Resultado a Simulação dos Cenários dos Projetos de Manutenção - Fábrica 2 
Neste caso verifica-se que o uso do modelo para os 4 cenários auxilia na gestão dos projetos,pois estabelece metas de desembolso para cada projeto individualmente. $O$ caso real, apesar de ter conseguido um bom desempenho em termos de alocação dos recursos financeiros, apresentou em muitos casos gastos superiores ao previstos, o que comprometeu a conclusão de outros projetos do portfólio.

A análise do quadro 29 mostra resultados semelhantes aos das análises dos quadros 27 e 28, sendo o cenário que permite o melhor uso dos recursos o cenário (2), com alocação parcial dos recursos aos projetos, porém sem o uso de rateio por subprojeto, resultado também encontrado por Greiner et al, 2003. Nesse caso o valor real gasto ficou muito próximo do resultado obtido com o cenário (2), sendo que 2 dos 3 projetos de maior prioridade foram concluídos. Os projetos 2373 e o 2301, que na simulação dos 4 cenários não foram contemplados, no cenário real obtiveram parte dos recursos solicitados. Esta unidade teve uma maior capacidade de execução de seus projetos, aproveitando bem os recursos concedidos.

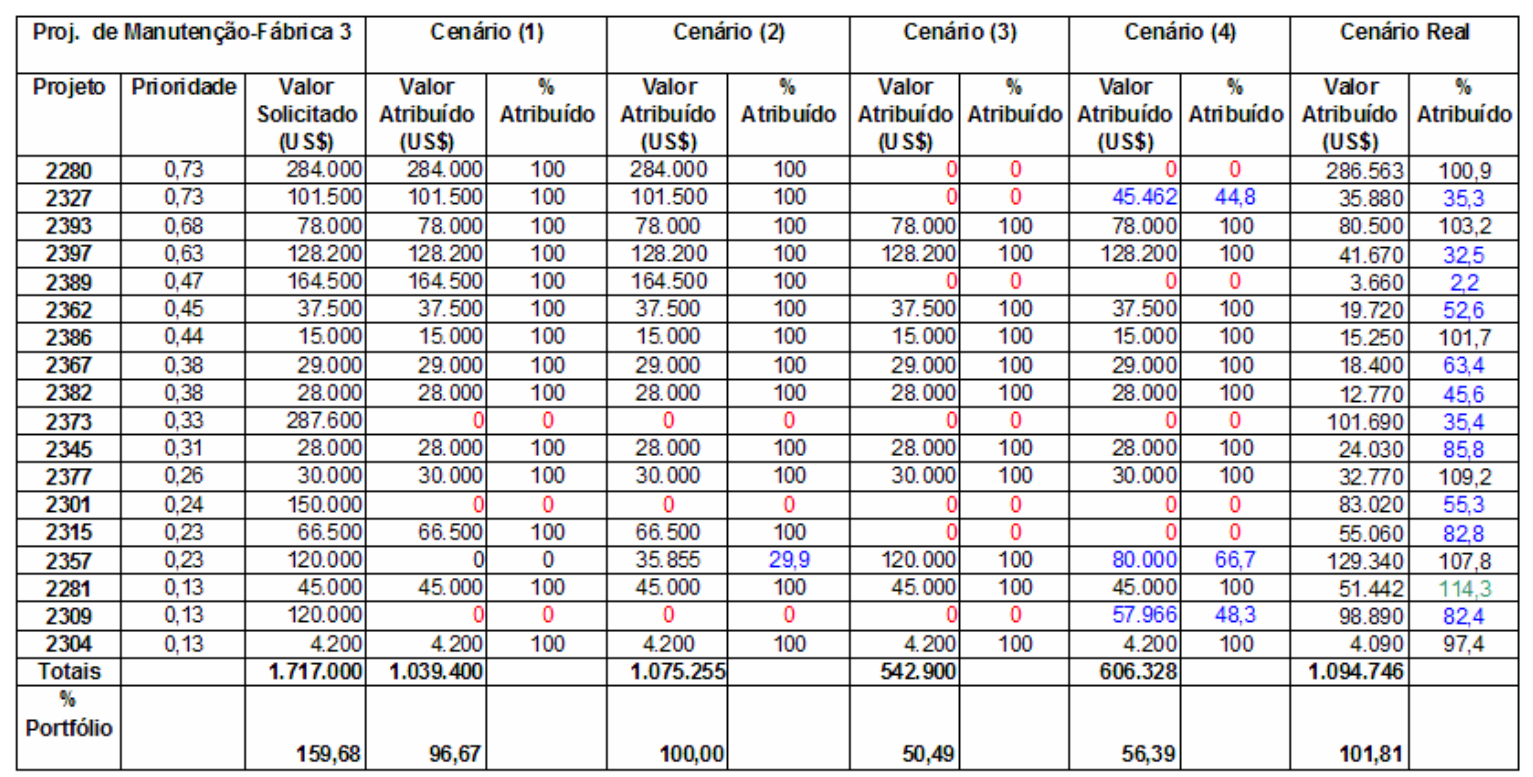

Quadro 29 - Resultado da Simulação dos Cenários dos Projetos de Manutenção - Fábrica 3

Por último, o quadro 30 mostra que para a fábrica 4, que o total de recursos disponível é maior que o solicitado. Apesar disso, o que foi solicitado, não foi realizado 
totalmente. Para a fábrica 4 todos os cenários de simulação resultaram em alocação de $100 \%$ dos recursos.

\begin{tabular}{|c|c|c|c|c|c|c|c|c|c|c|c|c|}
\hline \multicolumn{3}{|c|}{ Proj. de Manutenção-Fábrica 4} & \multicolumn{2}{|c|}{ Cenário (1) } & \multicolumn{2}{|c|}{ Cenário (2) } & \multicolumn{2}{|c|}{ Cenário (3) } & \multicolumn{2}{|c|}{ Cenário (4) } & \multicolumn{2}{|c|}{ Cenário Real } \\
\hline 2361 & 0,44 & 105.000 & 105.000 & 100 & 105.000 & 100 & 105.000 & 100 & 105.000 & 100 & 47.970 & 45,7 \\
\hline 2356 & 0,34 & 90.000 & 90.000 & 100 & 90.000 & 100 & 90.000 & 100 & 90.000 & 100 & 12.110 & 13,5 \\
\hline 2366 & 0,32 & 12.000 & 12.000 & 100 & 12.000 & 100 & 12.000 & 100 & 12.000 & 100 & 12.050 & 100,4 \\
\hline 2384 & 0,16 & 4.200 & 4.200 & 100 & 4.200 & 100 & 4.200 & 100 & 4.200 & 100 & 4.360 & 103,8 \\
\hline 2329 & 0,09 & 30.000 & 30.000 & 100 & 30.000 & 100 & 30.000 & 100 & 30.000 & 100 & 430 & 1,4 \\
\hline Totais & & 346.200 & 346.200 & & 346.200 & & 346.200 & & 346.200 & & 150.850 & \\
\hline $\begin{array}{c}\% \\
\text { Portfólio }\end{array}$ & & 32,0 & 32,0 & & 32,0 & & 32,0 & & 32,0 & & 14,0 & \\
\hline
\end{tabular}

Quadro 30 - Resultado da Simulação dos Cenários dos Projetos de Manutenção - Fábrica 4

\subsection{Análise dos Resultados Apresentados}

Para a estrutura de projetos de P\&D foram definidos critérios de decisão conforme recomendado por Jolly (2003), sendo os critérios mais importantes àqueles relacionados com atratividade e posicionamento. $\mathrm{O}$ critério risco também foi utilizado no modelo, estando de acordo com as recomendações de McFarlan (1981). A complexidade da decisão é citada na literatura nos trabalhos de Saaty (1991), Shimizu (2001), Forman e Selly (2001) e foi considerado um critério importante sob os aspectos relacionados com a disponibilidade de recursos humanos e de infraestrutura, que limitam a capacidade de execução dos projetos, e tipo de projeto.

Os critérios de decisão estabelecidos levam em consideração o atendimento aos stakeholders primários da organização (clientes, funcionários, acionistas, fornecedores) e os stakeholders públicos, que são o governo e a comunidade, que provêem infra-estrutura e mercado e cujas leis e regulações devem ser obedecidas, conforme definições de Clarkson (1995).

Ao analisarmos o processo de aplicação/validação da estrutura de projetos de P\&D usando método AHP, descrito no item 5.3.1, constatou-se que o AHP não é prático de ser aplicado quando o número de projetos é maior que uma centena ou, quando faltam informações que permitam aos decisores dar notas aos projetos em relação a cada critério/subcritério da estrutura de decisões definida ou, quando o 
conhecimento do decisor sobre os projetos e como gerenciá-los. Esta constatação confirma a observações de Elmaghraby e Moder (1978) que já haviam identificado esse problema indicando o uso dos modelos de checklists ou requisitos de desempenho, como mais adequados. Também foi possível verificar através da análise das estruturas de engenharia, manutenção, TI e infra-estrutura de P\&D que quanto maior o número de projetos a serem votados, o tempo de processamento aumenta. Para contornar esses problemas no caso do portfólio de P\&D da empresa, o autor propôs que os 378 projetos fossem fragmentados por área de negócio e que cada gerente de área de negócio fizesse a votação dos projetos de sua área separadamente, junto a outras pessoas de sua equipe e áreas de interface. Esse filtro permitiria que o número de projetos a ser votado por equipe fosse reduzido a um número menor que 100, tornando o modelo viável. Essa proposição é suportada por Clemen (1991) e Garber (2002), que sugerem que a técnica de decomposição do problema em modelos de estrutura seja usada para simplificar problemas complexos que envolvam um grupo de pessoas e por McFarlan (1981), que afirma que é necessário classificar os projetos de modo que seja possível diferenciá-los e comparálos com projetos similares. Como essa sugestão não pode ser testada, não houve comprovação de sua validade.

No caso da seleção e priorização de projetos com investimento, a proposição do uso de uma estrutura principal para estabelecer um critério de alocação do valor de investimento máximo, por tipo de projeto, teve como objetivo obter um portfólio de projetos balanceado em termos de curto e médio prazo, risco e oportunidade, crescimento e manutenção das instalações, uso de tecnologia existente e de novas tecnologias e alinhado com a estratégia da organização, conforme recomendado por Adner e Levinthal (2001); Roussel et al (1991); Cooper et al (1997, 1998, 1999 e 2001); Tritle et al. (2000); Wheelwright and Clark (1992) e Archer et al (1999). Com a aplicação do modelo, verificou-se que ele ajuda o tomador de decisão a enxergar o todo, de modo que a decisão seja mais coerente com a estratégia. A possibilidade de simulação de cenários e de se fazer a análise de sensibilidade, conforme proposto por Clemen (1991) e Shimizu, Laurindo e Morita (2001), permitiu que fosse avaliada a consistência e o impacto das decisões tomadas no nível de diretoria.

A análise da estrutura de projetos de infra-estrutura de P\&D, apresentada nos itens 5.3.2.2 e 5.4.1 deste trabalho, mostra que a adoção da técnica de brainstorming para se determinar os critérios de decisão a serem utilizados no modelo hierárquico 
de infra-estrutura de P\&D auxiliou na obtenção de um consenso e levou os participantes a um aprendizado coletivo, resultando numa estrutura de decisões mais simples que a proposta pelo autor. Esta técnica foi utilizada nos trabalhos de Greiner et al, 2003, Murakami (2003), Forman e Selly (2001), sendo uma das técnicas recomendadas por Thiollent (2004) com o objetivo de equalização do conhecimento, aprendizado coletivo e obtenção de consenso quanto aos objetivos, critérios e subcritérios que compõe a estrutura de decisões.

$\mathrm{Na}$ estrutura de projetos de infra-estrutura de P\&D proposta, os critérios de decisão mais importantes são a relação com a estratégia da organização e a prioridade no atendimento. Esse resultado mostra a preocupação da organização com o alinhamento estratégico e com o atendimento aos stakeholders mais importantes, estando de acordo com Carvalho e Laurindo (2003) e Clarkson (1995).

Como projetos de infra-estrutura de P\&D são considerados estratégicos pela empresa estudada, na prática não existem restrições de recursos financeiros. A simulação do cenário (1) impondo uma restrição de investimento com valor de $50 \%$ inferior ao valor disponível para o caso em que se admitia atribuição de valores parciais de investimento, permitiu que se identificasse nesse caso, qual projeto não teria $100 \%$ dos recursos solicitados alocados. O cenário simulado mostrou ser melhor que o valor de portfólio real, esse resultado também foi encontrado por Greiner et al (2003). Verificou-se neste caso que os desvios entre valores orçados e reais são devidos a gestão individual dos projetos, sendo tais problemas relatados na literatura por Goldratt (1998), Kaufmann (1975) e Hammond, Keeney e Raiffa, (1998).

A análise do coeficiente de inconsistência na atribuição dos pesos dos critérios de decisão na hierarquia de infra-estrutura de P\&D mostrou que a votação deveria ser revisada no caso da comparação dos critérios "relação com a estratégia da empresa" e "prioridade no atendimento", devido ao valor calculado ser superior a 0,10; conforme recomendado por Saaty (1991), Garber (2002). O fato dos participantes da empresa não terem alterado seus votos mostra indícios da existência de falta de alinhamento entre eles e falta de entendimento sobre a estratégia da empresa, conforme Forman e Selly (2001).

Observando-se os resultados da hierarquia dos projetos de tecnologia da informação, apresentados nos itens 5.3.2.3 e 5.4.2, verificou-se que, para a empresa, o critério de decisão mais importante é o risco da implantação, seguida da complexidade do projeto. Esses dois critérios foram citados na literatura por McFarlan 
(1981) e Shimizu (2001). A estrutura hierárquica de decisões elaborada não tem as características de empresas que utilizam "Políticas de Governança Corporativa em Tecnologia de Informação", visto que a empresa não considera a área de Tecnologia da Informação como estratégica e sim como apoio às operações, sendo esta área subordinada a uma de suas diretorias.

A estrutura de decisão para projetos de TI resultante mostra que os critérios de decisão mais importantes para esse tipo de projeto são os riscos e a complexidade. Esses critérios conforme mencionado anteriormente são encontrados nos trabalhos de McFarlan (1981) e Shimizu (2001). Dentre o subcritérios de riscos, o mais importante citado pela empresa foi o risco de resistência à mudança, esse fator também é encontrado na literatura nos estudos de Kaufmann (1975), Simon (1997) e Garvin \& Roberto (2001). Segundo estes autores, o processo de decisão envolve a cultura das organizações, jogos de poder e políticas, estando repleto de tons pessoais. Ao analisar os resultados da simulação dos cenários de priorização dos projetos de TI obtidos com o AHP verificou-se que o cenário (2), que permite a alocação parcial de recursos para os projetos $(0<x i<1)$, sendo menos restritiva, permite uma melhor utilização do valor disponível para investir que o cenário (1) que só admite valores totais de investimentos para cada projeto (xi =1). Observou-se, ainda, que ambos os cenários tem desempenho melhor na alocação dos recursos disponíveis que o cenário real. Estes resultados também foram encontrados por Greiner et al (2003). Durante a reunião de validação do modelo, foram identificadas oportunidades de melhoria tanto na forma de gerenciar o portfólio como na elaboração das justificativas de investimento. Constatou-se que o modelo permite que a decisão seja tomada com base em critérios lógicos, previamente estabelecidos e de conhecimento de todos os solicitantes, o que facilita a negociação com os clientes das diversas áreas. Estas conclusões são previstas na literatura por Saaty (1991), Forman \& Selly (2002), Archer e Ghasemzadeh (1999) e Greiner et al (2003), pois o uso do AHP e da programação inteira ajuda o decisor a compreender melhor o processo de decisão e as variáveis envolvidas, melhorando a qualidade da decisão e contribuindo para o melhor desempenho dos gestores nas funções de organizar, implementar e controlar.

A análise dos resultados apresentados nos itens 5.3.2.4 e 5.4.3, sobre a estrutura de decisão para os projetos de engenharia, apresenta como critério mais importante para a decisão o impacto no negócio, seguido dos riscos. Observa-se através desses critérios a intenção de se atender aos stakeholders primários ou 
definitivos da organização (acionistas/ investidores), conforme definições de Clarkson (1995) e de Mitchell et al (1997). Dentre os subcritérios relacionados com o impacto no negócio os mais importantes definidos pelos participantes da empresa são o avanço físico do projeto, a sustentabilidade do negócio e sinergia com os negócios da empresa. Conforme discutido anteriormente, o avanço físico não é recomendado pela literatura como um critério de decisão, podendo induzir os decisores a cair na armadilha do custo afundado (Sunk-Cost) descrita no trabalho de Hammond, Keeney e Raiffa (1998). Observando-se os subcritérios relacionados com riscos, verifica-se que a organização considera o riscos da implantação os mais importantes, estando este resultado de acordo com a proposição de McFarlan (1981).

Analisando-se o processo de validação e aplicação da estrutura de projetos de engenharia, identificou-se uma possível falta de alinhamento entre os participantes na votação dos subcritérios relacionados com o risco, evidenciado pelo índice de inconsistência obtido de 0,123. Conforme anteriormente descrito, Forman e Selly (2001) e Saaty (1991) prevêem em seus trabalhos que esse desalinhamento possa existir e recomendam que a votação dos pesos dos critérios e subcritérios seja refeita, mas o desvio pode persistir, dependendo da organização.

Para os projetos de engenharia foram simulados 5 cenários para que fosse verificada a influência de se permitir que apenas valores totais de projetos fossem selecionados, valores parciais e da introdução de relações de dependência e o uso de rateios para os diferentes tipos de projeto no valor do portfólio obtido. A proposição do rateio por tipo de projeto visava a obtenção de um cenário balanceado conforme proposto por Adner e Levinthal (2001); Roussel et al (1991); Cooper et al (1997, 1998, 1999 e 2001); Tritle et al. (2000); Wheelwright and Clark (1992) e Archer et al (1999). Como resultado da simulação dos cenários, verificou-se que o cenário (2) onde se permite alocação de valores parciais aos projetos $(0<x i<1)$ teve o melhor resultado no valor do portfólio obtido, tendo $100 \%$ dos recursos alocados. Observou-se, também, que não houve influência nos resultados obtidos ao serem introduzidas as relações de dependência (cenários 3 e 4). No caso do cenário (5), que utilizou o rateio por tipo de projeto obteve-se uma alocação de recursos de 78,12\%, inferior aos cenários de 1 a 4, mas melhor que o resultado real, se expurgarmos da análise os projetos estratégicos aprovados em caráter extra-orçamentário. O resultado obtido para os cenários 1, 2 e 5 foram os mesmos obtidos por Greiner et al (2003). Não foram 
encontrados na literatura estudos que avaliem a influência da introdução de relações de dependências entre os projetos no valor do portfólio obtido.

A análise da hierarquia de decisão obtida para os projetos de manutenção, descritos nos itens 5.3.2.5 e 5.4.4, mostra que para a organização o risco da não execução é o critério mais crítico em decisões para este tipo de projetos, porque a ele estão relacionadas as conseqüências de não se implantar um projeto. Tais conseqüências vão desde a autuação ou fechamento de unidades produtivas até acidentes com mortes. Através do critério riscos da não-execução, a organização tenta atender aos stakeholders primários ou definitivos, conforme Clarkson (1995) e Mitchell et al (1997). Através do segundo critério mais importante, ganhos esperados, mostra a intenção da organização em obter vantagens competitivas através de redução de custos, melhoria de qualidade e produtividade. Esses critérios e subcritérios são propostos na literatura por Slack et al. (1997) e Prahalad e Hamel (1990). Segundo os participantes das 4 fábricas a árvore de decisões obtida foi extremamente coerente refletindo exatamente a estratégia da organização, no que se refere às políticas de manutenção industrial. Esse resultado vai ao encontro dos objetivos descritos por Saaty (1991) sobre o uso do AHP de ser uma ferramenta que permita simular como as pessoas pensam. Na etapa de validação da estrutura de decisão de projetos de manutenção, foram obtidos valores de inconsistência acima do valor definido por Saaty (1991) como aceitável. Entretanto, os participantes dessa etapa do trabalho revisaram as votações até se obter um consenso. Constatou-se que os desvios obtidos tinham como causa a diferença de experiência entre os participantes e o uso do brainstorming e aplicação do modelo proposto permitiram o aprendizado coletivo, conforme previsto por Thiollent (2004). O resultado da simulação dos 4 cenários propostos, mostrou também neste caso que o cenário que melhor utiliza os recursos disponíveis é o cenário (2), onde $0<x i<1$. Os cenários que utilizam rateio por tipo de projeto tiveram como objetivo obter um portfólio balanceado, estes cenários (3) e (4) são mais restritivos que s cenários (1) e (2),tendo um valor de portfólio menos otimizado. Observou-se que para as fábricas 1, 2 e 4 o cenário 2 foi o melhor de todos em termos de alocação dos recursos disponíveis. Esse resultado confirma os resultados encontrados por Greiner et al (2003). No caso da fábrica 3, o melhor cenário de simulação também foi o 2 , entretanto, o cenário real teve igual desempenho. 
A análise das estruturas de todos os tipos de projetos mostra a importância da etapa de definição de critérios e subcritérios de decisão, de tal forma que todos os participantes do processo de comparação dos critérios aos pares tenham uma compreensão clara do seu significado, minimizando desvios nos resultados. Também foi observado que a etapa de classificação dos projetos, utilizando-se diferentes métodos, tal como proposto por Cooper et al. (1999) e Archer et al. (1999) é útil não só para gerenciar o portfólio, mas para construir hierarquias de decisões válidas para os grupos de projetos identificados.

No caso dos projetos de manutenção, a proposta inicial deste trabalho era a de que os projetos de todas as fábricas fossem votados juntos por um grupo de gestores com conhecimento suficiente para atribuir pesos de um projeto de uma fábrica em relação ao projeto de outra. Como no nosso estudo a equipe era composta por chefes de manutenção, esse cenário não foi simulado. Entretanto, a adoção do rateio do valor de investimento teto por site, segundo o valor dos ativos permitiu a obtenção de um portfólio balanceado para cada fábrica,garantindo recursos para a manutenção de suas instalações.

Ao analisar os resultados das otimizações realizadas com o uso da programação inteira associada a restrições e dependência entre projetos para as diversas estruturas de decisão, verificou-se que o uso de critérios de rateio restringe o uso dos recursos, porém possibilita o balanceamento do portfólio. 


\section{CONCLUSÕES E SUGESTÕES PARA TRABALHOS FUTUROS}

Neste trabalho foi apresentada uma metodologia híbrida para auxiliar os tomadores de decisão na seleção de projetos de uma organização do setor químico/ petroquímico nacional. A metodologia híbrida integra os métodos AHP com a programação inteira.

Este estudo teve como objetivo aplicar e verificar a utilidade e a importância do modelo proposto para o processo de tomada de decisões da empresa estudada. Como resultado da aplicação da metodologia híbrida utilizada no modelo foi possível observar que ela oferece aos gestores um processo de suporte a decisão eficiente e eficaz para o tratamento de restrições, conforme descrito por Greiner et al (2003), Archer e Ghasemzadeh (1999), Saaty (1991) e Forman e Selly (2001).

Um dos benefícios do uso do AHP, também comprovado neste projeto de pesquisa, é a sua facilidade de estruturar o processo de tomada de decisão, através da elaboração de uma hierarquia de critérios de decisão que podem ser tangíveis ou intangíveis aos quais se pode atribuir pesos relativos. Essa estrutura de decisão sistematiza o pensamento e permite aos decisores enxergarem as alternativas de forma relativa, pois conseguem ver o conjunto de possibilidades para compor o portfólio, melhorando a qualidade das decisões tomadas.

O modelo proposto foi baseado nos mesmos passos propostos por Greiner et al. (2003). Com ele foi possível, através da comparação dos resultados dos cenários simulados com o cenário real, identificar-se um potencial de melhoria na qualidade do processo decisório. O fato de modelo proposto permitir a simulação de diferentes cenários faz com que os decisores tenham parâmetros para balizar suas decisões e uma ferramenta para avaliar mudanças que venham a ocorrer ao longo do tempo, dado que o ambiente de decisões é dinâmico, conforme definição de Cooper et al. (1999).

Observou-se potencial de melhoria no aproveitamento dos recursos disponíveis em ambientes onde existem restrições. Essa melhoria potencial foi descrita por Elmaghraby e Moder (1978) e comprovada nas simulações dos diferentes cenários para os projetos de engenharia, manutenção, informática e infra-estrutura de P\&D.

Verificou-se que o uso do modelo proposto minimiza o risco do decisor cair na armadilha da âncora, onde a mente dá pesos desproporcionais às informações 
recebidas no momento da tomada de decisões, conforme descrito por Hammond, Keeney e Raiffa (1998). Também foi possível verificar que com o uso do método AHP minimiza o risco do decisor cair na armadilha da forma, também descrita pelos mesmos autores, onde dependendo do modo como dado são apresentados e da formulação do problema pode-se induzir o decisor a uma opção equivocada. Esse fato foi comprovado quando se analisou os dados dos projetos após a reclassificação apresentada no item 5.2 e confrontou-se suas observações com a análise do portfólio feita no item 4.

Ao elaborar a estrutura de decisões para os projetos de uma empresa com a participação de uma equipe de decisores, minimiza-se ou elimina-se o problema relatado por Nutt (2002) de ocorrer imposição de idéias que no final levem ao fracasso dos projetos. O AHP permite, ao mesmo tempo, que exista integração, compartilhamento de informações, comprometimento entre os decisores e aprendizado da equipe (Greiner et al, 2003; Archer e Ghasemzadeh, 1999; Saaty, 1991; Forman e Selly, 2001)

Ao analisar o portfólio da empresa, verificou-se que o grande número de projetos existentes levava à falta de foco na tomada de decisões. Tinha-se como expectativa que o modelo proporcionasse uma redução do número de projetos por vincular o número de projetos à quantidade de recursos disponíveis. Este trabalho conseguiu comprovar que para ambientes onde existam restrições de recursos financeiros, o número de projetos fica limitado e está de acordo com as proposições de Archer e Ghasemzadeh (1999).

Foram observados no portfólio da empresa problemas de "estouro" no orçamento e atraso na implantação conforme descrito por McFarlan (1981). O uso do modelo proposto não elimina a necessidade de que os gestores administrem os projetos individualmente, usando as técnicas específicas para esse fim. Entretanto, o modelo, através do uso da programação inteira, permite ao gestor que, ao simular cenários, use os resultados obtidos nos cenários como parâmetros de referência que o auxiliem na administração individual dos projetos.

Também é importante destacar que para a aplicação do método AHP é necessário que a empresa tenha uma sistemática de classificação de projetos implantada, com dados confiáveis. O uso de diferentes metodologias de classificação de projetos, conforme proposto por Jolly (2003) e Archer et al (1999), possibilita que a análise do portfólio seja feita sob diferentes perspectivas e facilite a construção da 
estrutura de decisões do AHP. No caso estudado, a classificação utilizada pela empresa não permitia a aplicação do método AHP de modo que as comparações aos pares dos critérios ficassem coerentes, por isso foi necessária a reclassificação dos projetos do portfólio.

Um outro objetivo do estudo era que o modelo proposto atendesse às necessidades de todos os stakeholders da organização. A construção e aplicação do modelo de decisão junto com funcionários de diferentes áreas da empresa permitiram que os critérios de decisão de stakeholders primários, segundo os critérios de Clarkson (1995), e internos à organização fossem contemplados. Representantes da área de P\&D, ao propor os critérios de decisão, tinham em mente a necessidade do cliente, podendo representá-los. Os representantes da engenharia e diretoria, ao proporem os critérios, procuraram expressar no modelo o seu entendimento dos desejos dos acionistas, órgãos governamentais e de financiamento. Os representantes da área de manutenção representavam os desejos dos funcionários de segurança, dos clientes, proporcionando garantia de fornecimento de produtos, da comunidade e do governo, ao propor projetos de controle ambiental e o de acionistas no que tange à necessidade de redução de custos. Nesse sentido, pode-se dizer que o modelo atende aos desejos dos stakeholders relevantes.

Identificaram-se na empresa estudada as dimensões estratégicas de especialização, qualidade do produto, liderança tecnológica, integração vertical e posição de custo, conforme definições de Carvalho e Laurindo (2003). A estratégia da empresa, cujos objetivos principais são crescimento e excelência operacional, levam as áreas da companhia a buscar diversificação de produtos, a ter flexibilidade de mix, de produto e de volume, esmerar-se na obtenção de qualidade das matérias-primas e produtos acabados em termos de atendimento a especificações, tolerância e características. Como forma de se manter competitiva a empresa adota iniciativas de integração vertical, aumento de capacidade para obter ganhos de escala e aquisições para crescer. As estratégias de crescimento adotadas pela empresa são relatadas por Roberts e Berry (1985) e Garcez (2005). No que se refere a inovação, constatou-se que a empresa estudada busca ser a primeira seguidora, não sendo a inovação de ruptura um item prioritário, observou-se que a empresa se utiliza de inovações de sustentação e sistêmica, conforme definições de Christensen \& Overdorf (2001) e Christensen et a.I (2001) . 
A aplicação do método AHP na organização estudada permitiu que se observassem os mesmos fatos relatados por Slack (1998) de que os gestores das organizações tendem a misturar trade-offs de desempenho operacional e financeiro e de que os trade-offs podem ser classificados em diferentes tipos de flexibilidade. A análise das estruturas de decisão de projetos de engenharia, projetos de manutenção, projetos de P\&D e TI apresentam critérios financeiros, como EVA ao lado de critérios operacionais como ganhos de produtividade e, estratégico, como impacto na imagem da organização. O fato das empresas terem cada vez mais projetos para executar mostra uma preocupação de superar os trade-offs através do ganho de flexibilidade que é obtida pela gestão da capacidade instalada através da construção de fábricas novas, ampliações, adequação da capacidade de estocagem e melhoria continua ou pela gestão do portfólio de produtos, através do lançamento de novos produtos, aquisições de novas plantas, licenciamentos e desenvolvimento de tecnologia, conforme proposto por Slack (1998).

Também foi proposto no início desta pesquisa que projetos de manutenção e engenharia fossem executados por equipes distintas, para que se reduzisse o problema da concorrência dos dois tipos de projetos pelos mesmos recursos humanos. Constatou-se que, devido à sobrecarga de trabalho nas diversas áreas da empresa, essa prática foi adotada no ano de 2006.

Como sugestão para trabalhos futuros, propõe-se que o modelo híbrido utilizando o AHP com a programação inteira seja aplicado no caso onde haja restrição de recursos humanos para a execução dos projetos, essa restrição foi identificada na organização analisada, mas não pode ser estudada devido a inexistência de dados de consumo de homem-hora por atividade e tipo de projeto.

Sugere-se também que a validação para a estrutura projetos de P\&D, proposta nesse trabalho, e que não pode ser concluída tenha continuidade para que se avalie sua aplicação, utilidade e possibilidade de generalizações.

Outro tema identificado como de interesse para estudos futuros é fazer um levantamento na literatura sobre os critérios de decisão existentes e em que organizações ou tipos de projetos são válidos, de forma que se crie estruturas de decisões para as organizações que possam ser generalizadas por tipo de empresa, projeto ou negócio. 
Outra sugestão é que se sejam realizados estudos comparativos entre as diferentes metodologias de gestão de portfólio existentes para se identificar quais são mais apropriadas e em quais condições.

Acredita-se que o uso da metodologia de pesquisa-ação tenha sido muito adequado para o desenvolvimento do presente projeto de pesquisa, dado que o autor trabalha na empresa estudada e teve condições não só de elaborar a coleta de dados nos diferentes meios disponíveis, fazer entrevistas estruturadas e não estruturadas, mas também vivenciar o dia a dia da gestão de portfólio, podendo interferir no ambiente de decisões. O uso da pesquisa-ação proporcionou como ganho o aprendizado conjunto de todos os participantes. O ciclo de pesquisa-ação proposto por Coughlan \& Coghlan (2002) foi percorrido para todos os tipos de projetos da organização estudada, desde a fase de coleta de dados até as etapas de aplicação/avaliação, percebendo-se muitas oportunidades de melhoria nos processos da empresa e também no modelo proposto. A utilização do modelo é possível desde que nova passagem pelo ciclo de pesquisa-ação seja realizada sendo introduzidas as lições aprendidas. 


\section{REFERÊNCIAS}

ADLER, P.S.; FERDOWS, K. The chief technology officer. California Management Review, Spring, p. 55-62, 1990.

ADNER, R.; LEVINTHAL, D. Demand heterogeneity and technology evolution: implications for product and process innovation. Management Science, v. 47, n. 5, p. $611-628,2001$.

ARCHER, N. P.; GHASEMZADEH, F. An integrated framework for project portfolio selection. International Journal of Project Management, v. 17, n. 4, p. 207 - 216, 1999.

BANERJEE, P. Resource dependence and core competence: insights from Indian Software Firms. Technovation, v. 23, p. 251 - 263, 2003.

BOLWIJN, P. T.; KUMPE, T. Manufacturing in the 1990s - Productivity, flexibility and innovation. Long Range Planning, v.23, Aug, 1990.

BROWN, S.; EISENHARDT, K. Competing on the edge: strategy as structured chaos. Harvard Business School Press, 1998.

BRYMAN, A. Research methods and organization studies. London: Unwin Hyman, 1989.

CARVALHO, M. M.; LAURINDO, F. J. B. Linking strategy with a network of performance indicators: a Brazilian Research Centre case study. International Journal of Business Performance Management, v.5, n.4, p. 285-301, 2003.

CARVALHO, M. M.; LAURINDO, F. J. B.; PESSOA, M. S. P. Information technology project management to achieve efficiency in Brazilian companies. In: KAMEL, Sherif. (Org.) Managing Globally with Information Technology, Hershey, p. 260-271, 2003.

CARVALHO, M. M.; LAURINDO, F. J. B. Estratégias para a competitividade. São Paulo: Futura, 2003.

CHESBROUGH, H.W.; TEECE, D.J. When is virtual virtuous? Harvard Business Review, v. 74, n.1, p. 65-73, May/June, 1996. 
CHRISTENSEN, C.M.; OVERDORF, M. Meeting the challenge of disruptive change. Harvard Business Review, p.66-76, Mar./Apr, 2000.

CHRISTENSEN, C.M., RAYNOR, M., VERLINDEN, M. Skate to where the money will be. Harvard Business Review, v.79, n.10, p.72-81, November, 2001.

CLARCKSON, M. B. E. A stakeholder framework for analyzing and evaluating corporate social performance. Academy of Management Review, 20: 92-117, 1995.

CLEMEN, R. T. Making hard decisions. Duxbury: Press-Wadsworth, 1991.

COOPER, R.; EDGETT, S.; KLEINSCHMIDT,E. Portfolio Management for New Product Development. R \& D Management, v.31, n.4, p.361-380, 2001.

COOPER, R.; EDGETT, S.; KLEINSCHMIDT, E. New product management: practices and performance. Journal of Product Innovation Management, v.16, p. 333, 1999.

COOPER, R.G.; EDGETT, S.J.; KLEINSCHMIDT, E.J. Portfolio management in new product development. Research Technology Management, v. 40, p.16-28, Sept/Oct,1997.

COOPER, R.G.; EDGETT, S.J.; KLEINSCHMIDT, E.J. Best practices for managing R\&D portfolios. Research Technology Management, p. 20-34, Jul/Augt,1998.

CORDERO, R. Managing for speed to avoid product obsolescence: a survey of techniques. Journal of Product Innovation Management, v.8, p. 283-294, 1991.

COUGHLAN, P.; COGHLAN, D. Action research for operations management. International Journal of Operations \& Production Management, v. 22, n. 2, p. 230 240, 2002.

DONALDSON, T.; PRESTON, L. E. The stakeholder theory of corporation: Concepts, evidence and implications. Academy of Management Review, v. 24: 237-241, 1995.

DRUCKER, P. F. Managing for business effectiveness. Harvard Business Review, 53-60, May/Jun, 1963. 
EISENHARDT, K.M. Building theory from case study research. Academy of Management Review, v.14, n.4, p.532-550, 1989.

EISENHARDAT, K.M.; ZBARACKI, M. J. Strategic decision making. Strategic Management Journal, v. 13, 1992.

EISENHARDT, K.M.; BROWN, S.L. Patching restitching Business portfolios in dynamic markets. Harvard Business Review, p.72-82, May/Jun. 2000.

ELIAS, A.A.; CAVANA, R.Y; JACKSON, L.S; Stakeholder analysis for R\&D project management. R\&D Management, v. 32, n.4, 2002.

ELMAGHRABY, S; MODER, J. J. Handbook of Operations Research: Models and applications. Published by Van Nostrand Reinhold Company, 1978.

ELTON, J.; ROE, J. Bringing discipline to project management. Harvard Business Review, p. 3-7, Mar/Apr, 1998.

FORMAN, E.; SELLY, M.A. Decision by objectives: how to convince others that you are right. World Scientific. ISBN: 9810241437, 2001.

FREEMAN, R.E. Strategic management: a stakeholder Approach. Boston MA; Pitman, 1984.

GARBER, M. F. Estruturas flutuantes para a exploração de campos de petróleo no mar (FPSO): Apoio à decisão na escolha do sistema, 2002. Dissertação (Mestrado), Escola Politécnica de Engenharia, Universidade de São Paulo, 2002.

GARCEZ, M.P. A seleção das estratégias de crescimento e diversificação: um estudo de casos na indústria petroquímica. 2005. Dissertação (Mestrado), Faculdade de Economia e Administração, Universidade de São Paulo, São Paulo, 2005.

GARVIN, D. A.; ROBERTO, M.A. What you don't know about making decisions. Harvard Business Review, Sept, 2001.

GOLDRATT, E.M. Corrente crítica. São Paulo, Livraria Nobel, 1998. 
GREINER, M. A.; FOWLER, J. W. A hybrid approach using the analytic hierarchy process and integer programming to screen weapon systems projects. IEEE Transactions on Engineering management, v. 50, n. 2, May, 2003.

HAMMOND, J. S.; KEENEY, R. L.; RAIFFA, H. The hidden traps in decision making. Harvard Business School, Boston, MA, USA, Sep-Oct;v.76(5):47-8, 50, 52, 1998.

JAWARHAR, I.M.; MCLAUGHLIN, G. L. Toward a descriptive stakeholder theory: an organizational life cycle approach. Academy of Management Review, v.26, n.3, p. 397- 414, 2001.

JOLLY, D. The Issue of weightings in technology portfólio management. Technovation, v. 23, p. 383-391, 2003.

KAUFMANN, A. A ciência da tomada de decisão. Tradução de Francisco José de Albuquerque Souza, 2a . Ed. Rio de Janeiro: Zahar Editores, 1975.

KEENEY, R. L.; RAIFFA, H. The hidden traps in decision making. Harvard Business Review, Sep/Oct, 1998.

KLUYVER, Cornelis A. de. Innovation and industrial product life cycles. California Management Review, v.20, n.1, p. 21, 1977.

LAGER, T. A structural analysis of process development in process industry: a new classification system for strategic project selection and portfolio balancing. R\&D Management, v.32, p.87- 95, 2002.

LUEHRMAN, T. A. Strategy as a portfolio of real options. Harvard Business Review, Sep/Oct, 1998.

MCFARLAN, F.W. Portfolio approach to information. Harvard Business Review, p.142 -150, Set/Oct, 1981.

MORITA, H, Revisão do método de análise hierárquica MAH (AHP - Analytic Hierarchy Process). 1998. Dissertação (Mestrado) - Escola Politécnica, Universidade de São Paulo, São Paulo, 1998. 
MURAKAMI, M. Decisão estratégica em TI: Estudo de Caso. 2003 Dissertação (Mestrado), Faculdade de Economia e Administração -Universidade de São Paulo, São Paulo, 2003.

MUSCAT, A.R.N. Introdução à gestão de operações e logística. Escola Politécnica - Universidade de São Paulo, 2004. Notas de aula.

NUTT, P. C. Formulation tactics and the success of organizational decision making. Decision Sciences, 1992.

PADOVANI, M.; CARVALHO, M.M.; MUSCAT, A.R.N. Portfolio management implementation in a chemistry Brazilian company. In Seventeenth Annual Conference of POMS, Boston, USA, MAPOMS, Abr, 2006.

PADOVANI, M.; CARVALHO, M.M.; MUSCAT, A.R.N. Critical gaps in portfolio management implementation: a Brazilian case study, In PICMET 2006 Proceedings, Jul 9-13, Istanbul, Turkey @), 2006, p.2209-2220.

PRAHALAD, C. K; HAMEL, G. The core competence of the corporation. Harvard Business Review, May/Jun, 1990.

RAIFFA, H. Teoria da decisão: aulas introdutórias sobre escolhas em condições de incerteza. Tradução de Sérgio Girão. Petrópolis, Vozes: São Paulo, EDUSP, 1977.

ROBERTS, E.B; BERRY, C. A. Entering New Businesses: Selecting strategies for success. Sloan Management Review, Cambridge, MA, spring, p.3-17, 1985.

ROUSSEL, P.; SAAD, K.N.; ERICKSON, T.J. Third generation R\&D managing the link to corporate strategy. Harvard Business School Press, Cambridge, MA, 1991.

SAATY, T.L., The Analytic Hierarchy Process - planning priority setting, resource allocation. New York: McGraw Hill, 1980.

SAATY, T.L., Método de Análise Hierárquica. Tradução de Wainer da Silveira e Silva. São Paulo. Ed. Makron Books do Brasil, 1991.

SAATY, T. L. The seven pillars of the hierarchy process. ISAHP Proceedings. Kobe, 1999. 
SHIMIZU, T. Decisão nas organizações: introdução aos problemas de decisão, encontrados nas organizações e nos sistemas de apoio à decisão. São Paulo: Atlas, 2001.

SIMON, H. A. The new science of management decision. New York. USA: Harper and Brothers Publishers, 1960.

SLACK, N. Vantagem Competitiva: Atingindo competitividade nas operações industriais. - Tradução Sônia Corrêa; revisão técnica Henrique Luiz Corrêa. São Paulo: Atlas, 1993.

SLACK, N. Generic trade-offs and responses: an operations strategy analysis. International Journal of Business Performance Management, v.1, n.1, 1998.

SLACK, N. et al. Administração da Produção: Edição Compacta. Revisão Técnica Henrique L. Corrêa, Irineu Gianesi. São Paulo: Atlas, 1999.

THIOLLENT, M. Metodologia da Pesquisa-Ação, 13ª Ed. - São Paulo: Cortez, 2004. (Coleção: temas básicos da pesquisa-ação).

TRITLE, G. L.; SCRIVEN, F.V.; FUSFELD, A.R. Resolving uncertainty in R\&D portfolios. Research Technology Management, v. 43, n. 6, p. 47-55, 2000.

UTTERBACK, J.M. Mastering the dynamics of innovation. Harvard Business School Press, Boston, MA, 1994.

VOSS, C.; TSIKRITSIS, N.; FROLICH, M. Case research in operations management. International Journal of Operations \& Production Management, v.22, n. 2, pp.195219, 2002.

WHEELWRIGHT, S.C.; CLARK, K.B. Revolutionizing new product development. The Free Press, New York, 1992.

WINSTON, W. L. Operations research: applications and algorithms. Fourth edition. Brooks/Cole, 2004.

YIN, R K. Case Study Research: design and methods. 2nd Edition, Thousand Oaks, Sage Publications, 1994. 


\section{APÊNDICE A - O Software Decision Lens Versão 1.6.16}

O software utilizado como ferramenta para o desenvolvimento do modelo proposto denominado Decision Lens, se baseia na metodologia ANP (Analytic Network Process) que integra as metodologias AHP (Analytic Hierarchy Process), sua predecessora, com a programação matemática, permitindo a análise de uma rede mais complexa de decisões e suas restrições. Essa metodologia se constitui num avançado recurso de suporte a decisão, quantificando fatores intangíveis e avaliando escolhas através de uma estrutura compreensível e racional. Tanto a ANP como o AHP foram criadas pelo Prof. Dr. Thomas Saaty, da Wharton School of Business e têm sido aplicados em organizações do mundo todo para seleção e priorização de projetos, levando empresas a redução de custos e alinhamento estratégico.

Neste trabalho de pesquisa foi utilizado o software Decision Lens versão 1.6.16 de 30/08/2006.

O sistema é constituído basicamente por cinco módulos, sendo o primeiro de construção do modelo, o segundo de comparação dos critérios, o terceiro de avaliação das alternativas, o quarto de alocação dos recursos e o último de geração de relatórios.

A figura 58, a seguir apresenta a tela inicial do sistema, com o fluxo de desenvolvimento das atividades disponível no sistema.

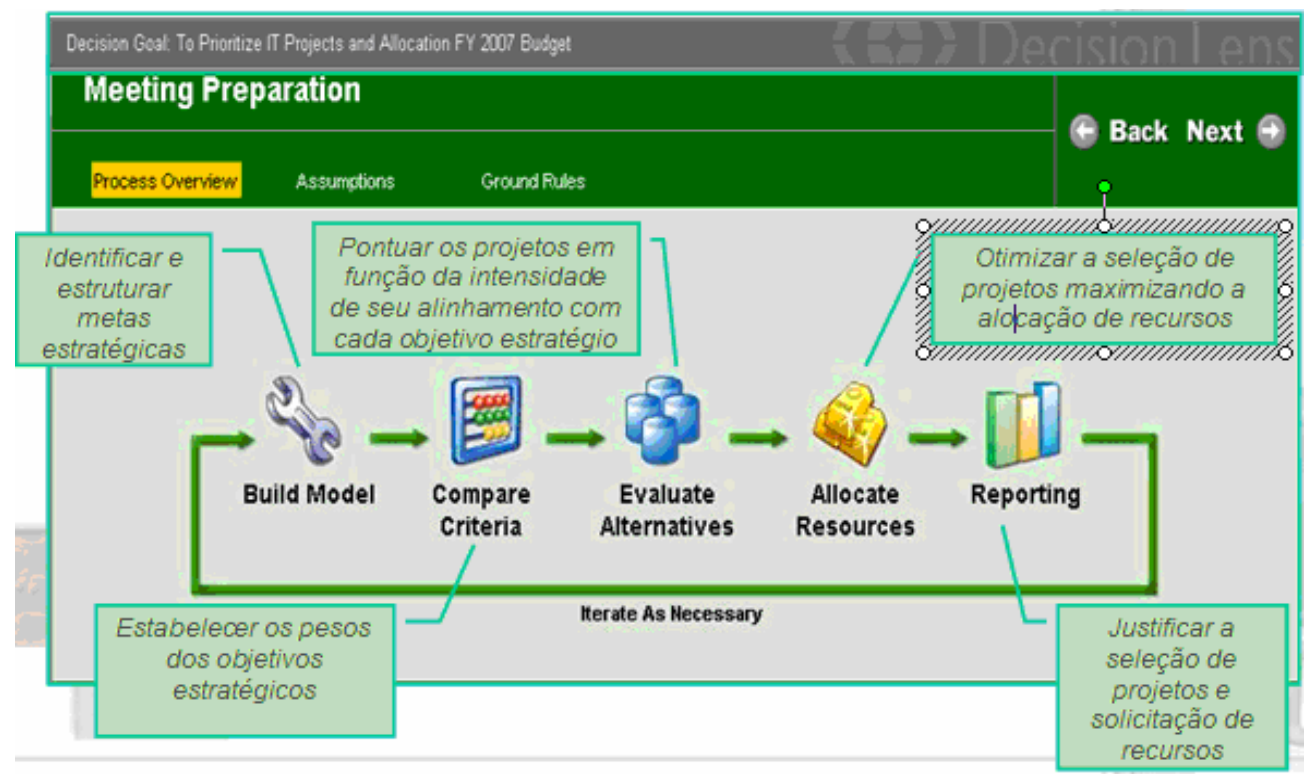

Figura 58 - Tela Principal do Software Decision Lens v.1.6.16

(Detalhe do Fluxo de Construção do Modelo) 
O módulo de construção do modelo é usado para definir as premissas do modelo com objetivos/metas, fazer o brainstorming para a definição e estruturação dos critérios e definição dos participantes. Nesse módulo deve-se desenhar a hierarquia de decisão, cadastrar os critérios de decisão, suas definições, nomes dos participantes e as alternativas de projetos a serem analisados. Uma ilustração com um exemplo de cadastro de estrutura de decisões é apresentada na figura 59.

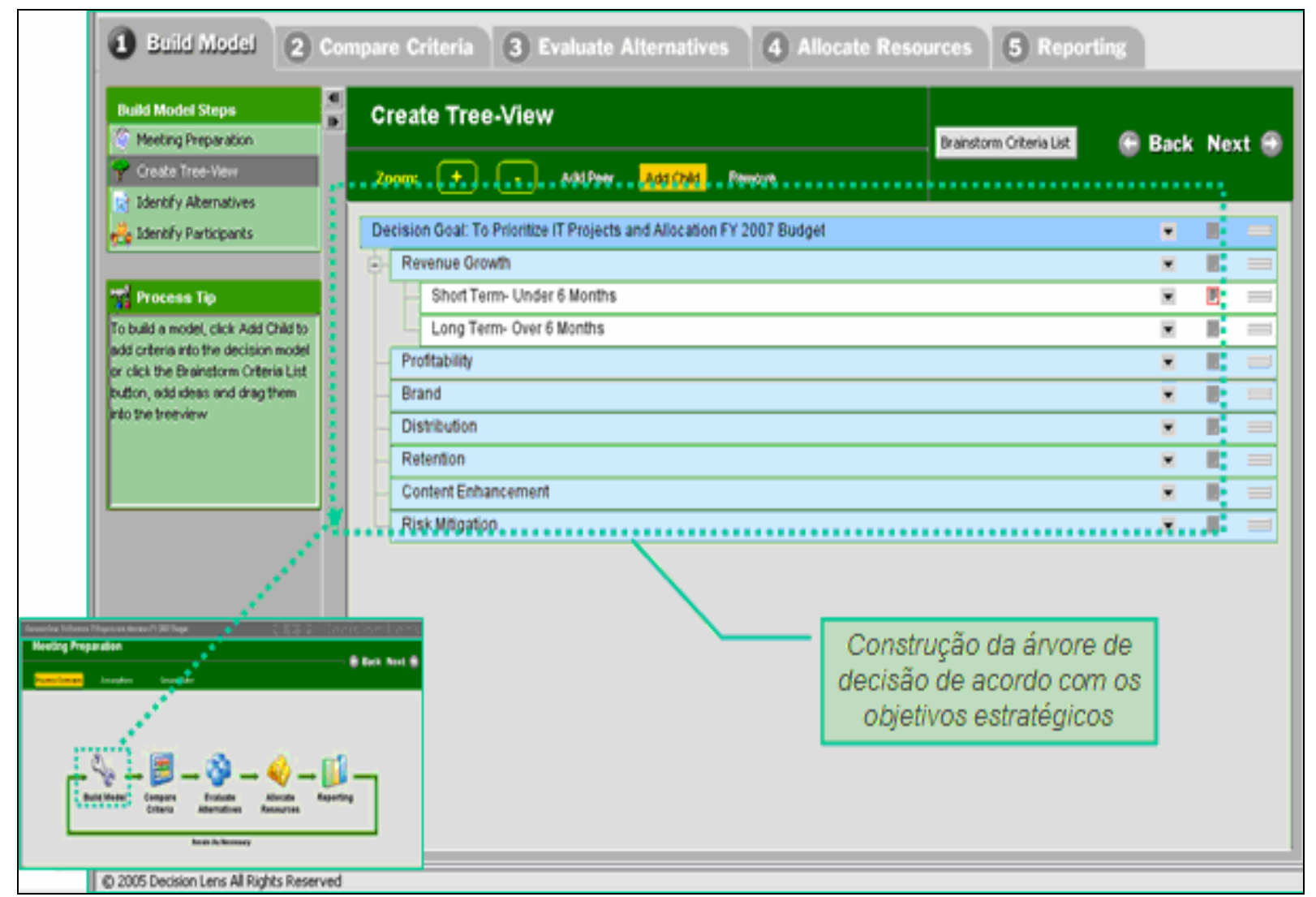

Figura 59 - Módulo de criação da Estrutura de Decisões- Software Decision Lens v.1.6.16 (Detalhe de Etapa de Construção do Modelo)

O módulo de comparação dos critérios contém uma tabela para os múltiplos objetivos de decisão que é usada como guia para a comparação por pares dos critérios e subcritérios de decisão. Este módulo tem um recurso de análise de inconsistência que ajuda os tomadores de decisão a avaliar onde a votação não foi coerente e retornarem para uma reavaliação.

A figura 60 apresenta a tela com o fluxo de atividades do módulo de comparação dos critérios. 


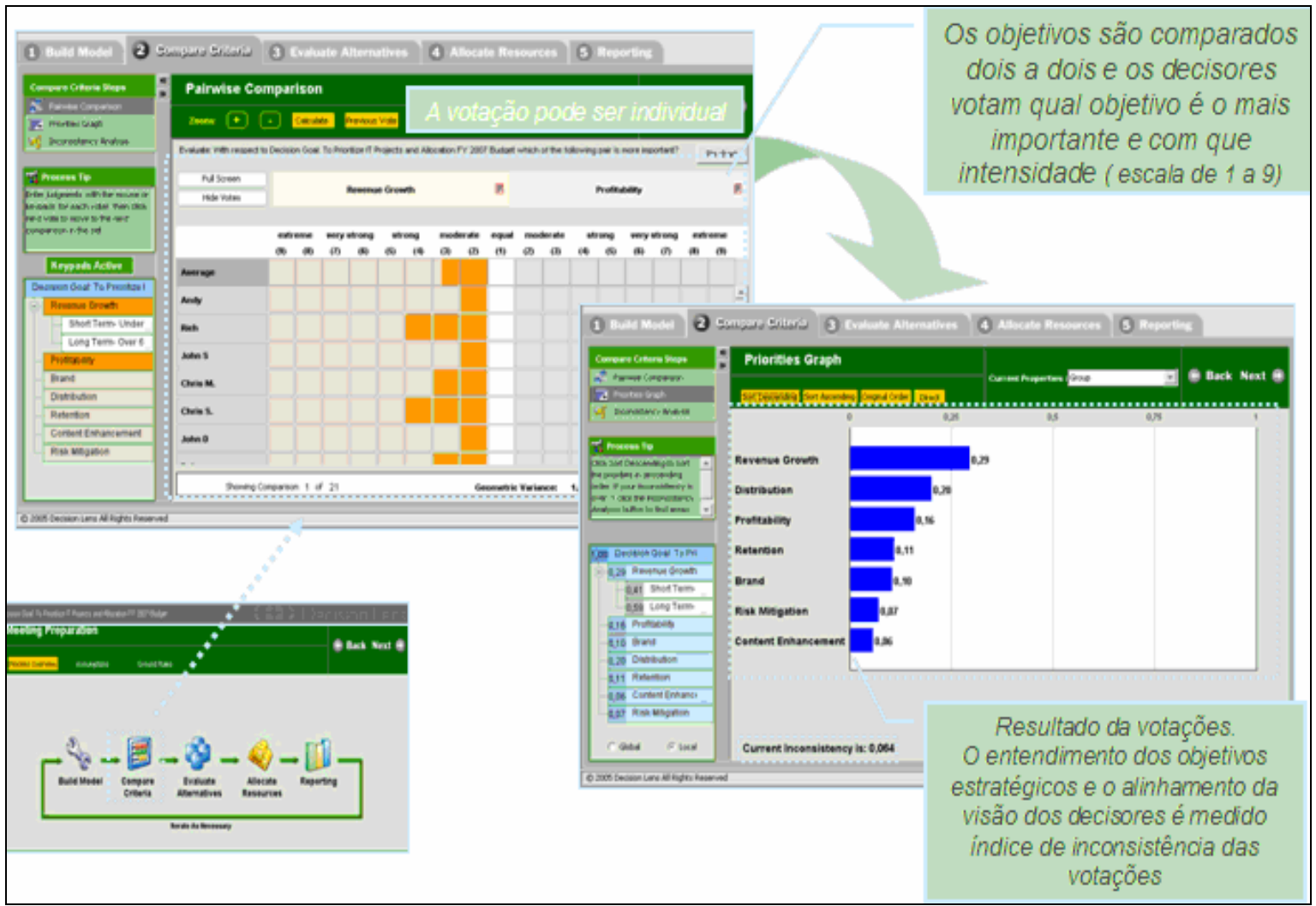

Figura 60- Módulo de Comparação dos Critérios - Software Decision Lens v.1.6.16 (Detalhe das Fases de Construção do Modelo e Apresentação dos Resultados)

O módulo de avaliação das alternativas é usado para construir e dar pesos qualitativos e quantitativos para as escalas de valores dos critérios e subcritérios, ou ratings, e depois avaliar as alternativas em relação ao nível mais baixo de subcritérios. Este módulo também dispõe do recurso de análise de sensibilidade, o que permite simular para diferentes pesos dos critérios se a seqüência dos projetos seria afetada. O fluxo deste módulo é apresentado na figura 61. 


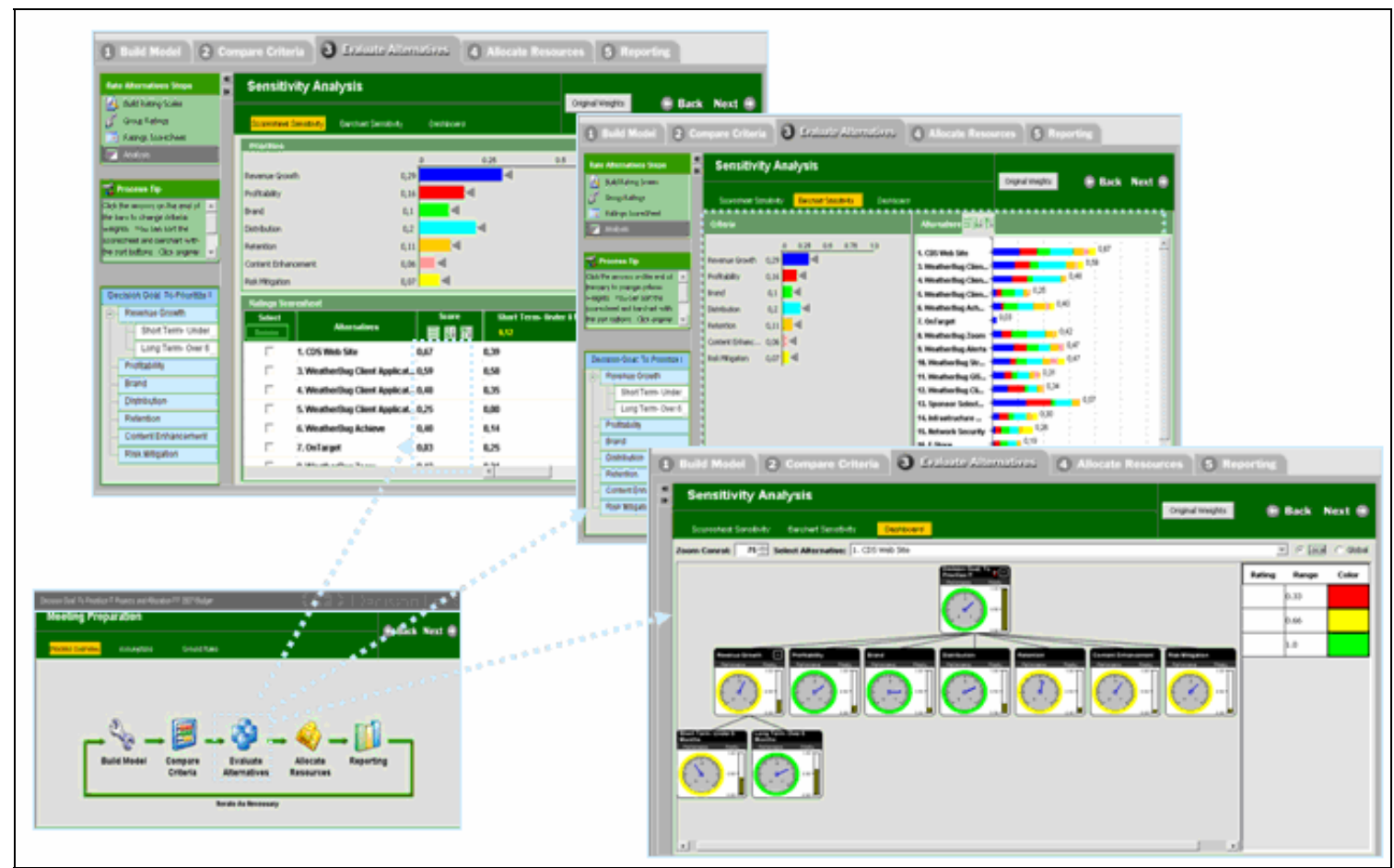

Figura 61 - Módulo de Avaliação de Alternativas do Software Decision Lens v.1.6.16 (Detalhe Recursos Disponíveis)

O módulo de alocação dos recursos é usado para a definição das restrições e, então, aperfeiçoar o orçamento chegando ao melhor mix de projetos suportados pelos objetivos estratégicos da organização. O otimizador dispõe de regras do tipo what-if para testar mudanças nos valores atribuídos a cada projeto por alterações em prioridades e orçamento. Nestas regras pode-se prever para cada projeto um valor mínimo, um valor máximo, um valor fixo e relações de dependência entre os projetos. A figura 62 apresenta o fluxo de atividades previsto no módulo de alocação de recursos. 


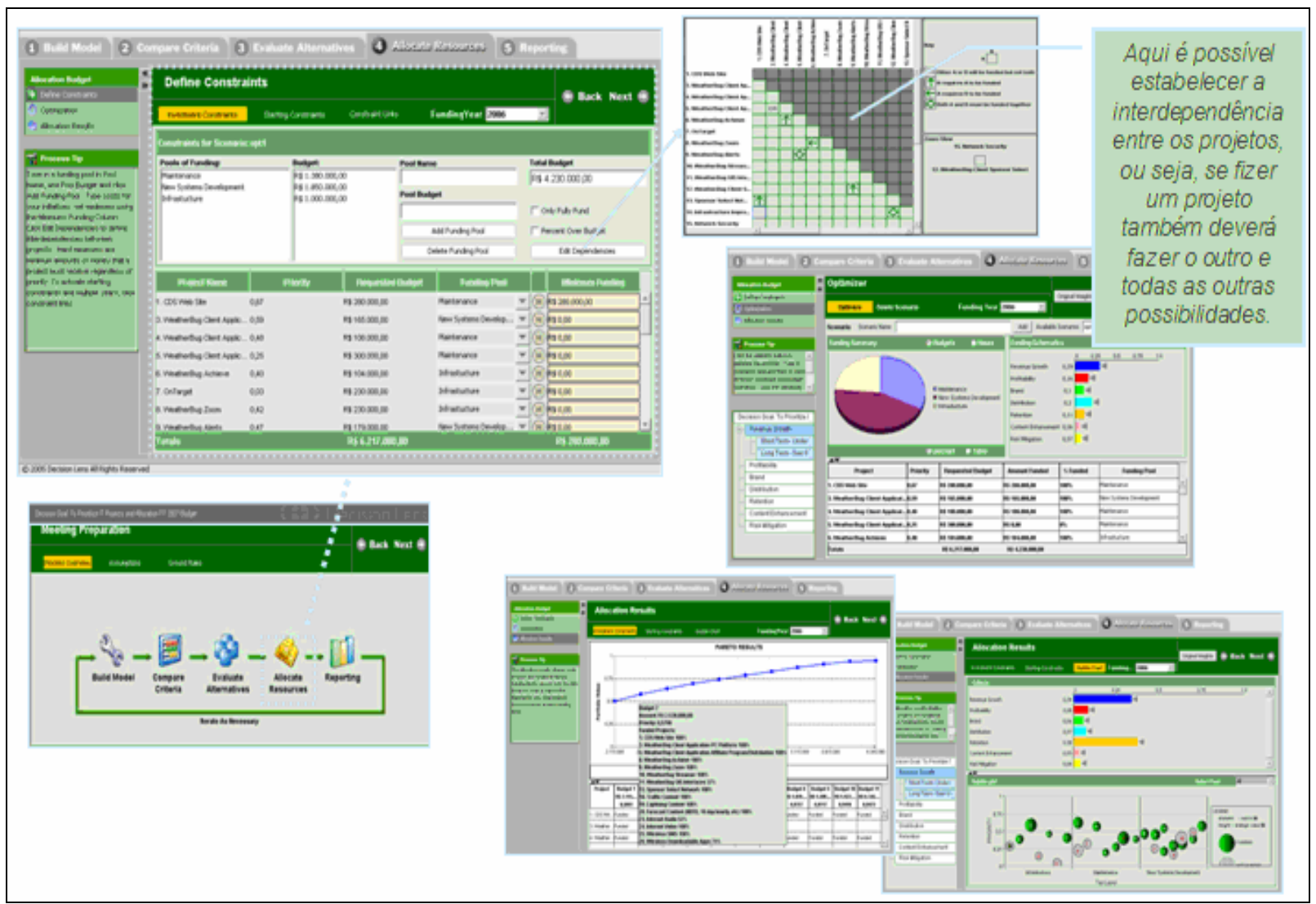

Figura 62 - Módulo de Alocação de Recursos do Software Decision Lens v.1.6.16

O módulo de relatórios permite a geração de relatórios em formato PDF e impressão dos mesmos. 
APÊNDICE B - Perfil dos Participantes da Validação do Modelo

É apresentado nesta seção o perfil dos funcionários da empresa que, juntamente com o autor deste trabalho de pesquisa, participaram das reuniões de validação do modelo de seleção e priorização de projetos proposto, em suas diferentes etapas de execução. Tais funcionários são denominados de participantes da pesquisa. 


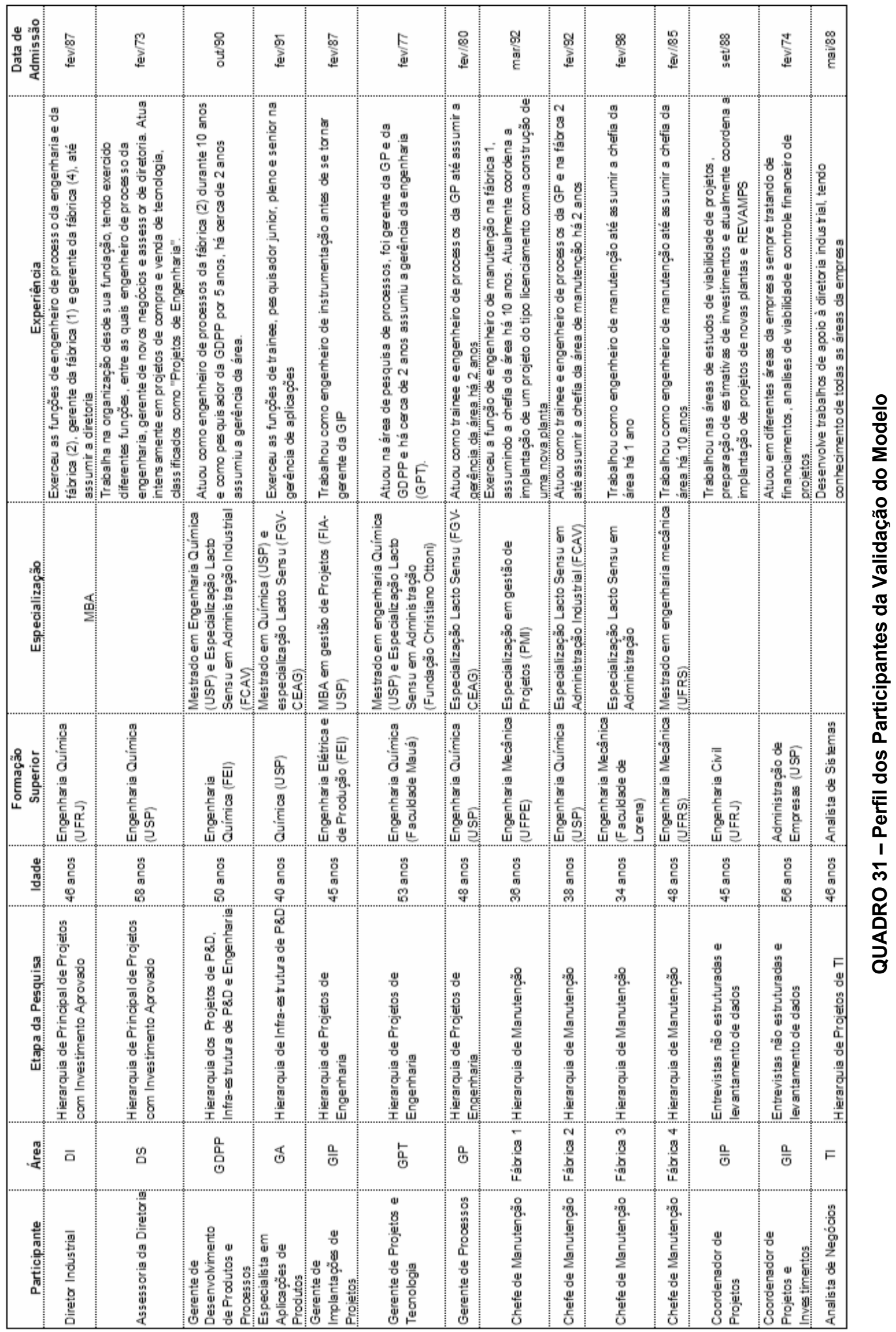


APÊNDICE C - Escala de Valores dos Subcritérios dos Projetos de P\&D

Esta seção apresenta a escala de valores definida para os projetos de P\&D durante as reuniões de validação do modelo com o gerente de desenvolvimento de produtos e processos (GDPP) 


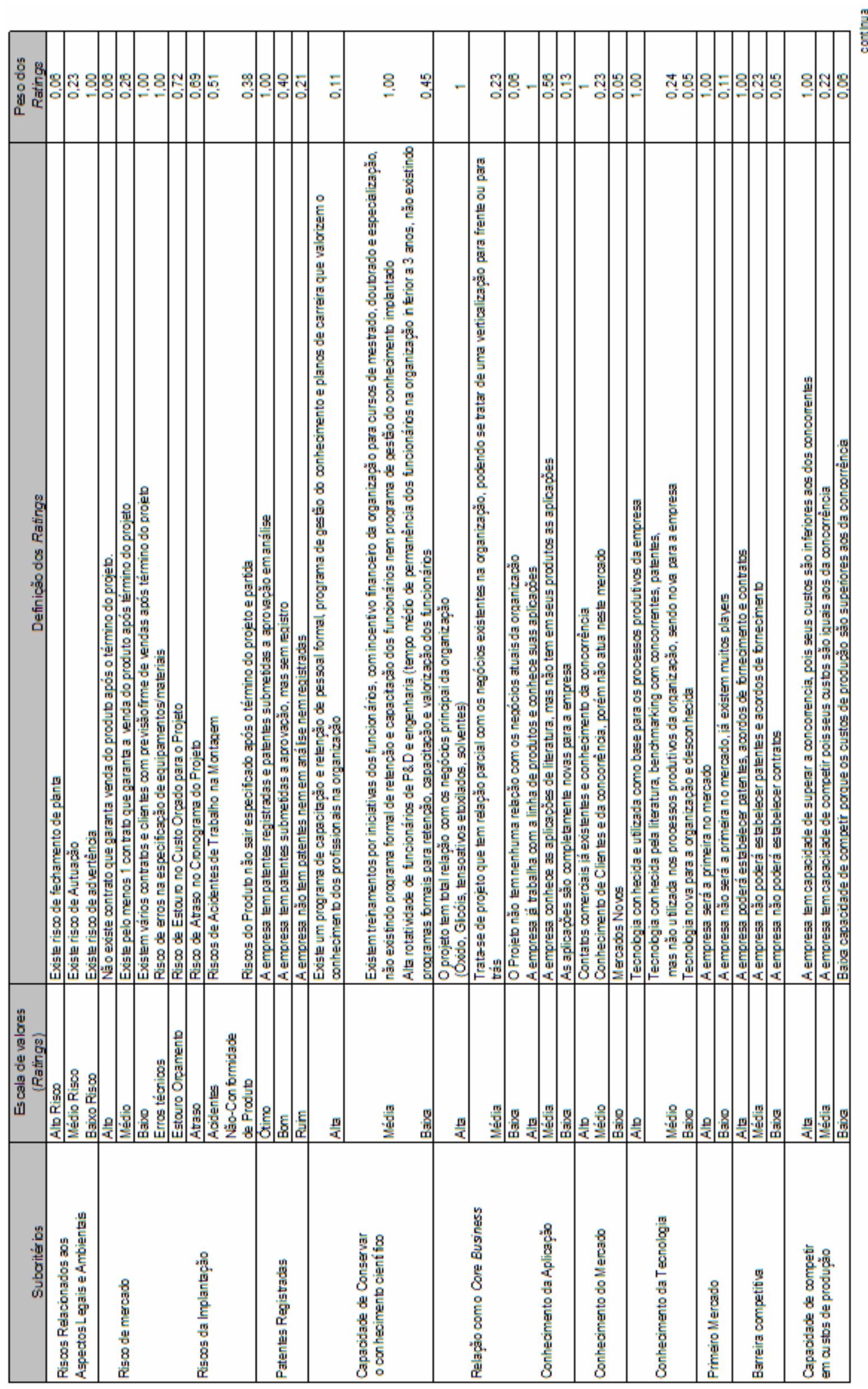




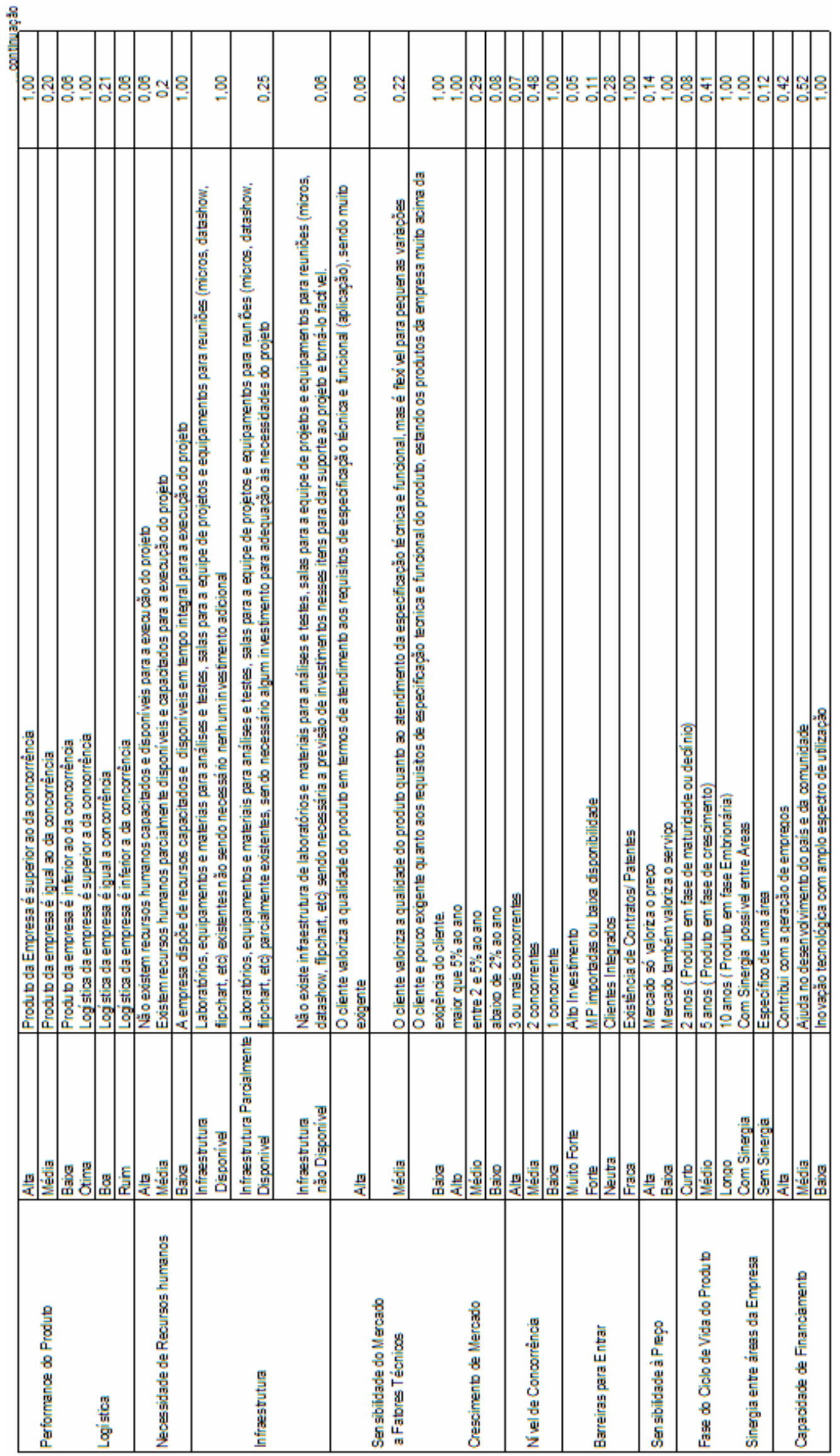

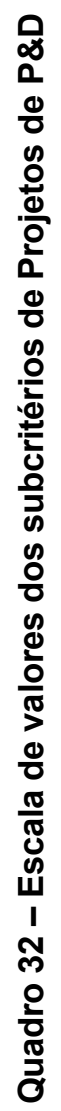


APÊNDICE D - Nova Classificação dos Projetos com Investimento Aprovado

Neste item, a relação dos projetos utilizados neste trabalho é apresentada utilizando-se a nova classificação proposta pelo autor desta dissertação, estando divididos em: Projetos de Engenharia, Projetos de Informática, Projetos de Infraestrutura de P\&D e Projetos de Manutenção. O período escolhido para a coleta e análise dos dados é de 2001 a 2005. 


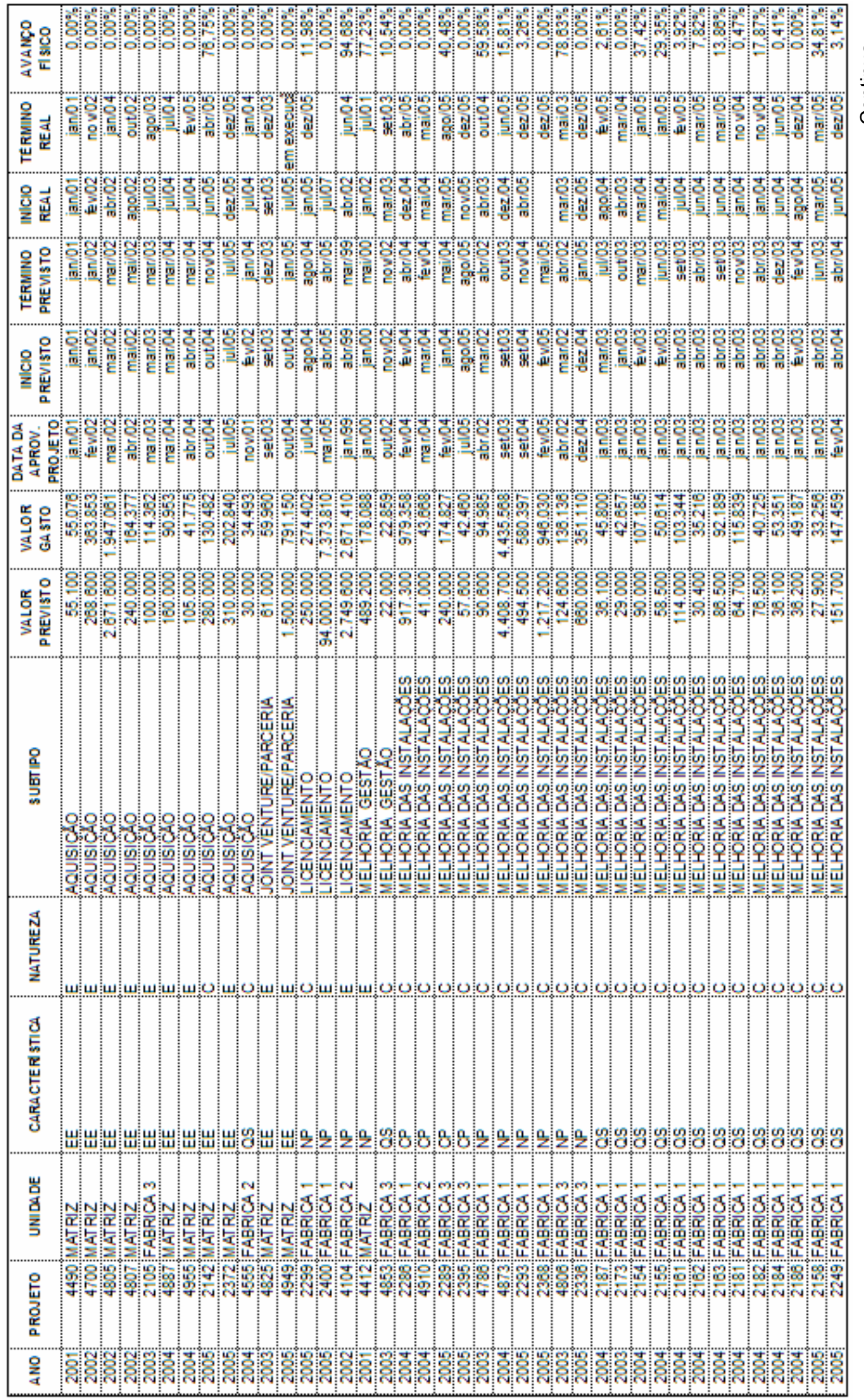


0
0 ó:0,

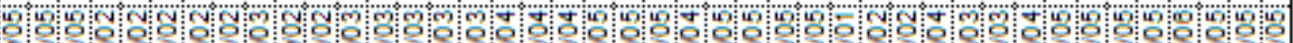

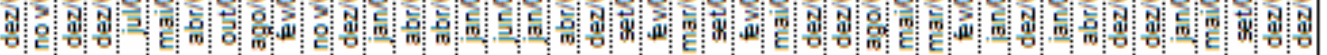

8:

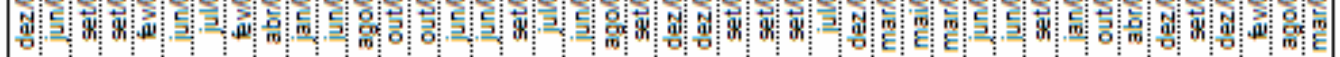

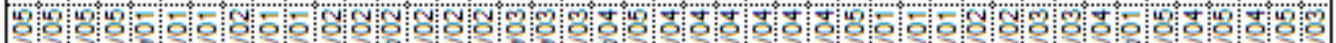

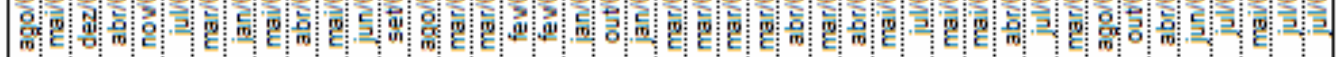

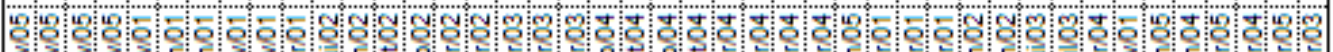
预,

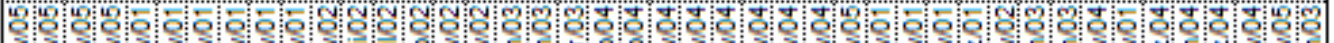
3. 3a.

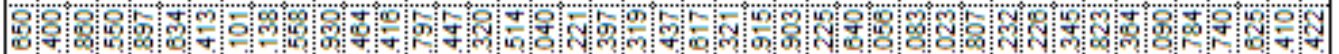
$\omega: 0 \%$ w

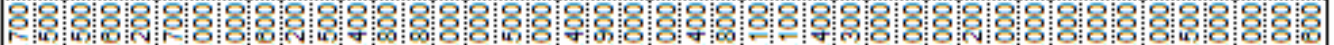
Fo

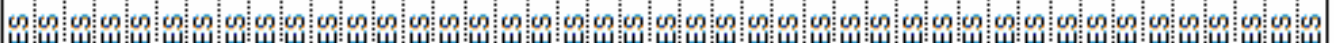

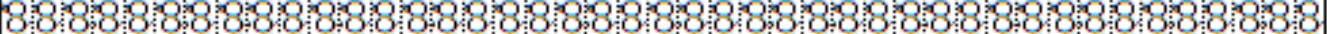
水

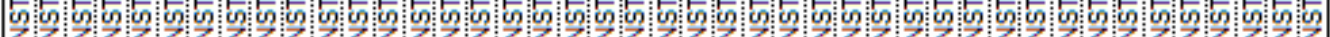
-

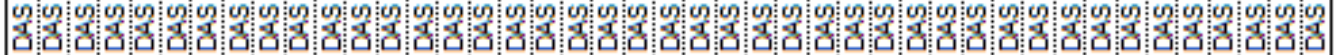

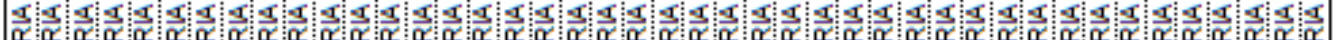

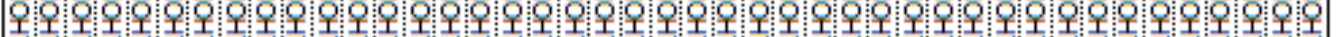

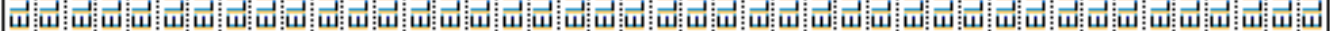
ш

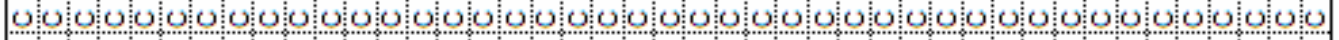

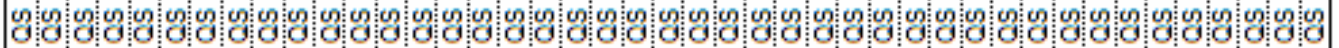

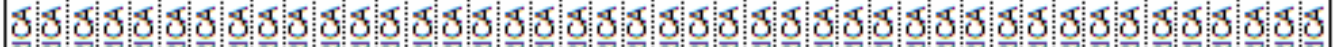

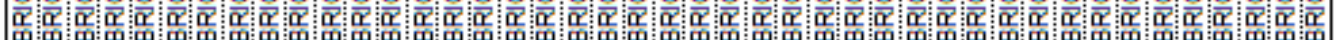

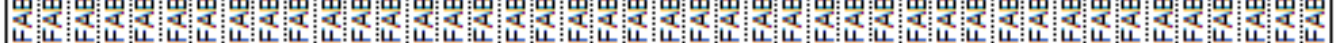

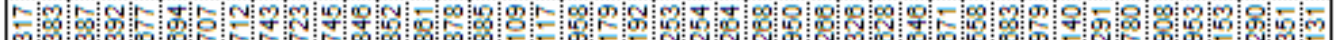

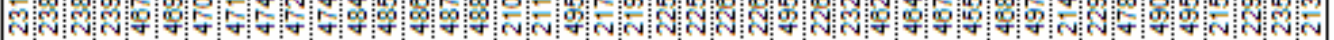




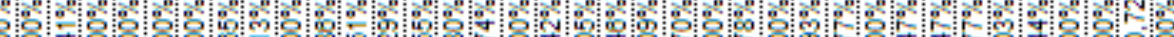
o:

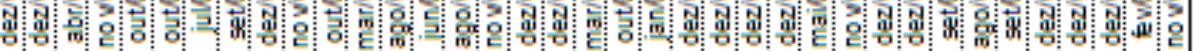

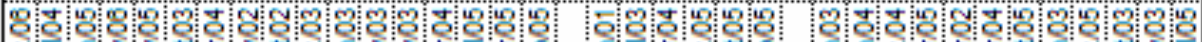

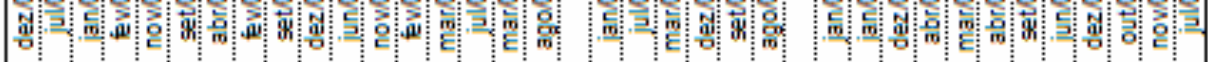

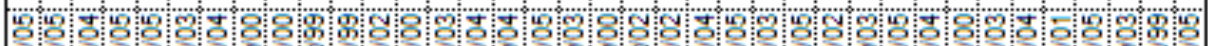

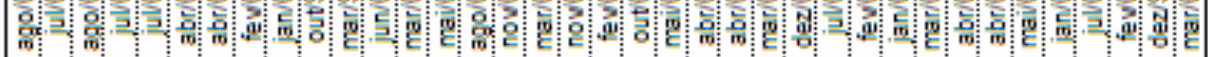

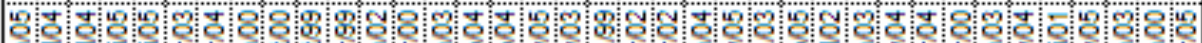

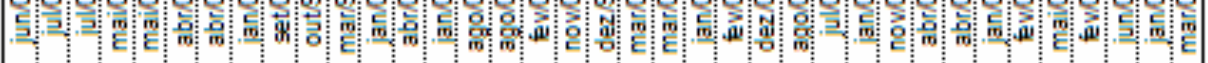

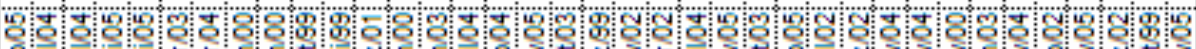

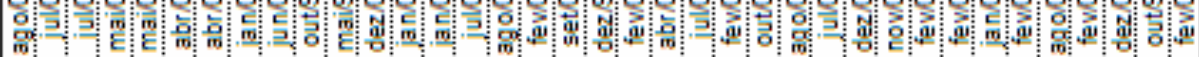

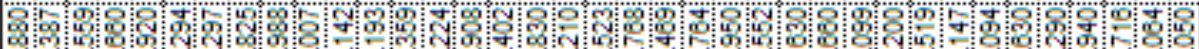
कW

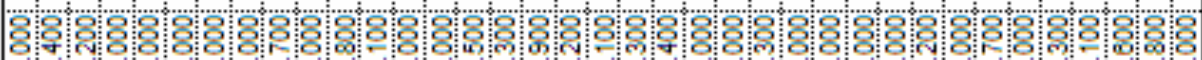

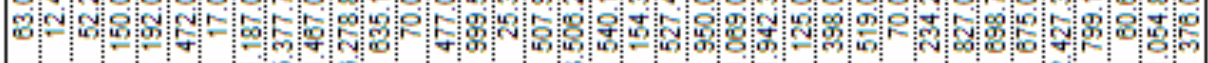

(n)

산:

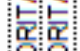

$x+\frac{x}{4} \leq 2$

obo:o w w

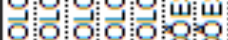

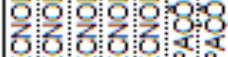

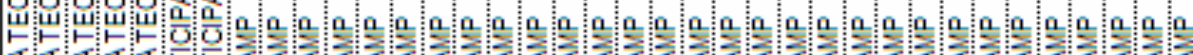

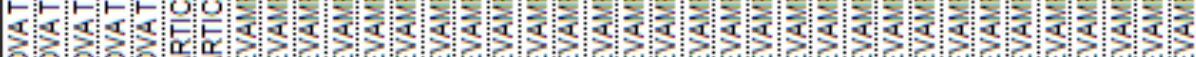

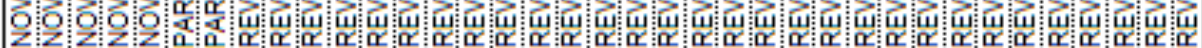

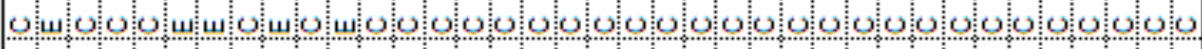

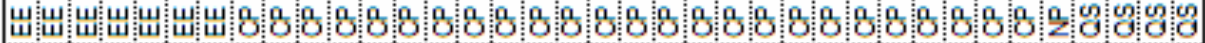

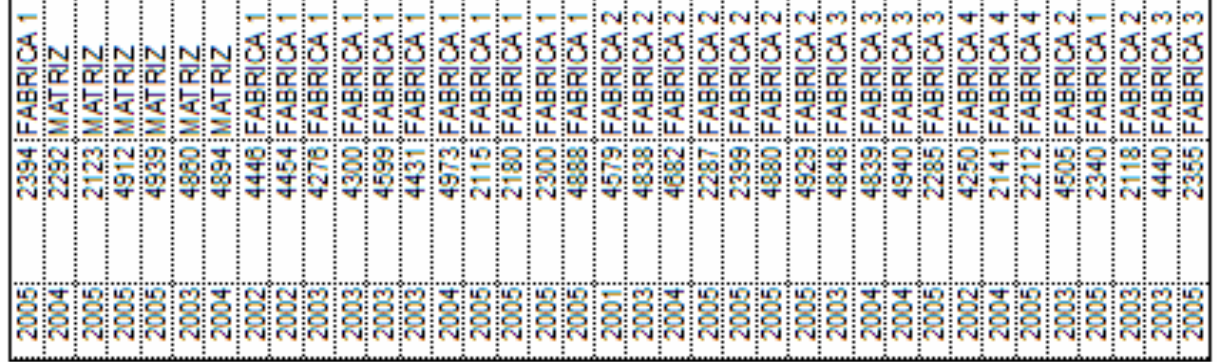




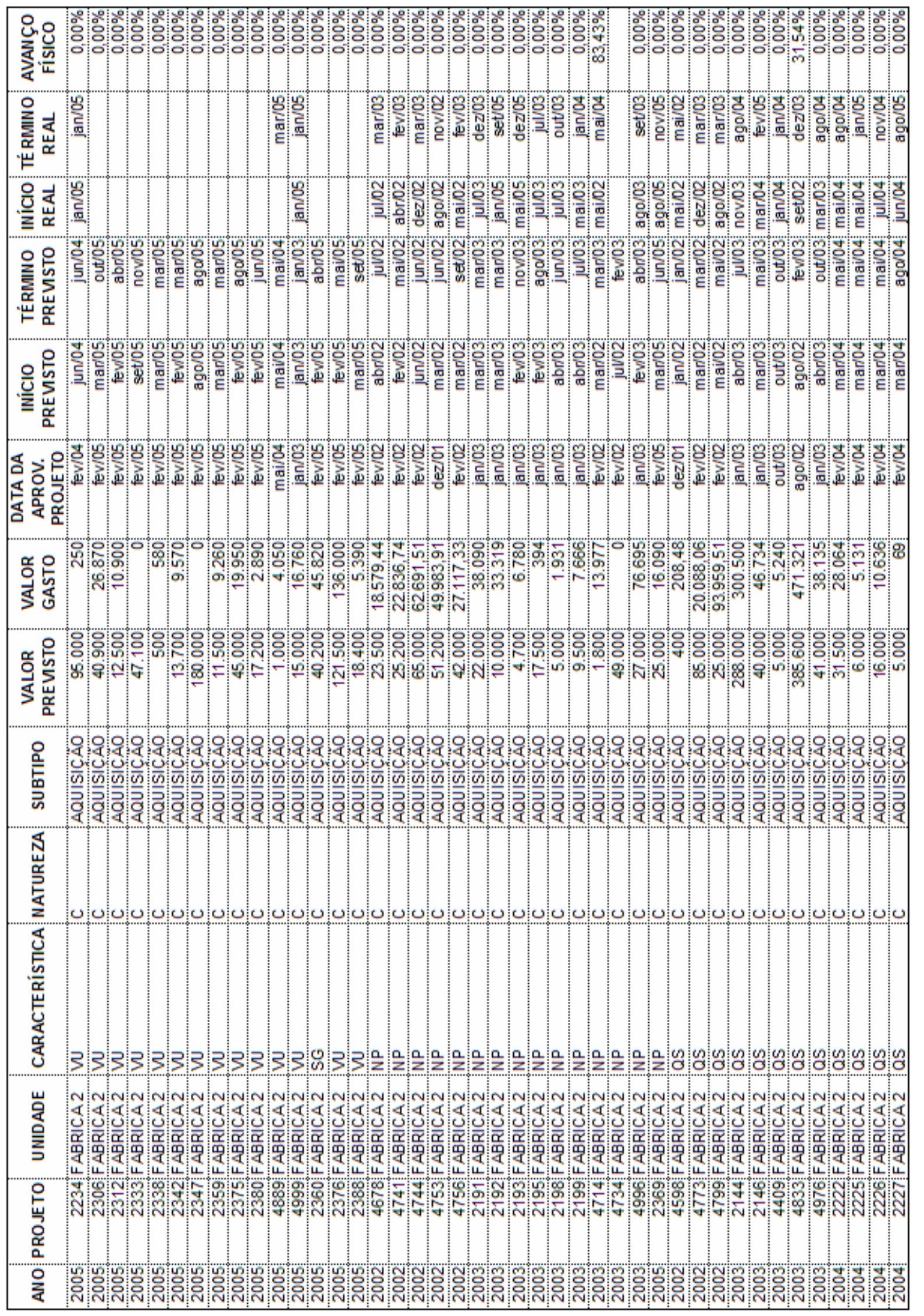




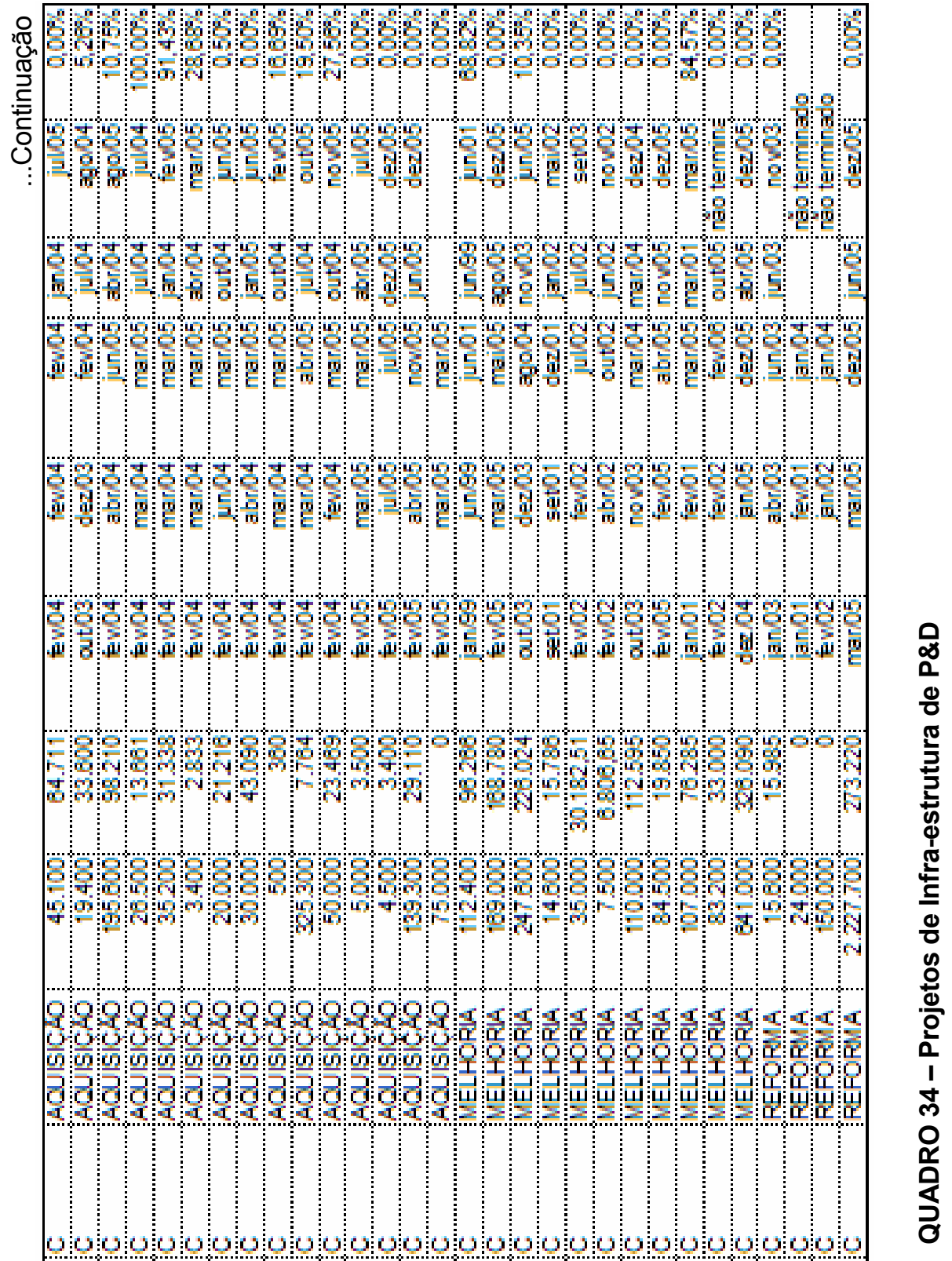

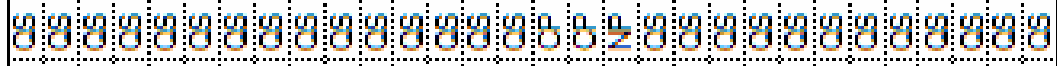

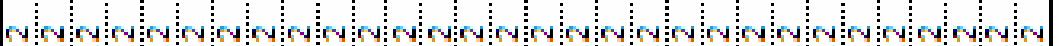

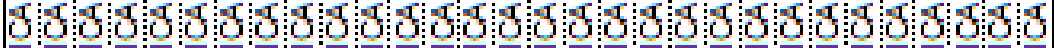

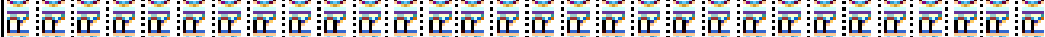

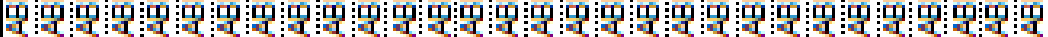

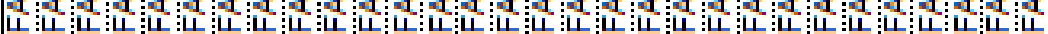

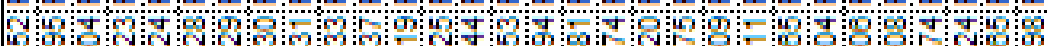

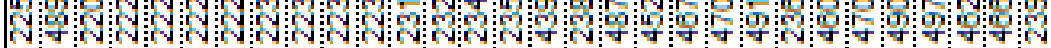

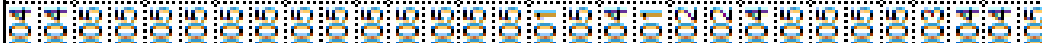

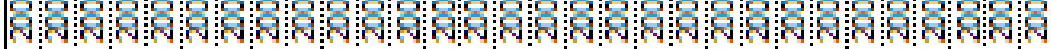




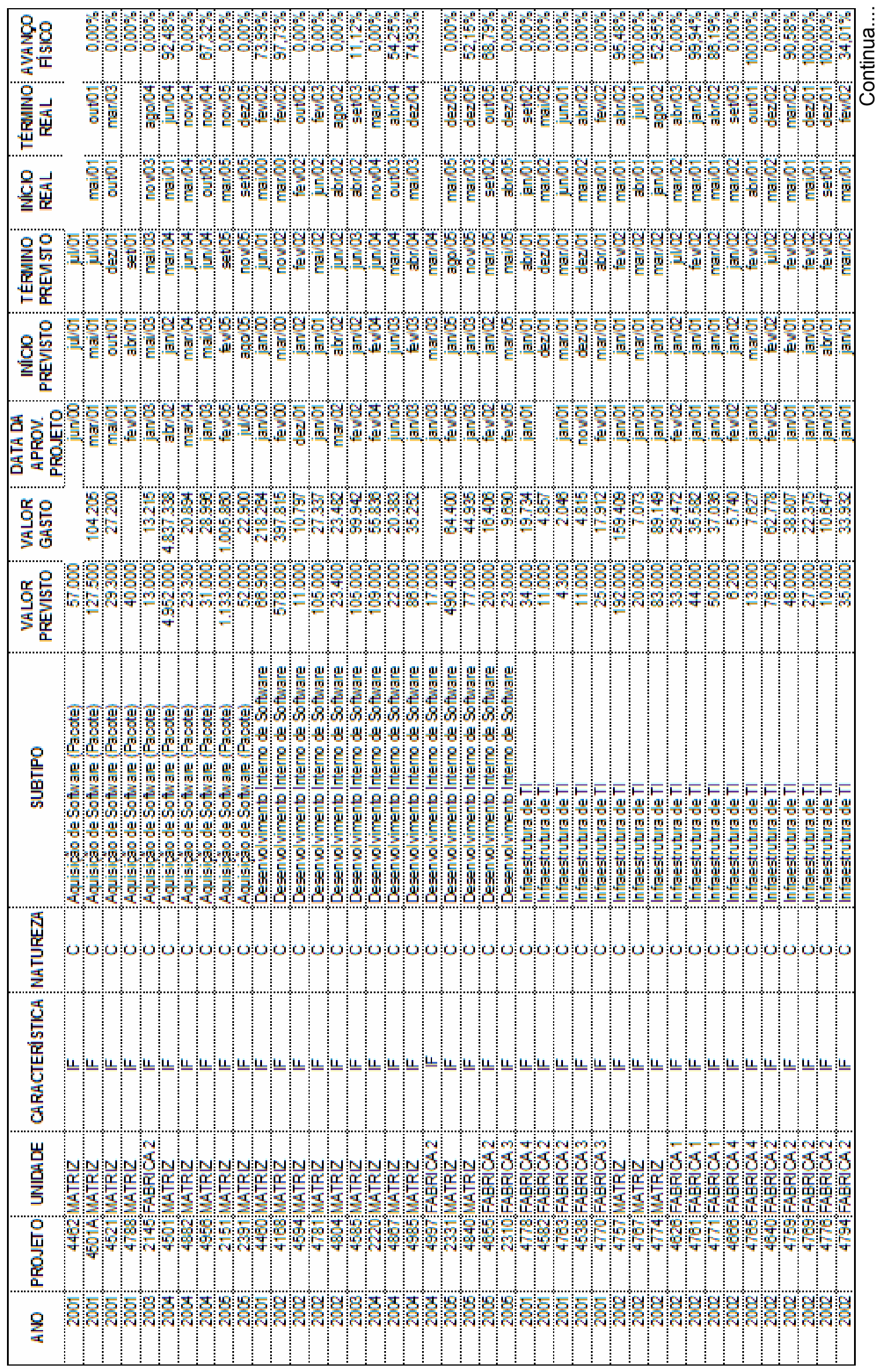




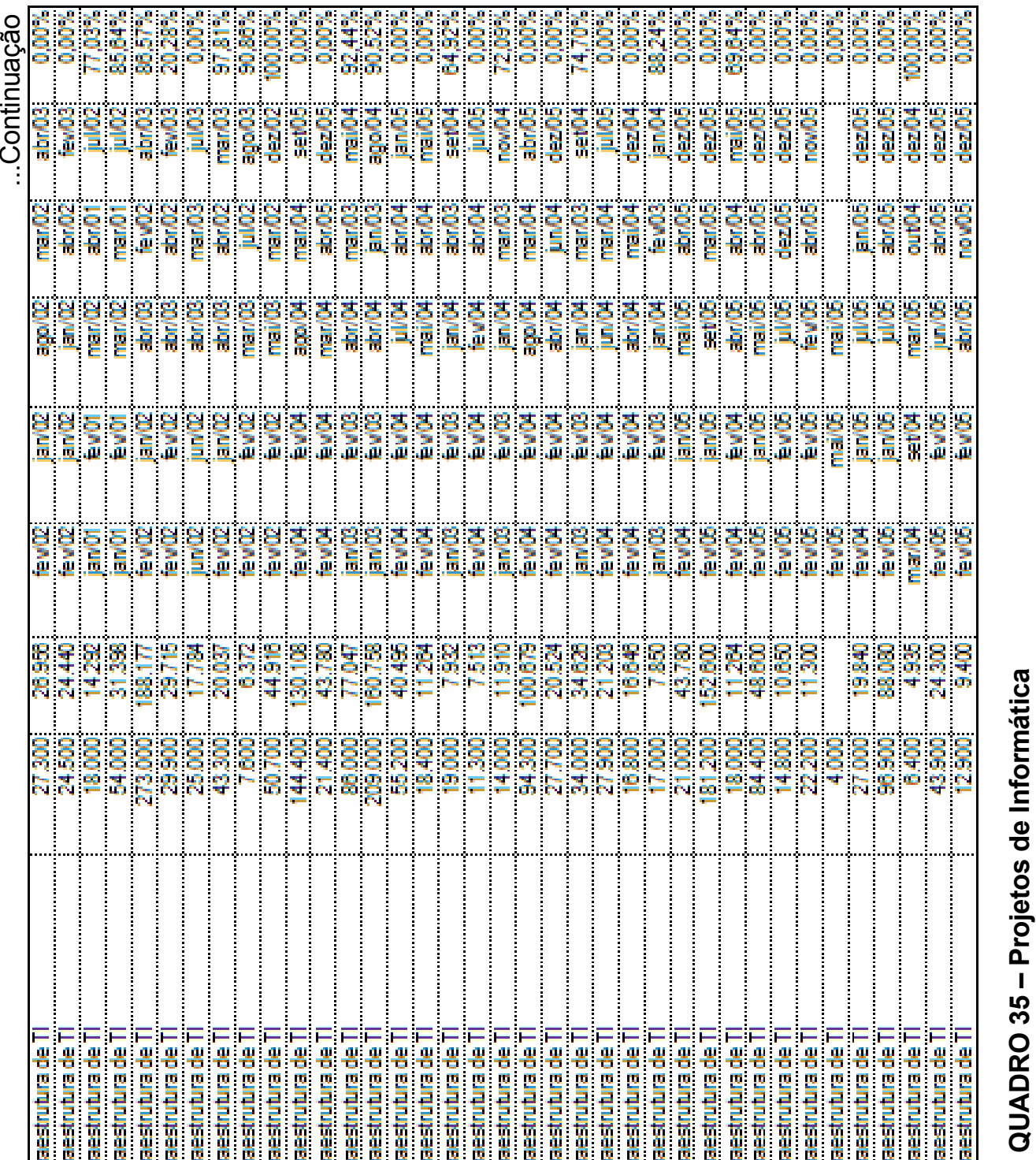




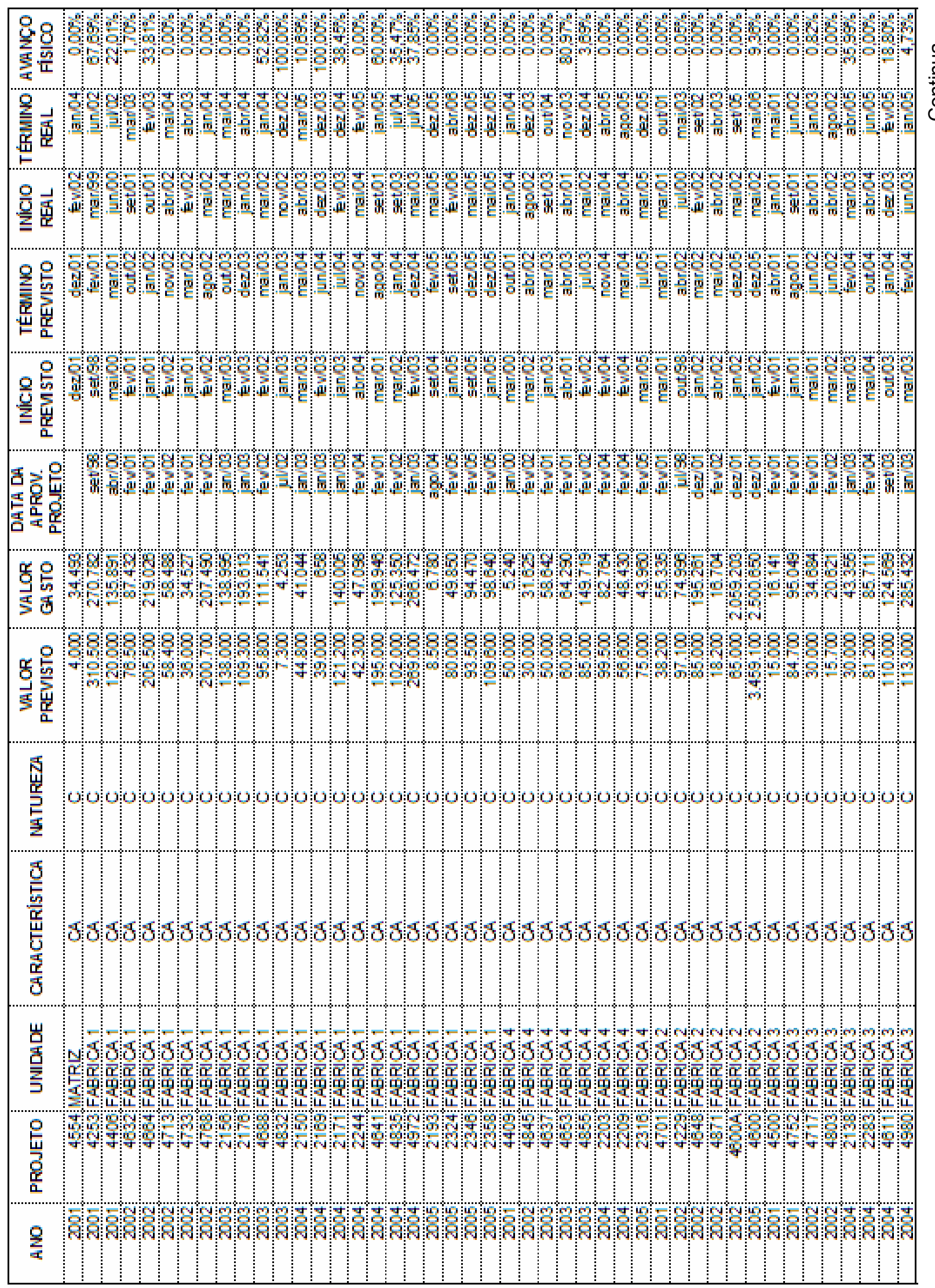




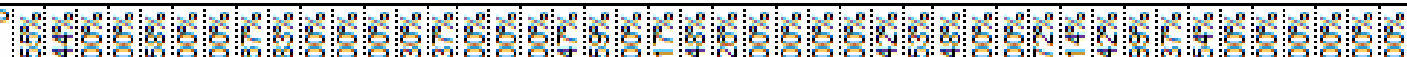

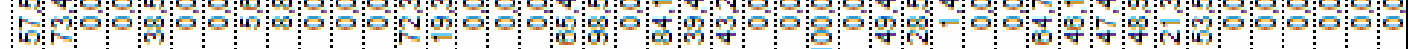

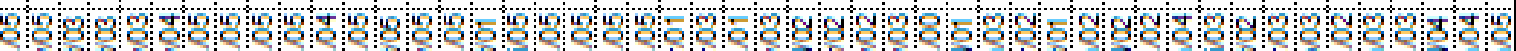

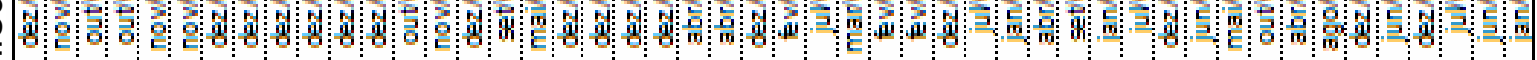

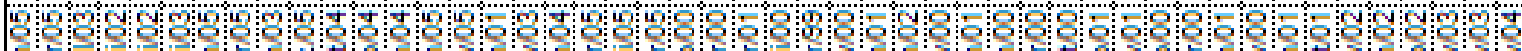

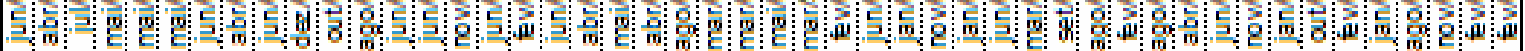

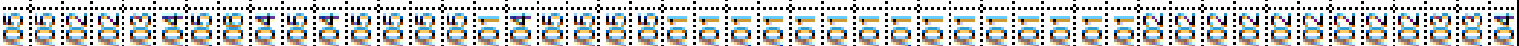

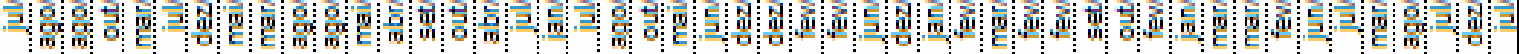

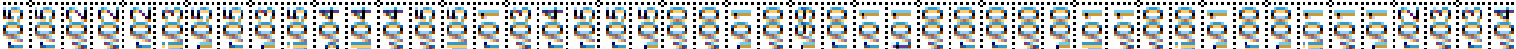

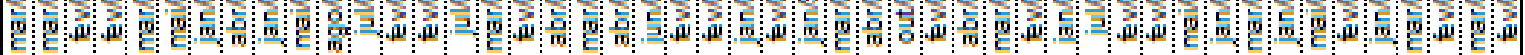

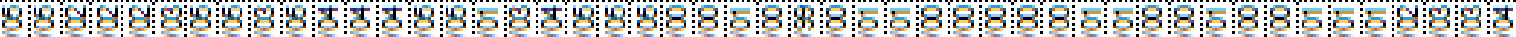

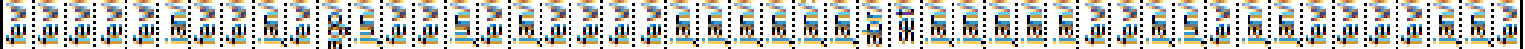

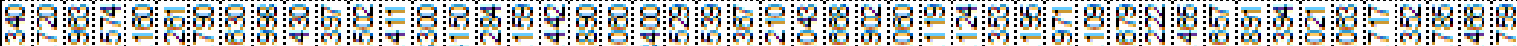

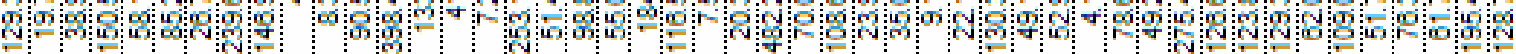

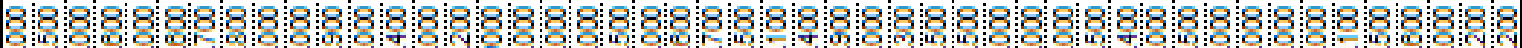

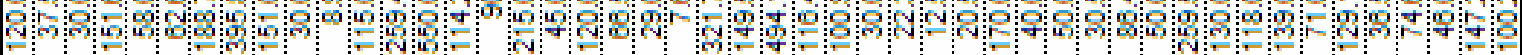

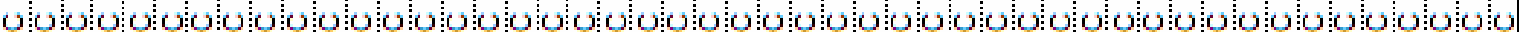

子女e

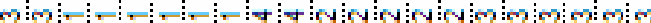

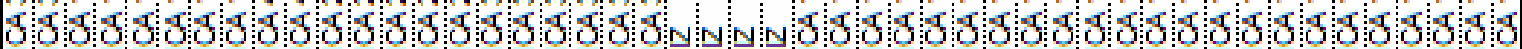
r

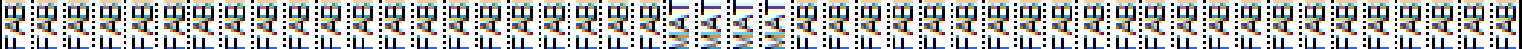
N 
เ

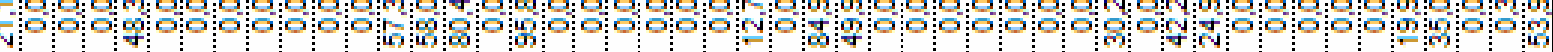

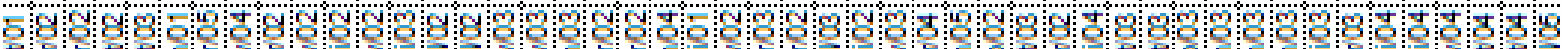
W Wh o o :

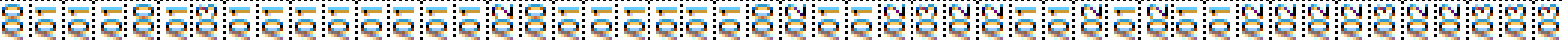

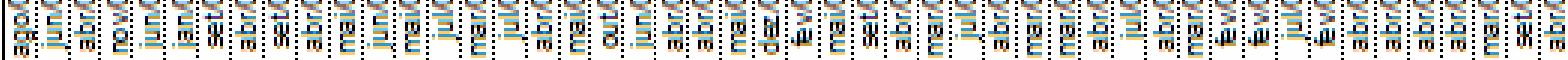

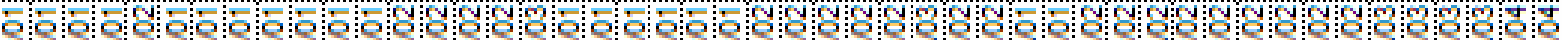
के

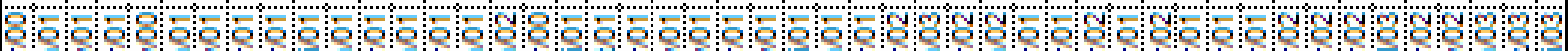

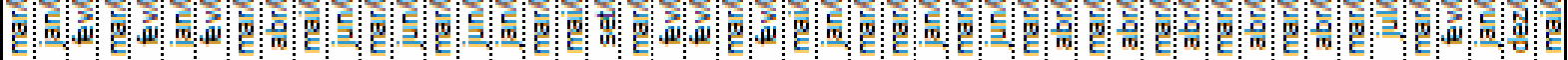

ఆ 웜

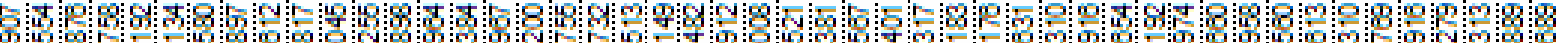
$N \omega \mathrm{N}$

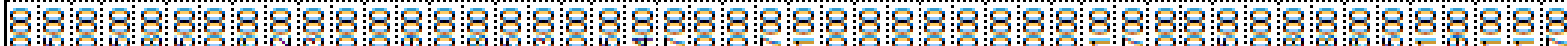
4r N N

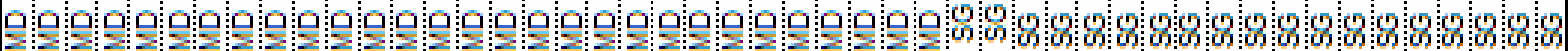

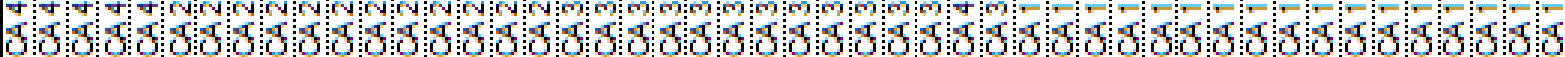

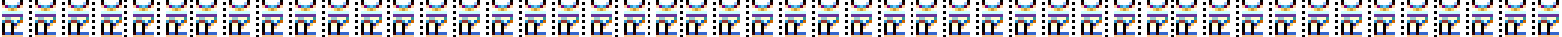

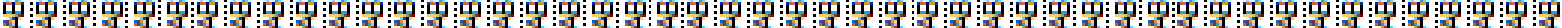
1 今ง

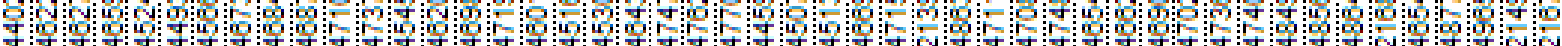

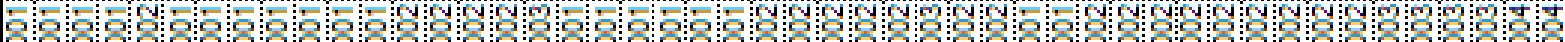

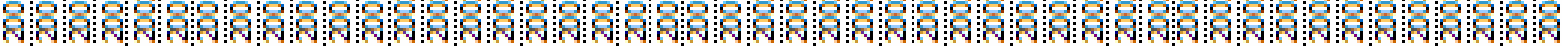




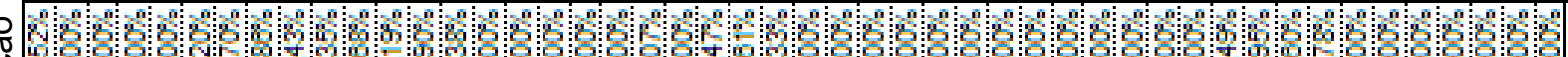
NDobofo

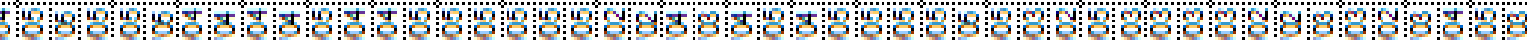
م:

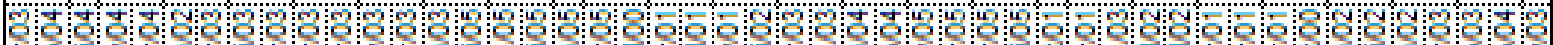

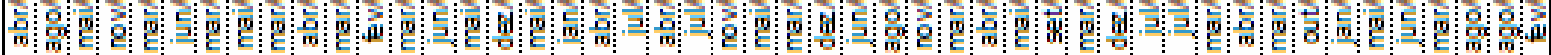

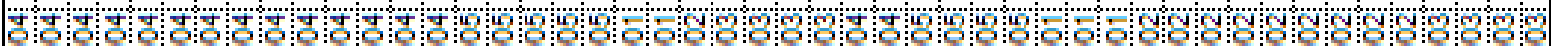

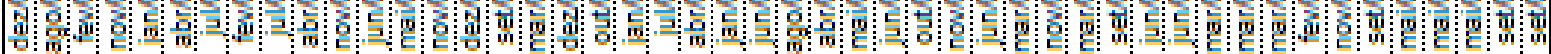

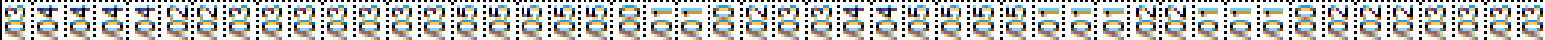
me

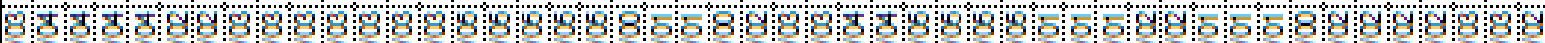

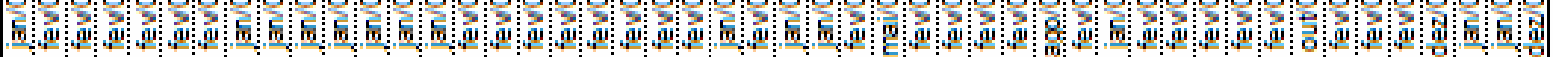

80

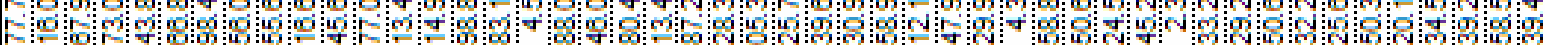

8 No

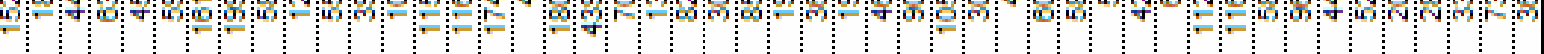

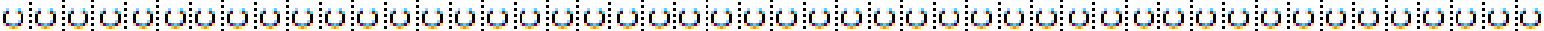

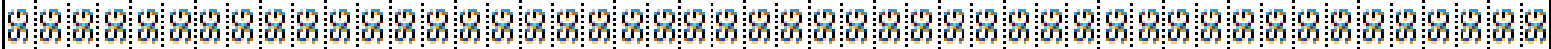

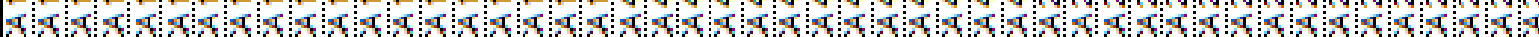

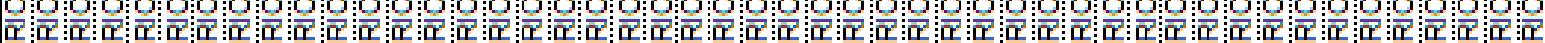

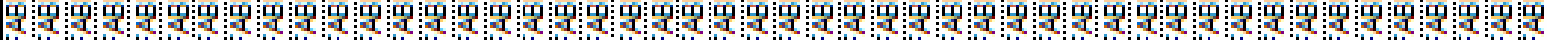

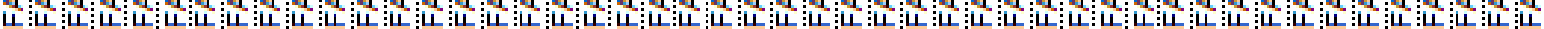
웜

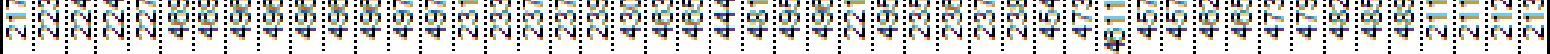

员官

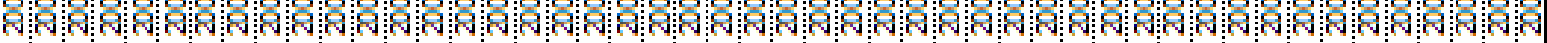


20 W Ob\%

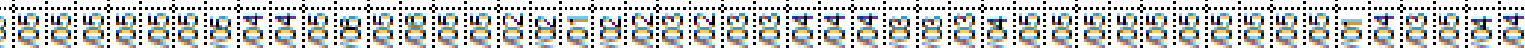

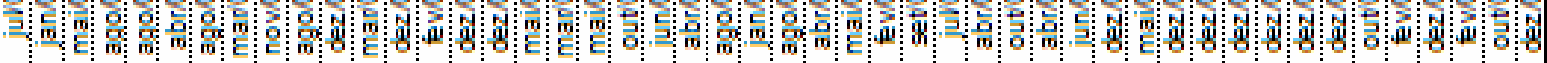

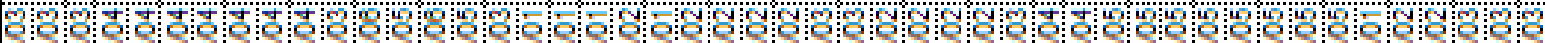
2)

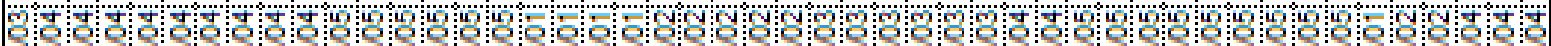

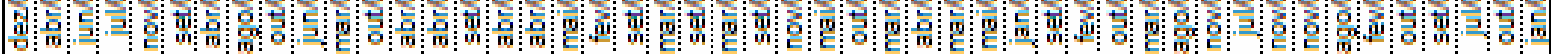

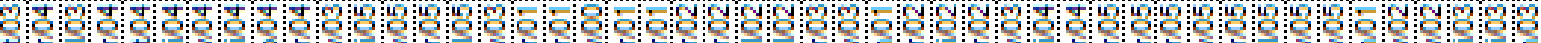
ô:

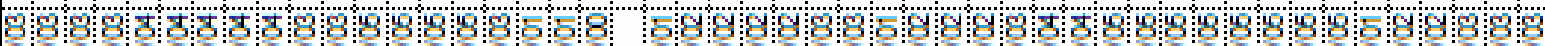

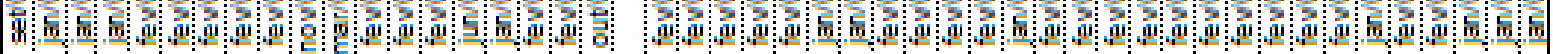

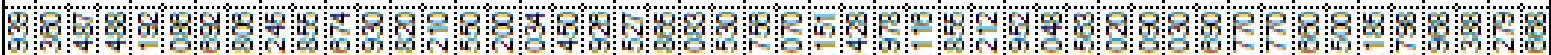

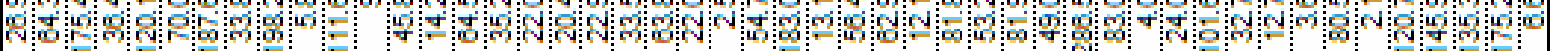

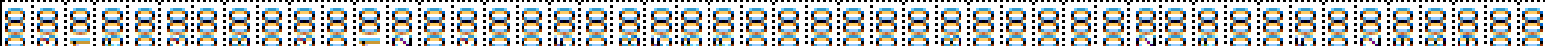
की:

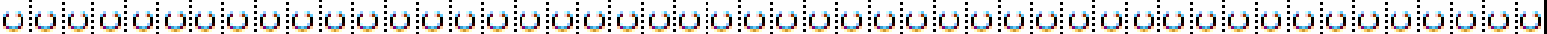

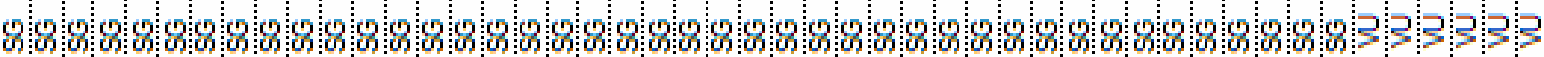

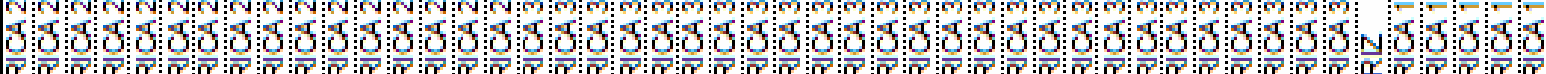

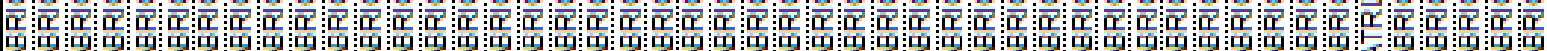

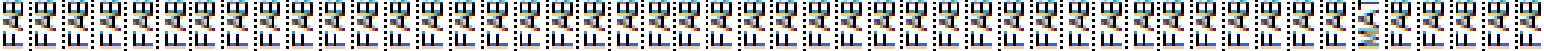

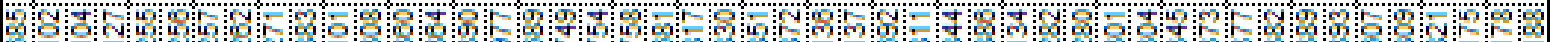

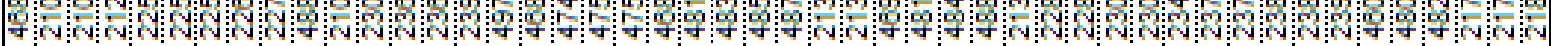

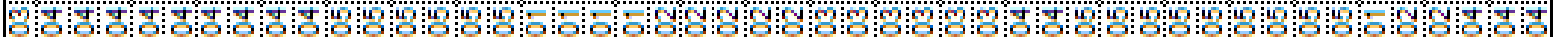

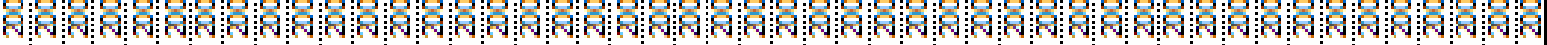




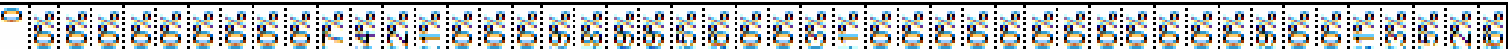

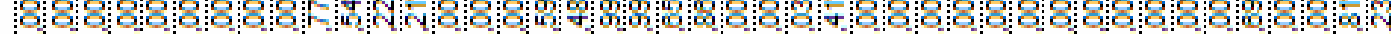

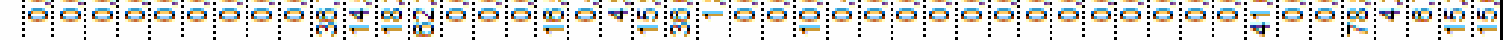

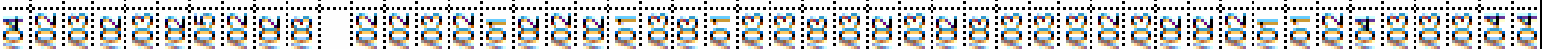

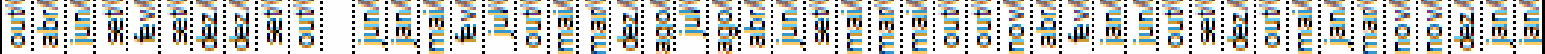

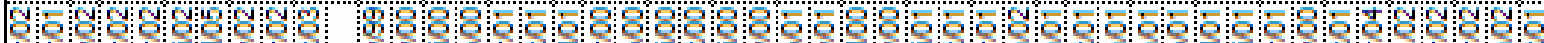

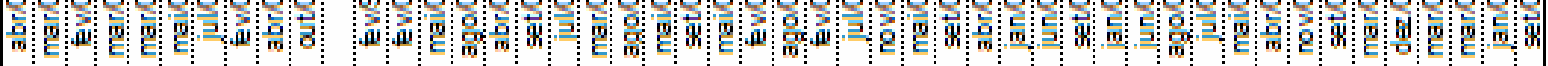

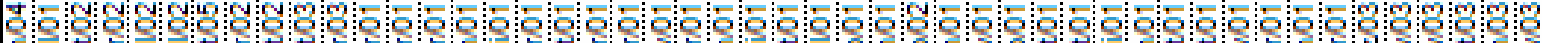

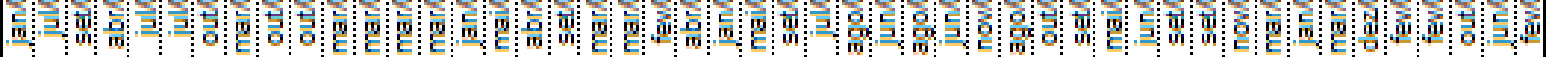

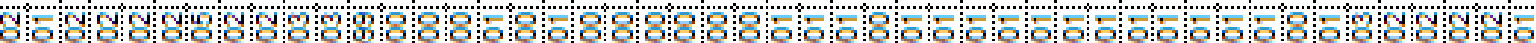

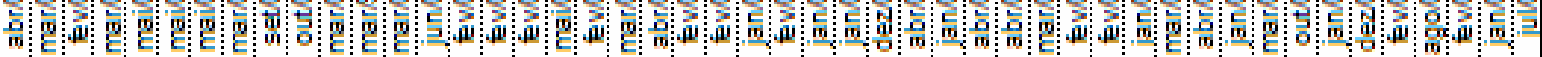

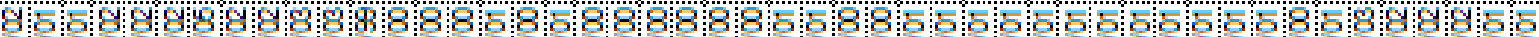
3.

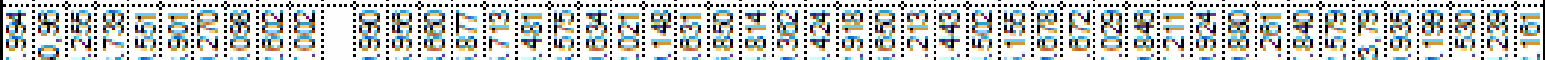
8.

og: \% m

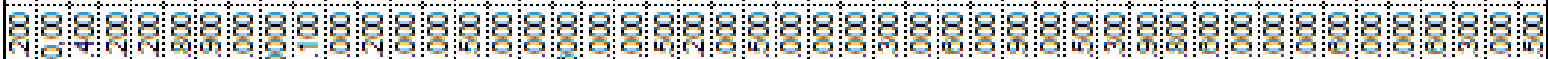

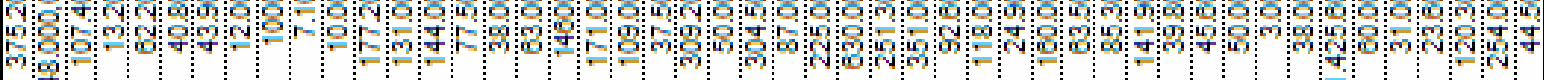
(a)

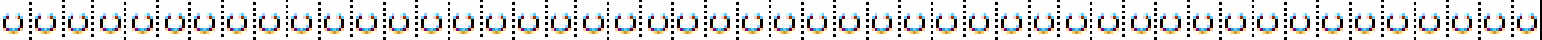

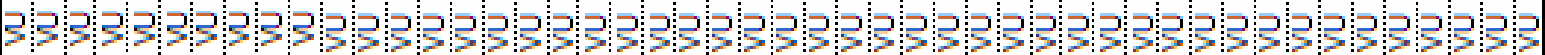

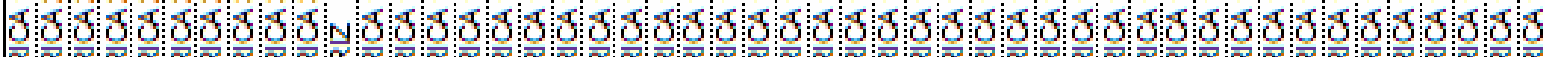

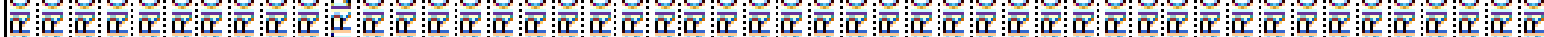

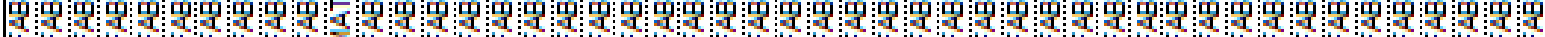

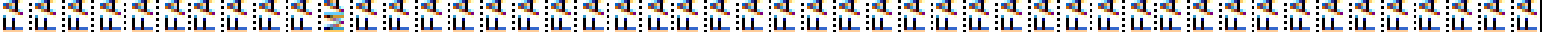

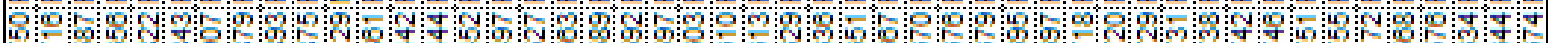
出:

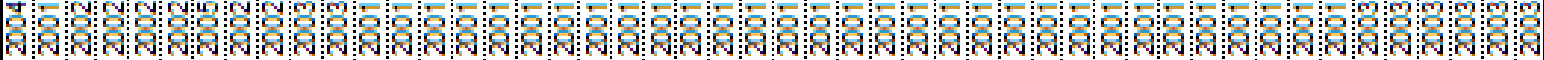




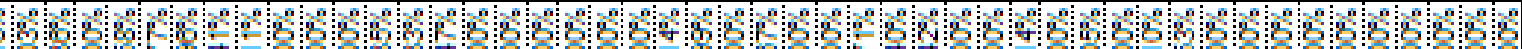

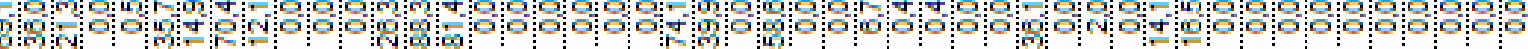

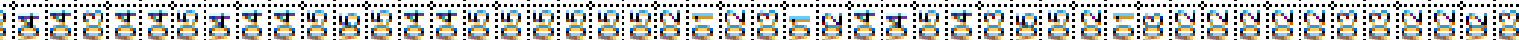
ó

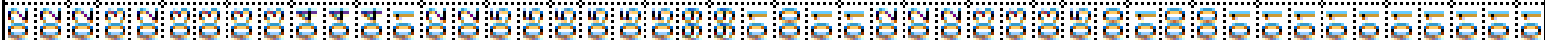

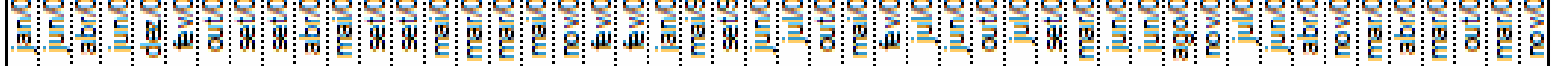

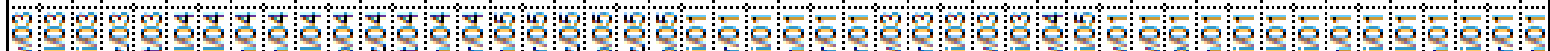

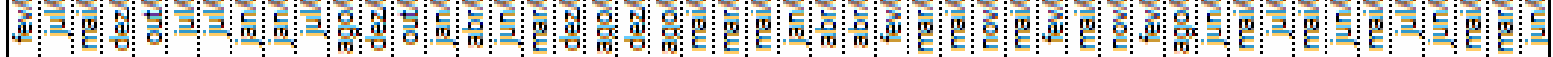

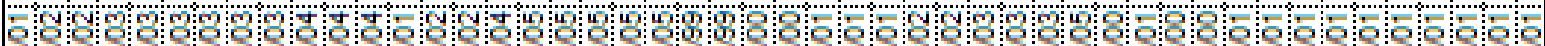

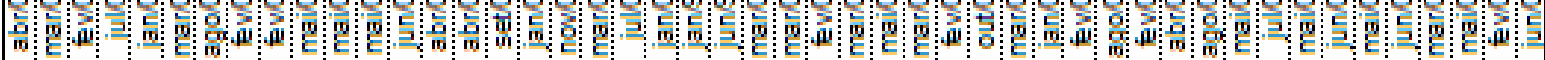

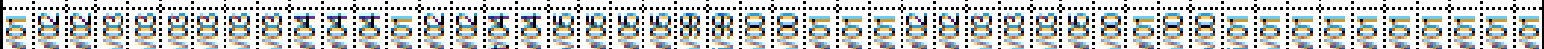
a.d

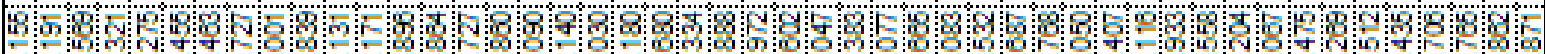
Noptrab

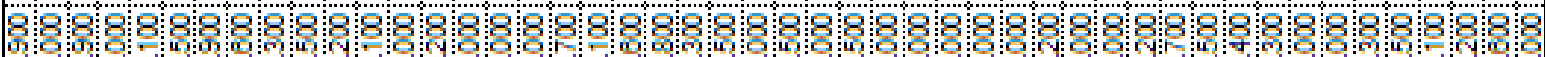

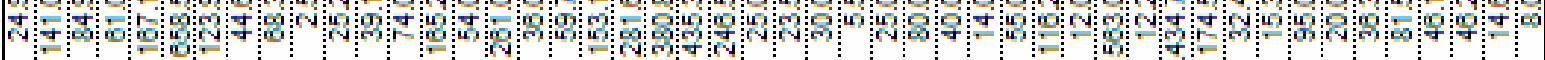

o O O O O O O O O O O O O O O O O O O O O O O O O O O O O O O O O O O O O O O O O O O O O O O

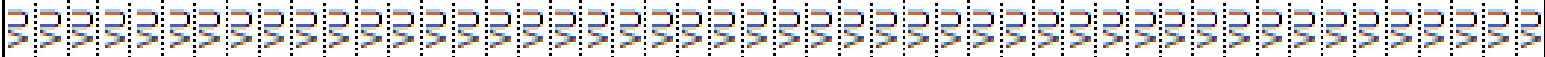

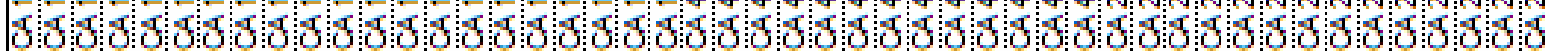

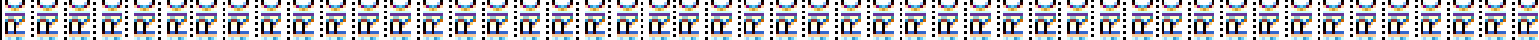

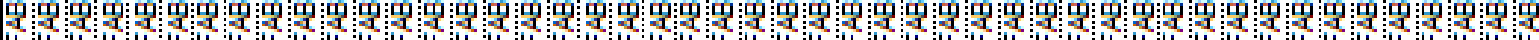

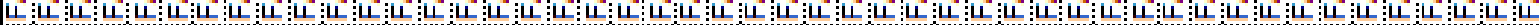

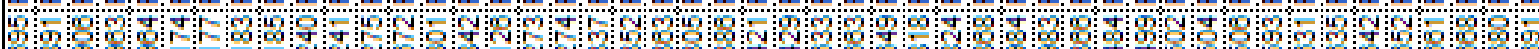

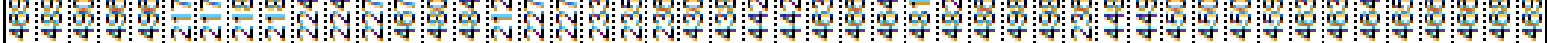

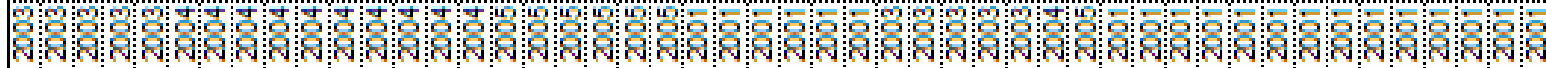


48

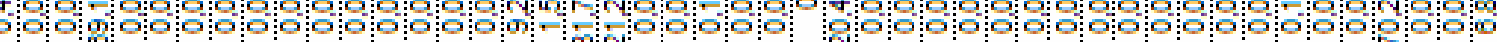

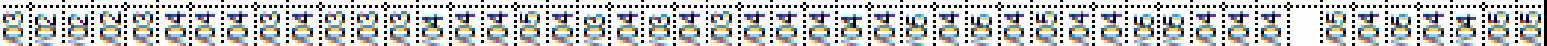
w ow w

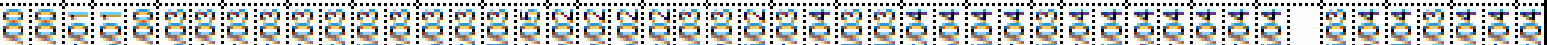

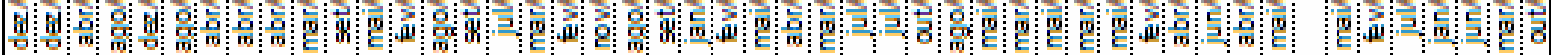

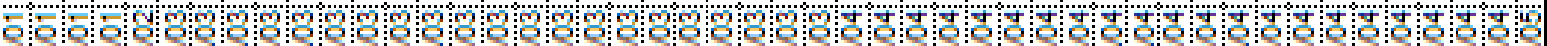

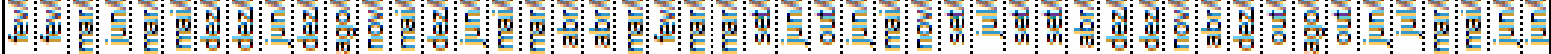

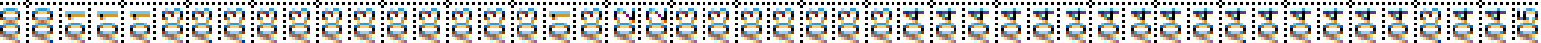

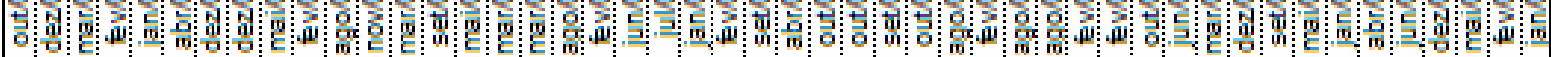

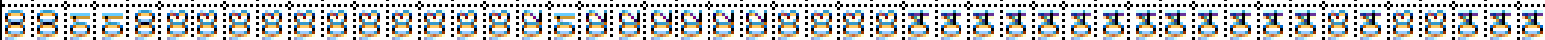

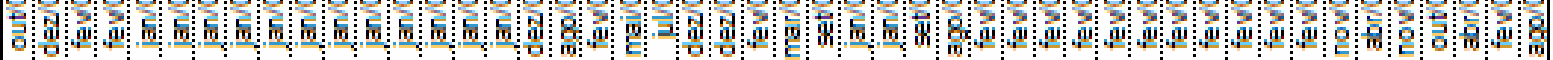

Ro or कr.

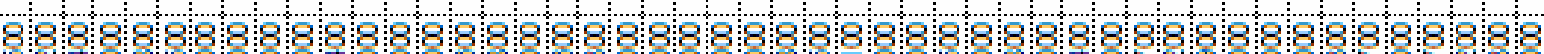
कि

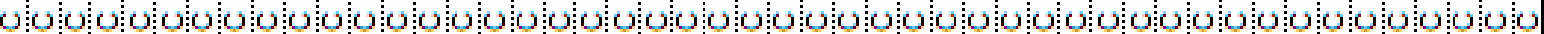

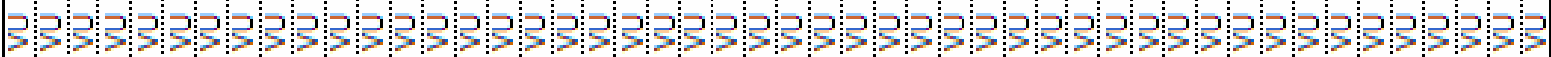

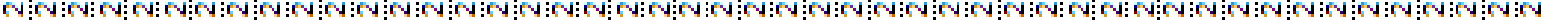

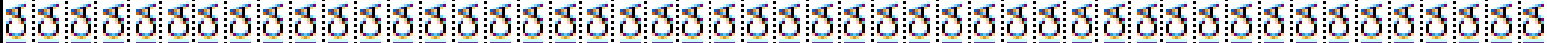

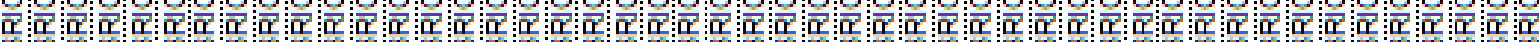

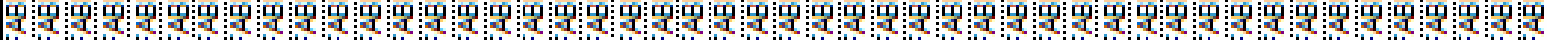
席:

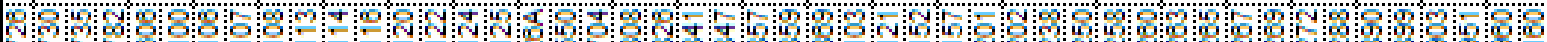

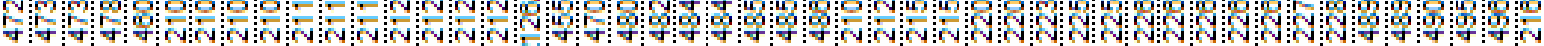




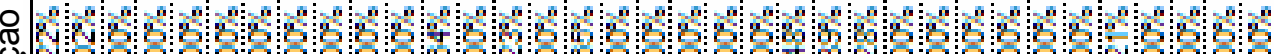
ONic $\frac{\pi}{2} \infty$

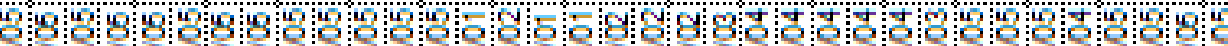

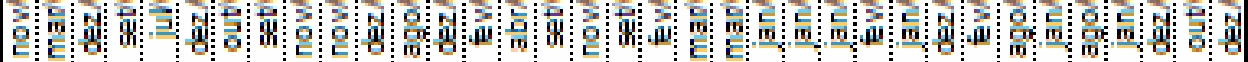

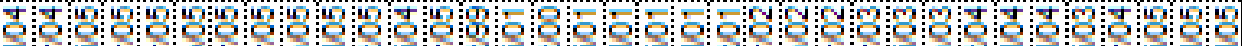

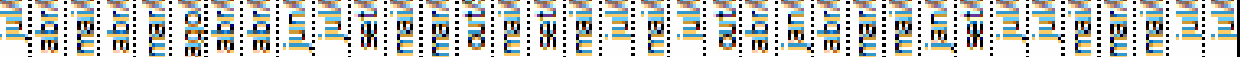

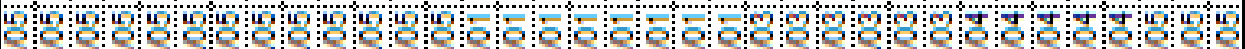

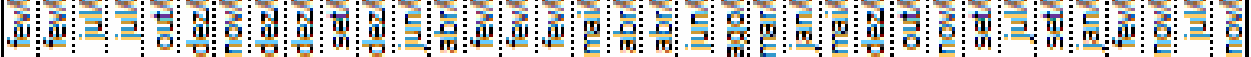

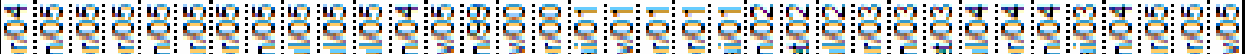

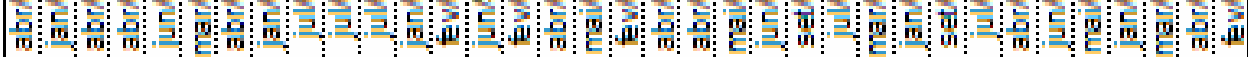

ооб:8:8:8:8:8:8:8:

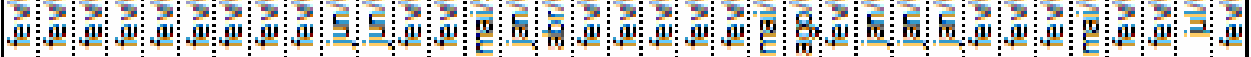

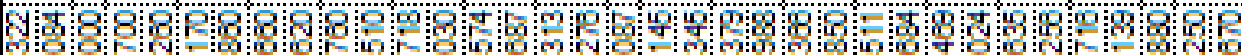
केक के

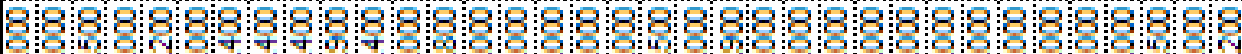
m. क अ

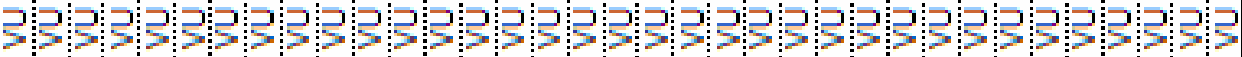

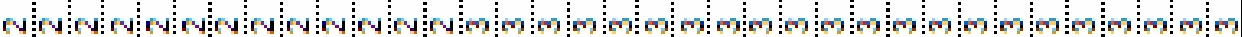
४⿻

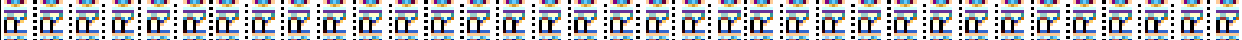

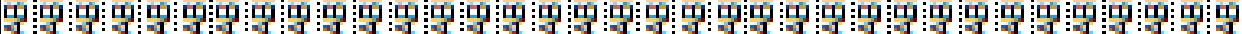

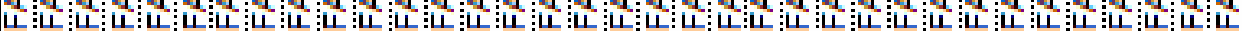

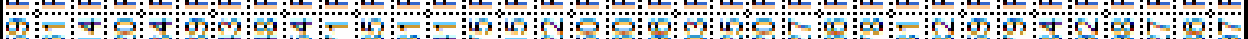

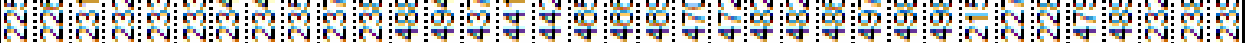

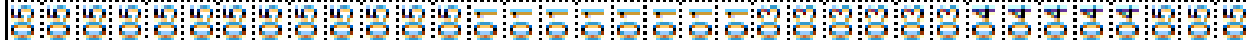

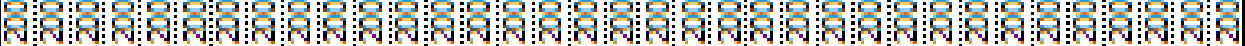


APÊNDICE E- Escala de Valores dos Subcritérios de Projetos de Engenharia

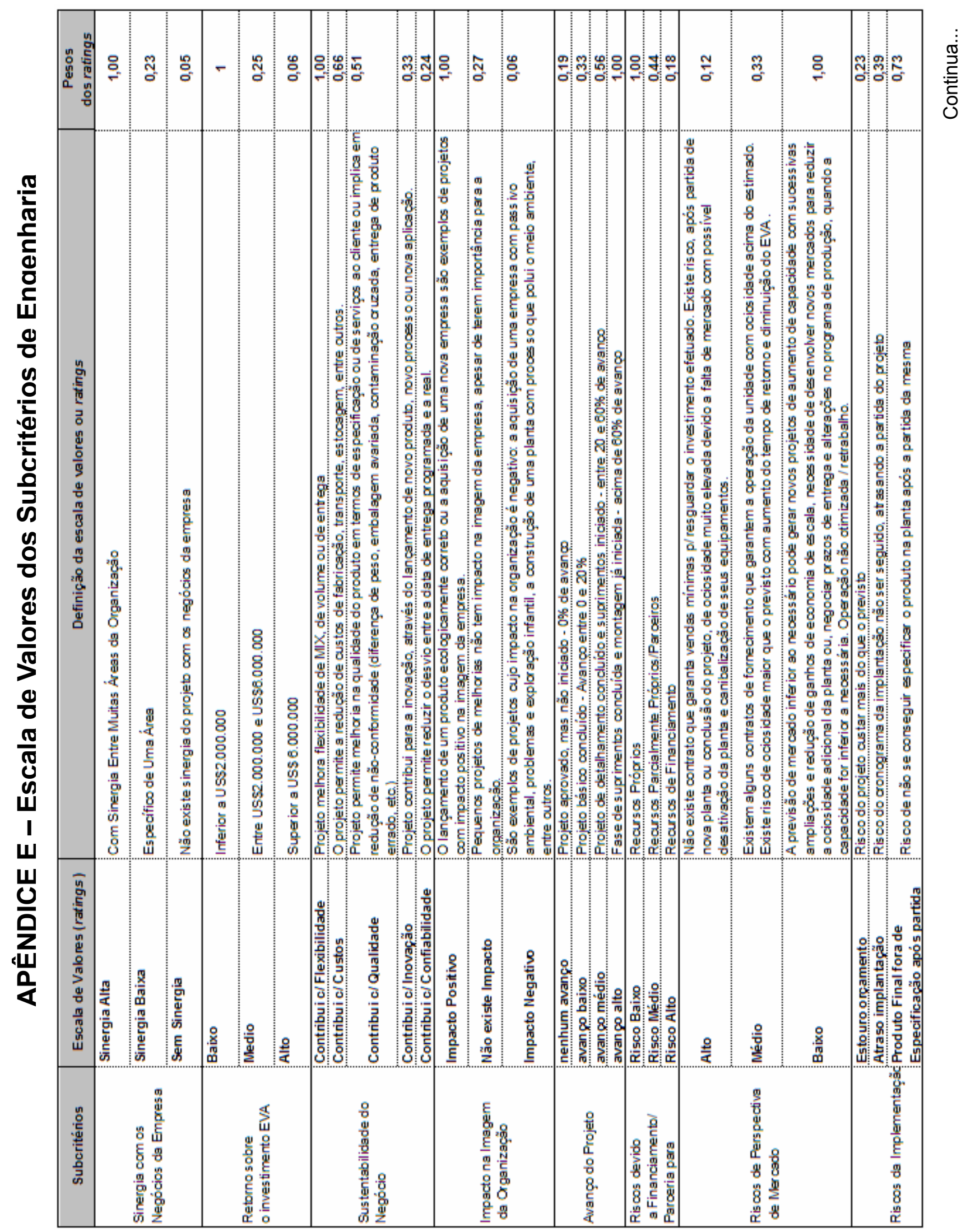




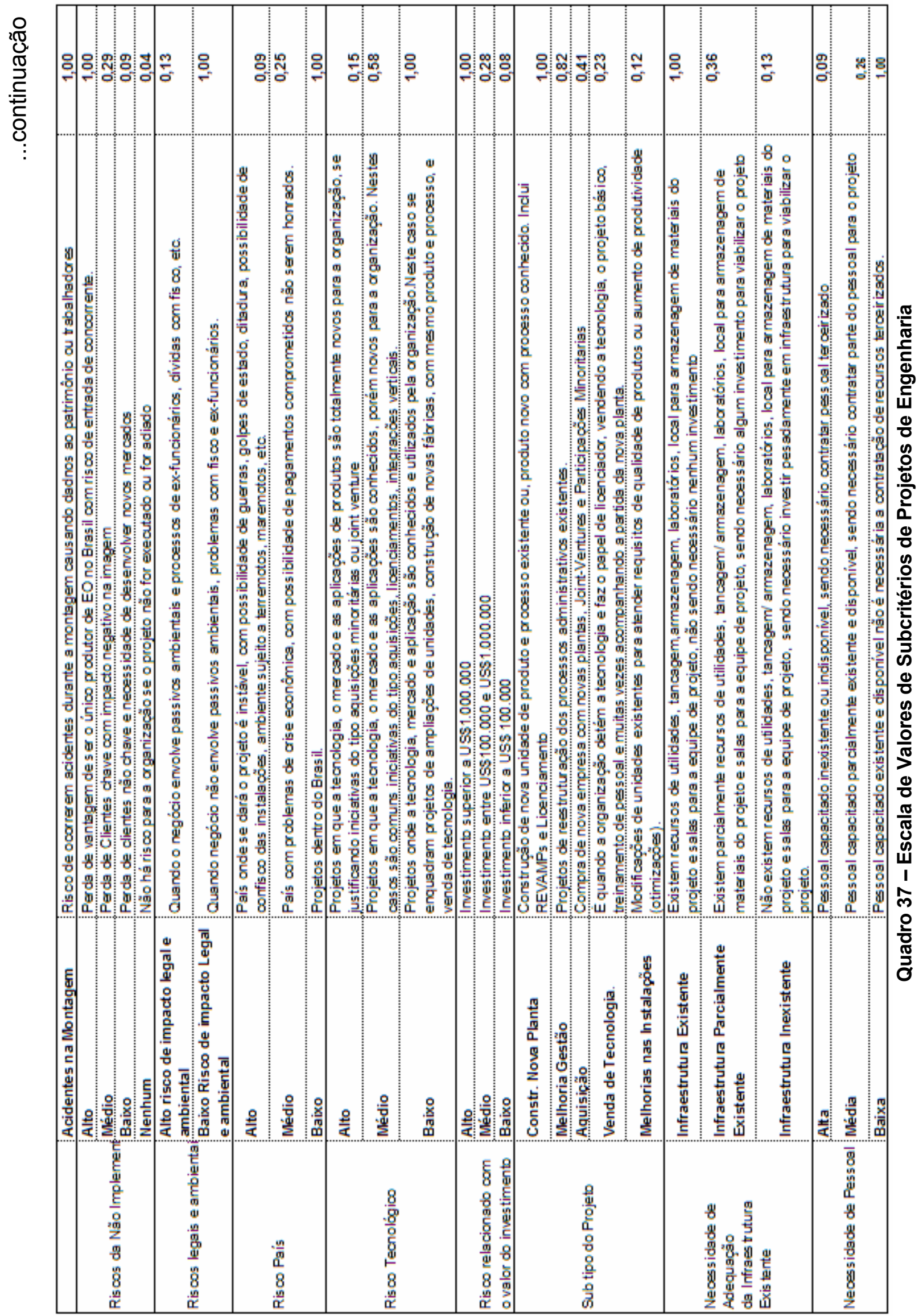


APÊNDICE F - Planilhas de Votação dos Projetos

\begin{tabular}{|c|c|c|c|c|c|c|c|c|c|c|c|c|c|c|c|c|c|c|}
\hline \multirow{3}{*}{ 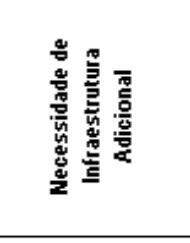 } & $\begin{array}{c}\text { әנиәзs!rau| } \\
\text { ejmunsaejyu| }\end{array}$ & & & & & & & & & & & & & & & & & \\
\hline & 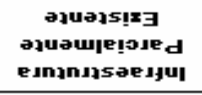 & & $x$ & $x=$ & $x=$ & $x$ & $x$ & $x$ & $x$ & & & & $x$ & $x$ & & & $x$ & \\
\hline & $\begin{array}{c}\text { ajuajs!xy } \\
\text { em\}nנ\}saej,ul }\end{array}$ & & & & & 2 & & & & $x=$ & $x:$ & $x$ & & & $x$ & & & \\
\hline \multirow{3}{*}{ 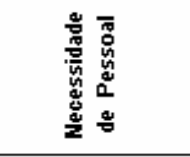 } & 18301 & & & & & & & & & & & & & & & & & \\
\hline & le!ojed & & & & 2 & $x$ & & & & & & & $x$ & $x$ & & $x=$ & $x$ & \\
\hline & unyuan & & $x$ & $x:$ & $x$ & 2 & $x$ & $x$ & $x$ & $x:$ & $\begin{array}{ll}x & \\
\end{array}$ & $x$ & & & $x$ & & & \\
\hline \multirow{3}{*}{ 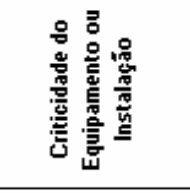 } & 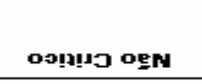 & & & $x$ : & $x$ & & $x$ & $x$ & & $x$ & & & $x$ & & $x{ }^{2}$ & $x \mid x$ & & \\
\hline & בינונוּס & & & & & & & & $x$ & & & $x$ & & & & & $x$ & \\
\hline & 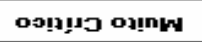 & & $x$ & & 2 & $x=$ & & & & & $x$ & $x$ & & $x$ & & & & \\
\hline \multirow{3}{*}{ 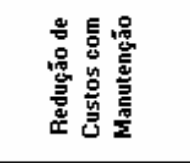 } & ox!eg & & & & $x$ & & $x$ & $x$ & & $x$ & & & $x$ & & $x$ & $x$ & $x$ & \\
\hline & olpow & & $x$ & & & & & & $x$ & & $x=$ & $x$ & & & & & & \\
\hline & Oנום & & & $x$ & 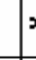 & $x=$ & & & & & & $x$ & & $x$ & & & $x$ & \\
\hline \multirow{2}{*}{ 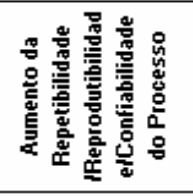 } & ejoedul OEN & & $x$ & & $x$ & & $x$ & $x$ & & $|x|=$ & $x$ & $x$ & & & $x$ & & $x$ & \\
\hline & ejoedul & & & & 2 & $x$ & & & $x$ & & & $x$ & $x$ & $x$ & & $x \mid x$ & $x$ & \\
\hline \multirow{3}{*}{ 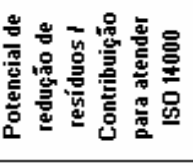 } & ox!eg & & $x$ & & $x=$ & $x=$ & $x$ & $x$ & $x$ & $x:$ & $x=$ & $x$ & $x$ & & $x$, & $x$, & $x$ & \\
\hline & o!pow & & & $x$ & & & & & & & & & & & & & & \\
\hline & Dנצ & & & & & & & & & & & & & & & & & \\
\hline \multirow{3}{*}{ 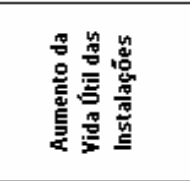 } & oxıeg & & & & $x$ & & $x$ & $x$ & $x$ & $x:$ & $x$ & & $x$ & $x$ & $x=$ & $x$ & $x$ & \\
\hline & o!pow & & & $x$ & ? & $x=$ & & & & & & & & & & & $x$ & \\
\hline & Oנו8 & & $x$ & & & & & & & & & $x$ & & $x$ & & & & \\
\hline \multirow{3}{*}{ 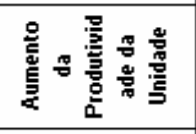 } & oxıeg & & $x$ & $x:$ & $x$ & $x$ & $x$ & $x$ & $x$ & $x:$ & $\begin{array}{ll}x \\
\end{array}$ & $x$ & & $x$ & $x=$ & $x$ & $x$ & \\
\hline & o!paw & & & & & & & & & & & & $x$ & & & & & \\
\hline & oנv & & & & & & & & & & & & & & & $x$ & & \\
\hline \multirow{3}{*}{ 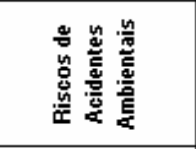 } & 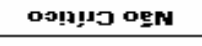 & & & & $x$ & $x$ & $x$ & $x$ & $x$ & $x:$ & $x$ & & & $x$ & $x$ & & $x$ & \\
\hline & כנונופס & & & $x$ & & 2 & c & & & & & $\begin{array}{ll}x & x \\
\end{array}$ & $x$ & & & $x$ & & \\
\hline & 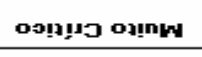 & & $x$ & & & & & & & & & & & & & & & \\
\hline \multirow{4}{*}{ 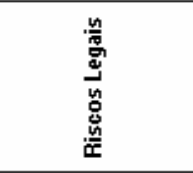 } & unyuar & & & & 3 & $x=$ & $x$ & & & & $x=$ & $x$ & $x$ & $x$ & & $x 2$ & $x$ & \\
\hline & oxieg & & & & $x$ & & & $x$ & $x$ & & & & & & & & & \\
\hline & o!pow & & $x$ & $x$ & & & & & & $x$ & & & & & $x$ & & & \\
\hline & OנY & & & & & & & & & & & & & & & & & \\
\hline \multirow{3}{*}{ 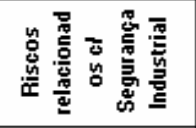 } & 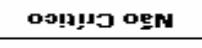 & & & $x$ & & 3 & $x$ & & & & & $x$ & $x$ & & $x=$ & $x$ & $x$ & 5 \\
\hline & ביננופס & & $x$ & & $x$ & & & $x$ & $x$ & $x$ & & & & $x$ & & & $x$ & $\bar{x}$ \\
\hline & & & & & 3 & $x$ & & & & & & $x$ & & & & & & 5 \\
\hline \multirow{3}{*}{ 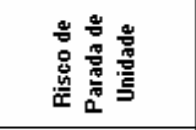 } & 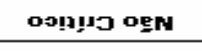 & & & $x:$ & $x=$ & $x$ & $x$ & $x$ & $x$ & $x$ & & $x$ & $x$ & & $x=$ & & \begin{tabular}{l|l}
$x$ & $x$ \\
\end{tabular} & 5 \\
\hline & כינונוּס & & & & & & & & & & & $x$ & & & & & & 至 \\
\hline & 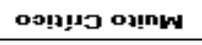 & & $x$ & & & 2 & & & & & & $x$ & & $x$ & & & & 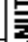 \\
\hline \multirow{2}{*}{ 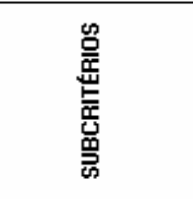 } & \multirow{2}{*}{ 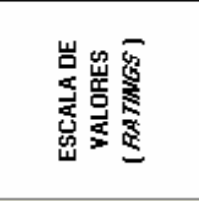 } & 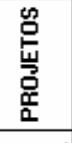 & సี & ڤึ) & సี้ & ละ & y & & స్ల్ & 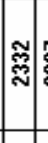 & ঋొm & & 3ิ & 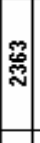 & 오ํ & & 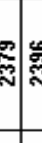 & 崖 \\
\hline & & 岁 & & & & & & & & & & & & & & 8 & $=$ & \\
\hline
\end{tabular}

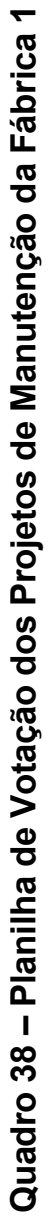




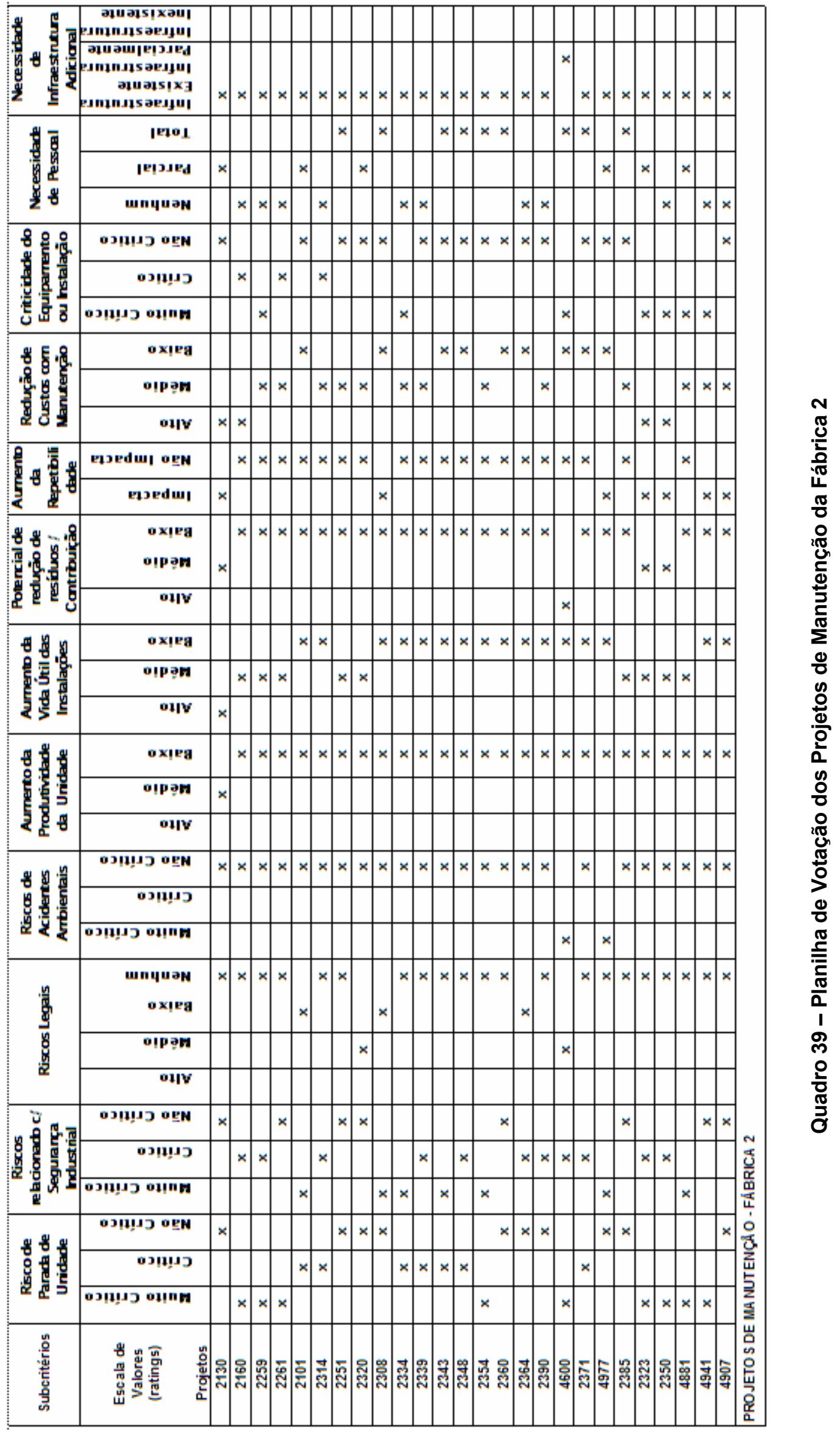




\begin{tabular}{|c|c|c|c|c|c|c|c|c|c|c|c|c|c|c|c|}
\hline \multirow{3}{*}{ 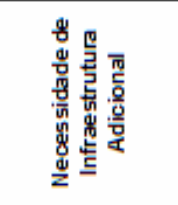 } & 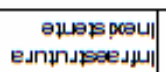 & & & & & & & & & & & & & & \\
\hline & 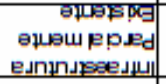 & & & & & & & & & & & & & & \\
\hline & 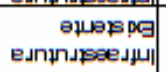 & $x$ & & $\times$ & & & $\times \times$ & & $\times$, & $x$ & & $\times$ & & $\times \times$ & $x$ \\
\hline \multirow{3}{*}{ 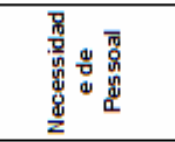 } & E101 & & & & & & & & & & & & & & \\
\hline & eped & & & & & & & & & & & & & & \\
\hline & แnLIப9N & $x$ & $\times$ & $\times$, & 4 & 4 & $\times x$ & $x$ & $\times$ & $x$ & $x$ & $x$ & $x$ & $\times \times$ & $x$ \\
\hline \multirow{3}{*}{ 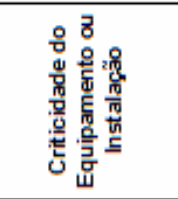 } & $\infty ! ! !\lrcorner \supset$ ๔eN & & $\times$ & x & $x$ & & & & $\times$ & & $\times$ & & & & \\
\hline & $\infty$ & & & $\times$ & & & $x$ & $x$ & 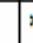 & $x$ & & $x$ & & & \\
\hline & $\infty$ & $x$ & & & & & $x$ & & & & & & $\times$ & $\times \times$ & $x$ \\
\hline \multirow{3}{*}{ 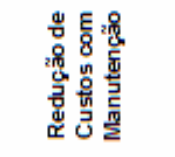 } & $\alpha x \in$ & & $\times$, & $\times$ & 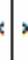 & 4 & & & $\times$ & & $x$ & & & & \\
\hline & o!psw & & & & & & & & & & & & & $x$ & \\
\hline & ofw & $x$ & & & & & $x \times$ & $x$ & ; & $x$ & & $x$ & $x$ & $x$ & $x$ \\
\hline \multirow{2}{*}{ 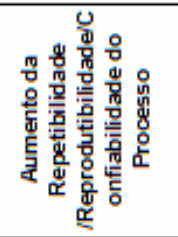 } & epedw/ cen & & $\times$, & $\times$ & 4 & 4 & $x$ & & $\times$ & & $\times$ & & & & \\
\hline & epedwi & $x$ & & & & & $\times$ & $\times$ & x & $x$ & & $\times$ & $\times$ & $\times \times$ & $x$ \\
\hline \multirow{4}{*}{ 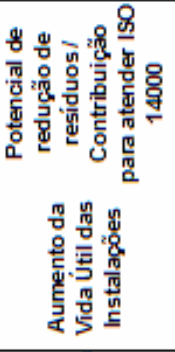 } & oxpg & $x$ & & $\times x$ & & & $\times \times$ & $\times$ & $\times x$ & $x$ & $x$ & $x$ & $x$ & $\begin{array}{r}x \\
\times\end{array}$ & $x$ \\
\hline & & & & x & 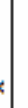 & & & & & & & & & & \\
\hline & o!psw & & $\times$, & $\times$ & , & 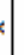 & & & $\times$ & & & & & & \\
\hline & Ot/ & $x$ & & & & & $\times \times$ & $x$ & 12 & $x$ & $x$ & $x$ & $x$ & $\times x$ & $x$ \\
\hline \multirow{3}{*}{ 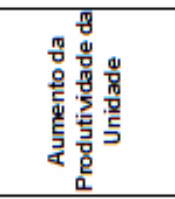 } & oxpeg & & $\times$ & $x$ & $x$ & & $x$ & & $\times$ & & & & & $\times \times$ & \\
\hline & o!psw & $\times$ & & $\times$ & & & $\times$ & $\times$ & , & $x$ & $\times$ & $\times$ & & & \\
\hline & otw & & & & & & & & & & & & $x$ & & $x$ \\
\hline \multirow{3}{*}{ 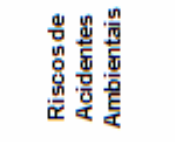 } & 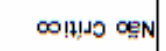 & $x$ & & $\times$ & & & $x \times$ & $\times$ & & $\times$ & $x$ & $\times$ & $\times$ & & \\
\hline & $\infty$ & & & & & & & & $\times$ & & & & & $\times \times$ & $x$ \\
\hline & 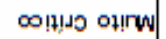 & & & & & & & & & & & & & & \\
\hline \multirow{4}{*}{ 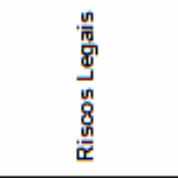 } & யாட|บ९N & & & & & & $x$ & & & & $x$ & & $x$ & & \\
\hline & oxpeg & & $x$, & $\times$ & $\times$ & & & $\times$ & $\times$ & $x$ & $x$ & $x$ & & & $x$ \\
\hline & o!paw & & & & & & & & 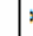 & & & & & $x$ & \\
\hline & orw & $x$ & & & & & $x$ & & & & & & & $x$ & \\
\hline \multirow{3}{*}{ 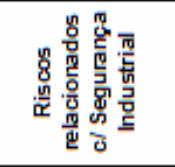 } & 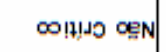 & & $\times$ & , & 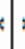 & & $x$ & $\times$ & & & $x$ & & $x$ & & \\
\hline & $\infty$ & & & $\times$ & & & & & $\times$ & $x$ & $\times$ & $\times$ & & $x$ & \\
\hline & $\infty$ & $x$ & & & & & $x$ & & & & & & & $\times$ & $x$ \\
\hline \multirow{2}{*}{ 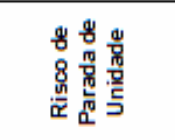 } & 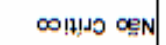 & & $\times$, & $\times \times$ & 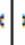 & & $x$ & & $\times$ & & $x$ & & $\times$ & $x$ & \\
\hline & 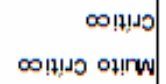 & $x$ & & & & & $\times$ & $x$ & $\left.\right|^{3}$ & $x$ & & $x$ & & $x$ & $x$ \\
\hline 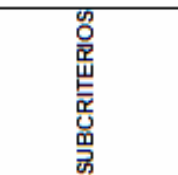 & 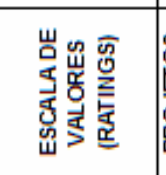 & บิ & & กูก & & & ले & & & s. & & & & 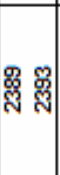 & \\
\hline
\end{tabular}

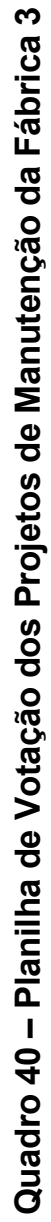




\begin{tabular}{|c|c|c|c|c|c|c|c|c|}
\hline \multirow{3}{*}{ 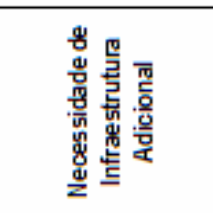 } & 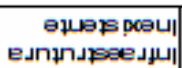 & & & & & & & \\
\hline & 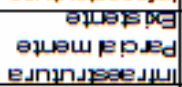 & & $\times x$ & $x$ & $\times$ & & & \\
\hline & 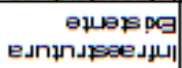 & & & & & $\times$ & $\times \times$ & \\
\hline \multirow{3}{*}{ 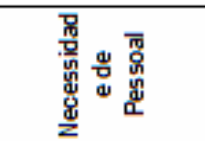 } & epol & & & & & & $x$ & \\
\hline & pped & & & & & & $x$ & \\
\hline & யnLIபפN & & $\times x$ & $x$ & $x$ & $x$ & & \\
\hline \multirow{3}{*}{ 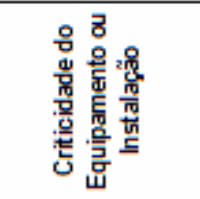 } & $\infty ! ! !\lrcorner \supset$ ๔en & & $\times \times$ & & $x$ & $\times$ & $\times x$ & \\
\hline & $\infty$ ) & & & $x$ & & & & \\
\hline & $\infty$ o & & & & & & & \\
\hline \multirow{3}{*}{ 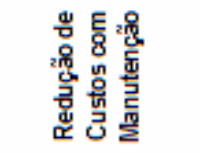 } & oxpeg & & $\times \times$ & & & $\times$ & $\times x$ & \\
\hline & o!pew & & & & $x$ & & & \\
\hline & otro & & & $x$ & & & & \\
\hline \multirow{2}{*}{ 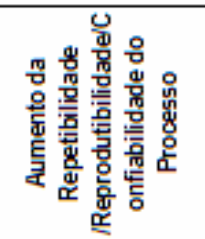 } & epedul oen & & $\times \times$ & $x$ & & $\times$ & $\times x$ & \\
\hline & epedul & & & & $\times$ & & & \\
\hline \multirow{4}{*}{ 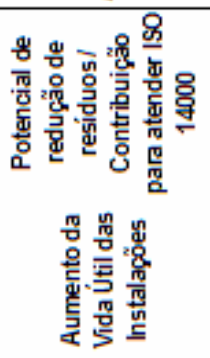 } & $\begin{array}{l}\text { oxpeg } \\
\text { o!pew }\end{array}$ & & $\times \times$ & $x$ & $\times$ & $\times$ & $\times x$ & \\
\hline & $\begin{array}{c}\text { ofrty } \\
\text { oxpeg }\end{array}$ & & $\times$ & & $\times$ & $\times$ & $\times x$ & \\
\hline & o!pew & & $x$ & $x$ & & & & \\
\hline & ofror & & & & & & & \\
\hline \multirow{3}{*}{ 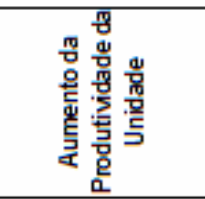 } & oxpeg & & $\times x$ & $\times$ & $\times$ & $\times$ & $\times \times$ & \\
\hline & o!pew & & & & & & & \\
\hline & Otry & & & & & & & \\
\hline \multirow{3}{*}{ 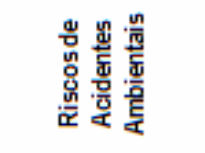 } & $\infty !$ & & $\times$ & $\times$ & & $\times$ & $\times x$ & \\
\hline & $\infty$ & & $x$ & & & & & \\
\hline & $\infty$ o!!ा & & & & $\times$ & & & \\
\hline \multirow{4}{*}{ 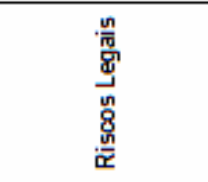 } & யnLILפN & & $x$ & $x$ & $x$ & & & \\
\hline & oxpeg & & & & & $x$ & & \\
\hline & o!pew & & $x$ & & & & $\times x$ & \\
\hline & ofly & & & & & & & \\
\hline \multirow{3}{*}{ 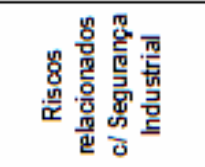 } & 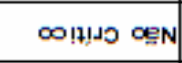 & & & & & & $x$ & 戞 \\
\hline & $\infty$ ڤ! & & $x$ & & & & & 兽 \\
\hline & $\infty !$ & & & $x$ & $x$ & $x$ & $\times$ & 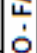 \\
\hline \multirow{2}{*}{ 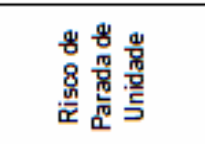 } & $\infty !$ & & $\times \times$ & & & $x$ & $\times x$ & us \\
\hline & 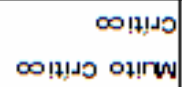 & & & $x$ & $x$ & & & 宸 \\
\hline $\begin{array}{l}\text { क } \\
\text { 趉 } \\
\text { 点 } \\
\text { 号 } \\
\text { 岇 }\end{array}$ & 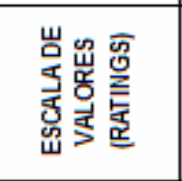 & 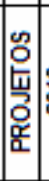 & న్ న్స & 怘 & స్লু & & 芯 & 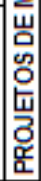 \\
\hline
\end{tabular}




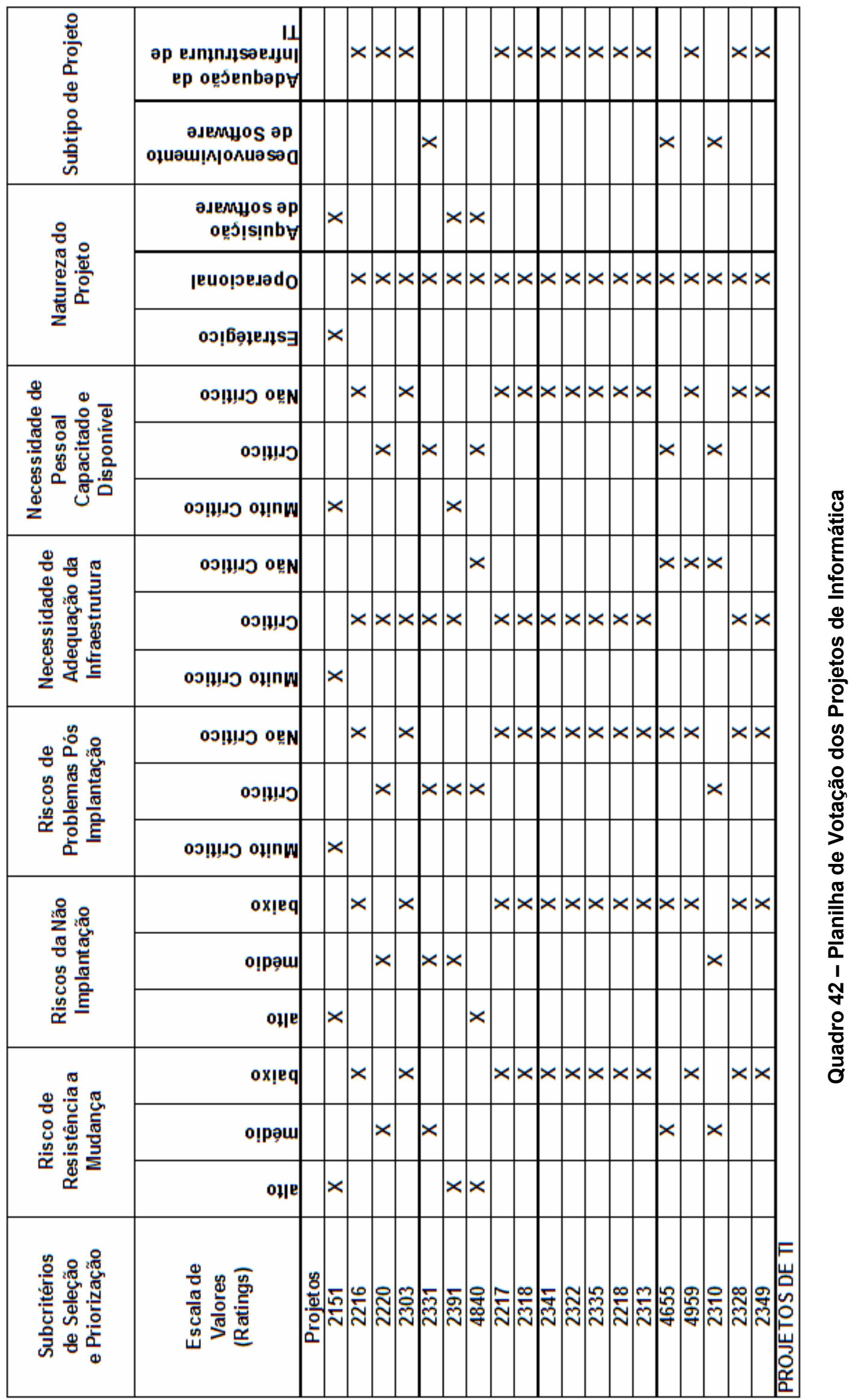




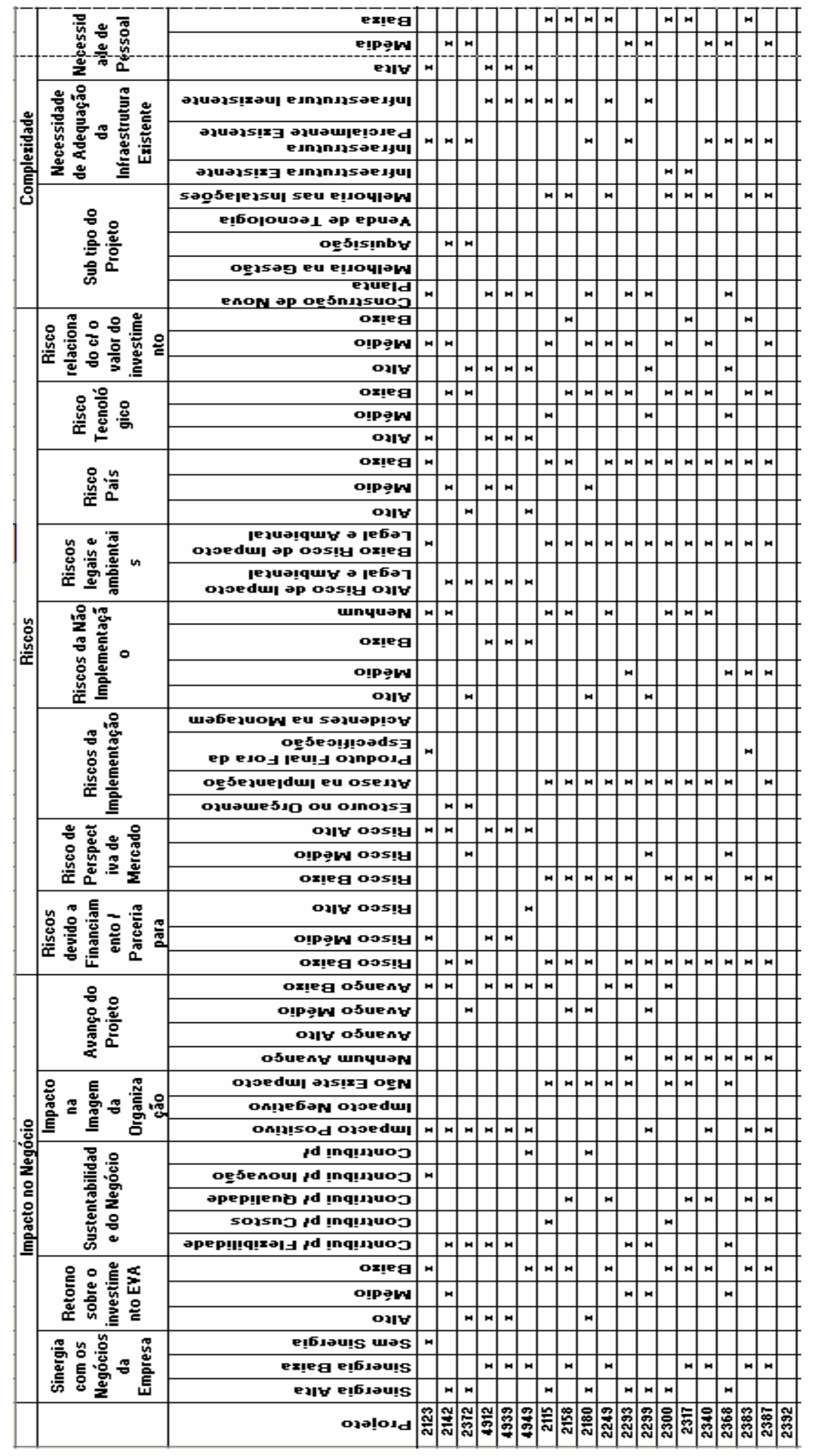




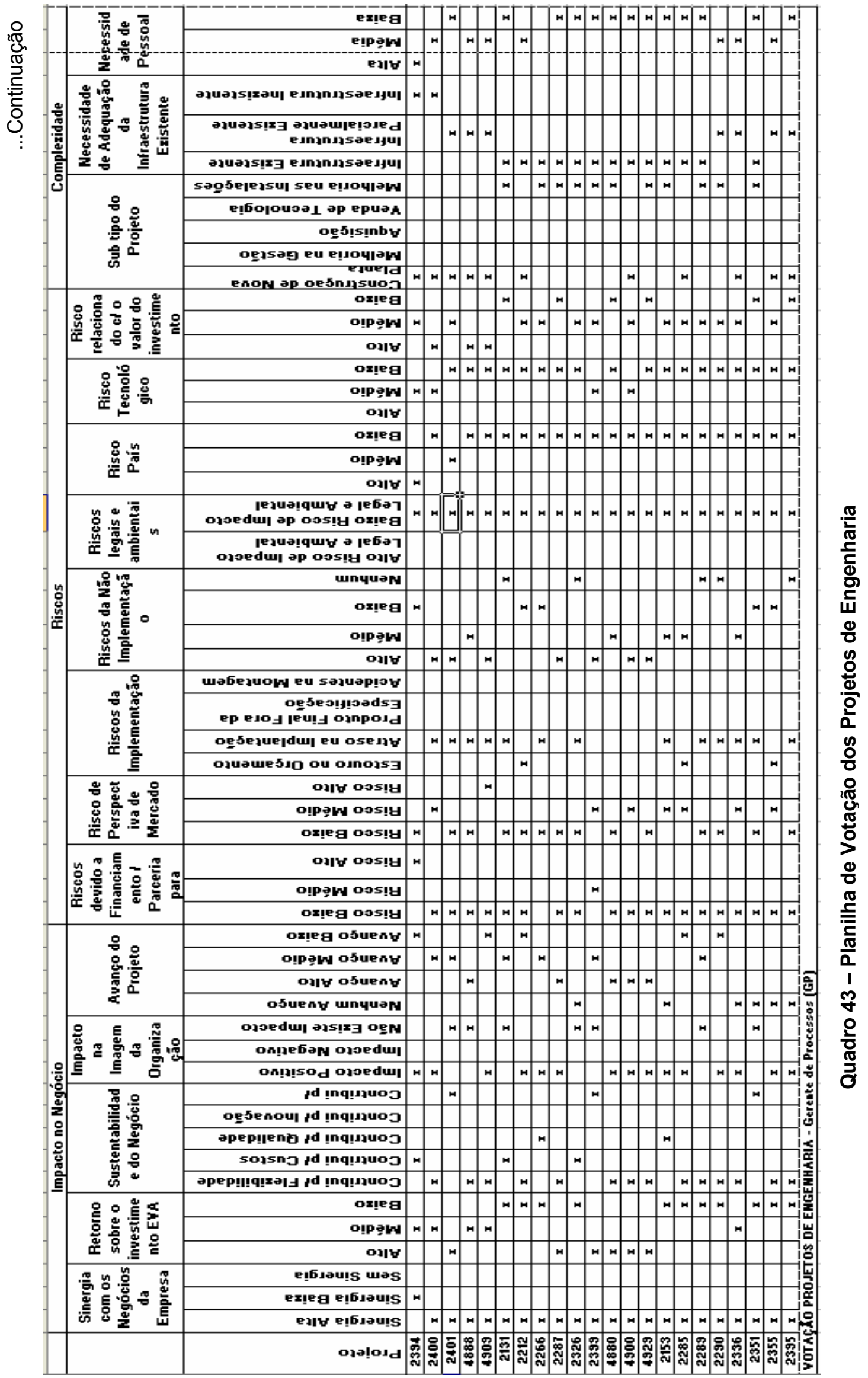




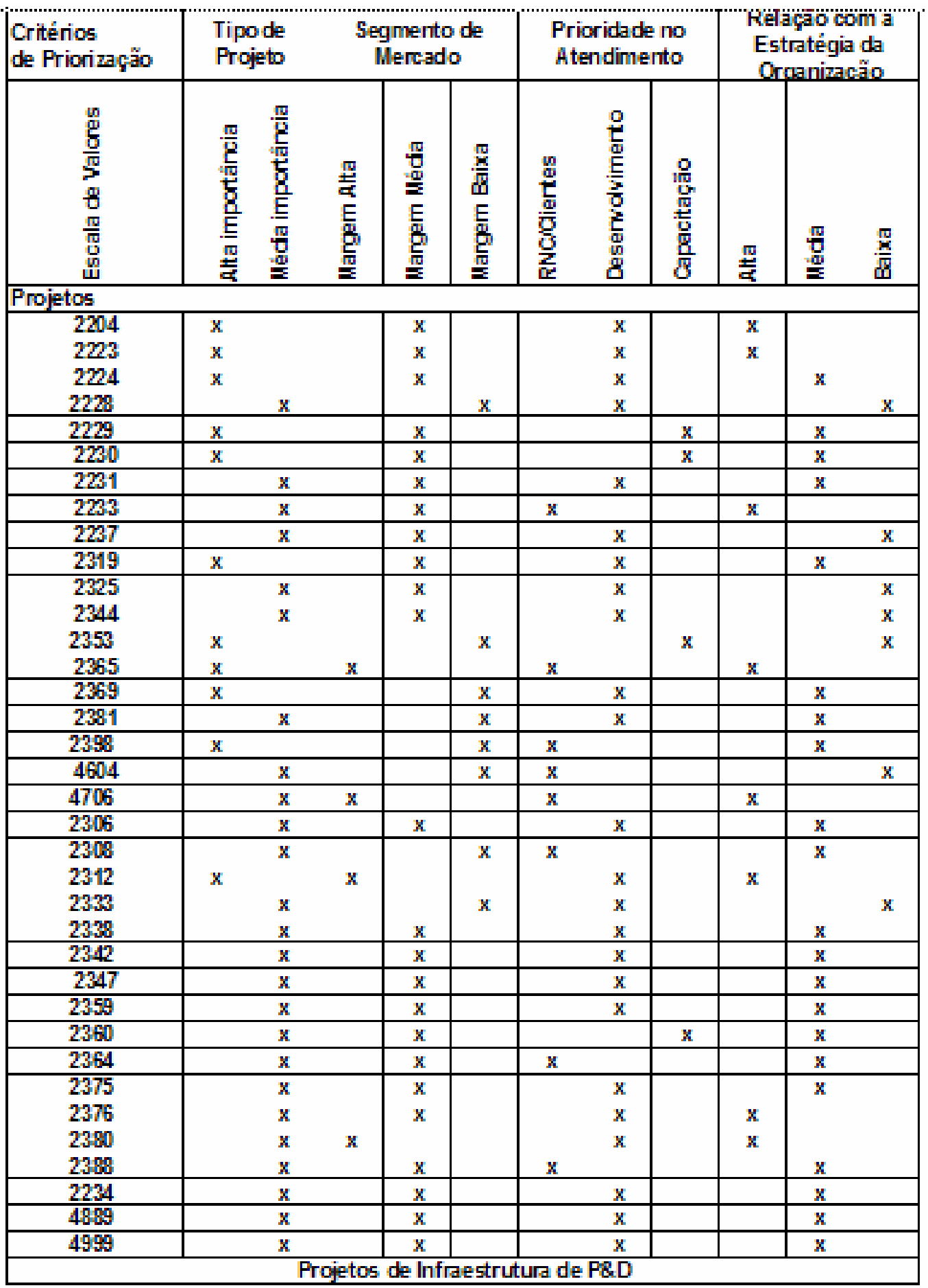

Quadro 44 - Planilha de Votação dos Projetos de Infra-estrutura de P\&D 
ANEXO A - Histórico de Projetos de 2001 a 2005 por site

Nesta seção são apresentados os dados dos projetos com investimento aprovado, utilizados neste projeto de pesquisa. As tabelas de 9 a 14 mostram os dados dos projetos para os anos de 2001 a 2005, ordenados por site. 


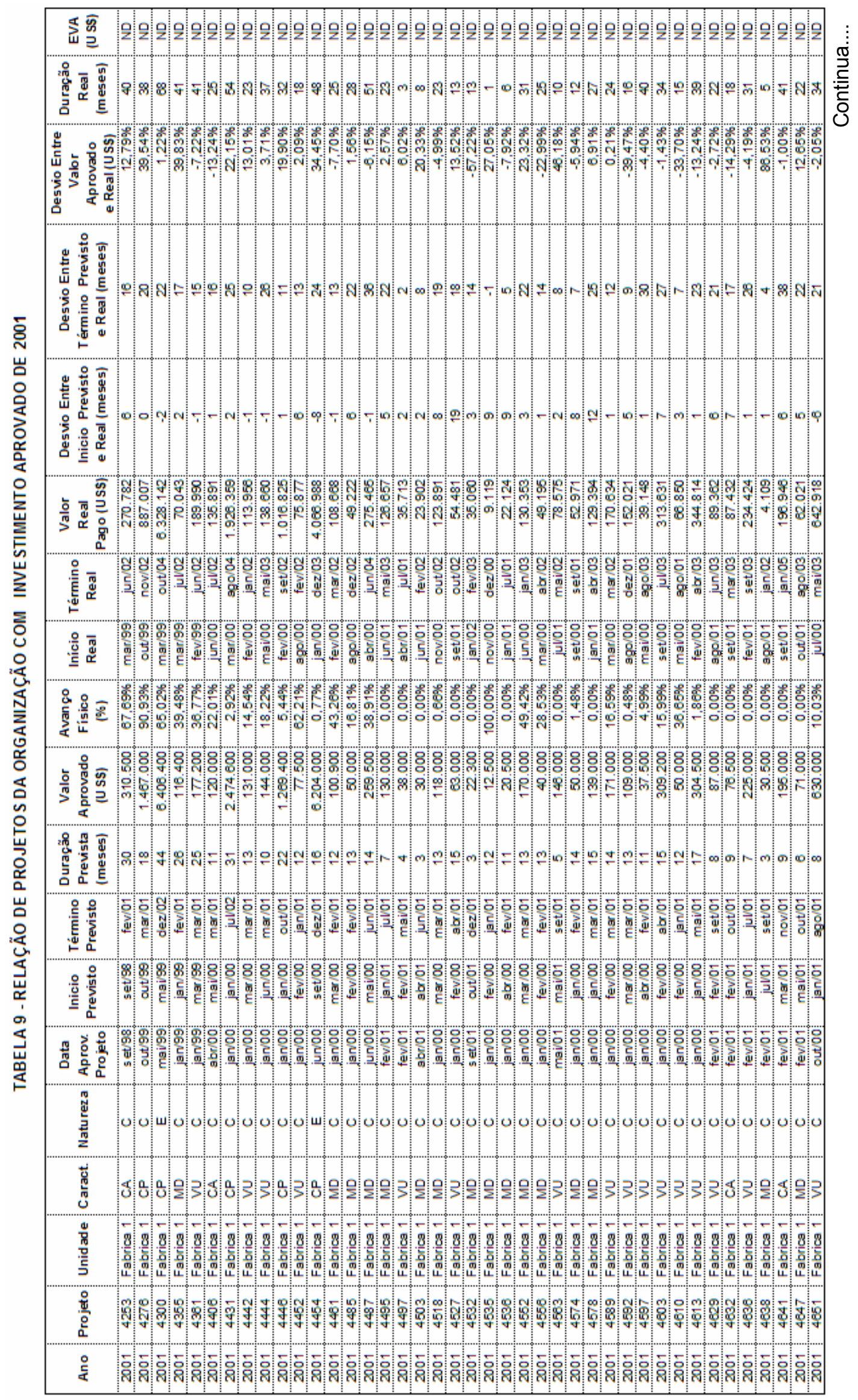




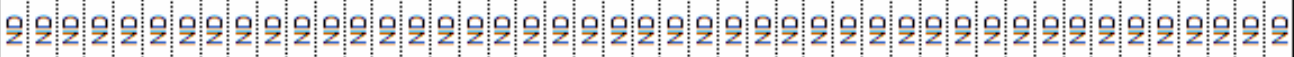

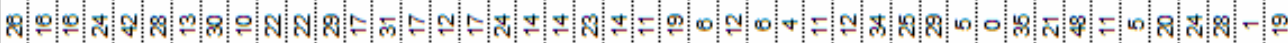

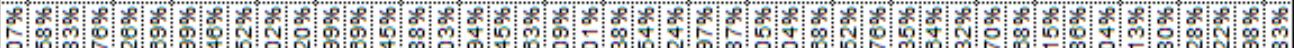

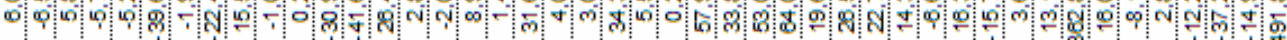

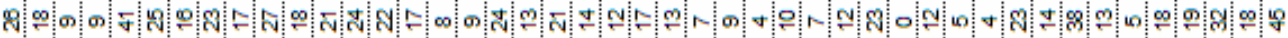

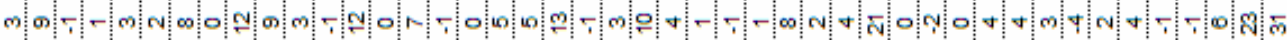

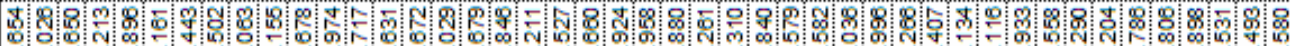
कुल

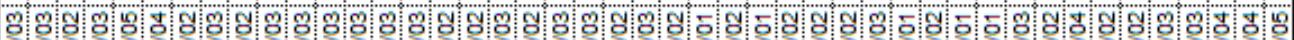

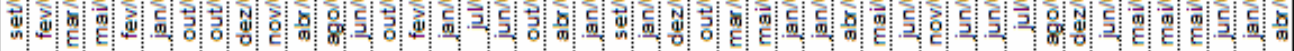

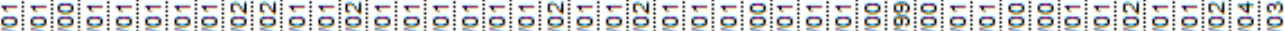

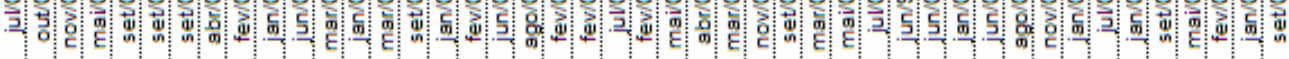

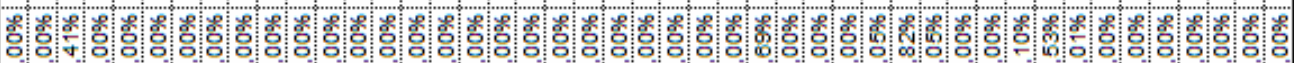

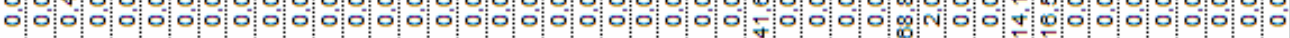

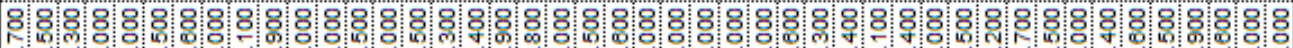

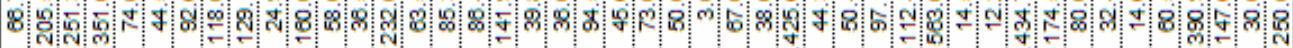

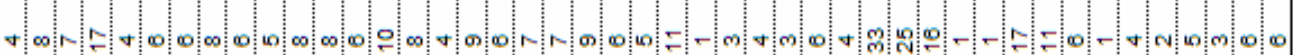

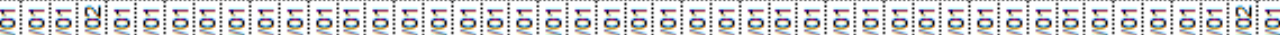

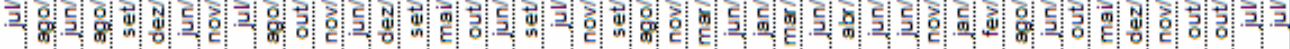

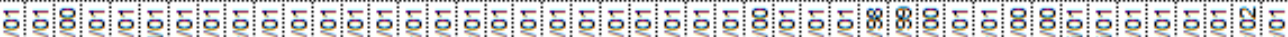

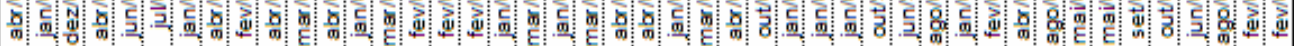

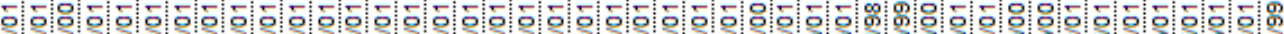
ب.

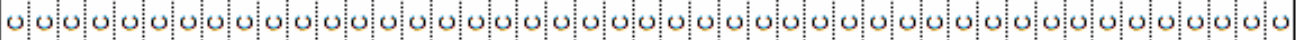

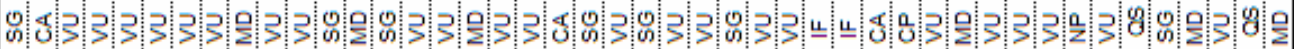
-

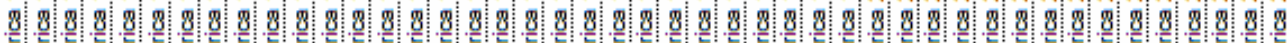

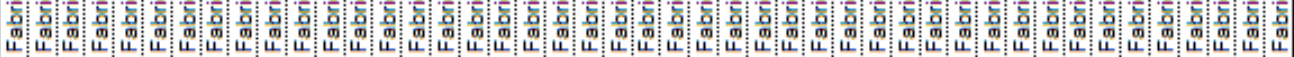

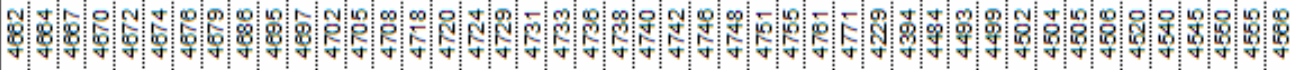

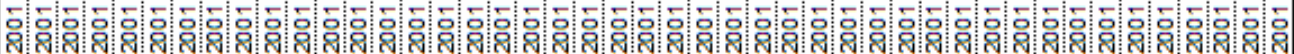


ب0

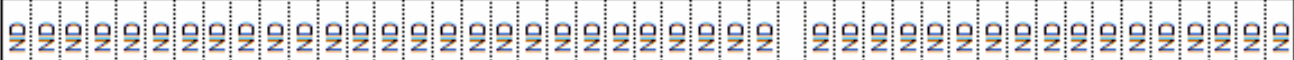

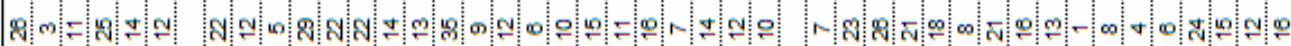

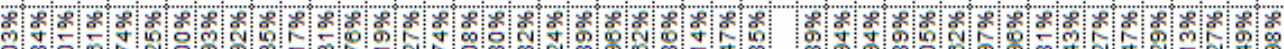

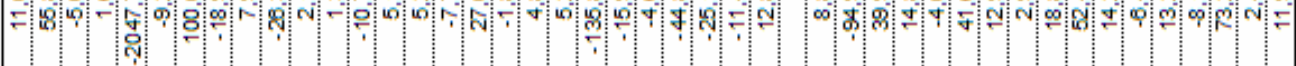

(1)

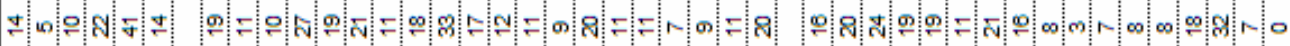

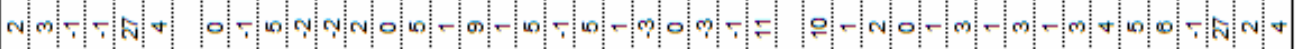

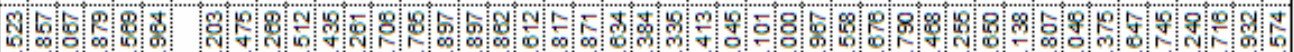

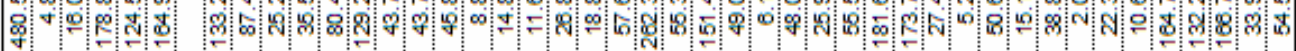

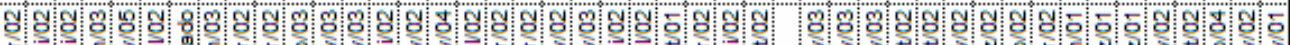
meta 8.0०\%ण

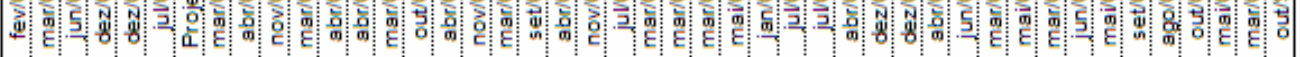

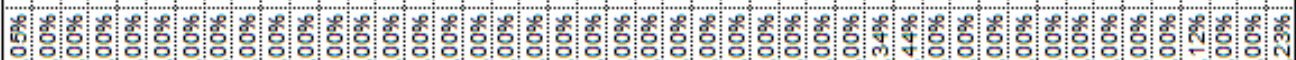

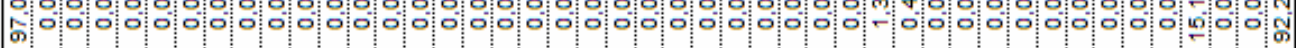

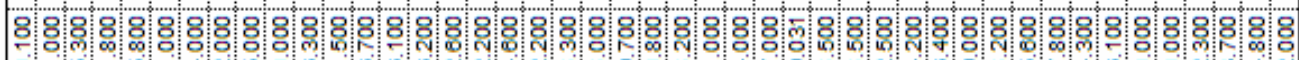
解

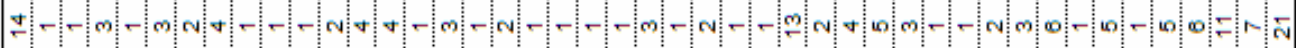

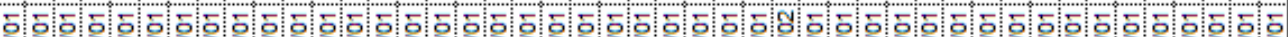

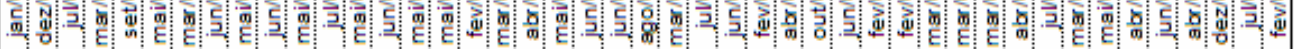

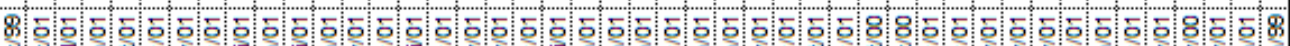

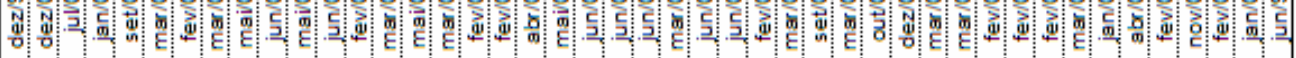

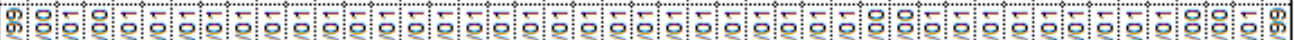

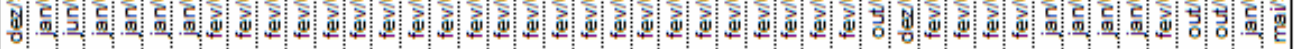

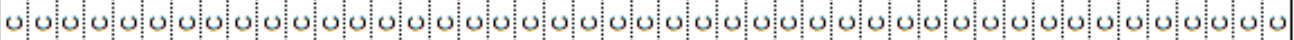

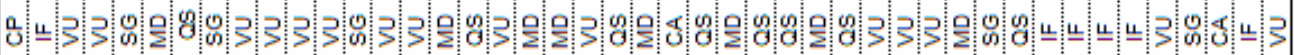

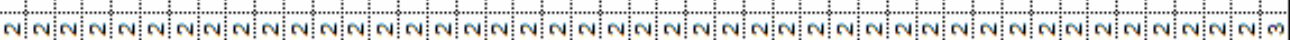

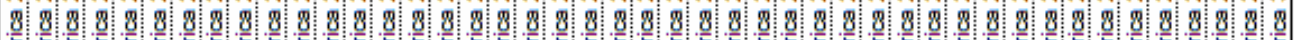

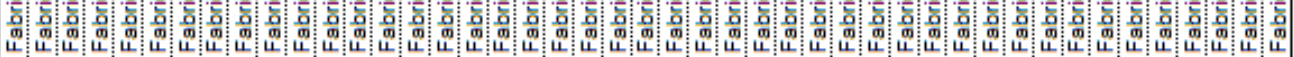

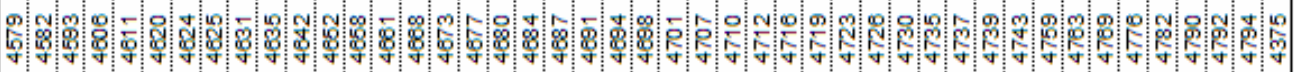

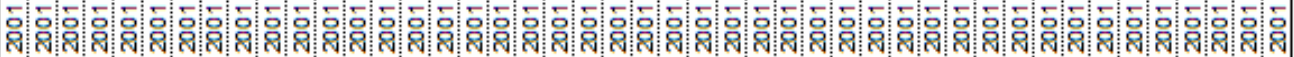




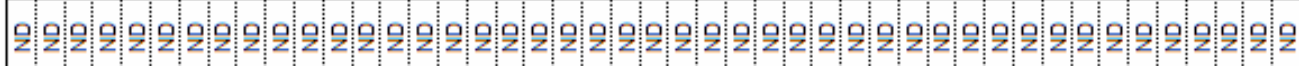

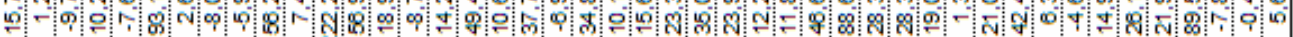

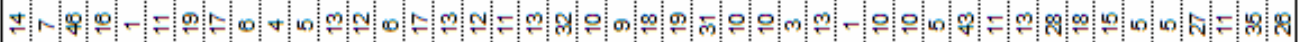

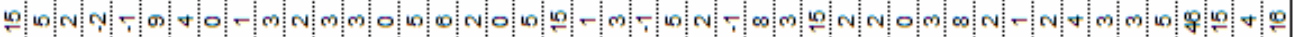

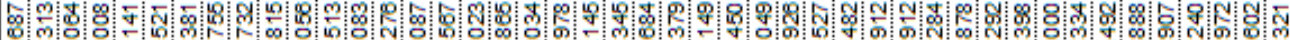

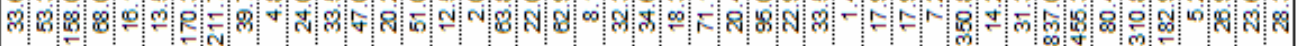

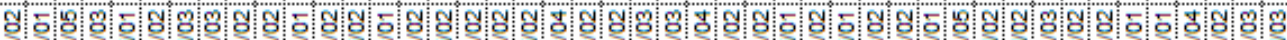

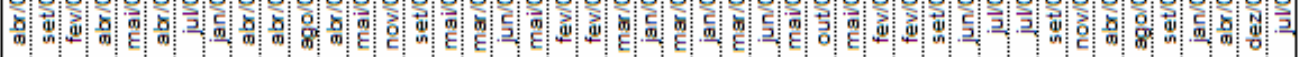

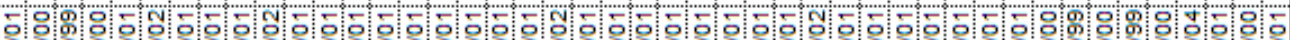
ติ

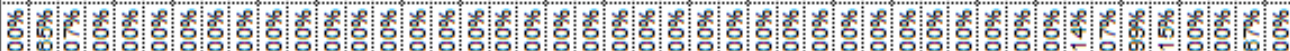
O. O

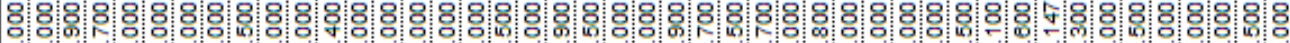

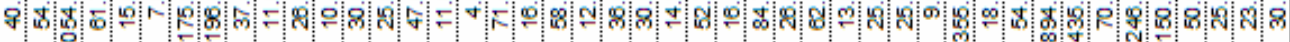

m닫ल

핳ㅎㅎㅎㅎㅎㅎㅎㅎㅎㅎㅎㅎㅎㅎㅎㅎㅎㅎㅎㅎㅎㅎㅎㅎㅎㅎㅎㅎㅎㅎㅎㅎㅎㅎㅎㅎㅎㅎㅎㅎㅎㅎㅎㅎㅎㅎㅎㅎㅎㅎㅎㅇ

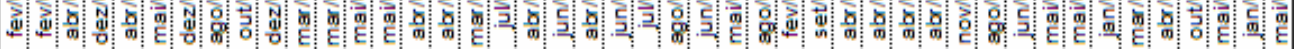

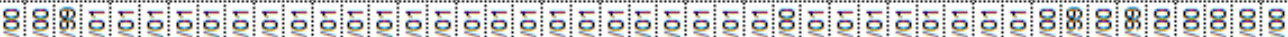

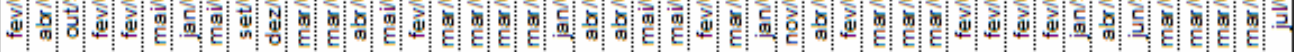

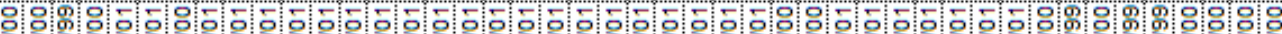

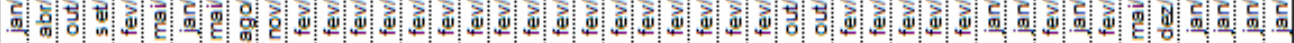

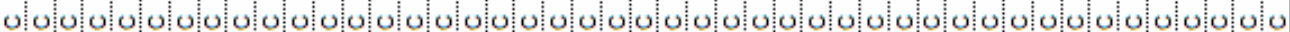

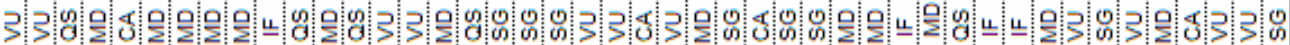

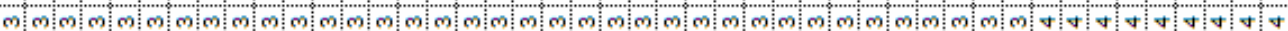

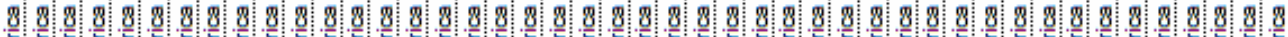

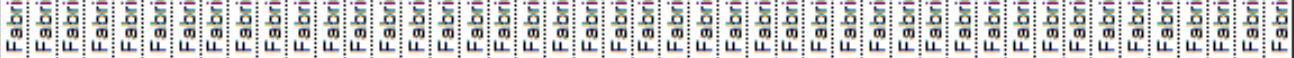

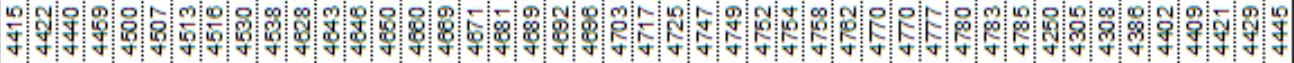

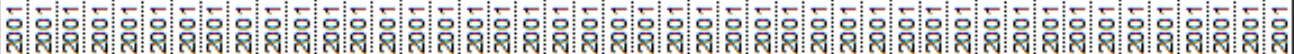




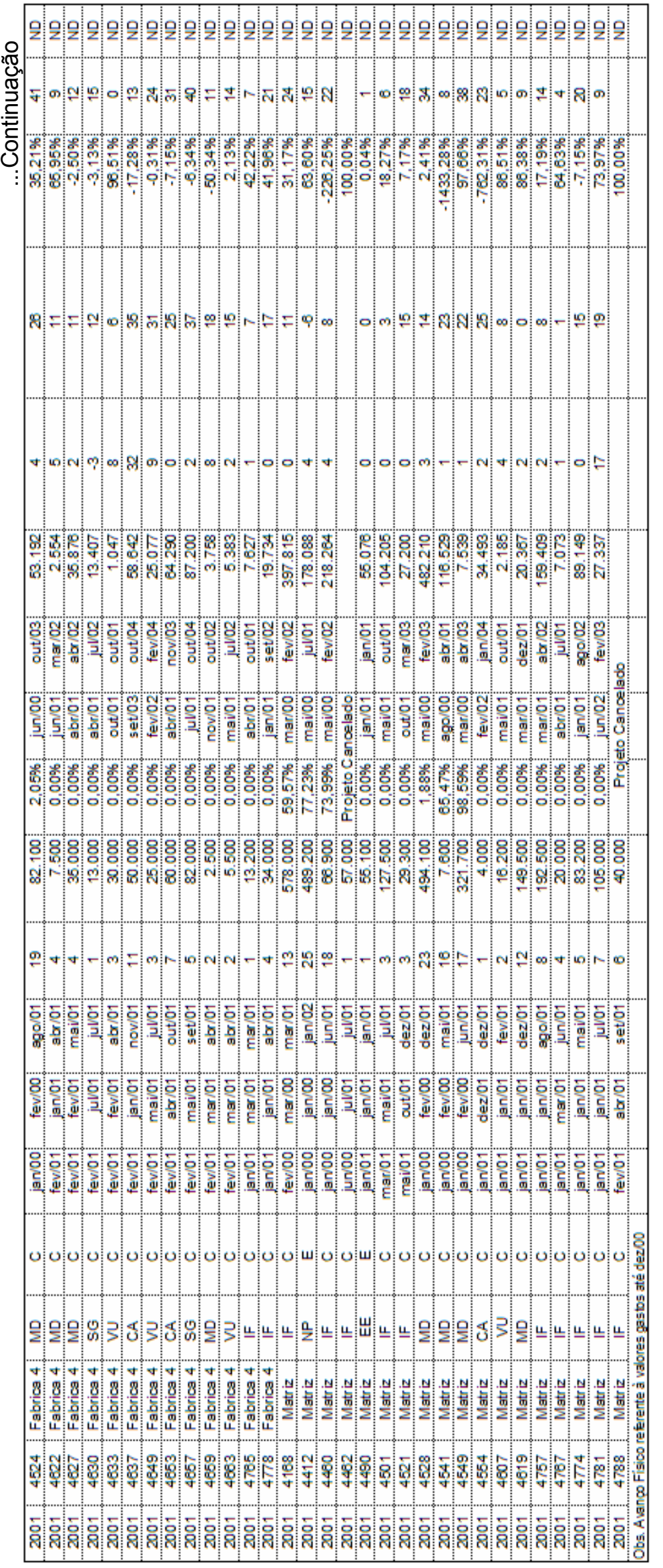




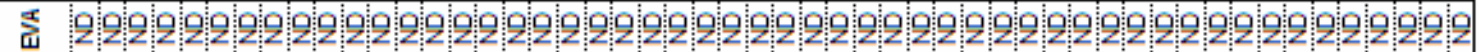

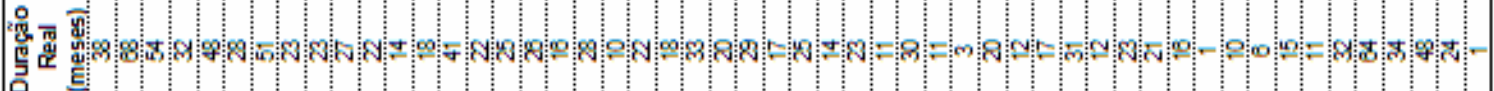

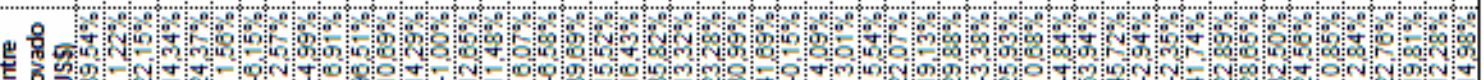

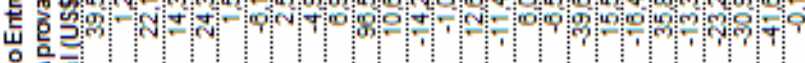

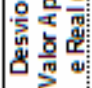

茊营邪

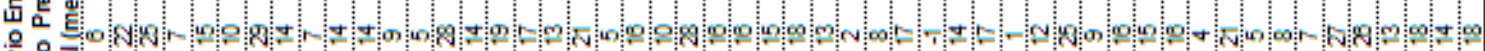
窟

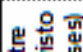

㟒

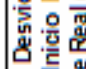

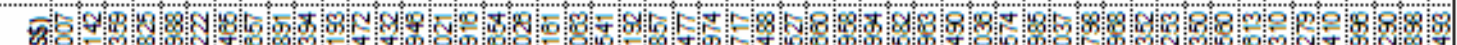
要 (6)

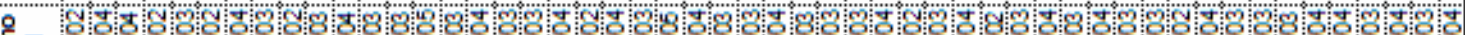

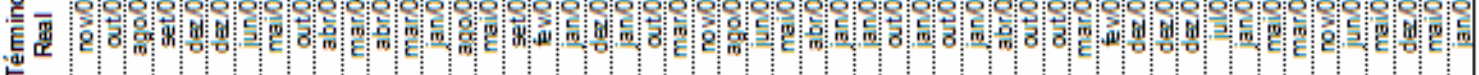
$\circ$ \% 递要

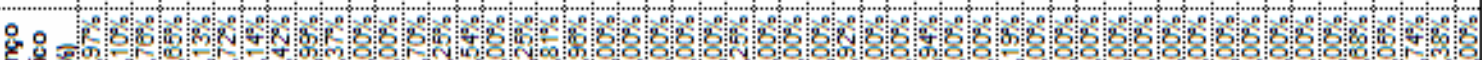
m.

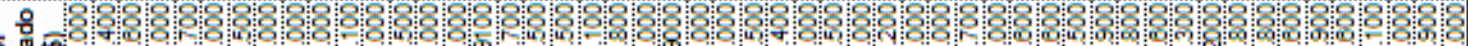

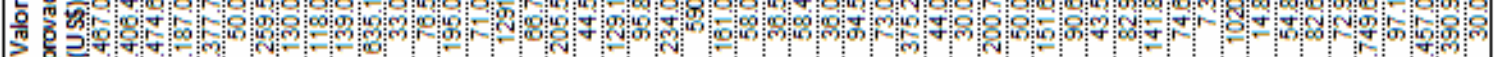
$\frac{1}{4}$

entin

S̆

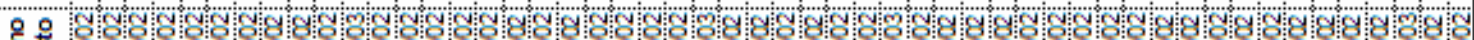

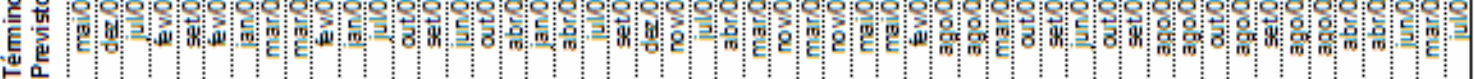

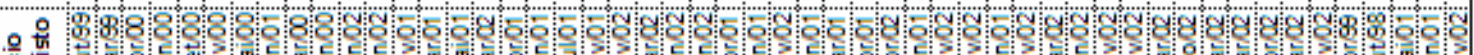

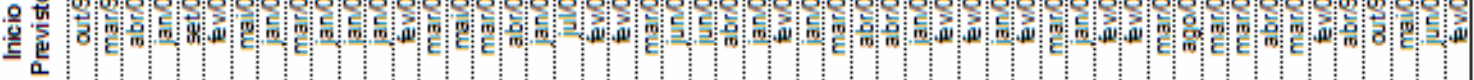

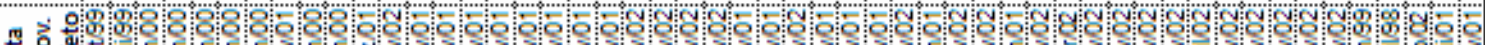

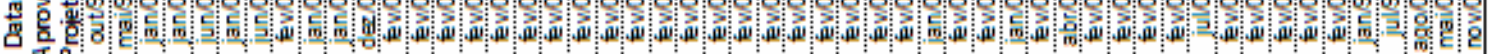

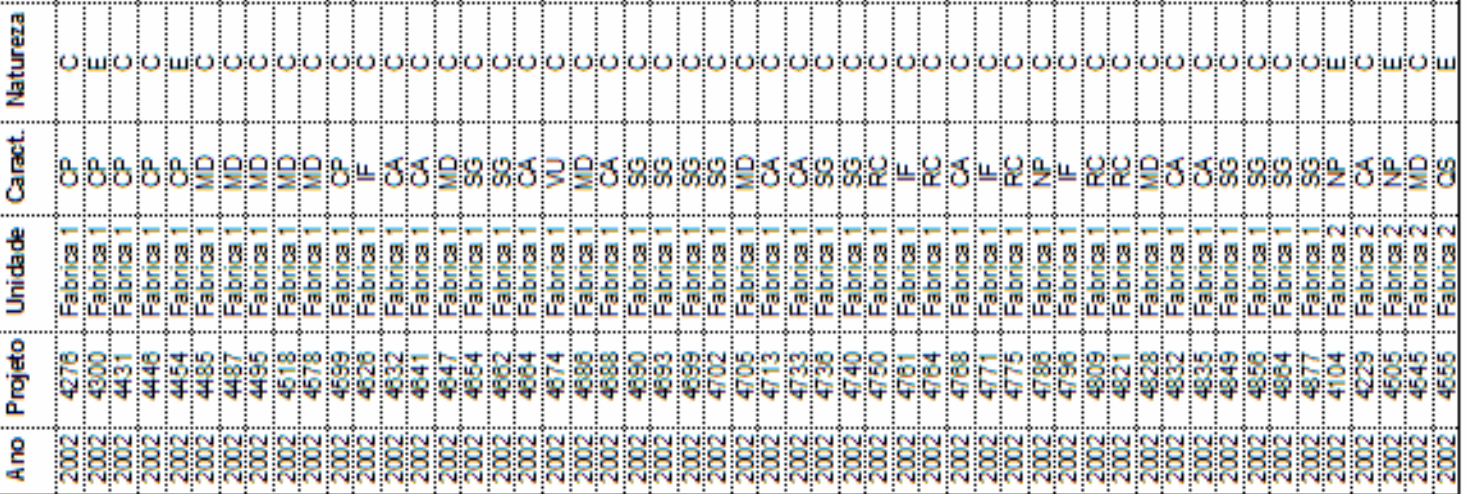




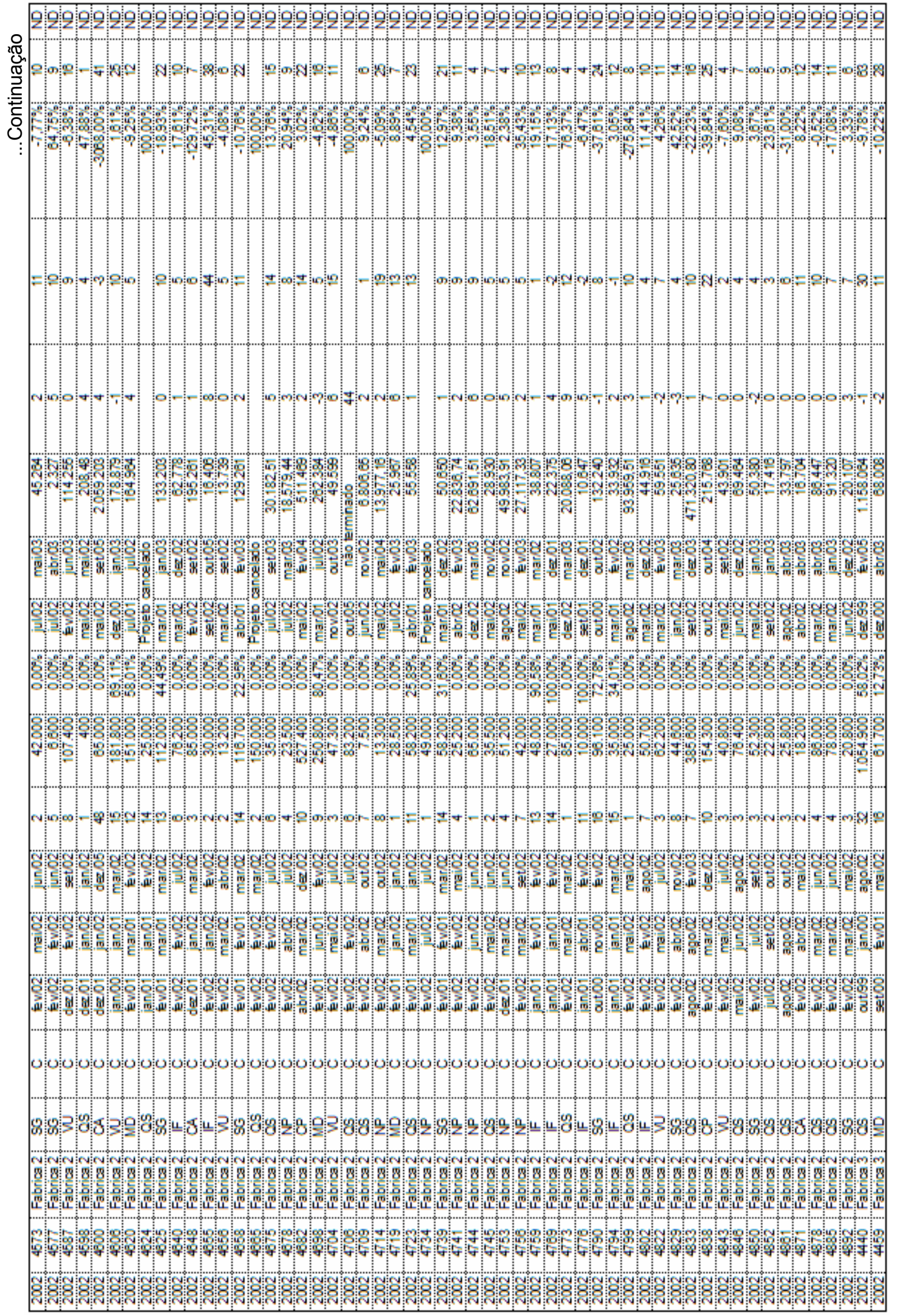




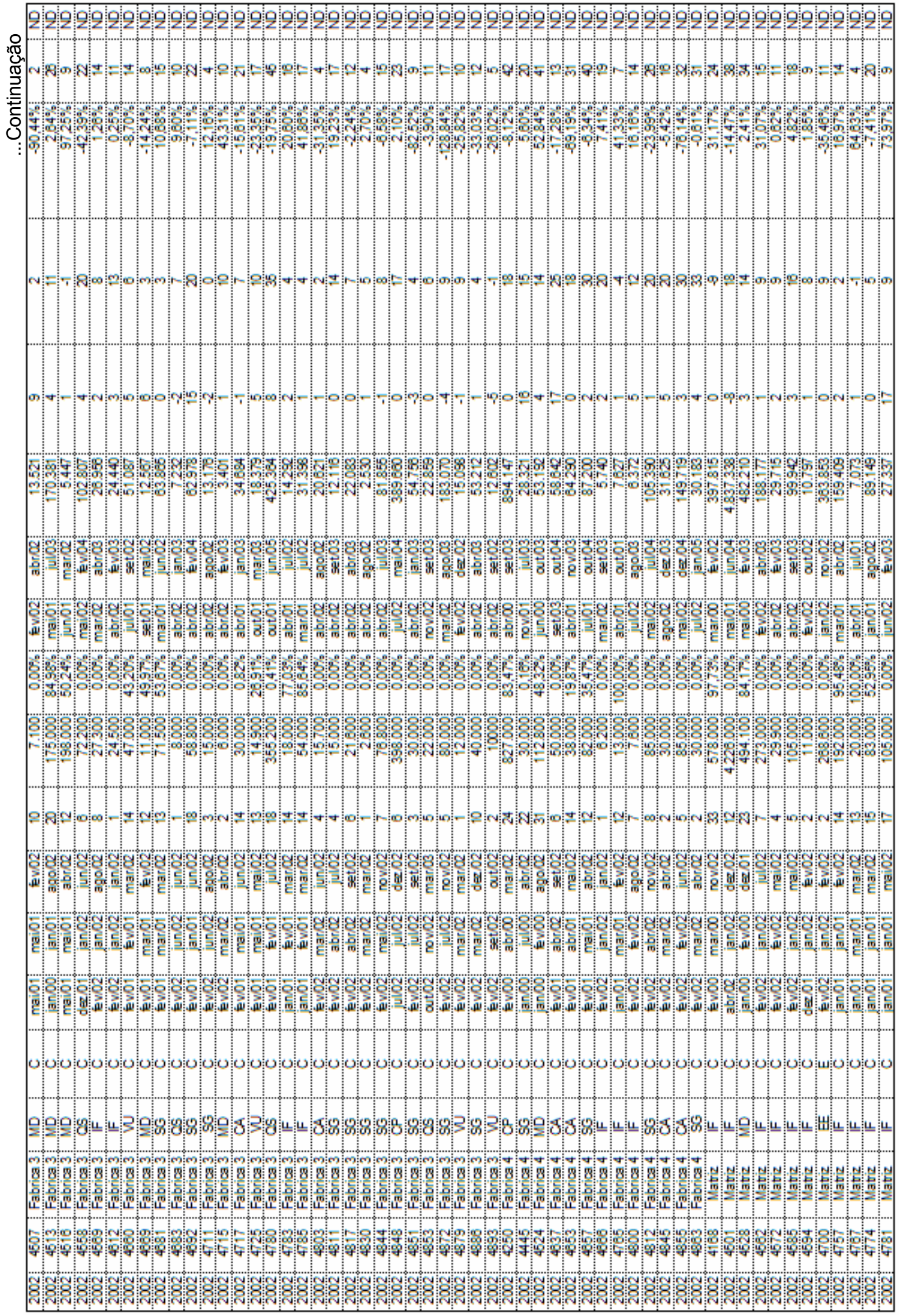




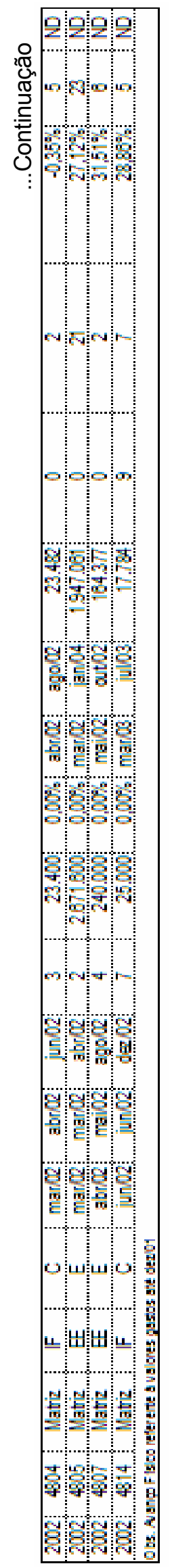




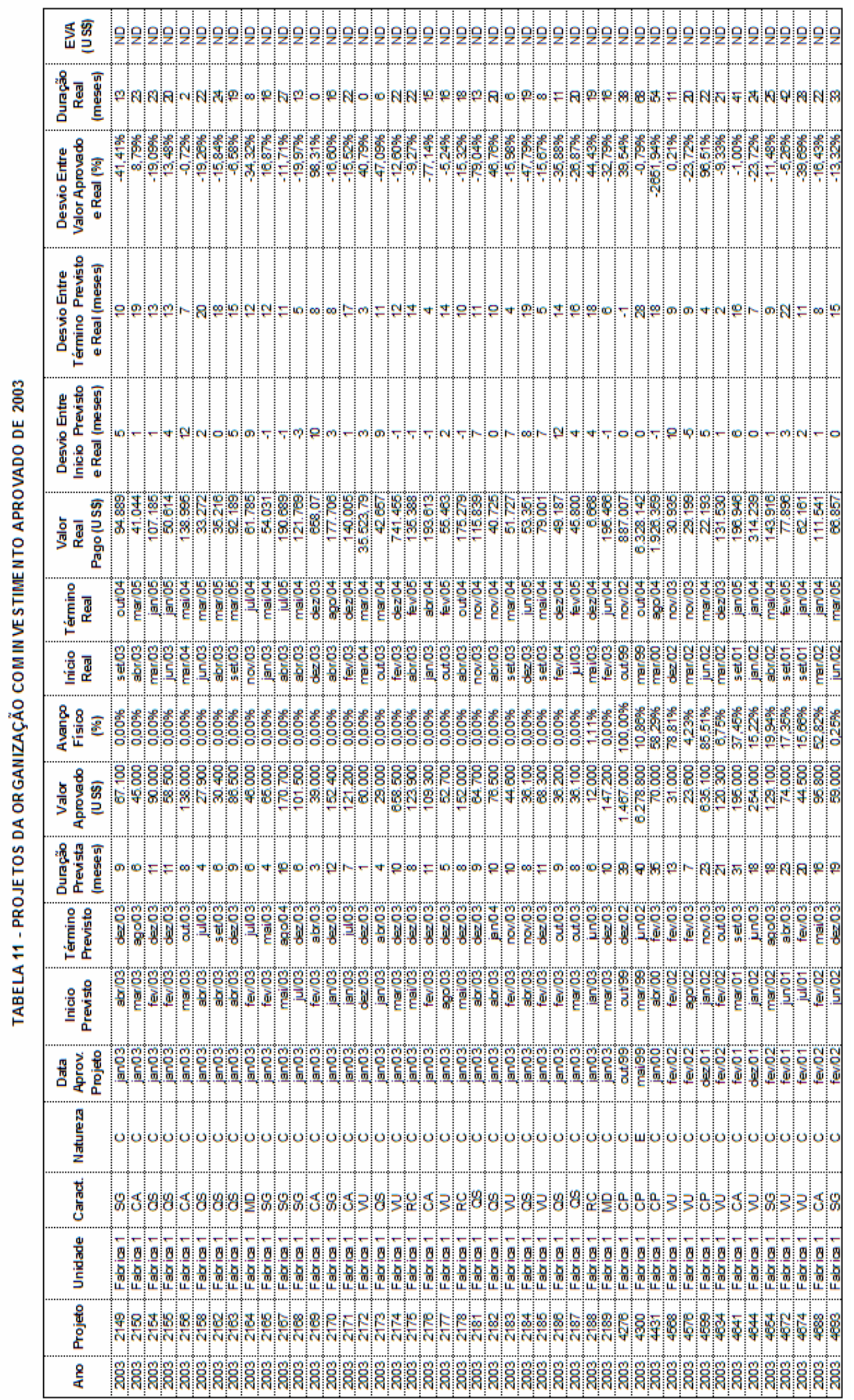




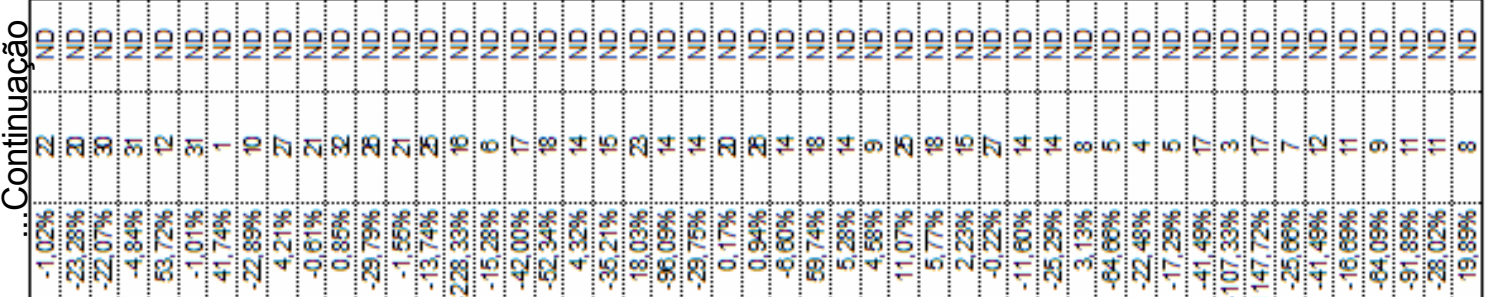

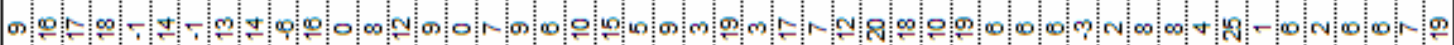

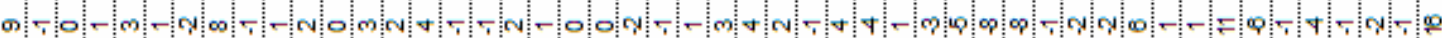

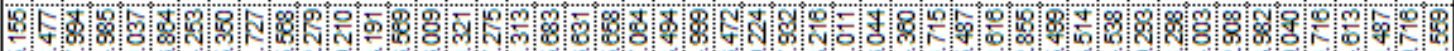

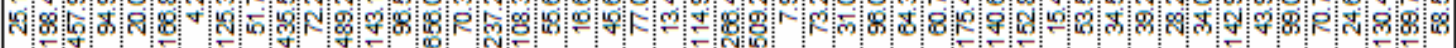

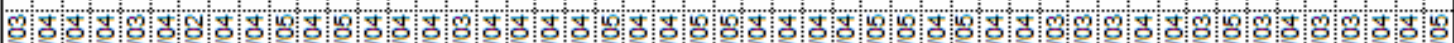
ह

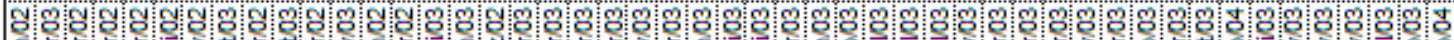

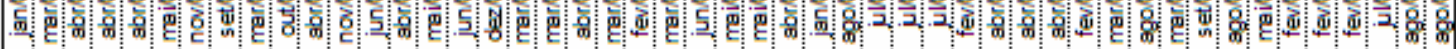

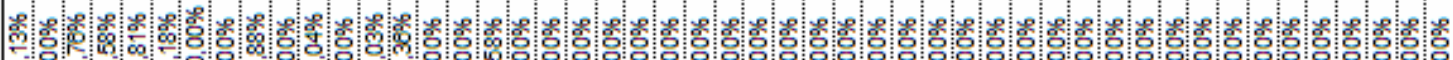

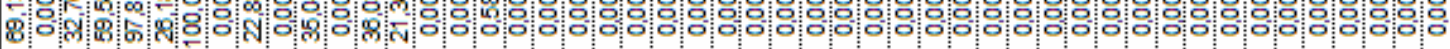

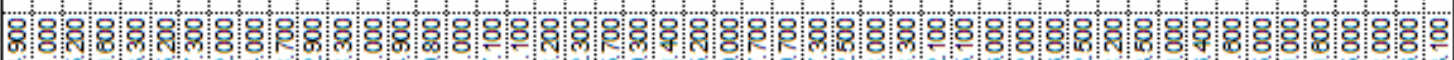
व்.

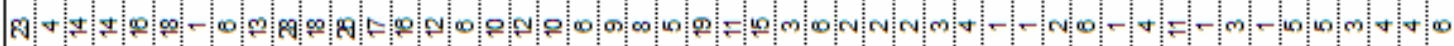

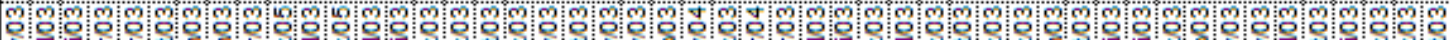
4

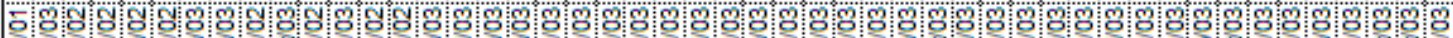

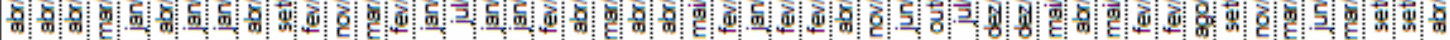

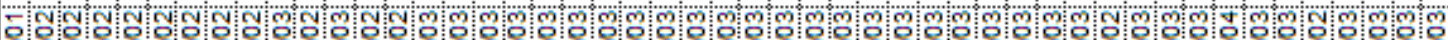

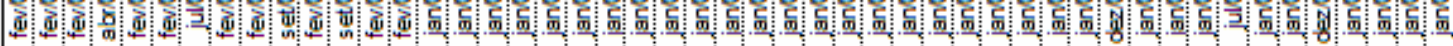

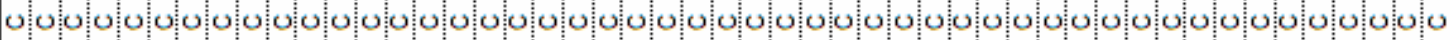

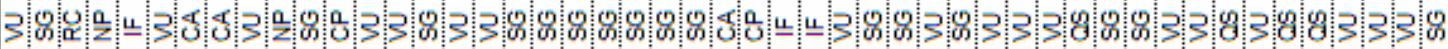

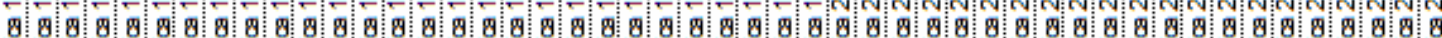
穴

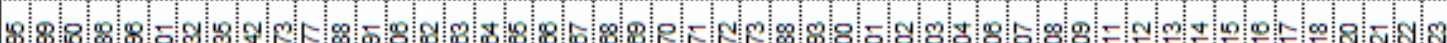

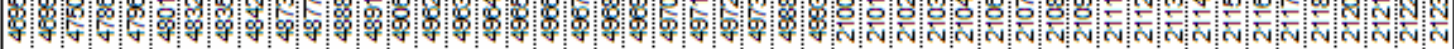

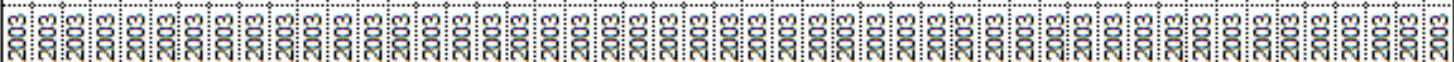




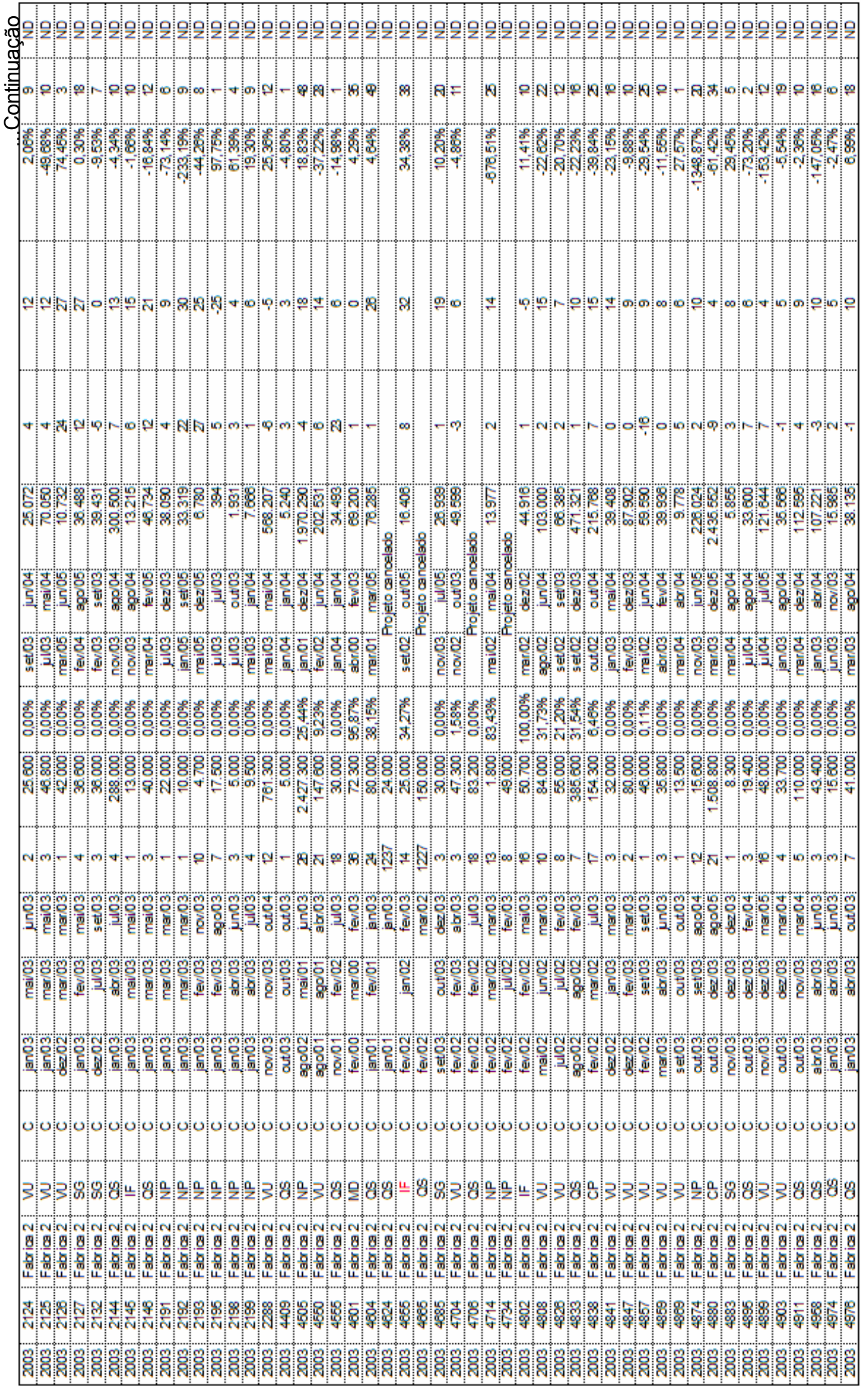




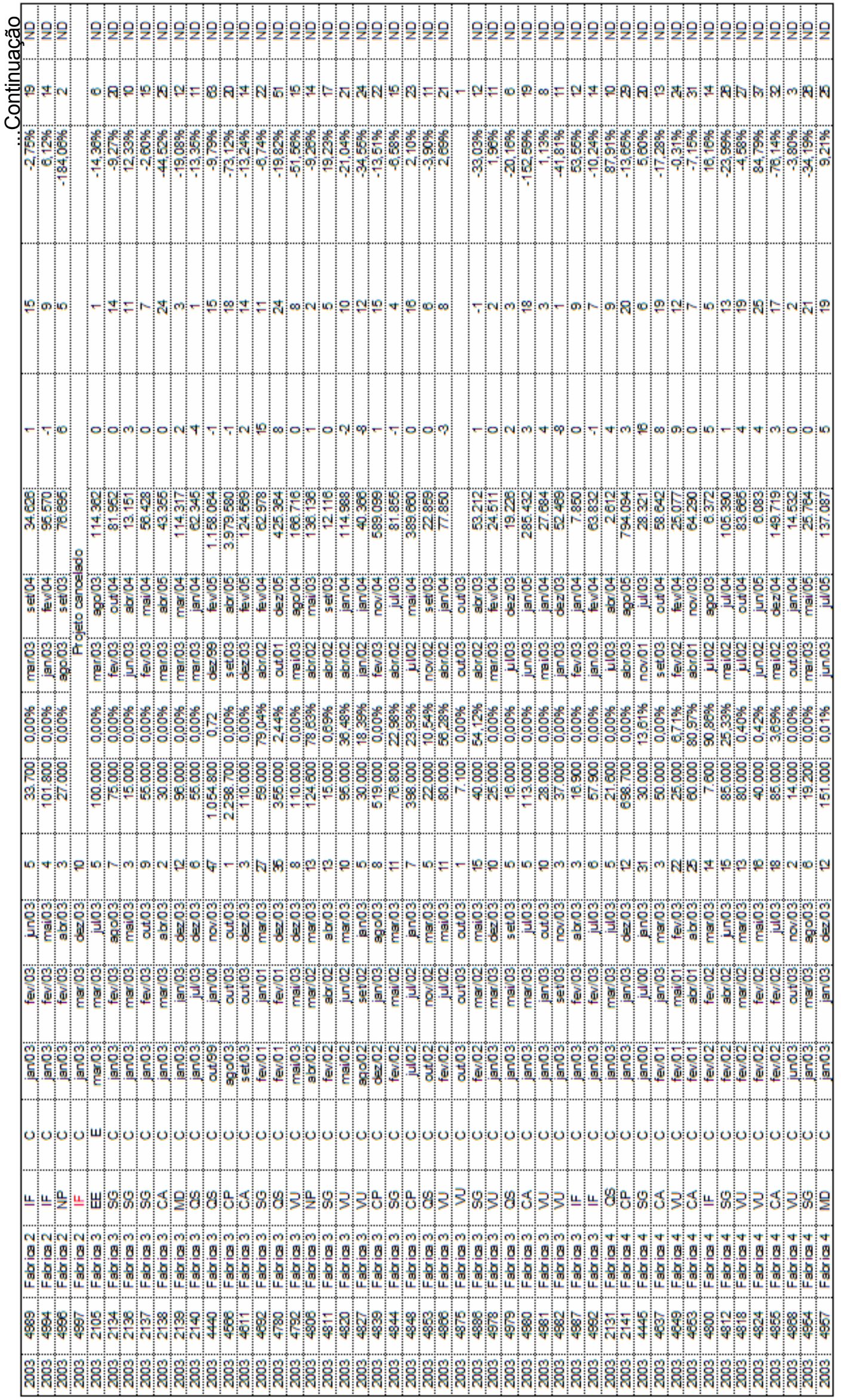




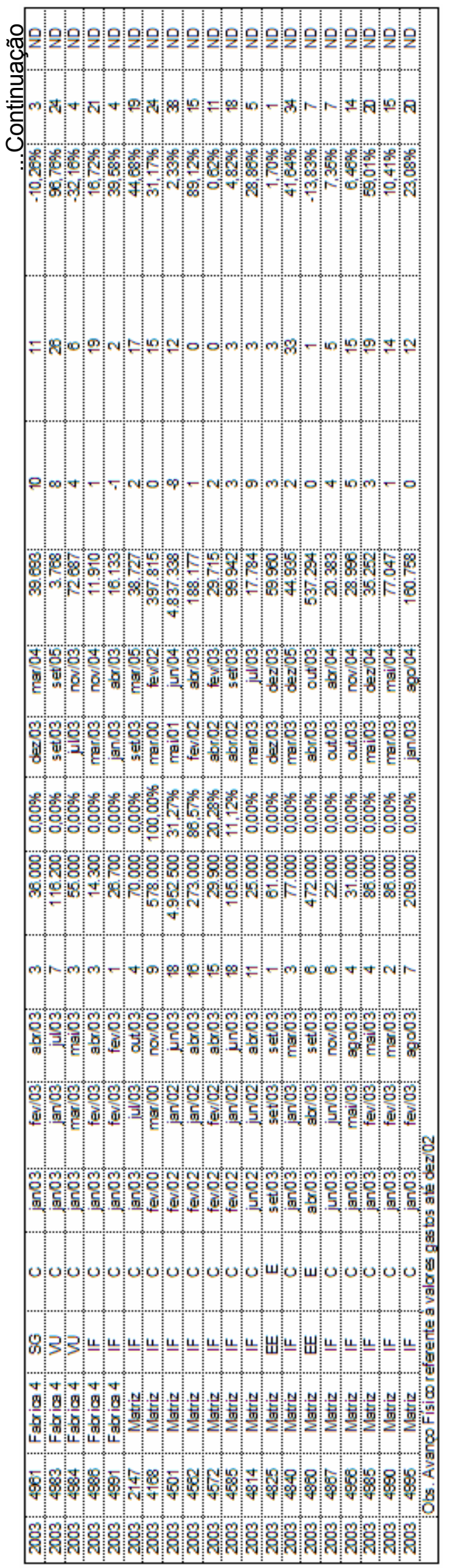




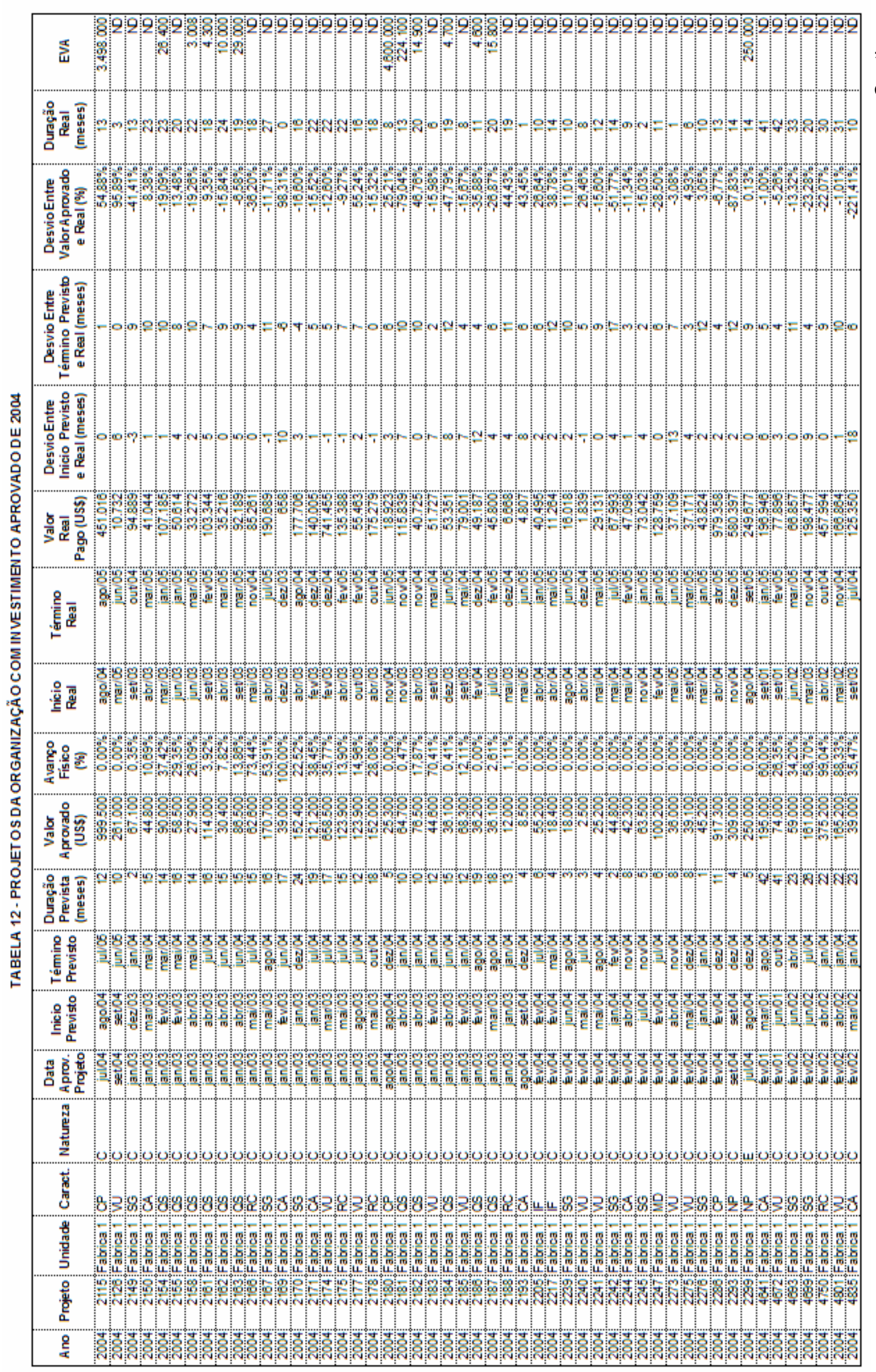




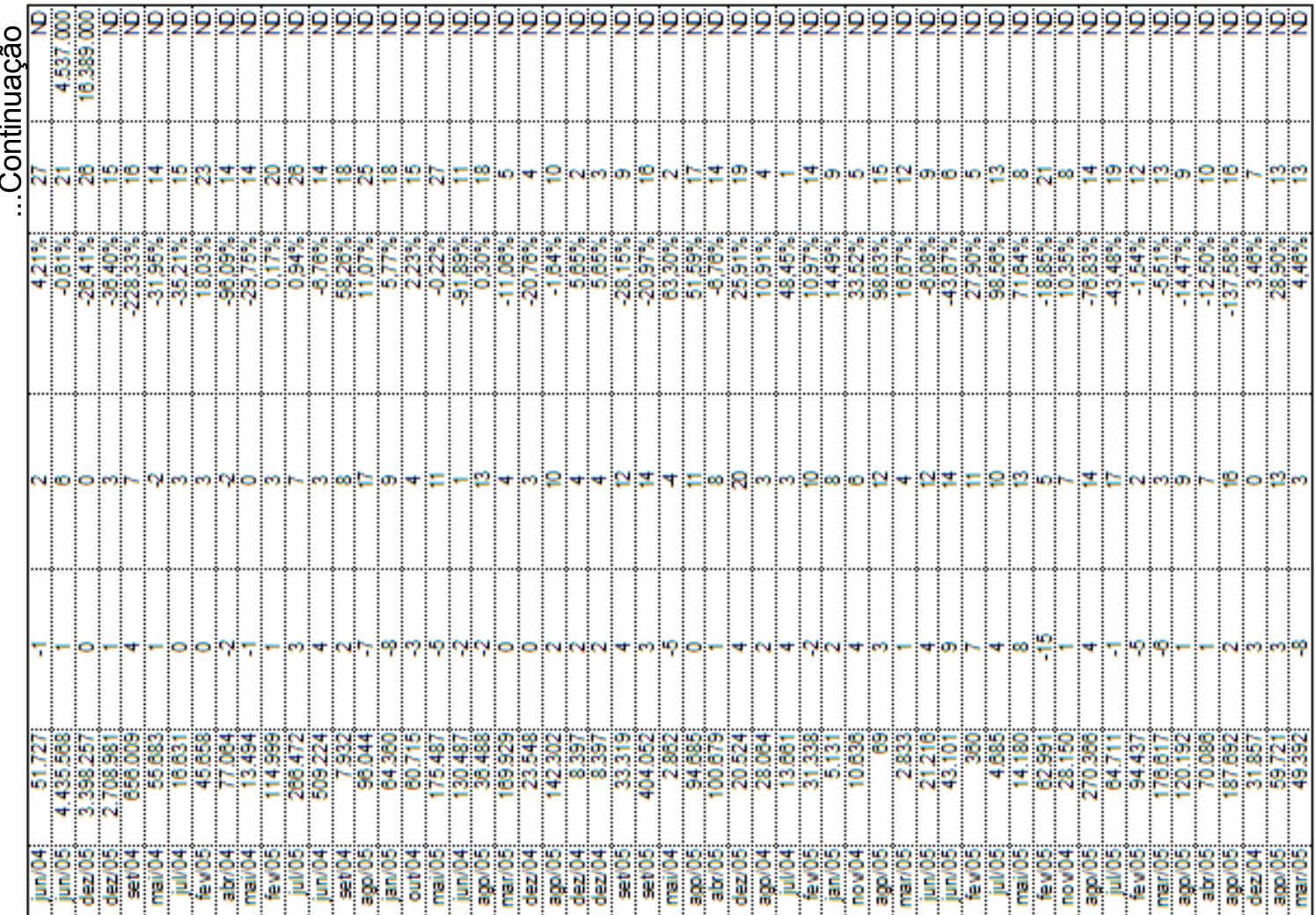

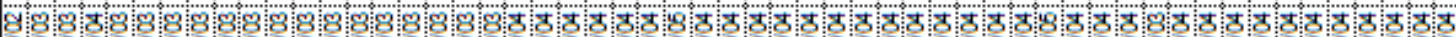

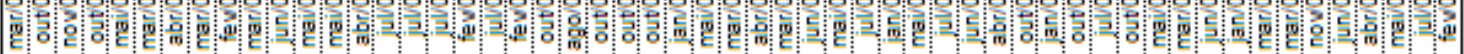

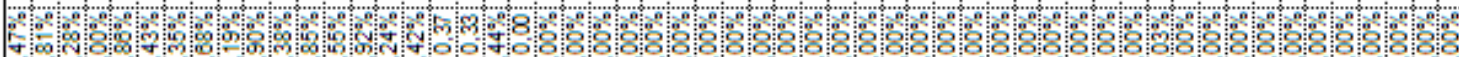
-

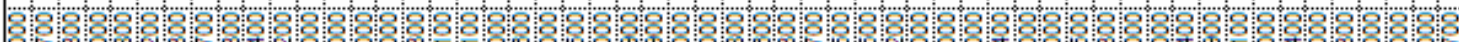
W: +o:

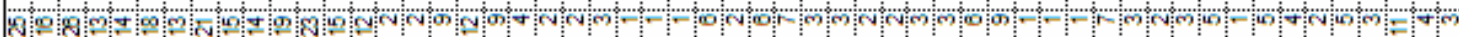

ठ

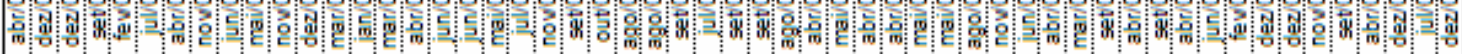

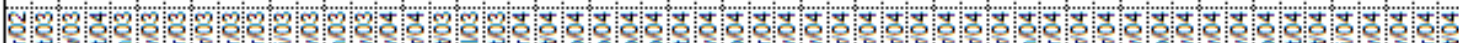

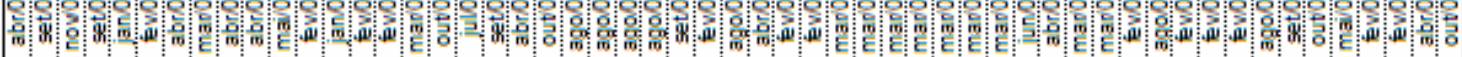

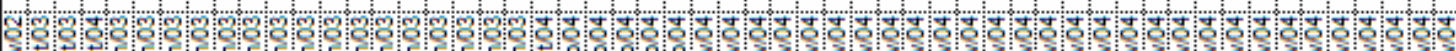
W

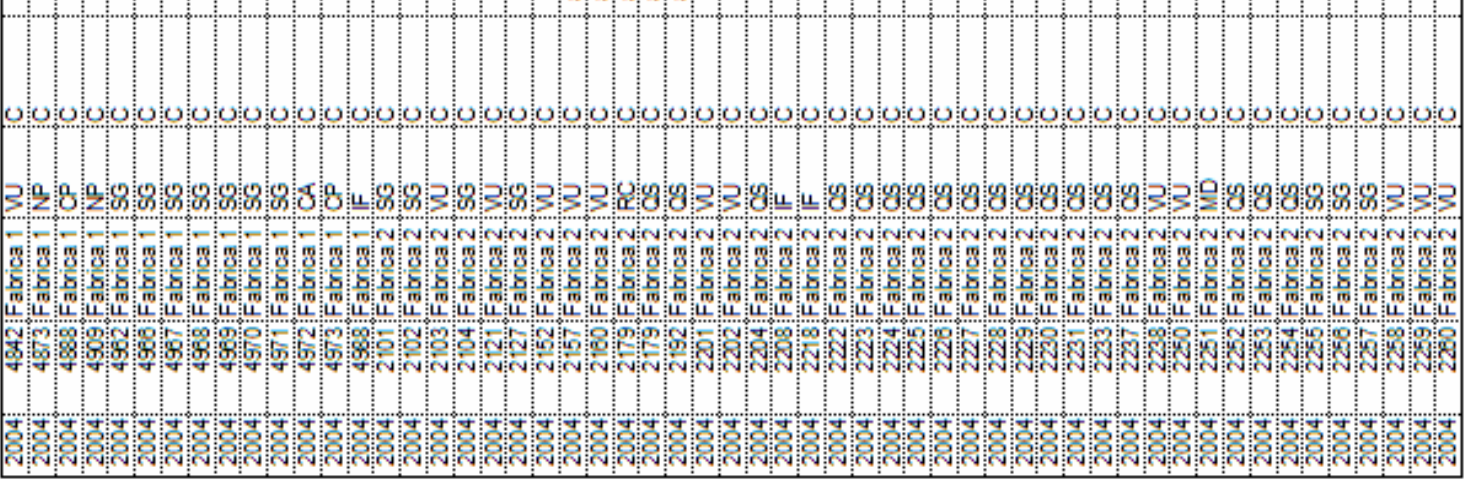




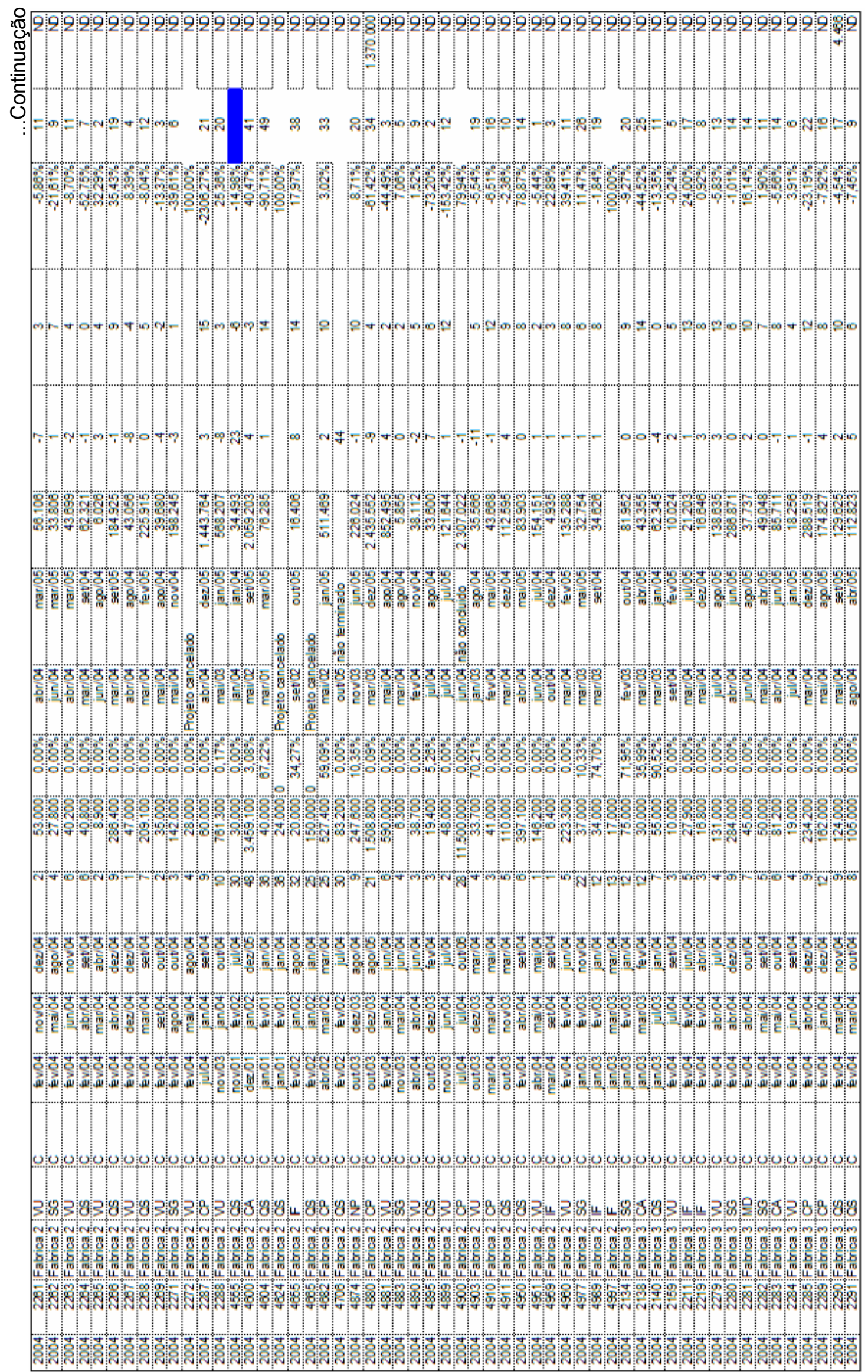




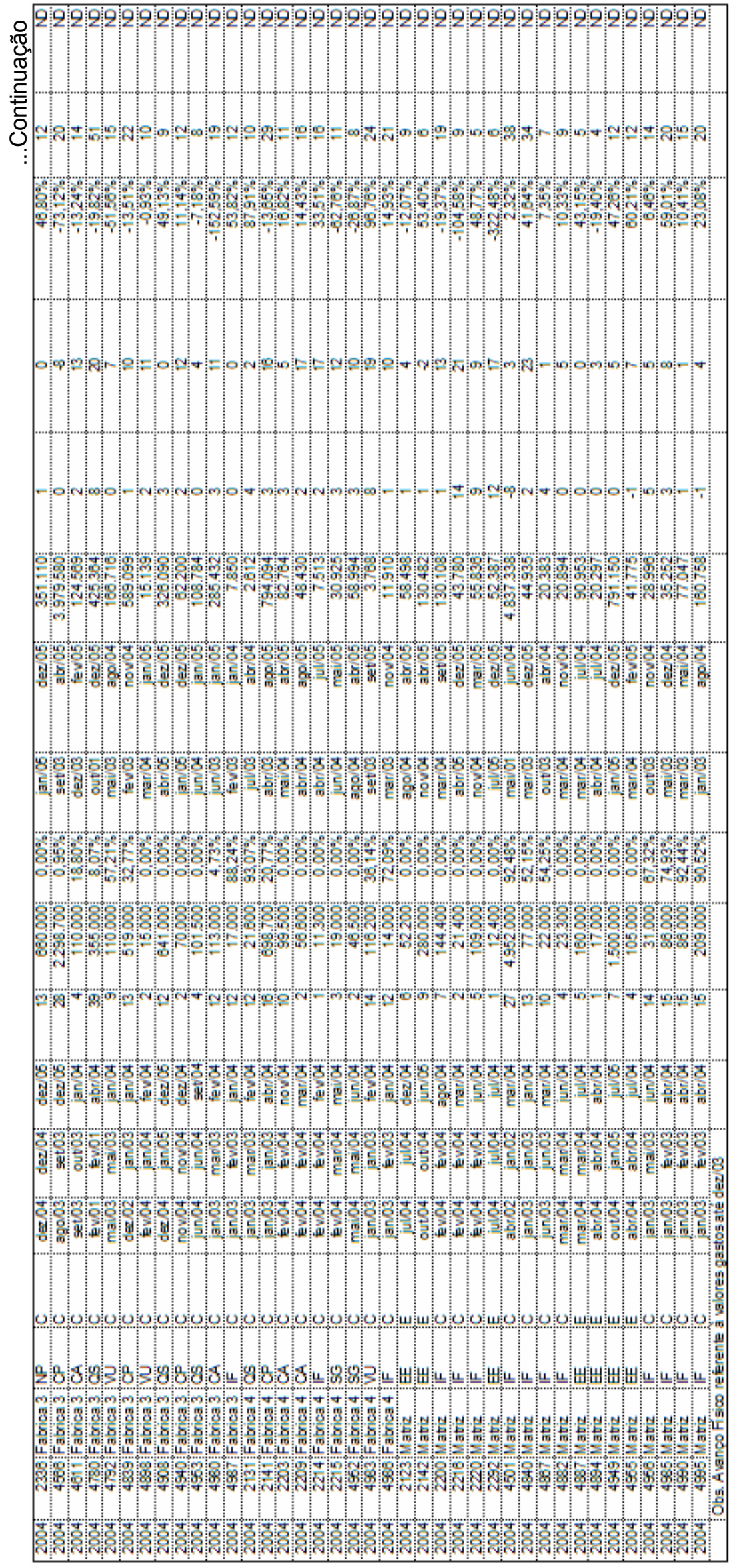




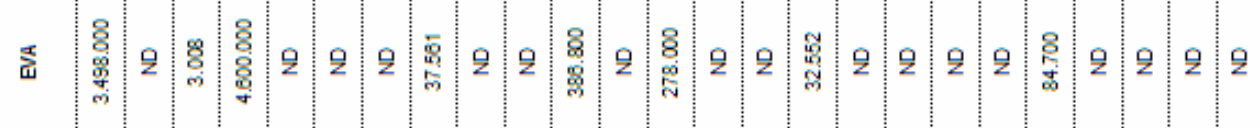

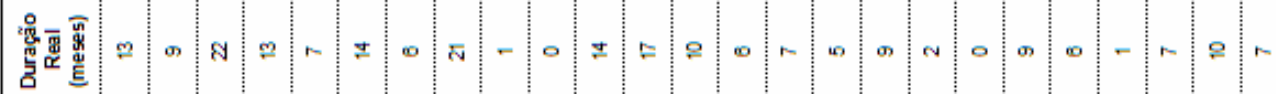

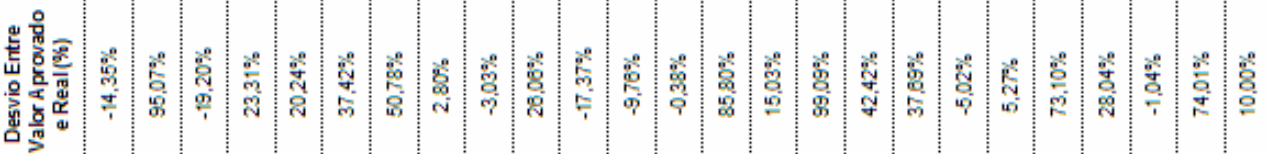

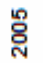

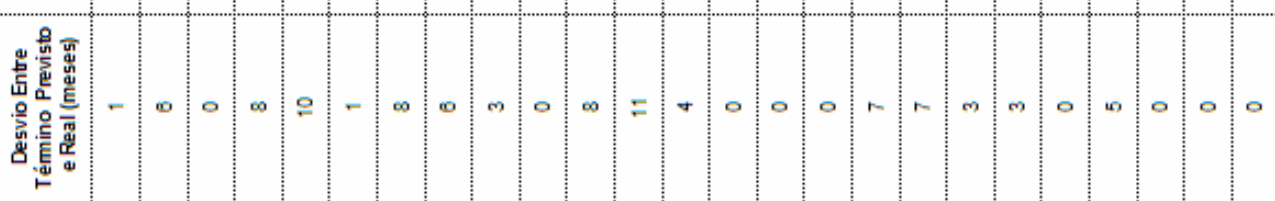

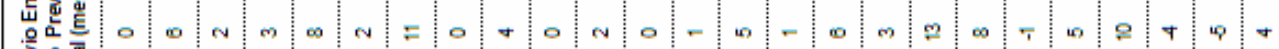
递尊

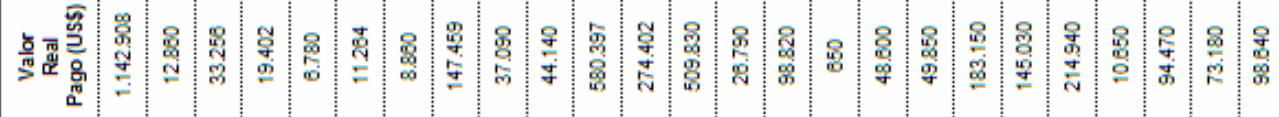

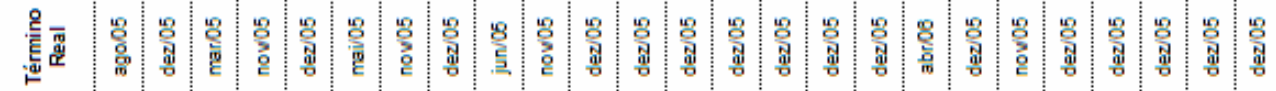

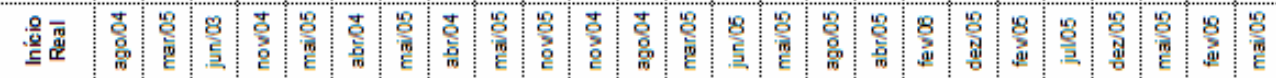

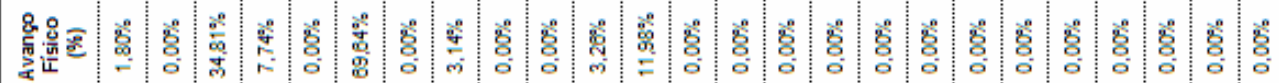

每意

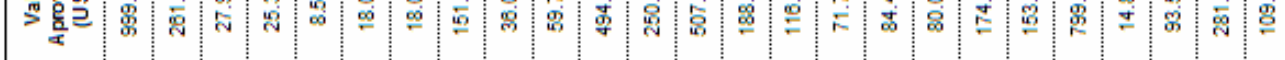

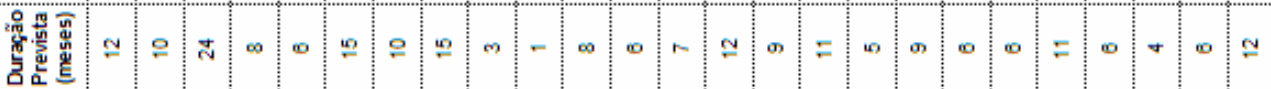

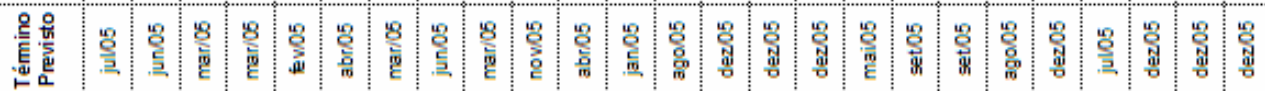

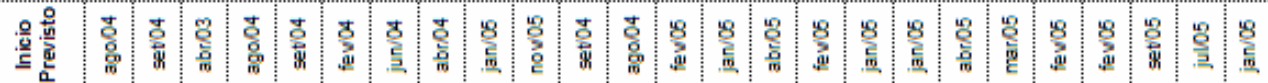

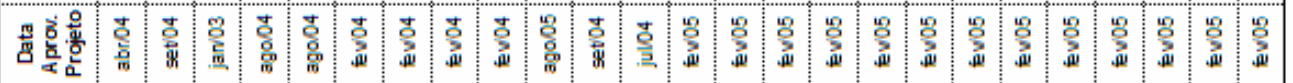

$\frac{1}{10} 000000000000000000000000000000$

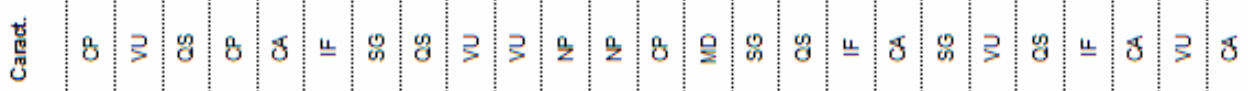

尊 $\begin{array}{llll}5 & \\ 5\end{array}$

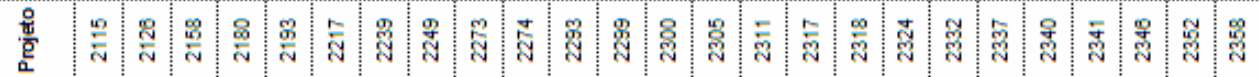

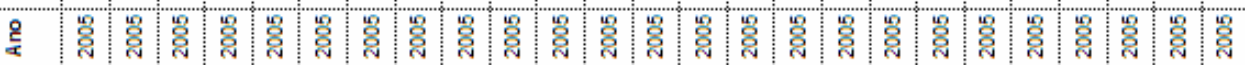




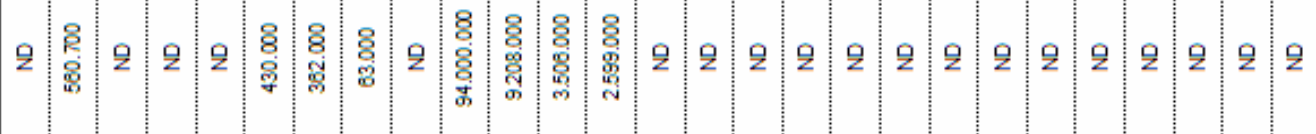
$=\infty:=\infty, \infty) \infty$

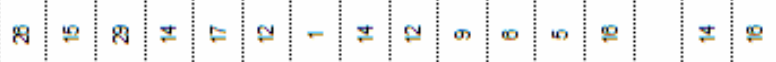

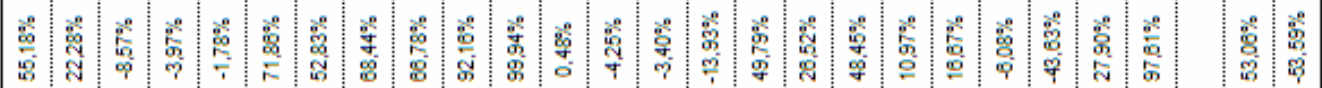

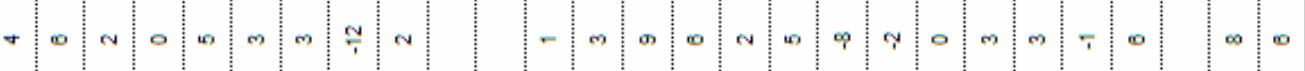

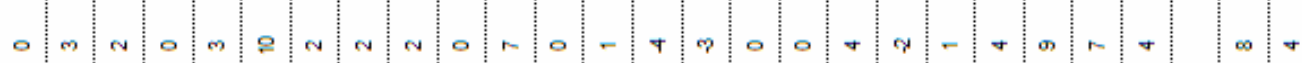

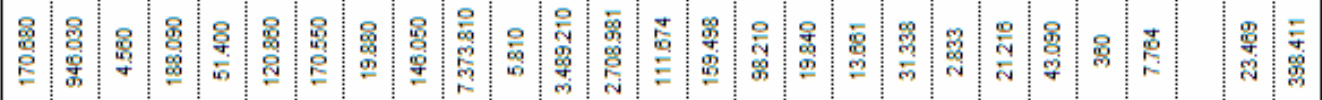

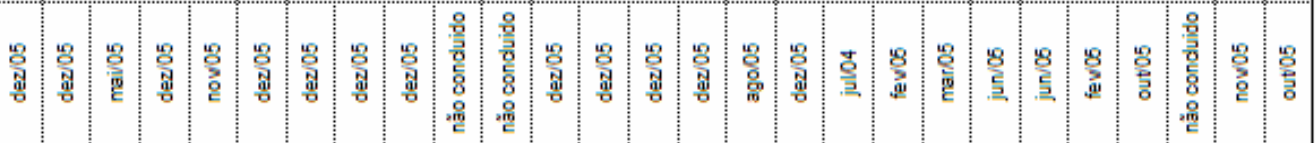

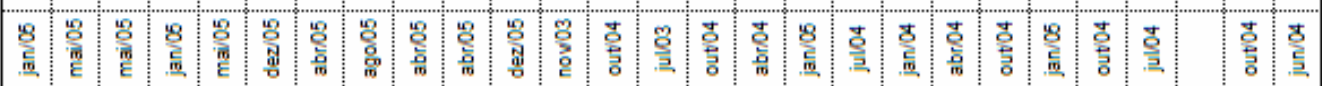

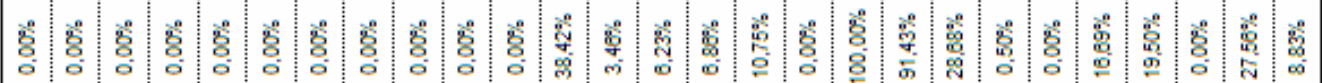
高参点

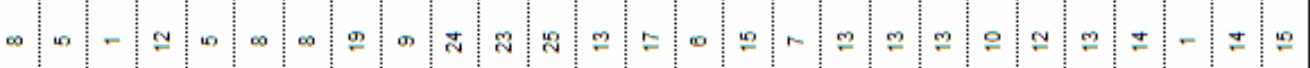

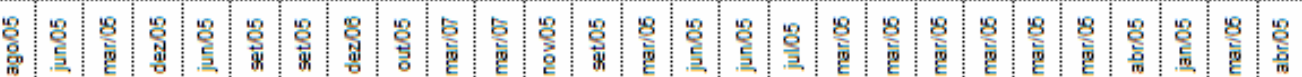

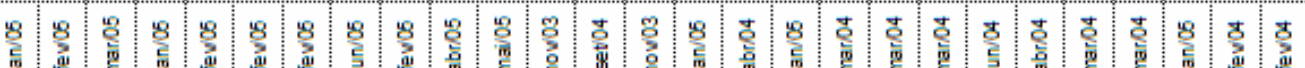

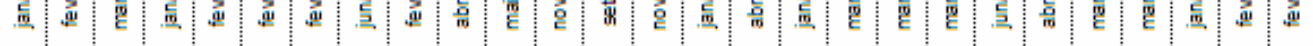

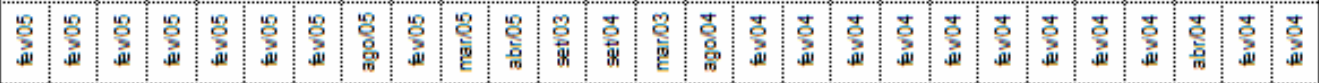
0 : 0 : 0 : 弓

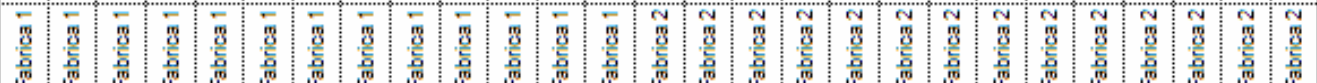

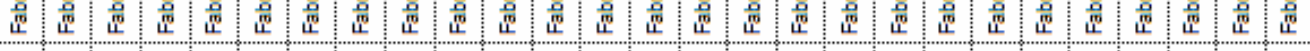

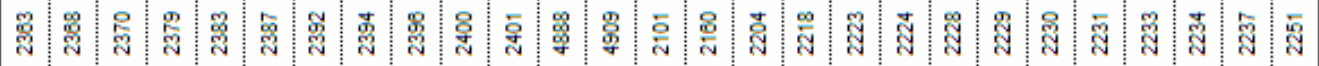

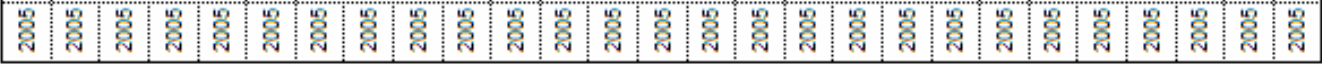




\begin{tabular}{|c|c|c|c|c|c|c|c|c|c|c|c|c|c|c|c|c|c|c|c|c|c|c|c|c|}
\hline & 2 & $\begin{array}{l}8 \\
\text { 总 } \\
\text { 品 }\end{array}$ & 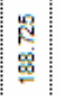 & $\frac{2}{2}$ & 2 & 2 & ? & 2 & 2 & 2 & 2 & 2 & 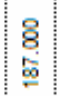 & 2 & 2 & 2 & Q & 2 & 2 & $q$ & $\frac{2}{2}$ & 2 & $2 \frac{c}{2}$ & $\frac{9}{2}$ \\
\hline 인 & $=$ & $\otimes$ & $\bar{N}$ & & - & & 0 & m & + & $\infty$ & 10 & - & $\infty$ & & + & & + & & $\infty$ & & 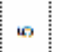 & -6 & o & \\
\hline 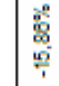 & : & 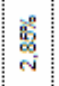 & 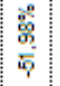 & & 禀 & & $\frac{8}{5}$ & 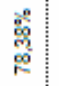 & : & | & 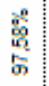 & $\frac{9}{4}$ & $\frac{6}{40}$ & & 总 & & 量 & & 裹 & & 复 & 畩 & 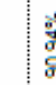 & \\
\hline o & - & $\infty$ & 10 & & 10 & & $\circ$ & 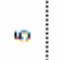 & + & $N$ & $N$ & $\infty$ & 0 & & $?$ & & 0 & & T & & $\%$ & $N$ & 7 & \\
\hline$m$ & $\infty$ & $\circ$ & $m$ & & $\sigma$ & & $m$ & - & - & ० & + & $\infty$ & 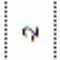 & & $\%$ & & $\omega$ & & 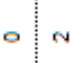 & & $m$ & + & 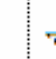 & \\
\hline 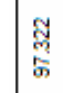 & $\begin{array}{l}\text { 墒 } \\
0 \\
0 \\
0\end{array}$ & 袊 & 竞 & & (8) & & $\begin{array}{l}\text { \% } \\
\text { क् }\end{array}$ & : & 密 & : & , & 竞 & : & & d্: & & 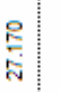 & & 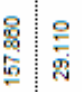 & & : & $\frac{8}{7}$ & 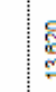 & \\
\hline 흘 & : & : & : & \begin{tabular}{|l|} 
\\
$:$
\end{tabular} & : & 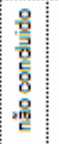 & : & : & 善 & : & : & 总 & 害 & 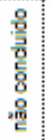 & 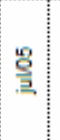 & 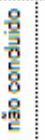 & , & 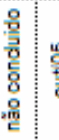 & 总 & 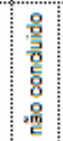 & 量 & 营 & & $\begin{array}{l}\frac{2}{2} \\
0 \\
8 \\
0 \\
0 \\
\end{array}$ \\
\hline 总 & 总 & 藅 & 䓂 & & 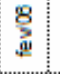 & & 兽 & : & 员 & $\begin{array}{l}\text { 总 } \\
\text { 恶 }\end{array}$ & 8 & 总 & 帘: & & : & & 总 & & 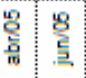 & & : & 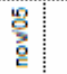 & 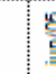 & \\
\hline స్త్ & की & 曾 & 点 & : & : & : & : & : & : & : & $\begin{array}{l}3 \\
8 \\
0\end{array}$ & 8 & $8:$ & : & : & 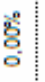 & 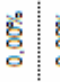 & ? & 8: & 8 & : & ? & : & 8 \\
\hline $\begin{array}{l}8 \\
0 \\
\dot{w}\end{array}$ & 8 & 总 & : & $\begin{array}{l}8 \\
\\
\end{array}$ & $\stackrel{8}{\frac{8}{\alpha}}$ & $\stackrel{8}{\stackrel{8}{\sim}}$ & $\begin{array}{l}8 \\
\vdots \\
\$\end{array}$ & $\begin{array}{l}8 \\
6 \\
6\end{array}$ & 8 & $\begin{array}{l}8 \\
0 \\
0\end{array}$ & $\mid \begin{array}{l}8 \\
0 \\
8 \\
0\end{array}$ & 8 & 总 & $\frac{8}{8}$ & d: & 8 & : & $\stackrel{8}{\stackrel{8}{p}}$ & $\begin{array}{l}8 \\
8 \\
0 \\
0\end{array}$ & 名 & 8: & $\stackrel{\mathrm{q}}{=}$ & 8 & 8 \\
\hline$=$ & $\infty$ & $=$ & 志 & $\infty$ & $\infty$ & $m$ & $m$ & + & - & + & $\infty$ & - & $m$ & $m$ & $\infty$ & - & 잉 & $N$ & $\infty$ & - & $\simeq$ & + , & $-\infty$ & + \\
\hline 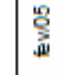 & 总 & 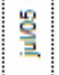 & : & : & 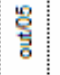 & : & 哭 & 을 & : & 哭 & 总 & 总 & 总 & : & : & : & 总 & 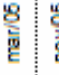 & 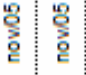 & 总 & : & 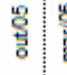 & 8 & : \\
\hline 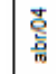 & 焉 & 总 & 总 & : & : & 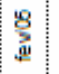 & 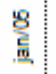 & : & 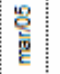 & $\begin{array}{l}\text { : } \\
\text { : }\end{array}$ & 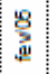 & 总 & 总 & 总 & 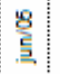 & 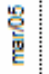 & 施 & $\frac{8}{3}$ & 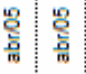 & : & 量 & $\frac{\mathrm{O}}{\mathrm{O}}$ & 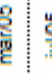 & 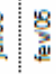 \\
\hline 总 & 总 & 总 & 总 & 普 & ) & : & 总 & 总 & 总 & 哭 & 道 & 常 & 总 & 总 & 总 & 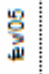 & 总 & $\mathrm{e}^{3}$ & 糆: & 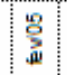 & 总 & 曽 & בֶ. & : \\
\hline 0 & 0 & $\circ$ & 0 & 0 & 0 & 0 & 0 & 0 & 0 & ० & 0 & 0 & $\circ$ & ० & $\circ$ & ० & 0 & o & 0 & 0 & 0 & o & u & 0 \\
\hline 3 & 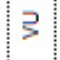 & g & 0 & 3 & o & 3 & $\underline{\underline{ }}$ & 3 & 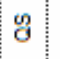 & ૩ & 岳 & $\%$ & $g$ & 3 & 3 & 3 & 3 & 3 & 3: & 3 & 3 & 范 & 8 & 3 \\
\hline 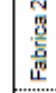 & 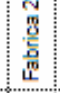 & 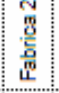 & 䇺 & 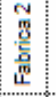 & 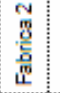 & 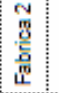 & 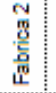 & 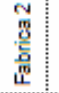 & 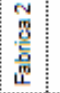 & 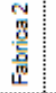 & 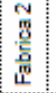 & 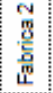 & 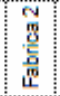 & 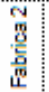 & 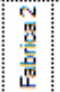 & 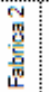 & 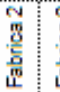 & 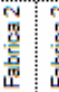 & 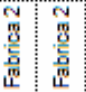 & 总 & 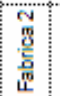 & 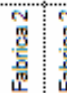 & 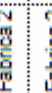 & 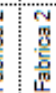 \\
\hline 㞼 & 商 & 急 & $\stackrel{a}{a}$ & $8 \%$ & : & $N^{\infty}$ & ํㅡㄹ & $\frac{ \pm}{2}$ & 웜 & ชี & $\tilde{N}$ & d & $\ddot{d}$ & 㩊 & 愚 & 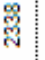 & 㠄 & $\mathrm{F}^{*}$ & 悉 & 年 & do & 郘: & S & 罚 \\
\hline 总 & : & : & : & 总 & : & d。 & 总 & 总 & : & 일 & 잉 & 兽 & : & ते & & 용 & 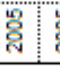 & & 荢: & 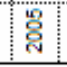 & & 恖! & & 808 \\
\hline
\end{tabular}




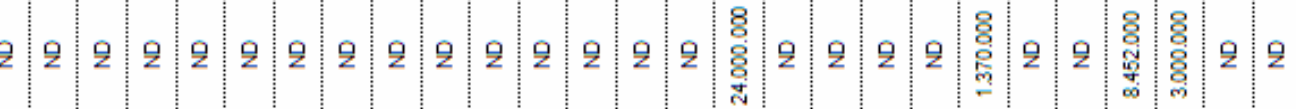

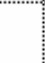

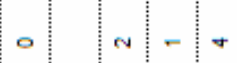

$\infty$

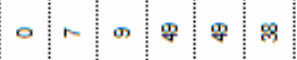

के

$\circ$

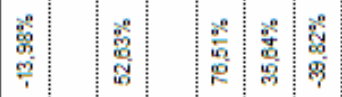

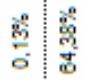

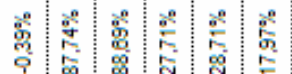

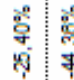

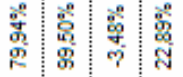

$\infty \quad \infty$

mo

$m \circ \%$

$+\infty$

$\infty$ ?

m:

$\infty$

$\circ \mathrm{N}+\infty$

of $\circ$

$+\cdot$

象

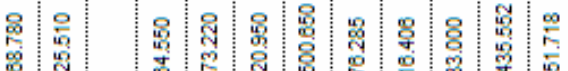

웡

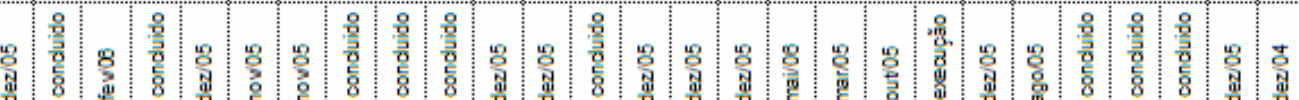

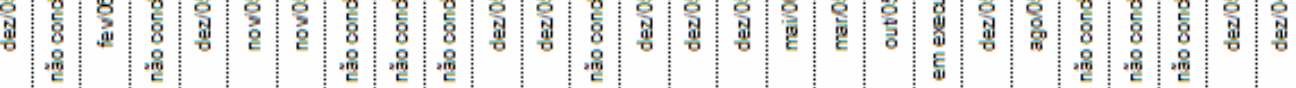

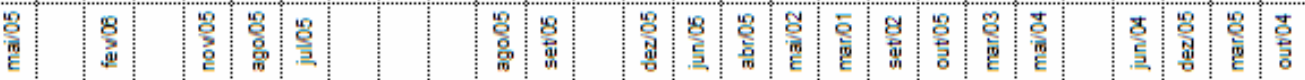

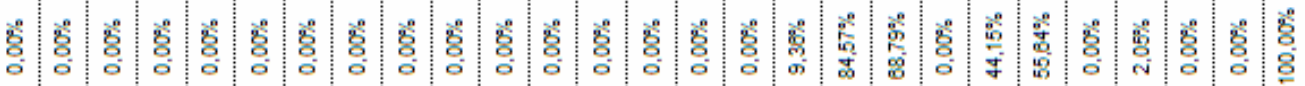
8.

( )

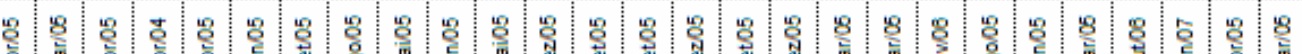

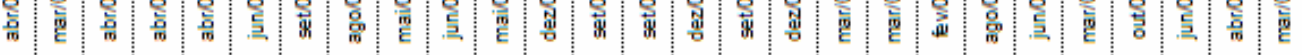
8 8 8 :

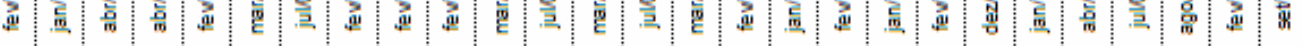
兽 0 :

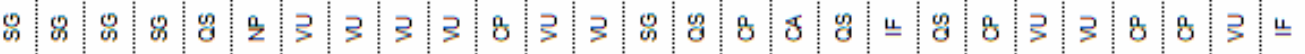
苗 点

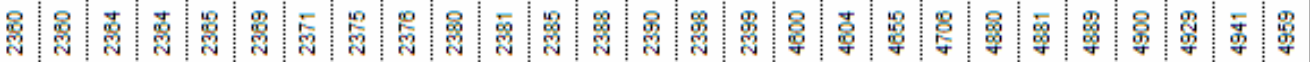

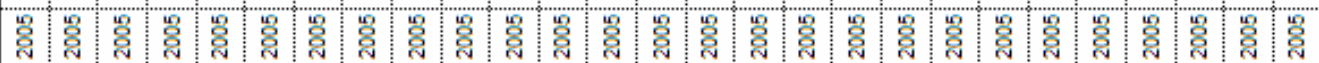




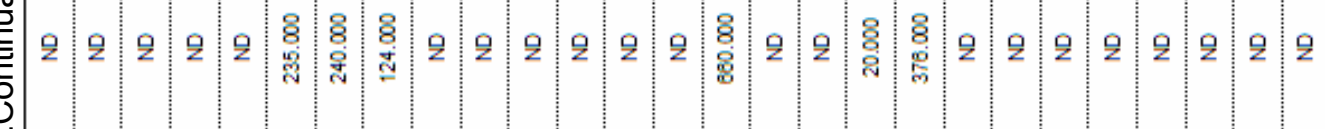

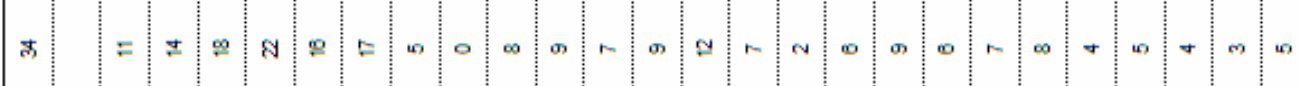
然

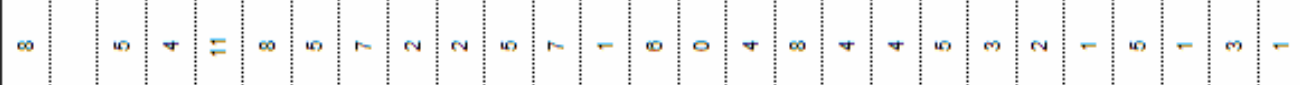

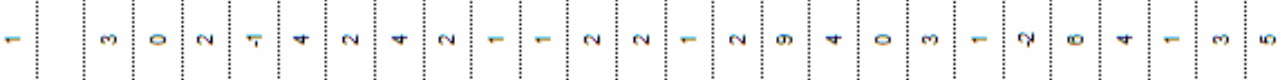
罒

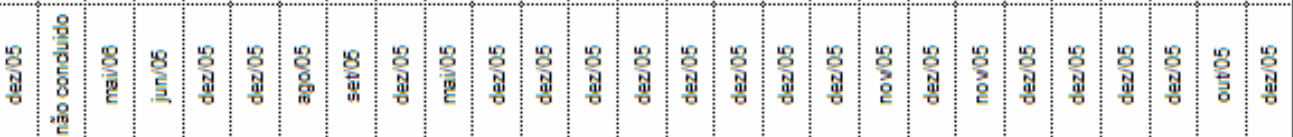

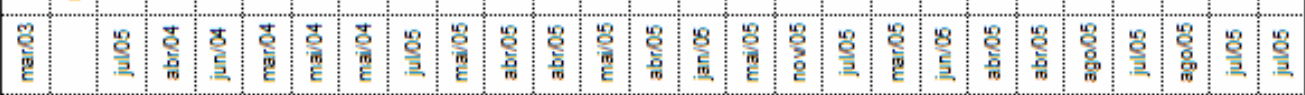
率

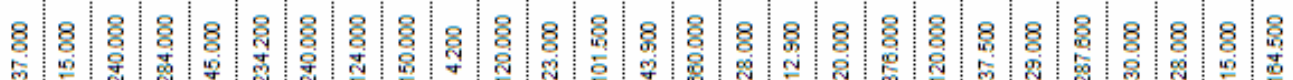

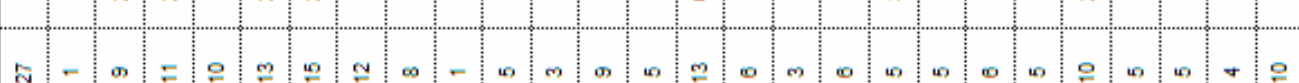
商

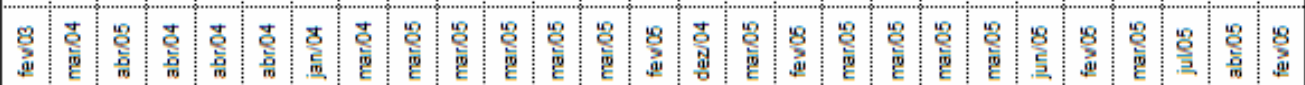

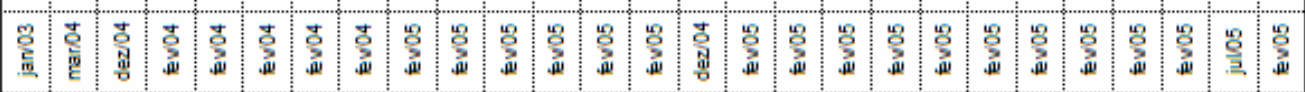
0 : о

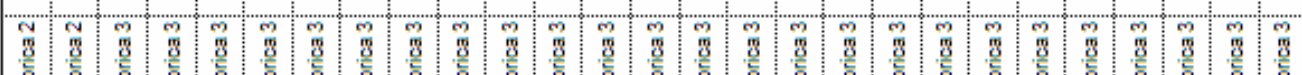

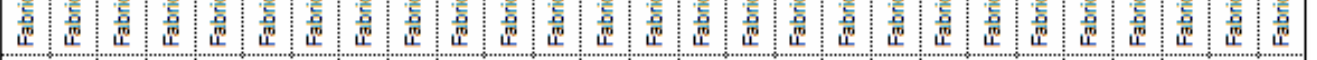

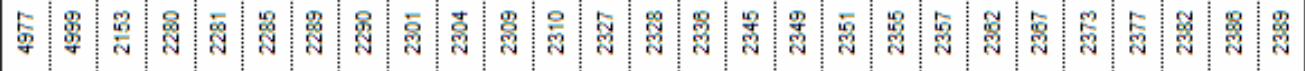

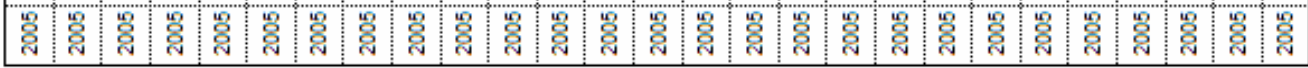




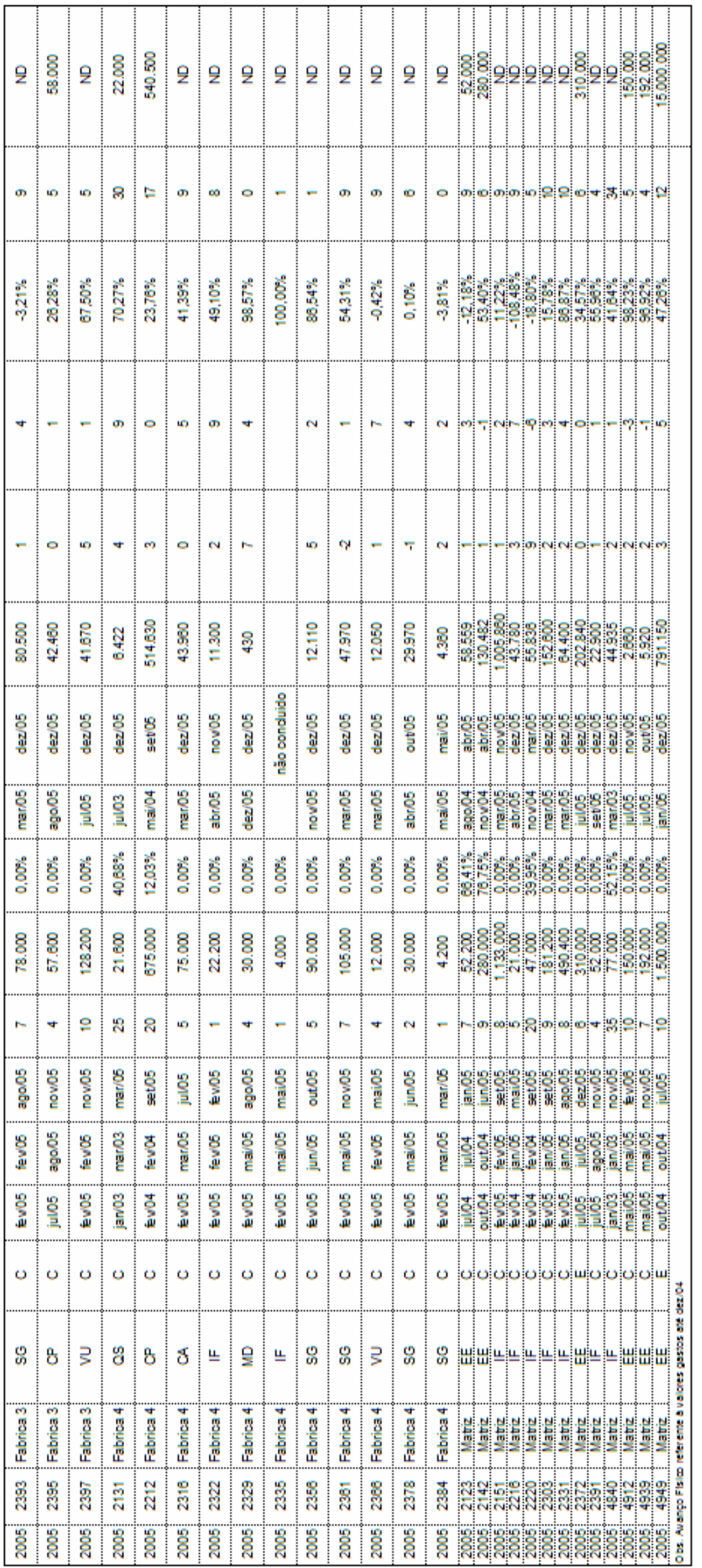


ANEXO B - Relação dos Projetos de P\&D

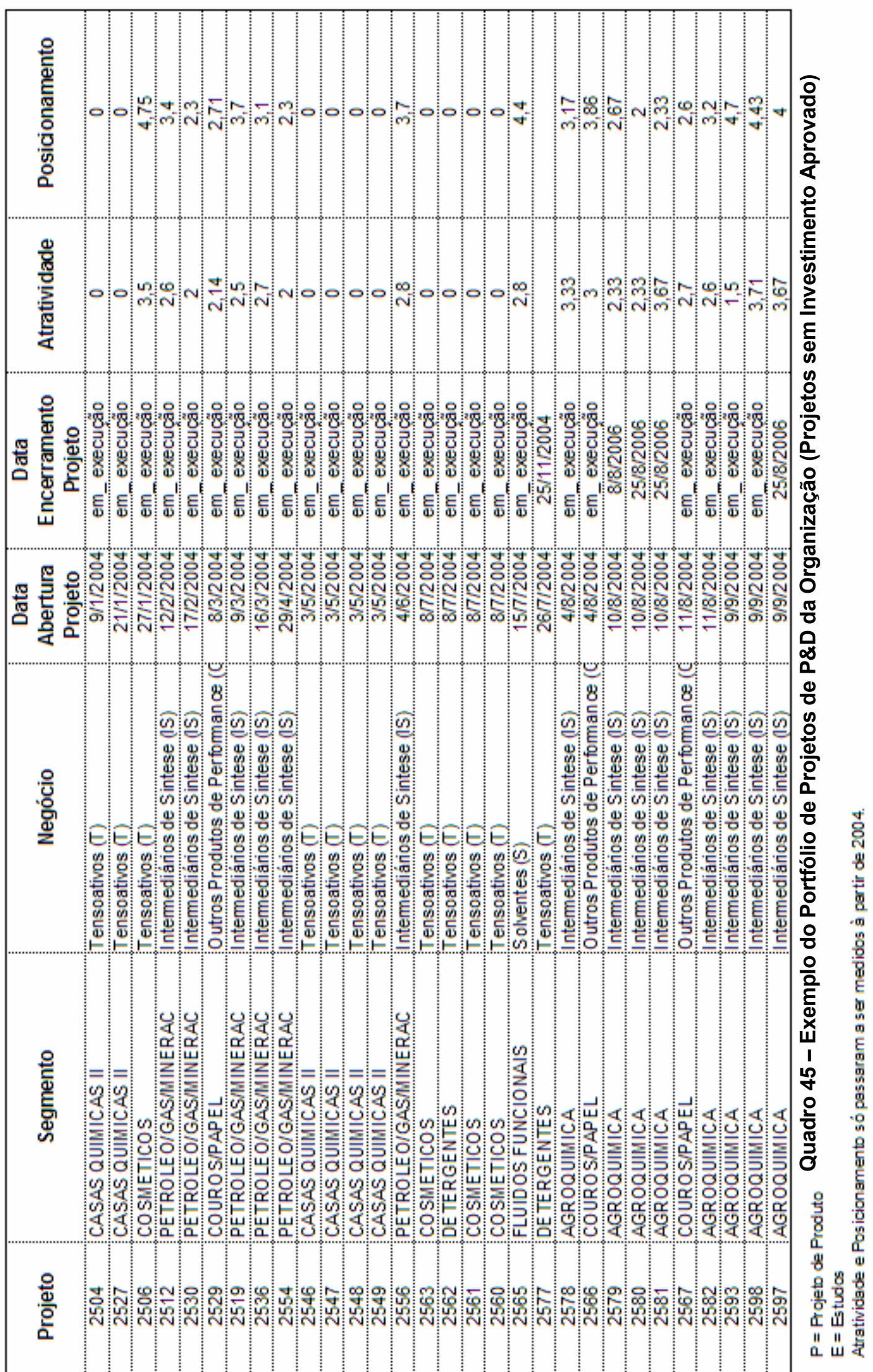

